\title{
A MULTI-COMPONENT INDICATOR OF STREAM CONDITION FOR WATERWAY MANAGERS: BALANCING SCIENTIFIC RIGOUR WITH THE NEED FOR UTILITY
}

\author{
Anthony Richard Ladson \\ Submitted in total fulfilment of the requirements of the degree of \\ Doctor of Philosophy
}

January 2000

The Department of Civil and Environmental Engineering

The University of Melbourne 
I declare that this thesis is less than 100000 words in length, exclusive of tables, maps, bibliographies, appendices and footnotes. The work embodied in this thesis is my own, except where otherwise acknowledged.

- Anthony Richard Ladson

(C) The University of Melbourne, 2000 


\section{ABSTRACT}

Measuring the environmental condition of waterways is of interest to river managers, governments and the community. In the State of Victoria, Australia and elsewhere, there is concern that environmental values of streams are declining and that information about the environment, needs to be considered when river management decisions are being made.

This thesis explores the use of environmental indicators as a tool to assist management of rivers. The promise of indicators is that they can turn large amounts of environmental data into simple, timely results and thereby provide an effective means of incorporating this information into river management decisions. It is also suggested that indicators will be useful for measuring the outcomes of management intervention and provide feedback on the effectiveness of strategies.

Can environmental indicators live up to this promise? This thesis examines this question by reviewing indicator systems that have been developed by others and then exploring, in detail, the Index of Stream Condition (ISC) that is intended as a tool to assist the management of rivers in Victoria. I argue that environmental indicators have a role at the level of regional waterway management authorities but only if they are closely aligned with managers' needs. Without consideration of non-technical issues, indicators are unlikely to be used, so it is important to establish a balance between pragmatic constraints and the need for scientific rigour. A procedure to achieve this balance is described in this thesis and was applied to the development of the ISC. Selection of indicators and the choice of indicator frameworks are explored and the value judgements behind the interpretation of indicator scores are examined.

It is also important to consider the accuracy and sensitivity of indicators. Possible objectives for the use of indicators include benchmarking, detecting change and providing information to trigger management intervention. Case studies are used to explore the performance of indicators in practical applications in streams in Victoria in relation to these objectives. Extensive use is made of non-traditional statistical procedures, including bootstrapping, and results are presented that show the likely variance of indicator scores and the relationship between indicator objectives and required sampling effort. 



\section{ACKNOWLEDGEMENTS}

I would like to acknowledge the many people and organisations who have assisted with this study. I am grateful for the financial support provided by the Department of Natural Resources and Environment, Commonwealth Government, and Department of Civil and Environmental Engineering at the University of Melbourne.

I would particularly like to thank my supervisors Rodger Grayson, Brian Finlayson and Tom McMahon. I appreciate their comments and suggestions and particularly their support. They have always been willing to share their knowledge and experience.

Boris Jawecki and Julian Thompson provided assistance with field data collection and their efforts were outstanding given the long days and hot dry conditions during the time they spent on the banks of Ryans Creek and the Broken River. Chandra Jayasuriya drafted the figures in this thesis and I appreciate her attention to detail and concern for quality.

I appreciate the contribution of all the people involved in the Index of Stream Condition project and particularly Dr Jane Doolan who provided encouragement and support and the authority required to get the task completed and Lindsay White for challenging discussions and sensible ideas. Lindsay also supplied the data that were used to examine errors associated with stream condition assessments carried out by different people.

Mike Stewardson has been a great source of ideas and information during our day to day discussions and he has particularly contributed to the analysis in Chapters 6 and 7.

My parents deserve acknowledgment and thanks for their help and support and finally, I would like to thank my wife, Sarah Ewing, for her encouragement, particularly during the final stages of the writing up. 



\section{TABLE OF CONTENTS}

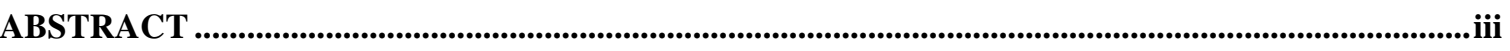

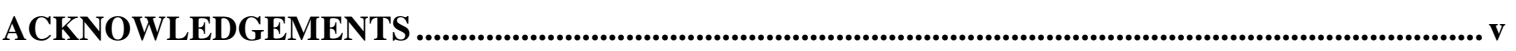

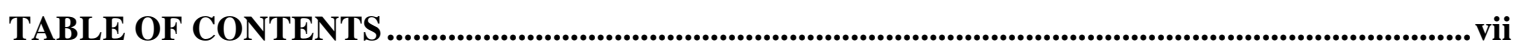

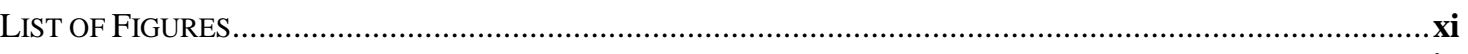

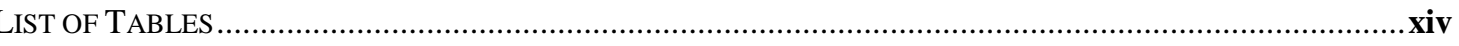

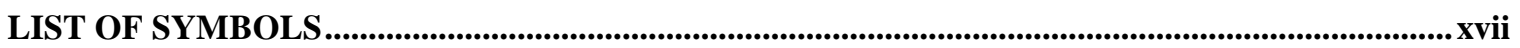

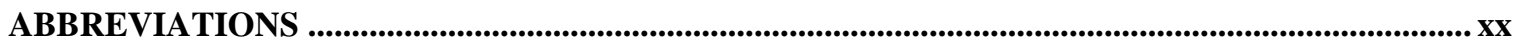

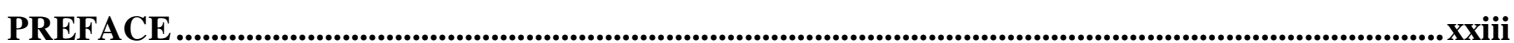

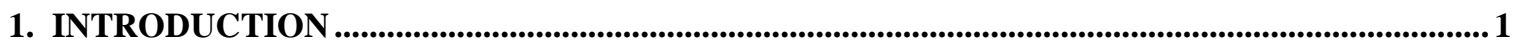

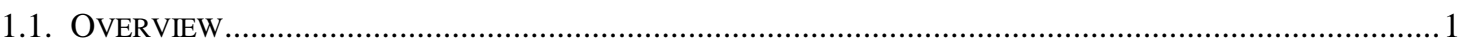

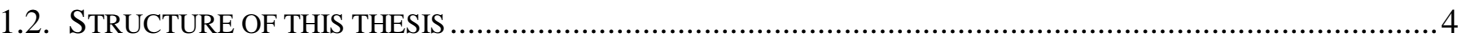

2. BRIEF HISTORY OF RIVER MANAGEMENT …........................................................................8

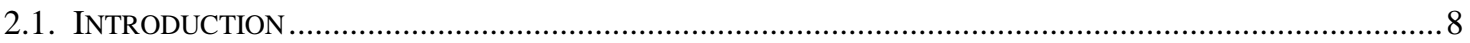

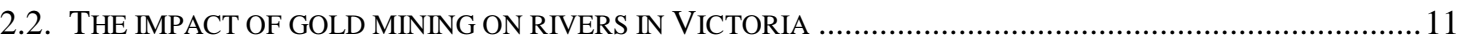

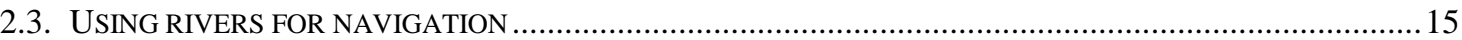

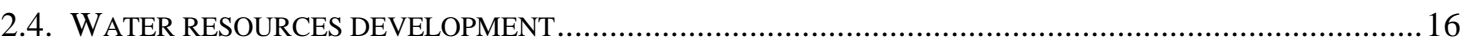

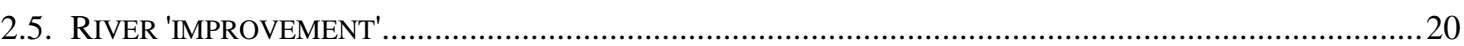

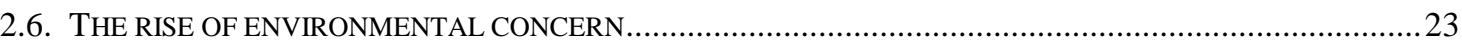

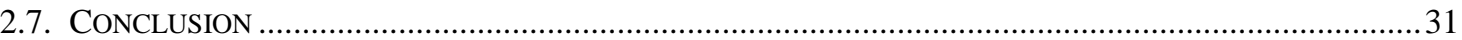

3. PATHOLOGIES OF RIVER MANAGEMENT ....................................................................................32

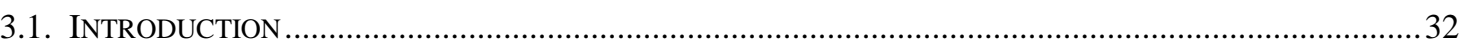

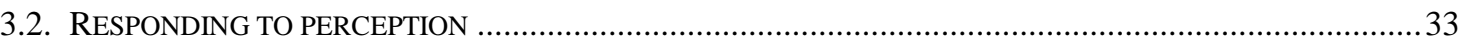

3.2.1. Case study: managing sediment in the Herbert River ....................................................... 34

3.3. A MISMATCH OF MONITORING AND MANAGEMENT .........................................................47

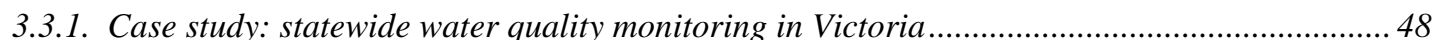

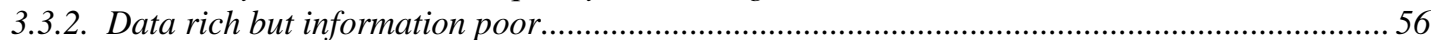

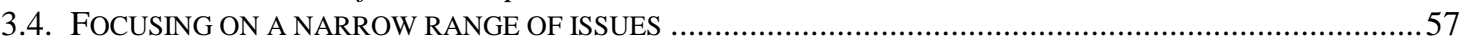

3.4.1. Case Study: implementation of bulk entitlements to water in Victoria .................................58

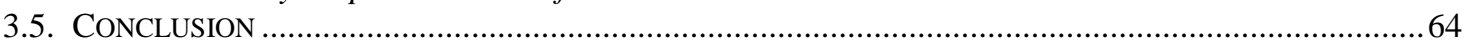

4. MONITORING STREAM CONDITION ..............................................................................66

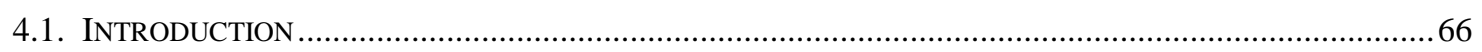

4.2. OVERVIEW OF EXISTING APPROACHES TO MEASURING OVERALL STREAM CONDITION ....................67

4.2.1. Environmental Condition of Victorian Streams ......................................................6.

4.2.2. State of the environment report - Victoria's inland waters ............................................... 74

4.2.3. State of the Rivers Project - Queensland, Australia ................................................................ 79

4.2.4. United States stream assessment programs .................................................................. 82

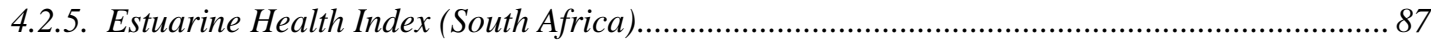

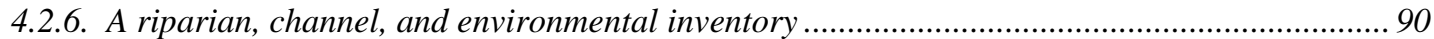

4.2.7. SERCON and RHS 93

4.3. INTENDED USES OF STREAM CONDITION MEASUREMENTS........................................................... 98

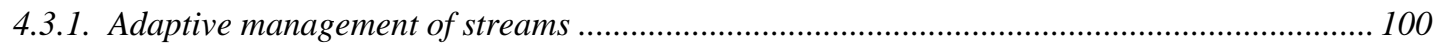

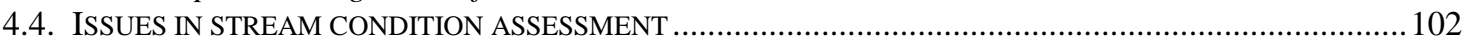

4.4.1. Objective setting ................................................................................................................. 102

4.4.2. Choosing indicators ....................................................................................... 103

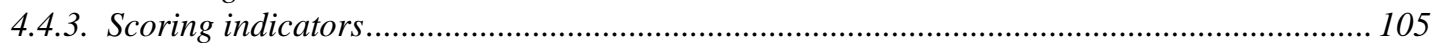

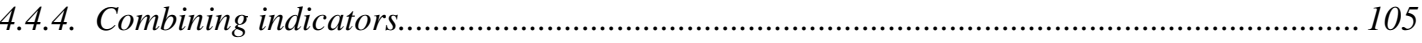




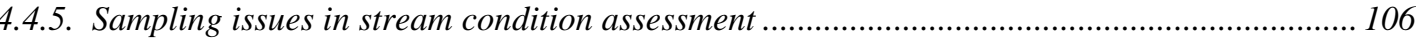

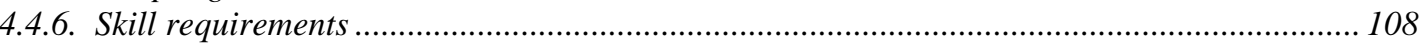

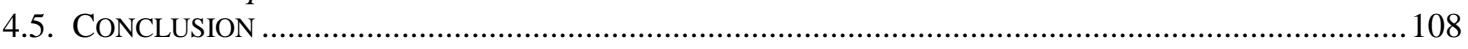

5. DEVELOPING AN INDEX OF STREAM CONDITION....................................................................110

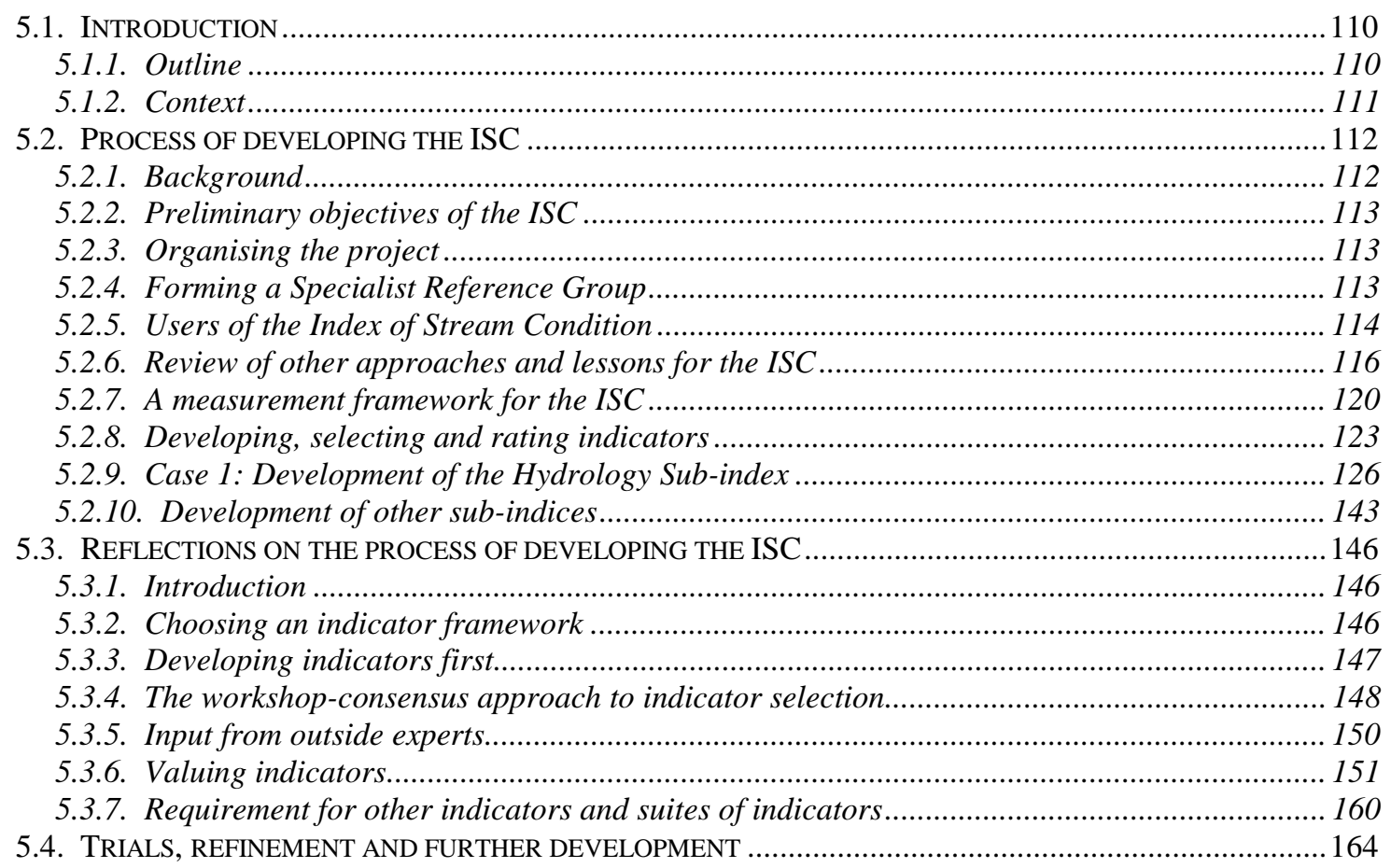

6. SAMPLING AND SENSITIVITY OF STREAMSIDE ZONE AND PHYSICAL FORM

INDICATORS .................................................................................................................................................................166

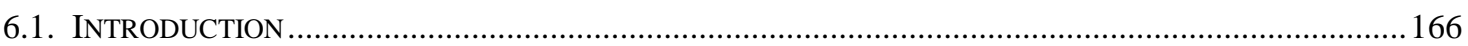

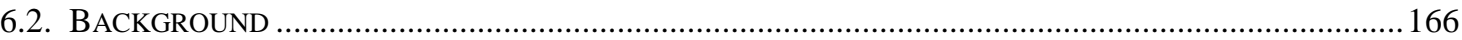

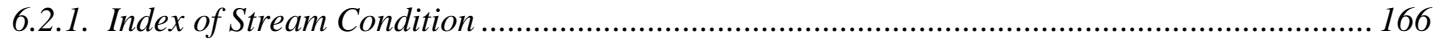

6.2.2. Collecting data on the streamside zone and physical form - the representative sub-reach.... 167

6.3. DEVELOPING A MEASUREMENT PROCEDURE BASED ON RANDOM SAMPLING .................................168

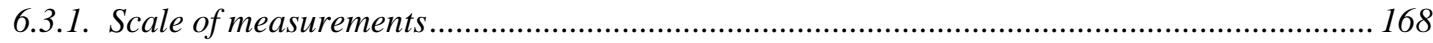

6.3.2. Stream classification ....................................................................................... 169

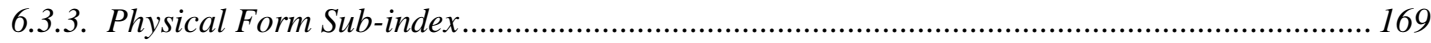

6.3.4. Streamside Zone Sub-index .......................................................................................... 171

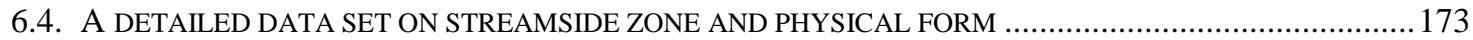

6.4.1. Description of the data ......................................................................................... 173

6.4.2. Testing the representative sub-reach approach ........................................................ 182

6.5. TESTING A MEASUREMENT PROCEDURE BASED ON RANDOM SAMPLING ............................... 183

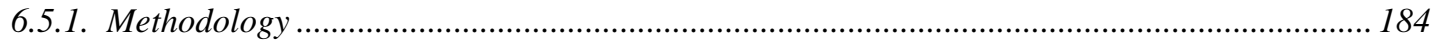

6.5.2. Benchmarking stream condition .................................................................. 185

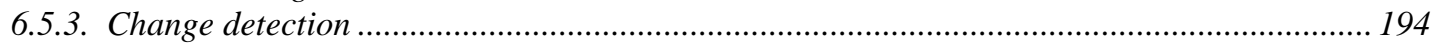

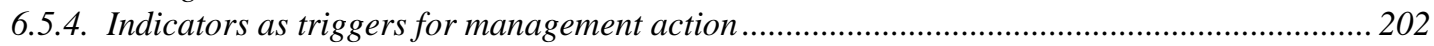

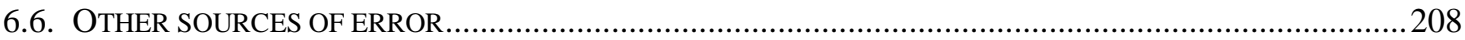

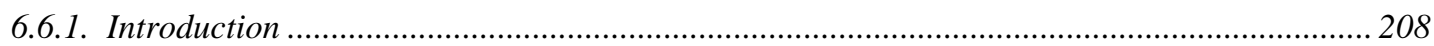

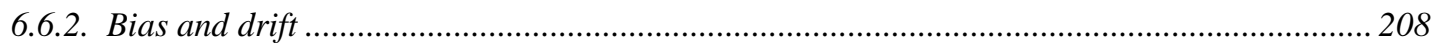

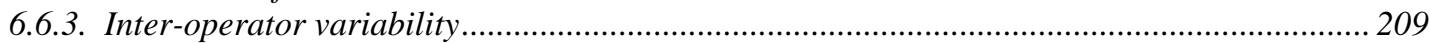

6.6.4. Reducing other sources of error ............................................................................ 212

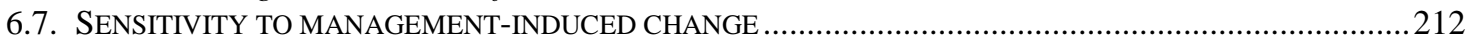

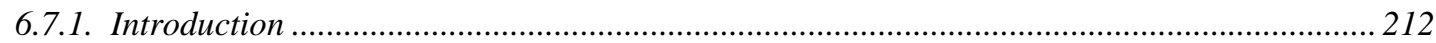

6.7.2. Calculating ISC values from historical data .......................................................... 213

6.7.3. Case study: Fifteen Mile Creek............................................................................... 213

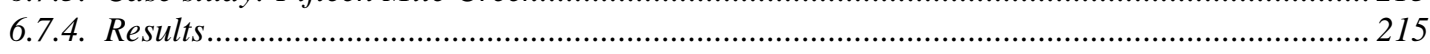

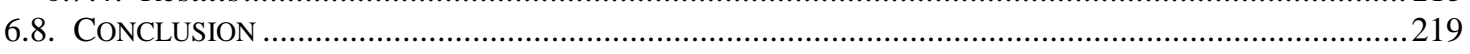


7. ACCURACY AND SENSITIVITY OF HYDROLOGY, WATER QUALITY AQUATIC LIFE

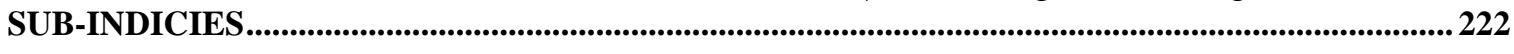

\begin{tabular}{|c|c|}
\hline \multicolumn{2}{|c|}{ 7.1. INTRODUCTION } \\
\hline \multicolumn{2}{|c|}{ 7.2. HYDROLOGY SUB-INDEX } \\
\hline \\
\hline \multicolumn{2}{|c|}{ 7.2.2. Sensitivity } \\
\hline \multicolumn{2}{|c|}{.3. WATER QUALITY } \\
\hline \multicolumn{2}{|c|}{ 7.3.1. Introduction ………………………………………………………………… 236} \\
\hline \multirow{2}{*}{\multicolumn{2}{|c|}{$\begin{array}{l}7.3 .2 \text { Case study: examining sensitivity and errors in water quality indicators } \\
7.4 . \text { AQUATIC LIFE }\end{array}$}} \\
\hline & \\
\hline \multicolumn{2}{|l|}{ 7.4.1. Introduction } \\
\hline \multicolumn{2}{|l|}{ 7.4.2. SIGNAL. } \\
\hline 7.4.3. AusRivAS. & $\overline{263}$ \\
\hline \multicolumn{2}{|l|}{ 7.5. CONCLUSION . } \\
\hline
\end{tabular}

8. IMPLICATIONS AND CHALLENGES FOR THE DEVELOPMENT AND USE OF INDICATORS IN ENVIRONMENTAL MANAGEMENT OF RIVERS

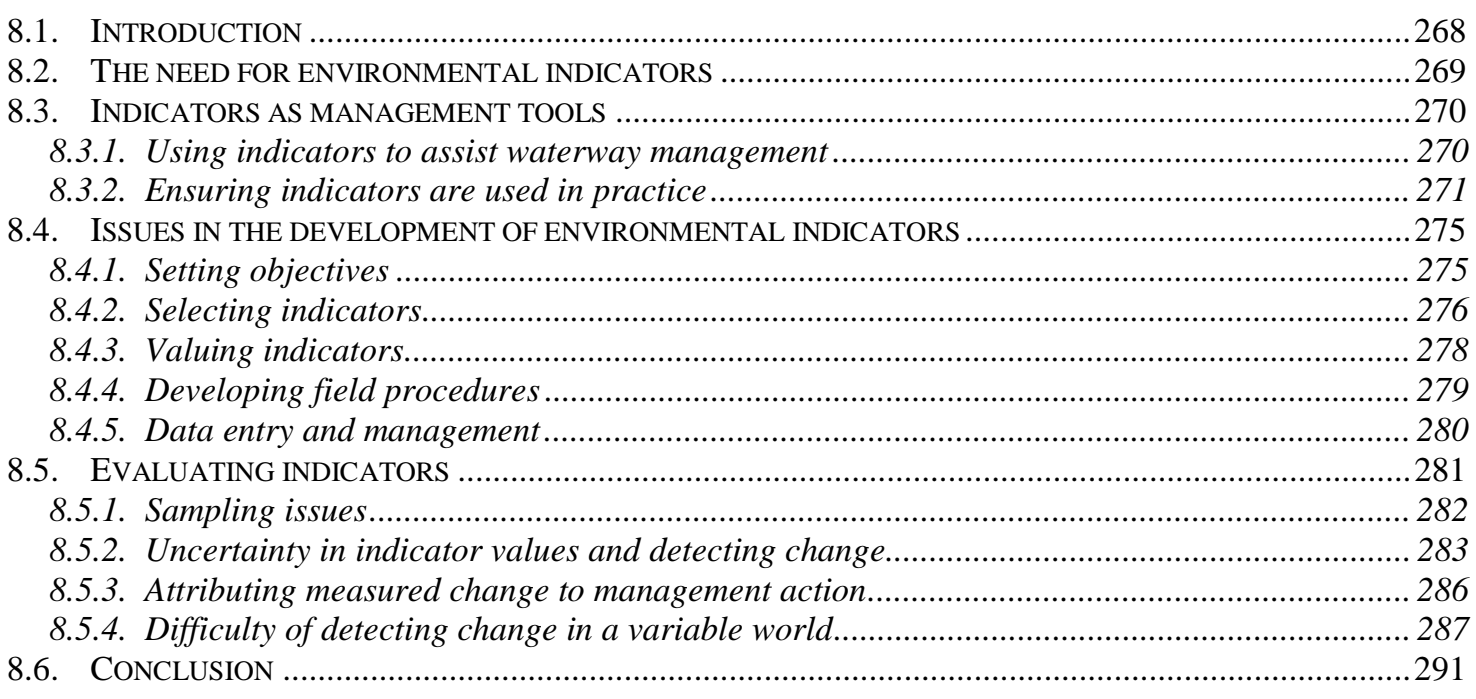

9. CONCLUSION ............................................................................................................................................... 292

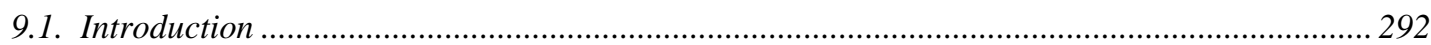

9.2. The promise of environmental indicators ……

9.3. Developing environmental indicators ............................................................... 294

9.4. Performance of environmental indicators ................................................................... 295

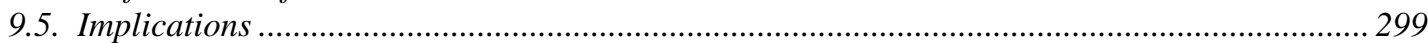

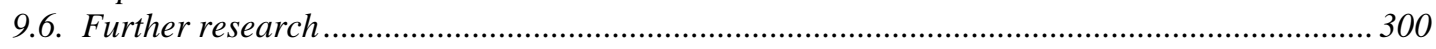

REFERENCES ...................................................................................................................................................302

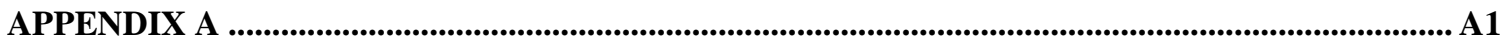

LADSON, A. R. AND TILLEARD, J. W. (1999). “THE HERBERT RiVER, QUEENSLAND, TROPICAL

AUSTRALIA: COMMUNITY PERCEPTION AND RIVER MANAGEMENT.” AUSTRALIAN GEOGRAPHICAL

STUDIES 37(3): 284-299.

APPENDIX B

LADSON, A. R. AND WHITE, L. J. (2000). MEASURING STREAM CONDITION. RIVER MANAGEMENT: THE

AUSTRALASIAN EXPERIENCE. S. O. BRIZGA AND B. L. FINLAYSON (EDS). JOHN WILEY AND SONS.

APPENDIX C

CENTRE For ENVIRONMENTAl APPLIED HydROLOGY, UnIVERSITY OF MELBOURNE AND ID\&A PTY LTD (1995). DEVELOPMENT OF AN INDEX OF STREAM CONDITION. DEPARTMENT OF CONSERVATION AND NATURAL RESOURCES. MELBOURNE. 
APPENDIX D

Ladson, A. R., White, L. J., Doolan, J. A., Finlayson, B. L., Hart, B. T., LaKe, P. S. AND TILLEARD, J. W. (1999). "DEVELOPMENT AND TESTING OF AN INDEX OF STREAM CONDITION FOR WATERWAY MANAGEMENT IN AUSTRALIA.” FRESHWATER BIOLOGY 41(2): 453-468.

APPENDIX E

HYDROLOGY DISCUSSION PAPER FOR MEETING OF THE SPECIALIST REFERENCE GROUP HELD ON JUNE 30,1998

APPENDIX F

HYDROLOGY DISCUSSION PAPER FOR MEETING OF THE SPECIALIST REFERENCE GROUP HELD ON NOVEMBER 30, 1998

APPENDIX G

EXTRACTS FROM: LADSON, A. AND WHITE, L. (1999). INDEX OF STREAM CONDITION: REFERENCE MANUAL. DEPARTMENT OF NATURAL RESOURCES AND ENVIRONMENT. MELBOURNE.

APPENDIX H

LADSON, A. R., White, L. AND DOOLAN, J. (1995). INDEX OF STREAM CONDITION, A TOOL TO AID MANAGEMENT OF RIVERS. 1995 FALL MEETING, DECEMBER 11-15, 1995, SAN FRANCISCO, CALIFORNIA: H21D-08. AMERICAN GEOPHYSICAL UNION.

APPENDIX I.

LAdson, A. R., Doolan, J., White, L., METZEling, L. AND ROBInSON, D. (1996). INDEX OF STREAM CONDITION AS A TOOL TO AID MANAGEMENT OF RIVERS. 23RD HYDROLOGY AND WATER RESOURCES SYMPOSIUM, 21-24 MAY, HOBART. InSTITUTION OF ENGINEERS, AUSTRALIA. 1: 325-331

APPENDIX J

LADSON, A. R. AND DOOLAN, J. A. (1997). INTEGRATED MEASURES OF RIVER HEALTH. MONITORING RIVER HEALTH, PROCEEDINGS OF THE RIVER BASIN MANAGEMENT SOCIETY WINTER CONFERENCE, JULY 7, LATROBE UNIVERSITY, MELBOURNE. RIVER BASIN MANAGEMENT SOCIETY.

APPENDIX K

Ladson, A. R., Tilleard, J. W., Ewing, S. A., Stewardson, M. And Rutherfurd, I. D. (1999). SUCCESSFUL STREAM REHABILITATION: FIRST SET THE GOALS. PROCEEDINGS, SECOND NATIONAL CONFERENCE ON STREAM MANAGEMENT IN Australia, Rutherfurd, I. D. AND BARTLEy, R. (EDS). 8-11 FeBruary 1999, AdElaide. CoOPERATIVE RESEARCH CENTRE FOR CATCHMENT HydRology. 381-387.

APPENDIX L

LADSON, A. R., White, L. J. AND DOOLAN, J. A. (1997). TRIALING THE INDEX OF STREAM CONDITION IN VICTORIA, AUSTRALIA. 24TH HYDROLOGY AND WATER RESOURCES SYMPOSIUM, 25-27 NOVEMBER 1997, AUCKLAND, NEW ZEALAND. INSTITUTION OF ENGINEERS AUSTRALIA. 109-114.

APPENDIX M.

STREAMSIDE ZONE AND PHYSICAL FORM DATA FOR RYANS CREEK AND THE BROKEN RIVER

APPENDIX N

COMPUTER PROGRAMS USED IN CHAPTER 6: BENCHMARK, EARLYWARNING

APPENDIX 0

CALCULATING INDEX OF STREAM CONDITION VALUES FROM INFORMATION COLLECTED FOR THE STATEWIDE ASSESSMENT OF PHYSICAL STREAM CONDITIONS

APPENDIX P

COMPUTER PROGRAM USED IN CHAPTER 7: WQ 


\section{List of Figures}

Figure 2.1 - Victorian rivers affected by goldmining and desnagging .........................................9

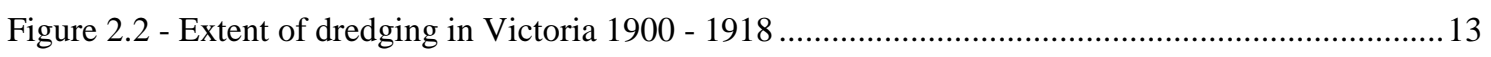

Figure 2.3 - Queensland rivers that were desnagged in the 1880s............................................ 17

Figure 2.4 - Water resources development in Victoria .......................................................... 19

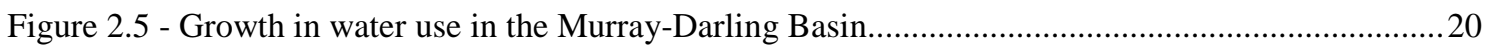

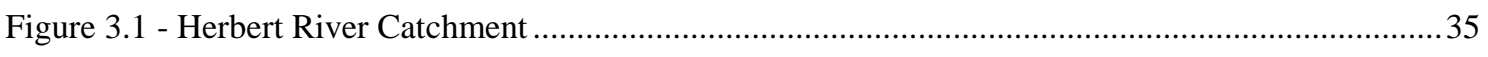

Figure 3.2 - The Herbert River and surrounds between Ingham and the mouth at Dungeness .................36

Figure 3.3 - Specific gauge plots for the Herbert River at Ingham ........................................... 39

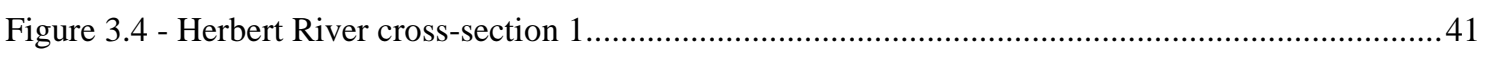

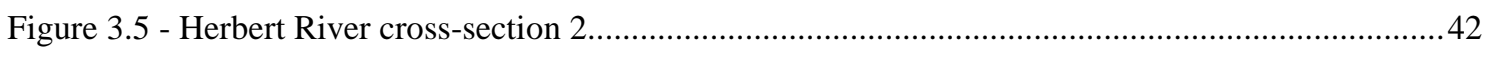

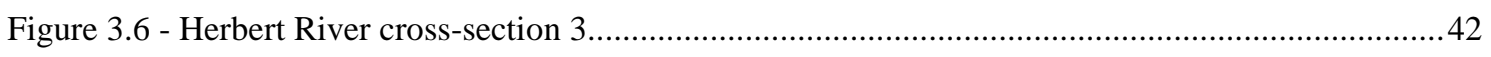

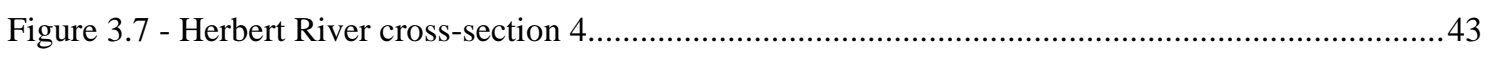

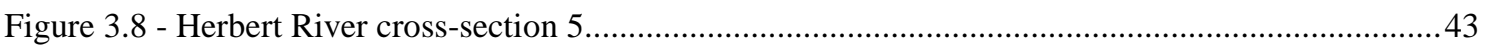

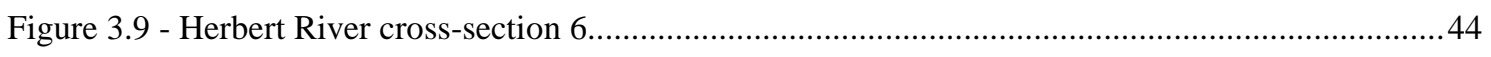

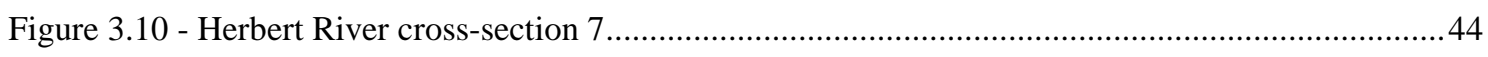

Figure 3.11 - Change in thalweg elevation at cross-sections on the Herbert River ...............................45

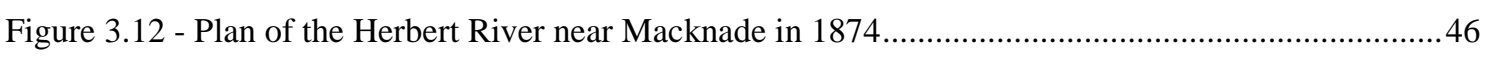

Figure 3.13 - Time (years) required to detect changes with various effect sizes, assuming monthly

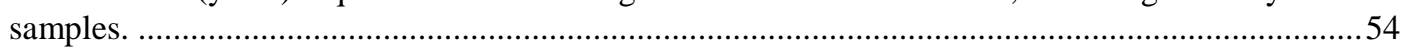

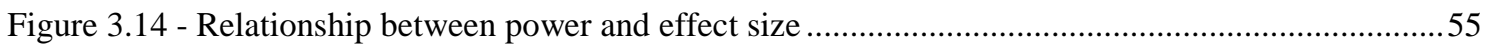

Figure 4.1 - Components of stream condition and examples of specific measures ............................68

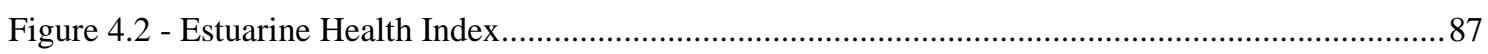

Figure 5.1 - Environmental indicators can measure pressure, state or response.................................120

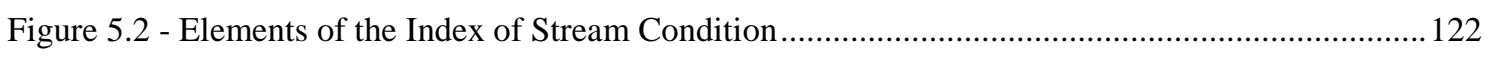

Figure 5.3 - Difference between actual and natural monthly discharge ........................................130

Figure 5.4 - Comparison of actual and natural monthly flows for the Goulburn River at Eildon ...........130

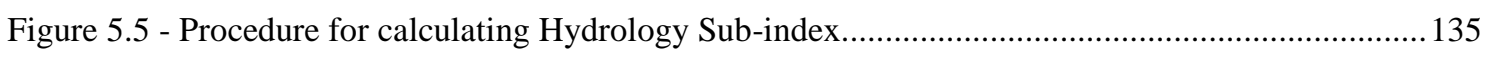

Figure 6.1 - Illustration of the three measurement scales ......................................................... 169

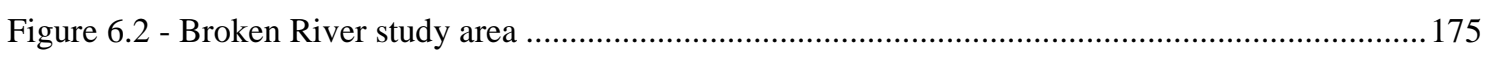

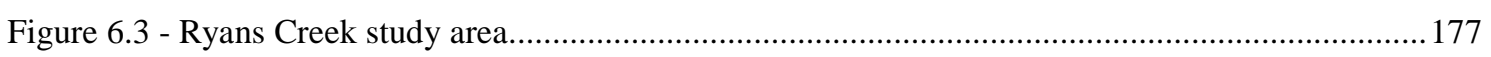

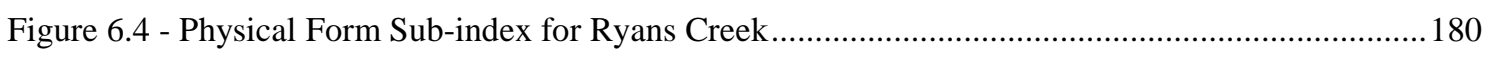

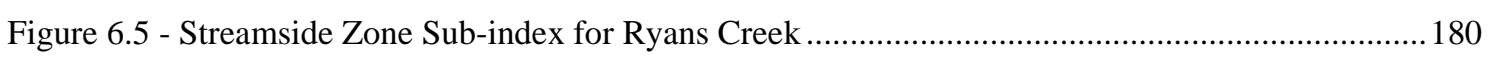

Figure 6.6 - Physical Form Sub-index for the Broken River ................................................... 181

Figure 6.7 - Streamside Zone Sub-index for the Broken River ................................................. 181

Figure 6.8 - Resampling procedure used to quantify errors associated with sampling to measure the

current values of the Physical Form and Streamside Zone Sub-indices ...............................187

Figure 6.9 - Relative errors (+/- 0.5) associated with estimates of the Physical Form Sub-index on Ryans

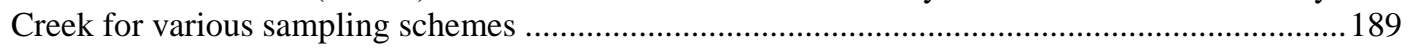


Figure 6.10 - Relative errors (+/- 1) associated with estimates of the Physical Form Sub-index on Ryans Creek for various sampling schemes

Figure 6.11 - Relative errors (+/- 0.5) associated with estimates of the Streamside Zone Sub-index on Ryans Creek for various sampling schemes.......

Figure 6.12 - Relative errors (+/- 1) associated with estimates of the Streamside Zone Sub-index on Ryans Creek for various sampling schemes ....

Figure 6.13 - Relative errors (+/- 0.5) associated with estimates of the Physical Form Sub-index on the Broken River for various sampling schemes

Figure 6.14 - Relative errors (+/- 1) associated with estimates of the Physical Form Sub-index on the Broken River for various sampling schemes ............................................................... 191

Figure 6.15 - Relative errors (+/- 0.5) associated with estimates of the Streamside Zone Sub-index on the Broken River for various sampling schemes ........................................................... 192

Figure 6.16 - Relative errors (+/- 1) associated with estimates of the Streamside Zone Sub-index on the Broken River for various sampling schemes

Figure 6.17 - Relative accuracy of the Physical Form Sub-index for sampling densities based on numbers of sites per $10 \mathrm{~km}$ of stream $(3$ transects per site) ............................................................. 193

Figure 6.18 - Relative accuracy of the Streamside Zone Sub-index for sampling densities based on numbers of sites per $10 \mathrm{~km}$ of stream (3 transects per site).

Figure 6.19 - Resampling procedure used to quantify errors associated with sampling to measure changes in the Physical Form and Streamside Zone Sub-indices ................................................... 196

Figure 6.20 - Relative errors (+/- 0.5) associated with estimates of change in the Physical Form Sub-index on Ryans Creek for various sampling schemes............................................................... 197

Figure 6.21 - Relative errors (+/- 1) associated with estimates of change in the Physical Form Sub-index on Ryans Creek for various sampling schemes............................................................... 197

Figure 6.22 - Relative errors (+/- 0.5) associated with estimates of change in the Streamside Zone Subindex on Ryans Creek for various sampling schemes....

Figure 6.23 - Relative errors (+/- 1) associated with estimates of change in the Streamside Zone Subindex on Ryans Creek for various sampling schemes...

Figure 6.24 - Relative errors (+/- 0.5) associated with estimates of change in the Physical Form Sub-index on the Broken River for various sampling schemes.......................................................... 199

Figure 6.25 - Relative errors (+/- 1) associated with estimates of change in the Physical Form Sub-index on the Broken River for various sampling schemes.

Figure 6.26 - Relative errors (+/- 0.5) associated with estimates of change in the Streamside Zone Subindex on the Broken River for various sampling schemes ....................................................200

Figure 6.27 - Relative errors (+/- 1) associated with estimates of change in the Streamside Zone Subindex on the Broken River for various sampling schemes ...............................................200

Figure 6.28 - Relative accuracy associated with estimates of change in the Physical Form Sub-index for sampling densities based on numbers of sites per $10 \mathrm{~km}$ of stream (3 transects per site)......

Figure 6.29 - Relative accuracy associated with estimates of change in the Streamside Zone Sub-index for sampling densities based on numbers of sites per $10 \mathrm{~km}$ of stream (3 transects per site).............201

Figure 6.30 - Performance of sampling schemes for providing early warning and avoiding false alarms

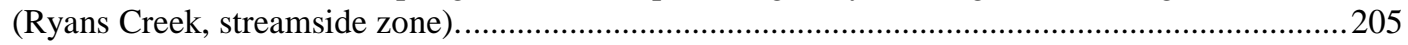

Figure 6.31 - Performance of sampling schemes for providing early warning and avoiding false alarms (Broken River, streamside zone) ........................................................................206

Figure 6.32 - Performance of sampling schemes for providing early warning and avoiding false alarms

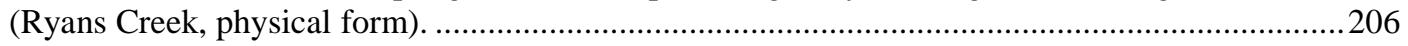

Figure 6.33 - Performance of sampling schemes for providing early warning and avoiding false alarms

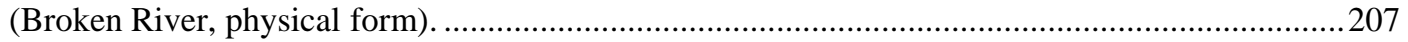


Figure 6.34 - Relationship between sampling density and probability of obtaining a critical change (physical form, 3 transects per site, 2000 replicates)

Figure 6.35 - Relationship between sampling density and probability of obtaining a critical change (streamside zone, 3 transects per site, 2000 replicates) .................................................208

Figure 6.36 - Accuracy of assessment of Physical Form Sub-index by trainees .................................211

Figure 6.37 - Accuracy of assessment of Streamside Zone Sub-index by trainees ...........................211

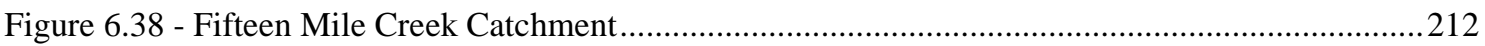

Figure 6.39 - Approximate statistical significance for measured changes in Physical Form Sub-index

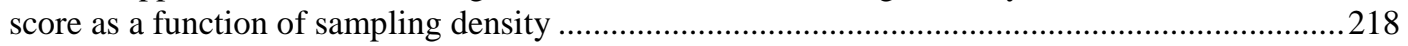

Figure 6.40 - Approximate statistical significance for measured changes in Streamside Zone Sub-index

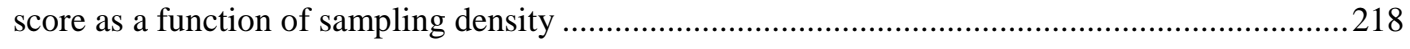

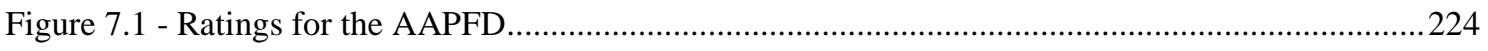

Figure 7.2 - Gellibrand River and Catchment showing the North Otway and South Otway Pipelines ....229

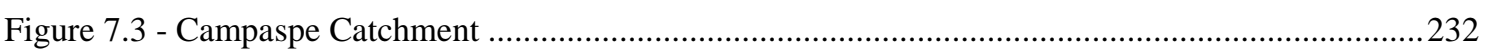

Figure 7.4 - Average monthly flows for the Campaspe River downstream of Lake Eppalock ..............233

Figure 7.5 - Hydrology Sub-index rating for the Campaspe River downstream of Lake Eppalock for the previous, and environmental, operating rules

Figure 7.6 - Hydrology Sub-index for the Campaspe River downstream of Lake Eppalock for the previous and the environmental operating rules; averages for periods of 5 years …..............................234

Figure 7.7 - Latrobe River Catchment ......................................................................................243

Figure 7.8 - Phosphorus concentration $\left[\mathrm{mg} \mathrm{m}^{-3}\right]$ for the Latrobe River at Rosedale showing recorded data,

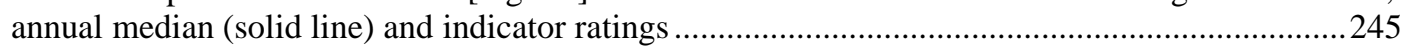

Figure 7.9 - Turbidity [NTU] for the Latrobe River at Rosedale showing recorded data and annual median (solid line). Data are plotted on a log scale to show the range of turbidity values......................245

Figure 7.10 - Turbidity [NTU] for the Latrobe River at Rosedale showing recorded data, annual median (solid line) and indicator ratings ..

Figure 7.11 - Electrical conductivity $[\mu \mathrm{S} / \mathrm{cm}]$ for the Latrobe River at Rosedale showing recorded data, annual median (solid line) and indicator ratings ....

Figure 7.12 - pH for the Latrobe River at Rosedale showing recorded data and annual median (solid line)

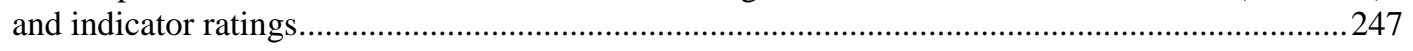

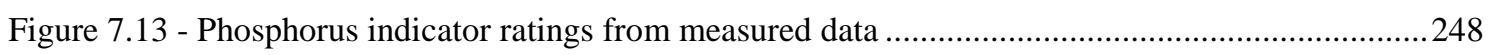

Figure 7.14 - Phosphorus indicator rating when phosphorus concentrations are reduced by $20 \%$..........248

Figure 7.15 - Phosphorus indicator rating when phosphorus concentrations are reduced by $40 \%$..........249

Figure 7.16 - Phosphorus indicator rating when phosphorus concentrations are reduced by $60 \%$..........249

Figure 7.17 - Phosphorus indicator rating when phosphorus concentrations are reduced by $80 \% \ldots \ldots \ldots .250$

Figure 7.18 - Turbidity indicator ratings from measured data ..............................................250

Figure 7.19 - Turbidity indicator rating when turbidity values are reduced by $20 \%$..........................251

Figure 7.20 - Turbidity indicator rating when turbidity values are reduced by $40 \% \ldots \ldots \ldots \ldots \ldots \ldots \ldots \ldots \ldots . \ldots \ldots 1$

Figure 7.21 - Turbidity indicator rating when turbidity values are reduced by $60 \% \ldots \ldots \ldots \ldots \ldots \ldots \ldots \ldots . \ldots . \ldots \ldots 2$

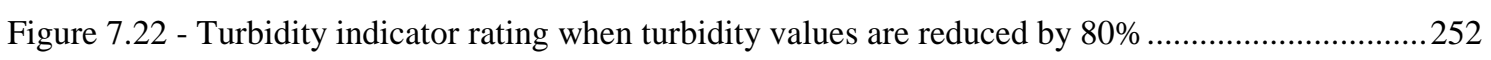

Figure 7.23 - Electrical conductivity indicator ratings from measured data ..................................253

Figure 7.24 - Electrical conductivity indicator rating when EC values reduced by $20 \% \ldots \ldots \ldots \ldots \ldots \ldots \ldots . . \ldots \ldots 3$

Figure 7.25 - Electrical conductivity indicator rating when EC values reduced by $40 \%$....................254 
Figure 7.26 - Electrical conductivity indicator rating when EC values reduced by $60 \% \ldots \ldots \ldots \ldots \ldots \ldots \ldots \ldots . .254$ Figure 7.27 - Electrical conductivity indicator rating when EC values reduced by $80 \%$........................255 Figure 7.28 - Water Quality Sub-index for the Latrobe River at Rosedale from 1967 to $1995 \ldots \ldots \ldots \ldots \ldots . . .256$ Figure 7.29 - Procedure to calculate confidence intervals for Water Quality Sub-index scores ..............257

Figure 7.30 - Water Quality Sub-index scores and 90\% confidence intervals for the Latrobe River at Rosedale ..........................................................................................................................25

\section{List of Tables}

Table 2.1 - Examples of management objectives from Victorian waterway management authorities .......26

Table 3.1 - Bankfull cross-section areas on the Herbert River ............................................................ 40

Table 3.2 - Sampling strategies for various water quality goals ........................................................ 50

Table 3.3 - Estimated phosphorus sources to the Williams River .......................................................52

Table 3.4 - Possible outcomes and states of nature when testing for change ...........................................53

Table 3.5 - Water quality parameters for the Latrobe River at Rosedale. ............................................56

Table 4.1 - Approaches to measuring stream condition ............................................................... 70

Table 4.2 - Criteria used by Mitchell (1990) to determine environmental ratings for rivers in Victoria....71

Table 4.3 - Environmental ratings for proportion of stream length in the Latrobe Basin, Victoria.............72

Table 4.4 - Sampling density for State of the Streams Survey ........................................................ 73

Table 4.5 - Index of Aquatic Environmental Quality ............................................................................. 76

Table 4.6 - Assessment of the Index of Aquatic Environmental Quality for the mountain segment of the

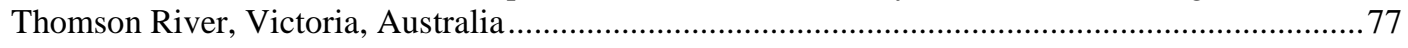

Table 4.7 - Criteria for assessing turbidity [NTU] .......................................................................

Table 4.8 - Criteria for assessing streams based on fish ............................................................... 78

Table 4.9 - Missing values from the statewide assessment of streams using the IAEQ ...........................78

Table 4.10 - Condition rating for the State of the Rivers project ......................................................... 80

Table 4.11 - Environmental Monitoring and Assessment Program (EMAP) indicators for lakes and

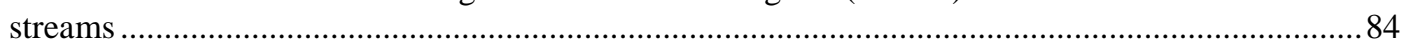

Table 4.12 - Water quality parameters used as part of the Estuarine Health Index ................................. 88

Table 4.13 - Assessment of the RCE (Riparian, Channel and Environmental) inventory .........................91

Table 4.13 - Assessment of the RCE (Riparian, Channel and Environmental) inventory (continued).......92

Table 4.14 - Classification of streams based on the RCE (Riparian, Channel and Environmental) inventory ................................................................................................................... 93

Table 4.15 - SERCON attributes and weights ....................................................................... 94

Table 4.16 - SERCON index values based on percentage of maximum possible score for each criterion.95

Table 4.17 - Available resources to support stream monitoring in different countries............................. 98

Table 5.1 - Core members of the Specialist Reference Group and project steering committee ...............114

Table 5.2 - Experts outside the Specialist Reference Group that were consulted as part of the development of the Index of Stream Condition........................................................................................ 115

Table 5.3 - Criteria for selecting indicators for the Index of Stream Condition .................................... 124

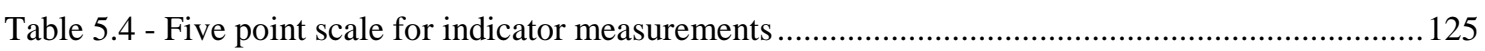

Table 5.5 - Suggested rating table for an indicator that measures changes in annual flow volumes caused by flow diversion ...................................................................................................... 127 
Table 5.6 - Summary of possible indicators for use in the ISC Hydrology Sub-index.......................129

Table 5.7 - Typical monthly flows in the Goulburn River at Eildon ......................................... 131

Table 5.8 - Rating table for the Hydrology Sub-index ........................................................... 131

Table 5.9 - Calculation of Hydrologic Deviation for a number of river reaches ...............................134

Table 5.10 - Rating of Hydrologic Deviation ................................................................ 136

Table 5.11 - Procedure to calculate Hydrology Sub-index ............................................................. 136

Table 5.12 - Hydrology indicators based on monthly flows (assuming 5 years of data are used)...........140

Table 5.13 - The Index of Stream Condition is based on 5 Sub-indices each consisting of various

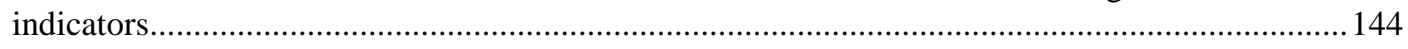

Table 5.14 - Underlying values of the some stream assessment systems ...................................... 152

Table 5.15 - Ability of ISC to act as a performance indicator over annual time periods.......................161

Table 5.16 - How well will project objectives be met? ............................................................... 162

Table 5.17 - Differences between annual performance measures and the Index of Stream Condition .... 163

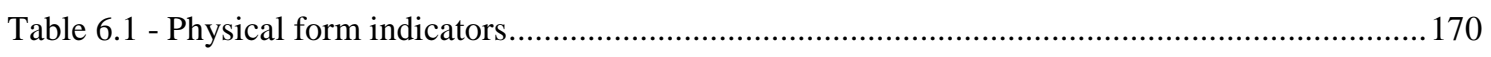

Table 6.2 - Streamside zone indicators ............................................................................... 171

Table 6.3 - Detailed information on the streamside zone and physical form was collected along Ryans

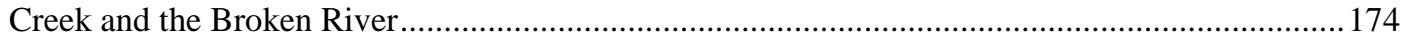

Table 6.4a - Example of Physical Form Sub-index data for the Broken River .................................179

Table 6.4b - Example of Streamside Zone Sub-index data for the Broken River ...............................179

Table 6.5 - Streamside Zone and Physical Form Sub-index scores based on values from a nominated 'representative' reach on the Broken River and Ryans Creek............................................ 183

Table 6.6 - ISC objectives that relate to the choice of sampling strategy .........................................185

Table 6.7 - Relative accuracy of assessment of current condition for a sampling scheme based on 3 sites

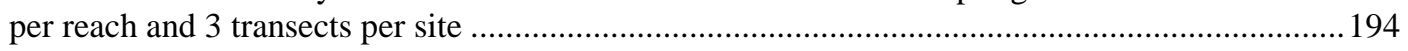

Table 6.8 - Relative accuracy of change detection for a sampling scheme based on 3 sites per reach and 3 transects per site

Table 6.9 - States of nature and associated errors and costs for decisions based on indicator values ......203

Table 6.10 - Inter-operator variability for Physical Form and Streamside Zone Sub-indices ...............210

Table 6.11 - Methods for estimating streamside zone and physical form indicators from historical data215

Table 6.12 - Authorities with responsibility for managing the Fifteen Mile Creek............................215

Table 6.13 - ISC scores for 1986 and 1997 for three sites on the Fifteen Mile Creek.........................217

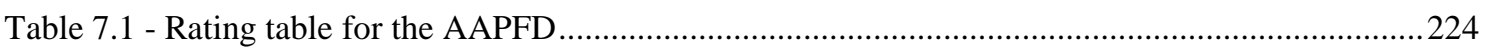

Table 7.2 - Summary of results for the Amended Annual Proportional Flow Deviation for selected

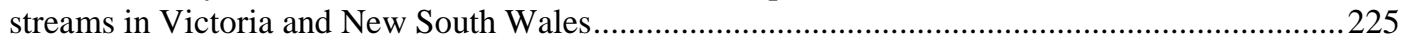

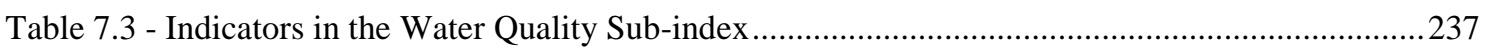

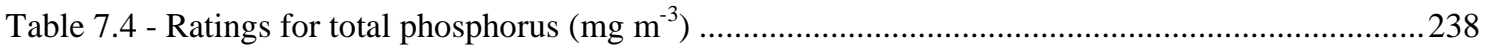

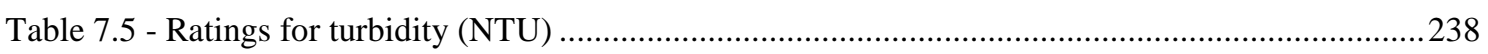

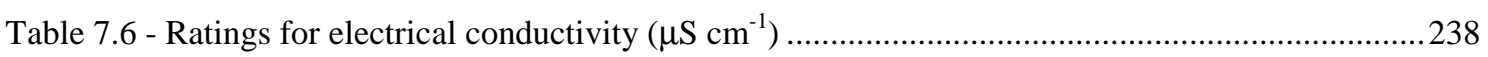

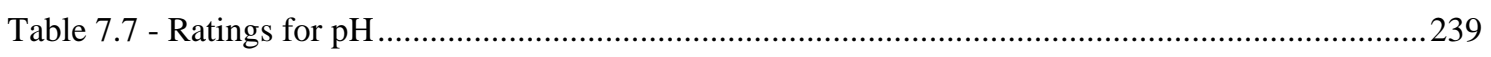

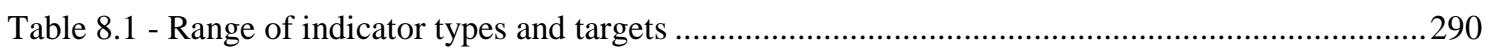





\section{LIST OF SYMBOLS}

\section{Symbol Definition}

$\alpha \quad$ Type I error probability

$\alpha_{1} \quad$ Percentile of the upper bound of a bootstrap confidence interval

$\alpha_{2} \quad$ Percentile of the lower bound of a bootstrap confidence interval

$\beta \quad$ Type II error probability

$\Delta_{b} \quad$ Difference between the true value of a sub-index score and the value estimated by sampling

$\Delta_{c} \quad$ Difference between the true change in a sub-index score and the change estimated by sampling

$\Delta_{\text {crit }} \quad$ Critical change in a sub-index score

$\Phi \quad$ Standard normal cumulative distribution function

$\Phi^{-1} \quad$ Inverse function of the standard normal cumulative distribution function

$\mu \quad$ Mean

$\theta \quad$ A statistic

$\hat{\theta}_{(i)} \quad$ Jackknife value of a statistic

$\hat{\theta}_{(.)} \quad$ Average of all the jackknife values of a statistic

$\hat{\theta}^{*} \quad$ A statistic calculated from a bootstrap data set

$\hat{\theta}^{*(\alpha)} \quad 100 \alpha$ percentile of the $\hat{\theta}^{*}$ distribution (e.g. if $\alpha=0.05$, then $\hat{\theta}^{*(\alpha)}$ would be the $5^{\text {th }}$ percentile of the $\hat{\theta}^{*}$ distribution)

$\sigma$

Standard deviation

$\sigma^{2} \quad$ Variance

$\hat{a} \quad$ Acceleration parameter

A Catchment area

$A B \quad$ Rating for artificial barriers

$b \quad$ A bootstrap data set

$B \quad$ The total number of bootstrap data sets

$\mathrm{Bb} \quad$ Rating for the condition of wetlands and billabongs

$B C \quad$ Rating for bed condition

$B S \quad$ Rating for bank stability

C Cost of management intervention

$C_{c} \quad$ Constant

$\mathrm{c}_{\mathrm{ij}} \quad$ Current flow for month $i$, in year $j$ 


\section{Symbol Definition}

$C_{m} \quad$ Measured change in a sub-index score

$C_{t} \quad$ True change in a sub-index score

$\mathrm{CV} \quad$ Coefficient of variation

$C W D \quad$ Rating for coarse woody debris

$d \quad$ Effect size

E Cost of environmental damage

EC Rating for electrical conductivity

g A grouping of reference sites used in AusRivAS

I Indicator value

$\mathrm{I}_{\mathrm{c}} \quad$ Critical value of an indicator

LC Rating for longitudinal continuity

$n \quad$ Sample size

$n_{i j} \quad$ Modelled natural flow for month $i$, in year $j$

$N_{s} \quad$ Number of sites

$N_{t} \quad$ Number of transects

$\mathrm{p} \quad$ Number of years of record

$P F \quad$ Physical Form Sub-index score

$p H \quad$ Rating for $\mathrm{pH}$

$P I G \quad$ Rating for proportion of groundcover that is indigenous

PIO Rating for proportion of overstorey cover that is indigenous

PIU Rating for proportion of understorey cover that is indigenous

$r \quad$ Reach

$\mathrm{R}_{\mathrm{a}} \quad$ Amended Annual Proportional Flow Deviation

Rg Rating for regeneration

$s \quad$ Site

$S \quad$ Bedload

$S_{1} \quad$ Sub-index score at time 1

$S_{2} \quad$ Sub-index score at time 2

$S_{c} \quad$ Streamside Zone Sub-index score based on the complete data set

SIG Rating for structural intactness of groundcover

SIO Rating for structural intactness of overstorey

SIU Rating for structural intactness of understorey

$S_{s} \quad$ Streamside Zone Sub-index estimated using a particular sampling scheme

$S_{t} \quad$ True value of the Streamside Zone Sub-index score 


\section{Symbol Definition}

SZ Streamside Zone Sub-index score

$t \quad$ Transect

$t \quad$ A particular macroinvertebrate taxa

$T \quad$ Rating for turbidity

TP Rating for total phosphorus concentration

Wd Rating for vegetation width

$z^{(\alpha)} \quad$ The $100 \alpha$ percentile point of the standard normal distribution (e.g. if $\alpha=$ 0.05 , then $z^{(\alpha)}$ would be the $5^{\text {th }}$ percentile of the standard normal distribution)

$\hat{z}_{0} \quad$ Bias-correction parameter 


\section{ABBREVIATIONS}

AAPFD Amended Annual Proportional Flow Deviation

ABS Australian Bureau of Statistics

AHI Aesthetic Health Index

AM Adaptive management

ASR Average Species Richness

AusRivAS Australian River Assessment Scheme

BEST Biomonitoring of Environmental Status and Trends

BHI Biological Health Index

CIA Central Intelligence Agency

CLPC Catchment and Land Protection Council

CMA Catchment Management Authority

CoA Commonwealth of Australia

COAG Council of Australian Governments

CSIRO Commonwealth Scientific and Industrial Research Organisation

DCE $^{1} \quad$ (Victorian) Department of Conservation and Environment

DCNR $^{1} \quad$ (Victorian) Department of Conservation and Natural Resources

DEST (CoA) Department of the Environment, Sport and Territories

DNRE $^{1} \quad$ (Victorian) Department of Natural Resources and Environment

EC Electrical conductivity

EHI Estuarine Health Index

EMAP Environmental Monitoring and Assessment Program

EPA Environment Protection Authority

HD Hydrologic deviation

HMS Habitat Modification Score

HQA Habitat Quality Assessment

IAEQ Index of Aquatic Environmental Quality

IRC Index of River Condition

ISC Index of Stream Condition

ITFM Intergovernmental Task Force on Monitoring Water Quality

\footnotetext{
${ }^{1}$ DCE, DCNR and DNRE are different names for the Victorian State Government department with responsibility for environmental management of rivers. The department was restructured and underwent the name changes as listed here (see Christoff, 1998).
} 
LWRRDC Land and Water Resources Research and Development Corporation

NASQAN National Stream Quality Accounting Network

NAWQA National Water Quality Assessment Program

NBS National Biological Service

NECMA North East Catchment Management Authority

NEW North East Waterways

NSW New South Wales

NWQI (US) National Water Quality Inventory

OECD Organisation for Economic Cooperation and Development

ORMB Ovens River Management Board

RCE Riparian Channel Environmental Inventory

RHS River Habitat Survey

SEAC State of the Environment Advisory Committee

SERCON System for Evaluating Rivers for Conservation

SERU State of the Environment Reporting Unit

SIGNAL Stream Invertebrate Grade Number Average Level

SRG Specialist Reference Group

SRWSC (Victorian) State Rivers and Water Supply Commission

SSS State of the Streams Survey

US EPA United States Environmental Protection Agency

USGS United States Geological Survey

VWQMN Victorian Water Quality Monitoring Network 



\section{PREFACE}

Sections of this thesis have been included in publications that are referred to in the text and included as appendices:

- part of Section 3.2 was published as Ladson and Tilleard (1999);

- part of Chapter 4 was published as Ladson and White (2000); and

- part of Chapter 5 was published as CEAH and IDA Pty Ltd (1995), Ladson et al. (1995; 1996), Ladson and Doolan (1997), Ladson et al. (1997b), Ladson and White (1999) and Ladson et al. (1999). 



\section{INTRODUCTION}

\subsection{Overview}

Managing the environmental values of waterways is an objective of state and federal governments in Australia. There is recognition that many rivers and streams have been degraded since European settlement and programs at federal, state and regional level have been established to improve their condition. Environmental indicators are increasingly being used as part of this management effort.

Environmental indicators are physical, chemical or biological measures that represent or summarise information on the key elements of an environmental system (Neimanis and Kerr, 1996). Environmental indicators allow identification and measurement of changes in the environment that are significant for humans and relate to particular issues (Elliot, 1996).

The promise of environmental indicators is that they can be useful management tools by turning large amounts of environmental data into simple results. Indicators can benchmark current condition and assist with strategy selection, establishing priorities and allocating resources. Ideally, they can track changes and allow assessment of the success of management strategies and provide information to refine those strategies. Environmental indicators are a key part of the Australian Federal Government's State of the Environment reporting (SEAC, 1996) and of adaptive management (Holling, 1978; Walters, 1986).

The application of environmental indicators to river management is the subject of this thesis. The focus is on river management authorities in Victoria, Australia although reference is made to other states in Australia as well as to international examples.

I argue that environmental indicators have a role at the level of regional waterway management authorities. Environmental indicators that can be incorporated into routine planning and reporting have the potential to overcome some of the pathologies of river management that relate to problems with the way environmental information has been incorporated into decision-making. At times, environmental information has been ignored or not collected. On other occasions, misguided decisions have been made based on perceptions of environmental change without rigorous assessment. In some 


\section{Introduction}

cases, environmental conditions have been measured but the data have been unsuitable for assisting managers' decisions.

The use of indicators implies a deliberate attempt to simplify an issue and the need to decide between key information and unimportant detail. There are hundreds of indicators to choose from, and more can be developed, but including them all would result in a detailed, expensive scientific study. Instead, a small group of indicators is required that captures important aspects of streams. If indicators are to be used as a management tool, they must meet the needs of managers. They must be able to be collected, understood and used with the skills available to management agencies and within their financial and resource constraints.

How can we decide which indicators to use? Specifying clear objectives is a critical first step that will determine the category of indicators that are required as well as the selection of individual indicators and how they will be valued. Individual indicators will also generally apply only within particular spatial and temporal bounds and to particular issues.

Indicators have been classified into several types.

- Indicators that are appropriate for benchmarking, that is, assessing the current condition of an aspect of the environment or characterising a resource.

- Indicators that are suitable for tracking changes or trends; these indicators require repeated measurements over time.

- Compliance indicators that are used to measure environmental condition in comparison to acceptable limits.

- Early warning indicators can provide evidence of significant change that may require management intervention.

Elliott (1996) lists the fundamental requirements of indicators.

- Relevance: indicators must relate to specified overall objectives.

- Measurability: practical methods must be available, or must be developed, so that indicators can be measured to an appropriate degree of accuracy.

- Repeatability: indicators must be able to be measured at different times and by different people. 
- Comparability: changes must be able to be calculated by comparing indicator values over time.

Conacher (1998) rightly points out that the selection of indicators is at least partly subjective. The chosen indicators depend on who does the choosing and what they think is important. Brunton (1994) shows that the choice of indicators can have political consequences and that indicators can be selected to support a particular point of view. Clearly, the selection process is important if indicators are to fulfil their potential roles and have credibility with those to whom they are being reported.

Valuing of indicators is also partly subjective. Raw data from measurements of environmental condition is rarely useful by itself; instead, the data must be placed into context through a comparison with reference conditions. The choice of reference conditions could include the natural or pristine state of a stream, conditions that favour a particular species or conditions that support designated uses. Deciding how indicators are to be valued is an important part of the development process.

The intended use of indicators determines the required accuracy. For benchmarking, indicators must reflect current conditions with an acceptable level of accuracy. Useful results may be obtained as part of a one-off assessment using indicators but they will also be an important part of environmental monitoring, which Meijers (1986) defines as the process of:

repetitive observing, for defined purposes, of one or more elements of the environment according to prearranged schedules in space and time using comparable methods of environmental sensing and data collection.

It is the systematic, repetitive element of monitoring that separates it from environmental survey (Cullen, 1990) and different types of indicators are likely to be required. When using indicators to detect changes they must be sensitive enough to respond to management intervention. Using indicators to evaluate and refine management strategies requires that they provide a signal that can be separated from the noise of spatial and temporal variability that occurs in any environmental system. Use of indicators as part of adaptive management requires that they are capable of providing unambiguous responses that can be used to assess the results of large scale management experiments (Walters and Holling, 1990). 


\section{Introduction}

When using indicators for strategy evaluation, stability of institutional arrangements is important. Since there will be a lag between implementation of strategies and changes in condition there needs to be focus on particular goals for some time before it is worth monitoring to detect change. This is an issue in Victoria where there has been rapid institutional reform in the last 10 years.

Finally, it is important to understand the limitations of environmental indicators. Environmental indicators can flag problems and show where detailed scientific studies are required. There will also be situations where simpler measures are appropriate that could relate directly to management actions rather than the measurement of physical changes in environmental condition.

These issues are explored through a review of indicator systems developed by others and a detailed analysis of the Index of Stream Condition (ISC), a system of indicators intended to assist river management in Victoria. The ISC project, which was funded by the Victorian Department of Natural Resources and Environment, is the result of input from a wide range of people as discussed in Chapter 5. This thesis reviews the development of the ISC highlighting the process and issues that were addressed. An initial index was developed, which was then trialed and refined before being tested. Limitations of the ISC and challenges and implications for similar indicator systems are described.

\subsection{Structure of this thesis}

This thesis is divided into nine chapters. Following this introduction, Chapter 2 provides the context by presenting a brief history of river management. For most of the period since the establishment of Victoria, the dominant influence has been one of development, which has been carried out with little regard for environmental values. The impacts of gold mining, navigation, water resource development and stream clearing and channelisation are discussed. A review of academic literature, magazine articles and newspaper stories is used to show that there has been a rise in environmental concern. The challenge is now to incorporate environmental information into river management decision-making.

In Chapter 3, literature reviews and case studies are presented that highlight some pathologies of the way environmental information has been collected and used to guide waterway management in the past. In the first case study, discussions of management 
of the Snowy River (Victoria), Nogoa River (Queensland), Avon River (Victoria) and particularly the Herbert River (Queensland) are used to show that management actions have often been in response to perceptions of the state of the environment. These perceptions may not be supported by objective information.

The second case study is a review of the collection and use of water quality data in Victoria. The broader lessons are that even where there has been rigorous monitoring of the environment, the information may not be suitable to assist management decisionmaking.

A third case study highlights the need for appropriate institutional arrangements if broader environmental issues are to be considered. This case study discusses the implementation of tradeable water entitlements in Victoria. Originally, uncertainties about the environmental consequences of this strategy were recognised and a comprehensive monitoring program was proposed. However, a review of government publications written at different times and the history of revisions to the Victorian Water Act are used to show that there has been a narrowing of the management focus, a restriction of monitoring and little opportunity for intervention if there are adverse consequences.

There are three main arguments in Chapter 3. Firstly, the systematic collection and reporting of environmental indicators can help to overcome these pathologies of river management; secondly, if monitoring is to guide the decisions of managers it must meet their needs; and thirdly, if environmental information is to be used effectively, it must be incorporated into routine planning and reporting by managers.

Chapter 4 critically reviews existing approaches to monitoring stream condition both in Victoria and internationally. For each method, the suitability and limitations are highlighted along with the objectives, scale of measurements, the aspects of stream condition that are included, and the basis for valuing the indicators.

The next three chapters investigate the Index of Stream Condition, a suite of indicators intended to assist waterway management in Victoria. Chapter 5 discusses the development of the ISC and reflects on the process. The ISC consists of five groups of indicators referred to as sub-indices. These are: hydrology (change in volume and seasonality of flow from natural conditions); physical form (bank stability, bed erosion or aggradation, influence of artificial barriers, and abundance and origin of coarse 


\section{Introduction}

woody debris); streamside zone (type of plants; spatial extent, width and intactness of riparian vegetation; regeneration of overstorey species and condition of wetlands and billabongs); water quality (phosphorus, turbidity, electrical conductivity and $\mathrm{pH}$ ); and aquatic life (macroinvertebrate families).

In Chapter 6, the issues associated with sampling, sensitivity and accuracy of the Streamside Zone and Physical Form Sub-indices are investigated. Data are analysed from two streams in northeastern Victoria, Ryans Creek and the Broken River. A sampling approach based on the subjective selection of a 'representative' reach is investigated and the analysis shows it is difficult to have confidence in the results. Instead a random sampling method is proposed and the required sampling density is related to the intended uses of the indicators. Different levels of accuracy are required if indicators are to be used for benchmarking, change detection or as triggers for management intervention. Chapter 6 also investigates the ability of the Streamside Zone and Physical Form Sub-indices to detect the types of changes that could occur over a decade of river management.

Chapter 7 investigates the Hydrology, Water Quality and Aquatic Life Sub-indices. The Hydrology Sub-index is calculated for 21 streams in Victoria and New South Wales that range from highly regulated such as the Goulburn River (Victoria), to those where there has been limited alteration to stream flows such the Gellibrand River (Victoria). The sensitivity of the Hydrology Sub-index is investigated through a case study of proposals to implement a changed flow regime to improve environmental values in the Campaspe River.

Long-term water quality data from the Latrobe River at Rosedale in Victoria, are used to investigate the behaviour of the four water quality indicators and the Water Quality Sub-index. Scenarios are developed to explore the response of indicator values to improvement in water quality.

The Aquatic Life Sub-index consists of two indicators that were developed by others: SIGNAL (Stream Invertebrate Grade Number Average Level) and AusRivAS (Australian River Assessment Scheme). Literature related to these indicators is reviewed to highlight issues associated with accuracy. 
Chapter 8 ties together the ideas of the thesis and draws out the implications and challenges for the development and use of indicators in environmental management of rivers. The main conclusions are summarised in Chapter 9. 


\section{BRIEF HISTORY OF RIVER MANAGEMENT}

'In river conservancy work also, there are only two broad choices - should one speed the flow of water to the sea, or should one heighten the dikes?'

K'ang-Hsi, Emperor of China 1661-1722 (Spence 1988, 47)

\subsection{Introduction}

This thesis lies within the context of river management and is particularly concerned with measuring environmental information that can be used to assist the decisions of managers. To set the scene for later chapters, it is important to consider the main activities that have affected Australian rivers and to map the rise of concern about the wider environmental condition of these rivers.

For most of Victoria's history, the dominant influence on rivers has been one of development. The first major impacts occurred as the Australian population expanded following the discovery of gold in 1851 , which coincided with the formation of the colony of Victoria. Use of rivers for gold mining and for navigation was important to about 1930. Most of the $20^{\text {th }}$ century has seen a major phase of water resource development and river improvement, which was carried out with little regard for the environment. More recently, there has been a rise in national and international concern about efficient water use, sustainable management of rivers and the need to protect their environmental values.

This chapter briefly describes these influences and charts the rise of environmentalism in the context of river management. Institutional arrangements for river management are discussed along with the need for, and use of, information from environmental indicators. While the focus of this chapter is on rivers in Victoria, there is also discussion of Australia-wide issues and international influences. It is considered that the development of river management in Victoria has followed essentially the same path as in other jurisdictions. This review is indicative rather than comprehensive and is presented to provide the context for the detailed discussion in later chapters. The geographic features in Victoria referred to in this chapter are shown in Figure 2.1. 


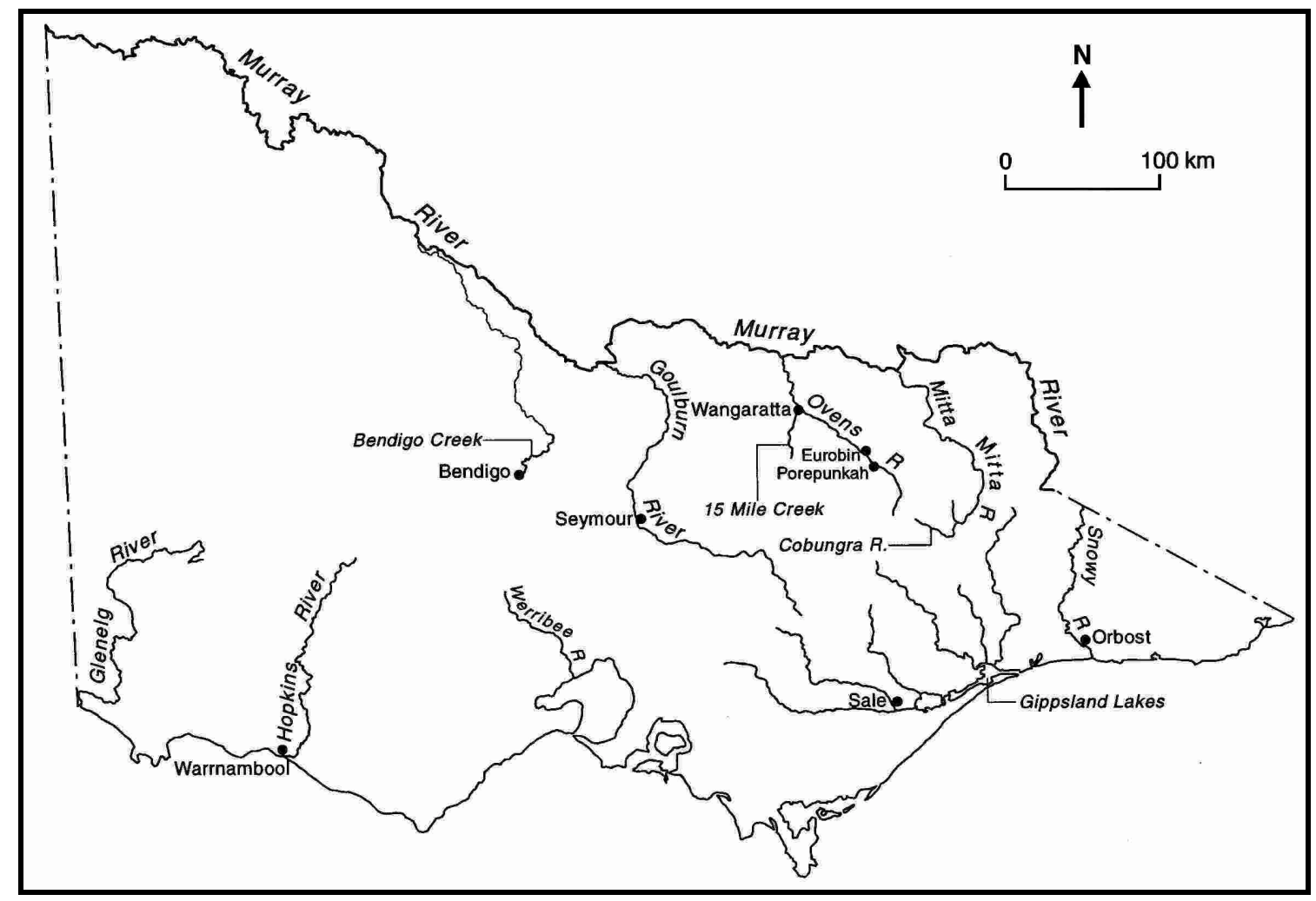

Figure 2.1 - Victorian rivers affected by goldmining and desnagging 



\subsection{The impact of gold mining on rivers in Victoria}

The decade 1851 to 1861 saw a major increase in population in Australia following the discovery of gold and the formation of Victoria as a separate colony from New South Wales as many settlers followed the rush to the Victorian goldfields (Peel, 1974). The first diggers placed great demands on water supply and altered the landscape and riparian areas by clearing trees:

Little more than a year ago, the whole of this valley on the Bendigo Creek seven miles long by one and a half wide, was an unbroken wood! It is now perfectly bare of trees, and the whole of it riddled with holes of from ten to eighty feet deep-all one huge chaos of clay, gravel, stones, and pipe-clay, thrown up out of the bowels of the earth! [The diggers are] like a flight of locusts, who tear up and leave the earth a desert in a few weeks (Howitt, 1972, 47-8).

Over time, the search for gold became more mechanised and the impact on the waterways and use of water resources more pronounced. The first mechanical introductions were horse drawn puddling machines that increased the quantity of material being processed. They required a reliable water supply and tailings and turbid water were discharged directly back into streams. By 1858, there were 5000 machines in use in Victoria (Powell, 1976). Sludge blocked natural watercourses and inundated surrounding land.

Pollution had become such an issue that in 1861, 10 years after the commencement of gold mining, the Victorian Parliament established a Sludge Select Committee to investigate the problem. This committee failed to report and in 1887 a Board was appointed to inquire into the sludge question and document damage caused by mining (Victoria, Parliament, 1887). Damage included:

...filling up large clear waterholes in the creeks and rivers (used for stock and domestic purposes), the silting up of the river beds, causing the sludge to overflow on the adjacent lands, the destruction of vegetation and fruit trees...These, and the destruction of roads and bridges, are some of the evils arising from the absence of foresight on the part of the Legislature in years gone by and the want of care on the part of the miners (Victoria, Parliament, 1887, 8). 


\section{Brief history of river management}

The Board was particularly concerned about new mechanised methods of mining:

The last branch of mining to be considered is sluicing by means of the giant nozzle. This system of mining has of late years been introduced into the Mitta Mitta and Cobungra districts from California...By means of it, the quantity of stuff that can be sent into the rivers is enormous. At present, there are only three of these nozzles at work in the colony, each of which displaces a ton of earth per minute, working day and night; but it is proposed shortly to increase the number to twelve, in which case not less than 7000 cubic yards per day [5 $350 \mathrm{~m}^{3}$ day $^{-1}$ ] of 24 hours will be discharged into the River Mitta Mitta. This amounts in one year to 2000000 cubic yards $\left[1.53 \times 10^{6} \mathrm{~m}^{3}\right]$, sufficient to fill a stream 104 feet [32 m] wide to a depth of three feet [1 m] for a distance of 32 miles [51 km] in twelve months (emphasis in the original, Victoria, Parliament, 1887, 13).

Later, bucket-wheel dredges were introduced that floated on an enlarged and deepened part of a stream and removed sediment from depths of $20 \mathrm{~m}$ (Beard, 1979). The gold was extracted and the turbid water and tailings discharged as the dredged moved on. A single dredge covered an area of about 1 ha per year, completely disrupting the stream bed, banks, wetlands and surrounding vegetation.

Between 1900 and 1908 it is estimated that over 109000000 cubic yards [ $83.3 \times 10^{6} \mathrm{~m}^{3}$ ] of material had been worked by bucket dredging, and hydraulic sluicing (Victoria, Parliament, 1909). In 1913 an estimated 46000000 cubic yards $\left[35 \times 10^{6} \mathrm{~m}^{3}\right]$ of material had been disturbed as part of mining operations in the Ovens catchment alone with most of this being washed into local streams and then into the Ovens River and further downstream (Victoria, Parliament, 1915; see Figure 2.1.

A measure of the possible impact of this sediment load can be gained by comparing it to the natural load in the Ovens River. The bedload of Australian rivers can be estimated from equations developed by Davis (Davis, 1996; Davis pers. comm.).

$$
S=700 A^{0.65}
$$

Where $S$ is the sediment load in tonnes per year and $A$ is the catchment area in $\mathrm{km}^{2}$. The catchment area of the Ovens River is $7800 \mathrm{~km}^{2}$ (Department of Water Resources, 1989a) giving an estimated annual sediment load of $240 \times 10^{3}$ tonnes or approximately $145 \times 10^{3} \mathrm{~m}^{3}$. Therefore, the mining induced sediment loads on the Ovens River are 
equivalent to about 240 years of natural bedload transport. Actually this is likely to be an underestimate since the equation developed by Davis was based on recent reservoir sedimentation rates which are likely to include higher sediment loads than those in undisturbed catchments.

There are incomplete records on the number of sluices operating in Victoria but the total seems to have peaked in 1908 when there were 84 operating; this decreased to 21 by 1918 (Victoria, Parliament, 1908; 1919; Wharton, 1969). The number of dredges and quantity of material worked was reported to Parliament for at least some years Figure 2.2.

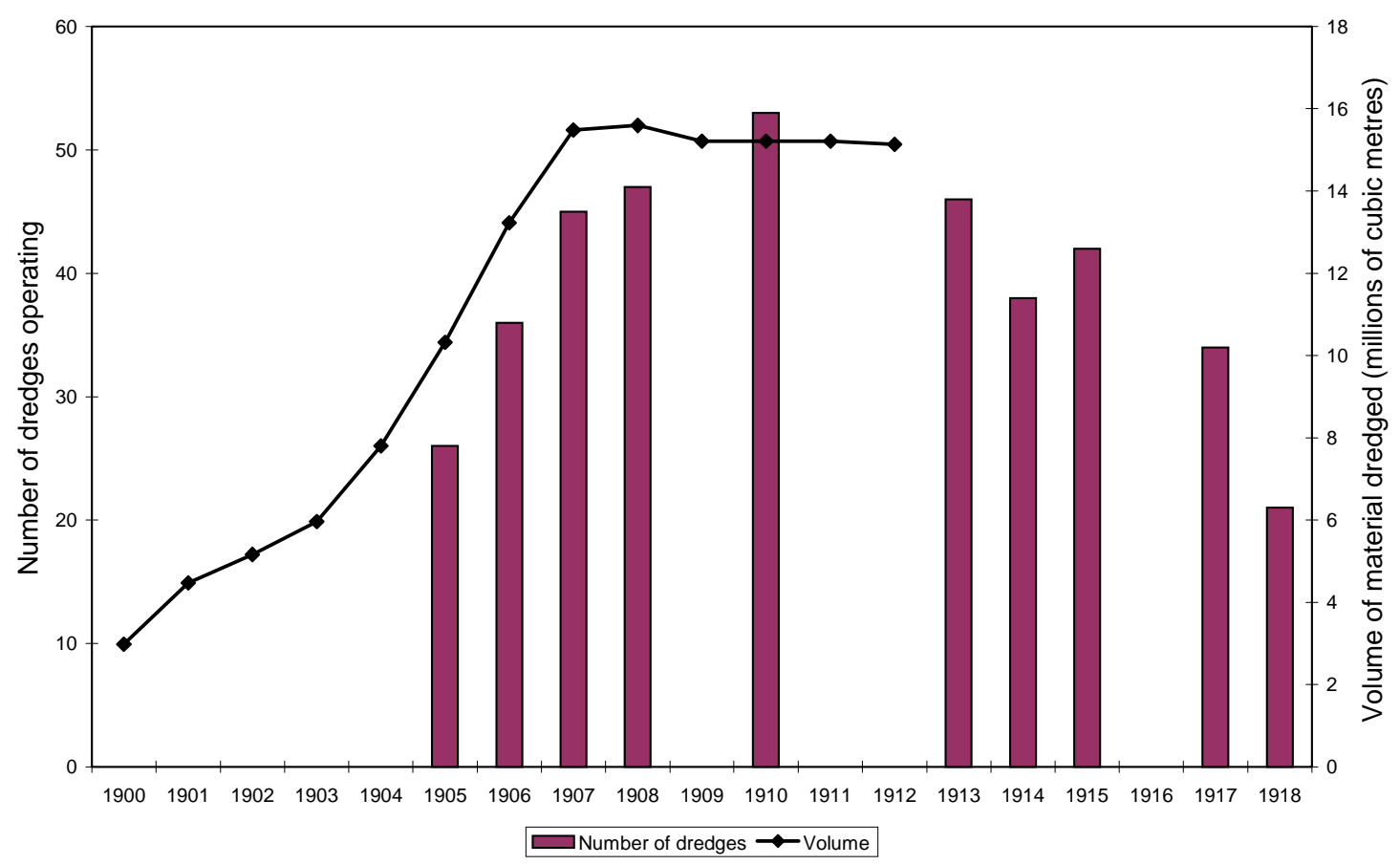

Figure 2.2 - Extent of dredging in Victoria 1900 - 1918, (adapted from Victoria,

\section{Parliament, 1913; all available information is plotted)}

The Victorian Government's response to concern about the damage from extreme sediment loads was to establish a Sludge Abatement Board on the $6^{\text {th }}$ of February 1905 which would be an ongoing authority to regulate any mining that caused tailings to be discharged to any watercourse (Victoria, Parliament, 1915). This Board inspected mining areas, investigated complaints, placed restrictions on mining licences and leases and issued orders to improve mining practices. Problems remained and the powers of the Sludge Abatement Board were increased with the passing of the Mines Act in December 1907. 


\section{Brief history of river management}

In 1913, a Dredging and Sluicing Inquiry Board was established to review the effect of mining on the waters of rivers and the lands alongside or downstream of mining. This inquiry supported the role of the Sludge Abatement Board and recommended that its power be increased to prescribe conditions on leases, enforce the conditions by suspending work as necessary and to control mining inspectors (Victoria, Parliament, 1915).

It is interesting to consider Parliament's concerns with rivers during this period. The issue was usually not the damage to the rivers themselves but to the surrounding land and water supply. There was concern that mining should not be allowed to affect valuable agricultural land and a Ministerial order was made in 1909 that only land worth

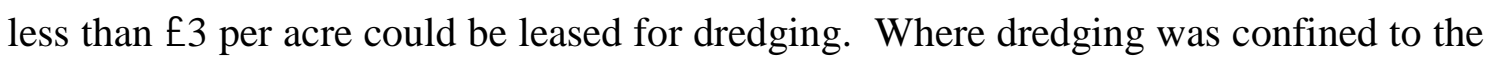
river bed it was not considered likely to cause a problem:

There is no reason, however, to believe that the turning over of the bed and beaches of the Mitta Mitta [River] by a limited number of such dredges would lead to well-grounded complaints about the pollution of the water. Obviously, if the operations were confined to the bed and beaches, there would be no destruction of valuable land, and if care were taken to do the work judiciously, the river channel might be improved in cross-section and discharging capacity, and the liability to flooding and siltation of the river flats considerably reduced (Victoria, Parliament, 1906, 71)

Similar sentiments were expressed in 1912:

During 1912 statements have appeared in the press that great devastation has been caused by the Ovens dredges. These complaints are evidently due largely to an imperfect knowledge of the facts, of which the following is a concise resume: since the inception of dredging in Victoria to date, the area classified as agricultural land dealt with by the dredges is, approximately, 200 acres [81 ha], and of pastoral land about 1200 acres [490 ha], the balance, about 5000 acres [2 000 ha], being river and creek bed and old worked mining ground (Victoria, Parliament, 1913, 56).

Apparently, dredging 2000 ha of river and creek bed could not be considered great devastation and the effect of any tailings deposited into streams was not even mentioned. 
The effect of the mining debris on fish was also not taken seriously by the Board:

Objection has been taken by anglers to the discoloration of the water of the Ovens and other rivers because they consider that it spoils their amusement, but, while it is to be regretted that any one should suffer inconvenience, however slight, it is scarcely reasonable to ask that an industry, returning $£ 300000$ and employing a large number of men at good wages, should be interfered with merely because it affects the sport of a few individuals (Victoria, Parliament, $1913,56)$.

The 1913 Dredging and Sluicing Inquiry did provide a rare mention of values other than utilitarian when it expressed concern about the effect of dredging on aesthetics:

Bucket dredging produces an appearance - as it does in fact - of devastation and desolation...the fact remains that the natural beauties of some districts, in which the whole community should have rights, have for the present, and probably permanently, been destroyed. No more striking instance of what might be termed this industrial vandalism can be cited than has occurred in the Ovens Valley in the neighbourhood of Porepunkah and Eurobin...This once beautiful valley is now largely a shingle waste... Much evil has been done here and elsewhere from this point of view; while it is certain that, under leases yet running, much more remains to be done if preventative steps be not taken (Victoria, Parliament, 1915).

\subsection{Using rivers for navigation}

The increase in settlement in NSW and Victoria following the discovery of gold in 1851 and the expanding regional economies, increased the need for transport and the era of river navigation began in earnest in 1853 (Murray-Darling Basin Commission, undated). Australian rivers in their natural state were generally unsuitable for shipping because they were shallow, full of fallen trees (snags) and the flow fluctuated greatly. Their only advantage was that overland transport was even more difficult and goods could be taken $1000 \mathrm{~km}$ by river for the same cost as a $60 \mathrm{~km}$ journey overland (Clark, 1989).

Efforts to improve navigation led firstly to river clearing and desnagging and proposals for elaborate schemes of weirs and locks. In 1867 a Royal Commission was established by the Victorian Parliament to examine the best means of clearing the Murray River 


\section{Brief history of river management}

(Figure 2.1 and special boats were constructed to facilitate snag removal. The Royal Commission reported that between January 1864 and December 1866 over 9900 snags with a volume of over $30900 \mathrm{~m}^{3}$ were removed from the river (Victoria, Parliament, 1867). It was recommended that snag removal should continue, to facilitate transport and to benefit the Victorian Railways, which could supply the paddle steamers at ports along the river. By 1878 the snagging vessel Bunyip had reached Seymour on the Goulburn River suggesting that over $350 \mathrm{~km}$ of that river may have been desnagged. The extent of normal commercial navigation on the Murray-Darling system was approximately $5500 \mathrm{~km}$ and it is likely that snags would have been removed over this length of river.

Victorian rivers outside the Murray-Darling Basin were used for navigation and were probably subject to desnagging. River transport became important in the Gippsland Lakes after 1858 and in 1864, it was recommended that snags be removed from the surrounding rivers to facilitate transport. There was also river transport on the Snowy, Glenelg, Hopkins, and Werribee Rivers Figure 2.1 and it is likely that desnagging and other river modifications would have occurred (Clark, 1989). Desnagging also occurred in rivers on the north coast of Queensland including the Barron, Daintree, Mossman, Mulgrave, Tully, Russell and Murray Rivers and Bedford Creek (Queensland, Parliament, 1887; 1889; see Figure 2.3. It is likely that a more complete search would find evidence of desnagging in other rivers throughout Australia.

Navigation peaked between 1870 and 1880. By the 1930s, the steamer traffic on the Murray River and other rivers had virtually disappeared because of competition of roads and railways (Clark, 1989; Murray-Darling Basin Commission, undated).

\subsection{Water resources development}

Following Australian federation in 1901, plans for the use of rivers became more elaborate and in 1902, an interstate Royal Commission was held into the use of the Murray River (Victoria, Parliament, 1902). Navigation was still important with 90 registered steamers and barges but attention had turned to water resource development with the majority report of the Royal Commission noting that 'On the whole, the weight of evidence is in favour of considering irrigation as superior in importance to navigation' (Victoria, Parliament, 1902, 35). There was no mention of snags as a barrier to navigation, the main concern being low water levels and fear by one commissioner, 


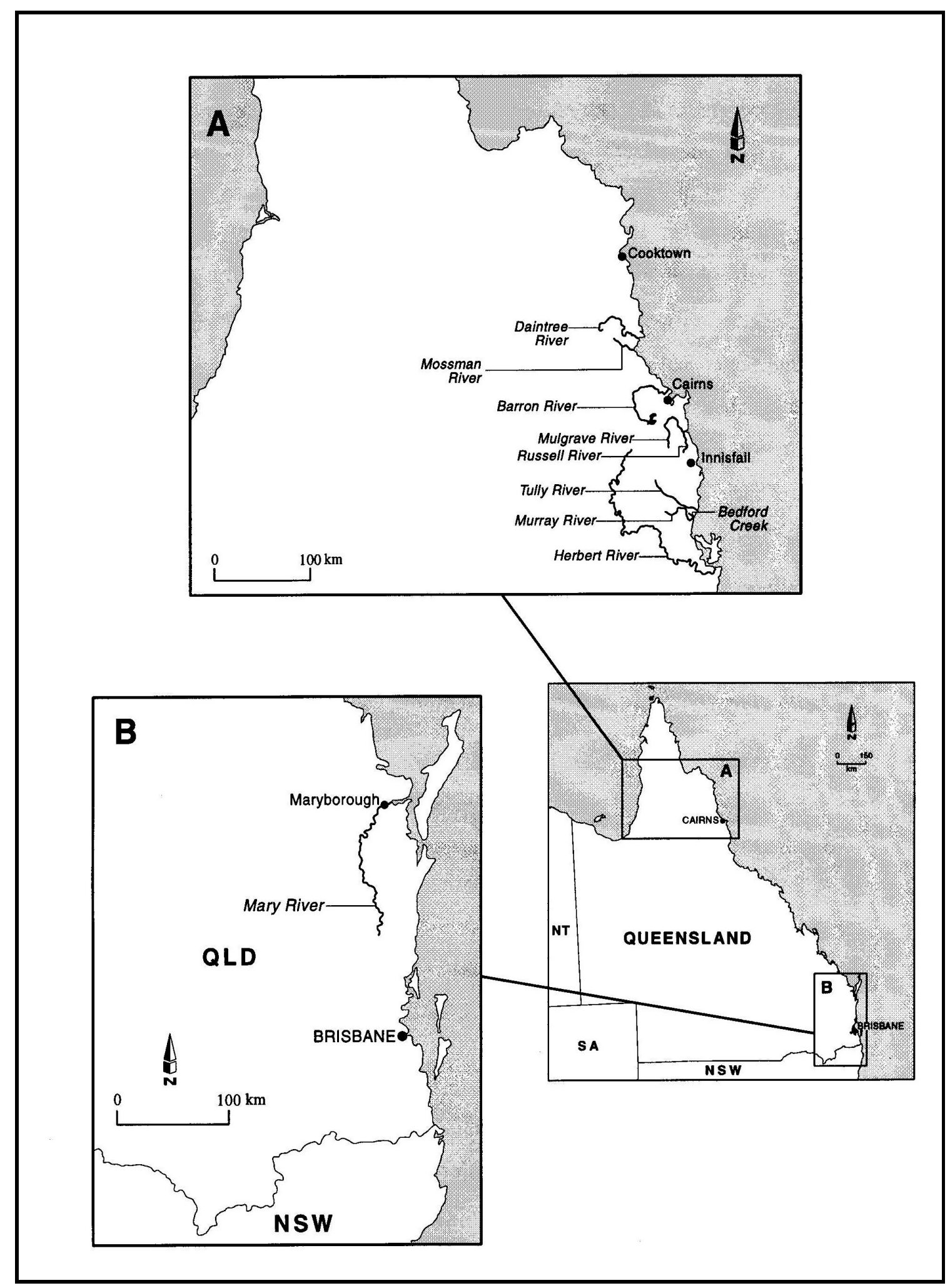

Figure 2.3 - Queensland rivers that were desnagged in the 1880s 

in a dissenting report, that water extractions for irrigation would threaten the navigability of the river. Perhaps because of dissent amongst the commissioners, the final report proposed an extensive series of locks and dams to satisfy both navigation and water resource development including 40 locks on the Darling River, 26 on the Murray and nine on the Murrumbidgee. Only 14 were ever built, one on the Darling River and 13 on the Murray River. There were proposals for extensive irrigation channels in Victoria and New South Wales and storages on the upper Murray, Lachlan and Murrumbidgee rivers.

Most of the earlier attempts to establish irrigation in Victoria had failed but in 1905, with the passing of the Victorian Water Act, the State Rivers and Water Supply Commission (SRWSC) was established to oversee irrigation and water resource developments (McCoy, 1988). This body was to dominate water resources development in the State for the next 85 years.

Following the First World War, construction of water storages began in earnest. Figure 2.4 shows the total storage capacity of reservoirs in Victoria and the capacity added per decade between 1850 and 1990. By 1991, half the State's water resources were harnessed (DCE, 1991). A similar pattern of development was followed in other states (Boughton, 1999).

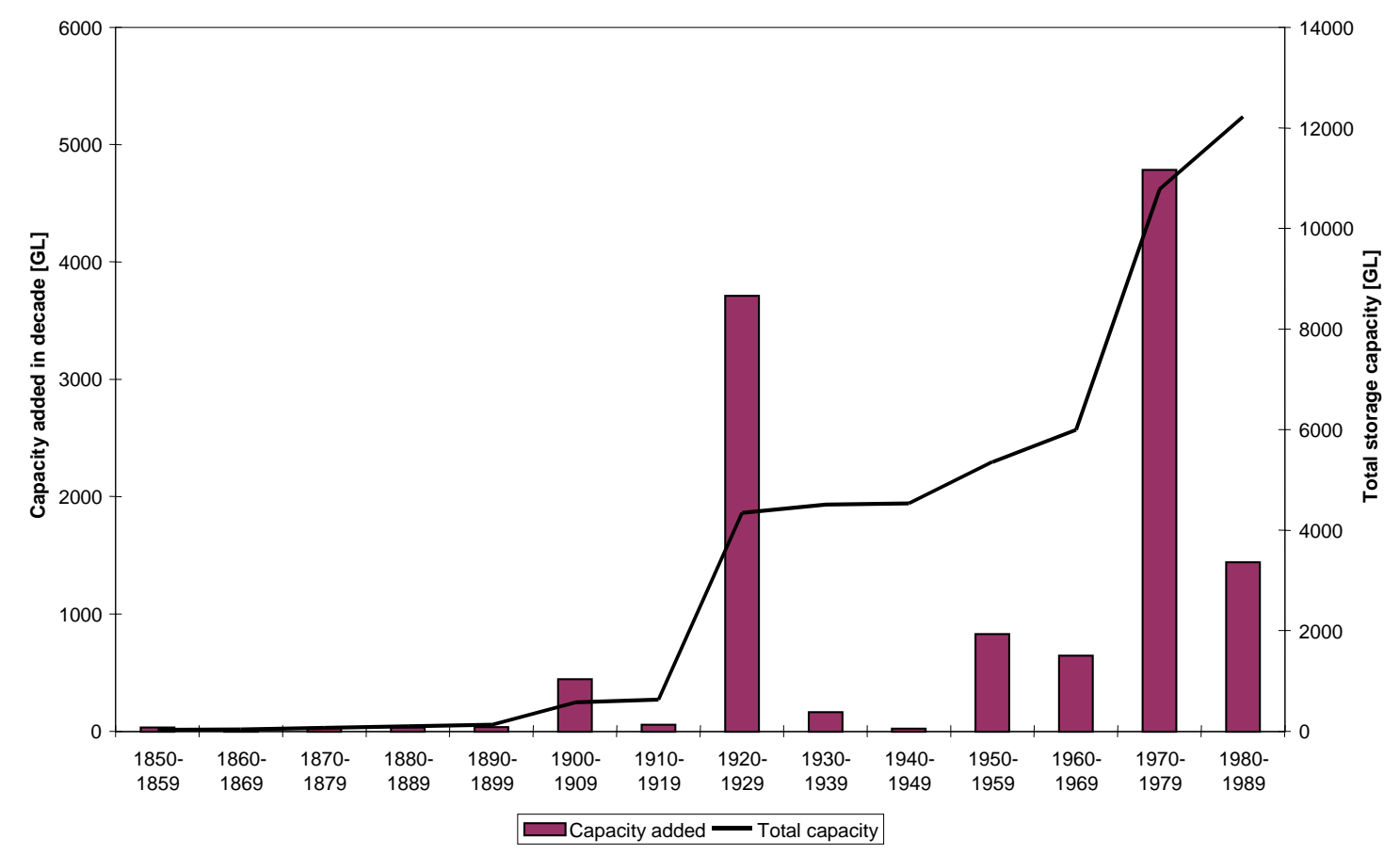

Figure 2.4 - Water resources development in Victoria (Boughton, 1999) 


\section{Brief history of river management}

Nationally, there was particular emphasis on dam construction in the Murray-Darling Basin. Between 1930 and 1985 over 1000 dams or weirs were built (Mallen-Cooper and Copeland, 1997) and by 1990 approximately $75 \%$ of the available water was diverted on average Figure 2.5.

The use of the rivers as part of the water supply system for irrigators also created further demands for another round of desnagging to increase flow capacity. For example, 24500 snags were removed from the Murray River between Hume Reservoir and Yarrawonga between 1976 and 1987 to improve conveyance (Gippel et al., 1992).

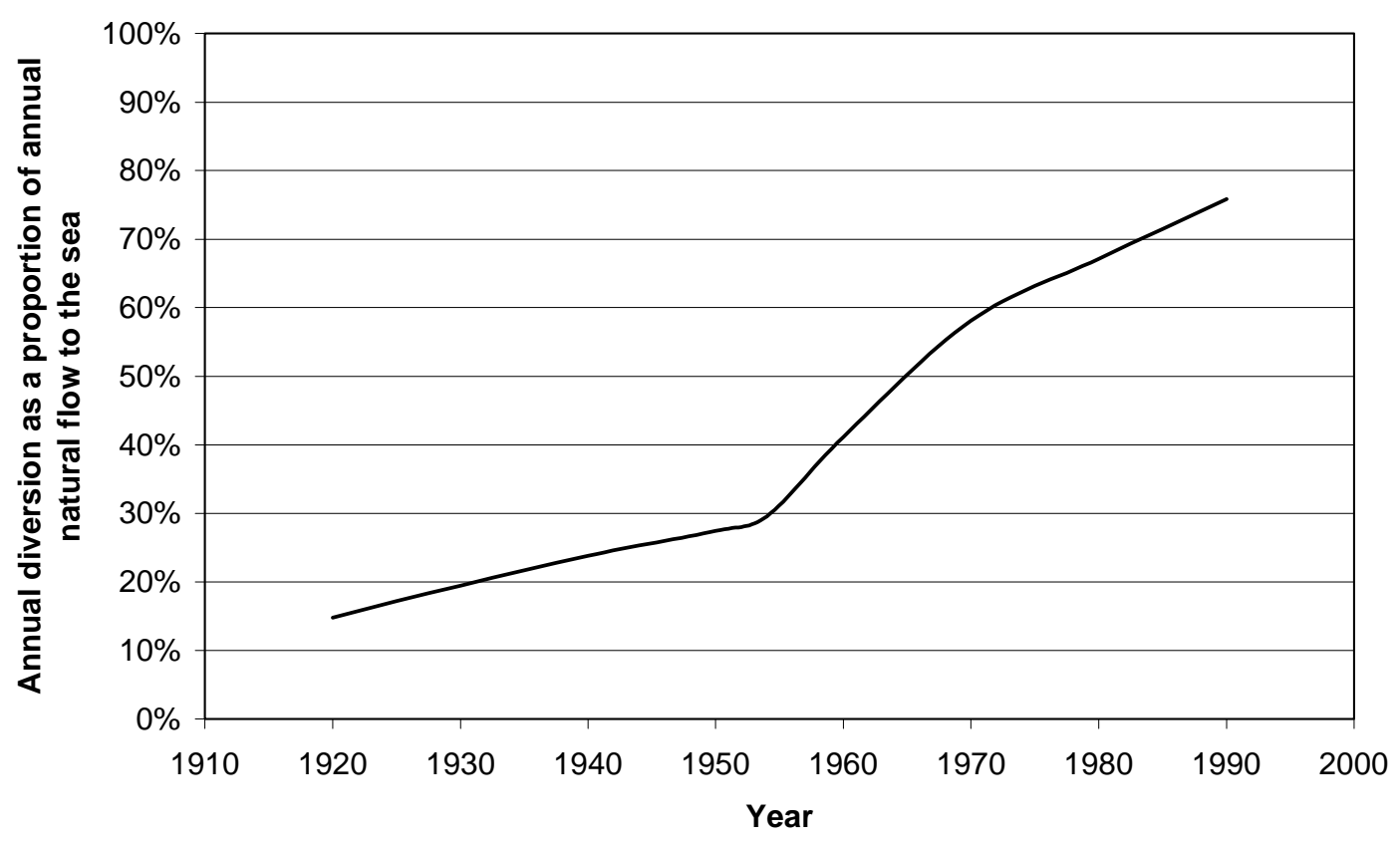

Figure 2.5 - Growth in water use in the Murray-Darling Basin (Murray-Darling Basin Ministerial Council, 1995)

\subsection{River 'improvement'}

Although the main function of the SRWSC was water resources development for irrigation, the Water Act of 1915 gave it power to investigate, and if appropriate, approve private works for flood protection, drainage and erosion control (although in general these would not be funded by the government or the SRWSC). By 1930 it was perceived that the need for these works warranted more State intervention and the 'Rivers and Streams' Fund was created to be used towards the removal of obstructions in 
rivers and streams and the prevention of bank erosion (Victoria, Parliament, 1931). According to Lewis R. East, Chairman of the SRWSC, the need for the fund was clear:

The rivers of all countries are amongst their most precious heritages, yet singularly little attention is given to their preservation until spectacular damage has been occasioned to valuable lands and to the rivers themselves as a result of the short-sighted or thoughtless destruction of vegetation which for ages has afforded natural protection to their banks [Lewis R. East (Later Sir Roland East), Chairman, State Rivers and Water Supply Commission (Strom, 1941, 5)].

East described the creation of the Rivers and Streams Fund as the turning point in the history of Victorian streams. Previously the SRWSC had only been able to offer advice and there had been 'no public authority [with] sufficient power to protect streams which have rapidly deteriorated' (Strom, 1941, 5).

Strom $(1941,98)$ noted the 'problems of river control in Victoria' which included flooding, blocking of streams by willows, bank erosion, and siltation. Suggested works to reduce flooding were levee banks, stream clearing including removal of snags (logs and trees) and removal of willows, cutting of new channels, channelisation, and flood retarding basins. Erosion control works included battering of riverbanks, laying trees against banks and various types of groynes. In Victoria, these types of activities would later become known as 'river improvement works'.

Strom (1941) also noted that vegetation was the best protection against erosion and that works of a mechanical nature were usually intended merely to check the erosion until the vegetative protection had a chance to become established. This enlightened idea was still being discussed in 1996 (Burston and Brown, 1996). Strom was also instrumental in undertaking comprehensive river surveys to provide information for planning works, determining the effect of proposed works on the river as a whole, and benchmarking current condition (Thompson, 1938; Strom, 1941, 101).

The demand for river improvement works continued and there was an important reform with the passing of the River Improvement Act of 1948 establishing River Improvement Trusts - local bodies with power to control, improve and maintain rivers (Strom, 1951; East, 1952). Strom (1951) outlined the work of the Trusts as 'improving and controlling the rivers of Victoria'. The main issues were waterlogging, flooding, erosion and 


\section{Brief history of river management}

siltation, and suggested works were similar to those that Strom had listed in 1941 (Strom, 1941).

There were further reforms in 1958 with the strengthening, by provisions of the Water Act 1958, of powers of the Crown to control the bed and banks of watercourses (Clark and Scovell, 1982). There was also the passage of the River Improvement Act 1958 that defined Trust works including:

- Clearing and removing obstructions from the bed and banks of a river;

- Widening, deepening, straightening, diverting or otherwise improving a river;

- Prevention of and defence against flooding by river waters;

- Making new courses or outfalls for a river, defining and constructing the course of a river through a swamp or otherwise draining land;

- Preventing or minimising erosion of the bed or banks of a river;

- Erecting any weir or any bank, groyne, dam or other defence against river waters;

- Cleansing a river or preventing or minimising its pollution;

- Planting, sowing and maintaining any trees shrubs plants or grasses in connection with river improvement works; and

- Any other works for general or any specific improvement of a river.

The Trusts were still under the control of the SRWSC, which supervised river improvement works and required that all plans and specifications be submitted for approval (River Improvement Act 1958, Section 23). The SRWSC also had control over research into river improvement work (River Improvement Act 1958, Section 32).

Strom again reviewed issues and techniques in 1962 (Strom, 1962) and included discussion of activities in other States. In NSW, in common with Victoria, difficulties on rivers included flooding that was often aggravated by snags or willow growth, erosion, course changes, water logging and inundation of low lying coastal areas by salt water (Strom, 1962, 210). Similar issues were listed for Queensland and Tasmania. In Western Australia and South Australia, there was limited need for river works with occasional drainage works required. Queensland had gone down a similar path to Victoria by establishing River Improvement Trusts. In New South Wales there was 
centralised control of river works with supervision from Sydney (Strom, 1962). A review of river improvement works in NSW by Shattock (1966) showed that the types of works were similar to those in Victoria.

\subsection{The rise of environmental concern}

The environmental impact of water resources development and river improvement works became apparent during the $20^{\text {th }}$ century. By 1950, a declining Murray Cod (Maccullochella peelii peelii) population was being blamed on construction of reservoirs that had reduced the floods which triggered Cod to spawn (Roughley, 1950).

Review articles in the 1960s (Pollard and Scott, 1966; Williams, 1967; Wharton, 1969) noted the major influence of dams on aquatic fauna, particularly cold water releases, changes in flood regime and their role as barriers to fish migration. There were also concerns about pollution, introduction of exotic taxa, and poor forestry and agricultural practices.

Wharton (1969) criticised the actions of River Improvement Trusts particularly desnagging, removal of standing trees, and straightening of rivers. These works were linked to destruction of the habitat that threatened native fish and aquatic fauna:

The pools and riffles created by fallen logs and flood debris and the nearly endless variety of hiding, resting and breeding places that they also provided for fish and other animals have been and are being eliminated by systematic river improvement and few, if any, of our native animals can use the new environment successfully (Wharton, 1969, 53).

Public criticism of the actions of River Improvement Trusts became more strident during the 1970s and 1980s (Green, 1975; Conservation Council of Victoria, 1977; Johnson, 1978; Lake, 1980; Gregory, 1981; Gregory and Pressey, 1982; Day, 1988), with the Conservation Council of Victoria conducting a political campaign to reform the Trusts and their activities. The main criticisms related to the narrow focus of the Trusts on benefiting agricultural production and protecting private land and the absence of consultation with environmental interests including government departments. Trusts were accused of carrying out river improvement works with little or no consideration of detrimental effects on stream biota (Lake, 1980). 


\section{Brief history of river management}

The published guidelines for river improvement works in Victoria span the period 1941 to 1991 (Strom, 1941; Strom, 1951; Strom, 1962; Turnbull, 1973; Turnbull, 1974; SRWSC, 1979; Standing Committee on Rivers and Catchments, 1991). There is virtually no change in recommended techniques during the 50 years of these publications suggesting that the River Improvement Trusts were slow to respond to criticisms of environmental groups and scientists. Although the works of river improvement do not appear to have changed between 1941 and 1991, there is growing acceptance of environmental concerns in the recent publications. In 1974, Turnbull acknowledged that Trusts had been criticised for destroying fish spawning grounds by removing snags, and for 'aesthetic consequences' following removal of overhanging trees but he simply states that these criticisms are not warranted (Turnbull, 1974, 17). By 1979 the SRWSC had set up a Standing Consultative Committee on River Improvement to 'prepare guidelines to assist River Improvement and Drainage Trusts in carrying out their statutory functions, ensuring in particular, that due regard is given to the environmental consequences of any proposed works' (SRWSC, 1979). The term 'river management' had replaced 'river improvement' although the works proposed were similar to those in earliest reports (Strom, 1941; SRWSC, 1979).

Reviews around 1980 further highlighted the changing fortunes of Australia's rivers and streams. Cadwallader (1979) noted the overall impact of water resources development and other activities on Murray Cod populations that were declining in range and abundance. The seminal work of Williams (1980) noted that almost every Australian river and stream was affected by humans and that the future of the inland aquatic environment would be determined by human activities. Harris (1984a; 1984b) found that fish passage in about half of the aquatic habitat of Australia's southeastern coastal drainages had been obstructed by dams, weirs and other man-made physical barriers.

It was also around this time that international attention was focused on water resources with the staging of the United Nations Water Conference at Mar del Plata in Argentina in 1977 (Biswas, 1978). Although environmental concerns were not a focus of this conference, there was an emphasis on increasing the efficiency of water use to secure the highest possible level of national welfare and on improving assessment of water resources.

The first attempt to identify the major in-stream uses of water in Australia, Water 2000: consultants report No. 9 (Department of Resources and Energy, 1983), highlighted 
many of the issues that are still current including the downstream effects of dams, the ecological effects of physical barriers in streams, the effects of river improvement and flood mitigation works and the biological effects of water contaminants.

By the mid 1980s environmental concern about rivers had become part of the Victorian Government's agenda with the publication of two widely distributed reports The State of the Rivers (Standing Consultative Committee on River Improvement, 1983) and Better Rivers and Catchments (State of the Rivers Taskforce, 1987). These reports reviewed the condition of Victoria's rivers and their catchments and concluded that 'the broad picture that emerges is an extremely disturbing one that the present condition of most Victorian rivers and our catchments is very unsatisfactory and is becoming worse with every flood' (Standing Consultative Committee on River Improvement, 1983, 9). The reports called for a policy commitment from government to improve waterways, their catchments and their environments. Around, 1985 there was a State Government directive that River Improvement Trusts prepare Master Plans which, in many cases, precipitated a change in the management objectives of Trusts, from a narrow focus on agricultural benefits to the goal of finding a balance in waterway management Table 2.1.

It was also around this time that the first attempts were made to quantify stream condition in Victoria. There was a statewide assessment of physical stream conditions in 1986 (Tilleard and DWR, 1986; Mitchell, 1990) and a broader assessment of the state of the environment of Victoria's inland waters in 1988 (Office of the Commissioner for the Environment, 1988). Both reports revealed that there was widespread environmental degradation. These reports were intended to be part on an ongoing program of environmental monitoring but this was never implemented (see Chapter 4).

Environmental concerns were recognised by the Victoria Water Act 1989, which states that river management authorities must perform their functions in an environmentally sound way (Water Act 1989, Section 190). Around the same time, environmental guidelines for river management works were published (Standing Committee on Rivers and Catchments, 1990) that examined river improvement techniques and suggested ways to decrease their environmental impact. By 1991 works such as desnagging were still listed as a technique for stabilising waterways but it was acknowledged that there was 'potential for severe adverse environmental impact' (Standing Committee on Rivers and Catchments, 1991). 
Table 2.1 - Examples of management objectives from Victorian waterway management authorities

\begin{tabular}{|l|l|l|}
\hline Period & Example management Agency & Summary of goal from strategic plans or other documents \\
\hline $1966-1984$ & 15 Mile Creek Improvement Trust & $\begin{array}{l}\text { The preservation and improvement of the productivity of the lands within the proposed district by } \\
\text { reducing the damage due to flooding and erosion of these lands, and preventing any undesirable } \\
\text { diversions of the Fifteen Mile Creek and/or its tributaries and anabranches from their present courses } \\
\text { (I. N. Drummond and Associates Pty Ltd, 1984). }\end{array}$ \\
\hline $1984-1988$ & 15 Mile Creek Improvement Trust & $\begin{array}{l}\text { To recognise the balance of community values in achieving a compromise between the following aims: } \\
\text { alleviate or prevent stream related damage to public and private lands and assets; and } \\
\text { retain and enhance the amenity of stream systems for the benefit of the general community (I. N. } \\
\text { Drummond and Associates Pty Ltd, 1984). }\end{array}$ \\
\hline $1989-1992$ & $\begin{array}{l}\text { Ovens River Management Board } \\
\text { (ORMB) } \\
\text { (ORMB took over the 15 Mile } \\
\text { Creek Improvement Trust in } \\
\text { 1989) }\end{array}$ & $\begin{array}{l}\text { When it was established the objectives of the ORMB were similar to those above. The Water Act was } \\
\text { enacted in 1989 and allowed waterway authorities to have broader functions than those specified in the } \\
\text { River Improvement Act of 1958. Functions of authorities include: to develop and to implement } \\
\text { effectively schemes for the use, protection and enhancement of land and waterways (Water Act 1989 } \\
\text { Section189 (b)). }\end{array}$ \\
\hline $1992-1995$ & $\begin{array}{l}\text { To protect public and private assets from stream related damage; } \\
\text { To improve the river environment and aesthetics by promoting good channel depth and current, good } \\
\text { instream cover and good bank vegetation; and } \\
\text { To work cooperatively with water authorities, to identify and implement joint ventures which will } \\
\text { improve the water quality and quantity problems in the catchment (Ovens River Management Board, } \\
\text { 1994). }\end{array}$ \\
\hline
\end{tabular}


Table 2.1 Examples of management objectives from Victorian waterway management authorities (continued)

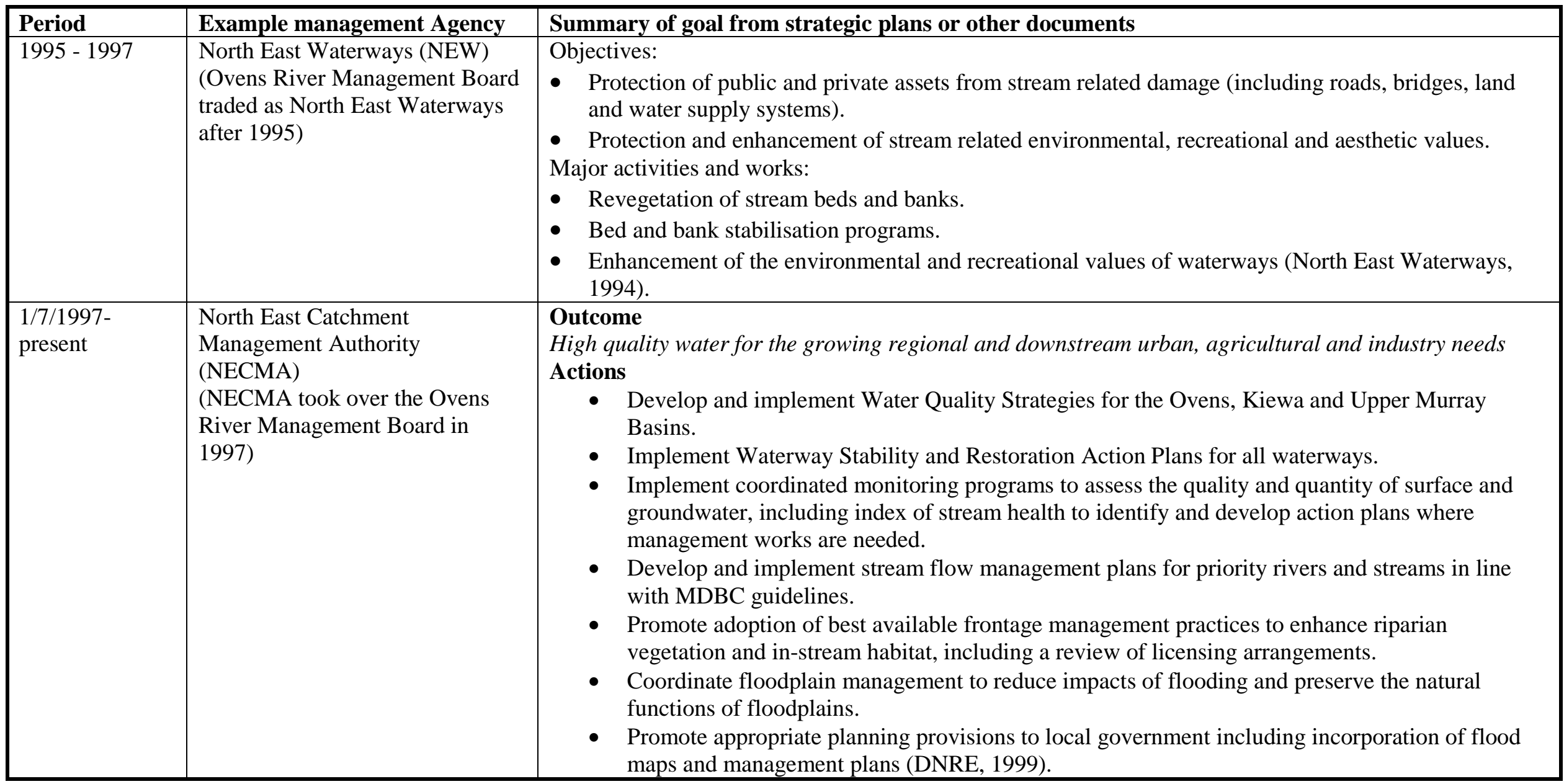




\section{Brief history of river management}

Also in 1991 removal of wood debris from streams and increasing sediment input to streams were listed as a potentially threatening processes in Schedule 3 of the Flora and Fauna Guarantee Act 1988 requiring the Victorian Department of Natural Resources and Environment to develop action statements to manage these processes.

By 1992 environmental concerns about water resources development were firmly on the international agenda with the release of the Dublin Statement on Water and Sustainable Development (1992) from the United Nations International Conference on Water and the Environment. This called for the protection of aquatic ecosystems from pollution and flow changes. Similar sentiments were expressed at the United Nations Conference on Environment and Development in 1992. At this conference objectives were adopted that included maintenance of ecosystem integrity and it was agreed that all states would implement an integrated approach to environmentally sustainable management of water resources including protection of aquatic ecosystems. Agreed actions included rehabilitation of polluted and degraded water bodies to restore aquatic habitats (Robinson, 1992). In Australia, these ideas were picked up in the National Strategy for Ecologically Sustainable Development (Commonwealth of Australia, 1992)

In 1994 the Council of Australian Governments (COAG) Water Resource Policy working group agreed that action needed to be taken to arrest widespread natural resource degradation in all jurisdictions and adopted a package of measures to achieve an efficient and sustainable water industry. States agreed to give priority to determining water allocations to the environment as a legitimate user of water (Working Group on Water Resource Policy Secretariat, 1994a; 1994b; 1995). This agreement was shown to have some teeth when, in 1999, the National Competition Council, formed to oversee the COAG agreement, recommended that the Queensland Government be denied Commonwealth payments of $\$ 15$ million because the economic viability and ecological sustainability of proposed water infrastructure investments had not been adequately assessed (National Competition Council, 1999).

The potential role of Adaptive Environmental Assessment and Management (AEAM) (Holling, 1978) in addressing environmental issues associated with Victoria's rivers was first recognised in the early 1990s (Grayson et al., 1994a; Grayson et al., 1994b; Grayson and Doolan, 1995). This provided the impetus for the development of environmental indicators that could be used to select and evaluate management strategies and has since been an important influence in river management in Victoria. 
It is not until the period 1996-1999 that the ideas of stream rehabilitation or restoration become prominent in Australia although they had occurred much earlier in the United States (e.g. Gore, 1985; National Research Council, 1992). In the proceedings of the First National Conference on Stream Management in Australia, of the 53 papers presented there is one paper with 'restoration' in the title and none with 'rehabilitation' (Rutherfurd and Walker, 1996). By the Second Australian Stream Management Conference, subtitled 'the challenge of rehabilitating Australia's streams', there are 30 (of 131) papers with either 'restoration' or 'rehabilitation' in the title (Rutherfurd and Bartley, 1999). Recently, there has also been a review of research and development needs in river restoration (Rutherfurd et al., 1998) and publication of a rehabilitation manual for Australia streams (Rutherfurd et al., 1999).

Rutherfurd et al. (1999) define stream rehabilitation as returning, as far as possible, stream vegetation, structure, hydrology, and water quality to their original i.e. preEuropean condition. This will involve, for example, changes to water quantity (environmental flow allocations), management of water quality issues such as salinity and nutrients and control of exotic biota such as European Carp (Cyprinus carpio) as well as geomorphic changes - all issues which have their own extensive literature (for recent reviews see; Barmuta et al., 1992; Johnson and Rix, 1993; Lake, 1994; Smith, 1998; Arthington and Zalucki, 1998; Rutherfurd, 2000).

Along with the focus on stream rehabilitation, there has been evolution in the management arrangements for rivers. The linkages between rivers and catchments have now been explicitly recognised. In Victoria, for example, river management is now the responsibility of Catchment Management Authorities (CMAs), which oversee Waterway Management Authorities as established under the Water Act 1989. There is also a focus on the role of the community in managing natural resources including rivers (Catchment Management Structures Working Party, 1997; DNRE, 1997; Ewing, 1999). The reform process that led to the CMAs has created authorities that are:

- $\quad$ large (there are nine across the State of Victoria);

- regionally focused (there is a management board of nine local people);

- accountable to government and the community through requirements for planning and reporting; 


\section{Brief history of river management}

- capable of raising their own funds and with opportunities to access a wide range of funding sources ${ }^{\square}$,

- integrated in that they deal with most, although not all, natural resource management issues in the region (they do not have control over water allocation as discussed in Section 3.4); and

- autonomous since there is only limited oversight by the central government through requirements for annual reporting and business planning.

These changes have increased the need for planning and reporting requirements and there is now a statutory responsibility for CMAs to report annually on the condition of land and water resources (Victorian Catchment Management Council, 1997).

Although there is the potential for CMAs to deal with environmental management of rivers and streams better than their predecessors, there are still many challenges (Ewing, 1999). There is a lack of integration in that water resources have not been brought under the umbrella of the CMAs but are managed by Rural Water Authorities with a focus on supplying water to irrigators. There is also an imperative to introduce economic reform to the water industry with the public service roles of water authorities being questioned under National Competition Policy (Hilmer et al., 1993). Conflicts between the objectives of water supply and environmental management of waterways are explored in a case study in Chapter 3. There are emerging issues of representation, funding, and potential conflicts between 'production' oriented interests such as farmers and irrigators and other interests such as tourism. There is also a concern that the new institutional arrangements may be more about saving money for the State Government, by shifting responsibilities to the regions and the community, than about improving environmental management (Ewing, 1999).

The rise of environmental concern has created the need to incorporate environmental information into management decisions. Although early attempts at assessing river condition did not engender long term support (Office of the Commissioner for the Environment, 1988; Mitchell, 1990; also see Chapter 4), there is interest in further applications of adaptive management, which will require the development of indicators and environmental monitoring (Walters, 1986; 1997; Grayson and Doolan, 1995).

\footnotetext{
${ }^{1}$ Recent changes have increased the reliance of these authorities on State Government funds (Barlow, 1999).
} 
There are also increasing requirements for monitoring and environmental indicators as part of the changing institutional arrangements for waterway managers and as part of planning, reporting and accountability requirements. Environmental monitoring is also part of State of the Environment reporting that has also been taken at the federal level (Wasson et al., 1996; Fairweather and Napier, 1998) and a National Land and Water Resources Audit has commenced that will include an assessment of environmental conditions of rivers (Young, 1998).

Issues associated with incorporating environmental information into river management decision-making are taken up in the next chapter where environmental indicators are proposed as a way forward in overcoming some pathologies of river management. Existing indicators of environmental conditions of rivers are reviewed in Chapter 4.

\subsection{Conclusion}

In Victoria most rivers have been physically altered by gold mining, works to improve navigation, water resources development and river 'improvement'. There has also been introduction of exotic flora and fauna, pollution and indirect affects of catchment clearing and agricultural development. The cumulation of these effects, and changing societal values away from an emphasis on development, has led to a rise in environmental concern that is reflected in the current institutional arrangements for managing rivers and in management objectives. There is a demand for better ways to incorporate environmental information into decision-making. The next chapter explores some management pathologies in the way environmental information has been used and shows that new approaches are required as discussed in Chapter 4. 


\section{PATHOLOGIES OF RIVER MANAGEMENT}

\subsection{Introduction}

The previous chapter presented a brief history of river management and argued management tasks have evolved from a single-issue focus on utilitarian values to broader objectives including environmental management. In this chapter, I will show that existing management systems are not capable of achieving these goals and that better ways of measuring and reporting environmental information are required.

There are a broad range of problems that have been identified with land and water management arrangements including inadequate policy responses, poor implementation, and institutional weaknesses (Industry Commission, 1998). A similar range of issues was identified a decade earlier (AWRC, 1988). This chapter does not discuss all these issues, instead it focuses on areas that could be assisted by development of better ways of collecting and analysing environmental information and incorporating it into decision-making about rivers.

Three problems with current management arrangements are discussed in this chapter and case studies are presented to illustrate each problem. The first case study discusses a situation where river management has been driven by the perception of environmental changes and decision-making has not included rigorous consideration of environmental information. The second case study reviews an area where environmental information is available but it has not contributed to decision-making. This 'data-rich but information poor' situation has arisen because of conflicts between the objectives of managers and those undertaking environmental monitoring and because of the high variability in some environmental parameters. These two case studies show that it is not sufficient just to collect environmental information; it must also be used to inform managers. The third case study reviews another barrier to the incorporation of environmental information into decision-making, that is, where a narrow and short-term management focus results in environmental issues being ignored.

Each case study is presented in detail to provide depth of understanding of some of the situations in which a management focused index might be used. The case studies 
include recent examples suggesting that although problems associated with the use of environmental information have been recognised for some time, they are yet to be addressed completely.

\subsection{Responding to perception}

A common criticism of current and past river management practice is that intervention has often been in response to perceived environmental change and that investigation of actual change has often been incomplete (Finlayson and Brizga, 1995). This has led to proposals or actions that appear to be misguided in light of all the available evidence. In particular, problems arise where river managers uncritically accept the local oral tradition even when this conflicts with documentary evidence. There is a danger that this acceptance may result in costly and inappropriate management intervention.

Management of the Nogoa River provides an example where management intervention seems to have been driven more by the oral tradition than interpretation of documentary evidence. Popular perception was that a lake had once been present on the Nogoa River and had since filled with sediment because of inappropriate land use (Finlayson and Brizga, 1995). This perception led to management efforts to control grazing including the establishment of a national park. When Finlayson and Brizga (1995) reviewed the available documentary evidence they disputed the oral tradition and argued it was unlikely that the lake ever existed. The origin of the belief in the mythical Lake Salvator could be traced to the writings of Sir Thomas Mitchell, an official explorer in this area in 1846, who used the term 'Lake' to describe a $13 \mathrm{~km}$ stretch of swampy floodplain. Up until about 1930 this stretching of the truth by Mitchell was recognised but later, the original explanation seems to have been forgotten and the claim that the lake had been drained or silted became an undisputed belief.

The example of the Nogoa River also shows that inadequate consideration of environmental information can lead to inappropriate management actions. The perception of a sedimentation problem led to land use controls but the interpretation by Finlayson and Brizga (1995) suggests that this may not have been an appropriate intervention.

The issue of sedimentation of the Nogoa River is paralleled by concerns about the Snowy River near Orbost in Victoria. Persistent claims have been made, mainly by Victorian farmers, that channel and floodplain aggradation is occurring on the Snowy 


\section{Pathologies of river management}

River. Brizga and Finlayson (1994) investigated these claims and found that there was no compelling evidence to suggest recent channel aggradation, a conclusion that has been disputed by local landholders and river managers.

Finlayson and Brizga (1995) also investigated management of the Avon River in southeastern Victoria and argue that beliefs about river channel change stemming from the oral tradition, have influenced the rhetoric and practice of river management and may have resulted in inappropriate management responses. A recent review of management of gravel extraction on the Avon River adds support to these comments (Davis et al., 1997).

\subsubsection{Case study: managing sediment in the Herbert River}

This case study examines management of the Herbert River and shows that management proposals have often been made in response to perceived increases in river sediment since European settlement. An examination of available data shows that there is no compelling evidence to support increased sedimentation and suggests that management effort would be better focused elsewhere. Part of the following discussion was published as Ladson and Tilleard (1999) (see Appendix A). The author's own work is presented here.

The Herbert River drains an area of $9000 \mathrm{~km}^{2}$ in northeastern Queensland $\left(146^{\circ} 00^{\prime} \mathrm{E}\right.$, $18^{\circ} 40^{\prime} S$ ) to the South Pacific Ocean. The majority of the catchment is sparsely settled with most development occurring on the river delta, which occupies an area of about $1000 \mathrm{~km}^{2}$. The most common agricultural activity in the delta area is sugar cane production and the largest town is Ingham (Ewing, 1985, 53; see Figure 3.1.

There is a belief amongst some sections of the community that there has been recent sedimentation of the Herbert River and that flood mitigation proposals and natural resource management and planning need to address this issue as a priority. The belief is that the river has 'filled up with sand'; that it is now shallower than it once was, that the channel capacity has been reduced and that there is more overbank flow than previously. It is claimed that sedimentation has occurred since settlement and perhaps as recently as the last 30 to 50 years.

Concerns about sedimentation of the Herbert River have surfaced over the last 20 years and have been documented during development of flood mitigation proposals as part of 
the Herbert River Flood Management Study (Cameron McNamara, 1980a), natural resource management plans (Ian Drummond and Associates Pty Ltd, 1993), an assessment of the condition of the Herbert River (Moller, 1996) and planning for integrated catchment management (McDonald and Bellamy, 1997), as well as in newspaper articles and in Queensland parliamentary debates.

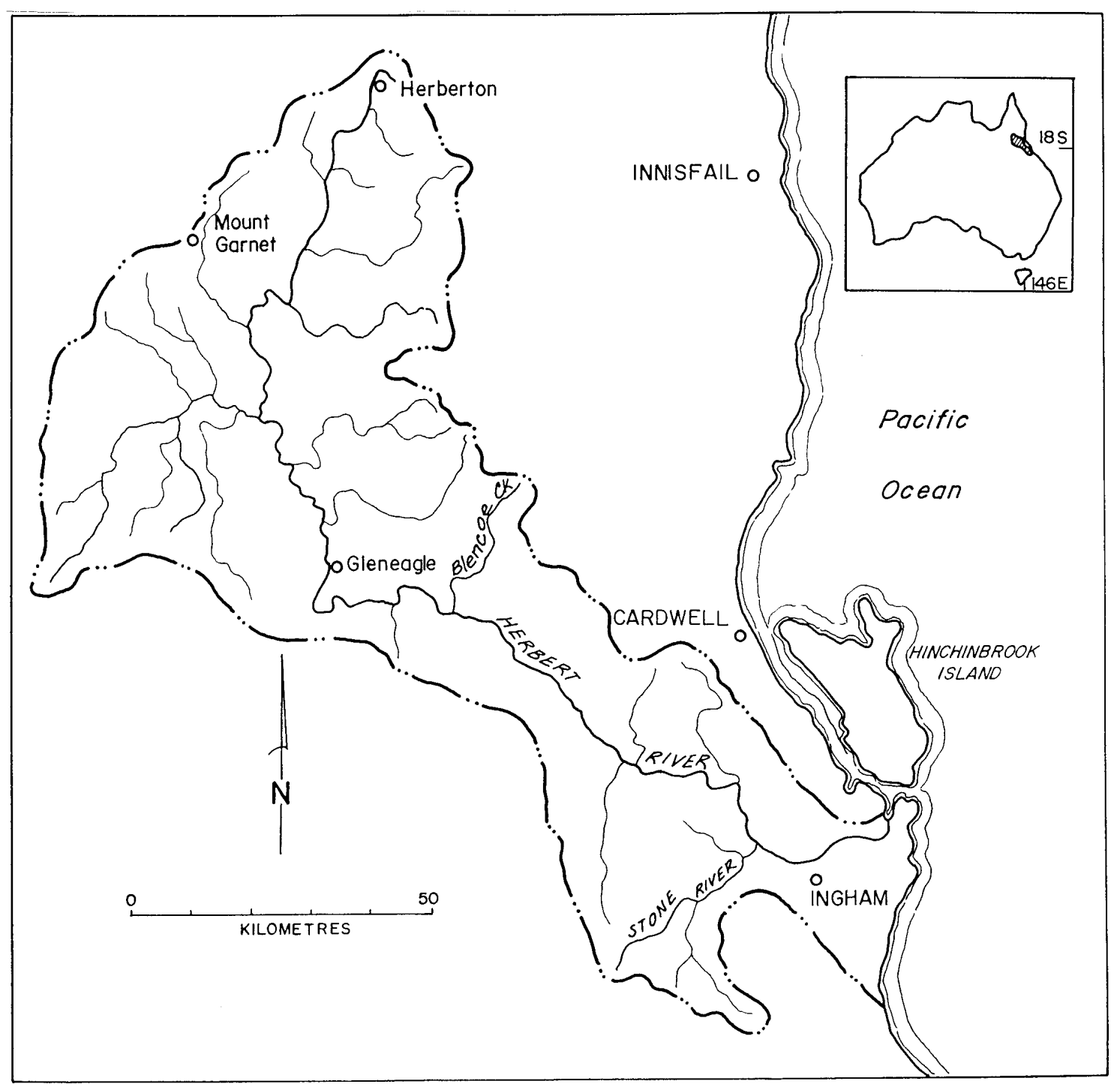

\section{Figure 3.1 - Herbert River Catchment}

Sedimentation of the Herbert River was an issue during the Herbert River Flood Management Study with the authors commenting 'That the river is aggrading at an appreciable rate is evidenced by historical records which show that once the river was navigable by small boats to Halifax. It is now no longer so.' (Cameron McNamara, 1980b, 8). The perception of sedimentation also influenced selection of flood mitigation proposals with only those options that would not increase the rate of river aggradation being carried through to final evaluation (Cameron McNamara, 1980b, 8). 


\section{Pathologies of river management}

Community perception of sedimentation problems in the Herbert River contributed to opposition to the recommendations of the flood study. A community group contended that insufficient regard was given to aggradation of the lower reaches of the river and the group was concerned that the levees proposed by Cameron McNamara (1980a, Chapter 8 p6-7) would aggravate these problems (Ewing, 1985, 114). The group proposed 'cheaper and safer options' for flood relief including 'dredging of the Herbert River from the John Row bridge to the sea' (see Figure 3.2. Gagliardi, 1984a). Evidence of sedimentation in the Herbert River included the claim by the group's chairman that 'Thirty years ago, steamers used to ply the Herbert. Today, in parts, you can walk across it' (Gagliardi, 1984a).

Other newspaper reports at the time show that there was a widespread perception that, in earlier times, the Herbert River was considerably deeper than it was in 1984 and that recent sedimentation had made the river shallower and less able to carry flood flows and had reduced the river's navigability (Gagliardi, 1984a; Gagliardi, 1984b; Gagliardi, 1984c; Anon., 1984).

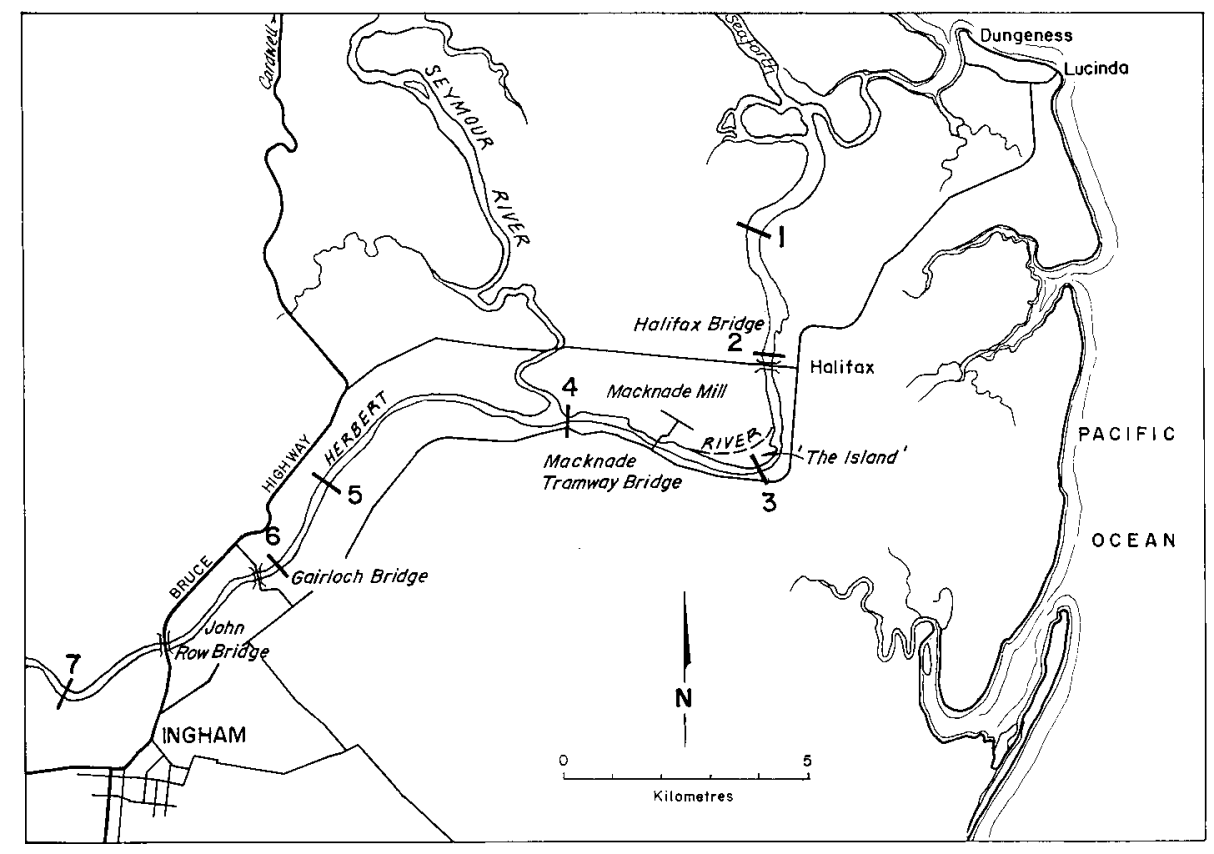

Figure 3.2 - The Herbert River and surrounds between Ingham and the mouth at Dungeness

Concern about sedimentation in the Herbert River also surfaced during community consultation carried out as part of development of a management plan for the Herbert 
River and district that was undertaken in 1992 (Ian Drummond and Associates Pty Ltd, 1993). At a public meeting, 73 participants were asked to evaluate possible responses to flooding. The most favoured option by far was to remove sediment from the river to increase its capacity, and there was agreement that widespread sedimentation in the river was the major issue (Ian Drummond and Associates Pty Ltd, 1993).

There were similar concerns expressed at an Integrated Catchment Management Evaluation Project Stakeholder Workshop in June 1995 (McDonald and Bellamy, 1997, 12). Increased erosion and sedimentation in the river, river aggradation and reduced stream capacity were identified as key natural resource management issues and impacts. These concerns were supported by a Queensland Government report that the bed in the lower reaches of the Herbert was moderately to severely aggrading (Moller, 1996, 23).

Local parliamentarians were also concerned about sediment in the Herbert River. In a 1991 debate on the River Improvement Trust Amendment Bill, members commented on sedimentation problems in the Herbert River.

The major problem is the accumulation of silt in the bed of the Herbert River, which is creating a number of major islands in the river (Hon. M. Rowell, Member for Hinchinbrook, Queensland, Parliament, 1991a, 7250).

Because I have been a Member of Parliament for a long time, I have been aware of that sand island problem in the Herbert River. I have heard the matter brought up in this Chamber and, in the past, even I have brought the matter up (Hon. E. Casey, Minister for Primary Industries, Queensland, Parliament, 1991b, 7256)

Two other members expressed similar statements during that debate and there were further comments in Parliament following flooding caused by Cyclone Joy in 1991 (Queensland, Parliament, 1991c, 6420-6435).

\section{Sedimentation of the Herbert River: the evidence}

Despite the widespread perception of recent sedimentation in the Herbert River, evidence from a variety of sources suggests that shallow sandy river conditions have existed, and indeed have been an issue, from the start of European settlement. Evidence suggests that there has not been a recent general increase in river bed levels or a recent increase in sedimentation. Sources include: historical accounts of the river, including written descriptions of river trade; documentary evidence of changes to a large point bar near Halifax; stream gauging records; and surveys of river cross-sections. 


\section{Pathologies of river management}

\section{Historical accounts of the river}

Comments made by early explorers and settlers show that the Herbert River could be shallow, sandy and difficult to navigate from earliest settlement. Arthur Neame, one of the first settlers in the Herbert Valley, had trouble transporting equipment up the river in the 1870 s and 1880 s and had to carry equipment in shallow draft punts (Neame undated). Newspaper reports at the time also mention shallow and sandy conditions in the Herbert River and tributaries (Anon., 1870a, 2-3; Anon., 1870b, 3).

The usefulness of the river was limited for transportation during early settlement because of its shallowness during the dry season (Cowley, 1878) with rowboats having to be used to transport passengers to Ingham (Anon., 1939, 48). In 1876 the Queensland Parliament allocated $£ 500$ for clearing and improving the navigation of the Herbert River (Queensland, Parliament, 1876, vol. 1, 987). By 1879 the money allocated to clear the Herbert was expended but there was much work remaining (Queensland, Parliament, 1879, vol. 2, 905) and an additional £2 000 was allocated (Queensland, Parliament, 1880, vol. 2, 1139). Yet, there were continual problems. In 1884 the Engineer for Harbours and Rivers for the State of Queensland reported that 'difficulties of transport between Dungeness and Ingham are very great' (Queensland, Parliament, 1884, vol. 3, 823) and recommended in 1884, and again in 1885, that a tramway be constructed so that the river was not needed for transport (Queensland, Parliament, 1885, vol. 3. 373).

In 1888 the residents of Herbert District presented their third petition to the Queensland Legislative Assembly requesting a railway from Dungeness to Ingham because they were:

subject to much loss and inconvenience through the unnavigable character of the Herbert River, which can only be used by vessels drawing from two to three feet [700mm to $1 \mathrm{~m}]$ of water and working with tides only for eight or nine miles $[12.8 \mathrm{~km}$ or $14.4 \mathrm{~km}$ ], the remainder of the distance having to be traversed overland (emphasis added) (Queensland, Parliament, 1888 vol. 3, 683).

Despite claims that steamers used to ply the Herbert River, it is unlikely that the river trade was ever important upstream of the Gairloch Bridge Figure 3.2. Construction of this low level bridge, which would have prevented passage of all but the smallest boats, commenced in January 1890 (Queensland, Parliament, 1891 vol. 4, 529). This was at 
least 5 years before the construction of the railway between Ingham and Dungeness and around the time that Ingham residents were petitioning State Parliament for the railway because of transportation difficulties. Presumably, the river was too shallow to allow cargo transport far upstream of Halifax.

Further evidence against recent sedimentation is provided by stream gauging records. The Herbert River is gauged at Ingham (Gauge No. 116001E) and rating tables are available that allow discharge to be determined from the river stage. The change in rating tables over time can be used to infer changes in the bed level of the river. Rating tables from 1940 to 1995 for the Herbert River at Ingham were used to imply changes to streambed levels. Specific gauge curves were prepared for two representative discharges at this site, $10 \mathrm{~m}^{3} \mathrm{~s}^{-1}$ and $100 \mathrm{~m}^{3} \mathrm{~s}^{-1}$. These curves indicate that stage for a given discharge can fluctuate by up to $300 \mathrm{~mm}$ over the period of a few months and suggest that bed levels can fluctuate by a similar amount Figure 3.3.

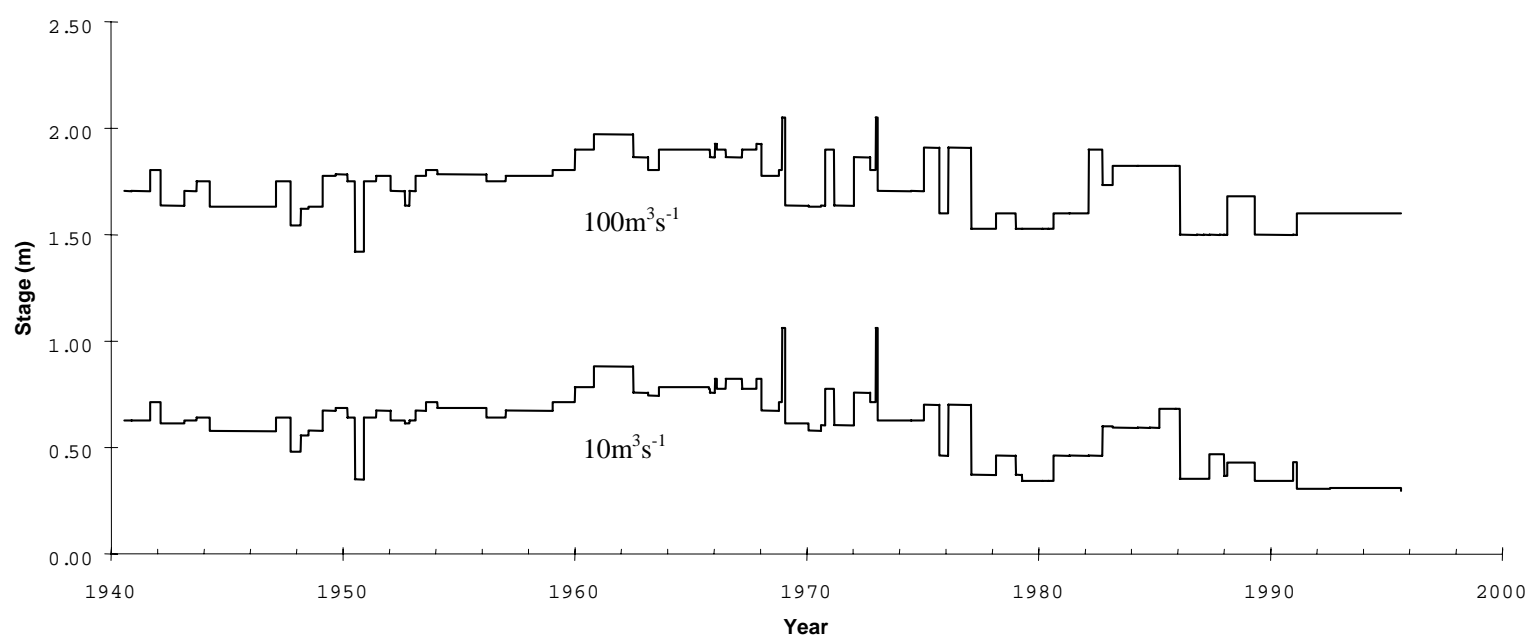

\section{Figure 3.3 - Specific gauge plots for the Herbert River at Ingham}

Stage for a given flow increased by about 100mm between 1940 and 1962 and has decreased between 1962 and 1995 by $300 \mathrm{~mm}$ to $400 \mathrm{~mm}$. If this change can be attributed to changes in river bed level then the bed of the river near the Ingham gauge is as low or lower than it has been at any time in the last 50 years.

It is also important to note that the stage-discharge relationship can be influenced by factors other than changes in bed elevation, namely changes in river width or flow 


\section{Pathologies of river management}

resistance. But neither of these causes is likely to explain the changes in specific gauge heights that are illustrated in Figure 3.3. A review of cross-sections (see below) shows there has been no consistent widening of the river at the surveyed points and there has been no activity to decrease flow resistance in recent times. This suggests that the major influence causing variation in ratings tables is changes in bed elevation. The frequency of change, as short as a few months, and the fact that both positive and negative changes occur, also suggests that the mechanism of change is mobilisation of bed sediments rather than widening or changes in resistance. These results suggest that the Herbert River at the Ingham gauging station has not been subject to recent sedimentation and, in fact, a marginal decrease in bed levels has occurred since around 1960.

Another source of evidence about bed level variation is from changes in cross-sections that have been measured over time. The Herbert River Improvement Trust has undertaken cross-section surveys of the river dating back to the 1960s. The locations of the seven cross-sections, in the area of interest with the largest amount of historical data, are shown in Figure 3.2 and plotted in Figures 3.4 to 3.10. Areas of |lach of thes crosssections to bank full were calculated and the change between the earliest and most recent cross-section noted (see Table 3.1).

Table 3.1 - Bankfull cross-section areas for the Herbert River (for locations see Figure 3.2

\begin{tabular}{|c|c|c|c|c|c|}
\hline \multirow[b]{2}{*}{$\begin{array}{l}\text { Cross- } \\
\text { section }\end{array}$} & \multirow[b]{2}{*}{ Figure } & \multicolumn{3}{|c|}{ Date of cross-section survey } & \multirow[b]{2}{*}{$\begin{array}{c}\text { Change from } \\
\text { earliest survey to } \\
\text { latest survey }\end{array}$} \\
\hline & & $\begin{array}{c}1968 \text { or } \\
1969^{1} \\
\left(\mathbf{m}^{2}\right)\end{array}$ & $\begin{array}{c}1982 \text { or } \\
1983^{1} \\
\left(\mathbf{m}^{2}\right)\end{array}$ & $\begin{array}{c}1991 \text { or } \\
1992^{1} \\
\left(\mathrm{~m}^{2}\right)\end{array}$ & \\
\hline 1 & 3.4 & 1200 & 1180 & 1220 & $2 \%$ \\
\hline 2 & 3.5 & 1050 & 1020 & 950 & $-10 \%$ \\
\hline 3 & 3.6 & 1850 & 1860 & 1850 & $0 \%$ \\
\hline 4 & 3.7 & 1470 & 1450 & 1420 & $-3 \%$ \\
\hline 5 & 3.8 & 1610 & 1650 & 1710 & $6 \%$ \\
\hline 6 & 3.9 & 1530 & 1560 & 1670 & $9 \%$ \\
\hline 7 & 3.10 & 1960 & 1950 & 2030 & $4 \%$ \\
\hline Mean & & 1520 & 1520 & 1550 & $2 \%$ \\
\hline
\end{tabular}

${ }^{1}$ For actual date of survey refer to figure as indicated.

The cross-sections show that there has been deposition and erosion since the first of these cross-sections in 1968 or 1969 but the overall change has been small. Four cross- 
sections increased in area, three decreased and one was constant. The overall estimate of the change in the mean cross-sectional area is an increase of $2 \%$ which is not statistically significant at $\alpha=0.2$ (one tailed, two sample t test, $\mathrm{p}=0.028$ ) and does not provide evidence for a decrease in area (or an increase). The area of cross-section 2 has decreased because of the build up of a point bar but the main channel has deepened which would increase flow conveyance and probably cause little change in flow capacity Figure 3.5.

Comparisons of minimum elevations show that six of the seven thalweg elevations have decreased between the late 1960s and the early 1990s with the mean depth increasing by $0.5 \mathrm{~m}$ suggesting recent degradation rather than aggradation (Figure 3.11. This change is of similar magnitude to that found from analysing the specific gauge curves Figure 3.3. Certainly, there are extensive areas between the cross-sections where localised changes to bed level could occur that would not be reflected in these surveys but the comparison provides evidence that there is no large scale aggradation occurring in the lower reaches of the Herbert River.

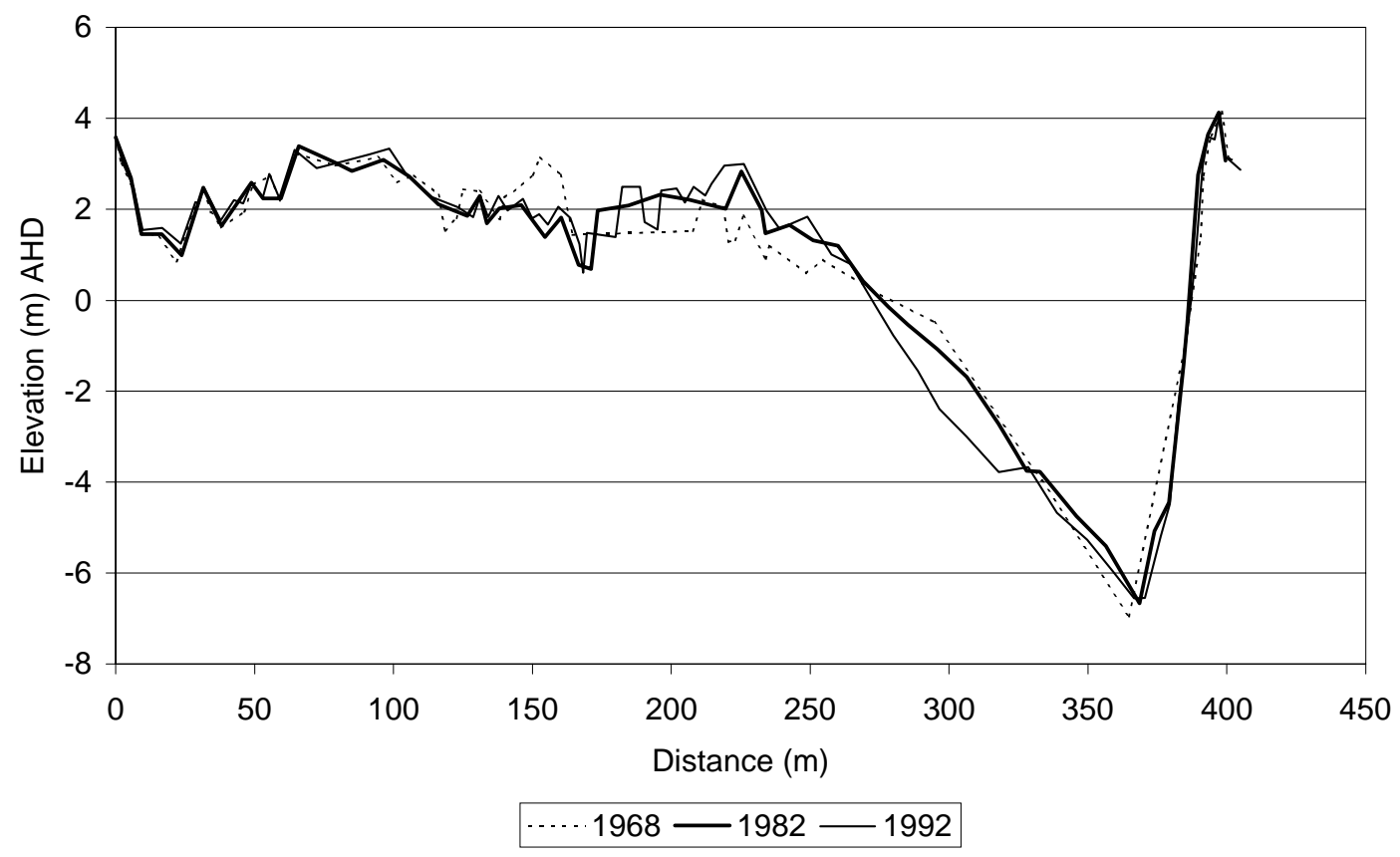

Figure 3.4 - Herbert River cross-section 1 


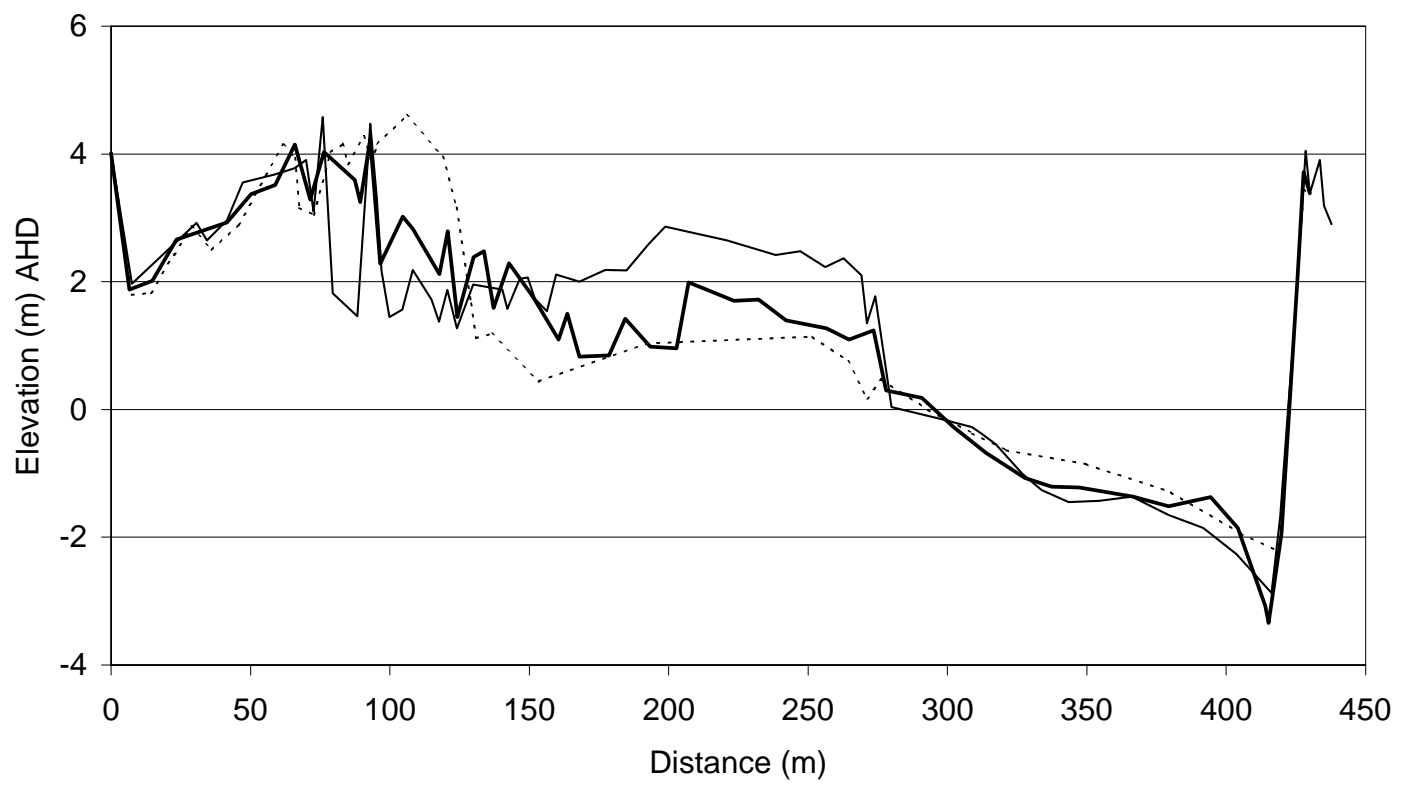

…1968 $1968-1992$

Figure 3.5 - Herbert River cross-section 2

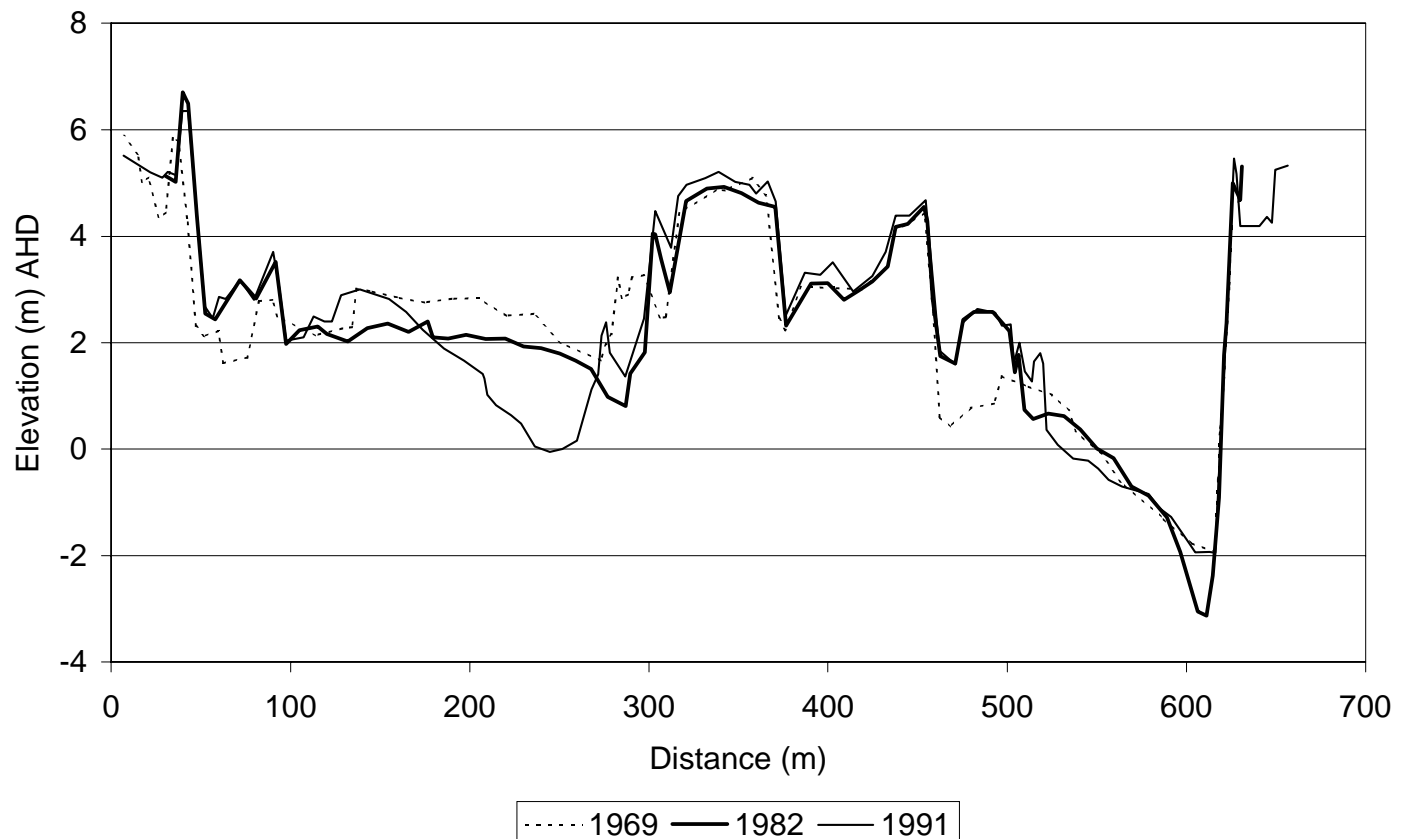

Figure 3.6 - Herbert River cross-section 3 


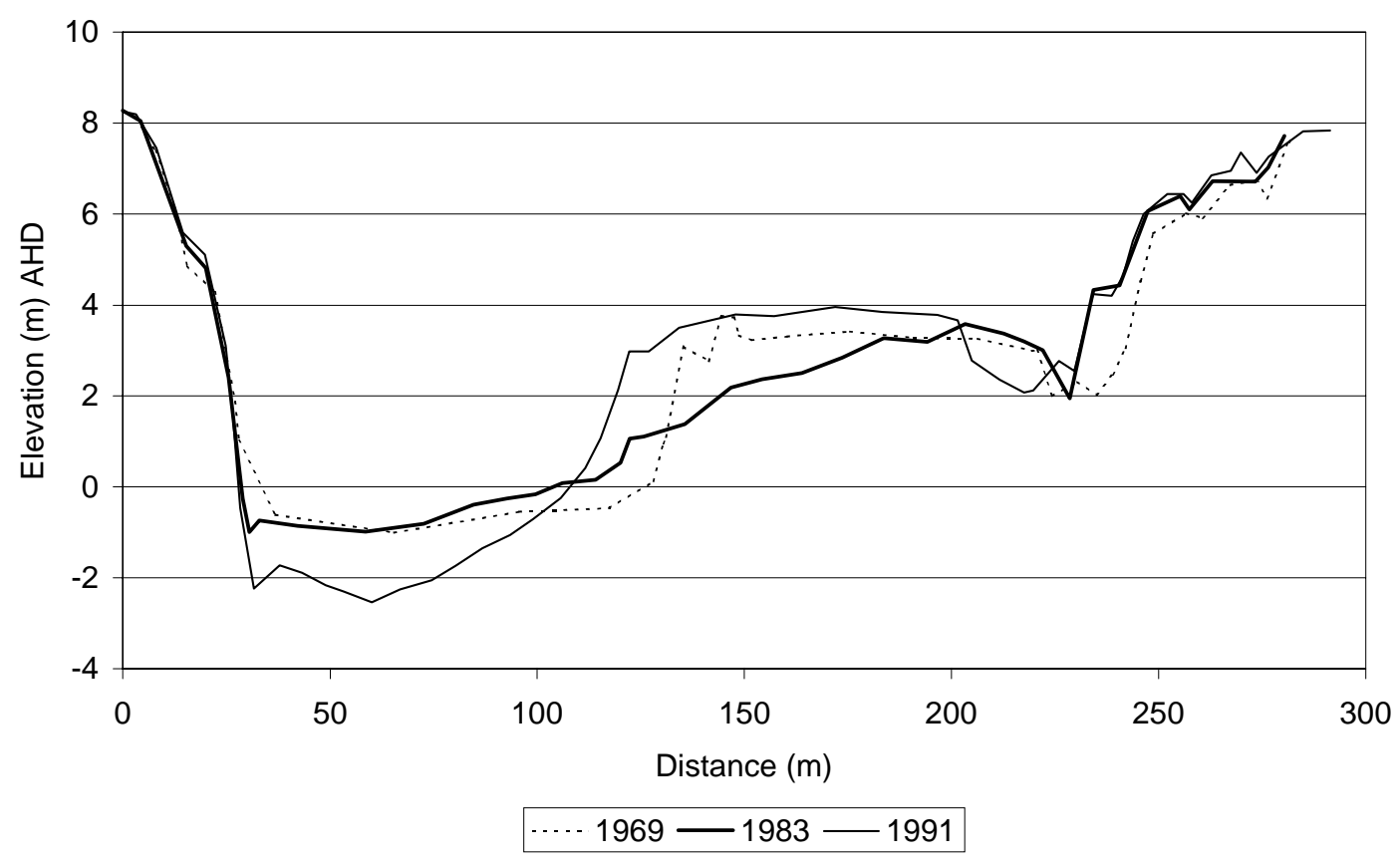

Figure 3.7 - Herbert River cross-section 4

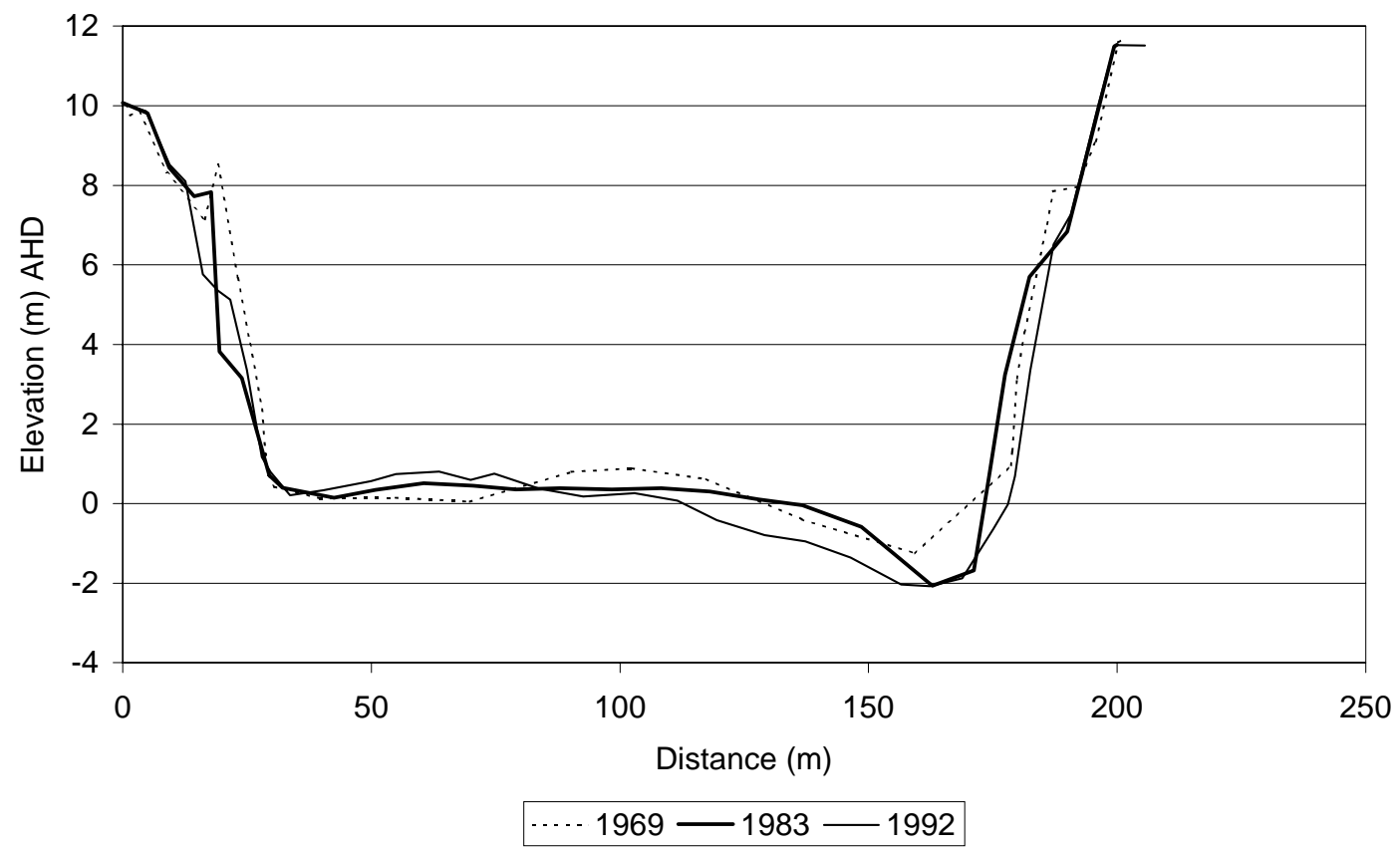

Figure 3.8 - Herbert River cross-section 5 


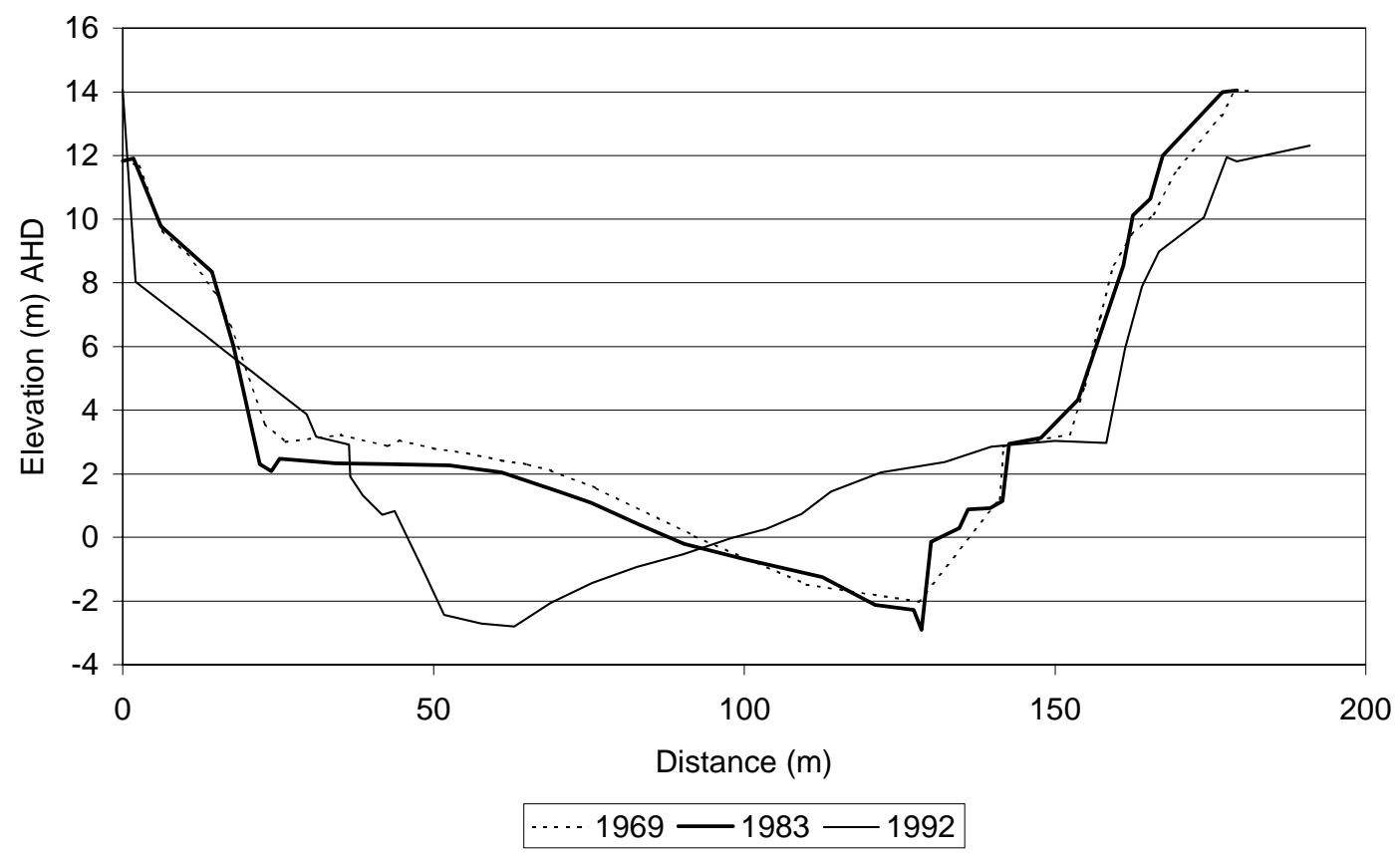

Figure 3.9 - Herbert River cross-section 6

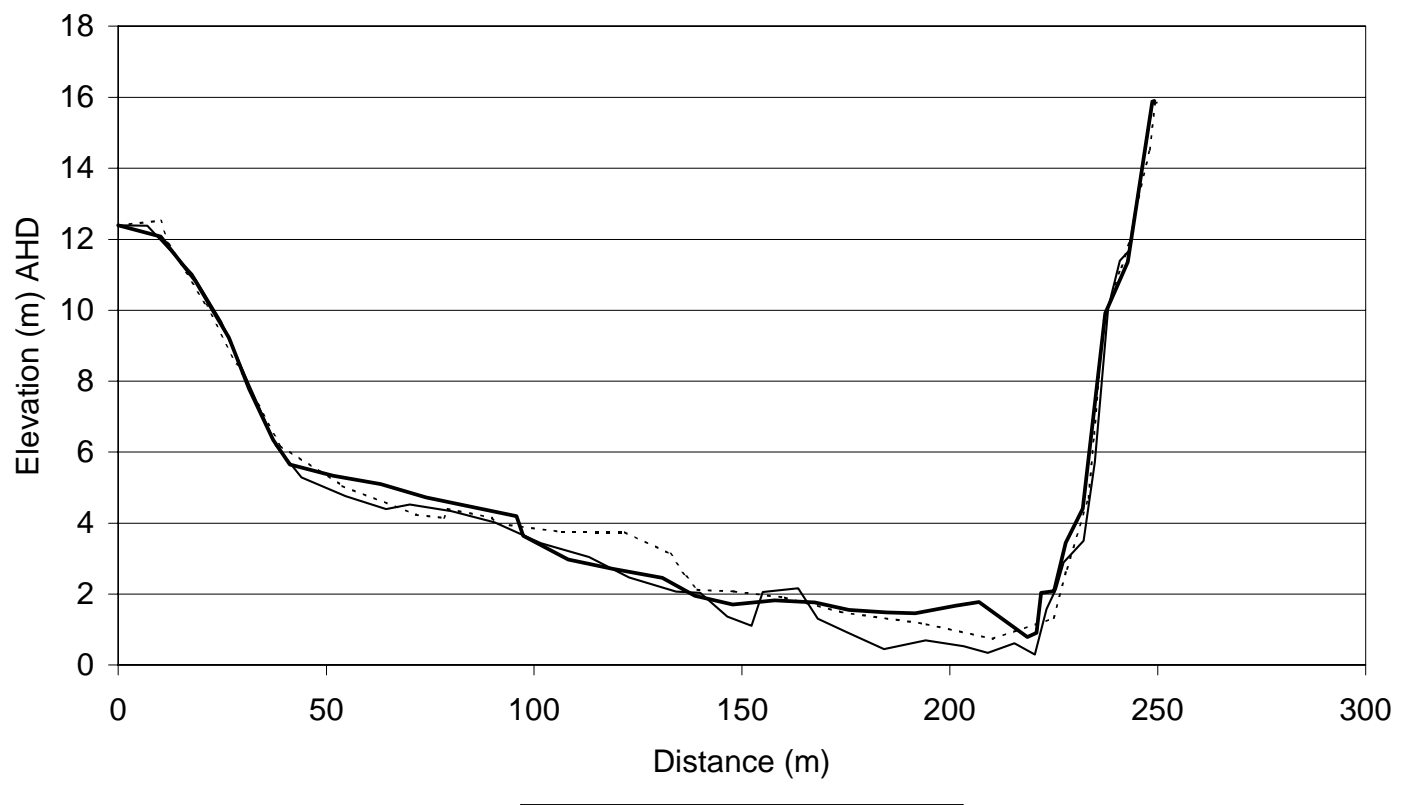

$1969-1983-1992$

Figure 3.10 - Herbert River cross-section 7 


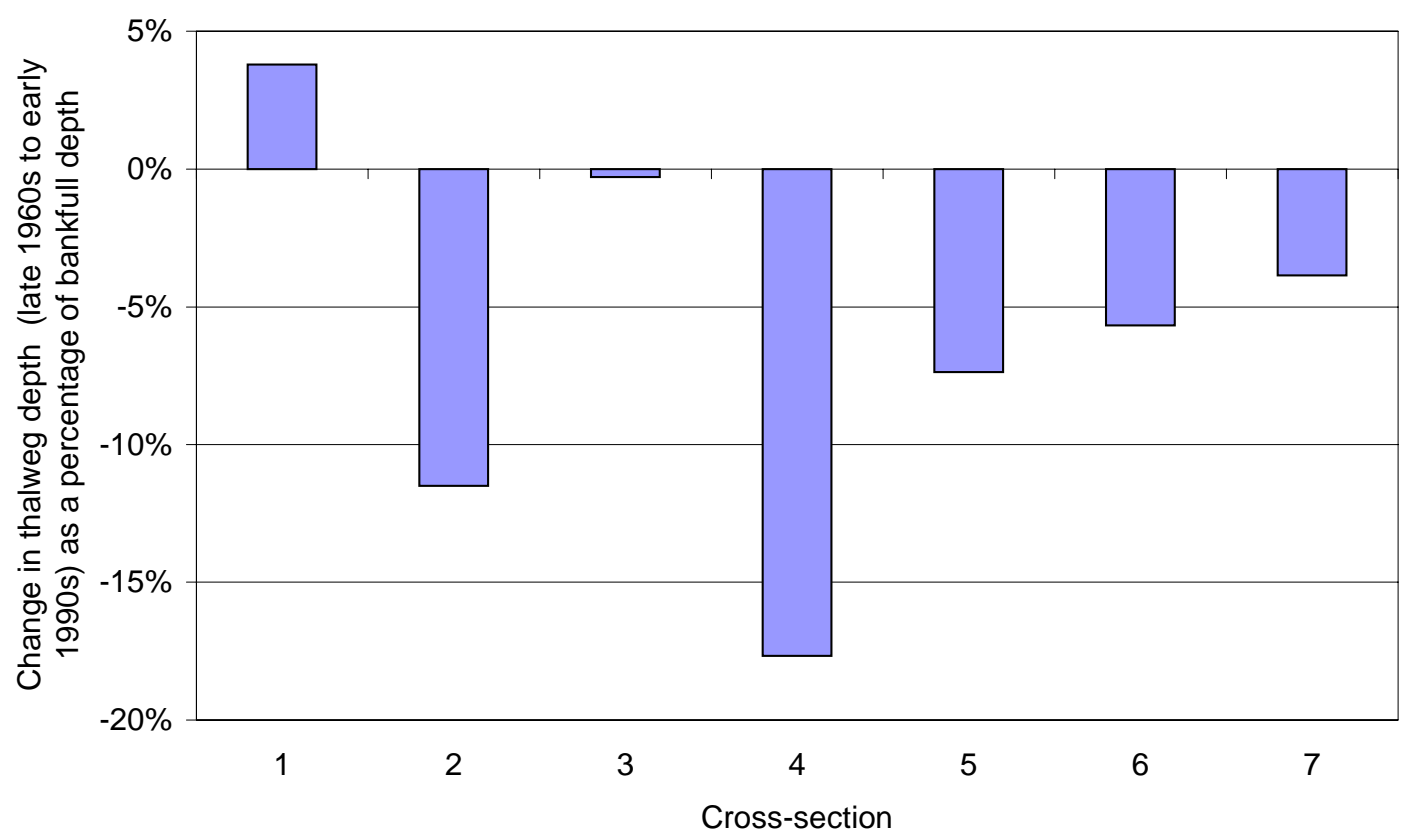

Figure 3.11 - Change in thalweg elevation at cross-sections on the Herbert River

\section{Point bar between Halifax and Macknade Mill}

An historical account of a large point bar in the Herbert River confirms that the river was shallow and sedimented from first settlement and cross-sections in this area confirm there has been little change in recent times. An historical map shows that this point bar existed prior to settlement. This area was surveyed in the early 1870 s soon after the arrival of Arthur Neame and an 1874 map shows the point bar and other sandbars in the river near Macknade Figure 3.12 Queensland, Department of Lands, 1874 plan K124395). Although it is not possible to compare accurately the location and size of the river of 1874 with that of the present day because the difficulty of interpreting the old survey, the plan does show that these bars are not a recent occurrence.

The Herbert River Improvement Trust surveyed cross-sections of the river in this area in 1969, 1982 and 1991 which show episodes of erosion and deposition between 1969 and 1991 but the overall change is small (cross-section 3, Figure 3.6. The main channel of the river is similar with some deposition about $150 \mathrm{~m}$ from the right bank. There is also approximately $2 \mathrm{~m}$ of scour about 400m from the right bank since 1969 which is part of a channel developing across the neck of the point bar. The area of the cross-section is the same in 1991 as it was in 1969 Table 3.1. 


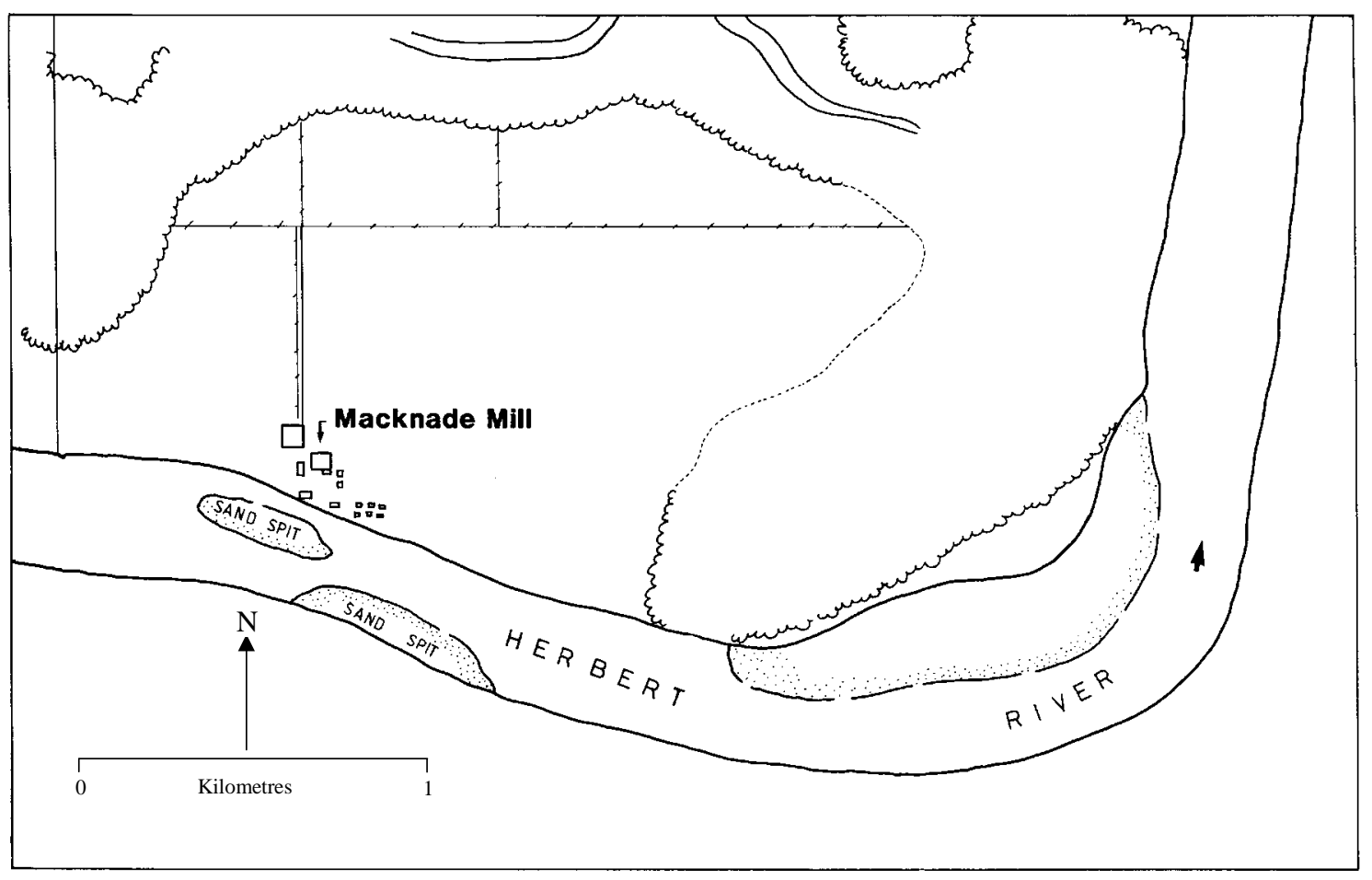

Figure 3.12 - Plan of the Herbert River near Macknade in 1874 (Queensland, Department of Lands, 1874 plan K124395). Sand deposits near the present site of the Macknade Tramway Bridge are clearly shown. These deposits exist to this day.

\section{Discussion}

Historical accounts show that the Herbert River was shallow and sandy from first settlement and that the point bar between Halifax and the Macknade Mill has been present at least since 1870. Evidence from cross-sectional surveys and records at the Ingham gauging station do not show aggradation since the 1960s. The strands of evidence are not conclusive, but they are at odds with the view that there has been a recent increase in the amount of sediment in the Herbert River. Clearly there is a discrepancy between local perception and the documentary evidence.

The local perception of increased sedimentation has led to strategies such as dredging the river being suggested. Flood mitigation proposals, such as levees, were not seen as dealing with the sedimentation issue and so were rejected by sections of the community. This contributed to the failure to implement the recommendations of the Herbert River Flood Management Study (Cameron McNamara, 1980a). This is despite the study becoming widely respected for the sound treatment of the hydraulics and hydrology of the Herbert River (Ewing, 1985, 83). 
There is a danger that the current integrated catchment management process in the Herbert Valley may experience the same problems of conflict and suggestions for inappropriate action. Strategies have been developed based on perceived key issues and impacts, one of which was sedimentation of the Herbert River (McDonald and Bellamy, 1997). There would seem to be limited value in addressing this issue until the cause of peoples' perceptions is more clearly identified, rather than just assuming sedimentation is taking place. There is potential for conflict unless there is reconciliation between community expectations and management proposals. There is potential to waste resources if objective information is ignored or if insufficient data are collected about the environment, before undertaking management strategies.

The way management authorities have addressed sedimentation of the Herbert River suggests they have not rigorously sought environmental information or tried to incorporate it into their decision-making. Instead, there has been a tendency for perception and folklore to dominate discussion of the issue and a lack of rigour in the treatment of historical data. Similar criticisms could be made of the management of the Nogoa, Snowy and Avon Rivers discussed above. These examples suggest there is a need to introduce rigour into the way environmental information is collected but it is also important that the information is used in river management. As discussed in the next chapter, a way forward may be to develop improved management systems where information on the environment is routinely collected and incorporated into planning, priority setting and used to evaluate outcomes. If problems are identified through routine monitoring, or public concern, then they should be considered for thorough investigation before strategies are developed and implemented.

\subsection{A mismatch of monitoring and management}

The previous section outlined problems that can occur when management is guided by perceptions of environmental change. This section explores another pathology of river management, that is, where there is extensive environmental monitoring, but data are not suited for incorporation into management decisions. This is a problem that Ward et al. (1986) refer to as the 'data rich but information poor syndrome'. 


\section{Pathologies of river management}

The main aspect of rivers that has been monitored to date is water quality. In Victoria, statewide water quality monitoring began in the mid 1970s and was reviewed in 1991 and 1996 (Catchment and Land Protection Council (CLPC) et al., 1996).

In their study of water quality monitoring Ward et al. (1986) state that it is often assumed that such monitoring plays a major role in management. However, a lack of clear purpose and insufficient documentation of monitoring has led to considerable data being collected without a means of converting them into information and without a defined use within the decision-making activities of management agencies. Other authors have expressed similar concerns that inappropriate monitoring can be a waste of effort (Norris and Cullen, 1987; Balls, 1989; Underwood, 1990, Underwood, 1991). Hughes et al. (1990) refer to biological data being collected, filed and then left unused.

\subsubsection{Case study: statewide water quality monitoring in Victoria}

A case study is presented of water quality monitoring in Victoria with examples drawn from the Latrobe River Catchment. Although water quality has been routinely monitored since the early 1970s, analysis shows that even if the objectives of the monitoring program are met the information produced may not be usefully related to managers' goals. The problem is that the monitoring program has been set up with its own objectives, independently of managers.

\section{Water quality goals of managers and the objectives of the Victorian Water Quality Monitoring Network}

A recent review of the Victorian Water Quality Monitoring Network (VWQMN) listed the objectives of the network, which included the general goal:

to provide the information needed for future management of the State's water resources, which would include the management and protection of the conservation values of the resources (CLPC et al., 1996).

The report also lists a specific goal related to the detection of trends. Actually, there are three slightly different statements of the objective for the trend detection on pages 12 , 19, and 48 (CLPC et al., 1996). In summary, the goal seems to be: to be able to detect linear trends in water quality equivalent in magnitude to one standard deviation of the detrended data at the $95 \%$ level of significance and $80 \%$ to $90 \%$ power after 8 to 10 years of monitoring, with step trends of the same magnitude and level of confidence 
detectable at $80 \%$ power after 5 years of monitoring. This is a similar goal as that for New Zealand's national water quality monitoring network (Smith and McBride, 1990). The trend objective has dominated the design of the VWQMN, which is based on monthly sampling of water quality data.

There were also general comments that the network should provide data capable of characterising water quality, for reporting and assessment, to determine compliance with management objectives and to identify emerging water quality problems. But no accuracy standards or statistical criteria were provided for these goals and they do not appear to have contributed to network design.

So the goals of the monitoring network relate to trend detection - what about the goals of the managers? A review of water quality management strategies and other documents revealed the goals as summarised in Table 3.2 Managers' objectives included a desire to detect upper and lower limits to concentrations, loads, and change from background conditions (also see Ellis and Lacey, 1980). Also listed in Table 3.2 is the ability of monthly sampling to assess the managers' objectives and alternative sampling strategies that are more appropriate. The design of sampling procedures to measure performance against specific water quality objectives should be tailored to provide accurate results for those objectives (Aspie and Barnes, 1990; Forsyth, 1997). It is clear from Table 3.2, that despite a large amount of monthly data being collected as part of the VWQMN, its use in addressing these management questions is limited. Regular monthly sampling used in the VWQMN is appropriate for assessing trends but is not optimal for the other objectives. There may be a number of reasons for this mismatch in objectives. For example, the difficulty of measuring loads is discussed by CLPC et al. (1996) where it is acknowledged that loads are unlikely to be estimated accurately without additional sampling. But the fact remains that unless data are useful to managers they are unlikely to be used.

\section{Assessing management effectiveness}

Another possible goal of water quality monitoring is to assess the effectiveness of strategies to improve water quality. Of interest, are strategies where outcomes are difficult to predict, for example, treatment of diffuse sources of pollution. 
Table 3.2 - Sampling strategies for various water quality goals

\begin{tabular}{|c|c|c|c|c|}
\hline Goal & Example & $\begin{array}{l}\text { Ability of monthly sampling to } \\
\text { assess goal }\end{array}$ & Comment on sampling needs & Suggested sampling strategy \\
\hline $\begin{array}{l}\text { Upper limits } \\
\text { to } \\
\text { concentrations }\end{array}$ & $\begin{array}{l}\text { Total phosphorus } \\
\text { concentration for streams } \\
\text { in the Murray Plains } \\
\text { should be less than } 0.100 \\
\text { mg/L (Tiller and Newall, } \\
\text { 1995) }\end{array}$ & $\begin{array}{l}\text { Not useful since peak } \\
\text { concentrations are unlikely to } \\
\text { coincide with times of regular } \\
\text { sampling }\end{array}$ & $\begin{array}{l}\text { Phosphorus levels and many other } \\
\text { water quality constituents are } \\
\text { likely to be highest during high } \\
\text { flows therefore sampling should } \\
\text { be concentrated during these } \\
\text { times (Cosser, 1989) }\end{array}$ & $\begin{array}{l}\text { Sample intensively when it is } \\
\text { most likely that concentration will } \\
\text { be at its maximum }\end{array}$ \\
\hline Lower limits & $\begin{array}{l}\mathrm{pH} \text { should be greater than } \\
5.5 \text { (Victorian } \\
\text { Government Gazette, } \\
1988 \text { ) }\end{array}$ & $\begin{array}{l}\text { Not useful since minimum } \\
\text { concentrations are unlikely to } \\
\text { coincide with times of regular } \\
\text { sampling }\end{array}$ & $\begin{array}{l}\text { May need to undertake a specific } \\
\text { study to determine optimal } \\
\text { sampling times for water quality } \\
\text { parameters where minima are } \\
\text { sought }\end{array}$ & $\begin{array}{l}\text { Sample intensively when it is } \\
\text { most likely that concentrations } \\
\text { will be at a minimum }\end{array}$ \\
\hline Percentiles & $\begin{array}{l}90^{\text {th }} \text { percentile reading for } \\
\text { total phosphorus in the } \\
\text { lower Latrobe river } \\
\text { should be }<0.100 \mathrm{mg} / \mathrm{L} \\
\text { (Victorian Government } \\
\text { Gazette, 1988) }\end{array}$ & $\begin{array}{l}\text { May be useful but a long } \\
\text { sampling record will be required } \\
\text { to estimate extreme percentiles } \\
\text { (e.g. } 90 \% \text { ) since rare events are } \\
\text { unlikely to coincide with regular } \\
\text { sampling }\end{array}$ & $\begin{array}{l}\text { Need to sample the full range of } \\
\text { concentrations to accurately } \\
\text { determine percentiles particularly } \\
\text { if they are to be estimated directly } \\
\text { from the data rather than by } \\
\text { assuming an analytical } \\
\text { distribution. }\end{array}$ & $\begin{array}{l}\text { Sample a full range of flow } \\
\text { conditions including high and low } \\
\text { flows }\end{array}$ \\
\hline
\end{tabular}


Table 3.2- Sampling strategies for various water quality goals (continued)

\begin{tabular}{|c|c|c|c|c|}
\hline Goal & Example & $\begin{array}{l}\text { Ability of monthly sampling to } \\
\text { assess objective }\end{array}$ & Comment on sampling needs & Suggested sampling strategy \\
\hline Loads & $\begin{array}{l}\text { Target phosphorus load to } \\
\text { Lake Wellington is } 115 \\
\text { tonnes per year by } 2005 \\
\text { (Central Gippsland Water } \\
\text { Quality Working Group, } \\
\text { 1995) }\end{array}$ & $\begin{array}{l}\text { Not useful because regular } \\
\text { sampling is likely to miss major } \\
\text { events and result in a significant } \\
\text { underestimation of loads } \\
\text { (Walling and Webb, 1985). } \\
\text { Sampling to accurately } \\
\text { determine loads may be } \\
\text { prohibitively expensive. }\end{array}$ & $\begin{array}{l}\text { A } 24 \text { month study of loads in the } \\
\text { South Pine River, southeast } \\
\text { Queensland shows the dominance } \\
\text { of high flows in determining } \\
\text { loads; } 86 \% \text { of the total } \\
\text { phosphorus load was carried in } \\
2.8 \% \text { of the time in three major } \\
\text { storms (Cosser, 1989) }\end{array}$ & $\begin{array}{l}\text { Annual loads are dominated by } \\
\text { high flow events therefore high } \\
\text { flow events must be sampled } \\
\text { intensively to accurately estimate } \\
\text { loads. Problems of estimating } \\
\text { loads using the VWQMN are } \\
\text { acknowledged in CLPC et al., } \\
1996\end{array}$ \\
\hline $\begin{array}{l}\text { Maximum } \\
\text { change from } \\
\text { background } \\
\text { condition }\end{array}$ & $\begin{array}{l}\text { In the Latrobe River the } \\
\text { maximum allowable } \\
\text { change in water } \\
\text { temperature from } \\
\text { background conditions is } \\
2^{\circ} \mathrm{C} \text { (Victorian } \\
\text { Government Gazette, } \\
\text { 1988); the maximum } \\
\text { allowable change in } \\
\text { turbidity is } 10 \% \text { (EPA, } \\
1996 \text { ) }\end{array}$ & $\begin{array}{l}\text { Not appropriate because regular } \\
\text { sampling at one location is } \\
\text { unlikely to provide information } \\
\text { that can be used to assess this } \\
\text { objective }\end{array}$ & $\begin{array}{l}\text { Sampling sites will depend on the } \\
\text { location of the pollution source } \\
\text { that is expected to change } \\
\text { background conditions }\end{array}$ & $\begin{array}{l}\text { Sample background condition } \\
\text { immediately upstream of point } \\
\text { discharge and changed conditions } \\
\text { immediately downstream }\end{array}$ \\
\hline $\begin{array}{l}\text { Rate of } \\
\text { change from } \\
\text { background } \\
\text { condition }\end{array}$ & $\begin{array}{l}\text { In the Latrobe River, } \\
\text { water temperature shall } \\
\text { not change by more than } \\
1^{\circ} \mathrm{C} \text { in } 30 \text { min (Victorian } \\
\text { Government Gazette, } \\
1988)\end{array}$ & $\begin{array}{l}\text { Not appropriate because regular } \\
\text { sampling at one location is } \\
\text { unlikely to provide information } \\
\text { that can be used to assess this } \\
\text { objective }\end{array}$ & $\begin{array}{l}\text { For the Latrobe River, water } \\
\text { temperature measurements would } \\
\text { be required every } 30 \text { mins } \\
\text { upstream and downstream of the } \\
\text { pollution source }\end{array}$ & $\begin{array}{l}\text { Need to sample background } \\
\text { temperature and changed } \\
\text { temperature in the area of interest } \\
\text { at a frequency that allows } \\
\text { assessment of the objective }\end{array}$ \\
\hline
\end{tabular}




\section{Pathologies of river management}

These types of strategies could include: limiting stock access to streams, reducing the amount of waste from dairy sheds that enter waterways or encouraging best practice in fertiliser application to limit runoff to streams. The aggregate impact of these strategies could be significant in some cases. For example in the Williams River in New South Wales, a large proportion of phosphorus loads are estimated to come from diffuse sources that may be amenable to reduction through management (Healthy Rivers Commission of New South Wales 1996; see Table 3.3. There are large uncertainties in estimating the impact of such strategies and the rate of uptake by landholders. It is reasonable to hope that the success of such strategies can be determined by monitoring water quality. Successful strategies would show up as reductions in loads or concentrations although it may be difficult to separate the effect of management strategies from uncontrolled influences (see Section 8.5.3).

Table 3.3 - Estimated phosphorus sources to the Williams River (Umwelt Pty Ltd, 1995)

\begin{tabular}{|l|c|c|}
\hline Source of phosphorus & $\begin{array}{c}\text { Estimated average } \\
\text { annual tonnes of } \\
\text { phosphorus }\end{array}$ & $\begin{array}{c}\text { Proportion of } \\
\text { annual } \\
\text { phosphorus load }\end{array}$ \\
\hline Background (from basaltic soils) & 6.0 & $19.7 \%$ \\
\hline Streambank and surface erosion & 6.5 & $21.2 \%$ \\
\hline $\begin{array}{l}\text { Fertiliser (loss of fertiliser to } \\
\text { drainage system) }\end{array}$ & 2.8 & $9.2 \%$ \\
\hline Cattle with direct access to the river & 8.7 & $28.4 \%$ \\
\hline Dairy effluent & 5.1 & $16.7 \%$ \\
\hline Domestic wastewater & 1.4 & $4.6 \%$ \\
\hline Urban stormwater & 0.1 & $0.2 \%$ \\
\hline Total & $\mathbf{3 0 . 6}$ & $\mathbf{1 0 0 \%}$ \\
\hline
\end{tabular}

Measuring a change in water quality can be considered in terms of the standard hypothesis-testing framework. If water quality data are available before and after an intervention then they could be analysed to determine if the null hypothesis, $\mathrm{H}_{\mathrm{o}}$, no change, should be rejected in favour of the alternative hypothesis, $\mathrm{H}_{1}$, that a change has occurred (Montgomery and Loftis, 1987). Statistical tests can be used to decide whether $\mathrm{H}_{\mathrm{o}}$, should be rejected. Possible outcomes, states of nature and errors are shown in Table 3.4 The Type I error, $\alpha$, is the probability of erroneously detecting a change when one does not exist. The statistical power, $1-\beta$ is the probability of detecting a change when a change actually occurs. The change could be either a trend 
or a step change in the mean (Lettenmaier, 1976). In general there is a relationship between the size of the change, the variance of the data, the number of samples and Type I and Type II error probabilities (Cohen, 1988). For testing changes in water quality, the key variable of interest is the number of samples (number of months of monthly data) following a change that are required to make a reasonable assessment of the change.

Table 3.4 - Possible outcomes and states of nature when testing for change

\begin{tabular}{|c|c|c|c|}
\hline & \multicolumn{2}{|c|}{ Test Outcome } \\
\hline & & $H_{o}$ true (no change) & $\mathrm{H}_{1}$ true (change) \\
\hline \multirow{2}{*}{$\begin{array}{c}\text { State } \\
\text { of } \\
\text { nature }\end{array}$} & $\mathrm{H}_{\mathrm{o}}$ true (no change) & $\begin{array}{l}\text { Correct } \\
\text { Probability }=1-\alpha\end{array}$ & $\begin{array}{l}\text { Type I error } \\
\text { Probability }=\alpha\end{array}$ \\
\hline & $\mathrm{H}_{1}$ true (change) & $\begin{array}{l}\text { Type II error } \\
\text { Probability }=\beta\end{array}$ & $\begin{array}{l}\text { Correct } \\
\text { Probability = } 1-\beta \\
\text { (power) }\end{array}$ \\
\hline
\end{tabular}

Consider the case of a step change in the data, with effect size, $d$

$d=\frac{\left|\mu_{1}-\mu_{2}\right|}{\sigma}$

where $\mu_{1}$, and $\mu_{2}$ are the mean values before and after the step change and $\sigma$ is the standard deviation. It is possible to calculate the number of samples that are required to detect changes with a particular effect size if the Type I and Type II errors are specified. The number of samples required to detect a change also depends on the time the change occurs i.e. at the start, middle or end of the record. If the variance is known and data are approximately normally distributed, the calculations are straightforward (Davies, 1966, 30-34). For unknown variance, numerical procedures must be used to calculate the sample size based on the non-central $t$ distribution (Walpole and Myers, 1978, 259). A computer program GPOWER has been developed to undertake these calculations (Faul and Erdfelder, 1992, Erdfelder et al., 1996).

Using the GPOWER program, the time to detect changes corresponding to various effect sizes was calculated Figure 3.13. Calculations are based on the assumption that there are 20 years of monthly data available before a change. The Type I probability $\alpha$ $=0.05$ and power $(1-\beta)=0.8$. The figure shows the number of years of monthly data required before the Type I and Type II errors are as specified for various effect sizes. The figure shows that effect sizes below $17 \%$ are difficult to detect with over 100 years 


\section{Pathologies of river management}

of monthly data required before the desired power and Type I error probabilities can be achieved. These values have been calculated assuming that samples are not autocorrelated. Autocorrelation will increase the number of samples, so that changes will take longer to detect (Bayley and Hammersley, 1946; Lettenmaier, 1978).

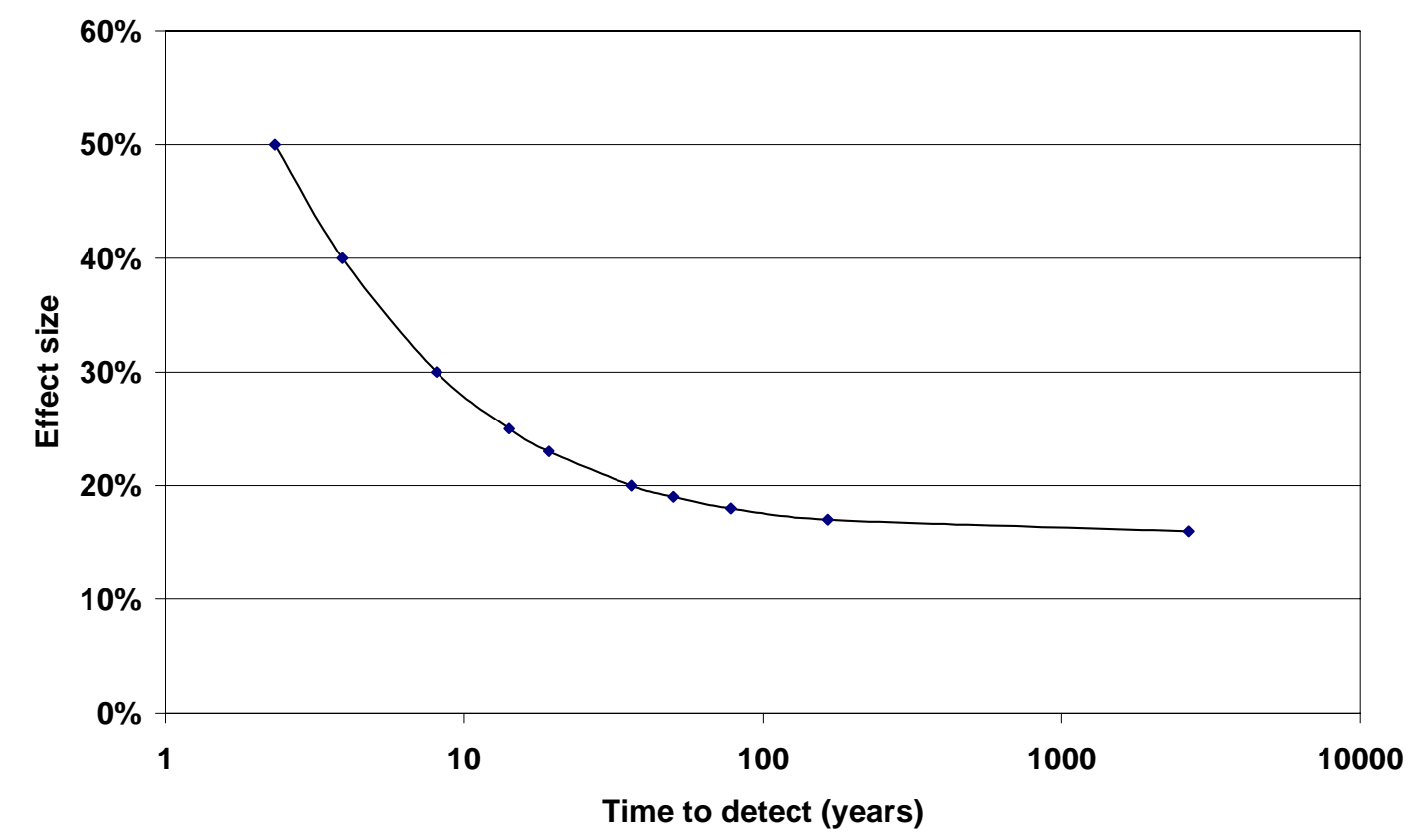

Figure 3.13 - Time (years) required to detect changes with various effect sizes, assuming monthly samples, $\alpha=0.05, \beta=0.2$. Calculations were made using GPOWER (Faul and Erdfelder, 1992).

It is also possible to calculate the power to detect changes over shorter periods. If it is assumed that 20 years of monthly data are available before and after a change, the relationship between power and effective size can be calculated as shown in Figure 3.14 The power to detect changes with effect sizes around $10 \%$ is low, less than $30 \%$. Effect sizes need to be greater than $23 \%$ before the power increases to greater than $80 \%$. Similar calculations could be made to estimate the number of samples required to detect linear trends of various sizes (Gerrodette, 1987; Link and Hatfield, 1990; Gerrodette, 1991), although the techniques appear to be controversial (Thomas and Krebs, 1997). It is also possible to test whether changes in mean values are greater than a particular size (McBride et al., 1993; McBride, 1999).

What type of change in water quality could we expect from an integrated catchment management program? Assuming management-induced changes in mean water quality 
concentrations of around $10 \%$ are plausible, the time required to detect these changes for a range of water quality parameters for the Latrobe river at Rosedale are calculated Table 3.5. Results are based on the assumption that there are 20 years of data available prior to the change, $\alpha=0.05$, and the desired power $(1-\beta)=80 \%$. The results show that for most water quality parameters changes in the mean of around $10 \%$ are undetectable over reasonable time frames.

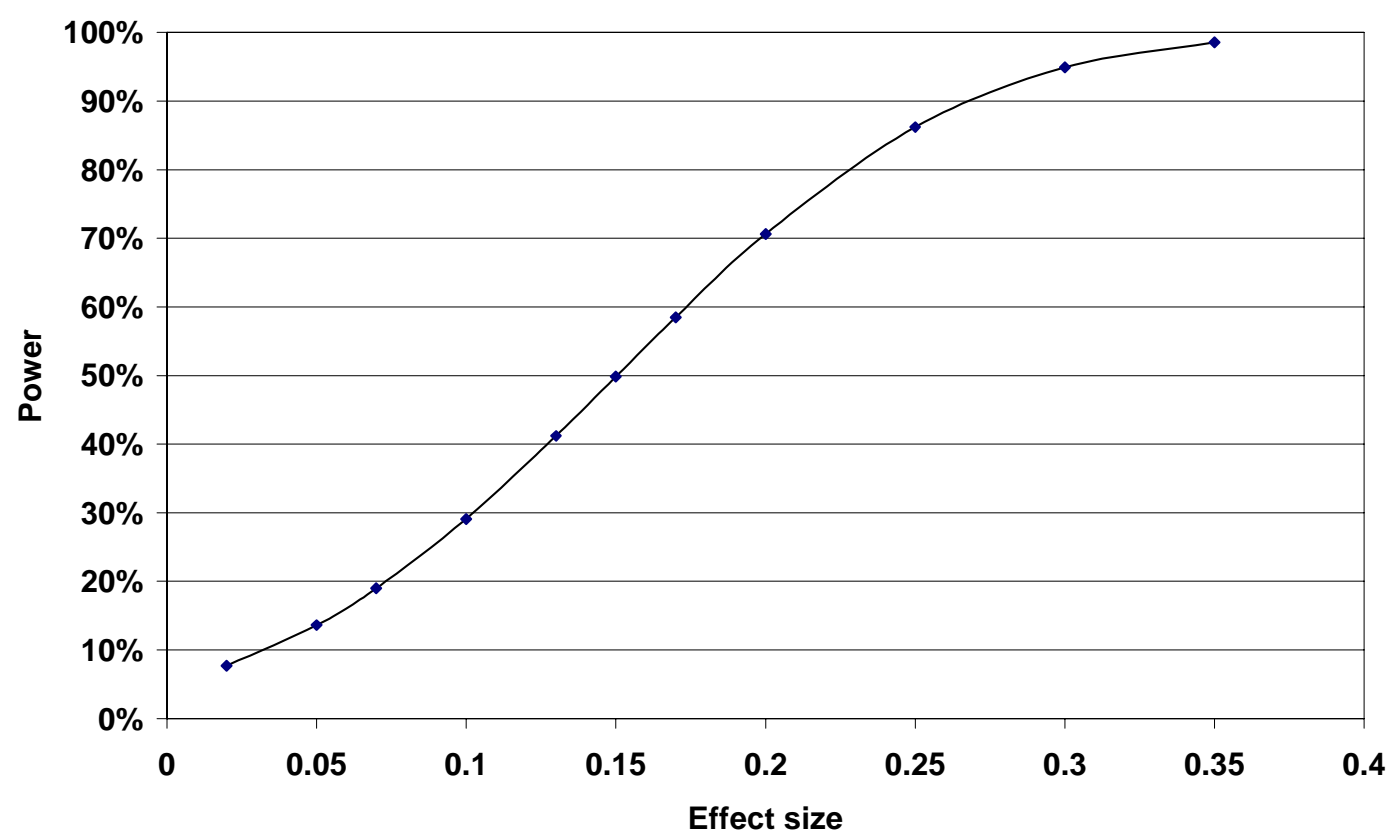

\section{Figure 3.14 - Relationship between power and effect size assuming 20 years of monthly data before and after a change, $\alpha=0.05$. Calculations were carried out using GPOWER (Faul and Erdfelder, 1992).}

The problem is that a $10 \%$ change in the mean is a relatively small effect size because the variance is high for phosphorus, turbidity, suspended solids and organic nitrogen. Detecting changes in electrical conductivity and $\mathrm{pH}$ are more straightforward. These high variances in water quality parameters cannot be explained by the variance in flow. Using methods recommended in Helsel and Hirsch (1992, 221-263), a regression equation was used to define a relationship between phosphorus, time and flow. This showed that only $2.2 \%$ of the variance in the phosphorus readings could be explained by the phosphorus-flow relationship, suggesting there is no simple way to reduce the variance in the estimates of phosphorus concentrations. These results show the difficulty of detecting management-induced changes where the effect size is small and the problems with using VWQMN data to track these types of interventions. 
Table 3.5 - Water quality parameters for the Latrobe River at Rosedale, based on water quality data from 29/8/1962 to $1 / 02 / 95$ provided by Gippsland Water.

\begin{tabular}{|l|r|r|r|r|r|}
\hline Parameter & Unit & Mean & $\begin{array}{r}\text { Standard } \\
\text { deviation }\end{array}$ & $\begin{array}{c}\text { Effect size for } \\
\text { 10\% change } \\
\text { in mean }\end{array}$ & $\begin{array}{c}\text { Years required to } \\
\text { detect a 10\% } \\
\text { change in the } \\
\text { mean using } \\
\text { monthly data }\end{array}$ \\
\hline Flow & ML/d & 2253 & 2313 & & $>3000$ \\
\hline Turbidity & N.T.U. & 42.3 & 43.1 & 0.1 & 8.1 \\
\hline $\begin{array}{l}\text { Electrical } \\
\text { conductivity }\end{array}$ & $\mu \mathrm{S} / \mathrm{m}$ & 32.7 & 9.5 & 0.3 & $>3000$ \\
\hline $\begin{array}{l}\text { Total } \\
\text { phosphorus }\end{array}$ & $\mathrm{mg} / \mathrm{L}$ & 0.11 & 0.16 & 0.07 & $>3000$ \\
\hline pH & & 7.2 & 0.43 & 1.7 & 2700 \\
\hline $\begin{array}{l}\text { Suspended } \\
\text { solids }\end{array}$ & $\mathrm{mg} / \mathrm{L}$ & 80.8 & 74.9 & 0.11 & \\
\hline $\begin{array}{l}\text { Organic } \\
\text { nitrogen }\end{array}$ & $\mathrm{mg} / \mathrm{L}$ & 0.50 & 0.32 & 0.16 & \\
\hline
\end{tabular}

1 - The effect size is the ratio of the difference in the means before and after the change to the standard deviation (see equation 3.1).

2 - Assumes that $\alpha=0.05$, Power $(1-\beta)=0.8,20$ years of monthly data are available before the change. Calculations were made using the program GPOWER (Faul and Erdfelder, 1992).

\subsubsection{Data rich but information poor}

The above analysis highlights two problems with the water quality monitoring program.

- Data collected to satisfy the objectives of the monitoring program (that is to be able to detect large trends) may not provide information that is useful to answer questions about the effectiveness of management programs.

- Assessing many of the water quality objectives developed by managers may require different sampling strategies to those needed to satisfy objectives of the VWQMN.

If the currently collected water quality data cannot satisfy management needs they are unlikely to be used routinely as part of decision-making or even analysed. This leads to the 'data rich but information poor' syndrome (Ward et al., 1986) where much data are collected but they are not routinely analysed or reported. Ward et al. (1986) argue that it is critical to document the objectives, the 'why' of sampling along with the where, what and when. Similar concerns have been expressed about biological monitoring 
with Underwood (1991) calling for the abolition of routine environmental monitoring programs because of inadequate and incompetent sampling design.

The analysis shows that much routinely collected water quality data will not be useful to managers and that better monitoring and reporting procedures are required if this type of information can usefully inform management decision-making. It also shows a danger for environmental monitoring in general, that information must be relevant to managers if it is to be used. The issues discussed here associated with Type I and Type II errors, effect sizes and number of samples, are similar for any system of indicators and are returned to throughout this thesis.

\subsection{Focusing on a narrow range of issues}

The previous case study showed the importance of environmental information being of use to managers. This case study explores another barrier to appropriate consideration of environmental issues, that is, a narrow management focus, which has long been recognised as a problem for environmental management.

In a review of catchment management in Australia in the 1980s, Laut and Taplin (1988, 22) found that catchment management, including river management, was usually single issue driven and there was a tendency to satisfy pressure groups without investigating or attempting to set priorities for issues. The creation of public agencies that have a narrow focus can result in the activities of one agency inadvertently undoing the work of another. There are also edge or boundary problems between agencies (AWRC, 1988). Similar problems of overlapping and poor coordination of functions and fragmentation of responsibilities were documented by the Day (1987), Industry Commission (1998), and Ewing et al. (1997) and have been identified internationally (Risser 1985; Born and Sonzogni 1995).

Holling (1995) argues that, over time, natural resource management organisations that are initially effective, narrow the range of issues they consider and tend to have a single scale of response, typically short-term and local. They become inward looking, focussing on an introspective search for efficiency and do not undertake any evaluation (why evaluate a success?). Nor do they do any monitoring for surprises (Gunderson et al., 1995). 


\section{Pathologies of river management}

In river management, an example of this tendency is the use of willows for control of bank erosion. Willows may be appropriate to address immediate erosion concerns but can cause long term problems when they proliferate along waterways, and cause environmental degradation and river management problems (Ladson et al., 1997a). The problems of willows were recognised as early as 1951 with Strom, Divisional Engineer with the Victorian State Rivers and Water Supply Commission, describing them as a 'Jekyll and Hyde' plant, very damaging in the wrong places, capable of spreading quickly, choking streams and reducing capacity (Strom, 1951). Yet river management authorities continued to use willows for erosion control. A State Government funded review, 46 years later, again highlighted problems and argued for a moratorium on further planting (Ladson et al., 1997a).

Another example of the short-term and local focus of river management activities in Victoria is the management of sand and gravel extraction on the Avon River in Gippsland. Despite erosion that was recognised as the worst in the State (Strom, 1951), local river managers allowed gravel to be extracted in excess of bedload transport rate for most of the 50 years prior to 1997. Extraction rates have been ten times the bedload transport rate for approximately 10 years prior to 1997. This excess extraction is likely to have caused bed and bank erosion, damaged publicly funded works and led to demands for further expenditure to repair erosion (Davis et al., 1997).

Problems with the excessively narrow focus of river management in the past have led to a series of institutional reforms (as discussed in Chapter 2) to broaden the roles, responsibilities and area of jurisdiction of authorities. These changes have, no doubt, decreased problems associated with single-issue management but there is still scope for improvement and areas where rhetoric is not matched by action. Some of the recent economic reforms in water management represent a narrowing of the focus of river management, as there has been little consideration of the environmental consequences. The following case study provides an example.

\subsubsection{Case Study: implementation of bulk entitlements to water in Victoria}

This case study reviews implementation of tradeable water allocations, which are being implemented as part of the reform of Victoria's water industry. The review focuses on the Victorian Water Act 1989, and two documents that specifically address 
implementation of these reforms (DCE 1992; DCNR 1995). These documents show that the focus of river management in Victoria has been narrowed to speed up the implementation of water reforms. Specifically, the ability to address environmental concerns arising from the reform process has been restricted. Part of this case study was published in Casey et al. (1997) but the material presented here is the author's own work.

\section{Background}

The economic and environmental problems associated with the Australian water industry have made it an important area of reform at both the Commonwealth and State levels (Working Group on Water Resource Policy Secretariat, 1994a; 1995). This reform process is advanced in Victoria where the 1989 Water Act included provisions for the granting of bulk entitlements. A Bulk Entitlement Order defines the legal right to take, from a river, a specified quantity of water over a specified period.

The use of bulk entitlements in the Victorian water industry is explained in two reports: Department of Conservation and Environment (DCE, 1992) and Department of Conservation and Natural Resources (DCNR, 1995). These reports were written to guide the implementation of the bulk entitlement provisions of the Water Act and are meant to facilitate:

- 'provision of greater legislative security and better clarity of the rights held by water authorities and other public bodies over their water assets'; and

- 'greater efficiency in the allocation of water since the instrument of allocation, the bulk entitlement, can withstand the rigours of market trading' (DCE, 1992, $1)$.

DCE (1992) explains the new framework of bulk entitlements to water and discusses water for the environment and the conversion of existing rights to water. DCNR (1995) explores these issues further and documents entitlement orders for the Goulburn River System.

The core proposals of these reports are similar. Both are about legally specifying a right to water that can then be traded and are consistent with a belief in market-based solutions to the economic and environmental problems facing Victoria's water industry. This core belief has been dominant at least since the early 1980s. Tradeable water 


\section{Pathologies of river management}

entitlements were highlighted in two reports in 1984, the Twelfth report of the Public Bodies Review Committee $(1984,243)$ and a report on water allocations in northern Victoria (Salinity Committee, 1984, 57). Dr John Paterson, then Director General of the Victorian Department of Water Resources publicly supported transferable water entitlements in 1984 (Department of Resources and Energy and Australia Water Resources Council, 1984). The 1986-1987 annual report of the Victorian Department of Water Resources further documents the creation of a market for water entitlements and the introduction of a temporary transfer system (Department of Water Resources, 1987). The annual report lists discussion papers and other reports commissioned by the Department on this issue. In 1989, bulk entitlements, an instrument to achieve market trading of water, were written into the new Victorian Water Act.

\section{A narrowing of the management focus}

The main differences between DCE (1992) and DCNR (1995) are in their handling of environmental issues associated with the granting of bulk entitlements. DCE (1992) takes a strong stand on the environment. DCNR (1995), completed during the first term of a new government, is focused mainly on the rapid conversion of existing entitlements with limited concern for environmental issues.

\section{Allocation of water to the environment}

The environmental benefits of bulk entitlements are highlighted in DCE (1992): '[bulk entitlements] provide a secure basis for the development of proper water entitlements to meet environmental needs'. DCE $(1992,18)$ documents the procedure for estimating environmental water requirements. This consists of:

- setting management objectives for each element of a river system (including river reaches, storages, and lakes); and

- specifying flow events to meet these management objectives (e.g. a spring flood may be required for the spawning of native fish).

The environmental emphasis of DCE (1992) contrasts with DCNR (1995). The procedure for estimating environmental water requirements outlined in 1992 was not followed during the specification of bulk entitlements for the Goulburn basin as documented in DCNR (1995). Management objectives for the river system are not reported. A flow event for the Goulburn River, downstream of Eildon Pondage weir, is 
specified (DCNR, 1995, 100) but the objective of providing this event is not clear and the environmental benefit of this flow event is limited. The released water is too cold to support native fish in the $(138 \mathrm{~km})$ section of the river between Eildon and Seymour (Gippel and Finlayson, 1993) and the volume of the specified flow event is also too small to achieve inundation of wetlands on the Goulburn River floodplain (Gippel, 2000). Increasing the water temperature would require artificial destratification of Eildon reservoir, which is not proposed as part of the bulk entitlement process. Gippel and Finlayson (1993) argue that the cost of destratification and an annual spring flood are probably prohibitive and that it may be more pragmatic to manage this section of the river for recreational fishing of introduced species.

There are two other areas where the scope of assessing and providing environmental flows is more limited in DCNR (1995) than is recommended in the earlier report (DCE, 1992). These relate to the use of scientific information and re-allocation of water from existing users.

At the June 1993 meeting of the Council of Australian Governments, Victoria agreed that 'environmental requirements, wherever possible, be determined on the best scientific information available' (Council of Australian Governments, 1994). DCNR (1995) comments that the Department of Conservation and Natural Resources has established internal arrangements to provide environmental input. The ability of these internal arrangements to provide the best available information is questionable given a lack of expertise within the Department and a decline in research effort with recent budget cuts (Christoff, 1998).

DCNR (1995) rules out reducing water allocation to current users to reallocate to environmental uses as part of the bulk entitlement conversion program (DCNR, 1995, 22). The report comments that applications can be made for new bulk entitlements for the environment but that procedures have not been developed. Clearly, developing these procedures was considered a lower priority than granting bulk entitlements to existing users on the Goulburn River.

\section{Monitoring the environmental effects of granting bulk entitlements}

DCE (1992) outlines a comprehensive monitoring program as part of the granting of bulk entitlements and comments that '[bulk entitlements] will prevent any further degradation of the State's water resource if an appropriate standard of monitoring and 


\section{Pathologies of river management}

reporting of entitlements is achieved'. The report argues that, as there is limited understanding of river environments, it is important to measure the response of the natural system to change and modify management intervention if necessary. Information gathering and performance monitoring are proposed to include:

- ecological surveys;

- catchment surveys;

- river channel surveys; and

- water quantity and quality monitoring.

This proposed monitoring effort contrasts with comments in DCNR (1995) which documents a much narrower range of reporting requirements for organisations granted bulk entitlements. For example, the reporting obligations for the Eildon-Goulburn Weir bulk entitlement (DCNR, 1995 Section 17, (a) to (o)) relate exclusively to water quantity. Environmental obligations (Section 15) are restricted to managing the environmental effects of silt removal from offtakes or other limited activities.

There is no requirement to consider any wider environmental issues associated with water trading such as those documented by Bjornlund and McKay (1995). For example, there is no requirement to monitor the effectiveness of the flow event to be released from Eildon pondage (discussed above).

Not only has the environmental monitoring proposed in DCE (1992) been reduced, the ability of other authorities to address environmental concerns has also been limited as part of the bulk entitlement process. For example, Waterway Management Authorities, whose functions include identification and protection of environmental values of waterways, are prevented by 1995 amendments to the Water Act, from acting inconsistently with bulk entitlement orders (compare sections 186 and 189 of the Water Act 1989). Therefore, the granting of a bulk entitlement to an irrigation authority reduces the ability of a Waterway Management Authority to address environmental issues that could be caused by the extraction of water under the bulk entitlement.

\section{Conclusion}

Comparison of the two reports highlights a narrowing of management focus that occurred between 1992 and 1995. The core proposals behind the reports are similar and 
represent an economic rationalist approach to reform of the water industry. These proposals have guided water reform since the early 1980 s.

The differences between the reports provide evidence of narrowing of the river management focus as bulk entitlements have been implemented. A summary of the changes between DCE (1992) and DCNR (1995) include:

- a decrease in the amount of environmental monitoring required as part of the granting of bulk entitlements;

- establishing internal procedures to review environmental requirements rather than seeking input from external scientific experts;

- restricting the extracting authority's responsibility for any environmental damage;

- restricting the ability of waterway management authorities to address environmental concerns that arise from the granting of bulk entitlements;

- decreasing the reporting requirements of authorities that are granted a bulk entitlement;

- reducing the requirement for the setting of management objectives as part of the bulk entitlement process; and

- reducing the need to specify specific environmental flow events.

There are many possible reasons for these changes. There may have been a fear amongst the economic reformers that environmental issues could delay the introduction of bulk entitlements. They may have considered it better to introduce the reforms and then address any environmental issues later if they engendered public concern. It is also possible that the reform agenda was captured by irrigation interests keen to maximise the amount of water that could be extracted and to limit the liability for any environmental damage.

At the broad level, the case study shows one way of addressing environmental concerns; that is, try to ignore them. Limit the amount of information collected, resist setting objectives, only undertake limited monitoring and reduce the ability of others to intervene. It is another example of the short-term and local management focus criticised by Gunderson et al. (1995) and Gunderson (1999). The difficultly is that environmental 


\section{Pathologies of river management}

concerns are unlikely to go away, a fact that has been acknowledged by governments (Commonwealth of Australia, 1992; Council of Australian Governments, 1994). The Commonwealth Government's Industry Commission argues that although market mechanisms have a role to play in ensuring ecologically sustainable development, governments have the final responsibility (Industry Commission, 1998).

The issues here concern the best way to collect environmental information and incorporate it into decision-making. Hammond et al. (1995) proposed environmental indicators as a systematic approach to measuring and reporting on performance. Holling (1995) argues that a lack of monitoring, particularly for surprises, can lead to a crisis when inflexible, narrowly focused organisations are confronted with environmental problems. A deliberate attempt to ignore environmental information, such as in the case presented here, is likely to lead to that crisis. Indicators do have a role to play in managing environmental effects and, as was documented in DCE (1992) the importance of monitoring and reporting is critical, especially given the limited understanding of river environments.

\subsection{Conclusion}

Literature reviews and case studies have highlighted pathologies in the way river managers have addressed environmental concerns. The first case study discussed situations where river management activities have been undertaken in the context of environmental change and shows that often information about the environment is not obtained rigorously. Instead, management actions are made in response to perceptions of the state of the environment. This can lead to inappropriate proposals and conflict. Systematic collection and reporting of environmental indicators could help to overcome this problem especially if integrated with management activities.

The second case study presented an example where there was rigorous monitoring of the environment but the information was not suitable to assist management decisionmaking. Two issues were uncovered. Firstly, there was disagreement between the goals of monitors and those of the managers, which means the collected information was often not be suitable to answer managers' questions. Secondly, high natural variability means that the performance of some management interventions may not be capable of being assessed over reasonable periods, regardless of the monitoring program. 
The third case study described the narrow, short-term management focus that means long-term environmental issues are not considered. This problem has long been recognised but the recent processes surrounding the creation of economic instruments for water trading shows there are situations where it is still not being addressed. This is despite government rhetoric about the need for ecologically sustainable development and the desire to recognise environmental needs when allocating water. Broad scale monitoring and reporting of environmental indicators was originally proposed as part of establishing bulk entitlements to water but recent efforts have been to limit environmental assessment. If long-term environmental issues are to be addressed then reporting of environmental indicators should be reconsidered.

Problems with the interaction between river managers and the environment have led to calls for better approaches. These include development of management systems that routinely consider environmental information and indicators to measure and report on environmental condition (Grayson and Doolan 1995; Hammond et al., 1995).

There is a specific proposal for the development of system of indicators to measure stream condition in Victoria as a tool to aid the management of rivers. This proposal, for an Index of Stream Condition, arose because of concerns about the pathologies of river management discussed in this chapter along with the changing institutional arrangements for waterway management discussed in Chapter 2. The background to the ISC is described in detail at the start of Chapter 5.

Part of the development of the ISC involved a review of existing indicator-systems for measuring stream condition to find out what had been done by others and to assess their suitability and limitations. This review is described in Chapter 4. 


\section{MONITORING STREAM CONDITION}

\subsection{Introduction}

The previous chapter discussed some of the problems in the interface between river management and the river environment and why monitoring is needed. This chapter reviews methods for gathering information about the overall condition of streams and discusses some of the intended uses of the information, including the role of monitoring in adaptive management.

This review provides background to the development of the Index of Stream Condition (ISC), which is described in the next chapter. The ISC is a suite of indicators to be used to assist management of waterways in Victoria and was developed as a response to concerns about the environmental condition of streams, the need for a system of reporting outcomes of a range of stream management activities and to overcome river management problems such as those identified in the previous chapter. Data will be collected and used by regional Catchment Management Authorities for tasks including benchmarking stream condition, setting priorities and evaluating management performance. As described in the next chapter, the ISC resulted from a process that encouraged input from a wide range of people with expertise in various aspects of rivers including water quality, riparian vegetation, geomorphology and aquatic biota.

Lessons from the existing approaches reviewed here, for the ISC, are noted throughout this chapter and then highlighted at the end. The process of building on these approaches to develop a system of indicators suitable for the Victorian context is described in Chapter 5.

The main emphasis of this chapter is on the Australian approaches to stream condition assessment but there is also discussion of procedures applied in the United Kingdom, United States of America, Europe and South Africa. There is also discussion of differences in intended use, the type of measurements made and the various components of stream condition, along with an assessment of the usefulness of these approaches to overcome the problems that have been highlighted in previous chapters. 
It is unlikely that this review is complete. Many jurisdictions will have developed their own assessment techniques that have limited documentation outside government reports, which are often difficult to access. There are also new methods being developed that are yet to be documented. This chapter does cover those techniques that have been well documented either in journal articles or in accessible government reports. It is biased toward Victorian examples because documentation was easier to obtain and I had access to government officials. The Victorian focus is justified because this work is the most relevant for overcoming problems associated with river management in Victoria and being able to build on previous work in the Victorian context is important. Peculiar characteristics of Victorian streams and management arrangements mean that a direct transfer of indicators from other areas may not be appropriate. The skills and resources available will differ between jurisdictions and there may be differences in issues associated with riparian flora (Ladson et al., 1997a), hydrologic characteristics (McMahon et al., 1992), catchment vegetation (Peel, 1999), sediment transport rates (Davis, 1996) and large woody debris (Gippel et al., 1996).

Part of this chapter is to be published in January 2000 as Ladson, A. R. and White, L. J. (2000). Measuring Stream Condition. River management: the Australasian experience. S. O. Brizga and B. L. Finlayson. (eds) John Wiley and Sons (see Appendix B). The material presented here represents the author's own work.

\subsection{Overview of existing approaches to measuring overall stream condition}

Measures of stream condition vary in the choice of:

- aspects of stream condition to be quantified; and

- the actual measurements that are required.

Stream condition can only be determined through a holistic appraisal of streams and their surrounds. There are linkages and overlaps but at least seven components of stream condition can be identified Figure 4.1. 


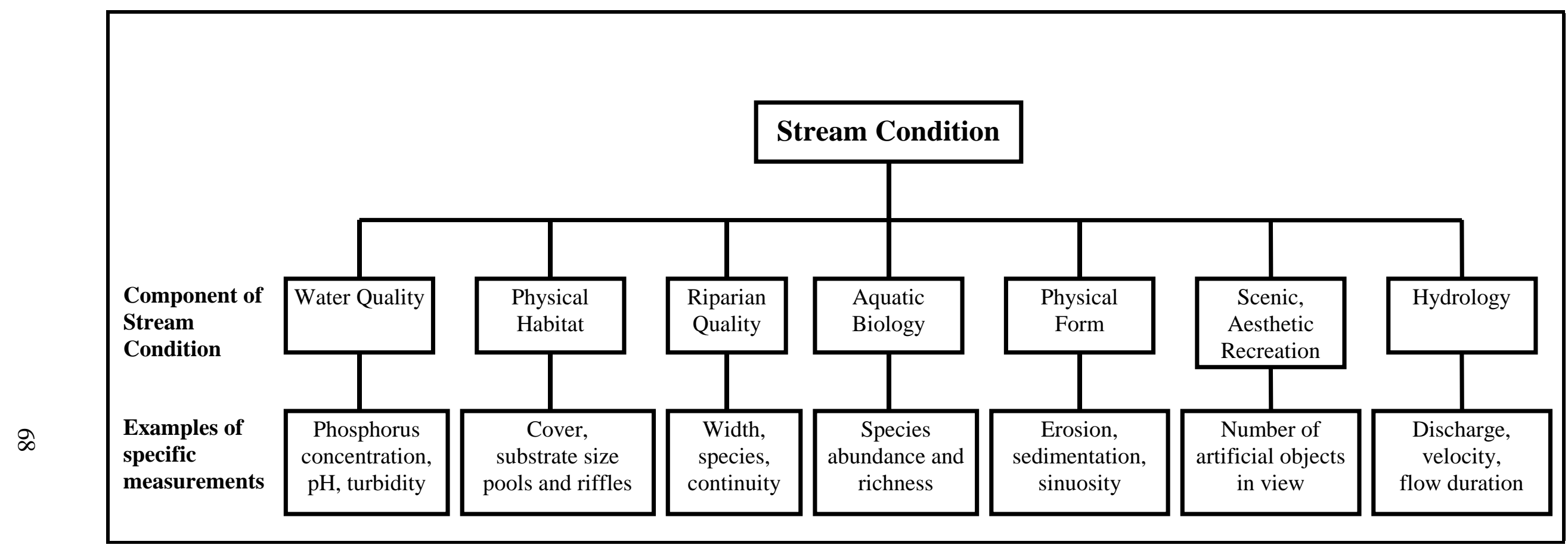

Figure 4.1 - Components of stream condition and examples of specific measures 
Stream condition measures have been developed for two main tasks.

1. A 'snap-shot' assessment of condition. These provide a one-off measurement that can be used to compare present condition with respect to a reference state, usually the stream condition before human intervention.

2. Ongoing management, to aid objective setting, planning and reporting.

Table 4.1 summarises some approaches to measuring stream condition, in terms of aspects of stream condition that are quantified and the intended use. Further details on each of these methods are provided below.

\subsubsection{Environmental Condition of Victorian Streams}

In 1986, the Victorian State Government commissioned a State of the Streams Survey (SSS) to assess physical stream conditions. The survey examined 868 sites that were chosen to be representative of all stream types within 28 drainage basins throughout the state. At each survey site, approximately 200 variables were recorded including catchment land use, stream bed and bank material, riparian vegetation, channel characteristics and aquatic habitat. Several photographs were also taken (Tilleard and DWR, 1986; Ian Drummond and Associates Pty Ltd, 1985). A subset of these variables (10 of the 200) was used by Mitchell (1990) to develop an assessment of the environmental condition of Victoria's rivers and streams (Table 4.2.

Within each basin, streams were divided into three classes: (1) minor streams catchment area less than 5000 ha; (2) tributary streams - catchment area between 5000 ha and 30000 ha; and (3) major streams - catchment area greater than 30000 ha. For each of these classes of stream, environmental condition was assessed on a five point scale as excellent, good, moderate, poor, or very poor with assessments based on ten indicators that were weighted and combined. The exact method of weighting indicators is not documented, but Mitchell states that most weight was generally given to bed composition, bank and verge vegetation and the amount of cover for fish. Low weight was given to underwater vegetation, amount of organic debris, depth and flow velocity (Mitchell, 1990). Indicator ratings are explained in Table 4.2 An example of assessments of environmental condition for streams in the Latrobe Basin is shown in Table 4.3 . 
Table 4.1 - Approaches to measuring stream condition

\begin{tabular}{|c|c|c|c|c|c|c|c|c|c|c|}
\hline \multirow[b]{2}{*}{ Approach } & \multirow[b]{2}{*}{ Used in } & \multicolumn{8}{|c|}{ Component of Stream Condition } & \multirow[b]{2}{*}{ Intended Use } \\
\hline & & $\begin{array}{l}\text { see } \\
\text { section }\end{array}$ & $\begin{array}{l}\text { Water } \\
\text { quality }\end{array}$ & $\begin{array}{l}\text { Physical } \\
\text { habitat }\end{array}$ & $\begin{array}{l}\text { Riparian } \\
\text { quality }\end{array}$ & $\begin{array}{l}\text { Aquatic } \\
\text { biology }\end{array}$ & $\begin{array}{l}\text { Physical } \\
\text { form }\end{array}$ & $\begin{array}{l}\text { Scenic, } \\
\text { aesthetic, } \\
\text { recreation }\end{array}$ & Hydrology & \\
\hline $\begin{array}{l}\text { Environmental } \\
\text { Condition of } \\
\text { Victorian Streams }\end{array}$ & $\begin{array}{l}\text { Victoria, } \\
\text { Australia }\end{array}$ & 4.2 .1 & & $\checkmark$ & $\checkmark$ & & $\checkmark$ & & $\checkmark$ & $\begin{array}{l}\text { Assessment of } \\
\text { environmental condition } \\
\text { from detailed assessment } \\
\text { of physical features. }\end{array}$ \\
\hline $\begin{array}{l}\text { State of the } \\
\text { Environment report }\end{array}$ & $\begin{array}{l}\text { Victoria, } \\
\text { Australia }\end{array}$ & 4.2 .2 & $\checkmark$ & $\checkmark$ & $\checkmark$ & $\checkmark$ & & & & $\begin{array}{l}\text { One-off assessment of the } \\
\text { environmental condition of } \\
\text { streams. }\end{array}$ \\
\hline State of the Rivers & $\begin{array}{l}\text { Queensland, } \\
\text { Australia } \\
\end{array}$ & 4.2 .3 & & $\checkmark$ & $\checkmark$ & & $\checkmark$ & $\checkmark$ & $\checkmark$ & $\begin{array}{l}\text { 'Snap-shot' assessment } \\
\text { from mainly physical data. }\end{array}$ \\
\hline $\begin{array}{l}\text { National Water } \\
\text { Quality Inventory }\end{array}$ & USA & 4.2 .4 & $\checkmark$ & $\checkmark$ & $\checkmark$ & $\checkmark$ & & & $\checkmark$ & $\begin{array}{l}\text { Overall ongoing } \\
\text { assessment of streams in } \\
\text { USA against objectives of } \\
\text { the Clean Water Act. }\end{array}$ \\
\hline $\begin{array}{l}\text { Estuarine Health } \\
\text { Index }\end{array}$ & South Africa & 4.2 .5 & $\checkmark$ & & & $\checkmark$ & & $\checkmark$ & & $\begin{array}{l}\text { 'Snap-shot' reporting of } \\
\text { estuary condition. }\end{array}$ \\
\hline $\begin{array}{l}\text { RCE: riparian, } \\
\text { channel and } \\
\text { environmental } \\
\text { inventory }\end{array}$ & $\begin{array}{l}\text { USA } \\
\text { Sweden } \\
\text { Italy }\end{array}$ & 4.2 .6 & & $\checkmark$ & $\checkmark$ & $\checkmark$ & $\checkmark$ & & & $\begin{array}{l}\text { Intended for small lowland } \\
\text { streams in agricultural } \\
\text { areas. }\end{array}$ \\
\hline SERCON/RHS & UK & 4.2 .7 & & $\checkmark$ & $\checkmark$ & & $\checkmark$ & $\checkmark$ & $\checkmark$ & $\begin{array}{l}\text { A detailed assessment of } \\
\text { current condition. }\end{array}$ \\
\hline
\end{tabular}


Table 4.2 - Criteria used by Mitchell (1990) to determine environmental ratings for rivers in Victoria (adapted from Barmuta et al., 1992)

\begin{tabular}{|c|c|c|c|c|c|}
\hline & Very Poor & Poor & Moderate & Good & Excellent \\
\hline \multicolumn{6}{|c|}{ 1. Bed composition } \\
\hline $\begin{array}{l}\text { Minor } \\
\text { stream } \square\end{array}$ & All sand & Gravel, sand & $\begin{array}{l}\text { Gravel, some } \\
\text { cobbles, some } \\
\text { sand }\end{array}$ & $\begin{array}{l}\text { With at least } 10 \% \\
\text { cobbles mainly } \\
\text { shingle }\end{array}$ & $\begin{array}{l}\text { Boulders, cobbles, } \\
\text { shingles, small } \\
\text { amount gravel or } \\
\text { finer }\end{array}$ \\
\hline $\begin{array}{l}\text { Tributary } \\
\text { stream }\end{array}$ & $\mathrm{N} / \mathrm{A}$ & All sand & Gravel, sand & Mainly shingle, gravel & $\begin{array}{l}\text { Shingle, cobble, } \\
\text { gravel }\end{array}$ \\
\hline $\begin{array}{l}\text { Major } \\
\text { stream }\end{array}$ & $\mathrm{N} / \mathrm{A}$ & $\mathrm{N} / \mathrm{A}$ & All sand & Shingle, gravel, sand & $\begin{array}{l}\text { Shingle, cobbles } \\
\text { present }\end{array}$ \\
\hline \multicolumn{6}{|c|}{ 2. Proportion of pools and riffles } \\
\hline $\begin{array}{l}\text { Minor } \\
\text { stream }\end{array}$ & $\begin{array}{l}100 \% \text { riffle } \\
\text { or pool }\end{array}$ & $90 \%$ riffle or pool & $\begin{array}{l}70-80 \% \text { riffle or } \\
\text { pool }\end{array}$ & $60 \%$ riffle or pool & $50 \%$ riffle or pool \\
\hline $\begin{array}{l}\text { Tributary } \\
\text { stream }\end{array}$ & $\begin{array}{l}\text { Intermittent } \\
\text { pools }\end{array}$ & All pools & $<10 \%$ riffles & $10-30 \%$ riffles & $>30 \%$ riffles \\
\hline $\begin{array}{l}\text { Major } \\
\text { stream }\end{array}$ & $\begin{array}{l}\text { Intermittent } \\
\text { pool or very } \\
\text { shallow }\end{array}$ & $\mathrm{N} / \mathrm{A}$ & $100 \%$ pools & $\mathrm{N} / \mathrm{A}$ & some riffles \\
\hline \multicolumn{6}{|c|}{ 3. Bank vegetation } \\
\hline All & $\begin{array}{l}\text { Exotic } \\
\text { ground } \\
\text { cover with } \\
\text { bare } \\
\text { ground, } \\
\text { occasional } \\
\text { tree }\end{array}$ & $\begin{array}{l}\text { Exotic ground } \\
\text { cover, little } \\
\text { native overstorey } \\
\text { or understorey or } \\
\text { predominantly } \\
\text { exotic cover. }\end{array}$ & $\begin{array}{l}\text { Moderate cover, } \\
\text { mixed } \\
\text { native/exotics, or } \\
\text { one side cleared, } \\
\text { other undisturbed }\end{array}$ & Minor clearing & $\begin{array}{l}\text { Mainly undisturbed } \\
\text { native vegetation }\end{array}$ \\
\hline \multicolumn{6}{|c|}{ 4. Verge vegetation } \\
\hline All & $\begin{array}{l}\text { Bare or } \\
\text { pasture }\end{array}$ & $\begin{array}{l}\text { Very narrow } \\
\text { corridor of native } \\
\text { vegetation or } \\
\text { exotics }\end{array}$ & $\begin{array}{l}\text { Wide corridor } \\
\text { mixed native and } \\
\text { exotics, or one } \\
\text { side cleared, and } \\
\text { other native and } \\
\text { wide }\end{array}$ & $\begin{array}{l}\text { Mainly undisturbed } \\
\text { native, }<30 \mathrm{~m} \text { wide or } \\
\text { some exotics or } \\
\text { reduced cover of } \\
\text { natives }\end{array}$ & $\begin{array}{l}\text { Mainly undisturbed } \\
\text { native vegetation, } \\
>30 \mathrm{~m} \text { wide }\end{array}$ \\
\hline \multicolumn{6}{|c|}{ 5. Cover for fish } \\
\hline All & none & Poor & Moderate & Good & Abundant \\
\hline \multicolumn{6}{|c|}{ 6. Average flow velocity } \\
\hline $\begin{array}{l}\text { Minor } \\
\text { stream }\end{array}$ & 0 & $0.1-0.2 \mathrm{~m} \mathrm{~s}^{-1}$ & $0.3-0.6 \mathrm{~m} \mathrm{~s}^{-1}$ & $0.6-0.7 \mathrm{~m} \mathrm{~s}^{-1}$ & $>0.8 \mathrm{~m} \mathrm{~s}^{-1}$ \\
\hline $\begin{array}{l}\text { Tributary } \\
\text { stream }\end{array}$ & 0 & $0.1-0.2 \mathrm{~m} \mathrm{~s}^{-1}$ & $0.3-0.6 \mathrm{~m} \mathrm{~s}^{-1}$ & $0.6-0.7 \mathrm{~m} \mathrm{~s}^{-1}$ & $>0.8 \mathrm{~m} \mathrm{~s}^{-1}$ \\
\hline $\begin{array}{l}\text { Major } \\
\text { stream }\end{array}$ & $\mathrm{N} / \mathrm{A}$ & 0 & $\begin{array}{l}0.1 \mathrm{~m} \mathrm{~s}^{-1} \\
\text { (pools) }\end{array}$ & $0.2 \mathrm{~m} \mathrm{~s}^{-1}$ (pools) & $\begin{array}{l}0.3 \mathrm{~m} \mathrm{~s}^{-1} \\
\text { (pools) }\end{array}$ \\
\hline \multicolumn{6}{|c|}{ 7. Water depth } \\
\hline $\begin{array}{l}\text { Minor } \\
\text { stream }\end{array}$ & $\begin{array}{l}\text { Dry or } \\
\text { trickle }\end{array}$ & $<0.2 \mathrm{~m}$ & $0.3-0.5 \mathrm{~m}$ & $0.6-1 \mathrm{~m}$ & $>1.0 \mathrm{~m}$ \\
\hline $\begin{array}{l}\text { Tributary } \\
\text { stream }\end{array}$ & $\begin{array}{l}\text { Dry or } \\
\text { trickle }\end{array}$ & $<0.2 \mathrm{~m}$ & $0.3-0.5 \mathrm{~m}$ & $0.6-1 \mathrm{~m}$ & $>1.0 \mathrm{~m}$ \\
\hline $\begin{array}{l}\text { Major } \\
\text { stream }\end{array}$ & $<0.3 \mathrm{~m}$ & $0.4 \mathrm{~m}$ & $0.5-0.9 \mathrm{~m}$ & $1.0-2.0 \mathrm{~m}$ & $>2.0 \mathrm{~m}$ \\
\hline \multicolumn{6}{|c|}{ 8. Underwater vegetation } \\
\hline All & $\begin{array}{l}0 \text { or } \\
>80 \% \\
\text { cover }\end{array}$ & $\begin{array}{l}1-5 \% \text { or } \\
60-80 \% \text { cover }\end{array}$ & $5-20 \%$ cover & $20-30 \%$ cover & $30-60 \%$ cover \\
\hline \multicolumn{6}{|c|}{ 9. Organic Debris } \\
\hline All & 0 & $0-10 \%$ cover & $10-20 \%$ cover & $20-40 \%$ cover & $40 \%$ cover \\
\hline \multicolumn{6}{|c|}{ 10. Erosion/sedimentation } \\
\hline All & Extensive & Significant & $\begin{array}{l}\text { Moderate, } \\
\text { affecting parts of } \\
\text { reach }\end{array}$ & Only spot erosion & $\begin{array}{l}\text { Stable no erosion } \\
\text { or sedimentation }\end{array}$ \\
\hline
\end{tabular}

\footnotetext{
1 minor streams - catchment area less than 5000 ha

2 tributary streams - catchment area between 5000 and 30000 ha

3 major streams - catchment area greater than 30000 ha
} 
Table 4.3 - Environmental ratings for proportion of stream length in the Latrobe Basin, Victoria (adapted from Mitchell, 1990)

\begin{tabular}{|c|c|c|c|c|c|}
\hline Streams & Very Poor & Poor & Moderate & Good & Excellent \\
\hline Minor & $5 \%$ & $13 \%$ & 0 & $33 \%$ & $49 \%$ \\
\hline Tributary & $18 \%$ & $23 \%$ & $13 \%$ & $23 \%$ & $23 \%$ \\
\hline Major & 0 & $55 \%$ & $23 \%$ & $7 \%$ & $15 \%$ \\
\hline
\end{tabular}

\section{Suitability and Limitations}

Mitchell (1990) defines environmental condition as the suitability of a stream as habitat for fish and aquatic invertebrates and, to a lesser extent, the condition of the riparian zone as habitat for native organisms. Therefore, ratings attempt to provide an absolute measure of environmental condition defined as habitat suitability. Independent checking of Mitchell's procedure shows that it successfully performed this task. Habitat suitability ratings were checked by experienced professional field biologists and there was reasonable agreement (Barmuta et al., 1992).

Rating streams according to Mitchell's criteria is not the same as comparing the present state of a stream to pristine conditions. It would be possible for a site in pristine condition to rate poorly if it did not conform to the assumed ideal. For example, an undisturbed stream, with a sandy bed, in low flow conditions would obtain a low score even if it were in natural condition. This limits the geographic flexibility of the technique (Grayson et al., 1996).

The State of the Streams Survey (Tilleard and DWR, 1986) was based on a 'snap shot' assessment of physical stream condition that was conducted in one season during low flow. It does not take account of factors, such as changes in hydrology or water quality, that influence streams over longer periods; nor does it include an assessment of aquatic biology.

Results of Mitchell's (1990) assessment are reported as length of stream (or proportion of stream length) with a particular rating for minor, moderate and major streams within each basin (see Table 4.3). In reality, assessments are not made for whole streams but at measuring sites - short stream lengths (2.5 times the meander wavelength or 25 times the width) that are 'representative' of longer stream reaches. The density of measuring 
sites varied depending on the size of the stream (see Table 4.4. 'Representative' measuring sites were chosen by experts during an aerial inspection of streams in Victoria (Tilleard pers. comm.).

Table 4.4 - Sampling density for State of the Streams Survey (Ian Drummond and Associates Pty Ltd, 1985)

\begin{tabular}{|l|c|}
\hline Stream size & Sampling density \\
\hline Minor streams (forested catchment) & 1 site per $500 \mathrm{~km}$ \\
\hline Minor streams (unforested catchment) & 1 site per $200 \mathrm{~km}$ \\
\hline Tributary streams & 1 site per $25 \mathrm{~km}$ \\
\hline Major streams & 1 site per $25 \mathrm{~km}$ \\
\hline
\end{tabular}

The use of 'representative' measuring sites to characterise stream reaches introduces the possibility of bias. If the measuring site is not truly representative, then the rating will be incorrect for many kilometres of stream. Choosing 'representative' sites maximises the use of expert knowledge and decreases the number of measurements that have to be made but means it is difficult to quantify errors. An alternative procedure would be to use random sites that would allow statistical analysis of the results see for example (Williams, 1996; Jeffers, 1998). The site selection issue is explored in Chapter 6 where it is shown that there can be large errors when using 'representative' sites to estimate condition.

It is also difficult to assess change in condition over time when assessment is based on 'representative' sites. Conservation activities at the previously chosen 'representative' site will have a disproportionate effect on the condition assessment for the whole reach. The method will tend to be overly sensitive to changes at the 'representative' site and insensitive to changes elsewhere. These concerns were born out by an assessment of condition in the Glenelg catchment in southwestern Victoria. In the original State of the Streams Survey, 58 sites were assessed along the Glenelg river and tributaries (Mitchell, 1990). These were reassessed by Davidson et al. (1994), who found that there were few changes in environmental condition, mainly because of the lack of sensitivity of the method. Of the 58 sites, seven had changed their condition category, with four sites improving and three getting worse. The changes from one category to another occurred where something calamitous had happened or conversely, where a sudden and extensive amount of conservation work had occurred along the site (Davidson et al., 1994). The 


\section{Monitoring stream condition}

main improvements were because of fencing to exclude stock and revegetation of the stream banks, while degradation occurred where there was stock damage or vegetation clearing. The issue of sensitivity will need to be considered in the development of any stream assessment technique.

In summary, the lessons from analysis of this approach are as follows. First, assessment of streams over a wide geographic area will require a methodology that takes account of different stream types. If a stream assessment technique is not generally applicable then it will be important to restrict its use to streams where correct results can be obtained. Secondly, selection of an appropriate sampling strategy is important. There are dangers in using a strategy that is not statistically rigorous as scientists are likely to question the validity of the results but there may be compelling reasons to ignore these concerns. Thirdly, it will be important to consider the sensitivity of the methods to the types of changes that are considered important to detect.

Apart from work in the Glenelg Catchment, the State of the Streams Survey has not been repeated and is unlikely to be. It is now seen more as an early stream assessment technique that may provide part of the background to an improved method.

\subsubsection{State of the environment report - Victoria's inland waters}

In 1988 the Office of the Commissioner for the Environment (1988) prepared a state of the environment report documenting the condition of Victoria's inland waters. This complemented the physical assessment undertaken in the State of the Streams survey by developing an Index of Aquatic Environmental Quality (IAEQ) that included an assessment of six components of stream condition:

1. physical water quality (turbidity, suspended solids, conductivity);

2. chemical water quality (Biochemical Oxygen Demand, $\mathrm{pH}$, phosphorus, nitrogen and toxicants);

3. amount of toxicants in sediments (metals and hydrocarbons);

4. macroinvertebrates (a comparison of abundance and diversity of species with those that would exist under natural conditions);

5. fish (type, abundance and diversity in comparison with natural conditions); and 
6. riparian vegetation (extent and quality).

Each of these components was rated on a five point scale i.e. excellent, good, moderate, poor, or degraded. A summary of the chosen indicators and rating system for the IAEQ is described in Table 4.5

Assessments were made for 28 basins in Victoria with condition generally being reported for streams in three areas: mountain, valley and plain. These areas were mapped and defined by the Office of the Commissioner for the Environment (1988). In mountain areas, streams have high gradients and flow through steep-sided valleys; in valley areas streams flow along relatively open valley floors with a mixture of erosional and depositional features; and in plains regions, streams pass across broad alluvial or coastal floodplains. The number of mountain, valley and plains streams in each basin varied depending on the topography. For example, basins in the flatter northwestern area of Victoria have no mountain streams but may have more than one valley segment. In total, stream conditions were assessed in 82 regions of the State made up of assessments of mountain, valley and plains segments for 28 stream basins. As an example, assessment of the mountain segment of the Thomson River is shown in Table 4.6.

For some indicators, particularly for water quality, the stream type influenced the rating that was used. Usually, in Victorian conditions, concentrations of nutrients and suspended sediments are expected to increase in the downstream reaches of streams even under natural conditions. Ratings were set up to reflect this. For example, the excellent category for turbidity requires NTU values less than 5 in a mountain segment, less than 10 for a valley segment and less than 15 for a plains segment (Table 4.7). Similar rating tables were used for indicators of physical water quality, chemical water quality and the amount of toxicants in sediments.

It was intended that water quality information would come from the existing stream monitoring network where possible and would be based on monthly values that were processed to provide a representative value for a site, that could then be rated. Usually ratings were based on the median or percentile values of at least ten monthly samples collected over a year. For example, the rating for turbidity was based on the 80th percentile of an annual series of monthly values. 
Table 4.5 - Index of Aquatic Environmental Quality (Office of the Commissioner for the Environment, 1988)

\begin{tabular}{|c|c|c|c|c|c|c|}
\hline & \multicolumn{3}{|c|}{ Water Quality Indicators } & \multicolumn{3}{|c|}{ Biological Indicators } \\
\hline & Physical & Chemical & Toxicants in sediments & Macroinvertebrates & Fish & Vegetation \\
\hline Excellent & $\begin{array}{l}\text { Water clear, minimal } \\
\text { turbidity, natural levels of } \\
\text { salinity and natural levels } \\
\text { of toxicants. }\end{array}$ & $\begin{array}{l}\text { Natural levels of } \\
\text { nutrients, and high } \\
\text { oxygen levels. }\end{array}$ & $\begin{array}{l}\text { Natural levels of } \\
\text { toxicants. }\end{array}$ & $\begin{array}{l}\text { Natural abundance and diversity } \\
\text { of species. }\end{array}$ & $\begin{array}{l}\text { Natural abundance and } \\
\text { diversity of native fish species; } \\
\text { no introduced species. }\end{array}$ & $\begin{array}{l}\text { Streamside vegetation intact for at } \\
\text { minimum } 100 \mathrm{~m} \text { width from bank, with } \\
\text { continuous cover essentially unmodified } \\
\text { and few exotics. Catchment vegetation } \\
\text { substantially uncleared. Less than } 10 \% \\
\text { catchment logged. }\end{array}$ \\
\hline Good & $\begin{array}{l}\text { Water clear, minimal } \\
\text { turbidity, natural levels of } \\
\text { salinity. }\end{array}$ & $\begin{array}{l}\text { Low nutrient and high } \\
\text { oxygen levels. }\end{array}$ & $\begin{array}{l}\text { No toxicant present in } \\
\text { quantities significant } \\
\text { enough to affect faunal } \\
\text { species. }\end{array}$ & $\begin{array}{l}\text { Communities intact, all species } \\
\text { present. Species abundance } \\
\text { reflecting low level input of } \\
\text { wastes and minor catchment } \\
\text { modifications. }\end{array}$ & $\begin{array}{l}\text { Predominantly native fish, with } \\
\text { no more than one introduced } \\
\text { species present. }\end{array}$ & $\begin{array}{l}\text { Streamside vegetation communities intact, } \\
\text { with cover essentially unmodified for, at } \\
\text { minimum } 30 \mathrm{~m} \text { width for over } 80 \% \text { of } \\
\text { segment. Infrequent exotics. Largely } \\
\text { undisturbed by roading. Limited permanent } \\
\text { clearing. }\end{array}$ \\
\hline Moderate & $\begin{array}{l}\text { Slight increases in one or } \\
\text { more of turbidity and } \\
\text { salinity. }\end{array}$ & $\begin{array}{l}\text { Slight increases in } \\
\text { nutrient levels. No } \\
\text { substantial change in } \\
\text { oxygen levels. }\end{array}$ & $\begin{array}{l}\text { Minor quantities of } \\
\text { cumulative or non- } \\
\text { cumulative toxicants } \\
\text { present, with minor } \\
\text { impact on faunal species. }\end{array}$ & $\begin{array}{l}\text { Minor changes in communities } \\
\text { including changes in community } \\
\text { structure and local loss of some } \\
\text { species, corresponding to } \\
\text { influence of input of wastes and } \\
\text { catchment modifications. }\end{array}$ & $\begin{array}{l}\text { Equal numbers of native fish } \\
\text { species \& exotics or majority } \\
\text { of native species with }>1 \\
\text { exotic fish species present. }\end{array}$ & $\begin{array}{l}\text { Stream vegetation communities } \\
\text { predominantly intact and exotics infrequent. } \\
\text { Riparian zone intact for } 30 \mathrm{~m} \text { width, at } \\
\text { minimum, for over } 60 \% \text { of catchment. }\end{array}$ \\
\hline Poor & $\begin{array}{l}\text { Marked increases in } \\
\text { turbidity or salinity. }\end{array}$ & $\begin{array}{l}\text { Marked increases in } \\
\text { nutrient levels, some } \\
\text { change in dissolved } \\
\text { oxygen levels. } \\
\text { Presence of } \\
\text { cumulative or non- } \\
\text { cumulative toxicants } \\
\text { present in water } \\
\text { column. }\end{array}$ & $\begin{array}{l}\text { Significant presence of } \\
\text { toxicants, with impact on } \\
\text { faunal species. }\end{array}$ & $\begin{array}{l}\text { Marked changes in communities, } \\
\text { including changes in structure } \\
\text { and local loss of species } \\
\text { reflecting significant inputs of } \\
\text { wastes, toxicants or other matter. }\end{array}$ & $\begin{array}{l}\text { Predominantly introduced } \\
\text { species present. }\end{array}$ & $\begin{array}{l}\text { Streamside vegetation largely fragmented } \\
\text { and exotics frequent. Riparian zone of } 30 \mathrm{~m} \\
\text { intact for less than } 60 \% \text { of catchment, and } \\
\text { frequently disturbed by roading. Stream } \\
\text { segment largely cleared of native } \\
\text { vegetation. }\end{array}$ \\
\hline Degraded & $\begin{array}{l}\text { Major increase in turbidity } \\
\text { or salinity. }\end{array}$ & $\begin{array}{l}\text { Major increase in } \\
\text { nutrient levels, } \\
\text { substantial change in } \\
\text { oxygen levels. } \\
\text { Cumulative or non- } \\
\text { cumulative toxicants } \\
\text { present in substantial } \\
\text { levels. }\end{array}$ & $\begin{array}{l}\text { Substantial levels of } \\
\text { cumulative or non- } \\
\text { cumulative toxicants, } \\
\text { with significant impact } \\
\text { on faunal species. }\end{array}$ & $\begin{array}{l}\text { Major changes in communities, } \\
\text { including changes in structure } \\
\text { and massive local loss of species. }\end{array}$ & $\begin{array}{l}\text { Few introduced and no native } \\
\text { species, or no fish found. }\end{array}$ & $\begin{array}{l}\text { Little remnant streamside vegetation. } \\
\text { Surviving patches fragmented. Exotics } \\
\text { frequent. Riparian zone of } 30 \mathrm{~m} \text { width intact } \\
\text { for less than } 25 \% \text { of catchment, and } \\
\text { frequently disturbed by roading, bare or } \\
\text { eroded. Stream segment substantially } \\
\text { cleared of native vegetation. }\end{array}$ \\
\hline
\end{tabular}


Table 4.6 - Assessment of the Index of Aquatic Environmental Quality for the mountain segment of the Thomson River, Victoria, Australia (Office of the Commissioner for the Environment, 1988)

\begin{tabular}{|c|c|c|c|c|c|}
\hline $\begin{array}{c}\text { Physical } \\
\text { Water } \\
\text { Quality }\end{array}$ & $\begin{array}{c}\text { Chemical } \\
\text { Water } \\
\text { Quality }\end{array}$ & $\begin{array}{c}\text { Toxicants } \\
\text { in } \\
\text { Sediments }\end{array}$ & $\begin{array}{c}\text { Macro- } \\
\text { invertebrates }\end{array}$ & Fish & Vegetation \\
\hline Poor & Good & $\begin{array}{c}\text { Insufficient } \\
\text { data }\end{array}$ & Good & Moderate & Excellent \\
\hline
\end{tabular}

Table 4.7 - Criteria for assessing turbidity [NTU] (Office of the Commissioner for the Environment, 1988)

\begin{tabular}{|l|r|r|r|}
\hline & \multicolumn{3}{|c|}{ Basin segment } \\
\hline Rating & Mountain & \multicolumn{1}{|c|}{ Valley } & \multicolumn{1}{c|}{ Plain } \\
\hline Excellent & $<5.0$ & $<10.0$ & $<15.0$ \\
\hline Good & $<7.5$ & $<12.5$ & $<17.5$ \\
\hline Moderate & $<10.0$ & $<15$ & $<20$ \\
\hline Poor & $<12.5$ & $<22.5$ & $<30.0$ \\
\hline Degraded & $>12.5$ & $>22.5$ & $>30.0$ \\
\hline
\end{tabular}

Where possible, macroinvertebrates were assessed using an Average Species Richness index (ASR). The index consists of the average of the number of invertebrate species found in a series of samples collected from a single occasion (Office of the Commissioner for the Environment, 1988). Criteria were established so that streams could be rated on a five point scale i.e. between excellent and degraded.

The rating of streams based on fish is predominantly determined by the occurrence of exotic species (Table 4.8). For vegetation, ratings are based on the width, disturbance and invasion of exotic species (Table 4.5).

\section{Suitability and limitations}

The Index of Aquatic Environmental Quality was intended as an assessment of the stream condition in Victoria at a particular point in time i.e. the current 'state of the environment'. The rating of condition is based on the criteria established by the Office of the Commissioner for the Environment. Ratings are based on historical data and are averages over a certain period (usually a year). The purpose of the assessments is to 


\section{Monitoring stream condition}

measure change in the environment: particularly long-term effects of activities such as agriculture. Originally, it was intended that state of the environment assessments would be repeated every 5 years so that trends could be detected (Office of the Commissioner for the Environment, 1988).

Table 4.8 - Criteria for assessing streams based on fish (Office of the Commissioner for the Environment, 1988)

\begin{tabular}{|l|l|}
\hline Rating & Description \\
\hline Excellent & Only native species present, and no exotics \\
\hline Good & Predominance of native species, and one or no exotics \\
\hline Moderate & $\begin{array}{l}\text { Equal abundance of both native and exotic species, or } \\
\text { predominance of exotics but presence of one or two } \\
\text { rare/endangered natives. }\end{array}$ \\
\hline Poor & Predominantly exotics \\
\hline Degraded & Few exotics or no fish. \\
\hline
\end{tabular}

The assessments proposed in the State of the Environment Report had significant data requirements. The lack of available data meant that environmental ratings could not be given for much of the State (see Table 4.9. Information on toxicants in sediments was not available for any basin, while an assessment for chemical water quality was missing in $91 \%$ of cases. This missing data significantly limited the value of Index of Aquatic Environmental Quality.

Table 4.9 - Missing values from the statewide assessment of streams using the IAEQ (adapted from Office of the Commissioner for the Environment, 1988)

\begin{tabular}{|l|l|c|}
\hline No. & Category & Proportion of missing values \\
\hline 1 & Physical water quality & $50 \%$ \\
\hline 2 & Chemical water quality & $91 \%$ \\
\hline 3 & Toxicants in sediment & $100 \%$ \\
\hline 4 & Macroinvertebrates & $55 \%$ \\
\hline 5 & Fish & $49 \%$ \\
\hline 6 & Vegetation & $21 \%$ \\
\hline
\end{tabular}

Insufficient data reveals a weakness of this type of 'state of the environment' reporting. A complete description of the environment requires a large amount of data, that would 
then have to be regularly processed to detect changes in the environment. The indicators selected for the IAEQ did not relate well to the available data so could not be assessed. This means that the results could not be used to benchmark current condition nor to detect trends, so the output becomes irrelevant for answering management questions and is unlikely to be used. The preface to Office of the Commissioner for the Environment (1988) states that there will be a five year program of State of the Environment Reporting, but no further assessments of inland waters have been published and the Office has been disbanded.

This highlights a problem in the process of developing stream condition indicators. If indicators are selected without considering data availability, or without a plan for data collection, then the result is unlikely to be useful.

\subsubsection{State of the Rivers Project - Queensland, Australia}

The State of the Rivers Project was conducted under the direction of the Queensland Department of Primary Industries. The aim of the project was to provide baseline information that could assist with setting priorities for stream rehabilitation and to determine trends in stream condition (Anderson, 1993a; Anderson, 1993b; Jackson and Anderson, 1994).

The assessment technique, the 'Anderson' method, involves a field-based appraisal of condition at selected sites throughout a river system. Assessments are made on data sheets that enable descriptions of:

- the climate and regional land system of the catchment;

- $\quad$ subcatchment features - land use, soils, geology, slope, gradient;

- $\quad$ site features - land use, vegetation, land tenure, floodplain features;

- channel form, shape and dimensions;

- banks, physical condition and process;

- bed and bars, physical condition and process;

- vegetation, aquatic, bank, riparian;

- aquatic habitat classification and condition; and 


\section{Monitoring stream condition}

- scenic, conservation and recreational value.

Ratings are produced using formulae, which combine the data weighted in terms of their relative importance (Jackson and Anderson, 1994). Ratings range from very good to degraded with streams classified on a five point scale as shown in Table 4.10. The very good condition criteria is set using a local undisturbed site as a reference so that the ratings indicate how far other sites have degraded from this standard.

Table 4.10 - Condition rating for the State of the Rivers project (Jackson and Anderson, 1994)

\begin{tabular}{|c|c|}
\hline Condition Category & Rating \\
\hline Very Good & $81-100 \%$ \\
\hline Good & $61-80 \%$ \\
\hline Moderate & $41-60 \%$ \\
\hline Poor & $21-40 \%$ \\
\hline Very Poor & $0-20 \%$ \\
\hline
\end{tabular}

The procedure uses a similar sampling technique to that in the State of the Streams Survey conducted in Victoria (Ian Drummond and Associates Pty Ltd, 1985; Tilleard and DWR, 1986; Mitchell, 1990). Measuring sites (about 50m long) are chosen that represent the condition of larger homogeneous reaches. The measuring sites are assessed in detail and this information is used to infer the condition of the reaches.

The Anderson procedure has been applied to streams in Queensland including the Maroochy River (Anderson, 1993c), Bremer River (Telfer et al., 1998), Herbert River (Moller, 1996), Mary River (Johnson, 1997), Lockyer Creek (Carter, 1997) and Condamine River (Phillips and Moller, 1995). It has also been applied in New South Wales (Jim Armstrong, Department of Land and Water Conservation, NSW pers. comm.).

\section{Suitability and limitations}

The State of the Rivers project has enjoyed support since its development, which suggests that results are seen as being useful. Most of the work to date has been to collect initial data for benchmarking exercises but plans were recently announced to repeat the survey of the Maroochy catchment and to evaluate the methodology (Neller, 1998). 
Assessment is limited to the physical characteristics of the stream channel and surrounds and the instream and riparian vegetation. There is no assessment of hydrology, water quality or aquatic biota.

The base data collected for the State of the Rivers Survey is similar although more extensive to that of the State of the Streams survey (Tilleard and DWR, 1986) but the procedure used to determine ratings differs from that used by Mitchell (1990). Mitchell's system was based on straightforward tabulated categories (Table 4.2) whereas Anderson (1993b) uses formulae with a number of dependent variables and a series of calculation steps. The procedure requires a level of mathematical sophistication that seems excessive given the likely accuracy of the data and the results. For example, calculation of the Aquatic Habitat Index, requires consideration of 17 different cover types, each with its own weighting. The values for each cover type are scaled using a $3^{\text {rd }}$ order quadratic function and then weighted and summed with the final output being rescaled using a logarithmic function to amplify the ratings where there is limited cover (Anderson, 1993b, 45). Most of the rating procedures are straightforward to apply since software has been developed to undertake the calculations but the system is more difficult to change than one based on tabulated ratings and harder to explain to users with limited mathematical background. It will also be harder to modify it for use in other areas where different ratings and weights may be appropriate. Given the lack of sophistication in other areas of the stream assessment, a more straightforward approach to calculating ratings seems appropriate.

Two issues emerged during the review that have implications for other assessments of stream condition. Firstly, there is the difference in sampling density between the similar survey techniques of the State of the Streams survey (Tilleard and DWR, 1986) and the State of the Rivers survey reviewed here. Although the sampling techniques are similar, the sampling density is much greater in the State of the Rivers Project. During assessment of $507 \mathrm{~km}$ of the Maroochy River, 209 sites were surveyed, about one site per $2.5 \mathrm{~km}$. This compares to one site for every $25 \mathrm{~km}$ in the State of the Streams Survey (see Table 4.4.

There is a trade-off between cost, accuracy, and the frequency of assessment. The correct balance of these conflicting requirements depends on the specific objectives of the stream monitoring exercise. It is likely that greater sampling density increases the accuracy of the assessment but requires an increased commitment of resources for the 


\section{Monitoring stream condition}

initial survey and for subsequent surveys. Sampling schemes do not seem to have been rigorously assessed in either case.

The second issue relates to the discussion of the sedimentation in the Herbert River in Chapter 3 that shows a difficulty with this assessment technique that is likely to apply to other rapid appraisal methods. The Anderson method was used to assess the condition of the Herbert River with results suggesting the bed in the lower reaches was moderately to severely aggrading (Moller, 1996, 23). A more thorough examination of the evidence presented in Chapter 3 brings this assessment into question.

The best way of treating the results from a rapid assessment is as a flag for further investigation. If problems are identified by poor indicator scores, then it may be appropriate to investigate the underlying causes and consider the processes involved, rather than taking indicator assessments at face value and using them to guide allocation of resources.

\subsubsection{United States stream assessment programs National Water Quality Inventory}

Protecting the physical, chemical, and biological integrity of rivers and streams is the primary goal of the US Clean Water Act (Rankin, 1995). Section 305(b) of the Clean Water Act requires States and other participating jurisdictions to assess and report on the quality of streams and other waterbodies. These biennial reports are the primary vehicle for informing Congress and the public about general water quality condition (including stream condition) in the United States (US Environmental Protection Agency, 1996).

Monitoring stream condition consists of data collection and sample analysis performed using accepted protocols and quality control procedures. Although assessment methods vary between participating jurisdictions, measurement of stream condition generally includes an assessment of:

- chemical and physical water quality data (e.g. temperature, turbidity, $\mathrm{pH}$, dissolved oxygen, and concentrations of specific pollutants) (US Environmental Protection Agency, 1996);

- biological data such as type and abundance of species (Karr and Dudley, 1981; Plafkin et al., 1989; Yoder and Rankin, 1994); and 
- habitat and ancillary data (such as land use information) (Platts et al., 1987; Plafkin et al., 1989; Rankin, 1995; Barbour et al., 1997).

Processes are also assessed such as hydrologic modification (e.g. flow reduction).

States are free to set their own standards for waterways related to designated beneficial uses, which at a minimum must provide for 'the protection and propagation of fish, shellfish, and wildlife' and provide for 'recreation in and on the water'. These are in line with goals of the Clean Water Act that water should be fishable and swimmable (US Environmental Protection Agency, 1996).

Stream quality is judged against criteria that are appropriate for the designated beneficial use. Criteria establish, for example, the maximum concentrations of pollutants, acceptable ranges of physical parameters, and minimum concentrations of parameters such as dissolved oxygen. There are also a range of biological criteria such as presence or absence of indicator taxa and species richness.

States assess and report the overall stream condition. For example in 1994, approximately 1 million $\mathrm{km}$ (of a total of 5.7 million river $\mathrm{km}$ ) were assessed. The States found that $57 \%$ fully support their designated uses, an additional $7 \%$ support uses but were threatened and may become impaired if pollution control actions are not taken, $22 \%$ of the assessed river length partially support uses and $14 \%$ of the assessed river miles did not support designated uses (US Environmental Protection Agency, 1996).

The National Water Quality Inventory is an ongoing assessment conducted every 2 years until 1996 (future reports will be every 5 years commencing in 2001). Because the assessment is conducted regularly it has the potential to track management performance and guide the selection of effective strategies.

\section{Environmental Assessment and Monitoring Program (EMAP) and other programs}

A companion program to the National Water Quality Inventory (NWQI) is the Environmental Assessment and Monitoring Program (EMAP) also overseen by the US EPA. Unlike the NWQI, this program has a standard set of indicators, sampling techniques and methods for data interpretation that are applied uniformly throughout the US Table 4.11. Concerns about inconsistencies in the NWQI as applied by the States and other jurisdictions within the US, led to the development of this federal program (Hughes et al., 1990). The EMAP site selection procedure involves stratified random 


\section{Monitoring stream condition}

sampling so that the geographical distribution of the sites reflects the occurrence of lakes and streams in the US.

EMAP indicators are divided into three types (Table 4.11. Response indicators are measures of biota including assemblages of diatoms, macroinvertebrates and fish. Stressor indicators measure human-induced stresses on the aquatic environment and Exposure/habitat indicators measure information about the physical and chemical environment of the biota. EMAP uses an indicator selection procedure that includes documentation of desirable attributes, matching candidate indicators with those attributes, short-term field testing to develop a preliminary set of indicators and longterm testing to identify the final indicators that will be used for monitoring (Reid and Brooks, 1998; Barber 1994).

Table 4.11 - Environmental Monitoring and Assessment Program (EMAP) indicators for lakes and streams (Hughes et al., 1990)

\begin{tabular}{|c|c|}
\hline Indicator category & Indicator \\
\hline \multirow[t]{6}{*}{ Response } & Trophic state index \\
\hline & Sedimentary diatom assemblage \\
\hline & Zooplankton assemblage \\
\hline & Macroinvertebrate assemblage \\
\hline & Fish assemblage \\
\hline & Semiaquatic wildlife assemblage \\
\hline \multirow[t]{5}{*}{ Exposure/habitat } & Physical habitat structure \\
\hline & Water quality \\
\hline & Sediment toxicity \\
\hline & Chemical contaminants in fish \\
\hline & Biomarkers in fish \\
\hline \multirow[t]{7}{*}{ Stressor } & Land use and land cover \\
\hline & Human and livestock population density \\
\hline & Chemical use \\
\hline & Pollutant loadings \\
\hline & Flow and channel modifications \\
\hline & Introduced species \\
\hline & Stocking and harvesting records \\
\hline
\end{tabular}

As well as EMAP and NWQI there are other federal programs concerned with assessment of stream condition. These include the USGS National Stream Quality Accounting Network (NASQAN) and the National Biological Service (NBS) Biomonitoring of Environmental Status and Trends (BEST) program (ITFM, 1995). 
There are also individual programs conducted by some States such as Ohio (Larsen et al., 1988; Yoder and Rankin, 1994) and New Mexico (Fleming, 1999).

\section{Suitability and limitation}

These stream assessments are based on a broad interpretation of the swimmable and fishable goals for streams that is specified by the Clean Water Act. The selection of indicators is guided by these goals (Table 4.11.

The main limitation of the National Water Quality Inventory is lack of consistency. States choose their sampling regime to fit with particular program objectives and resource constraints. Possible inconsistencies mean that comparisons between states and between 2 yearly reports must be undertaken with care.

Inconsistencies arise because of variation in:

- sampling site selection: sampling may be conducted at fixed sampling stations, randomly selected stations, stations near suspected water quality problems, or stations in pristine waters;

- sampling frequency: sampling may occur at regular intervals (such as monthly, quarterly, or annually), irregular intervals, or during one-time intensive surveys; and

- chosen parameters: for example the particular chemical concentrations that are measured.

Concerns were expressed by the Intergovernmental Task Force on Monitoring Water Quality (ITFM, 1995), which noted that data from different jurisdictions were often not comparable so that they are difficult to aggregate at the national level. Also, less than half of all water bodies are assessed (Fortner and Schechter, 1996).

An example of measurement variability is described by Rankin (1995), who comments on extreme inconsistencies in reporting aquatic habitat problems across the US. Of the 47 jurisdictions reporting impairment data on streams and rivers for the 1992 report, 25 did not report habitat as a cause of problems. Yet, there is extensive stream modification (and consequently habitat degradation) in many of these areas (Rankin, 1995). 


\section{Monitoring stream condition}

Despite concerns about inconsistency and lack of comprehensiveness of the assessments, the 305(b) reports are frequently cited by the EPA and Congress to document water quality improvements (Fortner and Schechter, 1996).

The EMAP program does not suffer from the same level of internal inconsistency as the National Water Quality Inventory but there are issues of coordination with other programs. For example, EMAP sites are selected using different criteria from the water quality measuring sites that are part of the United States Geological Survey's National Water Quality Assessment (NAWQA) program so may involve duplication of monitoring effort (Hughes et al., 1990). It is also not clear how the Federal EMAP assessments match with the assessments used for the 305 (b) reports.

In an effort to improve coordination, the USGS and US EPA set up an Intergovernmental Task Force on Monitoring Water Quality in 1991 (USGS, 1999a) which recommended mechanisms to improve cooperation such as joint planning, common core indicators, comparable methods, and linked databases (ITFM, 1995). The role of the ITFM has now been taken over by the National Water Quality Monitoring Council, which has representatives of over 50 agencies. This council aims to encourage improvements in monitoring programs to achieve comparable and scientifically defensible information, interpretations, and evaluations of water quality conditions to support decision-making at local, State, interstate, and national scales USGS (1999b).

The National Monitoring Council will provide guidelines and support for comparable field and laboratory methods, quality assurance/quality control, environmental indicator selection criteria, data management and sharing, ancillary data, interpretation, and training. NWQI reports will also be produced every 5 years instead of every 2 years to allow more water bodies to be assessed (ITFM, 1995; US Environmental Protection Agency, 1996).

There are lessons from the NWQI and EMAP for the Victorian context. Firstly, coordination between monitoring agencies is important. There are similar issues of coordination between federal, state and regional authorities in Australia as there are in the US. Within Victoria, it will be important to ensure the Catchment Management Authorities use a consistent approach and that there is liaison with other authorities involved in managing rivers or collecting data on their condition. If possible, there should be consistent sampling site selection, sampling frequency and chosen 
parameters. The different methods used to select water quality sites by the NAWQA and EMAP suggest that site selection procedures include consideration of locations where other agencies collect data with practical outcomes requiring compromise. The experience of the NWQI shows some of the problems that can occur if there is insufficient rigour applied to indicator and sample site selection; where results have limited credibility with some scientists (e.g. Rankin 1995).

\subsubsection{Estuarine Health Index (South Africa)}

An Estuarine Health Index (EHI) has been developed and applied in South Africa (Cooper et al., 1993; Ramm et al., 1994; Cooper et al., 1994). Although assessment of estuaries and assessment of streams may involve different indicators, the EHI is of interest because of collaboration between Australian and South African scientists and managers (Uys, 1994) and because the way information is summarised and presented in the EHI is a useful guide (Cooper et al., 1994).

Three components make up a composite Estuarine Health Index, which is a single value representing the condition of an estuary. These are a Biological Health Index, a Water Quality Index, and an Aesthetic Health Index. Each of the indices are scaled to be between 0 and 10, with an overall rating from 0 to 30 . The EHI is shown as a stacked bar graph so that each of the components is reported separately along with the aggregated score (Ramm et al., 1994; see Figure 4.2). In Figure 4.2, biology is rated as 7, water quality as 10 and Aesthetics as 6 giving a total score of 23 out of 30 .

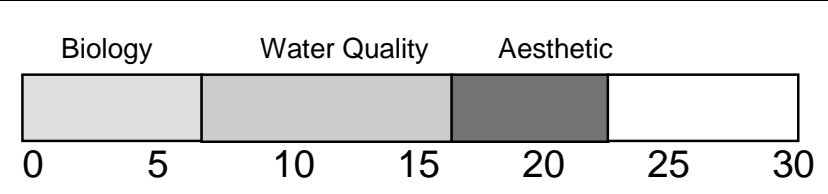

Figure 4.2 - Estuarine Health Index (Ramm et al., 1994)

\section{Biological Health}

The Biological Health Index (BHI) is intended as a relative measure to be used in comparing estuaries and in monitoring the state of a particular system over time. The BHI is based on a comparison of fish species present at a measurement site with those expected to be present under pristine conditions and is based on the Community Degradation Index (Ramm, 1988). The comparison excludes rare or uncommon species 


\section{Monitoring stream condition}

and exotic species (Cooper et al., 1994). The value of the BHI is used to rate biological health on a scale of 0 to 10 .

\section{Water Quality Index}

Seven water quality parameters are used for the EHI as summarised in Table 4.12. Rating curves were developed to convert measured concentrations to standardised values that are weighted and combined to produce a single number between zero and ten (Cooper et al., 1994).

Table 4.12 - Water quality parameters used as part of the Estuarine Health Index (Cooper et al., 1994)

\begin{tabular}{|l|l|l|}
\hline \multicolumn{1}{|c|}{ Suitability for aquatic life } & $\begin{array}{c}\text { Suitability for human } \\
\text { contact }\end{array}$ & \multicolumn{1}{|c|}{ Trophic status } \\
\hline$\bullet \begin{array}{l}\text { Dissolved Oxygen (essential } \\
\text { to aquatic faunal } \\
\text { metabolism) }\end{array}$ & $\bullet \begin{array}{l}\text { E. coli (indicator of } \\
\text { human pathogens) }\end{array}$ & $\begin{array}{l}\text { Nitrate Nitrogen (aquatic } \\
\text { nutrient) }\end{array}$ \\
$\begin{array}{l}\text { Oxygen Absorbed (measure } \\
\text { of organic loading) }\end{array}$ & $\begin{array}{l}\text { Ortho-phosphate (aquatic } \\
\text { nutrient) }\end{array}$ \\
$\begin{array}{l}\text { Ammonia Nitrogen (toxicity } \\
\text { to aquatic fauna) }\end{array}$ & & $\begin{array}{l}\text { Chlorophyll-a (indicator of } \\
\text { algal growth) }\end{array}$ \\
\hline
\end{tabular}

\section{Aesthetic Health Index}

An Aesthetic Health Index (AHI) was developed to quantify current appearance of the estuary compared to what it would be like under pristine conditions. The procedure for measuring the AHI is to start with a perfect score of ten and then deduct points according to the type and degree of change from natural conditions. Parameters taken into account include smell, presence of exotic vegetation, incongruous buildings, oil sheen, presence of bridges and persistent noise (Cooper et al., 1993). A near pristine estuary would score close to 10 , while a severely modified estuary would have a value tending toward 0 .

\section{Suitability and limitations}

The objective of the EHI is to provide a 'fast and effective means of assessing current state [of estuaries] in relation to the undisturbed, or pristine state' (Cooper et al., 1993). The idea is to construct a picture of the contemporary state of the estuarine environment to act as a baseline for future monitoring and as a means of comparing the relative wellbeing of estuaries at present. 
It can be seen that the objectives and use of the EHI differs from monitoring done for the US National Water Quality Inventory (NWQI) described above. The EHI is an attempt to compare current state with pristine conditions, whereas the NWQI compares current state against that required to fulfil a designated use. It is likely that for the same site, different ratings would be obtained using these two approaches.

On closer examination, the EHI does involve subjective judgements and includes a consideration of the proposed use of the water in the estuaries. For example, the Biological Health Index (BHI) is intended to be based on a comparison of fish species present now, with those that would have been present under natural conditions. But to make the BHI work as it should (i.e. as it would be subjectively expected to), it was necessary to exclude rare or uncommon species. A similar process occurred with the water quality index. To calculate the water quality component of the EHI, the parameters in Table 4.12 are scored on the basis of rating curves that were established through a questionnaire survey of water quality experts (Moore, 1990). Experts were instructed that the water quality rating should indicate the suitability for 'general use' (Moore, 1990, 48) so the scores assigned to the water quality index reflect the appropriateness of water for general use, rather than providing a comparison between existing and pristine water quality (see House, 1989).

The Estuarine Health Index provides a 'snap-shot' report on estuary condition. Information transfer was a major consideration in the development and use of the EHI and its strength is the reporting scheme that summaries the condition of a large number of estuaries at a glance (Cooper et al., 1994). It is also one of the few condition measures that includes an assessment of aesthetics. The Estuarine Health Index does not include a specific assessment of all the components shown in Table 4.1. Riparian quality, physical habitat, or physical form are not included, nor does it include direct consideration of changes in the hydrology of the estuary.

The water quality assessments for published values of the EHI (Cooper et al., 1993) were based on samples collected over a 4 week period. It is not clear how representative this period was, nor is there any consideration of the variability of water quality. It is likely that water quality could vary by orders of magnitude between high and low flow. Water quality variability would prevent comparison of values of the EHI measured at different times in the same estuary. In the Victorian context, water quality 


\section{Monitoring stream condition}

is certain to be highly variable, so condition assessments based on samples collected in a short period are not likely to be reliable.

The final value of the EHI depends on combining the scores of three indices. Two of these, the Water Quality Index and the Aesthetic Health Index are combinations of other parameters. The current formulation of the EHI involves equal weighting of the water quality, biological and aesthetic components. Equal weighting does not reflect the different data demands and rigour of the three indicators but does suggest that the developers thought the three components contributed equally to the objective of assessing current condition compared to a pristine state.

\subsubsection{A riparian, channel, and environmental inventory}

Petersen (1992) outlines a Riparian Channel and Environmental (RCE) inventory to assess the physical and biological condition of small streams in lowland areas where non-point source pollution and agriculture dominate. The RCE has been used in Sweden, Italy and Idaho (US). A value for the RCE is obtained by rating the stream on the basis of 16 characteristics as shown in Table 4.13 The score for each characteristic is added to provide an overall classification for the stream along with a colour coded rating as shown in Table 4.14.

\section{Suitability and limitations}

The RCE inventory is a rapid assessment method that can provide an overview of streams in a short period. It is based on the assumption that the environmental condition of small streams can be assessed by an appraisal of the physical condition of the riparian zone and stream channel. Petersen (1992) argues that this assumption will be true in landscapes where non-point source pollution and agriculture dominate. This assumption justifies the exclusion of indicators of water quality, hydrology and aesthetics.

Ratings are based on the difference between streams in their current state and an implicitly defined 'pristine' state. Petersen (1992) claims that the lowest score will be given to streams that have been channelised and cleared of riparian vegetation while highest ratings will be for streams with no physical disturbance. Care should be used when applying this procedure to streams where the pristine state is different from that used by Petersen. For example, streams are likely to obtain a low rating if the bed 
material is fine (sand or silt). Yet, some streams naturally have fine bed material, even when they are completely undisturbed. There may be examples of lowland streams that are environmentally degraded yet score well under Petersen's criteria. For example, in Victoria this could occur where there is dense riparian vegetation dominated by exotic taxa. The lesson is that stream assessment criteria need to be appropriate for the geographical area where they will be used. Consideration of local conditions and river management goals is an important part of defining a rating system.

\section{Table 4.13 - Assessment of the RCE (Riparian, Channel and Environmental) inventory (Petersen, 1992)}

\begin{tabular}{|c|c|}
\hline 1. Land use pattern beyond the immediate riparian zone & Score \\
\hline Undisturbed, consisting of forest, natural woodlands, bogs and/or mires & 30 \\
\hline Permanent pasture mixed with woodlots and swamps, few row crops & 20 \\
\hline Mixed row crops and pasture & 10 \\
\hline Mainly row crops & 1 \\
\hline \multicolumn{2}{|l|}{ 2. Width of riparian zone from stream edge to field } \\
\hline Marshy or woody riparian zone $>30 \mathrm{~m}$ wide & 30 \\
\hline Marshy or woody riparian zone varying from 5 to $30 \mathrm{~m}$ & 20 \\
\hline Marshy or woody riparian zone $1-5 \mathrm{~m}$ & 5 \\
\hline Marshy or woody riparian zone absent & 1 \\
\hline \multicolumn{2}{|l|}{ 3. Completeness of riparian zone } \\
\hline Riparian zone intact without breaks in vegetation & 30 \\
\hline Breaks occurring at intervals of $>50 \mathrm{~m}$ & 20 \\
\hline Breaks frequent with some gullies and scars every $50 \mathrm{~m}$ & 5 \\
\hline Deeply scarred with gullies all along its length & 1 \\
\hline \multicolumn{2}{|l|}{ 4. Vegetation of riparian zone within $10 \mathrm{~m}$ of the channel } \\
\hline$>90 \%$ plant density of non-pioneer trees or shrubs, or native marsh plants & 25 \\
\hline Mixed pioneer species along channel and mature trees behind & 15 \\
\hline Vegetation of mixed grasses and sparse pioneer tree or shrub species & 5 \\
\hline Vegetation consisting of grasses, few trees shrubs & 1 \\
\hline \multicolumn{2}{|l|}{ 5. Retention devices } \\
\hline Channel with rocks and old logs firmly set in place & 15 \\
\hline Rocks and logs present but back filled with sediment & 10 \\
\hline Retention devices loose; moving with floods & 5 \\
\hline Channel of loose sandy silt; few channel obstructions & 1 \\
\hline \multicolumn{2}{|l|}{ 6. Channel structure } \\
\hline Ample for present and annual peak flows, width/depth $<7$ & 15 \\
\hline Adequate, overbank flows rare, W/D 8 to 15 & 10 \\
\hline Barely contains present peak, W/D 15 to 25 & 5 \\
\hline Overbank flows common, W/D $>25$ or stream is channelised & 1 \\
\hline \multicolumn{2}{|l|}{ 7. Channel sediments } \\
\hline Little or no channel enlargement resulting from sediment accumulation & 15 \\
\hline Some gravel bars of coarse stones and well-washed debris present, little silt & 10 \\
\hline Sediment bars of rocks, sand and silt common & 5 \\
\hline Channel divided into braids or stream is channelised & 1 \\
\hline
\end{tabular}




\section{Table 4.13 - Assessment of the RCE (Riparian, Channel and Environmental) inventory (Petersen, 1992) (continued)}

\begin{tabular}{|c|c|}
\hline \multicolumn{2}{|l|}{ 8. Stream-bank structure } \\
\hline Banks stable, of rock and soil held firmly by grasses shrubs and tree roots & 25 \\
\hline Banks firm but loosely held by grass and shrubs & 15 \\
\hline Banks of loose soil held by a sparse layer of grass and shrubs & 5 \\
\hline Banks unstable, of loose soil or sand easily disturbed & 1 \\
\hline 9. Bank undercutting & Score \\
\hline Little or none evident or restricted to areas with tree root support & 20 \\
\hline Cutting only on curves and at constrictions & 15 \\
\hline Cutting frequent, undercutting of banks and roots & 5 \\
\hline Severe cutting along channel, banks falling in & 1 \\
\hline \multicolumn{2}{|l|}{ 10. Stony substrate; feel and appearance } \\
\hline Stones clean, rounded without sharp edges; may have a blacked colour & 25 \\
\hline Stones without sharp edges and with slight sand, silt, gritty feel & 15 \\
\hline Some stones with sharp edges obvious gritty cover & 5 \\
\hline Stones bright; silt, grit cover and sharp edges common & 1 \\
\hline \multicolumn{2}{|l|}{ 11. Stream bottom } \\
\hline Stony bottom of several sizes packed together, interstices obvious & 25 \\
\hline Stony bottom easily moved, with little silt & 15 \\
\hline Bottom of silt, gravel and sand, stable in places & 5 \\
\hline Uniform bottom of sand and silt loosely held together, stony substrate absent & 1 \\
\hline \multicolumn{2}{|l|}{ 12. Riffles and pools, or meanders } \\
\hline Distinct, occurring at intervals of 5-7x stream width & 25 \\
\hline Irregularly spaced & 20 \\
\hline Long pools separating short riffles, meanders absent & 10 \\
\hline Meanders and riffles/pools absent or stream channelised & 1 \\
\hline \multicolumn{2}{|l|}{ 13. Aquatic vegetation } \\
\hline When present consists of moss and patches of algae & 15 \\
\hline Algae dominant in pools, vascular plants along edge & 10 \\
\hline Algal mats present, some vascular plants, few mosses & 5 \\
\hline Algal mats cover bottom, vascular plants dominate channel & 1 \\
\hline \multicolumn{2}{|l|}{ 14. Fish } \\
\hline Rheophilous fish present, native population, present in most pools & 20 \\
\hline Rheophilous fish scarce and difficult to locate & 15 \\
\hline No rheophilous fish, some lentic fish present in pools & 10 \\
\hline Fish absent or scarce & 1 \\
\hline \multicolumn{2}{|l|}{ 15. Detritus } \\
\hline Mainly consisting of leaves and wood without sediment & 25 \\
\hline Leaves and wood scarce; fine flocculent organic debris without sediment & 10 \\
\hline No leaves or weedy debris; coarse and find organic matter with sediment & 5 \\
\hline Fine, anaerobic sediment, no coarse debris & 1 \\
\hline \multicolumn{2}{|l|}{ 16. Macrobenthos } \\
\hline Many species present on all types of substrate & 20 \\
\hline Many species but only in well-aerated habitats & 15 \\
\hline Few species present but found in most habitats & 5 \\
\hline Few if any species and only in well-aerated habitats & 1 \\
\hline
\end{tabular}


Table 4.14 - Classification of streams based on the RCE (Riparian, Channel and Environmental) inventory (Petersen, 1992)

\begin{tabular}{|c|c|c|c|l|}
\hline Class & Score & Evaluation & Colour & Recommended action \\
\hline I & $293-360$ & Excellent & Blue & $\begin{array}{l}\text { Biomonitoring and protection of existing } \\
\text { status }\end{array}$ \\
\hline II & $224-292$ & Very good & Green & $\begin{array}{l}\text { Selected alterations and monitoring for } \\
\text { changes }\end{array}$ \\
\hline III & $154-223$ & Good & Yellow & Minor alterations needed \\
\hline IV & $86-153$ & Fair & Brown & Major alterations needed \\
\hline V & $16-85$ & Poor & Red & Complete structural reorganisation \\
\hline
\end{tabular}

\subsubsection{SERCON and RHS}

SERCON (System for Evaluating Rivers for Conservation) is a technique developed in the United Kingdom to assess the nature conservation value of rivers (Johnson and Law, 1995). It is a broad-based method that includes assessment of 35 attributes grouped under six headings: physical diversity, naturalness, representativeness, rarity, species richness, and special features. Impacts are also listed although are not used to calculate indices of conservation value (Boon et al., 1994; Boon et al., 1997; Table 4.15. Attributes are weighted as indicated in the table with weights determined from consultation with specialists.

The main objectives of SERCON are: to enable the assessment of the conservation value of rivers with a wide range of environmental quality; to assist in predicting the impact of different development options on river conservation value; and to aid in the assessment of the rehabilitation potential of degraded rivers. The focus of the SERCON assessment is the bed and banks of the river and the adjacent floodplains and wetlands, with less emphasis on the surrounding catchment. Attributes were selected using input from a specialist group of over 150 individuals with additional input from 25 organisations. Communication with the specialists was by written reports and invited responses. Assessments are made over reaches (Evaluated Catchment Sections) $10 \mathrm{~km}$ to $30 \mathrm{~km}$ in length with reach boundaries located on tributary junctions, changes in geomorphology, lakes or reservoirs (Boon et al., 1997).

For each Evaluated Catchment Section, SERCON index values are calculated for the six conservation criteria and for impacts. Index values are based on the percentage of the maximum possible scores (Table 4.16). The seven index scores are always reported rather than combining the values into one overall SERCON conservation index. 
Table 4.15 - SERCON attributes and weights (Boon et al., 1997)

\begin{tabular}{|c|c|c|c|}
\hline Conservation criteria & Attributes & $\begin{array}{l}\text { Attribute } \\
\text { weight }\end{array}$ & Criteria weight \\
\hline \multirow[t]{3}{*}{ Physical diversity } & Fluvial features & 5 & \multirow[t]{3}{*}{3} \\
\hline & Substrates & 4 & \\
\hline & Structure of aquatic vegetation & 1 & \\
\hline \multirow[t]{8}{*}{ Naturalness } & Channel naturalness & 5 & \multirow[t]{4}{*}{5} \\
\hline & Physical features of the bank & 3.5 & \\
\hline & Plant assemblages on the bank & 2 & \\
\hline & Riparian zone & 2 & \\
\hline & Aquatic and marginal macrophytes & 4 & \multirow[t]{4}{*}{1.5} \\
\hline & Aquatic invertebrates & 3.5 & \\
\hline & Fish & 2.5 & \\
\hline & Breeding birds & 1 & \\
\hline \multirow[t]{6}{*}{ Representativeness } & Fluvial features & 5 & \multirow[t]{6}{*}{3} \\
\hline & Aquatic macrophytes & 4 & \\
\hline & Aquatic invertebrates & 4 & \\
\hline & Fish & 2.5 & \\
\hline & Substrate diversity & 2 & \\
\hline & Breeding birds & 1 & \\
\hline \multirow[t]{6}{*}{ Rarity } & $\begin{array}{l}\text { EC habitats directive/Bern convention } \\
\text { species that are rare in UK }\end{array}$ & 4.5 & \multirow[t]{6}{*}{2} \\
\hline & Scheduled species & 4 & \\
\hline & $\begin{array}{l}\text { EC habitats directive/Bern convention } \\
\text { species not rare in UK }\end{array}$ & 3.5 & \\
\hline & Nationally scarce macrophyte species & 2 & \\
\hline & Nationally scarce invertebrate species & 2 & \\
\hline & Regionally rare macrophyte species & 1 & \\
\hline \multirow[t]{4}{*}{ Species richness } & Aquatic and marginal macrophytes & 4.5 & \multirow[t]{4}{*}{2.5} \\
\hline & Aquatic invertebrates & 4.5 & \\
\hline & Fish & 2 & \\
\hline & Breeding birds & 1 & \\
\hline \multirow[t]{8}{*}{ Special features } & Extent and character of riparian zone & 4.5 & \multirow[t]{8}{*}{1} \\
\hline & $\begin{array}{l}\text { Floodplain: unrecreatable water- } \\
\text { dependent habitats }\end{array}$ & 4.5 & \\
\hline & Influence of natural on-line lakes & 3.5 & \\
\hline & $\begin{array}{l}\text { Invertebrates of river margins and } \\
\text { banks }\end{array}$ & 2.5 & \\
\hline & Mammals & 2.5 & \\
\hline & $\begin{array}{l}\text { Floodplain: recreatable water- } \\
\text { dependent habitats }\end{array}$ & 2 & \\
\hline & Amphibians & 1.5 & \\
\hline & Winter birds on adjacent floodplain & 1.5 & \\
\hline \multirow{11}{*}{ Impacts } & Sewage effluent & 4.5 & \\
\hline & Channelisation & 4.5 & \\
\hline & Toxic/industrial/agricultural effluent & 4 & \\
\hline & Acidification & 3 & \\
\hline & Groundwater abstraction & 3 & \\
\hline & Management for flood defence & 2.5 & \\
\hline & Man-made structures & 2.5 & \\
\hline & Surface water abstraction & 2 & \\
\hline & Recreational pressures & 2 & \\
\hline & Introduced species & 2 & \\
\hline & Inter-river transfers & 1 & \\
\hline
\end{tabular}


Table 4.16 - SERCON index values based on percentage of maximum possible score for each criterion (Boon et al., 1997)

\begin{tabular}{|l|c|c|c|c|c|}
\hline & \multicolumn{5}{c|}{ SERCON index value } \\
\hline \multicolumn{1}{|c|}{ Criterion $^{\mathbf{1}}$} & A & B & C & D & E \\
\hline Physical diversity & $>80 \%-100 \%$ & $>60 \%-80 \%$ & $>40 \%-60 \%$ & $>20 \%-40 \%$ & $0-20 \%$ \\
\hline Naturalness & $>80 \%-100 \%$ & $>60 \%-80 \%$ & $>40 \%-60 \%$ & $>20 \%-40 \%$ & $0-20 \%$ \\
\hline Representativeness & $>90 \%-100 \%$ & $>75 \%-90 \%$ & $>60 \%-75 \%$ & $>30 \%-60 \%$ & $0-30 \%$ \\
\hline Rarity & $>60 \%-100 \%$ & $>45 \%-60 \%$ & $>30 \%-45 \%$ & $>15 \%-30 \%$ & $0-15 \%$ \\
\hline Species richness & $>80 \%-100 \%$ & $>60 \%-80 \%$ & $>40 \%-60 \%$ & $>20 \%-40 \%$ & $0-20 \%$ \\
\hline Special features & $>60 \%-100 \%$ & $>45 \%-60 \%$ & $>30 \%-45 \%$ & $>15 \%-30 \%$ & $0-15 \%$ \\
\hline Impacts & $0-15 \%$ & $>15 \%-30 \%$ & $>30 \%-45 \%$ & $>45 \%-60 \%$ & $>60 \%-100 \%$ \\
\hline
\end{tabular}

1 - based on a percentage of the maximum value.

At present, SERCON only assesses conservation values but future extension could include assessment of other values including recreational, economic, fisheries, landscape and amenity. A similar system to SERCON has been developed for Swedish rivers and lakes (Willen et al., 1997).

The development of SERCON took place in parallel with the River Habitat Survey (RHS), a technique to evaluate river physical features (Raven et al., 1997; Wilkinson et al., 1998). Data from a RHS evaluation provides most of the physical information components of SERCON.

There are four components to the RHS assessment method: (1) standard field survey techniques (Fox et al., 1998); (2) a computer database where results are entered and compared with information from other sites throughout the UK and the Isle of Man; (3) a suite of methods for assessing habitat quality and (4) techniques to assess the extent of channel modification (Raven et al., 1998). Assessments are made at three randomly chosen sites in each $10 \mathrm{~km}$ by $10 \mathrm{~km}$ grid square covering the whole of England and Wales with lower sampling density in Scotland and Northern Ireland. Sites are $500 \mathrm{~m}$ long and assessments are made on standard field sheets with guidance from an illustrated survey manual (Environment Agency, 1997). Attributes assessed during the RHS include:

- Valley form;

- Number of pools, riffles and point bars;

- Bank material (e.g. bedrock, cobble, concrete);

- Bank modifications (e.g. berm, reinforced, embanked); 
- Bank features (e.g. eroding earth cliff, unvegetated point bar, vegetated side bar);

- Channel substrate (e.g. bedrock, sand, artificial);

- Predominant flow (e.g. free fall, chute, rippled);

- Channel modifications (e.g. culverted, dam/weir, ford);

- Channel features (e.g. exposed bedrock/boulders, vegetated mid channel bar, mature island) and their extent;

- Banktop land use and vegetation structure;

- Channel vegetation types (e.g. emergent broad-leaved herbs, filamentous algae);

- Land use within 50m of the banktop (e.g. wetland, tilled land, rough pasture);

- Bank profile;

- Extent of trees and associated features;

- Channel dimensions;

- Artificial features (e.g. weirs, sluices, culverts, bridges, outfalls);

- Evidence of recent management (e.g. dredging, mowing weed-cutting);

- Features of special interest (e.g. waterfalls $>5 \mathrm{~m}$ high, Bog, Carr);

- Choked channel (channel more than 33\% choked with vegetation);

- Notable nuisance plants;

- Overall characteristics (major impacts, land management, animals, other observations); and

- Alders (none, present, extensive, diseased).

RHS field surveyors are trained, tested and accredited at approved courses (Fox et al., 1998).

Once the data are collected, a rule-based procedure is used to determine if the site is outstanding in terms of habitat quality. A Habitat Quality Assessment (HQA) score can also be derived from the presence and extent of desirable habitat features. This is reported as a rank in comparison with streams of the same type e.g. the site is within the 
bottom $20 \%$ of HQA scores for streams of its type. The RHS data can also be used to derive a Habitat Modification Score (HMS), based on modification to the river channel, which is used to classify streams on a scale from pristine to severely modified.

The River Habitat Survey has been used to assess the physical character of rivers and streams in the UK and Isle of Man (Raven et al., 1998). There has been an extensive survey effort with assessment of 4559 sites in England and Wales, 769 in Scotland, 266 in Northern Ireland and 18 sites on the Isle of Man, a total of 5612 reference sites (Raven et al., 1998).

Proposed uses of the RHS scores include application to catchment management plans, environmental impact assessment and as a guide to works such as habitat enhancement. Information can also be used to protect special sites and resolve conflicts about uses. It is also proposed that the information from the initial survey could be used to assess the impacts of water transfers and climate change (Jeffers, 1998).

RHS does not include chemical water quality or biological assessment but this information is available from other databases for all reference sites. Classification schemes for aquatic plants and fish have also been developed.

\section{Suitability and limitations}

The SERCON - RHS assessment system appears to be a comprehensive and thorough process for assessing condition. Although biota and water quality are not explicitly included in the assessments there is sufficient information available from other databases in the UK that can be linked to SERCON and RHS results.

The main limitation of the approach is the scale of its application. Measuring streams in each $10 \mathrm{~km}$ by $10 \mathrm{~km}$ grid cell, although an affordable task in the UK, would probably require excessive resources for less populated areas. For example, the land area of the UK and Victoria is about the same but the population and GDP per kilometre of stream length is an order of magnitude less in Victoria and in the US (Table 4.17). Although this is a crude comparison, it does suggest that an approach simpler than SERCON and RHS is likely to be required in less densely populated areas. This has implications for the ISC which must be able to be implemented using the financial resources of the Victorian Catchment Management Authorities. It is also not clear from Raven et al. (1998) when the reference sites are to be reassessed. RHS does not appear to be intended for regular monitoring; instead, it has been used to develop a comprehensive 


\section{Monitoring stream condition}

database of present stream condition. A system for regular stream assessment is likely to have to be less comprehensive, so that it is less expensive and can be regularly repeated.

Table 4.17 - Available resources to support stream monitoring in different countries

\begin{tabular}{|l|c|r|r|r|r|r|}
\hline $\begin{array}{l}\text { Country } \\
\text { or State }\end{array}$ & $\begin{array}{c}\text { Total land } \\
\text { area } \\
\left(\mathbf{k m}^{2}\right)\end{array}$ & $\begin{array}{c}\text { Total } \\
\text { stream } \\
\text { length } \\
(\mathbf{k m})\end{array}$ & $\begin{array}{c}\text { Population } \\
\text { July 1998 } \\
\text { est } \\
\text { [million] }\end{array}$ & $\begin{array}{c}\text { Persons } \\
\text { per } \\
\text { stream } \\
\mathbf{k m}\end{array}$ & $\begin{array}{c}\text { GDP } \\
\text { [\$US billion] } \\
(\mathbf{e s t} \mathbf{J u l} \text { 97) }\end{array}$ & $\begin{array}{c}\text { GDP/stream } \\
\text { length } \\
\text { [\$US } \\
\text { million/km] }\end{array}$ \\
\hline $\begin{array}{l}\text { United } \\
\text { States of } \\
\text { America }\end{array}$ & $9160000^{3}$ & $5700000^{1}$ & $270.3^{3}$ & 47 & $\$ 8083^{3}$ & 1.4 \\
\hline $\begin{array}{l}\text { United } \\
\text { Kingdom }\end{array}$ & $241000^{3}$ & $85000^{2}$ & $59.0^{3}$ & 693 & $\$ 1242^{3}$ & 14.6 \\
\hline Victoria & $227000^{4}$ & $56000^{5}$ & $4.6^{4}$ & 82 & $\$ 103^{3,4}$ & 1.8 \\
\hline
\end{tabular}

1 - US Environmental Protection Agency (1996)

2 - Raven et al., 1998

3 - CIA (1998)

4 - Australian Bureau of Statistics (1999)

5 - Office of the Commissioner for the Environment $(1998,17)$

\subsection{Intended uses of stream condition}

\section{measurements}

The promise of stream condition measurements is that they can serve a wide range of management needs. Possible uses of stream condition measurements are identified and briefly described below, followed by a more detailed discussion of the role of these environmental indicators in adaptive management.

- Choosing effective stream rehabilitation activities

When rehabilitating streams, the most cost effective group of strategies should be chosen to achieve the desired change in stream condition. For example rehabilitation strategies for a regulated river could include:

- installing fish ladders at barriers;

- improving riparian vegetation;

- increasing in-stream habitat; 
- improving water quality; or

- changing timing and quantity of flow.

Considering the likely change in stream condition from these strategies and their cost of implementation will allow selection of the most cost effective package of measures (Lucas et al., 1999).

\section{- Developing Decision Support Systems}

There is increasing interest in the use of Decision Support Systems to assist in managing the environmental condition of waterways (Young et al., 1995; Davis and Young, 1998). Decision support systems can assist the evaluation of management scenarios by predicting likely changes to stream condition. Measures of stream condition could be useful in validating these predicted changes.

Those aspects of stream condition that can be measured, will be a useful guide to those parts of the river system that are worth modelling. A recent review of the feasibility of a decision support system for allocation of water to the environment highlighted the need for accurate indicators as surrogates for important but poorly defined quantities such as 'health' or 'sustainability'. The development of suitable indicators was seen as a key requirement in the initial stages of the project (Young et al., 1995; Davis and Young, 1998).

\section{- Negotiating trade-offs}

Assessment of stream condition can help provide information to quantify environmental consequences of decisions more accurately. This information can then feed into negotiations about environmental, economic, and social costs and benefits.

\section{- Reporting on the State of the Environment}

All OECD countries, including Australia, must prepare state of the environment reports (DEST, 1994; SEAC, 1996). Assessments of overall stream condition are likely to be an important part of this process. For example, in Australia, an Inland Waters Reference Group has been recently established to review and 


\section{Monitoring stream condition}

develop appropriate indicators for assessing the state of the stream environment (Fairweather and Napier, 1998).

\section{- Planning and reporting by waterway managers}

Measures of stream condition can help waterway managers set objectives and monitor performance. They can be used to aggregate a large amount of data and will be useful in communications to the public and higher level management or funding agencies.

Measures of stream condition could be used by managers to get an overview of problems in a particular region or at a statewide or national scale. This can assist in decisions about allocating funding and resources.

\section{- Measuring the success of environmental policy}

Actual physical improvement in environmental quality is the key indicator of the success of environmental policy. In the case of waterways, assessments of stream condition have been proposed to test the success of policy and the effectiveness of the whole suite of intervention measures such as regulations, incentives and government programs aimed at waterway management (Hunter and Waterman, 1996, 199-216).

Often there will be a number of specific programs aimed at improving waterways but there may also be a need to assess the entire integrated effort in stream management; the cumulation of management programs that impact on waterways. Measuring overall condition allows an assessment of waterways against an overarching objective, such as the desire to achieve 'healthy' or 'sustainable' rivers.

\subsubsection{Adaptive management of streams}

The term adaptive management refers to a structured management process developed by Holling, Walters and others during the 1970s (Holling, 1978) that has since been widely applied to natural resource management problems in several countries including Canada, Australia and the US (Haney and Power, 1996). Key references include Holling (1978), Walters (1986), Lee (1993) and Gunderson et al. (1995).

Walters (1997) describes adaptive management as a structured process of learning by doing. The idea of adaptive management is to gain experience of the system through 
management rather than basic research or theory (Walters, 1986). Policies are seen as experiments with outcomes guiding future activities (Walters and Holling, 1990; Gunderson, 1999). Walters (1986) proposes using management policies that deliberately enhance the experience that is necessary to deal with complex problems. Adaptive management may be appropriate where there is uncertainty and where the knowledge can be gained more cost effectively from undertaking management actions as experiments, than from alternatives such as laboratory research (Walters, 1986; Johnson, 1999a).

There are two elements to an adaptive management process. Firstly, existing knowledge of the system is used to develop a model that is capable of making predictions about the impacts of alternative policies. This model is developed during a workshop of scientists and stakeholders to incorporate interdisciplinary experience and scientific knowledge. The aim of the model is to make prediction about impacts of alternative policies (Walters, 1997). Secondly, the policies are implemented and monitored to investigate key management uncertainties. It is the monitoring aspect of adaptive management that is of interest here.

Application of adaptive management to riparian ecosystems includes work on the Columbia River (Lee, 1993), the Everglades (Walters et al., 1992), water quality management in the Latrobe and Goulburn Rivers in Victoria (Grayson et al., 1994b; Grayson, 1994; Grayson pers. comm.), Ovens River, Victoria (Felton and Martin, 1996) and to riparian research in Australia (Wilson et al., 1996). See Gilmour et al. (1999) for other Australian riparian adaptive management projects.

The use of adaptive management to assist management of riparian ecosystems has not always been successful. Walters (1997) notes that in many cases, useful models have not been produced and that experimental policies are seen as too costly or risky. Of the 25 adaptive management exercises he has been involved in over 20 years, only 2 wellplanned, large-scale management experiments have been undertaken.

Measures of stream condition can assist in this adaptive management approach. Benchmarking stream condition can assist in identifying areas that are not being managed well under current arrangements and where adaptive approaches should be considered. Stream condition assessments could be part of the monitoring that is required to determine the result of management experiments. The complexity of stream 


\section{Monitoring stream condition}

systems often means that there are no clear linkages between management actions and system response, therefore, feedback from the managed system is required to select and refine strategies (Lee, 1993).

But it is also clear that adaptive management is more than just monitoring. A genuine attempt to manage river systems using adaptive management procedures requires all the steps listed above: integration of existing knowledge; modelling to determine possible scenarios; and implementation of large-scale management experiments. Improved monitoring of stream condition can only be part of this process. Although adaptive management is often listed as part of the justification for developing a monitoring program, true adaptive management requires these other elements as well.

Johnson (1999b) describes other management arrangements that involve the use of environmental indicators. Firstly, there is the best-current-data approach, which involves assessment of current conditions to guide strategy selection. Secondly, the monitor-and-modify approach, which is less rigorous than adaptive management and involves implementing strategies, assessing their performance through monitoring and refining the management intervention if appropriate. Although Walters and Holling (1990) criticise this approach, it is likely to remain a practical management strategy particularly where uncertainties are not great enough to warrant the expense of the formal adaptive management approach (Lee, 1999). A combination of these two approaches would involve initial assessment using indicators and then further monitoring to provide feedback on strategy performance.

\subsection{Issues in stream condition assessment}

The techniques presented here represent a variety of approaches to measuring the overall condition of streams. Reviewing these approaches highlights the range of issues associated with the use of monitoring in the management of stream condition, including setting objectives, choosing, scoring, and combining indicators; and issues associated with sampling and errors.

\subsubsection{Objective setting}

These stream assessment procedures have been developed to meet a wide range of objectives that can be related to the use of the assessment methodology, the users and 
available skills and resources. Intended uses are summarised in Table 4.1 and range from one-off rapid assessments of streams over a wide area, to 'snap-shot' assessment of specific types of streams and ongoing assessments. Specification of objectives will drive the processes of indicator development including decisions about indicator selection, scoring and reporting and considerations of required accuracy.

In large and climatically diverse countries such as Australia and the US, specific assessment methods will be required in different locations because there will be a large range of stream types and institutional arrangements. There is also a major difference in funds that can be allocated to stream condition assessment because of differing population densities and financial resources Thable 4.17). The discussion of stream assessment methods in the United States showed the differences in objectives between jurisdictions and between agencies and the potential for coordination problems. The US experience contrasts with the use of SERCON and RHS in the UK where the whole country has been assessed using standard techniques.

In Australia, States have developed assessment systems to meet their own needs (Lloyd, 1996) with methods used in Queensland and Victoria discussed above. A similar system is being developed in New South Wales (B. Chessman pers. comm.). At the national level, macroinvertebrates are proposed to be assessed using the Australian River Assessment System (AusRivAS) (Marchant et al., 1997; Norris et al., 1998; Marchant et al., 1999; Smith et al., 1999; Turak et al., 1999). There are also national assessments of stream condition undertaken as part of state of the environment reporting (Fairweather and Napier, 1998; SEAC, 1996; SERU, 1996; Smith 1997). Although this range of assessment procedures represents different requirements, it is also important to coordinate approaches federally and between the States where possible. This will allow comparison of stream condition across State boundaries and decrease the cost of indicator development if procedures from other States can be adopted with little modification.

\subsubsection{Choosing indicators}

The selection of indicators is guided by the overall objectives and involves choosing which aspects of stream condition are to be assessed and then describing the actual measurements that are to be made. 


\section{Monitoring stream condition}

There are seven aspects of stream condition that are identified from the reviewed approaches Table 4.1. Which aspects to include depends on the objectives of the assessment, what it is possible to measure and the resources and expertise available. The titles of several of the methods suggest a broad assessment of environmental condition but several key aspects of streams are not measured. For example, the 'State of the Rivers' assessments (Anderson, 1993a) sounds comprehensive, yet water quality and aquatic biota are not considered. Similarly, the 'Environmental condition of Victorian streams' does not include an assessment of water quality or aquatic biota and there is only a rudimentary consideration of hydrology.

Selection of the actual indicators to be measured is a key aspect of developing tools to assess stream condition. Guidelines have been published by several authors (Division of Water Resources, 1992; Cairns et al., 1993; DEST, 1994; Walker and Reuter 1996; Reid and Brookes, 1998) but it is probably impossible to achieve all the desirable criteria. The final choice will depend on the local conditions and specific objectives. There is greater availability of some types of indicators; for example, there is a long history of water quality assessments but, until recently, biological monitoring was not well enough developed to be included.

For most of the stream assessment methods there is little discussion about why the final set of indicators was chosen from all those that were available. An important consideration is the information requirements. One of the reviewed approaches, the Index of Aquatic Environmental Quality (Office of the Commissioner for the Environment, 1988), had excessive data requirements that devalued its usefulness because it could not be assessed completely at any sites. For the State of the Streams Survey (Section 4.2.1), a large number of variables were collected but the analysis of only a small subset of these was ever published (Mitchell 1990) suggesting that indicators were specified without considering their ultimate use. Different information requirements in different areas devalued the usefulness of the NWQI (Section 4.2.4) and it was suggested that leaving out key indicators gives a false impression of stream quality (Rankin 1995). EMAP (Hughes et al., 1990) did consider indicator selection in more detail and their suggestions of starting with a group of indicators and then refining them until a core set remains, seems a reasonable approach (Reid and Brookes, 1998). A similar methodology was suggested by Verhallen et al. (1996). 


\subsubsection{Scoring indicators}

Usually indicators are reported as a score, either a narrative expression (such as excellent, good, poor), or as a numerical rating. The development of this scoring system is an important part of the indicator selection process. There are a number of different bases for comparison discussed in the reviewed approaches. These include assessing streams against their ability to support designated uses, comparison with 'natural' conditions, comparison with a biological ideal and assessment against reference conditions (Reynoldson et al., 1997). The selection of the overall objective will influence the choice of indicators, rating and results. This issue is explored further in Chapter 5.

\subsubsection{Combining indicators}

Determining an overall rating of stream condition requires a number of indicators to be considered together. There are two main approaches: (1) weighting and combining indicators to give a composite score or number of composite scores; and (2) reporting indicators separately.

A large number of methods have been proposed for combining indicators (Ott, 1978). Ten schemes are discussed by Moore (1990), that range from simple averages (weighted or unweighted), to geometric means and more complex functions. Smith (1990) proposes using the minimum operator i.e. basing the overall score on the indicator with the lowest rating.

In their discussion of catchment health indicators, Walker et al. (1996) are critical of merging indicator values to create composite indicators. They argue that combining indicators causes information loss and interpretation problems and that the approach is methodologically flawed (Walker et al., 1996, 10). Instead, they propose a 'report card' where individual indicators are presented. They suggest that the suite of indicators should not be evaluated; instead individual indicator values should be examined for overall trends.

Most practical stream assessment methods include at least some aggregation of indicators, usually based on a weighted or unweighted sum. Of the methods discussed in this chapter, the approaches developed by Petersen (1992) and Mitchell (1990) result in a single overall assessment. The US 305(b) reports are also distilled to a highly aggregated result. For the EHI (Cooper et al., 1994), IAEQ (Office of the 


\section{Monitoring stream condition}

Commissioner for the Environment, 1988) and EMAP (Hughes et al., 1990) assessments are made in terms of a number of scores that are aggregates of similar indicators. Hughes et al. (1990) favour aggregate indicators because they are less variable than individual scores. Aggregation requires decisions about the weights to be applied and these will usually have to be made subjectively.

Partial aggregation of indicators seems a reasonable approach. No doubt combining indicators does result in some information loss, but any system of indicators will be a contraction of the environmental information that could be collected. Different levels of aggregation will be appropriate in different circumstances; for example, when reporting to politicians or newspapers, a high level of aggregation is likely to be demanded.

\subsubsection{Sampling issues in stream condition assessment}

An important source of variance for most assessment techniques will be associated with sampling. In most cases, indicators are measured at a particular location and results extrapolated to assess condition over a much larger reach. The choice of sampling scheme will be a major factor in determining the accuracy of the assessment (Williams, 1996; Mac Nally, 1997; Jeffers, 1998).

Several of the approaches discussed here (Tilleard and DWR, 1985; Mitchell 1990; Anderson 1993a) use the concept of homogeneous stream sections to extrapolate point data to a length of stream. Expert judgement is used to select the stream reaches and the measuring sites that are representative of those reaches. For the State of the Streams Survey, the sample sites were selected based on an aerial inspection of most of the streams in Victoria where measurements were to be made (Tilleard pers. comm.). The appeal of using subjectively chosen sites is that problems of random sampling are avoided; these are likely to include access difficulties and the need for a larger number of sample sites. The difficultly is that the approach is not statistically rigorous. The error involved in extrapolating from a single 'representative' site to a reach is difficult to determine but could be examined by rating a reach using both 'representative' sites and random sampling. This is explored in Chapter 6. EMAP and RHS are based on rigorous sampling schemes (Hughes et al. 1990; Jeffers 1998). One difficulty with the EMAP scheme is that it is difficult to make use of water quality data collected by others because the randomly selected sites do not match with the judgement based sites used 
by the USGS (Hughes et al. 1990). This suggests that site selection criteria should include consideration of situations where others are collecting data.

The temporal variability of indicators must also be considered when developing sampling schemes. Some aspects of stream condition, such as water quality and hydrology, are highly variable in time. Developing procedures to deal with this variability is important, particularly if assessment is to be compared over different time scales or if the influence of management is to be separated from natural variation. Several of the approaches ignore temporal variability. The assessments by Mitchell (1990) included a consideration of hydrologic variables, flow velocity and water depth (Table 4.2, but only on the one occasion when measurements were made. The EHI (Cooper et al. 1994) assessment involved limited sampling over a 4 week period so the water quality variability throughout the year was not considered (Cooper et al. 1993). Sampling frequency used for the NWQI is variable, so the influence of temporal variability will depend on the procedures used in different jurisdictions. IAEQ (Office of the Commissioner for the Environment, 1988) used water quality indicators that are based on the annual median of monthly water quality measurements to reduce the variability.

It is important to consider the time scale of interest. If the purpose of the condition assessment is to provide information on management effectiveness, then it is important that changes be detected on time scales that are of interest to managers. Although this is likely to be variable, a time scale of 2 to 5 years will be more appropriate than 20 to 50 years. Usually a pilot study will be necessary to determine the natural variability of indicators and scenario modelling may be necessary to determine likely changes over time (Reid and Brookes, 1998). If it is necessary to compare assessments at different times, then there is a requirement for consistency in measurement, including sampling site selection, sampling frequency and chosen parameters.

A related question is the statistical power of the indicators to detect changes of interest. If a monitoring scheme lacks statistical power, changes are unlikely to be detected which can lead to the false conclusion that there is no cause for concern. A key determinant of the sampling scheme will be the acceptable statistical power, Type I error probability and detectable effect size (Green, 1989; Peterman, 1990; Fairweather, 1991; Osenbert et al., 1994; Mapstone, 1995; Power et al., 1995; see Chapter 6). If it is necessary to detect changes that are about the same size or smaller than the standard 


\section{Monitoring stream condition}

deviation of the indicator measurements, then it will be necessary to carefully consider the statistical issues associated with sampling (Millard, 1987).

Many of the stream assessment techniques are based on visual assessments so interoperator variability is likely to be a significant source of variance. The importance of training to reduce variability was highlighted by Wang et al. (1996) and Hannaford et al. (1997). Often it will be difficult to determine the likely size of the errors, so it will be important to include procedures to reduce their significance such as training, auditing and adequate sampling designs. Issues of sampling design, statistical power and interoperator variability are examined in Chapter 6.

\subsubsection{Skill requirements}

The stream condition assessments also vary in the level of training, knowledge and experience that is required to measure and understand the indicators. Some of the methods require a range of experts to collect and interpret the data, with collation of reports to produce the final assessment. For example, EMAP will require a team of people with expertise in a wide range of areas including taxonomic knowledge of diatoms, zooplankton, macroinvertebrates, fish and semi-aquatic wildlife (Hughes et al. 1990). The EHI (Cooper et al. 1994) has similar requirements for expertise, with detailed assessments of water quality and biota and an aesthetic assessment that is likely to require training if it is to be repeatable.

Other methods were developed by experts but are proposed to be conducted by nonspecialists after they have had adequate training; for example, the State of the Streams Survey (Tilleard and DWR, 1986) and RCE (Petersen 1992). The requirement for specialist knowledge rules out the use of some indicators in Victoria. For example, the identification of diatoms would likely require the transporting of samples to the United States, since there is limited expertise in Australia in diatom identification (B. Chessman pers. comm.). Selection of indicators must take account of the level of skill available to the organisations that will be measuring and interpreting the results.

\subsection{Conclusion}

This chapter has reviewed approaches to measuring stream condition that have been developed and used in Victoria, Queensland and examples from the UK, South Africa, 
Europe and the US. There are several key lessons for the development of a system of indicators to assist waterway management in Victoria.

Firstly, clear objectives will be important to guide all the subsequent stages in the project. The purpose of the stream condition assessment needs to be considered, along with the users and what will happen to the information once it is assembled.

Secondly, the choice of indicators is key step. This will depend on the objectives as well as the intended users and their level of resources and the availability of specialist skills and knowledge. The choice of indicators will also depend on which aspects of stream condition are to be measured (Table 4.1.

Thirdly, the indicators do not usually consist of raw data; instead, they are reported as a narrative score or a numerical rating. The procedure to determine the indicator values requires decisions about the reference conditions that will be used.

Finally, both spatial and temporal variability must be considered in selecting indicators, designing the sampling scheme and interpreting the results.

These issues are considered further in the next chapter, which discusses development of a specific stream assessment technique, the Index of Stream Condition, to meet the goals of improving river management in Victoria. 


\section{DEVELOPING AN INDEX OF STREAM CONDITION}

\subsection{Introduction}

Previous chapters have discussed some of the problems associated with river management in Australia. These include focussing on single issues, responding to perception rather than collecting objective information about the river environment, and only making limited use of this environmental information when it is available. There has also been discussion of alternative approaches to managing rivers, namely the use of environmental indicators and development of adaptive management approaches. The previous chapter was a review of stream assessment indicators.

This chapter describes the development of a system of indicators to measure the condition of streams - the Index of Stream Condition (ISC) - a tool to aid river management in Victoria.

\subsubsection{Outline}

This chapter includes a discussion of the process of developing the Index of Stream Condition. Broadly, this process included: developing preliminary objectives for a system of indicators to assist river management, the preparation of a project brief, and recruitment of a Specialist Reference Group (SRG) to assist with the development. The SRG then assisted in making the pragmatic decisions to address the myriad of issues that arose in developing the ISC.

Specific stages in this process included: developing clear objectives, a review of other approaches for assessing waterway condition (Chapter 4), and decisions about the proposed users and uses of the ISC. The target audience of the ISC was a major constraint on the selection of indicators. It was also necessary to develop a measurement framework and decide on individual indicators and how they should be combined to form the overall condition assessment.

A key decision was choosing the standard for comparison of stream condition. The raw data collected for the indicators needed to be placed into context by comparing it to some reference condition. Indicators could be developed to assess streams in terms of 
their 'naturalness', 'health', their ability to support a designated use, or their suitability for a particular species.

The final Index of Stream Condition included input from a variety of people. My role was to guide the process, research the key questions, prepare discussion papers, make recommendations, chair the meetings of the SRG and write the final report of this stage of the project (CEAH and ID\&A Pty Ltd, 1995; see Appendix C). The contributions of others are acknowledged throughout this chapter. Further developments of the ISC since the version discussed here, are described at the end of this chapter.

An important contribution of this thesis is the formulation of the ISC approach to deal with some of the problems outlined earlier and the development and practical application of the process. In this chapter, I focus on the development and practical application as well as briefly describing the ISC, which is then tested in later chapters.

\subsubsection{Context}

As well being a response to the river management problems identified in Chapter 3, the ISC was developed in the international context of concerns about environmental management and increased use of environmental indicators (see Chapter 4). In the Victorian context, there are also changing roles for waterway management authorities, which have evolved from small, single purpose, River Trusts funded primarily by the State Government and with a high level of government direction, to large, multipurpose catchment management authorities with a range of funding opportunities, reduced government control of day to day operations but with increased requirements for accountability (Ian Drummond and Associates Pty Ltd, 1995; see Chapter 2).

There is also recognition that overall stream management goals require a range of programs delivered by government, regional authorities and community groups. Each of these programs may have their own performance indicators but there is also a need for broad scale indicators to measure performance against overall objectives. The ISC is developed to provide that overall measure of condition for river management in Victoria. 


\subsection{Process of developing the ISC}

\subsubsection{Background}

Evolving arrangements for river and catchment management meant that a broad indicator of management outcomes came to be on the agenda of the Victorian State Government. The Government had sponsored earlier work in this area (Tilleard and DWR, 1986; Mitchell, 1990; Office of the Commissioner for the Environment, 1988) but the need remained for a more management-oriented, targeted approach.

The idea was further developed during a visit to South Africa by a delegation of Australian scientists and managers to a joint South African/Australian workshop on the Classification of Rivers and Environmental Health Indicators (Uys, 1994). Dr Jane Doolan, head of the Waterways Unit of the Department of the Natural Resources and Environment (DNRE) attended the workshop and was introduced to the Estuarine Health Index (EHI) that had been developed to assist South African natural resource managers (Ramm et al., 1994; see Section 4.2.5). She also discussed ideas for a river health indicator with both Australian and South African scientists and became convinced it was a feasible project. Upon returning to Australia, Dr Doolan commenced a research project within the Waterways Unit, DNRE to gather information on indicator systems, similar to the EHI, which had been developed internationally. There was also work on a planning and reporting framework for Victorian waterway management authorities, in which I was involved, that proposed the use of a range of indicator types including indicators associated with changes in environmental condition (Ian Drummond and Associates Pty Ltd, 1995).

In mid-1994 the Waterways Unit and Victorian EPA, applied for funding from the Land and Water Resources Research and Development Corporation (LWRRDC) to develop a 'River Health Index' to assist management of Victorians waterways. This funding bid was successful and the Waterways Unit prepared a brief for the project that was subsequently awarded to the Centre for Environmental Applied Hydrology within the Department of Civil and Environmental Engineering at the University of Melbourne. It was my responsibility to undertake this applied research project. 


\subsubsection{Preliminary objectives of the ISC}

Preliminary objectives were 'to develop an Index of River Condition (IRC) [later Index of Stream Condition] as a tool for assessing the condition of rivers as part of adaptive management of waterways and catchments' (Heeps, 1994).

Other objectives were to develop a mechanism for assessing river condition that could be used as a performance indicator, or suite of indicators, for waterway management and catchment management strategies. It was also proposed that these indicators be used for benchmarking river condition and assessing the effectiveness of management strategies.

Scientific credibility was a key requirement: '...it is essential that it have a sound scientific basis and credibility within both the natural resource management sector and the research/academic community' (Heeps, 1994).

\subsubsection{Organising the project}

It was clear that developing a suite of indicators of river health would be a complicated project requiring a wide range of expertise. Although the general goals of the project were specified, the outcome could not be established until there was a clearer idea about what could be achieved. Because of this, DNRE acknowledged that it was inappropriate to run the project without their involvement; instead, they would be engaged in the discussion and negotiations as the project proceeded.

The broad methodology was to develop an Index of Stream Condition, by drawing on expertise throughout Australia. A Specialist Reference Group would be established to provide input and ratify decisions. My role was to use the combined expertise of the group, along with my own research and discussions with others not represented in the core group, to develop the aims of the project.

\subsubsection{Forming a Specialist Reference Group}

A Specialist Reference Group (SRG) was formed that included people with expertise in various aspects of rivers and river management (see Table 5.1). This group also made up the project steering committee.

There was also a wide range of people outside the specialist group, who were consulted during the project. These included people with expertise in water quality, hydrology, the riparian zone, physical condition of streams and biological indicators (see Table 


\section{Developing an Index of Stream Condition}

5.2). These people were approached early in the project, the general objectives of the ISC were discussed and their opinions sought on important issues and possible indicators. Input from these specialists was incorporated into discussion papers that were prepared for the SRG.

Table 5.1 - Core members of the Specialist Reference Group and project steering committee

\begin{tabular}{|c|c|c|}
\hline Member & Expertise & Position/Employer \\
\hline $\begin{array}{l}\text { Mr Chris } \\
\text { Chesterfield }\end{array}$ & $\begin{array}{l}\text { Waterway } \\
\text { management/ riparian } \\
\text { vegetation }\end{array}$ & Melbourne Water Corporation \\
\hline Ms Lisa Dixon & Stream ecology & $\begin{array}{l}\text { Manager, Freshwater Science Unit, } \\
\text { Victorian Environment Protection } \\
\text { Authority }\end{array}$ \\
\hline Dr Jane Doolan & Waterway management & $\begin{array}{l}\text { Manager, Waterways Unit } \\
\text { Department of Natural Resources and } \\
\text { Environment, Victoria }\end{array}$ \\
\hline $\begin{array}{l}\text { Associate } \\
\text { Professor Brian } \\
\text { Finlayson }\end{array}$ & $\begin{array}{l}\text { Geomorphology and } \\
\text { Hydrology }\end{array}$ & $\begin{array}{l}\text { Department of Geography and } \\
\text { Environmental Studies, University of } \\
\text { Melbourne }\end{array}$ \\
\hline $\begin{array}{l}\text { Professor Barry } \\
\text { Hart }\end{array}$ & $\begin{array}{l}\text { Water quality, aquatic } \\
\text { chemistry }\end{array}$ & $\begin{array}{l}\text { Director, Water Studies Centre, } \\
\text { Monash University }\end{array}$ \\
\hline Mr Graham Hunter & $\begin{array}{l}\text { Environmental } \\
\text { legislation }\end{array}$ & $\begin{array}{l}\text { Department of Natural Resources and } \\
\text { Environment }\end{array}$ \\
\hline $\begin{array}{l}\text { Professor Sam } \\
\text { Lake }\end{array}$ & Stream ecology & $\begin{array}{l}\text { Department of Ecology and } \\
\text { Evolutionary Biology, Monash } \\
\text { University }\end{array}$ \\
\hline Mr Ian Morgans & Waterway management & $\begin{array}{l}\text { Association of Victorian River } \\
\text { Management Authorities }\end{array}$ \\
\hline Mr John Tilleard & $\begin{array}{l}\text { River restoration, } \\
\text { Waterway management, } \\
\text { Water resources } \\
\text { management }\end{array}$ & $\begin{array}{l}\text { Chairman, ID\&A Pty Ltd; Director, } \\
\text { Southern Rural Water }\end{array}$ \\
\hline Mr Paul Wilson & Waterway management & $\begin{array}{l}\text { Department of Natural Resources and } \\
\text { Environment. }\end{array}$ \\
\hline
\end{tabular}

\subsubsection{Users of the Index of Stream Condition}

The ISC is intended to be a management tool and is therefore aimed at waterway management in the State of Victoria which is one of the roles of regional catchment 
management authorities (see Chapter 2). Waterway management authorities are expected to use the ISC for their internal planning and reporting and external reporting to local, regional and state resource management agencies and the community. The ISC will be collected and processed by these authorities while making use of existing environmental information networks.

Table 5.2 - Experts outside the Specialist Reference Group that were consulted as part of the development of the Index of Stream Condition

\begin{tabular}{|c|c|c|}
\hline Person & Expertise & Position/Employer \\
\hline $\begin{array}{l}\text { Professor Angela } \\
\text { Arthington }\end{array}$ & $\begin{array}{l}\text { Stream ecology, } \\
\text { Environmental flows }\end{array}$ & $\begin{array}{l}\text { Centre for Catchment and Instream } \\
\text { Research, Griffith University }\end{array}$ \\
\hline Dr Sandra Brizga & Geomorphology & Brizga and Associates Pty Ltd \\
\hline Dr Stuart Bunn & Riparian vegetation & $\begin{array}{l}\text { Centre for Catchment and Instream } \\
\text { Research, Griffith University. }\end{array}$ \\
\hline Dr Ian Campbell & Stream ecology & $\begin{array}{l}\text { Department of Ecology and } \\
\text { Evolutionary Biology, Monash } \\
\text { University, Clayton }\end{array}$ \\
\hline Dr Peter Davies & Stream ecology & $\begin{array}{l}\text { Department of Zoology, University } \\
\text { of Tasmania }\end{array}$ \\
\hline Dr Wayne Erskine & Geomorphology & $\begin{array}{l}\text { Formerly at University of New South } \\
\text { Wales; now at State Forests of New } \\
\text { South Wales }\end{array}$ \\
\hline Dr Peter Hairsine & Riparian vegetation & CSIRO Division of Soils \\
\hline Dr John Koehn & Fish ecology & Arthur Rylah Institute \\
\hline Dr Lance Lloyd & $\begin{array}{l}\text { Water quality, stream } \\
\text { ecology }\end{array}$ & Water Ecoscience \\
\hline $\begin{array}{l}\text { Dr Richard } \\
\text { Marchant }\end{array}$ & Stream ecology & Museum of Victoria \\
\hline Mr Noel Morgan & Water chemistry & \\
\hline $\begin{array}{l}\text { Associate } \\
\text { Professor Richard } \\
\text { Norris }\end{array}$ & Stream ecology & $\begin{array}{l}\text { University of Canberra and } \\
\text { Cooperative Research Centre for } \\
\text { Freshwater Ecology }\end{array}$ \\
\hline Dr Luke Pen & River assessment & $\begin{array}{l}\text { Water Authority of Western } \\
\text { Australia }\end{array}$ \\
\hline Mr Scott Seymour & Stream assessment & Melbourne Water Corporation \\
\hline $\begin{array}{l}\text { Mr Edward } \\
\text { Thexton }\end{array}$ & Riparian vegetation & Riparian Australia \\
\hline Dr Cathy Wilson & Geomorphology & CSIRO Division of Water Resources \\
\hline
\end{tabular}




\section{Developing an Index of Stream Condition}

This approach differs from many other environmental monitoring programs. Often data are collected centrally and there are inadequate links between monitors and managers which can lead to a 'data-rich but information-poor syndrome' (Ward et al., 1986; Ward et al., 1990), as was discussed in Chapter 3. The intention of the ISC was that users would be involved in deciding what data to collect, collect that data in the field or gather it from existing sources, process it, and use the results.

These requirements had important implications for the development of the ISC and were a severe constraint on indicator selection and specification. In general, indicators were to be chosen so that they could be measured, used and understood by the target audience. They also had to be tailored, where possible, so that they could be collected and processed by people with the skills available to catchment and waterway management authorities and without the requirement for extensive additional funding.

\subsubsection{Review of other approaches and lessons for the ISC}

Given these ideas about the objectives of the ISC and the target users, the next step was to review existing approaches to monitoring stream condition both in Australia and internationally (see Chapter 4).

A specific review was also made of approaches to stream condition assessment in other Australian states and officers from appropriate government departments were approached to obtain relevant internal reports. There was some limited work in Western Australia (Water Authority of Western Australia, c1995; Pen, 1994; Pen pers. comm.), New South Wales (Department of Water Resources, 1992) and the Commonwealth (Division of Water Resources, 1992). There was more work in Queensland, for example Anderson (1993a; 1993b; 1993c). A large amount of material was available from Victoria both because more work had been done and because I had better access to libraries and public servants from State and local government and resource management agencies (Tilleard and DWR, 1986; Office of the Commissioner for the Environment, 1988; Mitchell, 1990; Macmillan, 1990; Macmillan and Kunert, 1990; Department of Water Resources, 1989a; Department of Water Resources, 1989b; Land Conservation Council, 1989; Melbourne Parks and Waterways, 1994; Melbourne Water Corporation, 1995; Victorian Government Gazette, 1988) (see Appendix C for further discussion). 
There are also national approaches to macroinvertebrate assessment, including the Australian River Assessment System (AusRivAS) (Parsons and Norris, 1996; Marchant et al., 1997; Norris et al., 1998) and SIGNAL (Stream Invertebrate Grade Number Average Level) (Chessman, 1995; Chessman et al., 1997).

Three approaches to assessing stream condition were particularly valuable during the development of the ISC. These were the State of the Streams Survey (Tilleard and DWR, 1986), which provided the data for Mitchell's (1990) report on environmental condition of Victorian streams; the South African Estuarine Health Index (Cooper et al., 1994); and the report on environmental condition of Victoria's streams (Office of the Commissioner for the Environment, 1988). These are discussed in more detail below.

\section{State of the Streams Survey}

The State of the Streams Survey (SSS) was an important precursor to the ISC because it involved collection of a large amount of data for streams across the whole of Victoria. Details of the study are provided in Chapter 4 and in Tilleard and DWR (1986), Mitchell (1990) and Barmuta et al. (1992). The main limitation of the SSS was that it only considered physical conditions, which were to be a subset of the ISC.

The sampling strategy used for the SSS was considered for the ISC. During the SSS, stream reaches (tens of $\mathrm{km}$ long) were classified on the basis of land use and physiography. Measuring sites were then selected to be 'representative' of these stream reaches. This selection was based on local knowledge and then checked and adjusted by specialists following aerial assessment (Tilleard pers. comm.). The number of measuring sites per length of stream (the sampling density), depended on the reach type. There was greatest sampling density in large lowland rivers and least in small forest streams. Overall, 868 sites were chosen to cover the State and information on 200 variables was collected at each site.

The SRG saw the sampling scheme based on 'representative' sites as a possible way to avoid the expense of a statistically rigorous approach to sampling condition, while still achieving accurate results. The sampling density used on the SSS was also seen as a useful guide although, subsequently, the accuracy of ISC results based on 'representative' sites was tested and found to be poor. A new sampling procedure was developed as discussed in Chapter 6. 


\section{Developing an Index of Stream Condition}

The original purpose of the SSS was to collect objective information that was not necessarily intended to guide management. The ISC was intended to be more management focused. A procedure was developed by Mitchell (1990) to generate environmental ratings from the survey information but this did not make reference to the natural characteristics of a site. A pristine stream may not necessarily score well under Mitchell's classification, which may not be an appropriate outcome for a management tool (Grayson et al., 1996).

\section{Estuarine Health Index}

Another important antecedent to the ISC was the Estuarine Health Index developed in South Africa (Cooper et al., 1993; Cooper et al., 1994; Ramm et al., 1994) (see Chapter 4). This included assessment of three aspects of estuaries: biology, water quality and aesthetic values, with data displayed as bar charts for each estuary.

There was general agreement that this method of displaying information could usefully guide the ISC. The three components were rated out of 10 , which provided a straightforward guide as to their quality, and were displayed together in a way that was compact and easy to understand without aggregating the data to a single score.

There were concerns about other aspects of the EHI. The water quality assessments used in the EHI were based on data that were collected over a 4-week period, which may not have been typical of conditions at other times of the year (Cooper at al. 1993). In Victoria, the likely variation in water quality needed to be considered in the development of the ISC.

Another concern was the detailed estuarine classification system that was developed as part of the EHI. This was apparently considered necessary in the early part of the EHI project but did not seem to be used as part of the process of developing EHI scores.

For the ISC it would clearly be a waste of resources to develop a more comprehensive stream classification system than was necessary. It was considered more appropriate to decide on the measurement framework and indicators first and then develop a stream classification system to specifically serve those indicators. This stream classification system would be guided by those already developed by Tilleard and DWR (1986) and the Office of the Commissioner for the Environment (1988). 


\section{State of the Environment Report - Victoria's inland waters}

The environmental assessment of Victoria's streams undertaken by the Office of the Commissioner for the Environment (1988) was another important precursor to the ISC. This study involved development of an Index of Aquatic Environmental Quality that was a broad ranging assessment of streams and catchments (see Chapter 4).

A major difficulty was the large data requirements of this scheme that could not be satisfied. The report urged further data collection and commented that:

[lack of data] should be a matter of great public concern. They generally point to human activities proceeding without adequate knowledge or monitoring of their impact on aquatic environments (Office of the Commissioner for the Environment, 1988, 39).

The difficulty with this comment is that many of the areas with data gaps were in parts of the State with few human activities e.g. National Parks or forested areas with low population density. It is difficult to justify allocating resources to data collection just so a system of indicators could be applied uniformly across the State.

There will always be limited resources for data collection and any assessment scheme must not impose too great a burden on the authorities that will collect and use the data, especially if assessments are to be made regularly. An important criterion for selection of indicators for the ISC was that data requirements be realistic and without an excessive cost burden. It is difficult to justify extensive data collection in areas where streams are likely to be in close to pristine condition, yet it is often in these areas where there is limited data. The strategy adopted in the ISC was to decrease the sampling density in these areas.

Despite problems related to data requirements, aspects of the approach developed by the Office of the Commissioner for the Environment (1988) guided the ISC. Their general approach to water quality assessment was adopted. This was based on analysing low flow data and scoring streams according to a rating table that was developed by specialists (see Section 7.2). This study also used a straightforward stream classification system (see Section 6.3), dividing streams into mountain, valley and plains reaches. 


\subsubsection{A measurement framework for the ISC}

Defining a measurement framework for the ISC was necessary to assist with indicator selection. A measurement framework defines those aspects of a social/environmental situation that are to be assessed. A common indicator framework in use in Australia is the OECD 'Pressure, State, Response' model (DEST, 1994; OECD, 1994; SEAC, 1996). Under this model, indicators would be required to quantify the human-induced pressures that could potentially degrade the environment, the state or condition of the environment and society's responses that relate to the environment.

Adapting this model to rivers divides environmental reporting into three categories: pressure on the river environment (human activities and impacts); state (condition of the river environment) and response (institutional and individual responses that relate to the river system (Figure 5.1).

A key issue was to decide where the ISC would fit into this framework. Decisions were required about whether to include indicators of each of the three categories, or to limit the scope of the ISC and acknowledge that other indicators may be required to be developed.

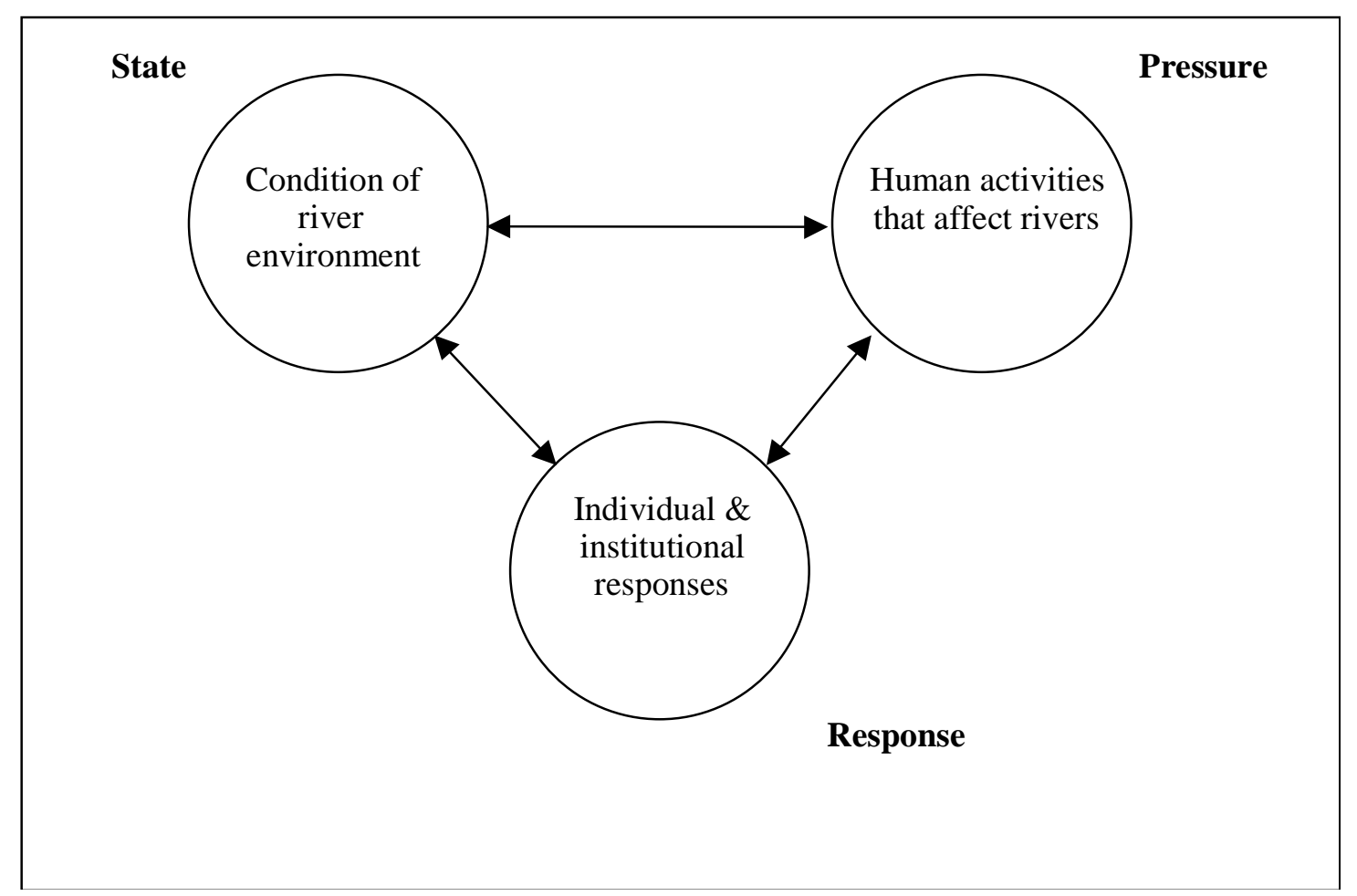

Figure 5.1 - Environmental indicators can measure pressure, state or response (adapted from SEAC, 1996) 
Firstly, it was decided that indicators of response would not be included. In the case of rivers, human response to environmental concerns could include the number and quality of policies and plans, works such as fish ladders to overcome barriers caused by dams, allocation of environmental flows in regulated rivers, and conversion of sewage treatment plants so that waste is discharged to land rather than to rivers (SERU, 1996). It seemed appropriate to develop indicators that characterised the river environment before developing those that measured human response to environmental problems. Developing indicators of response would be left to another project.

Although response indicators would not be included, it was hoped that ISC results would encourage managers to respond to identified problems by developing programs that had their own performance indicators (Ian Drummond and Associates Pty Ltd, 1995). It was also intended that the ISC be sensitive enough to detect managementinduced changes over a reasonable time frame, so that changes in ISC scores would indicate the effectiveness of a response.

\section{What aspects of stream condition should be measured?}

Given that the project was to be restricted to measuring river state or condition, what aspects of that condition should be measured? The review in Chapter 4 listed aspects of condition that had been measured in other integrated assessment approaches: water quality, water quantity, physical habitat, physical form, riparian quality, aquatic biology, scenic, aesthetic and recreational features.

It was decided to concentrate on a sub-set of five aspects of condition:

1. hydrology

2. physical form of the channel (including physical habitat);

3. riparian vegetation;

4. water quality; and

5. aquatic life.

Scenic, aesthetic and recreation aspects were excluded because developing indicators of these stream components was not part of the ISC goals and it was likely to be difficult to develop objective indicators for these aspects of condition. An early attempt to do this by Macmillan and Kunert (1990) was inaccessible and difficult to apply within the context of the ISC. 


\section{Developing an Index of Stream Condition}

\section{Terminology: river health or river condition?}

At the start of this project, it was originally proposed to develop an index of river 'health'. Using the term 'health' in the context of rivers or ecosystems has become widespread and is based on a metaphor with the health of individual organisms (Costanza et al., 1992; Division of Water Resources, 1992; Hart et al., 1993; Boulton, 1999; Fairweather, 1999; Karr, 1999; Norris and Thoms, 1999). Some authors have also questioned the use of 'health' in this context. For example, Suter (1993) argues that it is a mistake for environmental scientists to treat this metaphor seriously. There are also difficulties when using the term health to describe non-biological aspects of rivers. Schofield and Davies (1996) acknowledge that 'river health' is difficult to define.

Considering the controversy surrounding the term 'river health' and the fact that four of the five components of the ISC were not biological, it was decided to adopt the name 'Index of Stream Condition' for this project and avoid reference to health.

\section{ISC sub-indices and indicators}

Each of the five components of stream condition was assessed by measuring certain key variables or indicators. The indicators were combined to form the sub-index values that were further aggregated to determine the value of the Index of Stream Condition (see Figure 5.2).

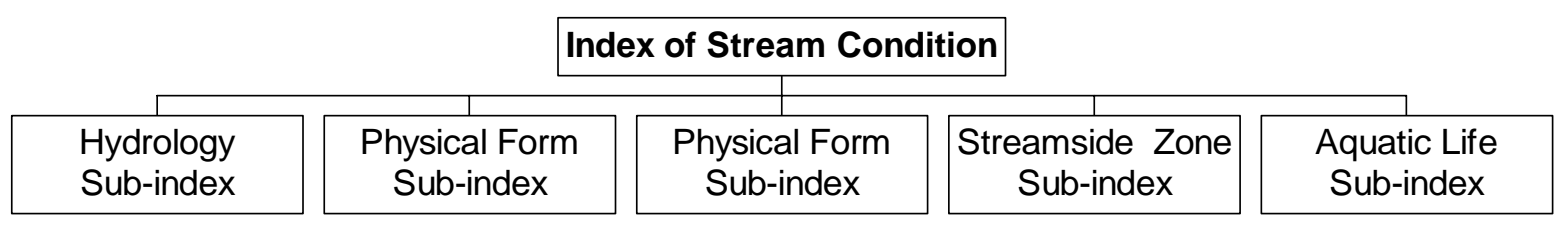

Figure 5.2 - Elements of the Index of Stream Condition 


\subsubsection{Developing, selecting and rating indicators}

\section{Summary of the process}

Indicators were required for all the sub-indices of the ISC: hydrology, physical form, riparian zone ${ }^{\square}$, water quality and aquatic life. Broadly, the process for selecting these indicators was as follows.

1. Consult with members of the SRG to develop a list of statewide issues that the subindex should try to address. It was also important to describe those issues, particularly local concerns, which would not be part of the ISC but may still be important to river managers.

2. Review the literature related to each component of stream condition and develop a list of possible indicators.

3. Consult with experts external to the SRG, to refine this list.

4. Consult with individual members of the SRG where their area of expertise coincided with a particular sub-index. The aim was to further refine the list of indicators and concentrate on those that were most likely to be suitable for the ISC. This selection was based on an assessment of likely availability of data and expert judgement about suitability and accuracy. Criteria for indicator selection are listed in Table 5.3. At this stage, draft rating tables for the indicators were developed (rating tables are described below).

5. Test the likely indicators and rating tables using readily available data from Victorian streams. Rating tables were refined and indicators further assessed for their suitability.

6. Develop discussion papers that listed possible indicators, recommended indicators, draft rating tables and an example application and circulate this to all members of the SRG. Generally the recommendations at this stage where considered as 'straw men' to provide a basis for discussion. They would be subject to substantial revision as the process proceeded.

\footnotetext{
${ }^{1}$ Later in the ISC project, 'streamside zone', was adopted as the name for the sub-index describing condition of the vegetation found near the stream. This was to avoid ambiguities in the term 'riparian', which is often used to refer to particular plant taxa irrespective of where they occur.
} 


\section{Developing an Index of Stream Condition}

7. Discuss indicators and rating tables in a workshop setting with all members of the SRG and document a list of issues to be addressed for the next meeting. Revise discussion papers, refine recommendations, and present material to additional meetings until a consensus was reached.

8. Develop a report that described chosen indicators and rating tables along with examples of their application.

\section{Table 5.3 - Criteria for selecting indicators for the Index of Stream Condition}

Suitable indicators:

- measure important statewide waterway management issues;

- are sensitive to change;

- are founded in science;

- are acknowledged by experts to measure important aspects of river condition;

- are appropriate for reporting at stream reach scales and over 5-yearly time periods;

- are cost effective;

- are easy to understand;

- are easy to measure;

- have a historical data base; and

- are capable of being measured using skills available to Victorian waterway management authorities.

(adapted from: DEST, 1994; Division of Water Resources, 1992).

\section{Indicator scores and rating}

The selected indicators determine the actual measurements that are required. Rather than use absolute values of these measurements it was decided to use indicator scores, usually on a 5-point scale (Table 5.4). These scores were either allocated directly when the indicator was assessed or determined from the measurement value and a rating table (Table 5.5 provides an example of a rating table). 
The final adoption of rating tables was another key task of the SRG. The number of categories had to be decided and definitions of each category specified. Again, the procedure was to discuss ratings with appropriate individual members of the SRG, review relevant literature, approach outside experts and prepare discussion papers that were workshopped by the whole SRG. Proposed rating systems were trialed on available data to determine if they seemed reasonable. Once there was consensus at the SRG meeting, the rating table was adopted. Ratings tables used in the ISC vary from 2 to 11 categories.

Clearly this procedure involved subjective judgements but included wide consultation, debate and discussion with specialists. The rating schemes were also applied to streams and checked by the SRG to determine that the outcome was as expected.

Table 5.4 - Five point scale for indicator measurements

\begin{tabular}{|l|c|}
\hline Category $^{1}$ & Rating \\
\hline Essentially natural & 4 \\
\hline Near natural & 3 \\
\hline Some modification & 2 \\
\hline Major modification & 1 \\
\hline Highly modified & 0 \\
\hline
\end{tabular}

1 - specific definitions are made for each indicator.

\section{Combining indicators to make up the sub-index score}

Once indicators were rated, the next step was to calculate sub-index scores. In most cases the sub-index score was based on the sum of the indicator ratings for that component of stream condition and then scaled to lie between zero and ten (Ladson et al., 1999a; see Appendix D).

Not all indicators made an equal contribution to the sub-index score. Some indicators were more difficult to define and hence less precise. Usually the less precise indicators had simpler rating tables, often just two categories, zero or 1 . When these were summed with an indicator with a five category rating, the less precise indicator had reduced weight.

Different weighting of the sub-indices was considered (see Section 4.4 .4 for a discussion of weighting schemes). There was discussion by the SRG about using the minimum sub-index value to characterise the overall ISC, as recommended by Smith 


\section{Developing an Index of Stream Condition}

(1990). For example, if the lowest sub-index score was 2 out of 10, then the ISC would be 2 . The maximum value for the ISC would be 10 if all the sub-indices scored 10 .

An advantage of this approach is that it highlights those reaches with low values and would direct attention to addressing the most severe problems in a reach. The problem is that it is not robust. An erroneously low value for one sub-index would dominate the value for the ISC. These concerns led the SRG to adopt equal weighting for all indicators, at least as a first step. The overall ISC score is the sum of the sub-index scores. Other weighting or averaging schemes were considered but it was difficult to justify anything more complex. It was also decided that all the sub-index scores would be reported, not just the overall score, so users would be able to decide on their own weightings.

\subsubsection{Case 1: Development of the Hydrology Sub- index}

In this section, the process of developing the ISC is explored through a case study of the Hydrology Sub-index. Early versions are presented followed by a listing of comments from the SRG meetings. Specialists in hydrology external to the SRG were consulted as shown in Table 5.2. The aim throughout this process was to develop a straightforward set of indicators, provided they conformed to the criteria in Table 5.3. The process described here shows the 'straw man' approach with simple indicators being developed first and then more detail being added to satisfy SRG members. The first stage in the process was to obtain agreement about statewide issues that that should be captured by indicators and then to select the appropriate indicators.

\section{Summary of Hydrology Sub-index at Specialist Reference Group meeting 1}

\section{Statewide issues}

The following statewide issues were considered as relevant for the hydrological aspects of the ISC: changes in flow conditions including flow regime, flood frequency, channel maintenance flows, available habitat and total flow volume.

\section{Possible indicators}

At this stage, only a preliminary review of the literature had been undertaken. It was considered that possible indicators could include those based on extent of regulation, 
flow duration analysis, flood frequency analysis, channel-forming discharge, or changes in monthly flows.

\section{Suggested indicators}

Two simple indicators based on changes in annual flows caused by regulation were suggested for further analysis. The first indicator measured changes to flow volume and was based on the actual annual discharge as a proportion of natural discharge (see Table 5.5). The second measured changes to flow seasonality and was based on the flow regime classification of Haines et al. (1988). Haines et al. (1988) present a series of 15 annual flow pattern groups that are based on the season in which the peak flow occurs. In Victoria, many streams have a winter dominated flow regime (group 12 or 13). With regulation, these are often changed to more summer dominated flows (group 6, 7 or 8) and it was proposed to develop an indicator based on this change.

Table 5.5 - Suggested rating table for an indicator that measures changes in annual flow volumes caused by flow diversion

\begin{tabular}{|l|c|}
\hline $\begin{array}{l}\text { Relationship between dam outflow and inflow based on } \\
\text { annual flows }\end{array}$ & Rating \\
\hline Actual = Natural & 4 \\
\hline Actual within $15 \%$ of natural & 3 \\
\hline Actual within 30\% of natural & 2 \\
\hline Actual within 40\% of natural & 1 \\
\hline Greater than 40\% difference between actual and natural & 0 \\
\hline
\end{tabular}

\section{Summary of comments from SRG}

The main comments were that the approaches suggested were too simplistic. In particular, other issues should be considered including changes in flow timing rather than just volume, flow changes caused by hydropower stations, the effect of urbanisation, influence of storages on lowering water temperature and the influence of catchment clearing, forestry and agriculture. It was also suggested that it was more appropriate to develop indicators based on monthly, rather than annual, flow changes. 


\section{Developing an Index of Stream Condition}

\section{Summary of Hydrology Sub-index at Specialist Reference Group meeting 2}

Following further discussion, statewide issues related to hydrology were expanded to include changes in flood frequency and magnitude, flow seasonality, flow peakedness, frequency of overbank flooding and occurrence of low flows. Despite this increased list of issues, there was still the desire to come up with a limited set of indicators consistent with the criteria listed in Table 5.3. A more complete review of hydrologic indicators had been undertaken and suggestions were made as to their suitability for use in the ISC (Table 5.6).

\section{Suggested indicator}

It was clear that only a complex set of hydrologic indicators could capture all the statewide issues. Instead, an indicator was proposed that would flag those streams with altered hydrology and suggest areas where detailed hydrologic investigation would be required.

The indicator suggested for the ISC was the Hydrologic Deviation $H D$ defined as the sum of the absolute differences between current and natural monthly flows, divided by the annual flow and expressed as a percentage.

$$
H D=\left(\frac{\sum_{i=1}^{12}\left|c_{i j}-n_{i j}\right|}{\sum_{i=1}^{12} n_{i j}}\right) \times 100 \%
$$

Where $c_{i j}$ is the current flow and $n_{i j}$ is the natural flow for month $i$ of year $j$ (Figure 5.3). Current flow, or actual flow, is the gauged flow in the river, natural flow is the flow that would occur in the absence of diversions and storages and must be estimated.

An example calculation for the Goulburn River at Eildon, a highly regulated stream, is shown in Figure 5.4 and Table 5.7. A preliminary rating table was developed as a starting point (Table 5.8). This was to be checked later following sample calculations. 
Table 5.6 - Summary of possible indicators for use in the ISC Hydrology Subindex

\begin{tabular}{|c|c|c|}
\hline Possible Indicator & Comment & $\begin{array}{l}\text { Suitable } \\
\text { ISC } \\
\text { indicator }\end{array}$ \\
\hline $\begin{array}{l}\text { Average flow velocity } \\
\text { (Mitchell, 1990) }\end{array}$ & $\begin{array}{l}\text { Highly variable at the time and space scales of } \\
\text { interest. Difficult to compare to a 'natural' value. }\end{array}$ & No \\
\hline $\begin{array}{l}\text { Water depth (Mitchell, } \\
\text { 1990) }\end{array}$ & $\begin{array}{l}\text { Highly variable at the time and space scales of } \\
\text { interest. Difficult to compare to a 'natural' value. }\end{array}$ & No \\
\hline $\begin{array}{l}\text { Flow duration analysis } \\
\text { (Maheshwari et al., } \\
\text { 1995; Knighton, 1988) }\end{array}$ & $\begin{array}{l}\text { Most comprehensive method of examining stream } \\
\text { hydrological characteristics. Difficult to } \\
\text { summarise to a single index value. Data and skill } \\
\text { requirements are large. }\end{array}$ & No \\
\hline $\begin{array}{l}\text { Flood frequency analysis } \\
\text { (Maheshwari et al., } \\
\text { 1995; Knighton, 1988) }\end{array}$ & $\begin{array}{l}\text { Not an appropriate measure at the time scale of } \\
\text { interest. }\end{array}$ & No \\
\hline $\begin{array}{l}\text { One day and } 30 \text { day } \\
\text { minimum flows } \\
\text { (Knighton, 1988) }\end{array}$ & $\begin{array}{l}\text { Requires detailed analysis of hydrographic record. } \\
\text { Not clear that these flow events are highly } \\
\text { significant. A local rather than a statewide issue. }\end{array}$ & No \\
\hline $\begin{array}{l}\text { Percentile flows eg } 1 \% \text {, } \\
5 \% \text {, mean annual, } 95 \% \\
\text { (Knighton, 1988) }\end{array}$ & $\begin{array}{l}\text { Requires analysis of daily flow duration curves. } \\
\text { Not clear that these flow events are highly } \\
\text { significant. A local rather than a statewide issue. }\end{array}$ & No \\
\hline $\begin{array}{l}\text { Minimum and average } \\
\text { monthly flows } \\
\text { (Maheshwari, et al., } \\
\text { 1995) }\end{array}$ & $\begin{array}{l}\text { Provide a summary of change rather than a year } \\
\text { by year assessment of condition. }\end{array}$ & No \\
\hline $\begin{array}{l}\text { Minimum and average } \\
\text { annual flows } \\
\text { (Maheshwari, et al., } \\
\text { 1995) }\end{array}$ & $\begin{array}{l}\text { Provide a summary of change rather than a year } \\
\text { by year assessment of condition. }\end{array}$ & No \\
\hline $\begin{array}{l}\text { Water level fluctuations } \\
\text { (Maheshwari, et al., } \\
\text { 1995) }\end{array}$ & Not a significant statewide issue. & No \\
\hline $\begin{array}{l}\text { Rates of water level rise } \\
\text { and fall (Maheshwari, et } \\
\text { al., 1995) }\end{array}$ & Not a significant statewide issue. & No \\
\hline Time of concentration & $\begin{array}{l}\text { Significant issue because of urbanisation. } \\
\text { Difficult to quantify. }\end{array}$ & No \\
\hline $\begin{array}{l}\text { Regime (Seasonality) } \\
\text { (Haines et al., 1988) }\end{array}$ & $\begin{array}{l}\text { Significant issue where irrigation releases change } \\
\text { stream regime from winter to summer dominated. }\end{array}$ & Possible \\
\hline Annual flow & $\begin{array}{l}\text { Significant issue where there are flow diversions } \\
\text { for irrigation or water supply. }\end{array}$ & Possible \\
\hline
\end{tabular}




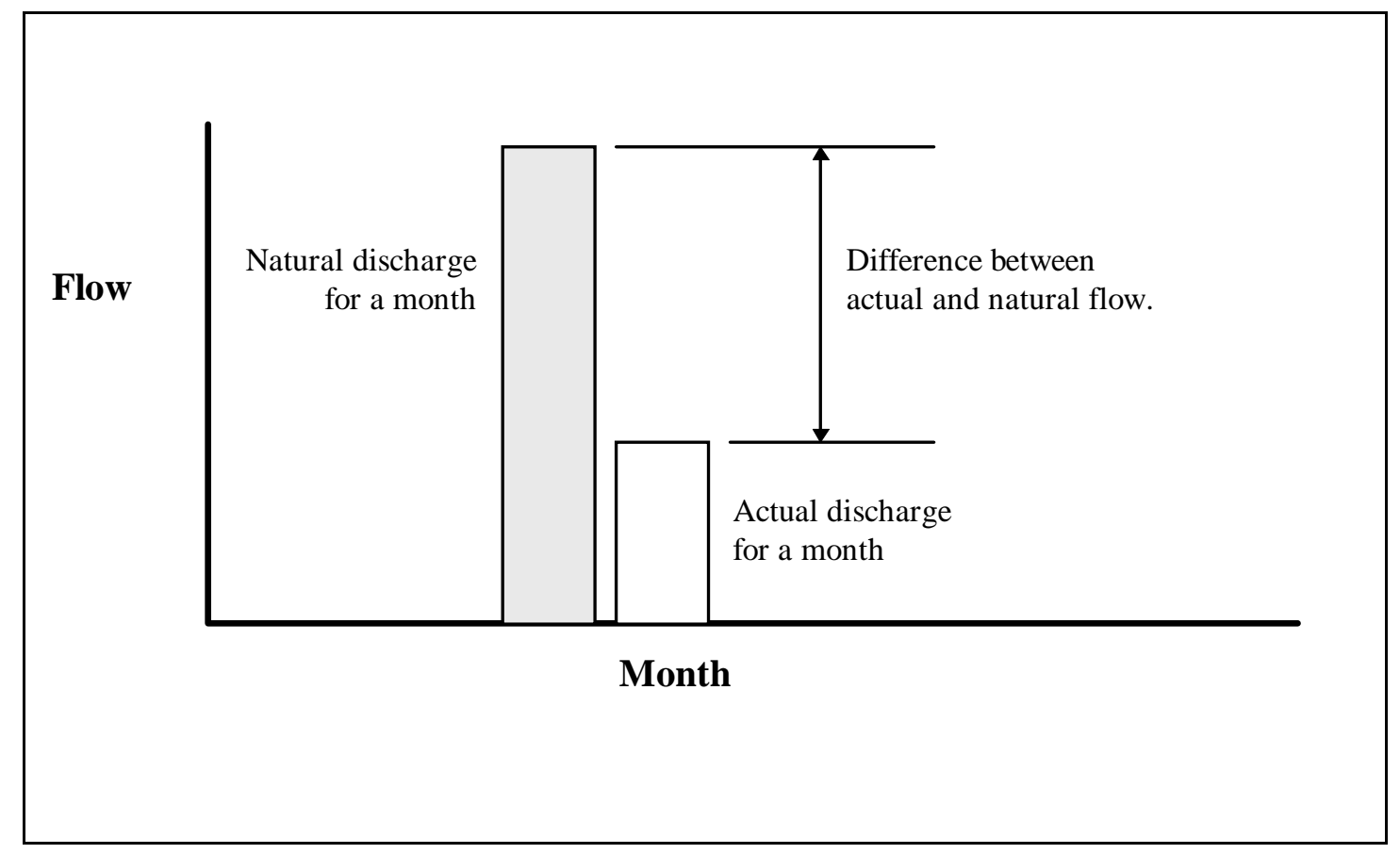

Figure 5.3 - Difference between actual and natural monthly discharge

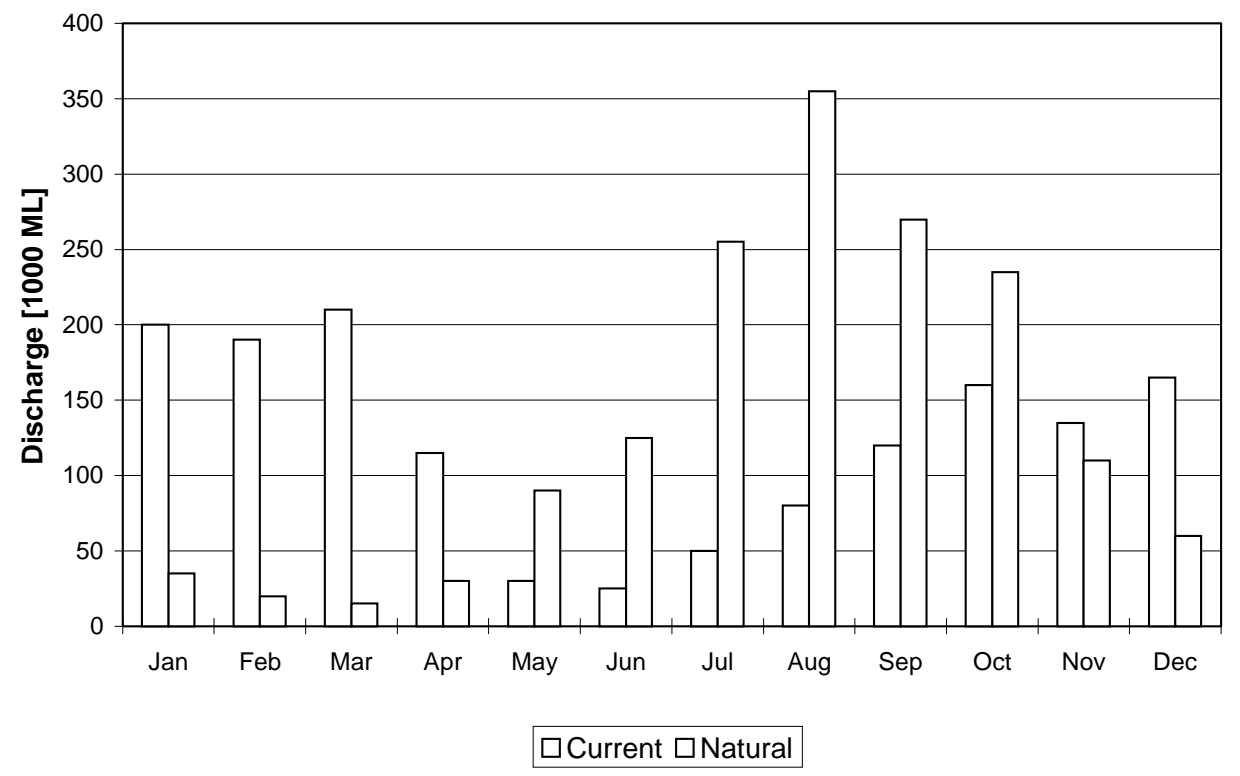

Figure 5.4 - Comparison of actual and natural monthly flows for the Goulburn River at Eildon 
Table 5.7 - Typical monthly flows in the Goulburn River at Eildon (adapted from Erskine 1996)

\begin{tabular}{|c|c|c|c|}
\hline Month & $\begin{array}{c}\text { Actual Monthly Flow } \\
\text { (ML) }\end{array}$ & $\begin{array}{c}\text { Natural } \\
\text { Monthly Flow } \\
\text { (estimated) } \\
\text { (ML) }\end{array}$ & $\begin{array}{c}\text { Difference } \\
\text { (absolute value) } \\
\text { (ML) }\end{array}$ \\
\hline Jan & 205 & 30 & 175 \\
\hline Feb & 200 & 15 & 185 \\
\hline Mar & 230 & 10 & 220 \\
\hline Apr & 125 & 30 & 95 \\
\hline May & 35 & 90 & 55 \\
\hline Jun & 30 & 125 & 95 \\
\hline Jul & 55 & 255 & 200 \\
\hline Aug & 90 & 355 & 265 \\
\hline Sep & 125 & 270 & 145 \\
\hline Oct & 170 & 235 & 65 \\
\hline Nov & 145 & 110 & 35 \\
\hline Dec & 175 & 60 & 115 \\
\hline Total & $\mathbf{1 5 8 5}$ & & $\mathbf{1 6 5 0}$ \\
\hline Hydrologic & $\frac{1650}{160} \times 100 \%$ & & \\
\hline Deviation & 1585 & & \\
\hline
\end{tabular}

Table 5.8 - Rating table for the Hydrology Sub-index

\begin{tabular}{|c|c|}
\hline Value of the hydrologic deviation & Hydrology Sub-index \\
\hline$<10 \%$ & 10 \\
\hline$<20 \%$ & 7.5 \\
\hline$<30 \%$ & 5 \\
\hline$<40 \%$ & 2.5 \\
\hline$>40 \%$ & 0 \\
\hline
\end{tabular}

It was acknowledged that the results from the calculation of the Hydrologic Deviation could not be used to distinguish between changes to flow seasonality and flow volume but this indicator would flag streams where there had been a change to hydrology. If necessary, a more detailed study could identify the exact nature of the hydrologic alteration. 


\section{Developing an Index of Stream Condition}

\section{Refinements following comments by the SRG}

The comments of the SRG are summarised in the meeting minutes (Wilson, 1995). The SRG agreed in principle that the Hydrologic Deviation was an appropriate indicator, as it provided a straightforward way of comparing actual and natural flows. The use of flow duration curves was discussed but it was believed to be difficult to determine flow duration for natural as well as current conditions, without developing daily hydrologic models for a large number of streams around the state. This was beyond the scope and budget of the current project. Estimates of monthly natural flows were likely to be available from modelling work that was being undertaken by the Office of Water Reform (DNRE) as part of projects to allocate water to competing users (DCNR, 1995).

The SRG was still concerned there was not a measure of the diurnal changes caused by hydropower stations and thought that a suitable indicator should be included. Hydroelectric stations (by themselves) do not necessarily change flow volume or flow seasonality but they may create water surges on a daily basis. These surges change stream hydrology and can have a significant influence on stream ecology (Cushman, 1985). Many hydroelectric stations are associated with irrigation or water supply dams where electricity is generated opportunistically from releases for other purposes, so that daily flow surges are not caused during power generation. In these cases, where there are specific short-term releases for hydroelectricity production, the sub-index value should be reduced by one category.

There was also concern that the effects of urbanisation would not be picked up by the proposed indicator. The presence of urban areas can have a major influence on hydrology. Urban areas can cause increased rainfall depths and frequency of thunderstorms by up to $15 \%$; peak discharge is increased by a factor of up to 20 for small events; catchment lag is reduced so that peak runoff occurs more quickly following rainfall; and catchment yield is increased (Codner et al., 1988; Mein and Goyen, 1988). These hydrologic changes cause corresponding physical changes in urban streams (Hammer, 1972; Cordery, 1976). Effects on biota have also been documented more recently (Suren, 1997; Walsh and Breen, 1999).

Clearly these effects should be reflected in the Hydrology Sub-index but they are difficult to quantify. Urbanisation also affects very few streams in rural Victoria, the proposed area of application of the ISC, and there are likely to be limited gauging records in these areas. 
Some authors have suggested that as the portion of a catchment that is urbanised increases, so does the influence on hydrology (Wallace, 1971) and an indicator was investigated that provided a score based on the percentage of a catchment that is urbanised. The SRG thought that an even simpler approach was sufficient. The Hydrology Sub-index will be reduced by one category where urbanisation exceeds $20 \%$ of the catchment area. This was later changed to $12 \%$ based on a study by Walsh and Breen (1999), who found that macroinvertebrate communities in urban streams were impoverished by changes in hydrology that were caused when greater than $12 \%$ of the catchment area was made impervious.

This simple indicator was justified because the ISC was not intended for use in large urban areas but rather was intended to ensure that those rural streams affected by urbanisation would not have unreasonably high ISC scores. It was acknowledged that a more detailed set of indicators would be required to assess urban stream condition.

\section{Further discussion of Hydrology Sub-index at Specialist Reference Group meeting 3}

Feedback on the Hydrology Sub-index was discussed at the SRG meeting 3. At that time, the cap on diversions in the Murray-Darling Basin had recently been implemented and DNRE was working to improve methods of allocating water (DCE, 1992; DCNR, 1995; Murray-Darling Basin Ministerial Council, 1995). No new diversion licences were being allocated but there was concern about 'creep' - a gradual increase in the amount of water being extracted as more of the existing entitlements were used. There was discussion about whether these types of changes would, or should, show up in the Hydrology Sub-index and it was agreed that more examples should be calculated to check on sensitivity. It was also agreed that biological response to changes in flow was unlikely to be linear, especially where there was limited flow, and that this should be recognised in the rating table.

The importance of indicators to assess barriers to fish migration and instream physical habitat was also discussed. It was decided that these should be included in the Physical Form Sub-index rather than being considered hydrologic indicators.

\section{Summary of Hydrology Sub-index at SRG meeting 4}

In preparing the next version of the Hydrology Sub-index, additional calculations of the hydrologic deviation were made for Victorian Streams using data from Phan (1994) (see 


\section{Developing an Index of Stream Condition}

Table 5.9). These results were used to modify the rating table (see Table 5.10). A step by step procedure was developed to allow calculation by users (Figure 5.5; Table 5.11).

Other land use changes, besides urbanisation, were considered for inclusion in the ISC. It has been reported that, for example, catchment clearing, grazing by hard-hoofed animals, construction of farm dams and soil conservation works are likely to change peak flow and catchment yield (Potter, 1991; Templet and Sorensen, 1995). However indicators of these impacts were not included in the ISC, as there is limited published information about the actual effects of these land use changes and the impacts are likely to be less significant than those included in the ISC i.e. large dams, urbanisation and hydroelectric stations. It would be possible to include other indicators if that proved necessary, following a trial application of the ISC.

Table 5.9 - Calculation of Hydrologic Deviation for a number of river reaches

\begin{tabular}{|c|c|c|c|c|}
\hline River Reach & $\begin{array}{c}\text { Period of } \\
\text { analysis } \\
\text { [years] }^{1}\end{array}$ & $\begin{array}{c}\text { Sum of absolute } \\
\text { difference in } \\
\text { monthly flows } \\
\text { [GL] }\end{array}$ & $\begin{array}{c}\text { Mean annual } \\
\text { natural flow } \\
{[\text { GL] }}\end{array}$ & $\begin{array}{c}\text { Hydrologic } \\
\text { Deviation }\end{array}$ \\
\hline $\begin{array}{l}\text { Buffalo River } \\
\text { downstream of Lake } \\
\text { Buffalo }\end{array}$ & 1968-1993 & 39.2 & 485.8 & $8 \%$ \\
\hline $\begin{array}{l}\text { Loddon River } \\
\text { downstream of } \\
\text { Laanecoorie Reservoir }\end{array}$ & $1943-1993$ & 90.9 & 320.8 & $28 \%$ \\
\hline $\begin{array}{l}\text { Moorabool River } \\
\text { downstream of Bungal } \\
\text { dam }\end{array}$ & 1973-1993 & 13.7 & 38.3 & $36 \%$ \\
\hline $\begin{array}{l}\text { Macalister River } \\
\text { downstream of Lake } \\
\text { Glenmaggie }\end{array}$ & $1975-1986$ & 266.8 & 555.8 & $48 \%$ \\
\hline $\begin{array}{l}\text { Jackson Creek } \\
\text { downstream of } \\
\text { Rosslynne dam } \\
\end{array}$ & $1975-1993$ & 9.5 & 18.6 & $51 \%$ \\
\hline $\begin{array}{l}\text { Tarago River } \\
\text { downstream of Tarago } \\
\text { dam }\end{array}$ & $1970-1993$ & 15.9 & 27.2 & $58 \%$ \\
\hline $\begin{array}{l}\text { Mitta Mitta River } \\
\text { downstream of } \\
\text { Dartmouth dam }\end{array}$ & 1980-1993 & 669.8 & 778.8 & $86 \%$ \\
\hline $\begin{array}{l}\text { Campaspe River } \\
\text { downstream of Lake } \\
\text { Eppalock }\end{array}$ & $1963-1993$ & 278.1 & 270.9 & $104 \%$ \\
\hline $\begin{array}{l}\text { Goulburn River } \\
\text { downstream of Lake } \\
\text { Eildon }\end{array}$ & $1970-1990$ & 1650 & 1585 & $104 \%$ \\
\hline
\end{tabular}

1 - all data are from Phan (1994) except for the Goulburn River, which is based on flow reported by Erskine (1996). 


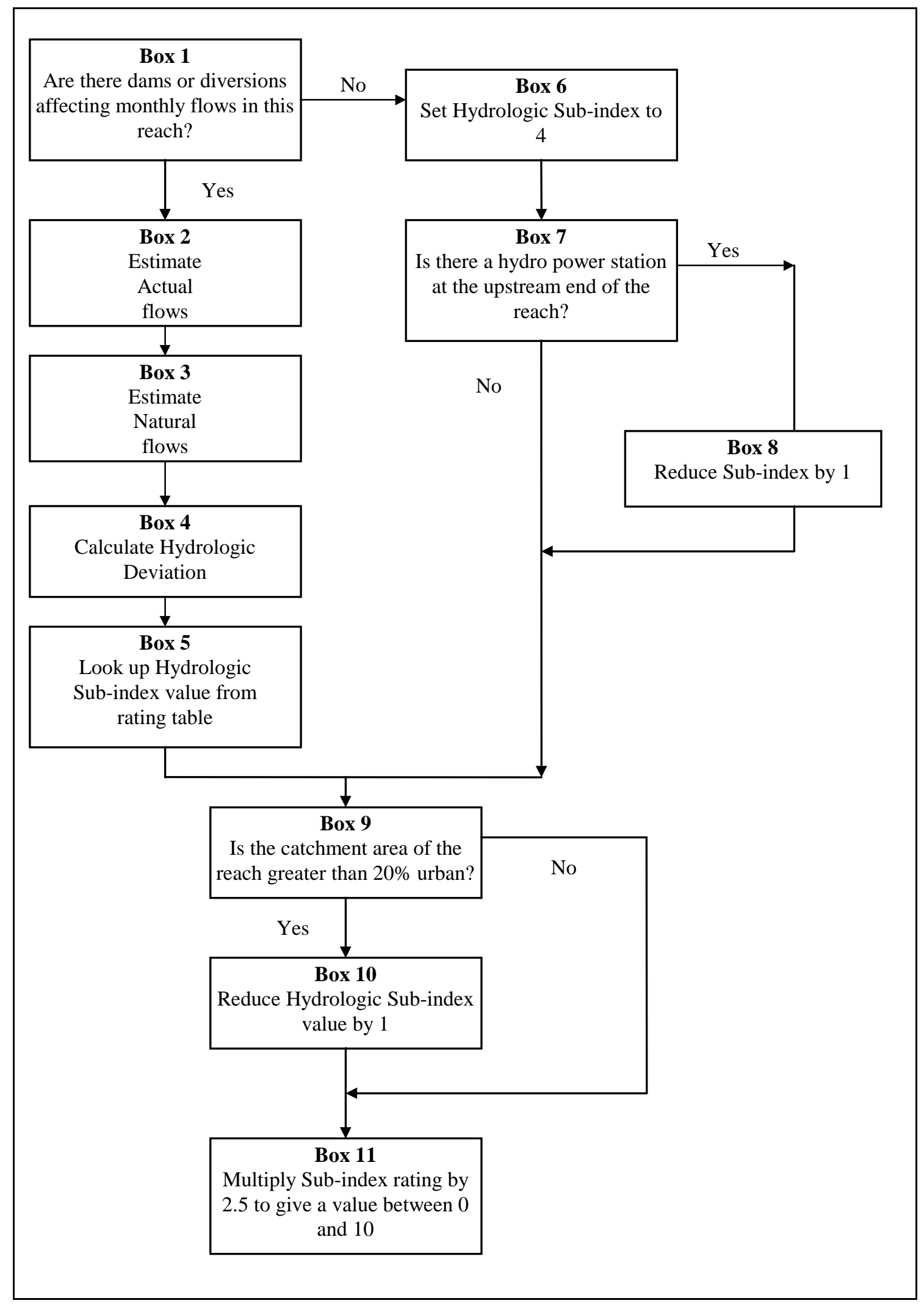

Figure 5.5 - Procedure for calculating Hydrology Sub-index 
Table 5.10 - Rating of Hydrologic Deviation

\begin{tabular}{|c|c|}
\hline Hydrologic Deviation & Rating \\
\hline$<2 \%$ & 4 \\
\hline$<10 \%$ & 3 \\
\hline$<30 \%$ & 2 \\
\hline$<60 \%$ & 1 \\
\hline$>60 \%$ & 0 \\
\hline
\end{tabular}

Table 5.11 - Procedure to calculate Hydrology Sub-index

Box 1: Are dams or diversions affecting monthly flows in this reach?

If flows in the reach have changed from natural conditions either by:

- a change in total annual volume; or

- a change in volumes for particular months;

then answer 'yes'.

\section{Box 2: Estimate Actual Flows.}

Characteristic actual monthly flows can usually be obtained from gauging stations within or near a reach. The flows used can be average monthly discharge over a number of years or monthly discharge for a particular year. Flows used in this step must be consistent with those used in Box 3. Generally, those reaches that are affected by dams or diversions have good data records.

\section{Box 3: Estimate Natural Flows.}

Estimate natural flows to compare with the actual flows from above. Flow diversions, dam storage and releases need to be considered. If there is limited information available, then average flows for the pre-regulation period could be used as the natural flow and compared to average flows for the post regulation period as the actual flow.

\section{Box 4: Calculate Hydrologic Deviation.}

The Hydrologic Deviation is calculated by summing, for the whole year, the absolute value of the differences between the actual and natural monthly flows and then dividing this total by the annual natural flow. 


\section{Box 5: Look up the Hydrology Sub-index rating.}

Using the Hydrologic Deviation from Box 4, look up the rating table to obtain the value of the Hydrology Sub-index for this reach.

\section{Box 6: Set Hydrology Sub-index to 4.}

Set the Hydrology Sub-index to 4 (the maximum value). It will be reduced in line with the procedures that follow.

\section{Box 7: Is there a hydroelectric station at the upstream end of the reach?}

If the reach is affected by a hydroelectric station, that causes water surges, then answer 'yes', and

Box 8: reduce the Sub-index value by 1 .

Box 9: Is the catchment area of the reach greater than $20 \%$ urbanised?

If the catchment area at the sample point is greater than $20 \%$ urban then [note, this was later changed to $12 \%$ impervious area as discussed in the text]

Box 10: reduce the Sub-index value by 1 if the Sub-index is 1 or greater (the minimum possible value is zero).

Box 11: Multiply the Sub-index value by 2.5 .

Multiply the sub-index rating by 2.5 to obtain the Hydrology Sub-index value to be incorporated into the Index of Stream Condition. The sub-index value will be between 0 and 10 .

Following these modifications the Hydrology Sub-index was at a stage where it could be trialed and discussed more widely amongst managers and other scientists. A complete description of the Hydrology Sub-index and other sub-indices developed for the trial version of the ISC is included in Appendix C.

\section{Further refinements to the Hydrology Sub-index}

The Hydrology Sub-index presented so far was developed to a stage where it was trialed by Catchment Management Authorities. It was also discussed at conferences and reviewed by two anonymous reviewers. Six specific criticisms were made as documented below. 


\section{Developing an Index of Stream Condition}

I prepared discussion papers focused on these issues and presented them at two meetings of the SRG. Details are provided in Appendices E and F. Based on feedback from these meetings, the final version of the Hydrology Sub-index (up to 1999) was prepared and is included in Appendix G (see also Ladson and White, 1999). A summary of concerns and responses to issues is provided below.

\section{Changes in high flow months are weighted more heavily than changes in low flow months}

\section{Concern:}

The main indicator is the Hydrologic Deviation, which is based on the absolute difference between current and natural monthly flow volumes. Taking a certain volume of water from the river during high flow (when it may be hardly noticeable) has the same influence on this indicator as removing an equal amount of water from the river during low flow, when it may result in the river drying up completely.

For a given volume of alteration, the influence is likely to be greater when the flow is low and this should be reflected in the hydrologic indicator.

\section{Response:}

The search for ways to address this issue was guided by a review of the literature as summarised in Appendix E and F. A large number and variety of hydrologic indicators have been proposed to measure biologically significant facets of a river's flow regime (Puckridge et al., 1998). From the literature, there appears to be no consensus as to the most biologically appropriate hydrologic variables and there has been limited empirical evaluation, especially under Australian conditions. After discussion with stream ecologists, it was difficult to find an ecological justification for choosing a hydrologic indicator that is sensitive to any particular aspect of hydrologic change as it seems to be possible to justify, ecologically, the retention of most aspects of the original hydrograph. Work is currently being undertaken by the Cooperative Research Centre for Freshwater Ecology (CRCFE) to test the value of over 100 hydrologic variables for identifying ecological differences between streams in southeastern Australia and the Murray-Darling Basin. The trial indicators are drawn mainly from Puckridge et al. (1998) and Richter et al. (1997).

The level of detail of most of these indicators is not appropriate for the ISC, especially as this is an active area of research and preferred indicators are yet to be 
identified. Outcomes from the above study along with the flow-ecology handbook also being developed by the CRCFE should be considered during future reviews of the ISC. At present, appropriate goals for the Hydrologic Sub-index are to identify streams with significant hydrologic change and indicate where detailed investigations should be considered. A straightforward indicator based on monthly flows was considered appropriate. Additional indicators of greater complexity could be used as part of specific investigations.

Four indicators based on monthly flows were explored as discussed in Table 5.12. After considering the merits of each approach and their performance when trialed on both regulated and unregulated streams in New South Wales and Victoria, the SRG decided to adopt the Amended Annual Proportional Flow Deviation (AAPFD) developed by Gehrke et al. (1995; Gehrke pers. comm. 1996). Although there is little difference in behaviour between the Hydrologic Deviation and the AAPFD, the latter had been shown to be related to fish species diversity by Gehrke et al. (1995) and was used by Thoms (1998) in his assessment of the Namoi River. A new rating table was developed for the AAPFD as discussed in Chapter 7.

\section{Management-induced changes to flows are unlikely to be reflected in changed} index scores

\section{Concern:}

Implementing environmental flows may not result in an improvement to the Hydrology Sub-index score because the change in flow volume is not large enough to change the sub-index rating.

\section{Response:}

It was decided to increase the number of categories in the Hydrology Sub-index rating table to make it easier for changes in hydrology to cause a rating change. The sensitivity of the Hydrology Sub-index is investigated in Chapter 7.

\section{Inadequate consideration of floods}

\section{Concern:}

The Hydrology Sub-index does not specifically include consideration of changes to flood regime resulting from regulation. Yet, changes in flood frequency, magnitude and timing can have a major influence on channel form and stream ecology. 
Table 5.12 - Hydrology indicators based on monthly flows (assuming 5 years of data are used)

\begin{tabular}{|c|c|c|c|}
\hline Name & Verbal definition & Mathematical definition & Comments \\
\hline $\begin{array}{l}\text { Hydrologic } \\
\text { Deviation, HD }\end{array}$ & $\begin{array}{l}\text { Sum of the absolute } \\
\text { differences between } \\
\text { actual and natural } \\
\text { monthly flows, divided } \\
\text { by the annual flow and } \\
\text { expressed as a } \\
\text { percentage. }\end{array}$ & $\begin{array}{l}H D=\frac{1}{5} \sum_{j=1}^{5}\left(\frac{\sum_{i=1}^{12}\left|c_{i j}-n_{i j}\right|}{\sum_{i=1}^{12} n_{i j}}\right) \times 100 \% \\
\text { Where } \\
c_{i j} \text { is the actual flow for month } i \text { of year } j \text {, and } \\
n_{i j} \text { is the natural flow for month } i \text { of year } j .\end{array}$ & $\begin{array}{l}\text { This indicator was used during } \\
\text { the early stages of the } \\
\text { development of the ISC (e.g. } \\
\text { CEAH and ID\&A Pty Ltd, 1995). }\end{array}$ \\
\hline $\begin{array}{l}\text { Ratio Flow } \\
\text { Deviation } \\
\text { (RFD) }\end{array}$ & $\begin{array}{l}\text { Sum of the ratios of } \\
\text { actual and natural } \\
\text { flows. }\end{array}$ & $\begin{array}{l}R F D=\frac{1}{5} \sum_{j=1}^{5}\left[\left(\frac{1}{12} \sum_{i=1}^{12} r_{i j}\right)-1\right] \\
\text { Where } r_{i j} \text { is the ratio of the differences between the actual flow and } \\
\text { the natural flow adjusted to be always greater than one. } \\
r_{i j}=\frac{c_{j i}}{n_{i j}} \text { if } c_{i j} \geq n_{i j} \text { and } r_{i j}=\frac{n_{i j}}{c_{i j}} \text { if } n_{i j} \geq c_{i j} \\
\text { Where } \\
c_{i j} \text { is the actual flow for month } i \text { of year } j \text {; and } \\
n_{i j} \text { is the natural flow for month } i \text { of year } j .\end{array}$ & $\begin{array}{l}\text { RFD will range between } 0 \text { for an } \\
\text { unaltered flow regime to }+\infty \\
\text { where natural or actual flow is } \\
\text { zero. } \\
\text { This indicator is equally sensitive } \\
\text { to changes in high and low flows. } \\
\text { Not easy to deal with } \\
\text { mathematically if actual or } \\
\text { natural flows are zero. }\end{array}$ \\
\hline
\end{tabular}


Table 5.12 - Hydrologic indicators based on monthly flows (continued) (assuming 5 years of data are used)

\begin{tabular}{|c|c|c|c|}
\hline Name & Verbal definition & Mathematical definition & Comments \\
\hline $\begin{array}{l}\text { Annual Proportional } \\
\text { Flow Deviation } \\
\text { (APFD) }\end{array}$ & $\begin{array}{l}\text { Sum of the ratios } \\
\text { of change in } \\
\text { monthly flow } \\
\text { (actual - natural) } \\
\text { to natural monthly } \\
\text { flow }\end{array}$ & $\begin{array}{l}A P F D=\frac{1}{5} \sum_{j=1}^{5}\left(\sum_{i=1}^{12}\left(\frac{\left(c_{i j}-n_{i j}\right)}{n_{i j}}\right)^{2}\right)^{\frac{1}{2}} \\
\text { Where } \\
c_{i j} \text { is the actual flow for month } i \text { of year } j \text {, and } \\
n_{i j} \text { is the natural flow for month } i \text { of year } j .\end{array}$ & $\begin{array}{l}\text { APFD will range from zero for an unregulated } \\
\text { river to } 3.46 \text { where there is a } 100 \% \text { increase or } \\
\text { decrease in flow and is also responsive to } \\
\text { seasonal changes. } \\
\text { Gehrke et al. (1995) found that this indicator was } \\
\text { related to diversity of fish species in regulated } \\
\text { rivers of the Murray-Darling Basin. May not be a } \\
\text { suitable indicator where natural monthly flows } \\
\text { are zero. }\end{array}$ \\
\hline $\begin{array}{l}\text { The amended APFD } \\
\text { was proposed by } \\
\text { Gehrke (pers } \\
\text { comm.) in } 1996 \text { to } \\
\text { overcome the } \\
\text { problem with the } \\
\text { APFD that when the } \\
\text { modelled natural } \\
\text { flow for a month } \\
\text { was zero, the APFD } \\
\text { could not be } \\
\text { calculated. }\end{array}$ & $\begin{array}{l}\text { Sum of the ratio } \\
\text { of change in flow } \\
\text { (actual - natural) } \\
\text { to average } \\
\text { monthly flow. }\end{array}$ & $\begin{array}{l}A A P F D=\frac{1}{5} \sum_{j=1}^{5}\left(\sum_{i=1}^{12}\left(\frac{\left(c_{i j}-n_{i j}\right)}{\overline{n_{j}}}\right)^{2}\right)^{\frac{1}{2}} \\
\text { Where: } \\
c_{i j} \text { is the actual flow for month } i \text { of year } j \text {; } \\
n_{i j} \text { is the natural flow for month } i \text { of year } j \text {; and } \\
\bar{n}_{j} \text { is the average monthly flow for year } j \text {, i.e. } \\
\bar{n}_{j}=\frac{1}{12} \sum_{i=1}^{12} n_{i j}\end{array}$ & $\begin{array}{l}\text { The greater the AAPFD value, the more } \\
\text { modified the flow regime is relative to natural } \\
\text { conditions. } \\
\text { P. Gehrke (pers. comm.) recommends this } \\
\text { indicator as an improvement over the APFD } \\
\text { described above. }\end{array}$ \\
\hline
\end{tabular}




\section{Response:}

It was decided to continue to base the Hydrology Sub-index on monthly flows. Although floods are not explicitly considered, it is likely that streams exhibiting the greatest changes in flood regimes will have the largest alteration of monthly flows and these changes will be reflected in the Hydrology Sub-index rating.

\section{Obtaining natural flows can be difficult and expensive}

\section{Concern:}

The Hydrology Sub-index requires both current and natural flows if a change to flow regime is expected. These natural flows can be difficult to obtain.

\section{Response:}

It is likely there will be flow models available in the northern part of the State because of need to determine compliance with the interstate agreement to cap diversions (Murray-Darling Basin Ministerial Council, 1995). There will also be many models south of the Great Dividing Range as part of developing Streamflow Management Plans (e.g. Southern Rural Water, 1998). It was decided to use modelled flows where they were available or develop a monthly water balance model, based on local flow and diversion data, to estimate natural flows. Details of the procedure to calculate monthly flows is discussed in Ladson and White (1999) and Appendix G.

\section{The Hydrology Sub-index does not include farm dams}

\section{Concern:}

There are concerns that farm dams significantly affect catchment yield and should be included in the Hydrology Sub-index.

\section{Response:}

This issue was investigated through a literature review and discussion with experts. The influence of farm dams on hydrology is an emerging issue and there are several research projects including work in New South Wales, Queensland and Victoria (GHD 1987; Good and McMurray 1997). Preliminary results show that farm dams can influence yield and low flow conditions but it is necessary to use process modelling to isolate their effects rather than just analysing flow data (R. Nathan 
pers. comm; ICAM Centre and SKM, 1999). It was decided that farm dams be excluded from the ISC at this stage. Once more research results are available, it may be possible to develop a suitable indicator.

\section{Unclear how many years of data should be included in sub-index calculations}

\section{Concern:}

The ISC is to be reported every 5 years but the Hydrology Sub-index is based on only one year's monthly data. Which one of the 5 years should be used to generate the sub-index score or should it be based on a number of years?

\section{Response:}

The response was that the Hydrology Sub-index should be averaged over 5 years except under special circumstances. Procedures are detailed in Ladson and White (1999). Equations are provided in Table 5.12.

\subsubsection{Development of other sub-indices}

The development of the other sub-indices was similar to that described for the Hydrology Sub-index. Different indicators were explored and, at various times throughout the project, added or removed from the sub-indices until there was an overall ISC that the SRG agreed could be used for further testing and refinement (CEAH and ID\&A Pty Ltd, 1995; Ladson et al., 1995; Ladson et al., 1996; Ladson et al., 1999a; see Appendices C, D, H and I). A summary of the ISC is provided in Table 5.13.

In developing the other sub-indices, in most cases my role was to research possible indicators, prepare discussion papers, organise and chair the meetings and try and establish a consensus for a set of indicators to take forward to the next stage. The major exception was the Aquatic Life Sub-index where there was a substantial contribution from David Robinson and Leon Metzeling (Officers from the Victorian EPA) who were the primary authors of the section on the Aquatic Life Sub-index included in CEAH and ID\&A Pty Ltd (1995). Even in this case the procedure to establish the indicators was the same as the other sub-indices, with initial recommendations and workshops to determine a consensus outcome. With most indicators, but particularly the Riparian or Streamside Zone Sub-index, I was assisted by Lindsay White. 
Table 5.13 - The Index of Stream Condition is based on 5 Sub-indices each consisting of various indicators

\begin{tabular}{|c|c|c|}
\hline Sub-index & $\begin{array}{l}\text { Sub-index value is } \\
\text { based on: }\end{array}$ & Indicators \\
\hline Hydrology & $\begin{array}{l}\text { Comparison of the } \\
\text { current flow regime } \\
\text { with the flow regime } \\
\text { existing under natural } \\
\text { conditions }\end{array}$ & $\begin{array}{l}\text { - AAPFD (comparison of monthly flows with } \\
\text { those that would have existed under natural } \\
\text { conditions) } \\
\text { - Percentage of catchment urbanised } \\
\text { - Presence of hydroelectric stations }\end{array}$ \\
\hline $\begin{array}{l}\text { Physical } \\
\text { Form }\end{array}$ & $\begin{array}{l}\text { Assessment of } \\
\text { channel stability and } \\
\text { amount of physical } \\
\text { habitat }\end{array}$ & $\begin{array}{l}\text { - } \text { Bank stability } \\
\text { - Bed condition } \\
\text { - Presence and influence of artificial barriers } \\
\text { - Origin and density of coarse woody debris }\end{array}$ \\
\hline $\begin{array}{l}\text { Riparian or } \\
\text { Streamside } \\
\text { Zone }\end{array}$ & $\begin{array}{l}\text { Assessment of quality } \\
\text { and quantity of } \\
\text { streamside vegetation }\end{array}$ & $\begin{array}{l}\text { - Width of vegetation } \\
\text { - Longitudinal continuity of vegetation (a } \\
\text { measure of the number and significance of } \\
\text { gaps in streamside vegetation) } \\
\text { - Structural intactness (comparison of } \\
\text { overstorey, understorey and groundcover } \\
\text { density with that existing under natural } \\
\text { conditions) } \\
\text { - Proportion of cover that is indigenous } \\
\text { - } \text { Presence of regeneration of indigenous species } \\
\text { - } \text { Condition of wetlands and billabongs }\end{array}$ \\
\hline $\begin{array}{l}\text { Water } \\
\text { Quality }\end{array}$ & $\begin{array}{l}\text { Assessment of key } \\
\text { water quality } \\
\text { parameters }\end{array}$ & $\begin{array}{ll}\text { - } & \text { Total phosphorus concentration } \\
\text { - } & \text { Turbidity } \\
\text { - } & \text { Salinity (EC) } \\
\text { - } & \text { Acidity }(\mathrm{pH})\end{array}$ \\
\hline $\begin{array}{l}\text { Aquatic } \\
\text { Life }\end{array}$ & $\begin{array}{l}\text { Assessment of aquatic } \\
\text { indicator species }\end{array}$ & $\begin{array}{l}\text { - } \text { SIGNAL index (Chessman, 1995; see Section } \\
\text { 7.4) } \\
\text { - AusRivAS (see Section 7.4) }\end{array}$ \\
\hline
\end{tabular}

The Water Quality Sub-index requires further discussion. The number of possible indicators was large (Appendix C) and a key task of the SRG was to select a minimum set that could still provide useful information. There is also a substantial amount of water quality data already being collected in Victoria by Waterwatch (P. Wilson, DNRE, pers. comm.) and the Victorian Water Quality Monitoring Network (VWQMN) and it was important to use this where possible (see Section 3.3).

Water quality can be highly variable in both space and time and a thorough review of water quality problems would require a substantial monitoring effort. There are also 
problems associated with detecting the types of changes that could be attributable to catchment management. The water quality component of the ISC could only ever be a limited part of efforts to manage the quality of water in Victoria's rivers and streams. Despite these concerns, it was considered important to include a Water Quality Subindex in the ISC. Managing water quality was a key task of catchment and waterway management authorities and although a simple approach was proposed, it was an attempt to establish the link between monitoring of water quality and management that is often lacking (Ward et al., 1986; see Section 3.3). It was also important to keep water quality concerns on a level equivalent to other aspects of condition included in the ISC. There is a place for more detailed water quality assessment than was included in the ISC and Catchment Management Authorities may be in a position to undertake detailed studies in the future.

The development of the Water Quality Sub-index required several simplifying decisions. Following discussion by the SRG, the number of indicators was limited to four: phosphorus, turbidity, conductivity and $\mathrm{pH}$ that were chosen to link with statewide water quality issues. Further discussion of indicator selection is included in Appendix C.

Rating of these indicators was be based on low flow conditions. It was acknowledged that monitoring high flows could be important, particularly when estimating loads (Walling and Webb, 1985; Littlewood, 1992) but there was limited high flow water quality data being collected by Waterwatch or VWQMN, and setting up specific programs for the ISC was prohibitively expensive. If necessary, high flow monitoring could take place as part of a detailed study, perhaps prompted by ISC results, that showed poor water quality.

A third simplifying decision was to use a straightforward regionalisation scheme for the water quality variables. Streams were classified into three regions (upland, valley and lowland) based on the different expectations about water quality in these areas 1 . This was a similar scheme to that proposed by the Office of the Commissioner for the Environment (1988). As with many of the indicators, the decision was made to adopt this scheme because it was the best available. Its simplicity was acknowledged and

\footnotetext{
1 This classification scheme has been further simplified to two categories, upland and lowland following additional work on Australian water quality guidelines (B. Hart pers. comm.; see Section 7.3).
} 


\section{Developing an Index of Stream Condition}

subsequently funding has been sought for a study on more comprehensive regionalisation scheme for Victorian streams (B. Hart pers. comm.). There was also some limited checking of the scheme where the SRG had specific concerns; for example, that streams with naturally high conductivities occurring in limestone catchments, such as those near Buchan in eastern Victoria, would be inappropriately downgraded. Analysis of available water quality data showed this was not likely to be a problem. High natural salinity levels in streams draining the western basalt plains were also investigated but it was decided to retain the proposed regionalisation scheme pending a thorough review.

\subsection{Reflections on the process of developing the ISC}

\subsubsection{Introduction}

The discussion so far has been about development of the ISC up to the stage where it could be trialed. This section describes some aspects of the development process and decisions in more detail, particularly those areas that were difficult problems to resolve or that are likely to be common in the development of any suite of environmental indicators.

\subsubsection{Choosing an indicator framework}

An early decision in the development of the ISC was to select an indicator framework. As discussed above, the 'Pressure, State, Response' model (DEST, 1994) was considered, but was not sufficiently straightforward to apply. The distinction between pressure and state depends on the boundary that is used to define the system whose state is to be determined. Pressures are external to the system, so that as the definition of a system becomes more encompassing, the definition of what is pressure and what is state will change. Genuine pressures should also be reflected in measurements of state. For example, a sewage treatment plant discharging to a stream could be considered a pressure on a stream system, whereas water quality could be considered part of the state of the stream system. It seems reasonable not to include both indicators; if the sewage treatment plant does not affect water quality then it probably should not be considered a pressure. If it does affect water quality, then its influence on the stream system will be captured in the water quality indicators. There may be an argument for including 
pressure indicators if the corresponding state indicators could not be developed (as has been done for parts of the Hydrology Sub-index).

There is a similar argument with response indicators. Genuine responses should be reflected in changes to state indicators, so it would seem reasonable to include either state or response, but not both. Including only state indicators means that it is not necessary to make assumptions about the effectiveness of responses, as the effectiveness will show up in changes to state. Again, if there is difficulty in selecting appropriate state indicators, then it may be appropriate to include indicators of response.

For the ISC it was decided to focus on indicators of the environmental condition or state of streams but to use a broad definition of a stream that includes the bed, banks, physical habitat, water quantity, water quality, streamside vegetation and aquatic life. Significant pressures and important responses will be captured in changes to these indicators, so separate pressure and response indicators have not been developed.

\subsubsection{Developing indicators first}

In a project such as the ISC, there are a number of tasks and a variety of ways that they can be tackled. Once the basic framework was decided, i.e. indicators would be sought to characterise stream condition, the next step was selecting the indicators and developing the entire ISC before testing. This means that some of the indicators were likely to be found to be inappropriate once field trials had been undertaken. For some indicators, measurement techniques would have to be developed and spatial and temporal sampling strategies decided. The sensitivity of indicators would also have to be examined to ensure they could detect changes of interest.

The strategy was to try to get as close as possible to a workable product using a workshop-consensus approach before field testing. It was hoped that the expertise available in the SRG would mean that a reasonably complete ISC could be rapidly developed.

It was also recognised that significant resources would be required to overcome issues associated with sampling, field collection techniques, data storage and processing.

\section{Level of scientific rigour}

Although there was extensive scientific input to the ISC, it was not intended as a scientific instrument and is unlikely to satisfy the needs of scientists. Although based 


\section{Developing an Index of Stream Condition}

on science, it is intended as a management tool and where pragmatic decisions were required, they were guided by this primary objective of the ISC. Where the ISC does identify a problem i.e. where there are particularly low scores, then it may be appropriate to undertake a more rigorous scientific study.

There was also concern that it was possible to be 'too rigorous'. Scientifically rigorous indicators tend not be used in management because they are expensive and require levels of skill that are not available to waterway authorities.

\subsubsection{The workshop-consensus approach to indicator selection}

With the agreement that the ISC would focus on stream state or condition, rather than pressure or response, the next difficulty related to the selection of indicators. Indicator selection was undertaken in a series of workshops with experts in a range of aspects of streams.

Consulting with a group of specialists in a workshop setting was critical to the development of the ISC. The ISC required many pragmatic decisions to be made guided by the goal to produce a tool suitable for managers. Deciding which particular indicators to include is partly based on objective criteria, but also depends on expert opinion about those indicators that must be included in the minimum set and those that can be omitted.

During the workshops there was a sense in which the various specialists kept each other honest. It was difficult for one disciplinary specialist to argue for a complicated indicator, with other experts reminding them of the compromises that had already been made in other areas and of decisions and discussion that had taken place. A key basis of the decision-making was that the indicators should be useable to waterway managers.

The workshop setting also provided pressure for the specialists to suggest indicators and move the process forward, even if they were concerned about a lack of sophistication or support from current research. If an indicator could not be suggested, then that particular aspect of a stream would not be included in the condition assessment. This meant that some of the indicators represent simplifications but the whole SRG supported their inclusion as they were considered the 'best possible' in the circumstances. It was also the necessity of an outcome that forced pragmatism, often lacking in science. 
The range of experts provided credibility, both real and perceived, to the project that would have been impossible for a single researcher to achieve, even if they consulted widely. Developing a stream assessment tool required knowledge of a broad range of disciplines and consequently an extensive literature. Consulting with specialists provided easier access to that literature.

Few 'cutting edge' techniques or knowledge were included in the ISC but it was important to consult with people who knew of the best possible methods, as that helped to justify the choice of less sophisticated approaches that were more suited to the particular objectives of this project. Having the ISC endorsed by specialists in a range of disciplines is also important for promoting it to other scientists, managers and the community and for deflecting criticism, especially that related to perceived lack of erudition.

\section{Alternatives to the workshop - consensus approach}

There are alternatives to the workshop - consensus approach used in development of the ISC. For example, Dinius (1987) and Smith (1990) used the Delphi method (Linstone and Turoff, 1975) in their development of water quality indices, where individual scientists were asked to nominate proposed indicators and ratings schemes. Results were collated and returned to the scientists who were asked to consider refining their suggestions based on ideas from others. The process was continued until a consensus was reached.

For the ISC, it may also have been possible to survey experts and ask them to nominate or vote on indicators. Results could have been collated and used to select the preferred set of indicators to be included in the ISC. With these methods, it is unlikely that the same level of pragmatic compromise would have been reached as was achieved during the workshops. A key requirement in achieving the ISC was an ongoing series of workshops with the same experts involved throughout the whole process, including them participating in those areas not directly related to their expertise.

\section{Composition of the SRG}

The SRG included people other than scientists. Two representatives were from the Department of Natural Resources and Environment (Table 5.1) who contributed expertise in river management and guided the project to meet the State Government's needs and were a key part of the success of this applied research project. 


\section{Developing an Index of Stream Condition}

Representatives of the river management industry were able to ensure the outcome would be appropriate for the intended audience and make sure there was ownership of the ISC by users.

The development process was conceptually similar to that recommended for Adaptive Environmental Assessment and Management (Holling, 1978) with discussion and evaluation in a workshop setting and 'straw man' proposals being suggested to move the process forward.

\subsubsection{Input from outside experts}

As noted earlier, input was obtained from a range of experts external to the SRG (Table 5.2). Originally it was intended to seek input from these experts, develop the ISC and then hold a workshop with both members of the SRG and the external experts to present proposals to that stage and seek further input. This idea was developed to the extent of preparing a list of people to invite and planning the workshop. I became concerned about this approach. Inviting external experts would open a lot of questions for debate that the SRG had already discussed and decided. External experts invited to a workshop would feel obliged to offer criticisms that would expand the range of issues to be considered, rather than move the ISC closer to a workable tool to be used by waterway management authorities. The problem of lack of ownership that may have arisen from this exclusion was not relevant, since the external experts were not users and their ability to undermine the use of the ISC was limited because of the strong support of the ISC from DNRE and the Catchment Management Authorities.

The preferred way of obtaining input was to develop the ISC to a state where it was a complete draft and then present it to users, as well as obtaining peer review through presentations at conferences, workshops and preparation of journal articles and a book chapter (Ladson et al., 1995; Ladson et al., 1996; Ladson and Doolan, 1997; Ladson et al., 1997b; Ladson et al., 1999a; Ladson and White, 2000). This included involvement in organising a conference on monitoring river health where the ISC was presented and discussed along with a range of other river assessment techniques (River Basin Management Society, 1997). There were also presentations to Catchment Management Authorities, the New South Wales Department of Land and Water Conservation and representatives from the New South Wales EPA. Copies of conference papers and journal articles are included in Appendices D and H, I and J. Through these 
presentations and peer review, input was received from a broad range of scientists and managers, which contributed to refinement of the ISC.

\subsubsection{Valuing indicators}

In developing the ISC, decisions were required about the most appropriate way to quantify condition. Producing scores for stream condition implies the concept of a scale - from streams that score highly to those with low scores - and perhaps maximum and/or minimum attainable values.

The existing approaches reviewed in Chapter 4, had to address similar issues. In the EHI (Cooper et al., 1994) there are three indicators: biological health, water quality and aesthetic health, which were rated on a scale of 0 to 10 . Streams that score more highly are in better condition than those that score near zero. A stream in the best possible condition would rate ten for all indicators. In the classification of environmental condition developed by Mitchell (1990) there is a five point rating from 'excellent' those streams in best condition to 'poor' - those streams in worst condition.

Using words like 'excellent', 'poor', 'best' and 'worst' suggest there are value judgements associated with condition assessment. They are not neutral statements about location of stream condition along a scale but rather suggest that a certain condition is more desirable, at least in the view of the person who developed the methodology. For example, Mitchell (1990) defines environmental condition as 'condition of the river as habitat for fish and aquatic invertebrates and, to a lesser extent, the condition of the riparian zone as habitat for native organisms' (Mitchell, 1990, 1).

Stream condition assessment will usually involve a value judgement and could, therefore, be open to challenge. Different condition assessment procedures will involve different value judgements and probably produce different results. Given that value judgements are necessary, the procedure for incorporating these judgements should be as transparent as possible.

It is possible to deconstruct the stream assessment systems described in Chapter 4 and determine the value judgement behind each scheme. For example, in the US EPA 305b procedure (Section 4.2.4), the value judgement is made first, in the selection of designated uses. The assessment measures the condition of streams relative to these uses. The procedure relates back to the utilitarian goals of the Clean Water Act i.e. that rivers should be swimmable and fishable. Other examples are shown in Table 5.14. 


\section{Developing an Index of Stream Condition}

Often the data that underlie the assessment are reasonably objective, for example the concentration of pollutants or number and type of macroinvertebrate taxa, but they are converted to a score based on a value judgement or comparison with an ideal, or with reference conditions. For example, the rating system developed by Mitchell (1990) was applied to data collected for a statewide survey of the physical stream conditions, which was an objective assessment of physical parameters such as flow velocity or substrate size. Mitchell developed a procedure to turn this predominantly objective data, into his five point system of rating environmental condition. This rating system provided a filter to summarise a large amount of stream data into information that was considered useful for managers. Value judgements are inherent in this process.

Table 5.14 - Underlying values of the some stream assessment systems

\begin{tabular}{|l|c|l|}
\hline \multicolumn{1}{|c|}{ Stream assessment system } & $\begin{array}{c}\text { See } \\
\text { section }\end{array}$ & \multicolumn{1}{c|}{ Assessment is relative to: } \\
\hline $\begin{array}{l}\text { Environmental Condition of } \\
\text { Victorian Streams (Mitchell, }\end{array}$ & 4.2 .1 & $\begin{array}{l}\text { Environmental condition - defined as } \\
\text { 'condition of the river as habitat for fish } \\
\text { and aquatic invertebrates and, to a lesser } \\
\text { extent, the condition of the riparian zone } \\
\text { as habitat for native organisms.' } \\
\text { (Mitchell, 1990, 1). }\end{array}$ \\
\hline $\begin{array}{l}\text { Index of Aquatic Environmental } \\
\text { Quality - water quality indicator } \\
\text { (Office of the Commissioner for } \\
\text { the Environment, 1988) }\end{array}$ & 4.2 .2 & $\begin{array}{l}\text { Water quality values defined by } \\
\text { specialists. }\end{array}$ \\
\hline US EPA305b & 4.2 .4 & Designated uses. \\
\hline $\begin{array}{l}\text { Estuarine Health Index (EHI) - } \\
\text { water quality indicator (Cooper et } \\
\text { al., 1994) }\end{array}$ & 4.2 .5 & $\begin{array}{l}\text { Water quality values defined by } \\
\text { specialists. }\end{array}$ \\
\hline EHI - biological indicator & 4.2 .5 & Biota that predates human interference. \\
\hline EHI - aesthetic health indicator & 4.2 .5 & Conditions prior to human settlement. \\
\hline $\begin{array}{l}\text { Riparian Channel and } \\
\text { Environmental Inventory RCE } \\
\text { (Petersen, 1992) }\end{array}$ & 4.2 .6 & $\begin{array}{l}\text { Ideal conditions as defined in rating } \\
\text { tables developed by Petersen (1992). }\end{array}$ \\
\hline $\begin{array}{l}\text { AusRivAS (Parsons and Norris, } \\
\text { 1996; Marchant et al., 1997; } \\
\text { Norris et al., 1998; Marchant et } \\
\text { al., 1999; Smith et al., 1999; } \\
\text { Turak et al., 1999) }\end{array}$ & 7.4 & $\begin{array}{l}\text { Reference condition as defined by } \\
\text { selected sites that have limited } \\
\text { disturbance by humans. }\end{array}$ \\
\hline
\end{tabular}

The importance of incorporating human values explicitly into environmental evaluations was also made by Woodley et al. (1993). They argued that ecologically 
sustainable management involves quantifiable measures of condition, as well as societal judgements of what is being sought. If societal values were not included, then the evaluation would reflect only the values and concerns of the evaluator and would be likely to be of little use to policy and decision-makers (Kay, 1993).

As the ISC is intended as a management tool, it will necessarily involve summarising objective data and producing ratings that incorporate value judgements so that the output provides specific guidance about desirable and undesirable condition. Incorporating value judgements into the rating system is not something to be avoided; rather it is a necessary part of the process.

\section{What type of value judgement is appropriate for the Index of Stream Condition?}

Since the ISC will necessarily involve value judgements about desirable condition, what is the appropriate judgement to make? Five approaches to quantifying stream condition were considered.

1. Comparison of current stream condition with a state that would be ideally suited to particular species; for example, Newbury (1995) discusses the characteristics of the ideal trout stream.

2. Comparison against specified goals for the river or designated uses. This is the approach used by the NWQI (Section 4.2.4) and the Victorian Environment Protection Authority (Victorian Government Gazette, 1988).

3. Comparison with control or reference sites.

4. Comparison with natural or pristine conditions. In Australia, comparison with pristine conditions usually refers to comparing streams with their assumed condition before European settlement.

5. Comparison with ideal condition as defined by expert judgement.

Each of these approaches are examined below. Ultimately, an approach that lies somewhere between four and five was adopted for the ISC.

\section{Comparison with conditions suitable for particular species}

A possible approach to developing the ISC would be to determine condition ratings based on a stream's suitability for particular species, for example trout or blackfish. 


\section{Developing an Index of Stream Condition}

Streams that were most suited to these species would have the highest score. There are a number of concerns with this approach and it was not adopted for the ISC.

Stream management approaches based on favouring chosen species have been criticised because, while they may benefit those species, the overall result for the river ecosystem may be undesirable and other species may be disadvantaged (National Research Council, 1992; Brookes et al., 1996; Poff et al., 1997).

These approaches have arisen where there is a particular species that is commercially desirable or has become symbolic of river health. Projects based on this notion include the Salmon 2000 project to restore Salmonids to the Rhine River by the year 2000 (International Commission for the Protection of the Rhine, 1999) and trout habitat enhancement in Canada (Newbury and Gaboury, 1993). This approach would be difficult to apply in Victoria where there are no similar species of commercial, environmental or symbolic importance.

There are concerns about the management implications of this type of rating scheme. If a site is rated as poor, what can be done to improve it? Should a stream be modified in such a way to make it more suitable for the chosen species, even if that moves it further away from natural conditions? Using this scheme there would be an incentive for managers to modify streams so they all ended up with the same characteristics, those suitable for the chosen species. For the ISC, which is intended as a management tool, this did not seem to be a reasonable outcome.

Another problem with this approach is that the value judgement is not made explicit. In Mitchell's (1990) rating scheme, streams are classified as excellent to poor, which implies a general statement about their suitability for a range of uses. In reality, they are being classified in terms of a reasonably narrow definition of environmental condition. Mitchell acknowledges this but his ratings have become widely used and the value judgement behind these ratings can be forgotten.

\section{Comparison against goals or designated uses}

An alternative approach is comparing the stream against specified management goals or designated uses. An advantage to this approach is that the value judgement inherent in the rating is made explicit in the selection of the goals or designated uses that precedes the development of a scheme for assessing condition. The difficulty in applying this 
approach in development of the ISC is that often there is no clear agreement about appropriate goals or designated uses for Victorian streams.

Water quality is an area where there has been most work on designated uses. The State Environment Protection Policy (Victorian Government Gazette, 1988) describes desirable concentrations of nutrients and pollutants for all streams and there are specific recommendations for particular streams e.g. Latrobe River and tributaries (EPA, 1996). Work has also been undertaken on particular water constituents e.g. nutrients (Tiller and Newall, 1995) and there are general guidelines for the whole of Australia (Australian and New Zealand Environment and Conservation Council, 1992), which are being updated and refined (Hart et al., 1993).

One reason why water quality assessment is advanced, is that physico-chemical constituents of water are aspects of stream condition that are straightforward to measure, standard techniques have been developed (Eaton et al., 1995) and effect on biota of various water quality variables has been documented (Dallas and Day, 1993).

For aspects of condition other than water quality there has been less work on appropriate goals and there has been limited discussion of the overall desirable state of rivers and streams. Goal setting has been identified as a barrier to successful stream management in Australia with the way forward being to develop participatory and repeatable approaches to assessing the need for, and setting the goals of, stream rehabilitation (Rutherfurd et al., 1998; Ladson et al., 1999b; see Appendix K).

Perhaps the best approach to developing the ISC would have been to undertake the process of setting goals for Victorian rivers and then choosing indicators to measure performance against these goals. This was not considered practical because of the time required and the lack of a clear process for achieving consensus about goals for rivers management.

\section{Comparison with control sites}

Stream condition can be compared with control sites that are chosen to represent a desirable state. Conditions at the control site are measured and used as a basis of comparison with the site of interest.

Measurements are usually made at sites that have minimal disturbance from humans and then the difference between these sites, and the stream being assessed, is the basis of the condition score. A more rigorous approach is to establish reference conditions based on 


\section{Developing an Index of Stream Condition}

groups of minimally disturbed sites (Reynoldson et al., 1997). This approach is used in AusRivAS (Parsons and Norris, 1996) where reference sites were used to develop a model to predict macroinvertebrate taxa expected to be present at a particular site (see Section 7.4). A condition score can then be calculated based on the ratio of observed to expected taxa.

The problem with a more general application of this approach to assessing overall condition is that, in many cases, undisturbed sites are difficult to find. There is only one river in Victoria where the lowland reaches have not been cleared for agriculture, the Thurra River in East Gippsland, and this would not provide an appropriate template for all the other rivers in the State. Most of the streams where management works will be undertaken are in lowland areas, where undisturbed sites are virtually nonexistent.

Even if control sites were available, it would be time consuming to identify them, measure those aspects of condition that are important, and then assess the rest of the stream against this template. The constraints on the ISC are that a more streamlined approach was required although the extensive work done on macroinvertebrates by Norris and others was incorporated into the Aquatic Life Sub-index of the ISC (Parsons and Norris, 1996; Marchant et al., 1997; Norris et al., 1998, see Section 7.4).

\section{Comparison with natural conditions}

It is also possible to assess streams by comparing their current condition with what they would have been like under natural or undisturbed conditions i.e. uninfluenced by human activity. Restoring a stream to natural condition is commonly cited as a goal of stream restoration (National Research Council, 1992) but how practical or defensible is naturalness as a goal of stream management?

There is a modern and naïve notion of natural systems undisturbed by 'technological' humans, as being self-regulating and in balance (Budiansky, 1995a). This is consistent with seeing modern humans as separate from nature and their interference as disturbing nature and moving natural systems away from their equilibrium state. This view is referred to as the 'equilibrium paradigm' and can be summarised as the idea of the 'balance of nature' (Pickett and McDonnell, 1993). Pickett and McDonnell (1993) trace the cultural roots of this view to the writing of George Perkins Marsh in his book Man and Nature published in 1864 (Marsh, 1864). Powell (1976) comments that, with the exception of the Bible and the Charles Darwin's On the Origin of Species by Means of 
Natural Selection, no other book has had such influence on ideas about human interaction with nature. Similar ideas are also presented in the writings of other late $19^{\text {th }}$ Century writers (Budiansky 1995b).

Accepting the equilibrium paradigm leads to the idea that 'nature knows best' (Commoner, 1972, 41), and that human attempts to manage nature are not appropriate, except perhaps to return a system disturbed by humans to a more natural state (Lewis, 1992).

There are four arguments against using this concept of 'naturalness' to guide river management. Firstly, it is questionable whether there really is a 'balance of nature'. The idea has been questioned in ecology (Budiansky, 1995a) and does not seem generally appropriate for rivers. Even without artificial interference, rivers are subject to a wide range of disturbances (Costa et al., 1995). Natural streams suffer catastrophic bank erosion, avulsions, channel enlargement, loss of riparian vegetation and changes in water quality and quantity; for example, see Brown (1972) and Chessman (1986) for a discussion of the effect of fire on streams. There is also the extreme disturbance that occurs when river channels are filled by lava flows or drowned by sea level rise, or where flows are reduced by long term changes in climate (Richards, 1985; De Deckker, 1986).

Walters and Holling (1990) note that 'Even unmanaged ecosystems are characterised by combinations of stability and instability and by unexpected shifts in behaviour from both internal and external causes'. This is similar to the dynamic, metastable equilibrium proposed by Schumm (1977) where rivers are subject to random fluctuations and threshold changes, although an underlying steady state may be able to be defined in some cases. Richards (1985) acknowledges the influence that human activities can have on river systems but also notes that they may be affected by individual random extreme events that may cause catastrophic changes of cross-section, plan and gradient over periods of days or hours. Brierley (1998) comments that Australian rivers tend not to demonstrate short-term changes around a mean or equilibrium condition but instead show intervals of dramatic change between periods of stability. Similar patterns were noted by Brizga et al. (1993) who related river erosion to flood dominated periods, with relative stability occurring during drought dominated periods. This is referred to as a disequilibrium or non-equilibrium condition (Brierley, 1998; Brierley et al., 1999). 


\section{Developing an Index of Stream Condition}

These comments suggest that 'natural' streams are subject to a wide range of disturbances and they will not necessarily be in a condition that would be an appropriate goal for management. An attraction of using naturalness is as a basis for comparison is the premise that natural streams are stable streams; in reality this is unlikely to be true. Indeed, an appropriate goal for management, in many instances, may be preventing the occurrence of, or reducing the impact of entirely natural events.

The second argument against using naturalness to guide river management is that human interests may not be compatible with notion that 'nature knows best'. Dryzek (1987) points out that natural systems must be modified to allow production for human use and argues that non-intervention in natural systems is untenable. In the case of rivers, insisting on non-intervention would exclude hydroelectric facilities, irrigation schemes, dams, diversions, fishing, urbanisation and catchment clearing. In fact, in Victoria most river systems have been modified since European settlement, so maximising naturalness may not be an appropriate goal. In places, increasing the naturalness of some aspect of a river may be out of place given the current state of development. Lewis (1992) and Budiansky (1995b) argue that the notion that nature knows best is not appropriate in a world already remade to anthropogenic contours.

The Goulburn River downstream of Eildon Dam in Victoria, provides an example where maximising naturalness may not be appropriate. Operation of the dam has resulted in reduced temperatures and decreased flood frequency which has 'alienated the section of the river between Eildon and Seymour $(138 \mathrm{~km})$ from habitation by native fish species' (Gippel and Finlayson, 1993). Gippel and Finlayson (1993) argued that it may more pragmatic to manage this section for recreational fishing of introduced species rather than to supply the environmental flows and reservoir destratification that would be necessary to provide for native fish. In compensation, the natural habitat value of the rest of the river could be protected or rehabilitated where necessary. This recommendation contrasts with the actions of the Victorian Government which has recently moved to increase environmental flows in this reach despite the water being too cold to allow spawning of native fish (DCNR, 1995; Gippel, 2000; Section 3.4).

To manage rivers, it would seem more appropriate to deal with systems as they are and aim to move them to a more desirable state, rather than arbitrarily moving parts of the system to a more natural condition. 
The third difficulty with the notion of naturalness as a goal for river management is that humans have influenced streams for a long period. This is obvious in Europe and China where technological civilisations have existed for thousands of years and river regulation has occurred for at least 4000 years (Dudgeon, 1995). In Australia, preEuropean conditions are sometimes described as natural, suggesting that they were not influenced by humans but this seems unlikely given that aboriginal burning and hunting have been linked to extensive climate and vegetation change over the last 40000 to 60000 years (Flannery, 1995, 217-236). It seems likely that if vegetation communities were changed by the earliest humans, then stream conditions would also have been changed (Zimmerman et al., 1967; Smith, 1991; Wilson et al., 1996). Pre-industrial societies in North America are also reported to have significantly modified the structure and function of ecosystems (Wagner and Kay, 1993). What then are natural conditions, pre-European (what streams were like 200 years ago) or streams as they were before human settlement of Australia, 40000 to 60000 years ago?

Fourthly, even if natural conditions could be considered to have existed 200 years ago, establishing those conditions is not straightforward, as there has been limited data collection until recently. Water quantity has been measured for about a century but there are few water quality measurements before the 1970s, and only limited surveys of biota until the last decade.

Clearly, there are conceptual difficulties with using 'naturalness' as the basis of comparison for the ISC but can naturalness be completely ignored? An alternative to basing river management goals on maximising naturalness is to move away from the idea that 'nature knows best' toward human management of river systems. Certainly, humans are capable of large-scale modification of many aspects of rivers. At the extreme, it would be possible to ignore the idea of naturalness and create a totally artificial river environment directed by human minds (Dryzek, 1987, 43).

In places, river management has already gone some way down this path. Flow rates are determined by the needs of irrigators (Davies et al., 1992), large woody debris have been removed from the river channel to decrease flow resistance (Gippel, 1995), stream temperature is determined by water released from the bottom of large storages (Gippel and Finlayson, 1993), and riparian areas have been cleared for agriculture. There are also interventions, including modifying flow conditions, breeding programs and fish stocking, to increase numbers of particular species e.g. Salmonids (Lee, 1993). 


\section{Developing an Index of Stream Condition}

A major difficulty with extreme intervention in river systems or creating artificial rivers is that understanding of stream ecology is limited. Intervention often results in impoverishment of the river ecosystem, or outcomes that were not predicted. Sometimes this is a side-effect of changes that have been made to increase utility of rivers; for example, one unintended consequence of constructing dams and other barriers to flow is a decline in native fish stocks (Mallen-Cooper, 1993). But even when ecological manipulation is intended, such as increasing salmon numbers, the results can be unexpected and undesirable (National Research Council, 1992). Setting goals that do not include some notion of 'naturalness' is likely to result in unsatisfactory outcomes.

While it is untenable to leave all rivers to flow as nature intended, it is also appropriate to make use of the spontaneous self-organising and self-regulating qualities of natural river systems (Dryzek, 1987). To this extent, a goal of increasing naturalness may be appropriate. Not as the naïve longing to recreate envisaged ideal rivers of the past, but as a practical tool to guide the maintenance of river ecosystems, given limited understanding of stream ecology and limited ability to agree on, set and move toward other goals.

The objections to naturalness listed above need to be addressed when developing a system to compare current and natural condition. A way forward is not to try to rigorously define natural condition but rather to ask experts to describe an ideal state based on best professional judgement. The pragmatic application of the concept of an ideal stream, in many cases based on natural conditions, has been used throughout the development of the ISC. The process of consulting with a range of experts and extensive peer review means some consensus in ideal conditions is implicitly reached. In the context of the ISC, these judgements manifest themselves via the selection of indicators and rating tables.

\subsubsection{Requirement for other indicators and suites of indicators}

With the selection of draft set of 'best available' indicators, it became clear there would be difficultly meeting some of the original objectives for, or at least expectations of, the ISC. Particular concerns were: the amount of time required before indicators would respond to management intervention; the need for other indicators besides the ISC to 
measure short-term project performance; and that some indicators measured conditions that are difficult for managers to influence.

During the early stages of this project it was hoped that the ISC would be useful as an annual measure of waterway condition; that is, it would be sensitive to managementinduced change over one year. This desire was partly driven by an expected statutory requirement that waterway management authorities would have to report annually. With the selection of indicators and the development of a draft ISC, it seemed unlikely that it would be a useful indicator over one year (see Table 5.15).

A large part of the problem was the spatial scale of the measurement task. The ISC was proposed to measure condition over the whole State with smallest unit of assessment being stream reaches tens of kilometres in length. Achieving measurable improvement in reaches of this length would be expected to take time, generally longer than 12 months. Plausible scenarios could be developed of rapid declines in condition but recovery was likely to be a long-term process (the sensitivity of the ISC is explored in Chapters 6 and 7).

Following discussion, the SRG agreed that the ISC should be reported every 5 years, rather than every year. This change required refinement of the project objectives as shown in Table 5.16. This change more clearly defined the role of the ISC as complementing other indicators of annual performance that were more closely related to the specific objectives of particular projects.

Table 5.15 - Ability of ISC to act as a performance indicator over annual time periods

\begin{tabular}{|l|l|}
\hline Sub-index & $\begin{array}{l}\text { Problem with sub-index as a performance indicator over } \\
\text { annual periods. }\end{array}$ \\
\hline Hydrology & $\begin{array}{l}\text { Small management interventions will not show up at the } \\
\text { scale of measurement proposed in the ISC. }\end{array}$ \\
\hline Physical Form & $\begin{array}{l}\text { Improvement in physical form will occur over long time } \\
\text { scales and will be site dependent. }\end{array}$ \\
\hline Riparian Zone & $\begin{array}{l}\text { Improvement in riparian vegetation will occur over long } \\
\text { time scales and will be site dependent. }\end{array}$ \\
\hline Water Quality & $\begin{array}{l}\text { High variability will mask any short-term improvement that } \\
\text { could be attributed to management. Identification of trends } \\
\text { requires long periods. }\end{array}$ \\
\hline Aquatic Life & $\begin{array}{l}\text { Recovery in macroinvertebrate populations is likely to take } \\
\text { longer than 12 months. }\end{array}$ \\
\hline
\end{tabular}




\section{Developing an Index of Stream Condition}

Effective planning and reporting of waterway management requires a suite of performance indicators that measure variables across a range of time scales. Indicators in the ISC measure outcomes of a range of management activities and many are outside the traditional role of waterway managers. This was considered appropriate because improving the condition of waterways requires cooperation between management agencies. Environmental managers can influence and advocate changes, even if they are not directly responsible for implementing them.

Table 5.16 - How well will project objectives be met?

\begin{tabular}{|l|l|}
\hline $\begin{array}{l}\text { Original project objective or } \\
\text { expectation }\end{array}$ & Comment \\
\hline $\begin{array}{l}\text { - To judge the effectiveness of } \\
\text { management intervention in restoring } \\
\text { and maintaining stream condition }\end{array}$ & $\begin{array}{l}\text { ISC provides information on management } \\
\text { effectiveness over long periods i.e. 5 years } \\
\text { or longer. }\end{array}$ \\
\hline $\begin{array}{l}\text { - To provide a performance indicator } \\
\text { for waterway management authorities }\end{array}$ & $\begin{array}{l}\text { ISC is probably not a useful performance } \\
\text { indicator because response time is too } \\
\text { long. Waterway management authorities } \\
\text { will require other performance indicators } \\
\text { probably related to policy adoption and } \\
\text { management action, rather than } \\
\text { environmental change. }\end{array}$ \\
\hline
\end{tabular}

Other indicators (apart from the Index of Stream Condition) include those that measure output by a waterway management authority e.g. length of stream verge fenced and planted. Output performance indicators will provide useful information for annual reporting in line with the planning and reporting framework that was developed by the author and others prior to development of the ISC (Ian Drummond and Associates Pty Ltd, 1995). The Index of Stream Condition could be incorporated into this framework. Distinctions between the ISC and annual performance measures are listed in Table 5.17.

The ISC also captures only part of managers' interests in streams. It measures environmental condition, whereas stream managers may have a wide range of objectives, some environmental, others utilitarian, such as delivering water for irrigation. To assess completely the effectiveness of waterway management, other indicators apart from the ISC will be required. DNRE representatives on the SRG acknowledged that ISC values would not drive policy or funding, without other factors being considered. 
Table 5.17 - Differences between annual performance measures and the Index of Stream Condition

\begin{tabular}{|l|l|l|}
\hline \multicolumn{1}{|c|}{ Index of Stream Condition } & \multicolumn{1}{|c|}{ Annual measures of performance } & \multicolumn{1}{c|}{ Comment } \\
\hline $\begin{array}{l}\text { Measures departure of stream } \\
\text { condition from some defined } \\
\text { ideal state. }\end{array}$ & $\begin{array}{l}\text { Should provide a measure that is closely } \\
\text { linked to targets of managers. No point } \\
\text { measuring something managers are not trying } \\
\text { to change (unless it is something they are } \\
\text { trying not to change). }\end{array}$ & $\begin{array}{l}\text { Condition is only one aspect that managers consider } \\
\text { when setting objectives. } \\
\text { Management effectiveness should be judged against } \\
\text { management intention. }\end{array}$ \\
\hline $\begin{array}{l}\text { An absolute measure is } \\
\text { important. The objective of the } \\
\text { measurements is to define } \\
\text { accurately the current condition } \\
\text { of the stream. }\end{array}$ & $\begin{array}{l}\text { Absolute values of an indicator are not as } \\
\text { important as relative values. Measurement of } \\
\text { change is the objective. It is better to know } \\
\text { the magnitude and direction of change than to } \\
\text { find out accurately current stream condition. }\end{array}$ & $\begin{array}{l}\text { Measures of change need to be more sensitive than } \\
\text { measures of condition. This applies at a spatial and } \\
\text { temporal scale. }\end{array}$ \\
\hline $\begin{array}{l}\text { Measurements are required over } \\
\text { large space scales to assess } \\
\text { statewide condition. }\end{array}$ & $\begin{array}{l}\text { For annual performance indicators, } \\
\text { measurements should be at approximately the } \\
\text { same space scales as the management targets } \\
\text { or actions. }\end{array}$ & $\begin{array}{l}\text { The space scale of performance indicators needs to } \\
\text { match the space scale of the management targets. For } \\
\text { more 'strategic' or 'outcome' performance indicators, } \\
\text { larger scale measurements are appropriate. These } \\
\text { performance indicators are reported over longer time } \\
\text { scales. }\end{array}$ \\
\hline $\begin{array}{l}\text { Statewide assessment requires } \\
\text { large space scales. This means } \\
\text { larger time scales (> 1 year) are } \\
\text { generally required before } \\
\text { management-induced changes } \\
\text { are seen. }\end{array}$ & $\begin{array}{l}\text { Annual performance indicators should be } \\
\text { focused on targets that are meant to be } \\
\text { achieved annually. }\end{array}$ & $\begin{array}{l}\text { The time scale of performance indicators needs to match } \\
\text { the time scale of the management targets. Longer term } \\
\text { measurements are appropriate for longer term targets. }\end{array}$ \\
\hline
\end{tabular}




\section{Developing an Index of Stream Condition}

There is a danger that because the ISC is sanctioned by Government, it may tend to dominate goal setting by river management authorities. There is a danger that 'what gets measured gets done' (James, 1998) and the ISC only measures part of what should be done. Acknowledging that other indicators are required is an important part of encouraging river management authorities to incorporate the ISC into their planning and reporting but to consider broader goals as well.

Following these changes the question of whether the ISC would be an effective indicator of management-induced change over 5 years remained and is explored in Chapters 6 and 7.

\subsection{Trials, refinement and further development}

This chapter has described the ISC to a stage just before field testing (with a brief discussion of some of the subsequent refinements to hydrology). The next step was to undertake field trials in cooperation with the then Broken River Management Board and the Lake Wellington Rivers Authority. Trials are summarised in Ladson et al. (1997b) and Ladson et al. (1999a) with full details in ID\&A Pty Ltd and CEAH (1997a) where there is a listing of 60 issues that arose during the trialing process and discussion of how they were addressed (see Appendix D and L). These are similar to the issues for the hydrology indicator that were discussed in Section 5.2.9.

The objectives of the trials were to undertake a practical application of the ISC with the assistance of staff from the river management authorities who would the ultimately be using the final version once it was developed. Results were used to refine the ISC to ensure it was appropriate for user groups and develop standard field procedures. The Specialist Reference Group was involved in field checking the assessments, to ensure that results were as expected and to identify any problems that would require addressing through revision of the ISC.

The types of changes that resulted from these field trials included: changes to wording of indicator descriptions to make them easier to understand; changing the weighting of some indicators; and revisions to rating tables including regionalisation of some rating tables to take account of the variation in expected conditions throughout the State (ID\&A Pty Ltd and CEAH, 1997a). These trials resulted in a range of refinements to 
the ISC as documented in An Index of Stream Condition Reference Manual (CEAH and ID\&A Pty Ltd, 1997) and An Index of Stream Condition: User's Manual (ID\&A Pty Ltd and CEAH, 1997b).

These trials were a critical step in the development process because it was the first time that field data collection requirements had been considered in detail. They were also important in ensuring that the ISC could be practically applied by the intended users. There were also workshops of the SRG during this period, to consider the results and discuss the required changes. At the end of this process, the ISC was released for general use by Catchment Management Authorities, although it was recognised there would be further revisions. Between 1997 and 1999 there was further development of the ISC based on the experience of the CMAs and some of the analysis that is presented here. The latest version of the ISC is published in three reports (Ladson and White, 1999; White and Ladson, 1999; and White and Ladson, 1999b). The next two chapters explore some of the sampling and sensitivity issues associated with the ISC. 


\section{SAMPLING AND SENSITIVITY OF STREAMSIDE ZONE AND PHYSICAL FORM INDICATORS}

\subsection{Introduction}

This chapter examines sampling and sensitivity for indicators of two aspects of stream condition: the streamside zone (quality and quantity of vegetation) and physical form (extent of erosion and amount of physical habitat). The development of these indicators was described in the previous chapter.

Initially, it was proposed that indicator scores would be based on stream condition in a 'representative' sub-reach, that is, a short stream segment subjectively selected to be representative of the whole reach being assessed. The 'representative' sub-reach approach was attractive because it made use of local knowledge, would be less expensive to implement and would provide fewer access problems than other approaches. It was also the approach used during the State of the Streams Survey (Tilleard and DWR, 1986; Mitchell, 1990).

Results presented here show that this approach can be subject to large errors that are difficult to quantify. Instead, a random sampling methodology is developed where errors can be quantified and are related to sampling effort. Likely errors are presented for various sampling strategies. Performance of these sampling schemes is related back to project objectives. Errors associated with inter-operator variability are also examined, along with a preliminary review of the sensitivity of the ISC to managementinduced change.

\subsection{Background}

\subsubsection{Index of Stream Condition}

As discussed in Chapter 5, the ISC provides scores for five components (sub-indices) of stream condition:

- hydrology (based on change in volume and seasonality of flow from natural conditions); 
- physical form (based on bank stability, bed erosion or aggradation, influence of artificial barriers, and abundance and origin of coarse woody debris);

- $\quad$ streamside zone (based on type of plants; spatial extent, width, and intactness, of riparian vegetation; regeneration of overstorey species, and condition of wetlands and billabongs);

- water quality (based on an assessment of phosphorus, turbidity, electrical conductivity, and $\mathrm{pH})$; and

- aquatic life (based on occurrence of families of macroinvertebrates).

This chapter discusses the collection of information for the Physical Form and Streamside Zone Sub-indices. These sub-indices are variable in space and to be useful for monitoring, an appropriate sampling scheme is required so that any temporal signal can be detected amongst the noise of the spatial variation. The other three sub-indices are discussed in the next chapter.

\subsubsection{Collecting data on the streamside zone and physical form - the representative sub-reach}

The ISC was designed to assess the condition of streams throughout the State of Victoria; therefore, data collection procedures must be cost effective and suitable for providing information at this broad scale. ISC scores are provided for stream reaches tens of $\mathrm{km}$ in length that are chosen to be approximately homogeneous in terms of stream condition. That is, they are expected to have reasonably consistent hydrology, water quality, and aquatic life and no step changes in physical form and streamside zone.

It was not considered feasible to collect information on the streamside zone and physical form along the whole stream reach. Instead information is collected by sampling the reach and the results used to infer the overall condition.

Initially, it was proposed to use a representative sub-reach approach to collect the data on the streamside zone and physical form. A sub-reach about $1 \mathrm{~km}$ long was to be chosen, using local knowledge, to be representative of the longer reach (tens of $\mathrm{km}$ long). Measurements of the streamside zone and physical form were then to be collected within this 'representative' sub-reach and the results used to characterise the whole reach. The subjective selection of a 'representative' sub-reach was thought to be a 


\section{Streamside zone and physical form}

quick and effective way of collecting accurate information and has been a common approach in previous efforts at stream assessment (Jeffers, 1998).

The 'representative' sub-reach approach was tested during a trial of the ISC as described in this chapter. It was found to provide inaccurate results. Two trials were conducted where a 'representative' sub-reach was chosen and conditions were assessed within this sub-reach and then in detail along larger reaches of about $30 \mathrm{~km}$.

Although the 'representative' sub-reaches were chosen by people with extensive local knowledge, it will be shown that they were not representative of the longer reach. The main problem was the assessment of the streamside zone. In one case, the 'representative' sub-reach was in the best condition of anywhere in the longer reach; in the other, it was in much worse condition than average. Clearly, it is difficult to expect someone, even with extensive local knowledge, to pick one short segment (perhaps 5\% to $10 \%$ of a longer reach) that represents the average condition of that longer reach. For variable data, even the concept of a 'representative' reach may be flawed. Problems with the representative sub-reach approach highlighted the need to develop an alternative sampling procedure.

\subsection{Developing a measurement procedure based on random sampling}

A new data collection procedure was developed based on measuring the streamside zone and physical form at randomly chosen locations within a reach and then taking the mean of these values as the score for the reach. In the following sections, terminology relating to scale of measurements and stream classification is explained and the indicators and calculation procedures are listed for both the Physical Form and Streamside Zone Sub-indices.

\subsubsection{Scale of measurements}

To characterise a reach, measurements are made at three scales: reach, site and transect. A reach is typically $10-30 \mathrm{~km}$ long, a measuring site is about a $400 \mathrm{~m}$ length of stream within the reach, depending on the number of transects, which are $50 \mathrm{~m}$ wide sections within each site (see Figure 6.1). Different indicators are measured at these various scales as explained below. 


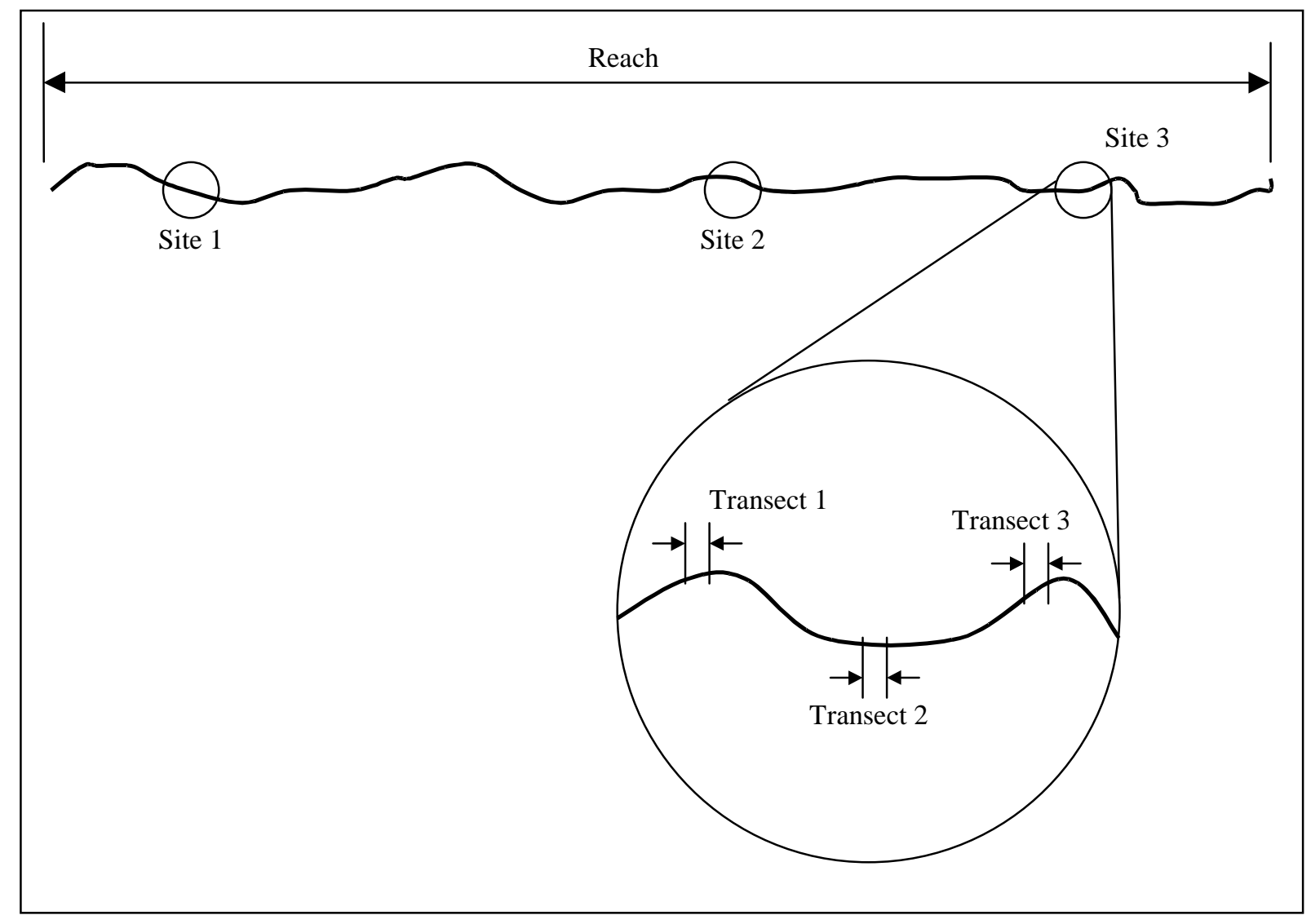

Figure 6.1 - Illustration of the three measurement scales: a reach - a length of stream tens of $\mathrm{km}$ long; a site - a length of stream about $400 \mathrm{~m}$ long; and a transect - a length of stream about $50 \mathrm{~m}$ long

\subsubsection{Stream classification}

The ISC uses a straightforward classification system that takes account of the expected natural longitudinal changes in streams. Reaches are divided into three categories, upland, valley and lowland, based on a scheme developed and mapped by the Office of the Commissioner for the Environment (1988). There are some minor differences in the way streamside zone and physical form are measured for streams within these categories, as described in the following sections.

\subsubsection{Physical Form Sub-index}

The Physical Form Sub-index captures information about the extent of stream bank and bed erosion and the amount of, and access to, physical habitat and includes measurement of four indicators as shown in Table 6.1. Bank stability is measured at transects, bed condition, and density and origin of course woody debris, are measured 


\section{Streamside zone and physical form}

over a site, and one score for artificial barriers is provided for a whole reach (see Table 6.1 and Figure 6.1).

Measurements in upland, valley and lowland reaches vary. All the indicators are included in the measurements for lowland reaches but density and origin of coarse woody debris is not included in measurements for upland or valley reaches, because coarse woody debris is less common in these reaches, since it is more easily mobilised and is a less important habitat component.

The indicators are given a rating between 0 and 4, with 4 implying a condition closer to 'ideal' as defined by the Specialist Reference Group of river scientists and managers as discussed in Chapter 5. Definitions of indicators, rating tables and measurement techniques are provided in CEAH and ID\&A Pty Ltd (1997), Ladson et al. (1999a) and Ladson and White (1999) (see Appendix D).

Table 6.1 - Physical form indicators

\begin{tabular}{|l|l|c|c|}
\hline Scale & Indicator & Symbol & Rating \\
\hline Reach & Artificial barriers & $A B$ & $(0-4)$ \\
\hline Site & Bed condition & $B C$ & $(0-4)$ \\
\hline & $\begin{array}{l}\text { Density and origin of coarse woody debris } \\
\text { (only measured in lowland reaches) }\end{array}$ & $C W D$ & $(0-4)$ \\
\hline Transect & Bank stability & $B S$ & $(0-4)$ \\
\hline
\end{tabular}

\section{Physical Form Sub-index score for a measuring site}

For a lowland reach, the Physical Form Sub-index score is based on the indicators as shown in Table 6.1 and scaled to lie between zero and ten (see equation 6.1).

$$
P F_{s}=\frac{10}{16}\left(\frac{1}{N_{t}} \sum_{t=1}^{N_{t}} B S_{t}+B C_{s}+C W D_{s}+A B_{r}\right)
$$

Where $P F_{s}$ is the Physical Form Sub-index score for a site and the subscripts $r, s$, and $t$, refer to transect, site and reach respectively (symbols are defined in Table 6.1.

For upland and valley reaches, the coarse woody debris indicator is not included, so the formula becomes:

$$
P F_{s}=\frac{10}{12}\left(\frac{1}{N_{t}} \sum_{t=1}^{N_{t}} B S_{t}+B C_{s}+A B_{r}\right)
$$

Where $P F_{s}$ is the Physical Form Sub-index score for a site and the subscripts $r, s$, and $t$, refer to transect, site and reach respectively (symbols are defined in Table 6.1. 


\section{Physical Form Sub-index score for a reach}

The Physical Form Sub-index score for a reach is the mean of the Physical Form Subindex scores for all the sites within a reach.

$P F_{r}=\frac{1}{N_{s}} \sum_{1}^{N_{s}} P F_{s}$

Where $P F_{r}$ is the Physical Form Sub-index score for a reach, $P F_{s}$ is the Physical Form Sub-index score for site $s, \mathrm{~N}_{\mathrm{s}}$ is the number of sites in the reach.

\subsubsection{Streamside Zone Sub-index}

The Streamside Zone Sub-index requires measurements of ten aspects of streamside condition; eight measurements are made at each transect, one (longitudinal continuity) at a measuring site and one (condition of wetlands and billabongs) is measured over the whole reach (see Table 6.2). The condition of wetlands and billabongs is measured only in lowland reaches.

A complete definition of these indicators, including measurement techniques and ratings, is provided by CEAH and ID\&A Pty Ltd (1997) and Ladson and White (1999) and summarised in Ladson et al. (1999a; see Chapter 5 and Appendix D).

Table 6.2 - Streamside zone indicators

\begin{tabular}{|l|l|c|c|}
\hline Scale & Indicator & Symbol & Range $^{\mathbf{1}}$ \\
\hline Reach & $\begin{array}{l}\text { Condition of wetlands and billabongs } \\
\text { (only measured in lowland reaches) }\end{array}$ & $B b$ & $(0-1)$ \\
\hline \multirow{4}{*}{ Trite } & Longitudinal continuity & $L C$ & $(0-4)$ \\
\cline { 2 - 4 } & Width of streamside zone & $W d$ & $(0-4)$ \\
\cline { 2 - 4 } & Structural intactness of overstorey & $S I O$ & $(0-2)$ \\
\cline { 2 - 4 } & Structural intactness of understorey & $S I U$ & $(0-2)$ \\
\cline { 2 - 4 } & Structural intactness of groundcover & $S I G$ & $(0-2)$ \\
\cline { 2 - 4 } & Proportion of overstorey cover that is indigenous & $P I O$ & $(0-4)$ \\
\cline { 2 - 4 } & Proportion of understorey cover that is indigenous & $P I U$ & $(0-4)$ \\
\cline { 2 - 4 } & Proportion of groundcover that is indigenous & $P I G$ & $(0-4)$ \\
\cline { 2 - 4 } & Regeneration & $R g$ & $(0-4)$ \\
\hline
\end{tabular}

These ranges are the ones used in the study described in this chapter. In other versions of the ISC, different ranges for the indicators may be used.

\section{Streamside Zone Sub-index score at a measuring site}

The Streamside Zone Sub-index score for a measuring site is a combination of the indicators in Table 6.2 (except that the condition of wetlands and billabongs indicator $(B b)$ is only measured in lowland reaches). 


\section{Streamside zone and physical form}

The Streamside Zone Sub-index score for a site within a lowland reach is given by equation 6.4 .

$$
S Z_{s}=\frac{10}{19}\left(\frac{1}{N_{t}} \sum_{t=1}^{N_{t}}\left[W d_{t}+\frac{2}{3}\left(S I O_{t}+S I U_{t}+S I G_{t}\right)+\frac{1}{3}\left(P I O_{t}+P I U_{t}+P I G_{t}\right)+\frac{1}{2} R g_{t}\right]+L C_{s}+B b_{r}\right)
$$

The Streamside Zone Sub-index score for a site within an upland or a valley reach is given by equation 6.5 .

$$
S Z_{s}=\frac{10}{18}\left(\frac{1}{N_{t}} \sum_{t=1}^{N_{t}}\left[W d_{t}+\frac{2}{3}\left(S I O_{t}+S I U_{t}+S I G_{t}\right)+\frac{1}{3}\left(P I O_{t}+P I U_{t}+P I G_{t}\right)+\frac{1}{2} R g_{t}\right]+L C_{s}\right)
$$

$S Z_{s}$ is the Streamside Zone Sub-index for a site. The subscript $t$ refers to ratings of an indicator for a particular transect: $W d$ is the width rating, $L C$ is the longitudinal continuity rating, SIO, SIU, SIG are the structural intactness ratings for overstorey, understorey and groundcover respectively, PIO, PIU are percentage indigenous for overstorey and understorey respectively, $P I G$ is the weeds rating, and $R g$ is the rating for regeneration. The subscripts $r, s$ and $t$ refer to values for a reach, site and transect respectively. $N_{t}$ is the number of transects within a site (see Table 6.2.

\section{Streamside Zone Sub-index score for a reach}

The Streamside Zone Sub-index score for a reach is the average of the scores at each of the sites.

$$
S Z_{r}=\frac{1}{N_{s}} \sum_{s=1}^{N_{s}} S Z_{s}
$$

Where $S Z_{r}$ is the Streamside Zone Sub-index score for a reach, $S Z_{s}$ is the Streamside Zone Sub-index score for site $s$, and $N_{s}$ is the number of sites, usually 3 for each reach. 


\subsection{A detailed data set on streamside zone and physical form}

The previous section defined the Streamside Zone and Physical Form Sub-indices in terms of their component indicators. Sub-index scores for a reach are defined as the average of the sub-index scores for a number of sites and the intention is that these sites are chosen randomly. This section introduces the data to test the random sampling procedure. The detailed data set on condition of streamside zone and physical form is briefly described and results presented. This data set was collected, under my guidance, by Boris Jawecki a student from the University of Agriculture in Vienna (Austria), who visited the Centre for Environmental Applied Hydrology at the University of Melbourne as part of the research component of his degree. Julian Thompson, a research assistant at the University of Melbourne assisted with the field work.

\subsubsection{Description of the data}

Detailed information on the streamside zone and physical form was collected on $22 \mathrm{~km}$ of lowland reach and, $5 \mathrm{~km}$ of valley reach on Ryans Creek, and $33 \mathrm{~km}$ of lowland reach on the Broken River (Figures 6.2 and 6.3). Only the lowland section of the Ryans Creek data is used in the following analysis, since the valley reach was too short to provide useful information using the subsampling procedures described here. Along these reaches, every second kilometre was sampled with measurements being made at five transects on each bank (see Table 6.3. The Physical Form and Streamside Zone Sub-index values are shown in Figures 6.4, 6.5, 6.6 and 6.7 and summarised in Table 6.5. An example of the physical form and streamside zone data are provided in Tables 6.4a and 6.4b and a complete list of the Physical Form and Streamside Zone Sub-index scores are included in Appendix M.

A limitation of this data set is that one of the streamside zone indicators - proportion of groundcover that is indigenous, PIG - was not used during the analysis. When reviewing the data, this indicator seemed highly variable and following discussions with field assessors, it was apparent that they did not have the skills to assess this indicator accurately under the conditions experienced. Extensive botanical knowledge is required to identify whether ground cover is exotic or native and insufficient attention had been given to this during training of assessors, particularly given that one was from Austria and had limited exposure to Australian native grasses. 


\section{Streamside zone and physical form}

The Streamside Zone Sub-index scores were based on equation 6.4 except that $P I G$ is excluded so the equation becomes:

$$
S Z_{s}=\frac{10}{19}\left(\frac{1}{N_{t}} \sum_{t=1}^{N_{t}}\left[W d_{t}+\frac{2}{3}\left(S I O_{t}+S I U_{t}+S I G_{t}\right)+\frac{1}{2}\left(P I O_{t}+P I U_{t}\right)+\frac{1}{2} R g_{t}\right]+L C_{s}+B b_{r}\right)
$$

This equation (6.7) was used to calculate the streamside zone scores shown in Figures 6.4 to 6.7, Table 6.4b and Appendix M.

The mean values of the Streamside Zone and Physical Form Sub-indices range from 3.4 to 6.9 , which is approximately in the middle of the maximum range $(0-10)$ of these sub-indices Table 6.5

Streams that score in the middle of the range, about 5 out of 10 , are likely to be more variable than streams that score near the end of the range, 0 or 10 . For streams in excellent condition, most transects will score close to 10 ; so the variance will be low but improvements in condition will be difficult to detect since the scope for improvement is limited. For streams in poor condition, most transects will score close to zero; so again, the variance will be low but in this case a decrease in condition will be difficult to detect since the possible extent of the decrease is limited. For streams in marginal condition, with sub-index scores in the middle of the range, around five, the variance is likely to be the highest with some parts of the stream scoring close to ten and others close to zero. The scope for change either to increase or decrease condition is also high. Ryans Creek and the Broken River are both streams where the sub-indices are near the middle of the range, so are expected to be representative of the more variable streams to be found in Victoria.

Table 6.3 - Detailed information on the streamside zone and physical form was collected along Ryans Creek and the Broken River

\begin{tabular}{|l|c|c|}
\hline & Broken River & $\begin{array}{c}\text { Ryans Creek } \\
\text { (lowland reach) }\end{array}$ \\
\hline Reach length $(\mathrm{km})$ & 33 & 22 \\
\hline Number of kilometres sampled & 17 & 11 \\
\hline Number transects per kilometre & $\begin{array}{c}10 \\
\text { (5 on each side of the } \\
\text { river) }\end{array}$ & $\begin{array}{c}10 \\
\text { (5 on each side of the } \\
\text { river })\end{array}$ \\
\hline Total number of transects & 170 & 110 \\
\hline
\end{tabular}




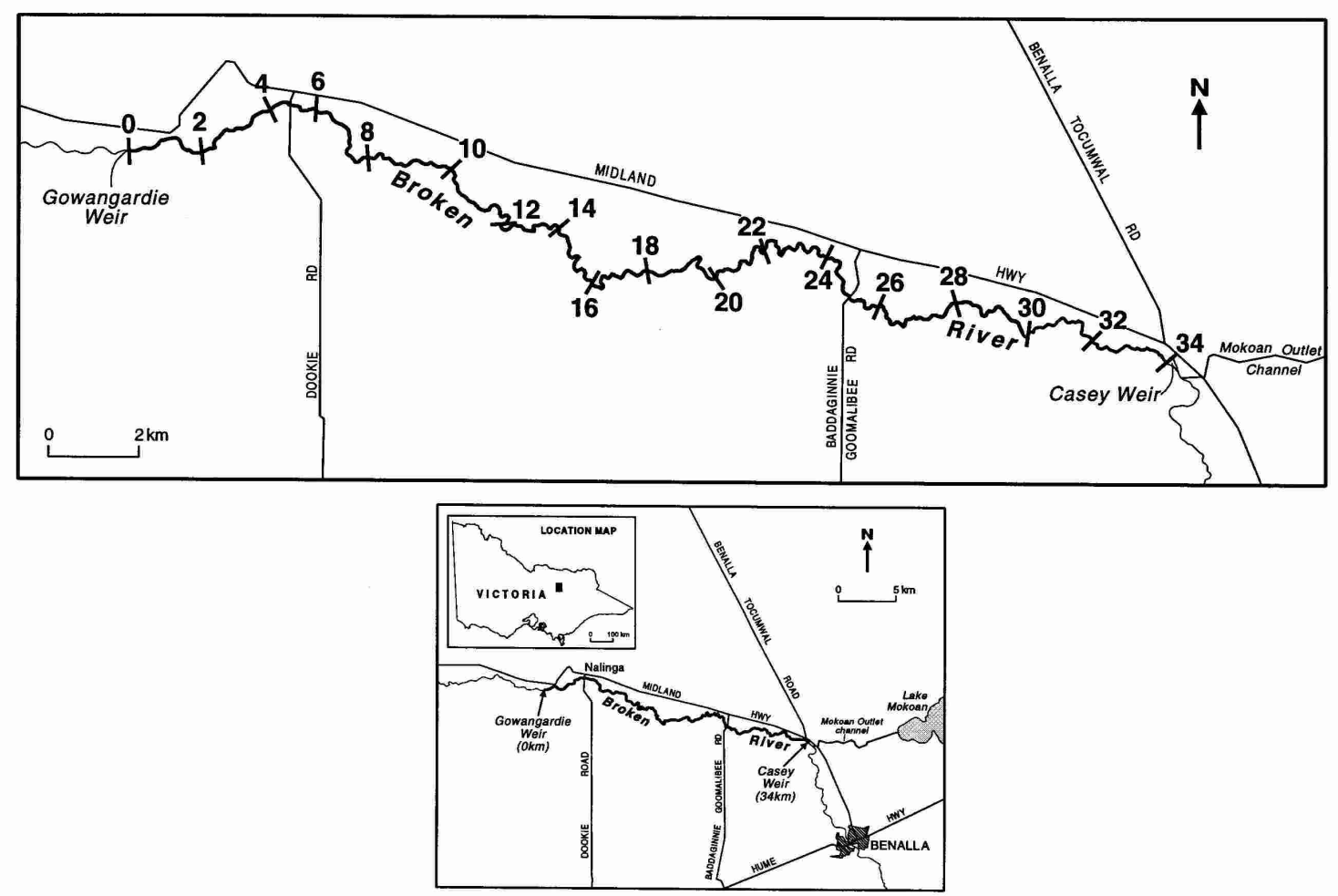

Figure 6.2 - Broken River study area 


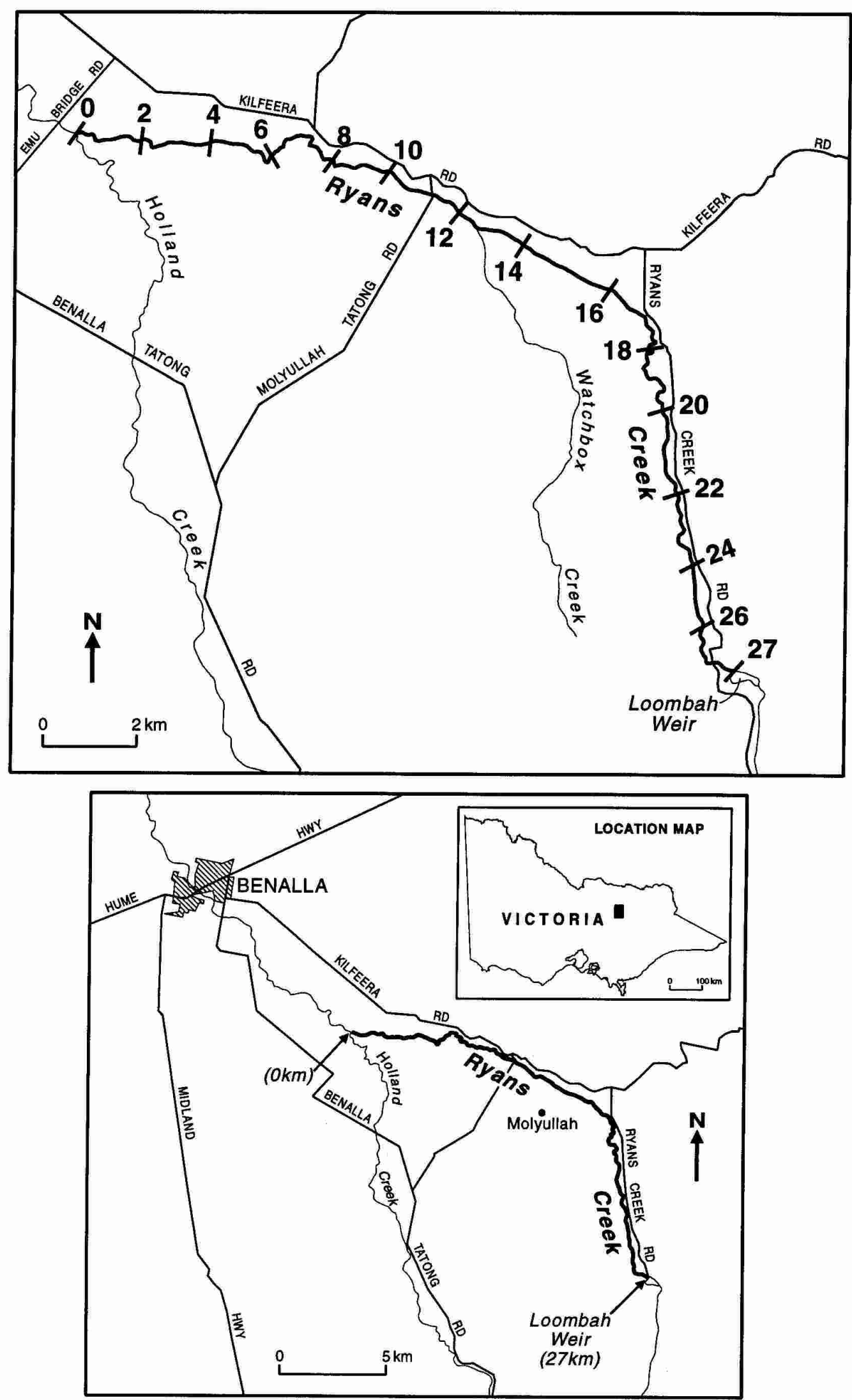

Figure 6.3 - Ryans Creek study area 

Table 6.4a - Example of Physical Form Sub-index data for the Broken River (see Appendix M for a complete listing)

\begin{tabular}{|c|c|c|c|c|c|c|c|c|c|}
\hline \multirow[t]{2}{*}{ Site } & \multirow[t]{2}{*}{ Transect } & \multirow[t]{2}{*}{$\begin{array}{c}\text { Distance } \\
{[\mathrm{m}]}\end{array}$} & \multicolumn{2}{|c|}{ Bank Condition } & \multirow[t]{2}{*}{$\begin{array}{c}\text { Bed } \\
\text { Condition }\end{array}$} & \multirow[t]{2}{*}{$\begin{array}{c}\text { Artificial } \\
\text { Barriers }\end{array}$} & \multirow{2}{*}{$\begin{array}{l}\text { Coarse } \\
\text { Woody } \\
\text { Debris }\end{array}$} & \multicolumn{2}{|c|}{$\begin{array}{c}\text { Physical Form } \\
\text { Sub-index }\end{array}$} \\
\hline & & & Left Bank & Right Bank & & & & $\begin{array}{c}\text { Left } \\
\text { Bank }\end{array}$ & $\begin{array}{l}\text { Right } \\
\text { Bank }\end{array}$ \\
\hline 1 & 1 & 100 & 4 & 3.4 & 4 & 2 & 2 & 7.50 & 7.13 \\
\hline & 2 & 300 & 2.7 & 2.7 & 4 & 2 & 1 & 6.06 & 6.06 \\
\hline & 3 & 500 & 2.7 & 4 & 2 & 2 & 3 & 6.06 & 6.88 \\
\hline & 4 & 700 & 2.5 & 3.7 & 4 & 2 & 1 & 5.94 & 6.69 \\
\hline & 5 & 900 & 3.2 & 3.8 & 4 & 2 & 2 & 7.00 & 7.38 \\
\hline
\end{tabular}

Table 6.4b - Example of Streamside Zone Sub-index data for the Broken River (see Appendix M for a complete listing)

\begin{tabular}{|c|c|c|c|c|c|c|c|c|c|c|c|c|c|c|c|c|c|c|}
\hline \multirow[t]{2}{*}{ Site } & \multirow[t]{2}{*}{ Trans. } & \multicolumn{2}{|c|}{$\begin{array}{c}\text { Overstorey \& } \\
\text { Understorey } \\
\text { Width }\end{array}$} & \multicolumn{2}{|c|}{$\begin{array}{l}\text { Overstorey } \\
\text { Structural } \\
\text { Intactness }\end{array}$} & \multicolumn{2}{|c|}{$\begin{array}{c}\text { Overstorey } \\
\text { Percent } \\
\text { Indigenous }\end{array}$} & \multicolumn{2}{|c|}{$\begin{array}{c}\text { Understorey } \\
\text { Structural } \\
\text { Intactness } \\
\end{array}$} & \multicolumn{2}{|c|}{$\begin{array}{c}\text { Understorey } \\
\text { Percent } \\
\text { Indigenous }\end{array}$} & \multicolumn{2}{|c|}{$\begin{array}{c}\text { Groundcover } \\
\text { Structural } \\
\text { Intactness } \\
\end{array}$} & \multicolumn{2}{|c|}{ Regeneration } & \multirow[t]{2}{*}{\begin{tabular}{|c|} 
Wetlands \\
$\&$ \\
Billabongs
\end{tabular}} & \multicolumn{2}{|c|}{ Streamside Zone } \\
\hline & & $\begin{array}{c}\text { Left } \\
\text { Bank }\end{array}$ & $\begin{array}{l}\text { Right } \\
\text { Bank }\end{array}$ & $\begin{array}{c}\text { Left } \\
\text { Bank }\end{array}$ & $\begin{array}{l}\text { Right } \\
\text { Bank }\end{array}$ & $\begin{array}{c}\text { Left } \\
\text { Bank }\end{array}$ & $\begin{array}{l}\text { Right } \\
\text { Bank }\end{array}$ & $\begin{array}{c}\text { Left } \\
\text { Bank }\end{array}$ & $\begin{array}{l}\text { Right } \\
\text { Bank }\end{array}$ & $\begin{array}{c}\text { Left } \\
\text { Bank }\end{array}$ & $\begin{array}{l}\text { Right } \\
\text { Bank }\end{array}$ & $\begin{array}{c}\text { Left } \\
\text { Bank }\end{array}$ & $\begin{array}{l}\text { Right } \\
\text { Bank }\end{array}$ & \begin{tabular}{|c|} 
Left \\
Bank
\end{tabular} & $\begin{array}{l}\text { Right } \\
\text { Bank } \\
\end{array}$ & & $\begin{array}{c}\text { Left } \\
\text { bank }\end{array}$ & $\begin{array}{l}\text { Right } \\
\text { bank }\end{array}$ \\
\hline 1 & 1 & 2 & 0 & 2 & 2 & 4 & 2 & 4 & 2 & 4 & 0 & 4 & 0 & 4 & 0 & 0 & 7.56 & 1.56 \\
\hline & 2 & 2 & 0 & 2 & 2 & 2 & 4 & 4 & 2 & 4 & 4 & 4 & 2 & 4 & 2 & 0 & 6.89 & 4.67 \\
\hline & 3 & 1 & 1 & 2 & 2 & 4 & 4 & 2 & 4 & 0 & 4 & 4 & 4 & 0 & 2 & 0 & 3.78 & 6.22 \\
\hline & 4 & 2 & 2 & 2 & 2 & 4 & 2 & 4 & 2 & 4 & 3 & 4 & 4 & 4 & 2 & 0 & 7.56 & 5.44 \\
\hline
\end{tabular}




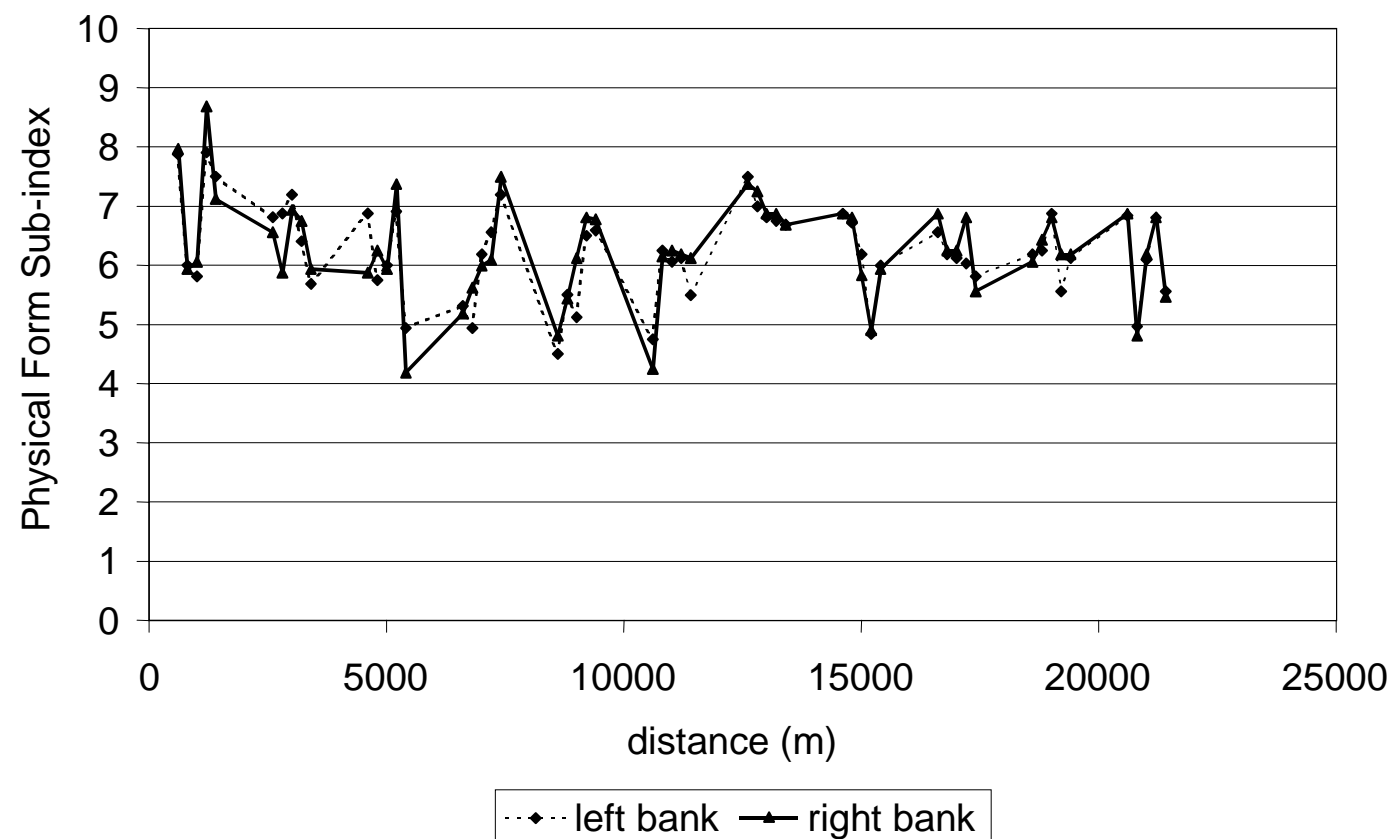

Figure 6.4 - Physical Form Sub-index for Ryans Creek (only the lowland reach is shown)

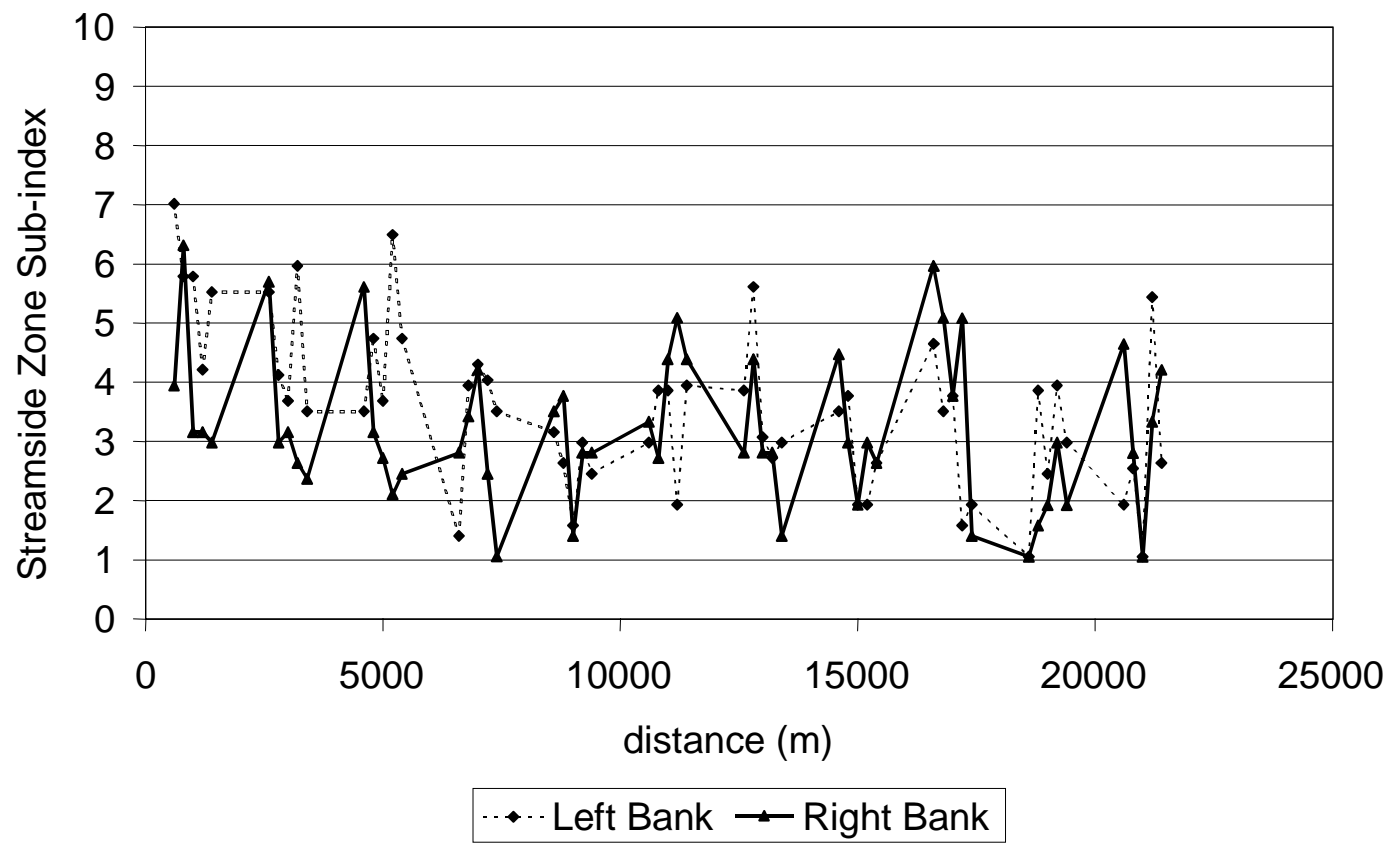

Figure 6.5 - Streamside Zone Sub-index for Ryans Creek (only the lowland reach is shown) 


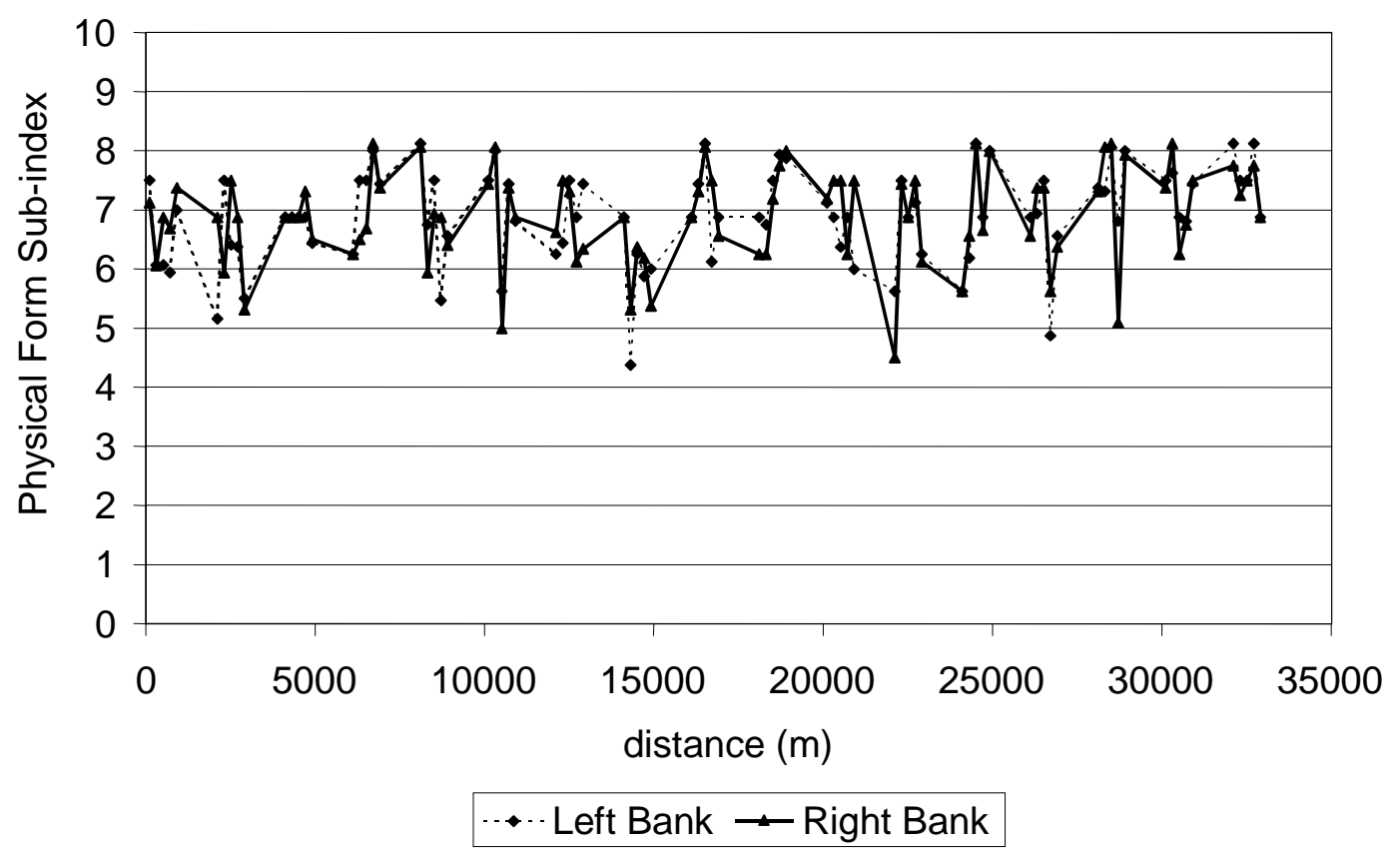

Figure 6.6 - Physical Form Sub-index for the Broken River

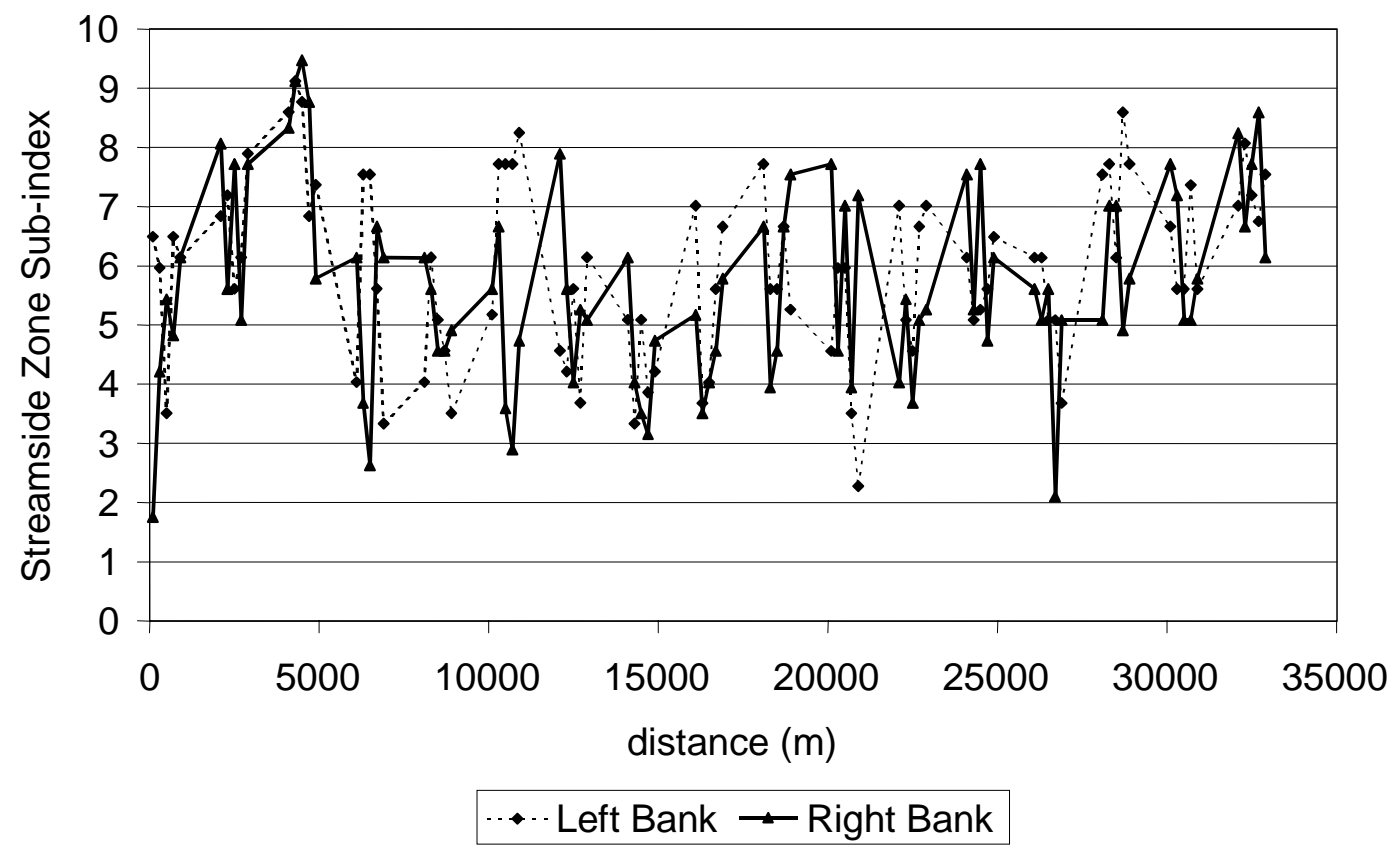

Figure 6.7 - Streamside Zone Sub-index for the Broken River 


\subsubsection{Testing the representative sub-reach approach}

The detailed data on physical form and streamside zone that were gathered along the Broken River and Ryans Creek provided an opportunity to test the reliability of using a 'representative' sub-reach to assess condition. Prior to the detailed survey, during an earlier trial (ID\&A Pty Ltd and CEAH, 1997a), staff from the local Catchment Management Authority (CMA) were asked to nominate sections of stream about $1 \mathrm{~km}$ long that they regarded as being representative of the longer reaches.

CMA staff were expected to have detailed local knowledge of river condition. They regularly visit sites within these reaches of the Broken River and Ryans Creek and have many years experience working in this area. It was originally intended that when applying the ISC throughout Victoria, CMA field staff would select 'representative' reaches for all the rivers in the state.

The Streamside Zone and Physical Form Sub-index scores based on these 'representative' sub-reaches are shown in Table 6.5 and compared with scores based on all the data from the survey. Results show the problems with the representative reach approach. The physical form scores based on the 'representative' sub-reach are close to those based on the complete data set but the streamside zone scores are quite different, especially for the Broken River. These results show that using the methodology of a 'representative' sub-reach can result in an inaccurate assessment of the condition.

It is impossible to estimate the variance of the data, or calculate confidence intervals, if information is only collected within the 'representative' sub-reach. It is also difficult to know how to use the 'representative' sub-reach when collecting data in the future. Would the same sub-reach be used for repeat measurements in 5 years? What if river management works had been undertaken at the 'representative' sub-reach? A new subreach would have to be chosen and the differences between the sub-reaches would likely mask any overall change in condition of the longer reach.

A sampling strategy based on a representative reach approach has been used in other stream surveys, for example, the Statewide Assessment of Physical Stream Condition (Tilleard and DWR, 1985; Mitchell, 1990) but the accuracy of this approach has not been tested elsewhere. Williams (1996) alludes to problems of using a 'representative' approach to measure stream data and comments that the reliability of results cannot be evaluated statistically. Jeffers (1998) notes the possibility of bias. The large variability 
suggests it would be very difficult to select transects that accurately represent reaches of any length. Using a 'representative' sub-reach selected by expert judgement also decreases the objectivity of the ISC. These problems suggest the need for an alternative sampling approach.

Table 6.5 - Streamside Zone and Physical Form Sub-index scores based on values from a nominated 'representative' reach on the Broken River and Ryans Creek

\begin{tabular}{|l|l|c|c|c|c|c|}
\hline \multirow{2}{*}{ Stream } & Sub-index & \multicolumn{2}{|c|}{$\begin{array}{c}\text { 'Representative' } \\
\text { Reach }\end{array}$} & \multicolumn{3}{|c|}{ All data } \\
\cline { 2 - 7 } & Mean & $\begin{array}{l}\text { Standard } \\
\text { deviation }\end{array}$ & Mean & $\begin{array}{l}\text { Standard } \\
\text { deviation }\end{array}$ & $\begin{array}{c}\text { Coefficient } \\
\text { of variation }\end{array}$ \\
\hline $\begin{array}{l}\text { Broken River } \\
\text { 'Representative' reach } \\
(3500 \mathrm{~m}-4500 \mathrm{~m})\end{array}$ & $\begin{array}{l}\text { Physical } \\
\text { Form }\end{array}$ & 6.9 & 0 & 6.9 & 0.8 & $12 \%$ \\
\cline { 2 - 7 } & $\begin{array}{l}\text { Streamside } \\
\text { Zone }\end{array}$ & 8.9 & 0.5 & 5.8 & 1.6 & $28 \%$ \\
\hline $\begin{array}{l}\text { Ryans Creek } \\
\text { 'Representative' reach } \\
(9000 \mathrm{~m}-10000 \mathrm{~m})\end{array}$ & $\begin{array}{l}\text { Physical } \\
\text { Form }\end{array}$ & 6.4 & 0.6 & 6.3 & 0.8 & $13 \%$ \\
\cline { 2 - 7 } & $\begin{array}{l}\text { Streamside } \\
\text { Zone - }\end{array}$ & 2.3 & 0.8 & 3.4 & 1.4 & $41 \%$ \\
\hline
\end{tabular}

\subsection{Testing a measurement procedure based on random sampling}

The detailed surveys of Ryans Creek and the Broken River were used to test a measurement procedure based on sampling the streamside zone and physical form at a number of random locations within a reach.

There are two variables of interest: (1) the number of sites per reach and (2) the number of transects per site (see Figure 6.1). The costs of the sampling procedure will also depend on these two factors. Site visits require travel in a vehicle, access through private property and are likely to be time consuming, whereas measuring an additional transect, once already at a site, will be reasonably quick. The ISC is intended as a management tool and cost was a major constraint on the selection of a sampling strategy. The objective of the following analysis was to examine the accuracy of a number of sampling strategies and present the results to the managers and scientists of the Specialist Reference Group, so they could make an informed decision about the best sampling scheme for the task. 


\subsubsection{Methodology}

The accuracy of sampling strategies was examined by randomly resampling the complete measured data set in a way that simulated proposed sampling schemes. Sampling strategies were specified in terms of (1) the number of sites per reach and (2) transects per site. The data were selected based on this scheme, the sub-index scores calculated and then the accuracy of the output compared to the values that where obtained using all the data.

The full data set consisted of 10 transects per kilometre, with every second kilometre being sampled at both Ryans Creek and the Broken River. In this analysis, the sampled kilometres were treated as sites, so there are 17 sites on the Broken River and 11 on Ryans Creek, and a maximum of 10 transects per site ( 5 being measured on each side of the river). The methodology is based on randomly selecting a site from all those that are available and then randomly selecting one or more transects associated with that site. The random selection procedure is repeated as required. Details of the methodology depend on the particular objective being assessed as explained below.

This methodology uses a numerical approach to assessing the performance of the sampling strategies, by using a suite of resampling schemes applied to the collected data. The resampling schemes simulate sampling strategies that are less comprehensive than that used to collect the complete data set. Data are always resampled with replacement and a large number of data sets are created for each sampling scheme under investigation. Mac Nally (1997) used a similar methodology where he resampled a set of data from a comprehensive survey of an avian community to determine the likely precision of less thorough monitoring. Mac Nally (1997) assumed that the comprehensive survey represented the 'true' state of nature and used this as the basis for comparison of the performance of alternative sampling schemes. A different approach is taken here. The comprehensive survey of streamside zone and physical form is not assumed to represent the true state of nature; rather, information on the distribution of values from this survey is obtained by bootstrapping the complete data set. Bootstrapping involves resampling the complete data set (with replacement) to create data sets of the same size as the comprehensive data set (Efron and Tibshirani 1993; Manly 1997). A large number of these bootstrap data sets are created. Values from these bootstrap data sets of the comprehensive data are compared with values from the less comprehensive sampling schemes, to assess the performance of these schemes. The 
specific methodology used to assess the performance of the sampling schemes depends on the objectives of monitoring as discussed below.

\section{Testing sampling strategies against objectives of the Index of Stream Condition}

As discussed in Chapter 5 there were a series of objectives for the ISC that helped guide its development. Some of these objectives will also relate to the choice of sampling strategy as listed in Table 6.6. The first two of these objectives - to benchmark stream condition and to measure change in stream condition - were included in the original project objectives. Another objective, related to early warning of major changes, was not part of the original project but is considered here as it may provide an important extension to the role of the ISC.

Table 6.6 - ISC objectives that relate to the choice of sampling strategy

\begin{tabular}{|l|l|l|}
\hline No & Objective & What this means in terms of sampling \\
\hline 1 & $\begin{array}{l}\text { To benchmark stream } \\
\text { condition }\end{array}$ & $\begin{array}{l}\text { The value of the indicator of condition should be } \\
\text { close to the true value of condition. }\end{array}$ \\
\hline 2 & $\begin{array}{l}\text { To measure change in } \\
\text { condition }\end{array}$ & $\begin{array}{l}\text { The difference between indicator values at time } 1 \\
\text { and time } 2 \text { should be } \text { close to the true value of the } \\
\text { change in condition between these times. }\end{array}$ \\
\hline 3 & $\begin{array}{l}\text { To provide early warning } \\
\text { of major changes so that } \\
\text { actions can be taken }\end{array}$ & $\begin{array}{l}\text { The indicator should provide appropriate warning } \\
\text { i.e. detect a major change when it really does } \\
\text { occur. The indicator should minimise false alarms } \\
\text { i.e. if there is not a major change then the } \\
\text { indicator should not suggest that a major change } \\
\text { has occurred. }\end{array}$ \\
\hline
\end{tabular}

\subsubsection{Benchmarking stream condition}

If a particular indicator is intended to benchmark stream condition, then it is important that the value of the indicator closely approximates the true value of condition. In this case, the Physical Form and Streamside Zone Sub-indices provide an estimate of the mean condition of the physical form and streamside zone for an entire reach.

Ideally, the true sub-index values would be compared with the values produced from random sampling to assess the accuracy of the sampling schemes. In reality, the true value was unknown but could be estimated from the complete data set. This estimate was then compared to the condition estimate produced by the random sampling 


\section{Streamside zone and physical form}

schemes. The statistic of interest is the difference, $\Delta_{\mathrm{b}}$, between the true value of condition and the value estimated by sampling.

$$
\Delta_{b}=S_{s}-S_{t}
$$

Where $S_{s}$ is the estimate of the sub-index score from sampling the reach using a particular scheme and $S_{t}$ is the true value of the sub-index score. Since the variance of the true value of the sub-index score is zero (it is not a random variable), the variance of $\Delta_{\mathrm{b}}$ will equal the variance of $S_{s}$. In reality $S_{t}$ is unknown and must be estimated using the complete data set. This estimate is denoted by $S_{c}$, so equation 6.8 becomes

$$
\Delta_{b}=S_{s}-S_{c}
$$

The variance of $\Delta_{\mathrm{b}}$ can be expressed as

$$
{\sigma_{\Delta_{b}}}^{2}={\sigma_{S_{s}}}^{2}+{\sigma_{S_{t}}}^{2}
$$

These variances were quantified using a numerical procedure based on replicated resampling similar to the bootstrap procedure of Efron and Tibshirani (1993).

The variance of the estimates based on random sampling, ${\sigma_{S_{s}}}^{2}$, were quantified by repeatedly resampling the complete data set using a particular sampling scheme (as specified by the number of sites per reach and number of transects per site). The variance of the scores based on all the data, $\sigma_{S_{t}}{ }^{2}$ was quantified by resampling the complete data set using the sampling scheme that was used to collect the data. For example, in the case of the Broken River, a possible sampling scheme could consist of 3 sites per reach and 3 transects per site. In comparison, the complete data set was collected at 17 sites and 10 transects per site (5 on each side of the river). The procedure is explained in Figure 6.8. 


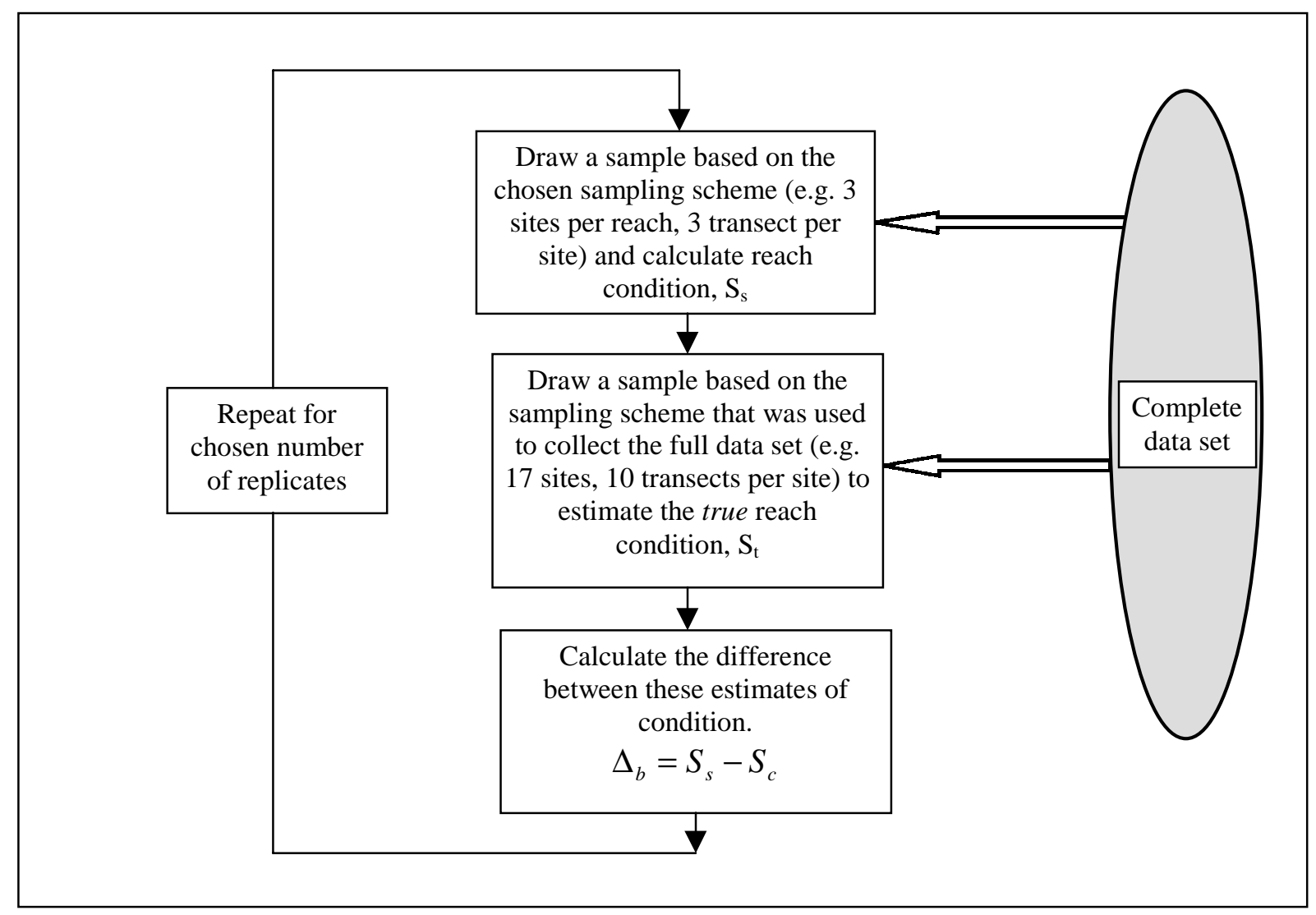

\section{Figure 6.8 - Resampling procedure used to quantify errors associated with} sampling to measure the current values of the Physical Form and Streamside Zone

\section{Sub-indices}

A computer program BENCHMARK was developed in Microsoft Visual Basic ${ }^{\mathrm{TM}}$ to process the data within Microsoft Excel ${ }^{\mathrm{TM}}$. This program is listed in Appendix N. The total number of replicates chosen was 5 000. This number was used by Mac Nally (1997) in a study that adopted a similar approach of replicated subsampling to determine the accuracy of monitoring. Efron and Tibshirani (1993), Williams (1996) and Manly (1997) suggest the number should be at least 2000 to achieve results of reasonable accuracy when calculating bootstrap confidence intervals.

Results were expressed in terms of the frequency with which the estimate of condition using the chosen sampling procedure was within $+/-0.5$ and $+/-1$ of the estimate using the full data set (see Figures 6.9 to 6.16). The results show the expected increase in accuracy as the sampling intensity increases.

The relative accuracy of a sampling scheme with three sites per reach and three transects per site is shown in Table 6.7 In the worst case, that is estimating the Streamside Zone Sub-index on the Broken River, the estimate will be within 1 of the 


\section{Streamside zone and physical form}

true value $82 \%$ of the time. Three transects per site were chosen because this provided a clear advantage over 2 transects per site (e.g. see Figure 6.9) but the relative accuracy was not much worse than for 4 or 5 transects per site. A more complete analysis to determine the best sampling scheme (number of sites per reach and transects per site) would require consideration of the costs associated with visits to sites and transects and the total budget for the sampling.

These results can also be used to explore the effect of sampling density; that is, the number of sites per unit length of stream. The variance of the physical form and streamside zone indicators using all the data is approximately the same for the Broken River and Ryans Creek (see Table 6.5); therefore, subsamples based on the same sampling density will have similar variance. Results from the two streams were combined to show the expected relative error for sampling densities from 1 site per $33 \mathrm{~km}$ to one site per $2.2 \mathrm{~km}$, with results expressed as a sampling density in terms of the number of sites per $10 \mathrm{~km}$ (see Figure 6.17 and 6.18). Results show that for sampling densities less than 1 site per 10km the accuracy decreases rapidly as fewer sites are used. This suggests that, for the purposes of benchmarking, 1 site per $10 \mathrm{~km}$ (with 3 transects per site) would be a reasonable first estimate for the minimum sampling density when assessing the ISC in these streams. The sampling density could be refined by choosing an acceptable relative error and then referring to Figures 6.17 and 6.18 to determine the required number of sites for a reach of a particular length. Alternatively, if the sampling density is known, then confidence intervals can be derived. For example, consider the Streamside Zone Sub-index (Figure 6.18). When assessing the streamside zone, if $90 \%$ of samples are required to be within $+/-1$ of the mean, then approximately 1.3 sampling sites are required per $10 \mathrm{~km}$ of reach. 


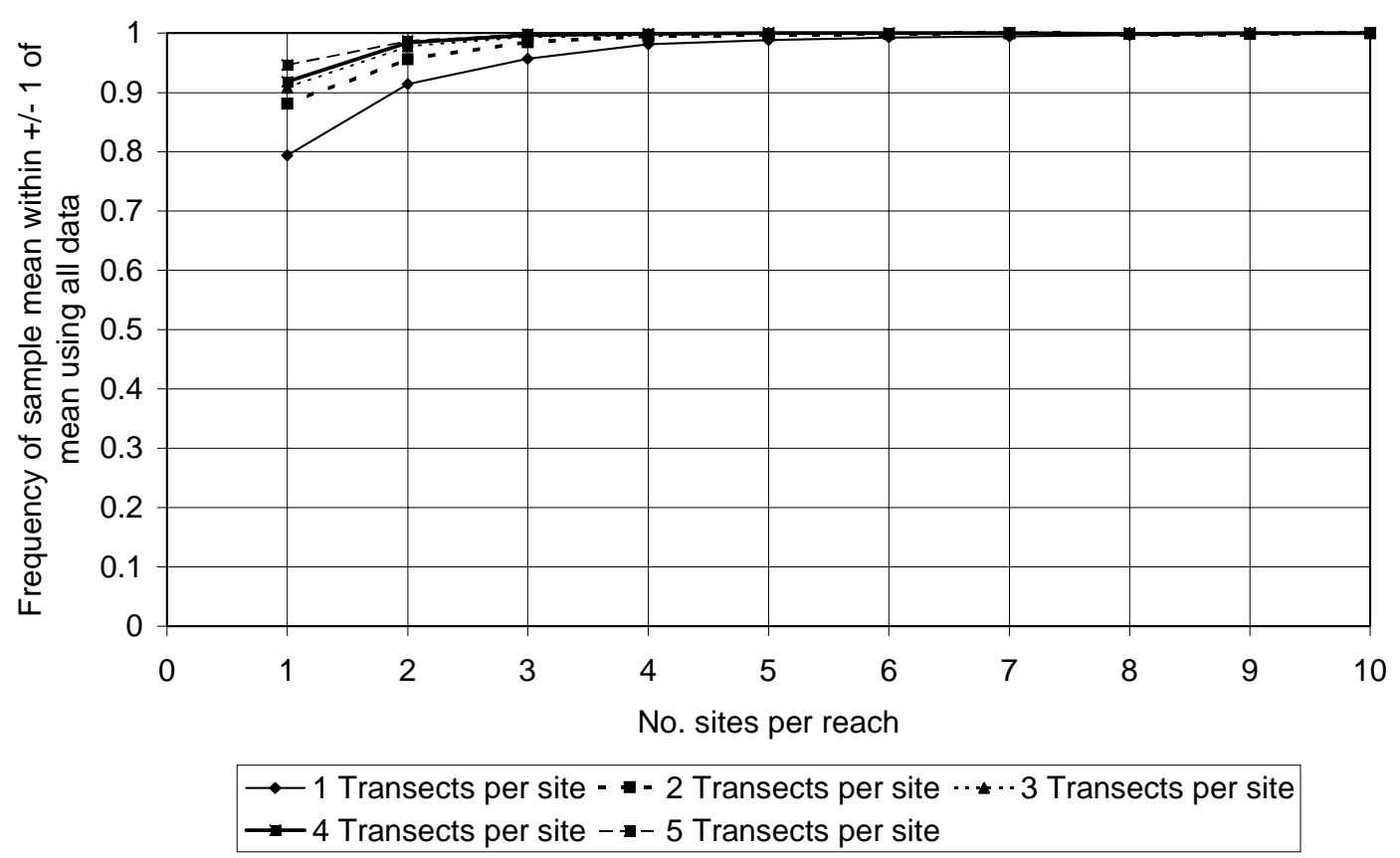

Figure 6.9 - Relative errors (+/- 0.5) associated with estimates of the Physical Form Sub-index on Ryans Creek for various sampling schemes

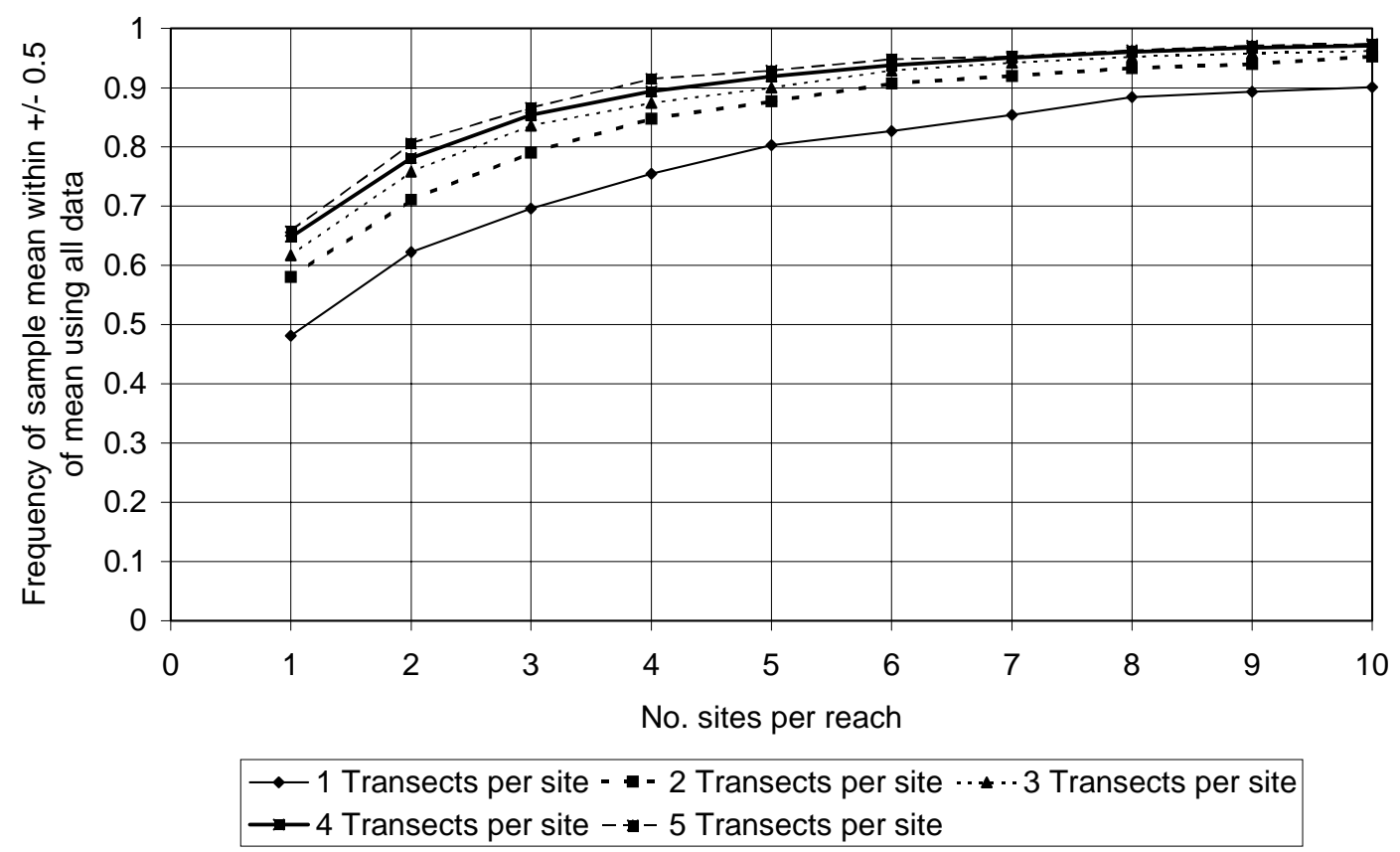

Figure 6.10 - Relative errors (+/- 1) associated with estimates of the Physical Form Sub-index on Ryans Creek for various sampling schemes 


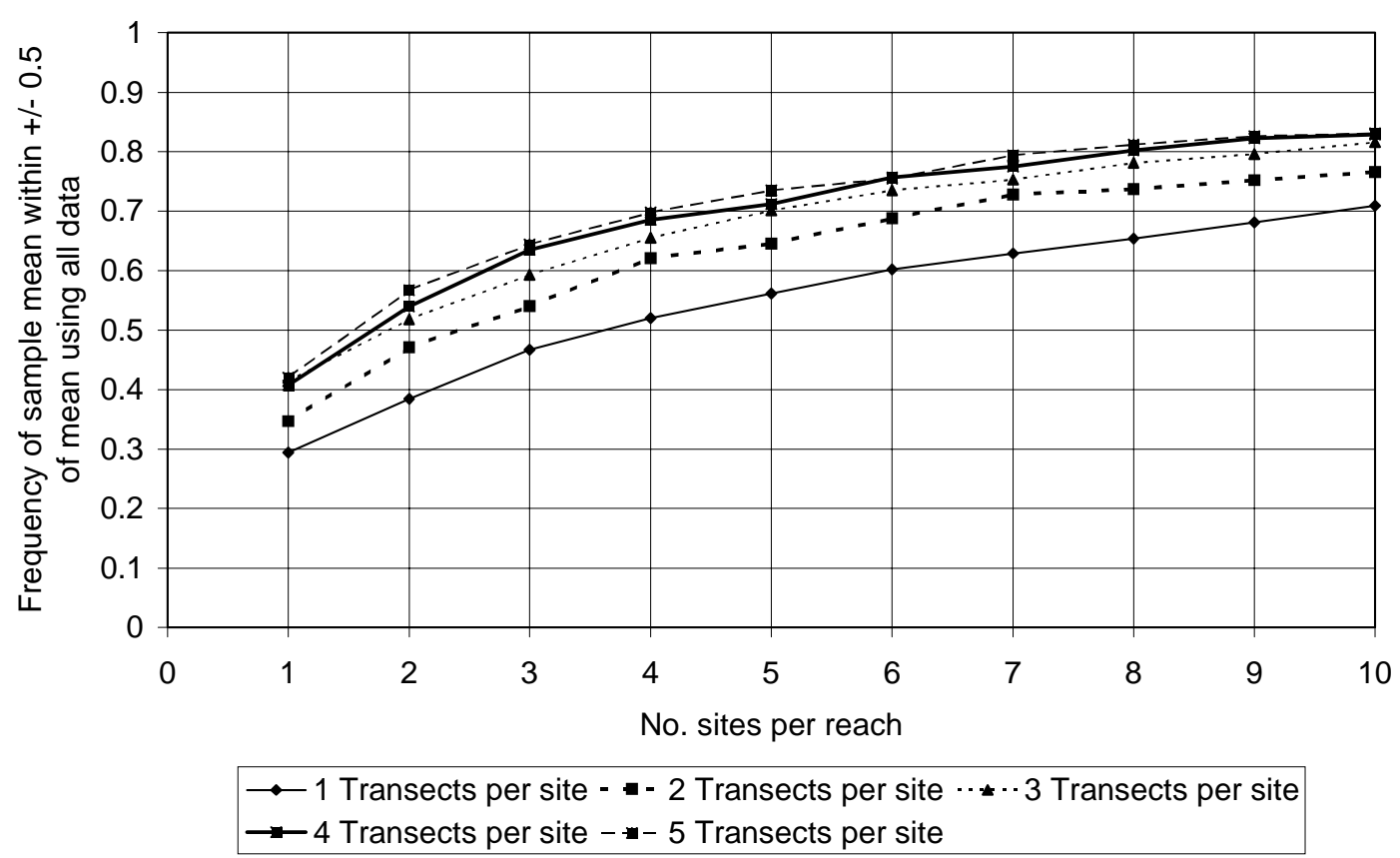

Figure 6.11 - Relative errors (+/- 0.5) associated with estimates of the Streamside Zone Sub-index on Ryans Creek for various sampling schemes

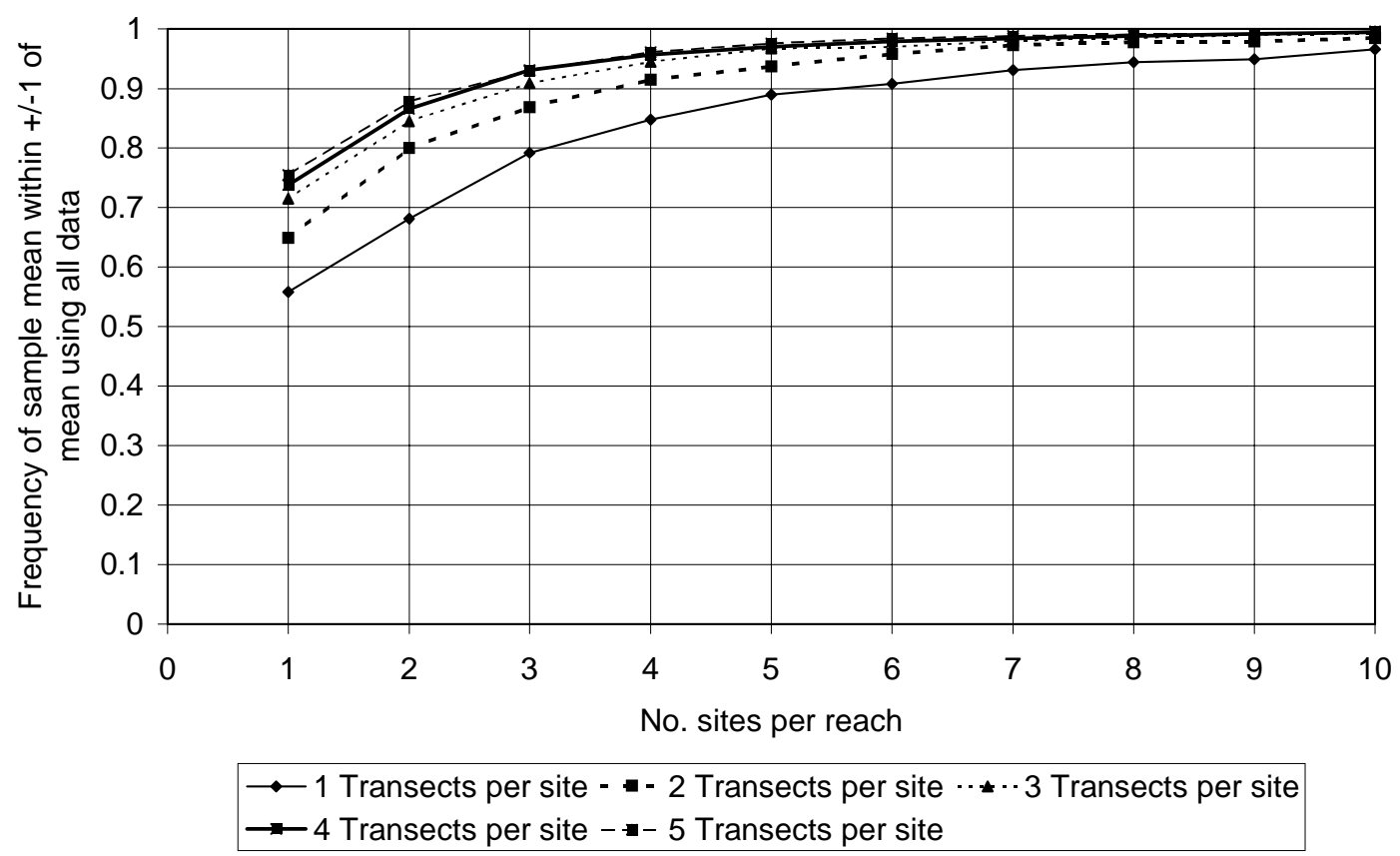

Figure 6.12 - Relative errors (+/- 1) associated with estimates of the Streamside Zone Sub-index on Ryans Creek for various sampling schemes 


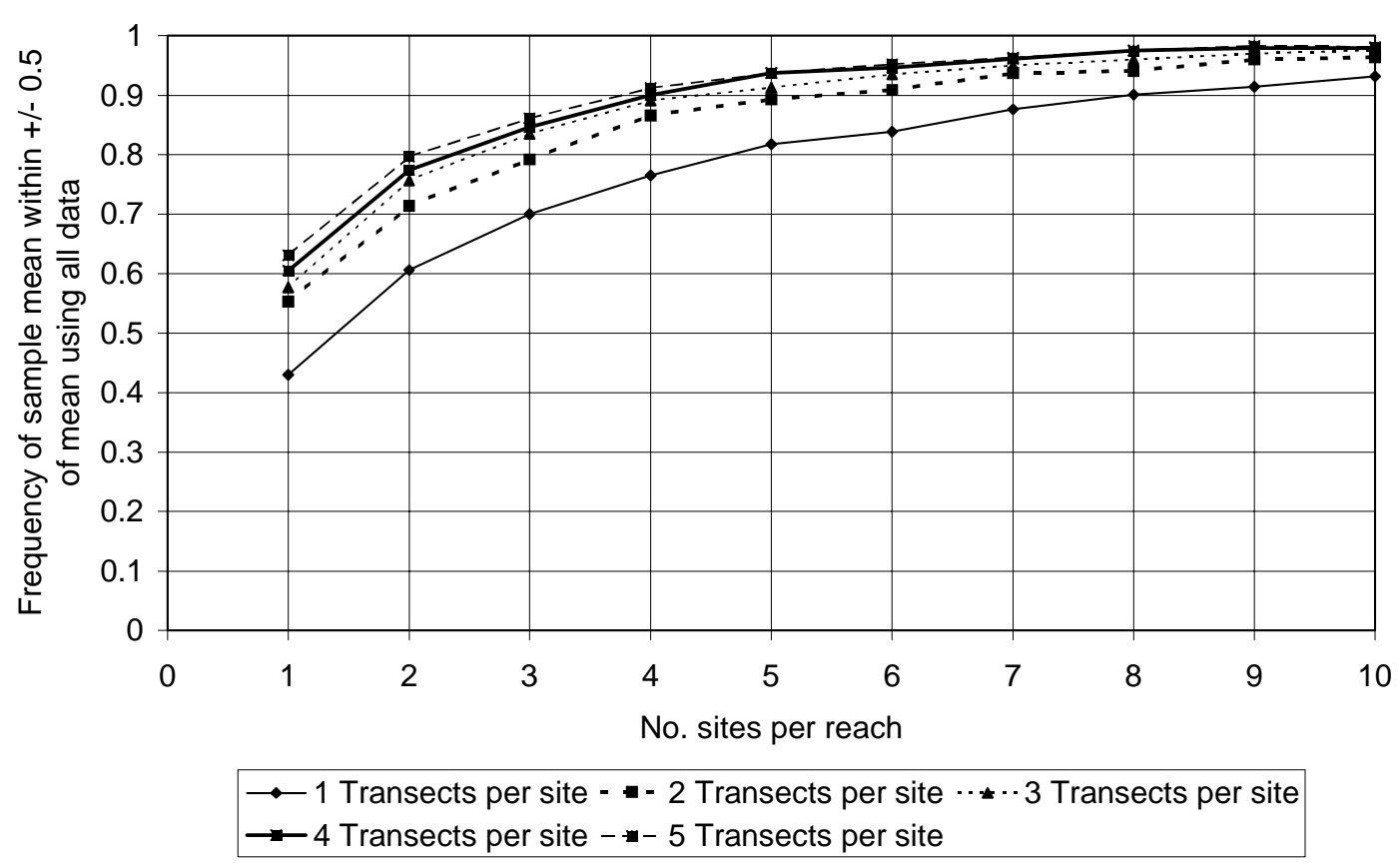

Figure 6.13 - Relative errors (+/- 0.5) associated with estimates of the Physical Form Sub-index on the Broken River for various sampling schemes

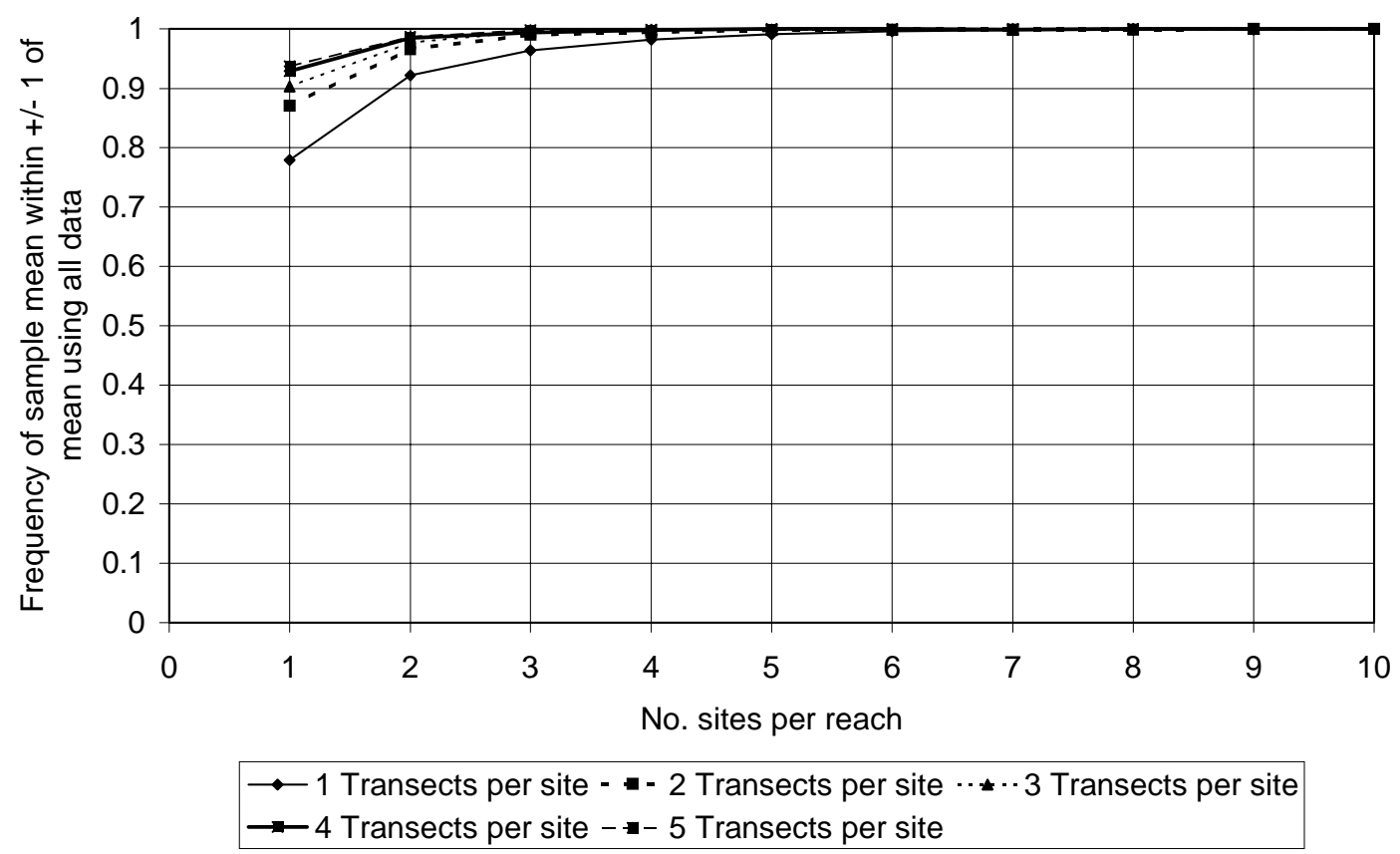

Figure 6.14 - Relative errors (+/- 1) associated with estimates of the Physical Form Sub-index on the Broken River for various sampling schemes 


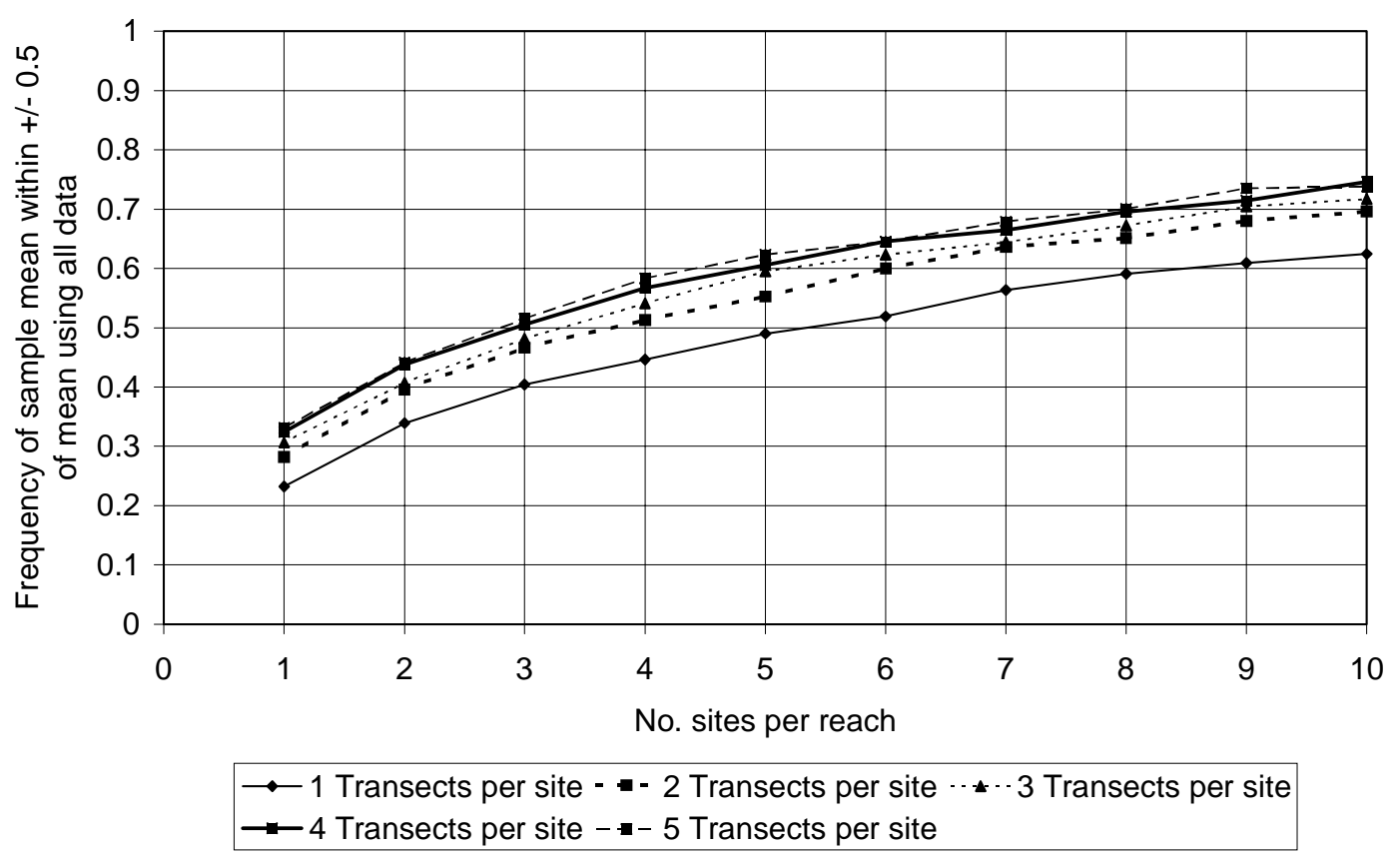

Figure 6.15 - Relative errors (+/- 0.5) associated with estimates of the Streamside Zone Sub-index on the Broken River for various sampling schemes

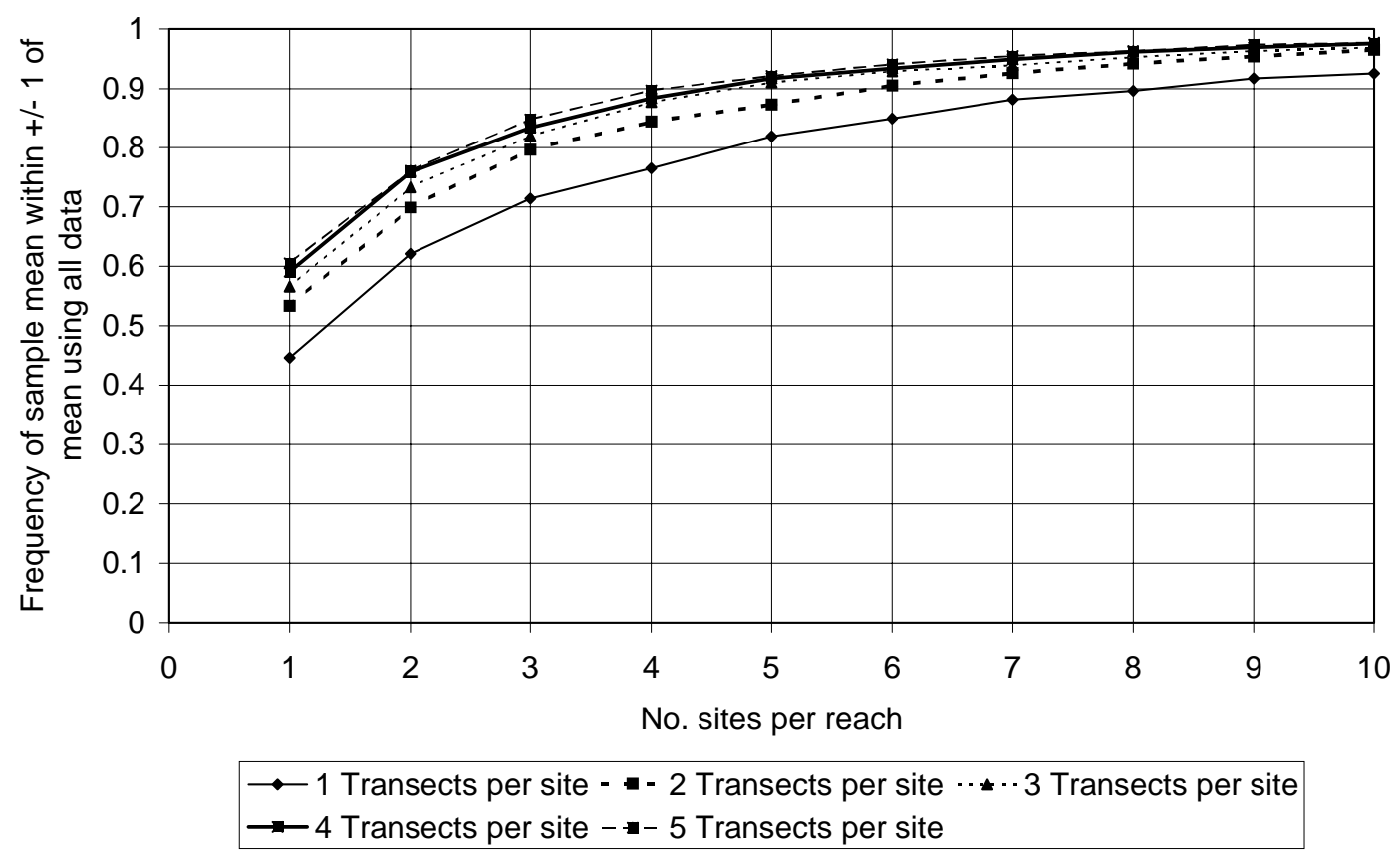

Figure 6.16 - Relative errors (+/- 1) associated with estimates of the Streamside Zone Sub-index on the Broken River for various sampling schemes 


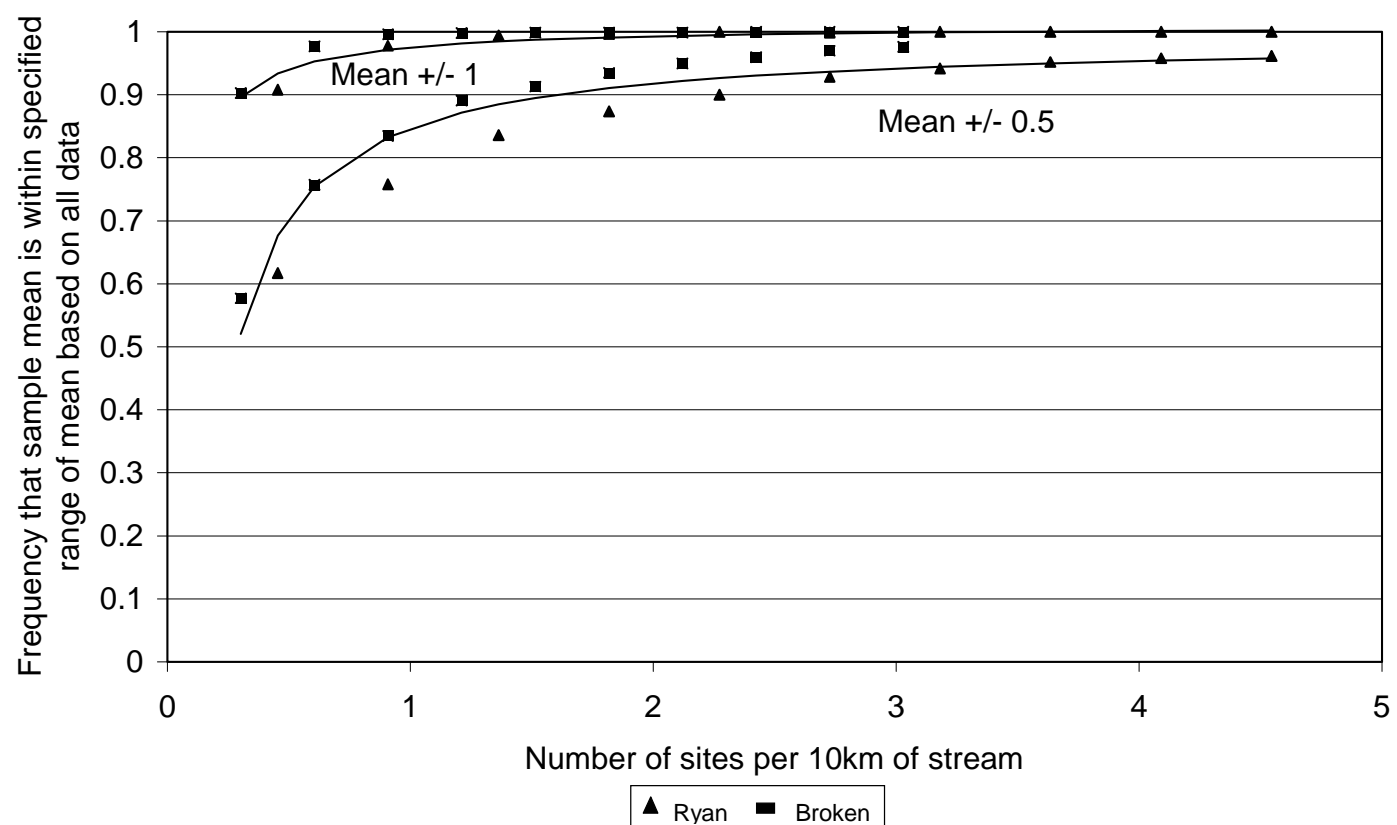

Figure 6.17 - Relative accuracy of the Physical Form Sub-index for sampling densities based on numbers of sites per $10 \mathrm{~km}$ of stream ( 3 transects per site)

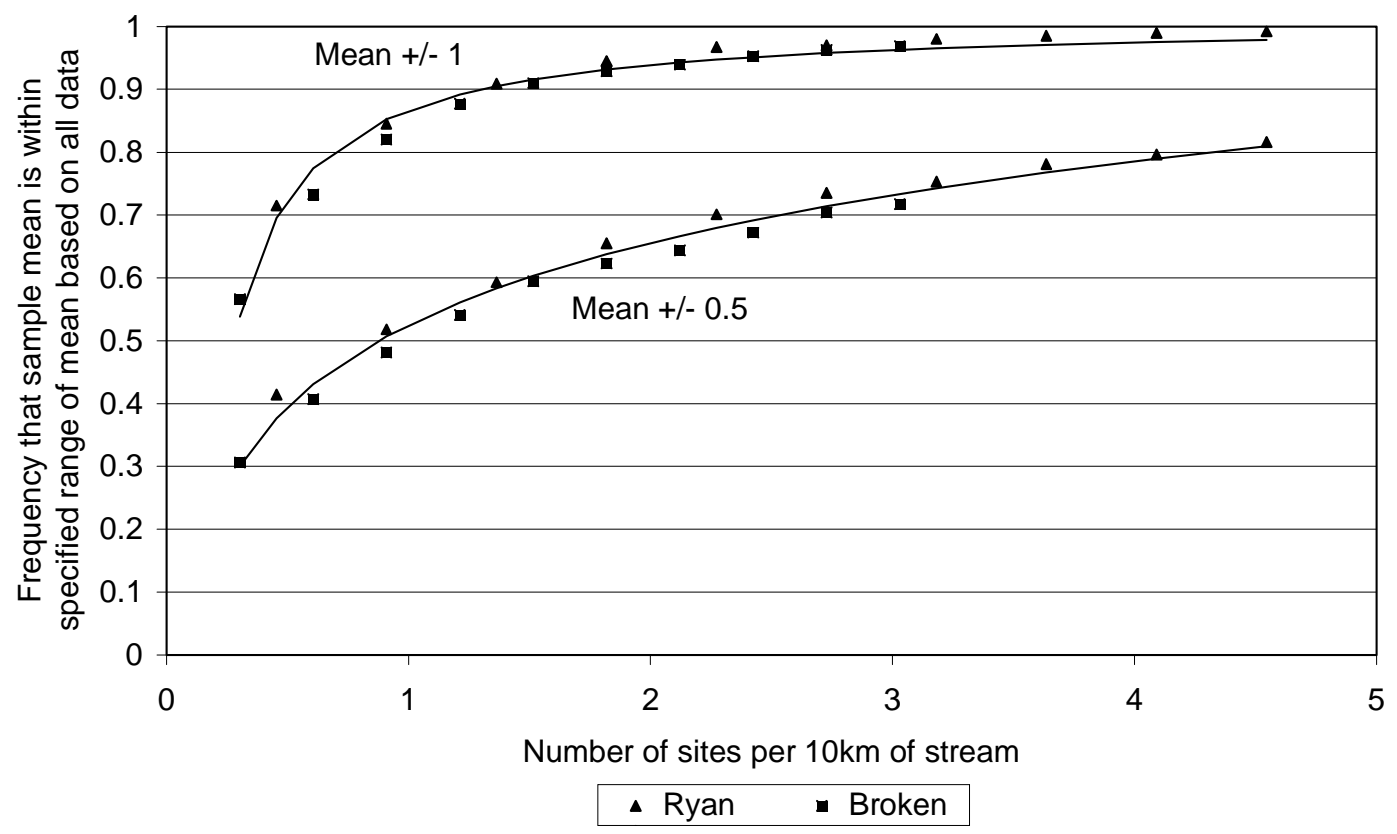

Figure 6.18 - Relative accuracy of the Streamside Zone Sub-index for sampling densities based on numbers of sites per $10 \mathrm{~km}$ of stream ( 3 transects per site) 
Table 6.7 - Relative accuracy of assessment of current condition for a sampling scheme based on 3 sites per reach and 3 transects per site

\begin{tabular}{|c|c|c|c|c|}
\hline \multirow[b]{3}{*}{ Range } & \multicolumn{4}{|c|}{$\begin{array}{l}\text { Frequency that mean of samples is within specified range of the } \\
\text { mean using all the data }\end{array}$} \\
\hline & \multicolumn{2}{|c|}{ Physical form } & \multicolumn{2}{|c|}{ Streamside zone } \\
\hline & $+/-0.5$ & $+/-1$ & $+/-0.5$ & $+/-1$ \\
\hline Broken River & $84 \%$ & $99.6 \%$ & $48 \%$ & $82 \%$ \\
\hline Ryans Creek & $84 \%$ & $99 \%$ & $59 \%$ & $91 \%$ \\
\hline
\end{tabular}

\subsubsection{Change detection}

An objective of the physical form and streamside zone indicators is to be able to detect changes in the true condition of streams. That is, the difference in the measured condition between two periods should be approximately equal to the true change that has occurred.

The performance of the sampling strategies can be assessed by calculating the difference, $\Delta_{\mathrm{c}}$ between the measured change $C_{m}$, and the true change, $C_{t}$.
$\Delta_{c}=C_{m}-C_{t}$

Where $C_{m}=S_{2}-S_{1}, \mathrm{~S}_{2}$ is the sub-index score at time 2 and $\mathrm{S}_{1}$ is the sub-index score at time 1.

Since the variance of the true change is zero (it is not a random variable), the variance of, $\Delta_{c}$, can be expressed as:

${\sigma_{\Delta_{c}}}^{2}={\sigma_{S_{2}}}^{2}+{\sigma_{S_{1}}}^{2}$

Comparing equation 6.12 with 6.10 shows that the variance associated with change detection is likely to be larger than that for benchmarking, since the sub-index scores at times 1 and 2 will both be based on random sampling.

The procedure to quantify the errors associated with change detection was similar to that for benchmarking. A sub-index score was estimated from the complete data set using a particular sampling scheme, a change was made to the data (by adding a constant $C_{c}$ ) and then another sub-index score was estimated again by random sampling. The difference between the first and second sub-index scores represents an estimate of the change in condition. This can be compared to the real change (approximately equal 
to the added constant). This procedure was repeated a large number of times (5000) to quantify the variance (see Figure 6.19). Calculation procedures were automated in a program CHANGEDETECTION developed in Visual Basic ${ }^{\mathrm{TM}}$ and is similar to the program BENCHMARK that is listed in Appendix N.

Results are presented as the frequency with which the measured change is within $+/-0.5$ and $+/-1$ of the true change (see Figures 6.20 to 6.27). Results for the sampling scheme of 3 sites per reach and 3 transects per site are shown in Table 6.8. Again, 3 transects per site seemed likely to be a reasonable comprise between the cost of measurements and benefit in increased accuracy, as more transects are measured. The effect of sampling density on error in detecting change is shown in Figures 6.28 and 6.29.

When adding a constant to the original data set to simulate the real change, the resultant values of condition for each transect were corrected to ensure that they were not outside the range of zero to ten. A small value of $C_{c}$ was used to ensure that few corrections were required and that $C_{c}$, was a good estimate of the true change in the data. For example, a value of $C_{c}$ of 1 was used to produce the results shown in Figures 6.20 to 6.27. Similar results were obtained when using changes of +2 to -2 and the results will be a guide as to the ability of the sampling schemes to detect larger changes. The procedure will become less valid as the sub-index score for the reach approaches 10 or 0 (i.e. the change is sufficient to force most transect scores to 10 or 0 ), in which case the added constant is not a good estimate of the average change in indicator values.

The method of simulating change (Figure 6.19) makes no allowance for possible changes in variance as the indicator values increase or decrease. In the case of the Physical Form and Streamside Zone Sub-indices the scores are forced within the range of 0 to 10 , so the variance is likely to be largest for scores about 5 and be lowest for scores at either end of the scale. For the streams examined, the sub-index scores ranged from 3.4 to 6.9 (see Table 6.5 , so are likely to have relatively high variance but probably similar to other streams that flow through farmed floodplains. 


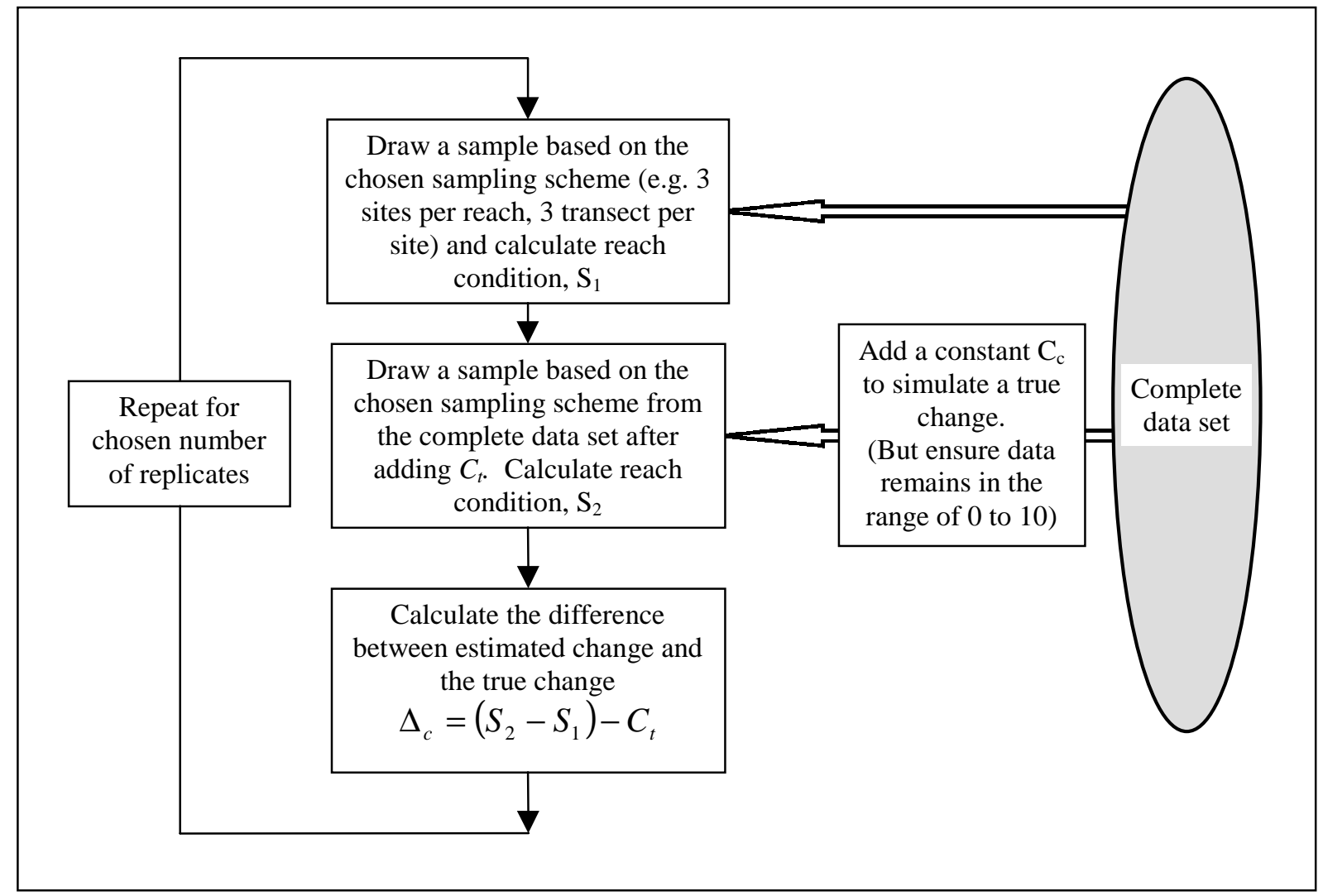

Figure 6.19 - Resampling procedure used to quantify errors associated with sampling to measure changes in the Physical Form and Streamside Zone Subindices

The accuracy of change detection was calculated in terms of sampling density as shown in Figures 6.28 and 6.29. These results again show that the ability to detect change accurately requires more sampling effort than benchmarking (compare Figures 6.17 and 6.18 with 6.28 and 6.29). For example, for the streamside zone, if $90 \%$ of detected change is to be within $+/-1$ of the true change then approximately 2.3 sampling sites are required per $10 \mathrm{~km}$ of reach. This compares to about 1.3 sampling sites per $10 \mathrm{~km}$ to ensure that $90 \%$ of reaches had a sampling mean within $+/-1$ of the true mean.

Table 6.8 - Relative accuracy of change detection for a sampling scheme based on 3 sites per reach and 3 transects per site

\begin{tabular}{|c|c|c|c|c|}
\hline \multirow[b]{3}{*}{ Range } & \multicolumn{4}{|c|}{$\begin{array}{l}\text { Frequency that estimate of change is within specified range of } \\
\text { the true change }\end{array}$} \\
\hline & \multicolumn{2}{|c|}{ Physical form } & \multicolumn{2}{|c|}{ Streamside zone } \\
\hline & $+/-0.5$ & $+/-1$ & $+/-0.5$ & $+/-1$ \\
\hline Broken River & $72 \%$ & $97 \%$ & $36 \%$ & $69 \%$ \\
\hline Ryans Creek & $72 \%$ & $96 \%$ & $49 \%$ & $80 \%$ \\
\hline
\end{tabular}




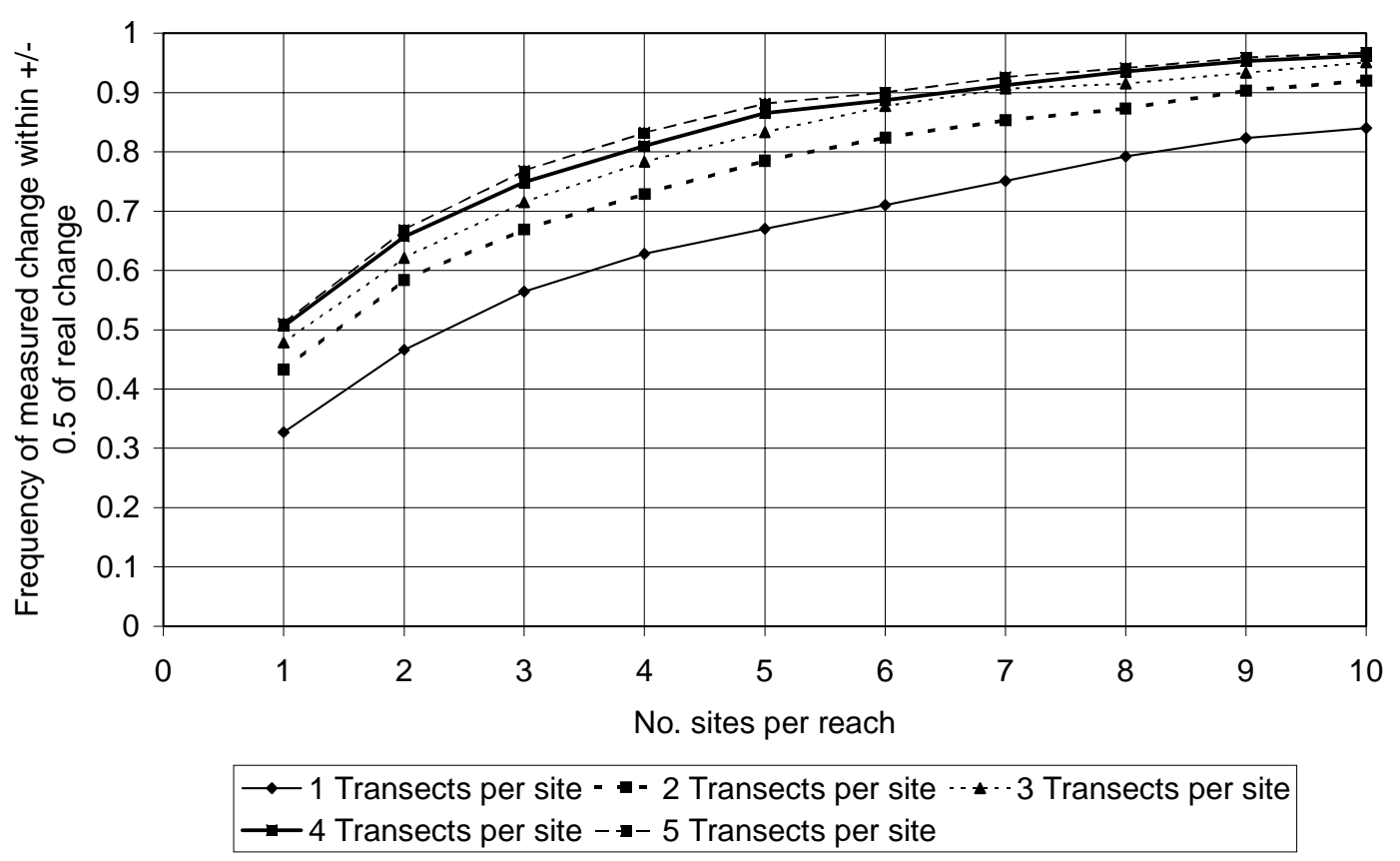

Figure 6.20 - Relative errors (+/- 0.5) associated with estimates of change in the Physical Form Sub-index on Ryans Creek for various sampling schemes

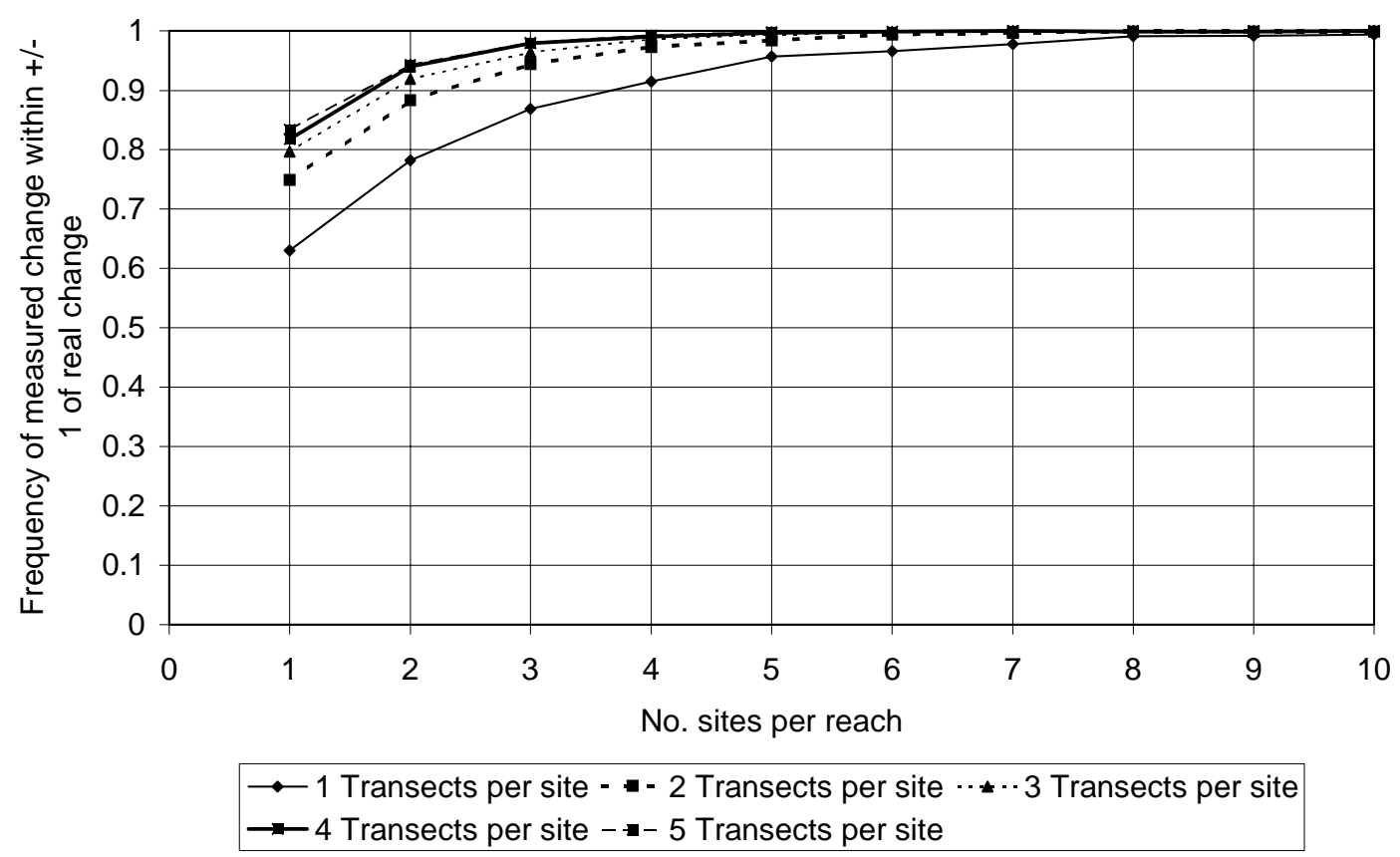

Figure 6.21 - Relative errors (+/- 1) associated with estimates of change in the Physical Form Sub-index on Ryans Creek for various sampling schemes 


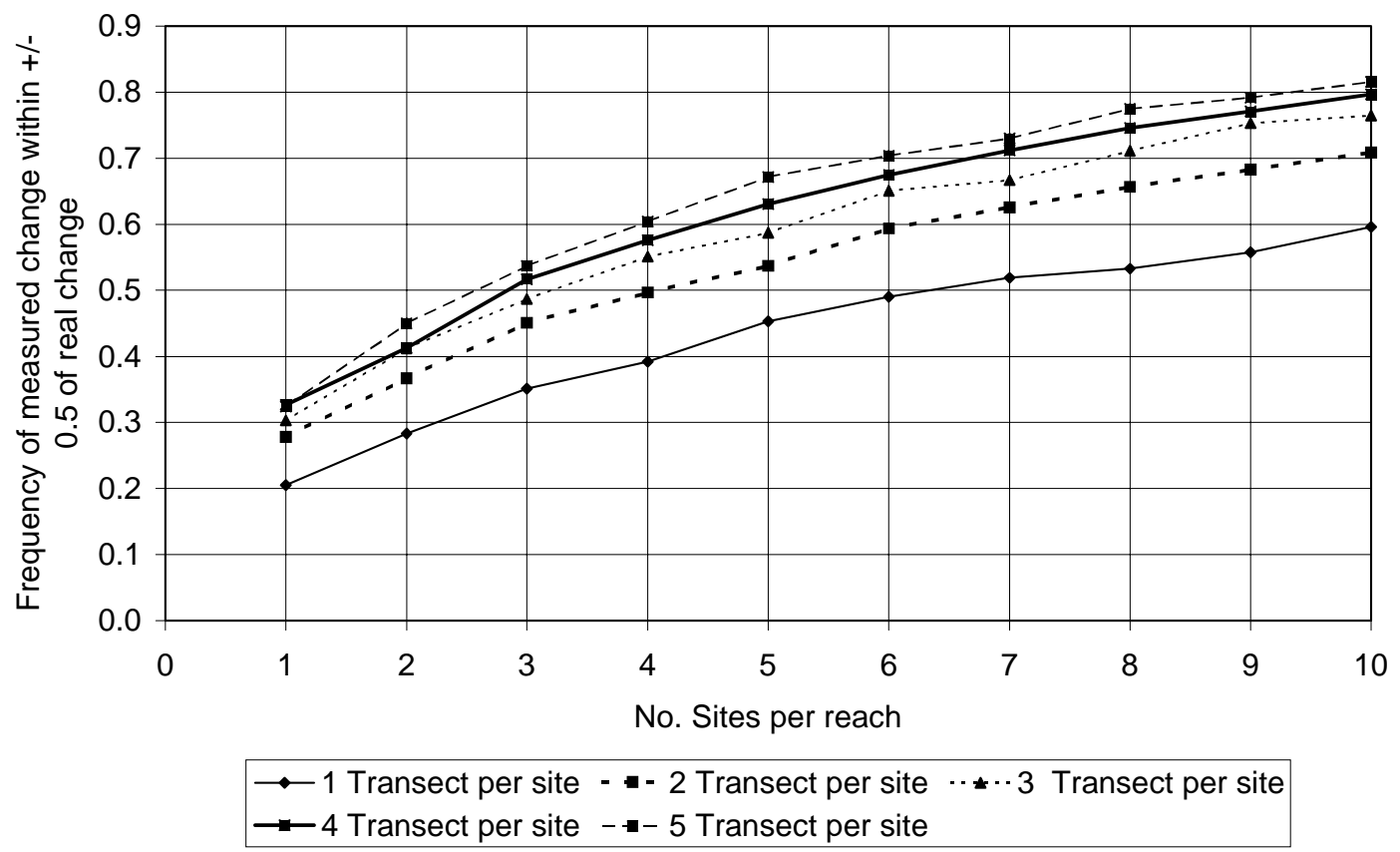

Figure 6.22 - Relative errors (+/- 0.5) associated with estimates of change in the Streamside Zone Sub-index on Ryans Creek for various sampling schemes

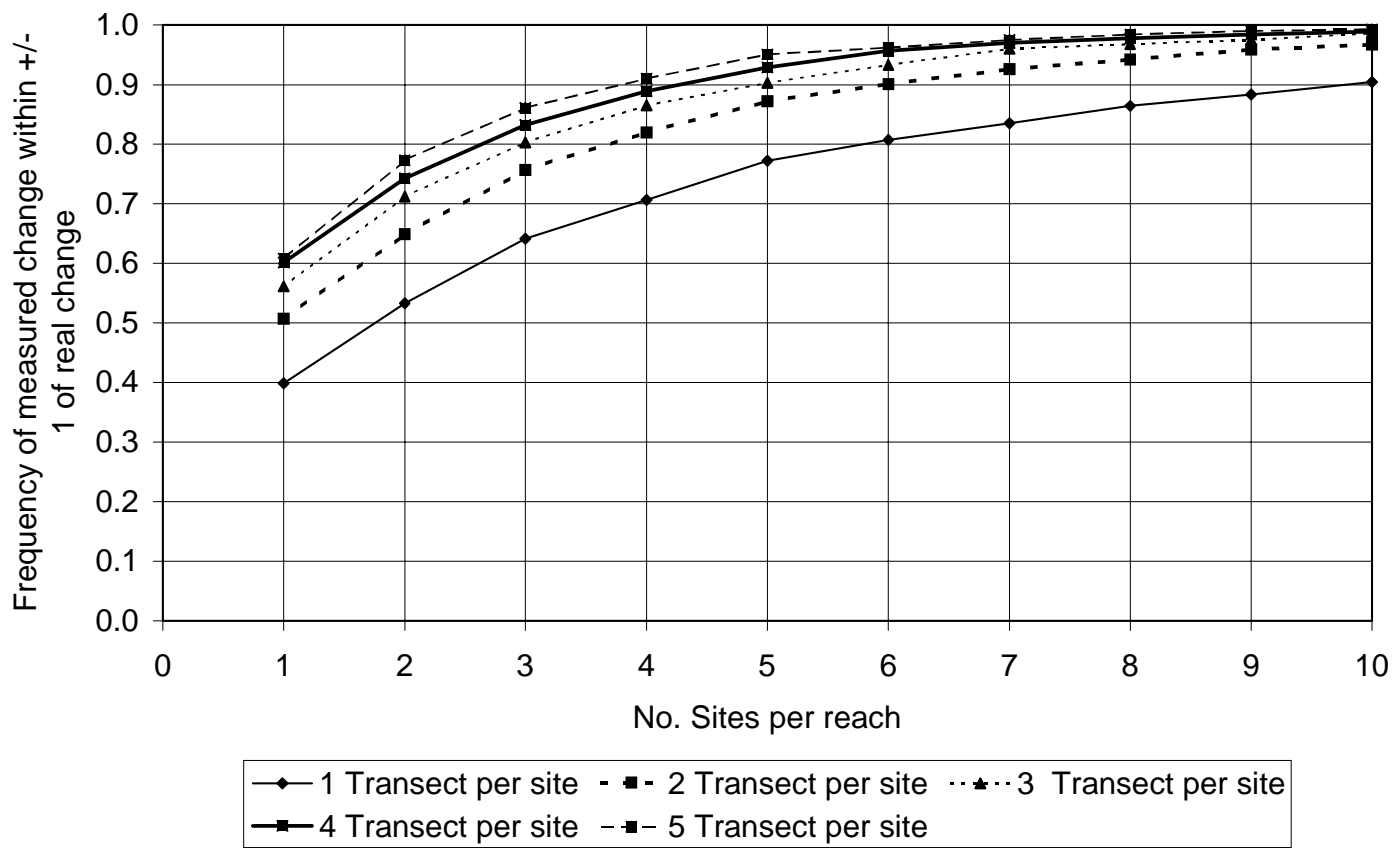

Figure 6.23 - Relative errors (+/- 1) associated with estimates of change in the Streamside Zone Sub-index on Ryans Creek for various sampling schemes 


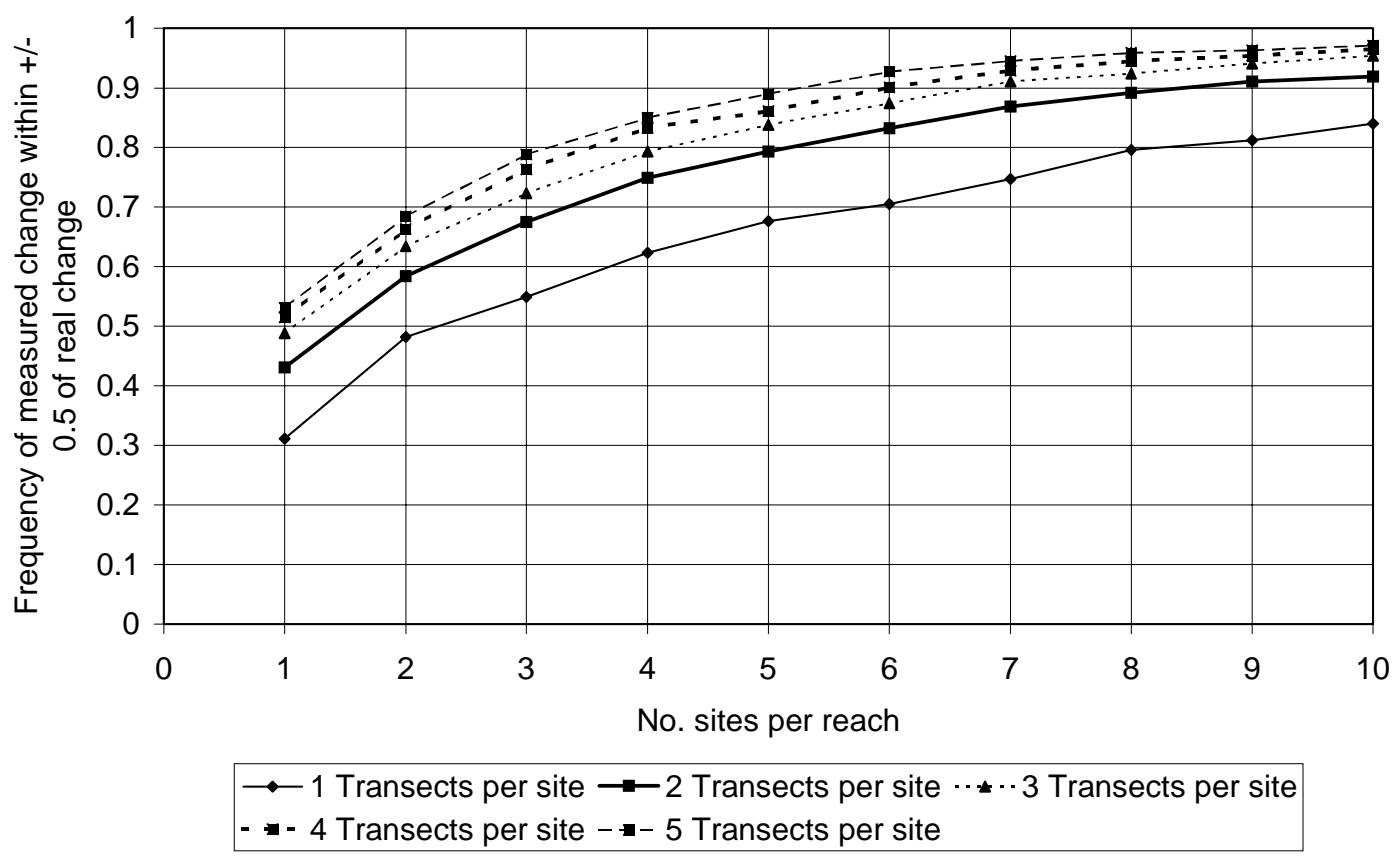

Figure 6.24 - Relative errors (+/- 0.5) associated with estimates of change in the Physical Form Sub-index on the Broken River for various sampling schemes

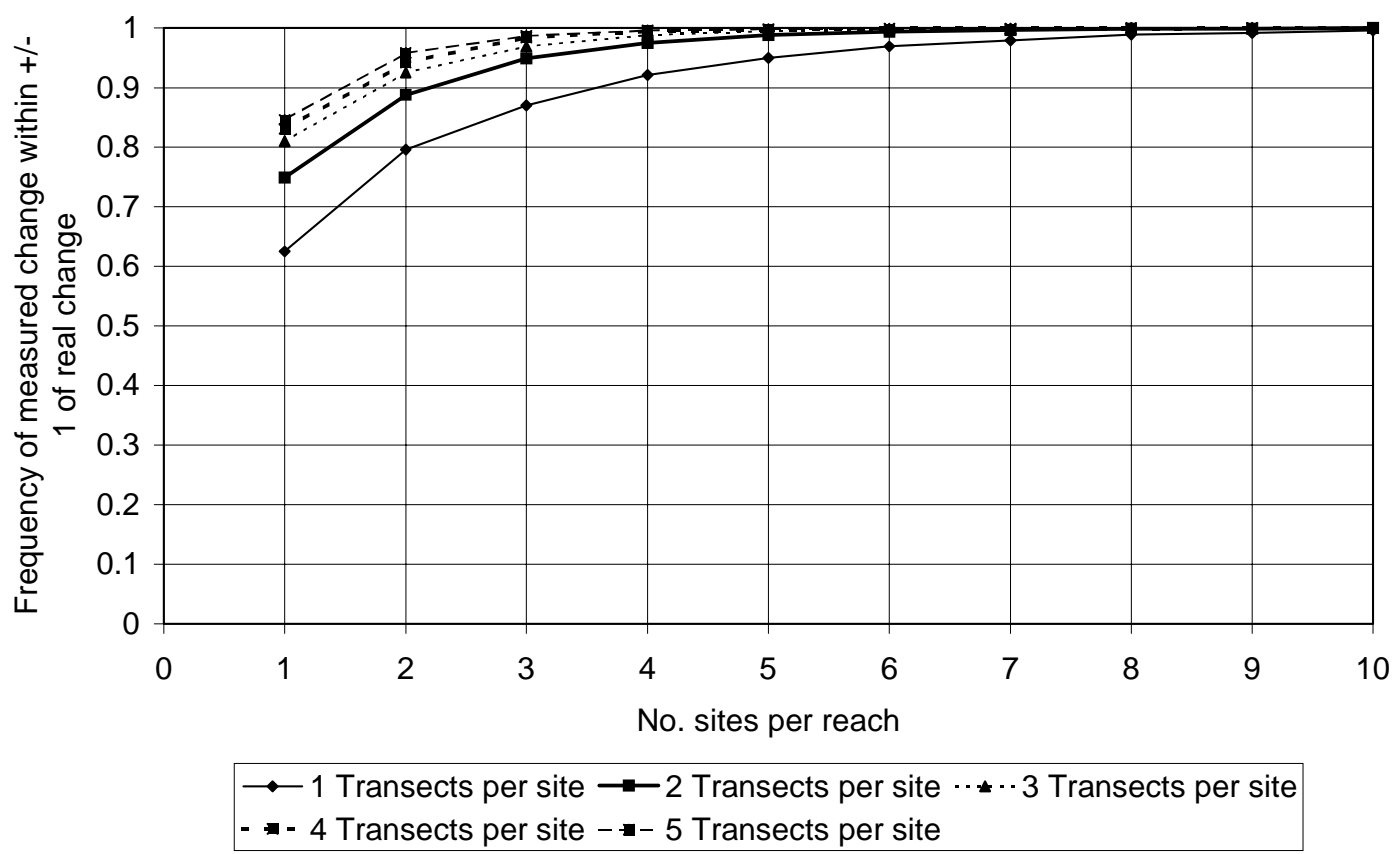

Figure 6.25 - Relative errors (+/- 1) associated with estimates of change in the Physical Form Sub-index on the Broken River for various sampling schemes 


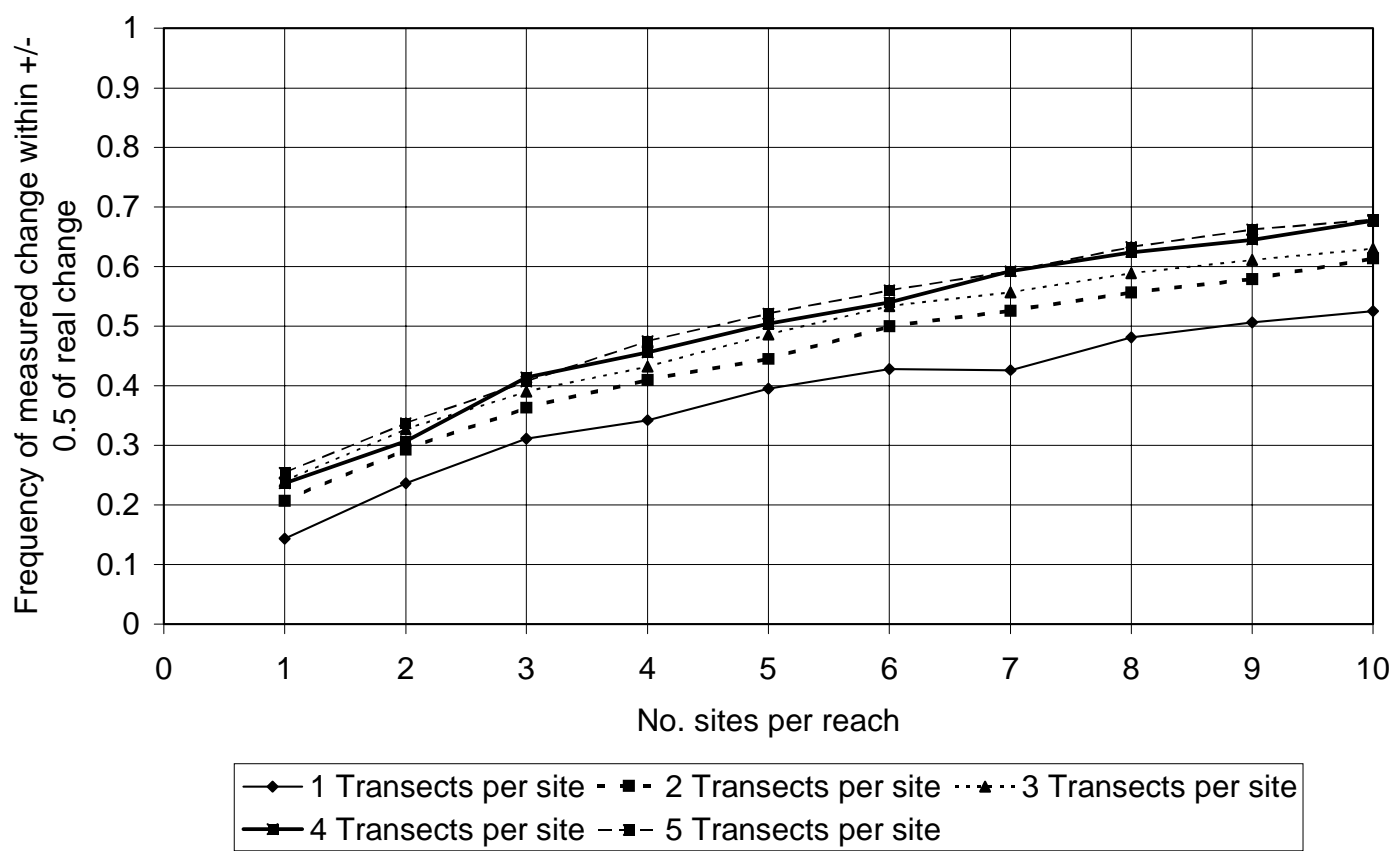

Figure 6.26 - Relative errors (+/- 0.5) associated with estimates of change in the Streamside Zone Sub-index on the Broken River for various sampling schemes

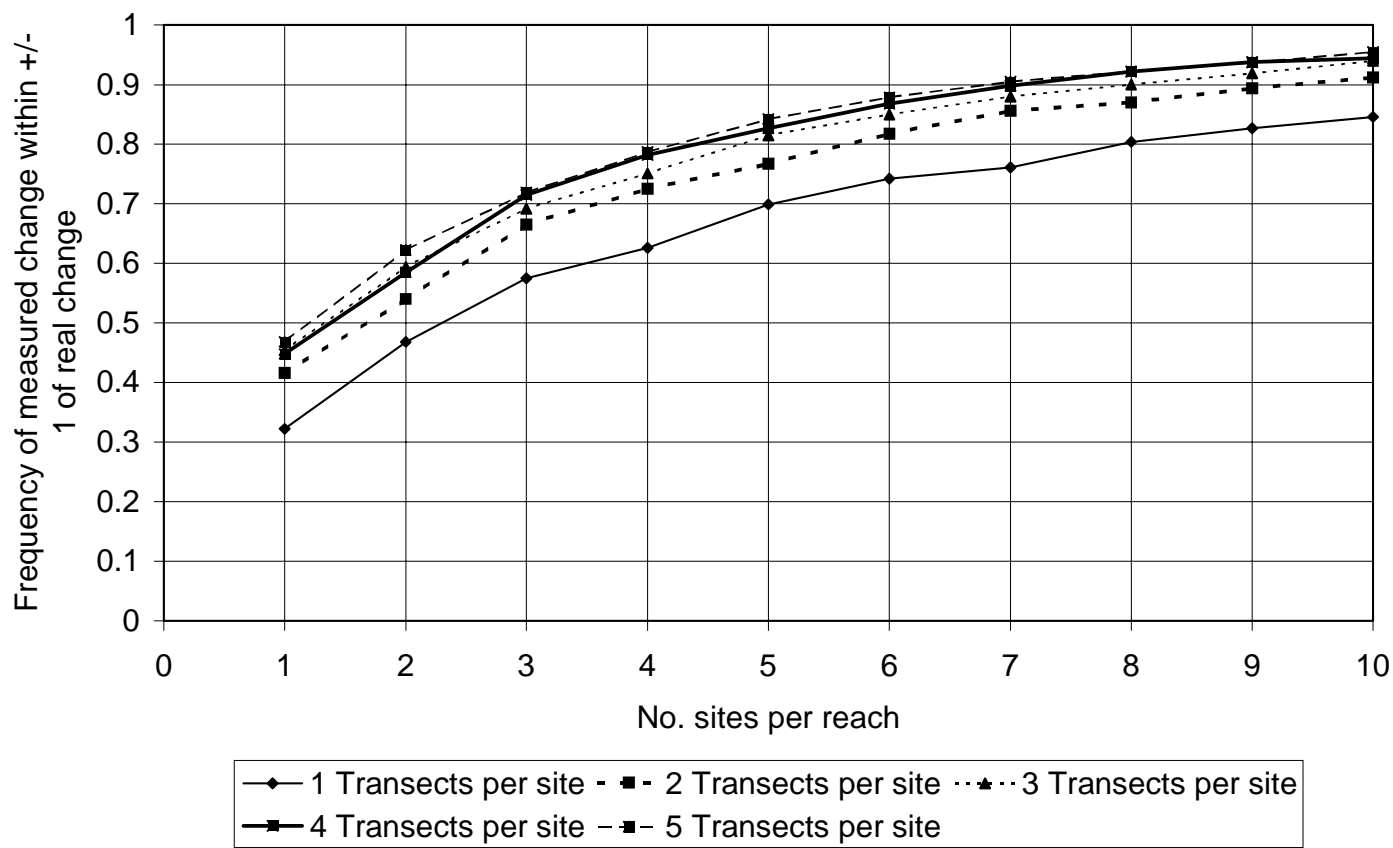

Figure 6.27 - Relative errors (+/- 1) associated with estimates of change in the Streamside Zone Sub-index on the Broken River for various sampling schemes 


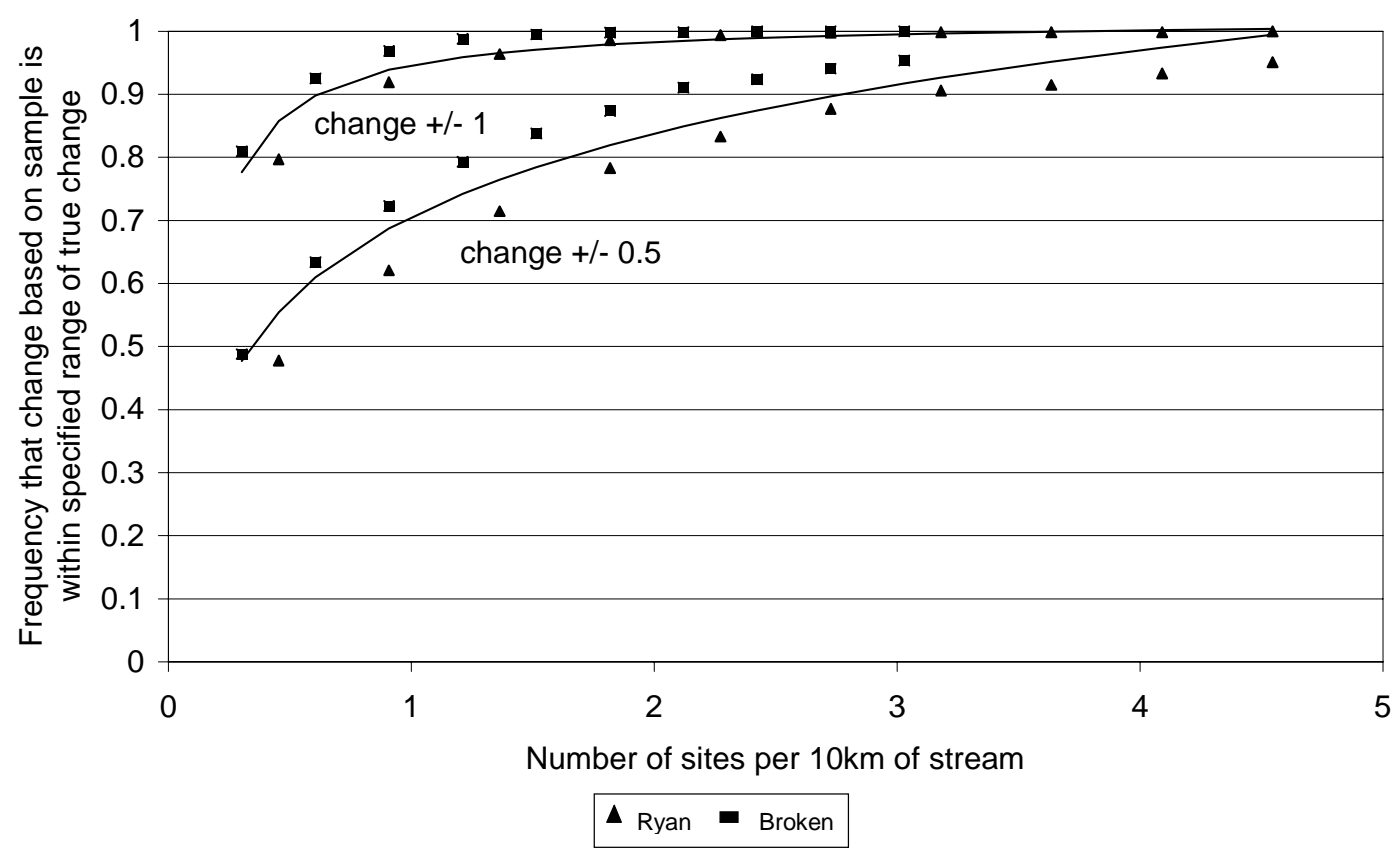

Figure 6.28 - Relative accuracy associated with estimates of change in the Physical Form Sub-index for sampling densities based on numbers of sites per $10 \mathrm{~km}$ of stream ( 3 transects per site)

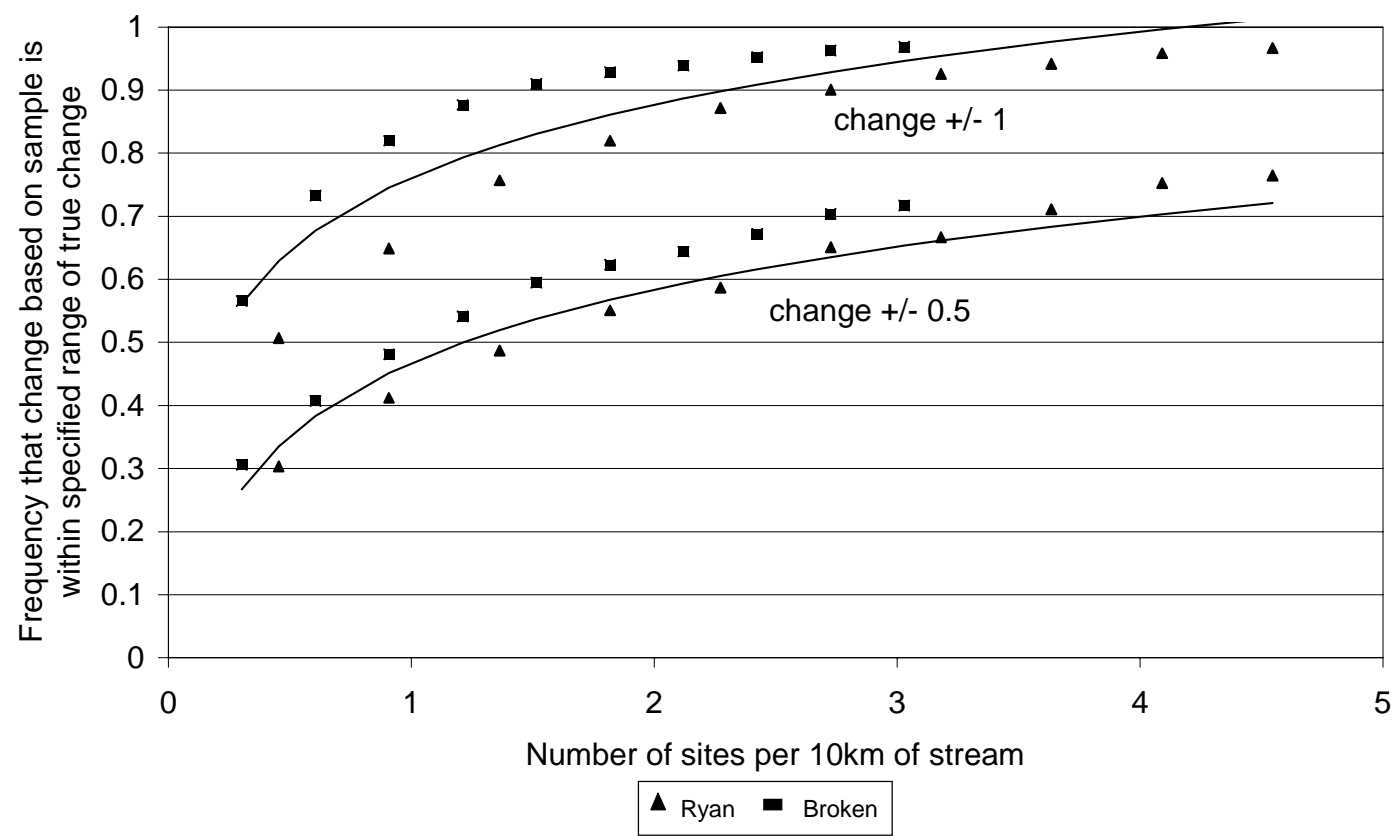

Figure 6.29 - Relative accuracy associated with estimates of change in the Streamside Zone Sub-index for sampling densities based on numbers of sites per $10 \mathrm{~km}$ of stream (3 transects per site) 


\subsubsection{Indicators as triggers for management action}

Objectives associated with benchmarking and change detection were part of the original ISC project. The performance of the streamside zone and physical form indicators in terms of these two objectives has been discussed in the previous two sections. Another possible objective of the ISC is to provide early warning of a change that requires management intervention. Intervention could be related to an indicator or sub-index such that if the score changes by a certain amount, or drops below a particular value, then some management response will occur.

Using indicators in this way can be subject to two types of error. Firstly, indicator values could provide a 'false alarm' (Type I error) where they show a change greater than a critical value but the true change is less than the critical change. Secondly there could be a 'false complacency' error (Type II error) where the indicator has not changed by a critical amount but in reality the critical change has occurred (Power et al., 1995; see Table 6.9. The standard notation of $\alpha$ and $\beta$ is used to describe the probabilities of Type I and Type II errors respectively (Peterman, 1990; Fairweather, 1991; Power et al., 1995; Mapstone, 1995). The costs associated with each of these errors are shown in Table 6.9 The performance of the Streamside Zone and Physical Form Sub-indices, based on various sampling strategies, can be assessed using this framework.

For example, consider the case where a manager believes that a true decrease in the Streamside Zone Sub-index of 3 is a serious situation. They decide to act when the subindex score decreases by 2 . The probability of getting a 'false alarm', $\alpha$ and the power of detecting the change $(1-\beta)$ can be calculated for various sampling strategies.

The first stage in the evaluation methodology is identical to that shown in Figure 6.19. A replicate procedure is used to calculate a series of values for the measured change $\Delta_{c}$ between two time periods subject to a specified true change $C_{t}$. Next, a critical value of change is specified $\Delta_{\text {crit }}$ and the proportion of values of the measured change greater than or equal to $\Delta_{\text {crit }}$ is calculated. This provides the probability of measuring a critical change for a particular true change and allows calculation of Type I and Type II errors. In the example above, the true change would be -3 and the critical change -2 and a replicated procedure is used to calculate the probability of measuring a critical change for the given true change. A Microsoft Visual Basic ${ }^{\mathrm{TM}}$ program EARLYWARNING was developed to undertake these calculations for range of values (see Appendix N). 
Table 6.9 - States of nature and associated errors and costs for decisions based on indicator values (adapted from Mapstone, 1995)

\begin{tabular}{|l|c|c|}
\hline State of nature & $\begin{array}{c}\text { Indicator value is less than } \\
\text { the critical value } \\
\mathbf{I}<\mathbf{I}_{\mathbf{c}}\end{array}$ & $\begin{array}{c}\text { Indicator value is greater than } \\
\text { or equal to critical value } \\
\mathbf{I} \geq \mathbf{I}_{\mathbf{c}}\end{array}$ \\
\hline $\begin{array}{l}\text { True change }< \\
\text { critical change }\end{array}$ & $\begin{array}{c}\text { Correct } \\
\text { Probability }=1-\alpha \\
\text { Cost }=0\end{array}$ & $\begin{array}{c}\text { Type I error } \\
\text { false alarm' } \\
\text { Probably }=\alpha \\
\text { Cost }=\mathrm{C}^{1}\end{array}$ \\
\hline $\begin{array}{l}\text { True change } \geq \\
\text { critical change }\end{array}$ & Type II error & Correct \\
& 'false complacency' & Probably $=(1-\beta)$ (power) \\
& Probably $=\beta$ & Cost $=\mathrm{C}-\mathrm{E}^{1}$ \\
\hline
\end{tabular}

${ }^{1}$ The cost of a Type I error (false alarm) is the cost of management intervention C. The cost of a type II error (false complacency) is the cost of environmental damage. In the case of a correct decision that a critical change has occurred, the total cost is the cost of intervention less the environmental damage avoided (C-E).

Results were calculated as the probability of seeing a critical change in the indicator given a particular true change to the underlying data (see Figures 6.30 to 6.33). These graphs were generated by holding the critical change at -2 for a variety of true changes but they provide a guide to other values of critical change. The number of replicates used was 2 000. The program EARLYWARNING allows gaming for a variety of true and critical changes and sampling strategies.

These graphs show the probability of getting a Type I 'false alarm' error and a Type II 'false complacency' error for various scenarios. Points to the right of the vertical axis show the probability of getting a critical change when the true change is less than the critical change - a 'false alarm'. For a given true change, specifying the critical change determines the value of $\alpha$ for a given sampling strategy. To the left, they show the probability of getting a critical change when the true change is larger than the critical change. This is equivalent to the statistical power i.e. the probability of detecting a change when it has occurred (see Table 6.9]. Subtracting this value from 1 will give the probability of a Type II error. An ideal indicator would take the value of zero to the right of the vertical axis and 1 to the left. Figures 6.30 to 6.33 show that the greater the sampling density, the more closely the indicator approaches the ideal. For the situation where the true change and the critical change are equal, both $\alpha$ and $\beta$ will be about $50 \%$ if the statistical distribution of the sub-indicators is approximately symmetrical. As the 


\section{Streamside zone and physical form}

sub-index value approaches 0 or 10 , the statistical distribution will become increasingly asymmetrical.

The results shown in Figures 6.30 to 6.33 can be used to relate five variables:

1. The true change that is a cause for concern $C_{t}$;

2. The critical change in the indicator, $\Delta_{\text {crit }}$;

3. The power (1- $\beta$ ) to detect a true change of a given magnitude (or $\beta$ the probability of a Type II error i.e. not detecting a change when it has occurred);

4. The probability that a true change of a certain size will trigger a false alarm (Type I error, $\alpha)$; and

5. The sampling strategy (number of sites, and number of transects per site).

Specifying any three of these variables will determine the other two. For example, in a management situation, it would be reasonable to specify $C_{t}$, $\alpha$, and $\beta$ which would determine the appropriate sampling strategy and value of critical change.

For example, consider the streamside zone on Ryans Creek. Specifying the true change of concern as -3 , power $=80 \%$ and the probability of a Type I error $\alpha=10 \%$ when the true change is -1 . The heuristic to select the sampling strategy is as follows.

Step 1 - choose a sampling strategy; that is, the number of sites per reach and the number of transects per site.

Step 2 - determine the critical change, $\Delta_{\text {crit }}$ from the abscissa corresponding to a probability of critical change of $80 \%$. $\Delta_{\text {crit }}=-3$ - abscissa (when true change of concern $=-3)$.

Step 3 - determine the value of $\alpha$ from the graph from the ordinate (for that sampling strategy) when the abscissa is $-1-\Delta_{\text {crit }}$ (when calculating $\alpha$ for true change $=-1$ ).

Step 4 - if $\alpha$ is greater than $10 \%$ then choose a denser sampling strategy; if less than $10 \%$ choose a sparser sampling strategy and repeat steps 2 to 4 until the constraints are satisfied.

Choosing appropriate values for $\alpha$, and $\beta$ remains a difficult problem and depends on the costs associated with Type I and Type II errors (see Table 6.9. A procedure for selecting these values is provided by Mapstone (1995). 
Results were also calculated to examine the influence of sampling density on the performance of indicators in terms of Type I and Type II errors (see Figures 6.34 and 6.35). As the number of sites per kilometre of stream length increases, so does the ability of the indicator to detect a major change when it has occurred (the top line in Figures 6.34 and 6.35) and to avoid a false alarm when there has not been an important change (bottom line in Figures 6.34 and 6.35). Results presented here are for 3 transects per site, a critical change of -2 and a true changes of -3 and -1 , to represent the cases of the major change actually occurring, or not occurring, respectively. For example, for streamside zone, a sampling density of 2 sites per $10 \mathrm{~km}$ provides a power to detect change (1- $\beta$ ) of about $90 \%$ with the probability of false alarm, $\alpha$ of about $7 \%$. Other cases could be examined if necessary. These figures could be used to guide selection of sampling densities if the acceptable error rate is nominated.

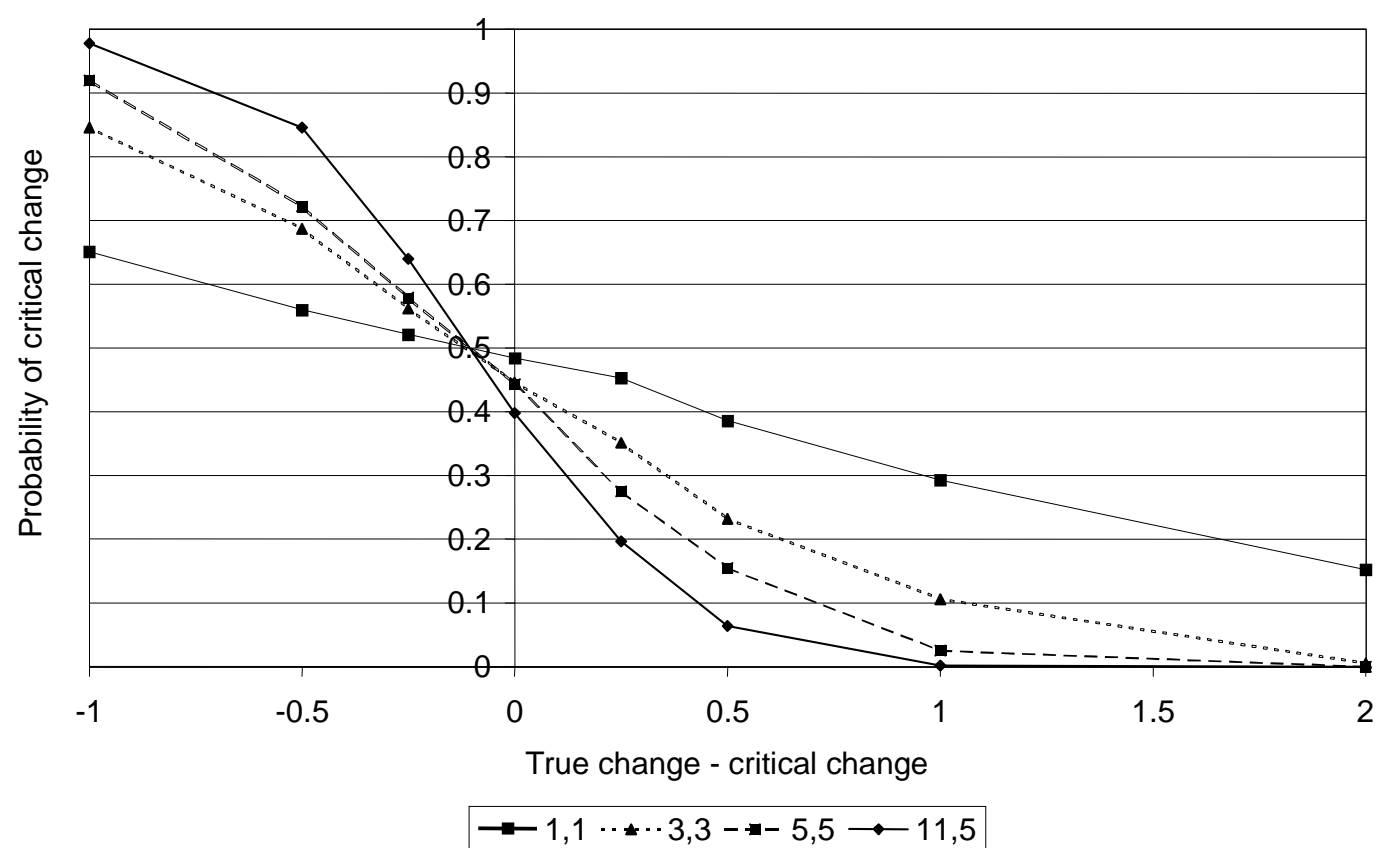

Figure 6.30 - Performance of sampling schemes for providing early warning and avoiding false alarms (Ryans Creek, streamside zone). Legend shows the no. of sites, no. of transects per site. Critical change of $-2,2000$ replicates. 


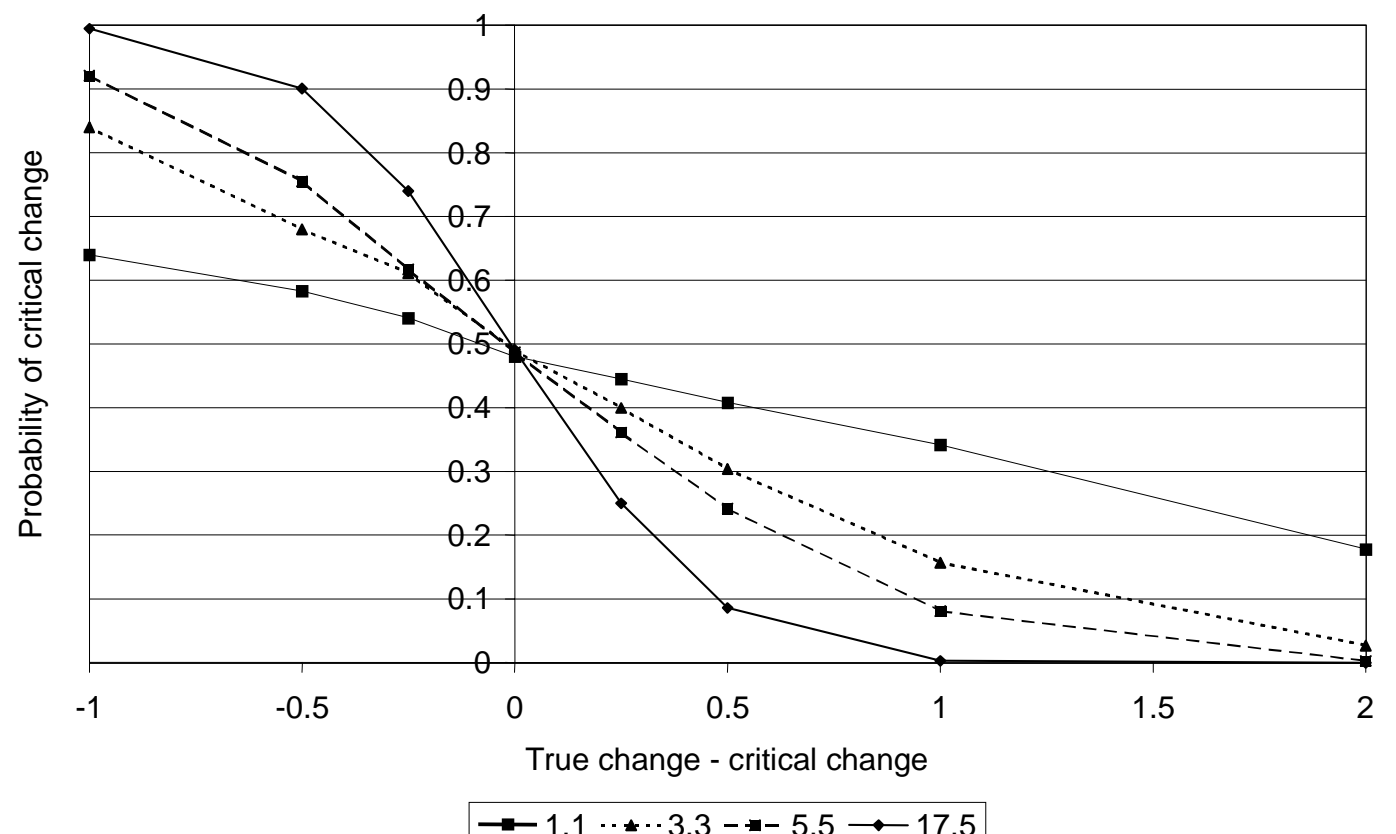

Figure 6.31 - Performance of sampling schemes for providing early warning and avoiding false alarms (Broken River, streamside zone). Legend shows the no. of sites, no. of transects per site. Critical change of $-2,2000$ replicates.

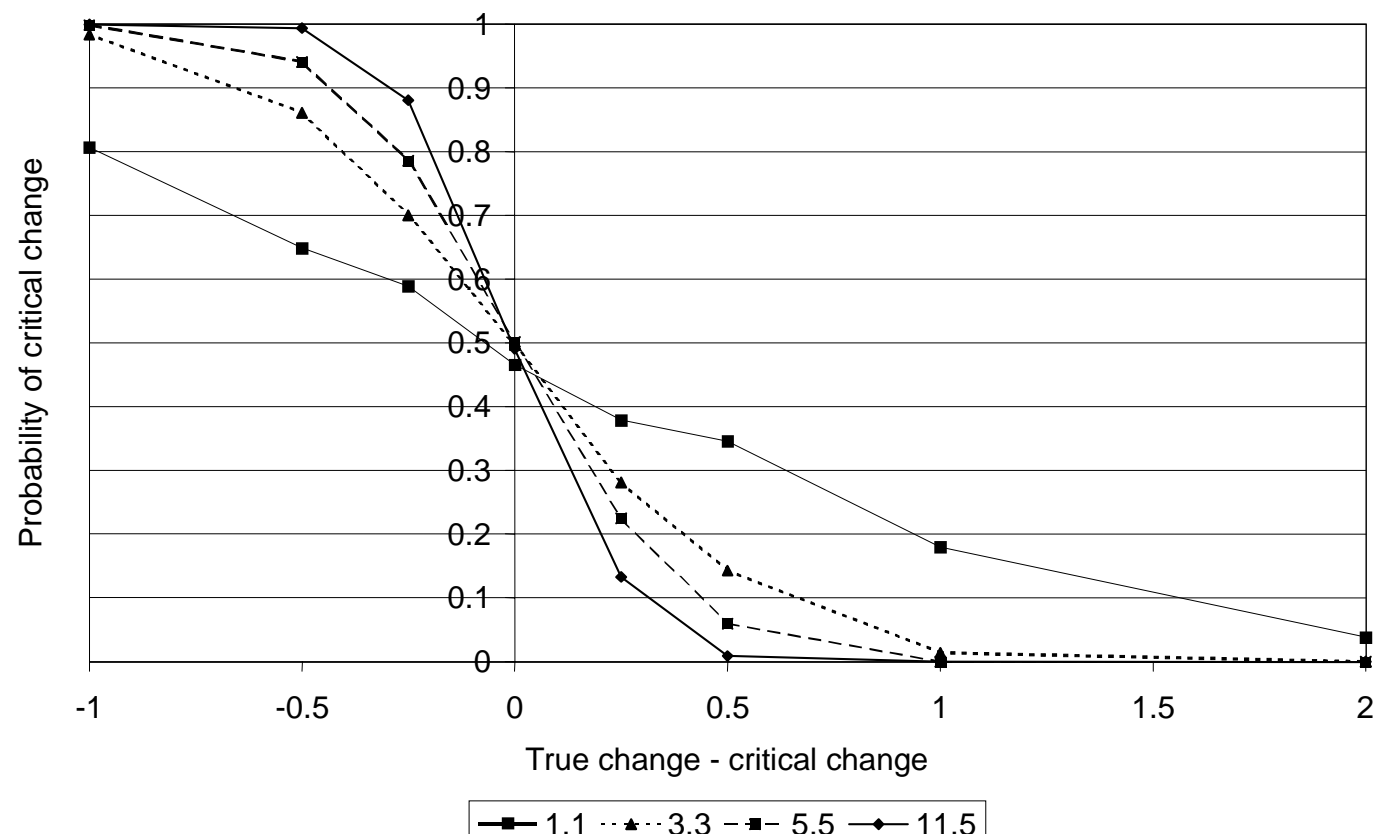

Figure 6.32 - Performance of sampling schemes for providing early warning and avoiding false alarms (Ryans Creek, physical form). Legend shows the no. of sites, no. of transects per site. Critical change of $-2,2000$ replicates. 


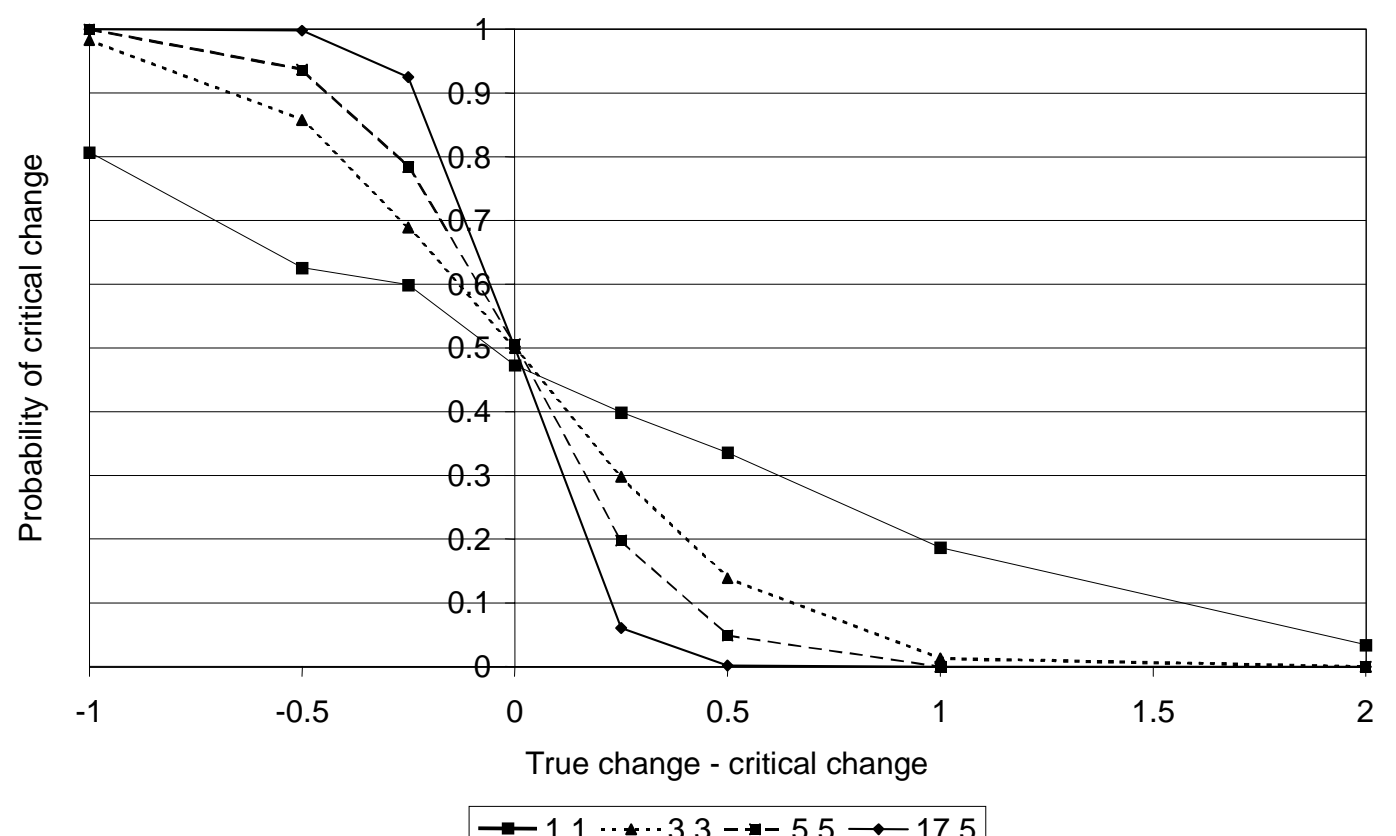

Figure 6.33 - Performance of sampling schemes for providing early warning and avoiding false alarms (Broken River, physical form). Legend shows the no. of sites, no. of transects per site. Critical change of $-2,2000$ replicates.

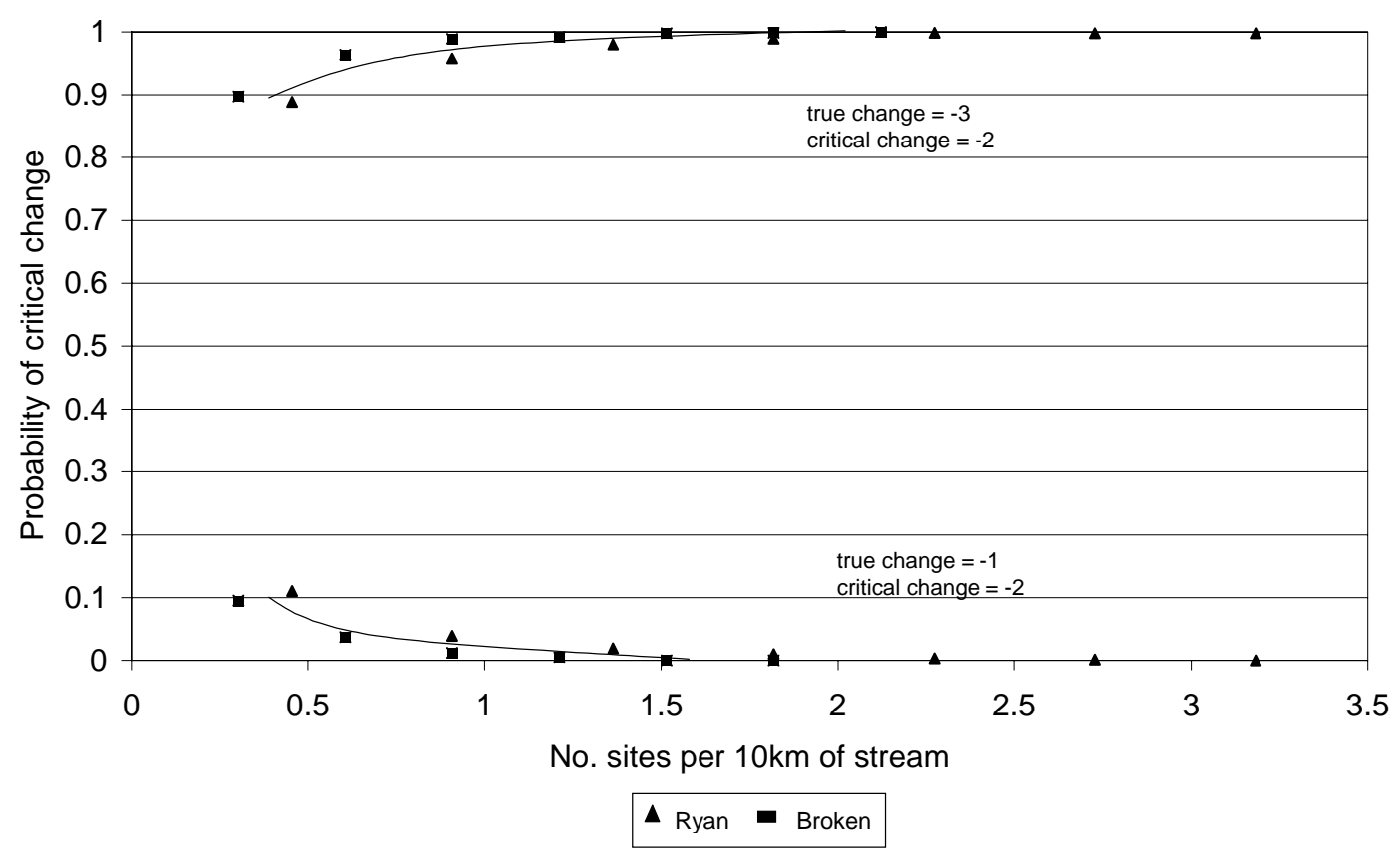

Figure 6.34 - Relationship between sampling density and probability of obtaining a critical change (physical form, 3 transects per site, 2000 replicates) 


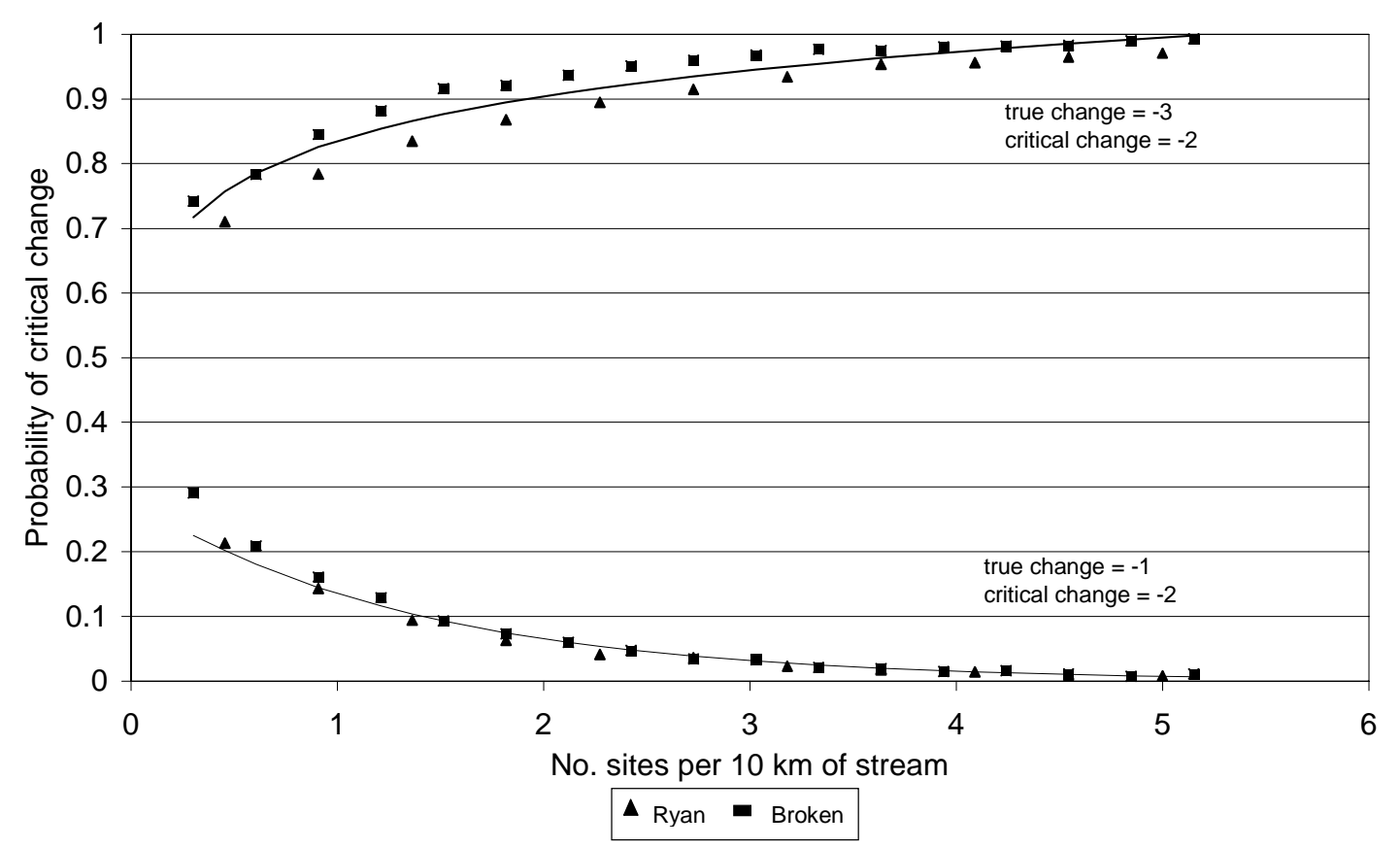

Figure 6.35 - Relationship between sampling density and probability of obtaining a critical change (streamside zone, 3 transects per site, 2000 replicates)

\subsection{Other sources of error}

\subsubsection{Introduction}

Widespread application of a stream assessment technique, such as the ISC will introduce errors that have not been considered in the analysis presented so far. It is planned that river management authorities will conduct ISC assessments throughout the State of Victoria. Measurements will be made in a variety of geographic locations and over several years. Numerous people, perhaps 40 or more, will be involved in the field measurements of physical form and streamside zone. Their assessments will subject to errors such as bias and drift. It is also likely that errors will be caused by inter-operator variability. It may be necessary to 'calibrate' assessors through training courses, audits and assessment of standard sites.

\subsubsection{Bias and drift}

Bias could occur where assessors consistently rate streams as being in better or worse condition than is appropriate. There are two ways to quantify bias. Firstly, it may be possible to have a standard way of measuring unbiased stream condition and then compare these accurate results with those of assessors that are suspected of being 
biased. Standard assessments could be made by a group of experts travelling around the State auditing stream condition assessments. A second approach would be to have assessors measure the ISC at a series of standard reaches that had been previously assessed by experts. A consistent difference in results would indicate bias.

Drift occurs where assessments become biased over time. Assessors may start out making measurements that agree with the expert standard but systematic inaccuracies may occur. Auditing results may detect bias which could suggest the need for refresher training courses.

\subsubsection{Inter-operator variability}

If different assessors collect ISC data, then inter-operator variability will contribute to measurement error. Inter-operator variability has not been considered in the results so far because data were collected by one team of two people. A Victoria-wide application of the ISC will involve assessments by nine Catchment Management Authorities over 29 basins. Measurements will be made by at least 10, and possibly up to 20, assessment teams.

It is possible to examine inter-operator variability by analysing data from training courses undertaken as part of the 1999 Victoria-wide application of the ISC (Table 6.10. Data are available for three training courses, conducted in Traralgon, Shepparton and Horsham which took place over 2 days. The first day consists of lectures and field exercises and concludes with all the participants being divided into teams of two who independently assess a site. The results of this assessment are used to determine where additional training is required on the second day, with emphasis on those indicators that show the greatest variability (L. White pers. comm.). Results from the assessment at the end of the first day at each of the workshops are shown in Table 6.10 The mean, standard deviation and an estimate of the standard error in the mean are reported in the table.

The measurements made by the sampling teams were also compared to the assessments made by the trainer at the same sites. To compare the results for all training teams at all sites, the proportional error was calculated for each assessment. Results were binned and plotted as histograms (Figure 6.36 and 6.37). These results show that most of the assessments are within $10 \%$ of the expert's value. Physical form is more accurately assessed than streamside zone with $38 \%$ of trainees with error in the zero bin (between 


\section{Streamside zone and physical form}

$+2.5 \%$ and $-2.5 \%$ ) compared to $21 \%$ for streamside zone. One assessment team made a large error in the streamside zone assessment at Horsham (the figure shaded in Table 6.10 which makes a major contribution to the variance.

The standard deviations and coefficients of variation attributable to inter-operator variability can be compared to variation in sub-index measurements from the Broken River and Ryans Creek (compare Table 6.5 with Table 6.10. A gross comparison can be made by averaging the coefficients of variation for each sub-index. For streamside zone the average CV from the field assessment of Broken River and Ryans Creek is $35 \%$ while the average $\mathrm{CV}$ attributed to inter-operator variability is $10 \%$. For physical form, the average $\mathrm{CV}$ from field assessments is $12 \%$, while that from inter-operator variability is about $7 \%$. This suggests that inter-operator variability could be a significant source of error in a large-scale application of the ISC.

Table 6.10 - Inter-operator variability for Physical Form and Streamside Zone Sub-indices

\begin{tabular}{|c|c|c|c|c|c|c|}
\hline \multirow[b]{2}{*}{$\begin{array}{c}\text { Sampling } \\
\text { Team }\end{array}$} & \multicolumn{3}{|c|}{ Physical form } & \multicolumn{3}{|c|}{ Streamside zone } \\
\hline & Traralgon & Shepparton & Horsham & Traralgon & Shepparton & Horsham \\
\hline 1 & 6.3 & 5.8 & 5.8 & 3.0 & 4.4 & 5.0 \\
\hline 2 & 6.5 & 6.9 & 5.8 & 3.3 & 4.7 & 4.9 \\
\hline 3 & 7.1 & 6.7 & 6.0 & 2.8 & 4.4 & 5.1 \\
\hline 4 & 6.3 & 6.9 & 6.0 & 3.2 & 4.5 & 5.2 \\
\hline 5 & 6.7 & 7.3 & 5.2 & 3.7 & 5.0 & 7.7 \\
\hline 6 & 6.9 & 7.1 & 6.0 & 3.9 & 4.3 & 5.8 \\
\hline 7 & 6.7 & 6.9 & 5.8 & 3.5 & 4.3 & 4.7 \\
\hline 8 & 6.7 & 5.2 & 5.6 & 3.6 & 4.2 & 6.6 \\
\hline 9 & & 5.4 & 6.3 & & 4.6 & 5.3 \\
\hline 10 & & 5.8 & 6.7 & & 4.8 & 6.2 \\
\hline 11 & & 6.7 & & & 4.5 & \\
\hline $\begin{array}{c}\text { Trainer's } \\
\text { assessment }\end{array}$ & 6.7 & 6.9 & 6.3 & 3.5 & 4.8 & 4.9 \\
\hline $\begin{array}{l}\text { Mean (of all } \\
\text { assessments) }\end{array}$ & 6.6 & 6.5 & 6.0 & 3.4 & 4.5 & 5.6 \\
\hline $\begin{array}{l}\text { Standard } \\
\text { deviation }\end{array}$ & 0.3 & 0.7 & 0.4 & 0.3 & 0.2 & 0.9 \\
\hline $\begin{array}{c}\text { Standard error } \\
\text { of mean }\end{array}$ & $9 \%$ & $20 \%$ & $11 \%$ & $11 \%$ & $7 \%$ & $28 \%$ \\
\hline $\begin{array}{c}\text { Coefficient of } \\
\text { variation }\end{array}$ & $4.5 \%$ & $11 \%$ & $6.7 \%$ & $8.8 \%$ & $4.4 \%$ & $16 \%$ \\
\hline
\end{tabular}

These results should be treated as indicative rather than accurate assessments of variability in each case, since the data set is small and assessments of the two types of 
error have been made at different sites. It is also expected that the inter-operator variability has been overestimated compared to the actual assessments to be undertaken as part of the Victoria-wide application of the ISC. These results are from the end of day 1 of a 2-day training course, so assessors will have one additional day of training which has been shown to reduce variability in visual based assessment of stream habitat (Wang et al., 1996; Hannaford et al., 1997). It is also likely that variability will decrease with experience, although problems of 'drift' are likely to increase over time.

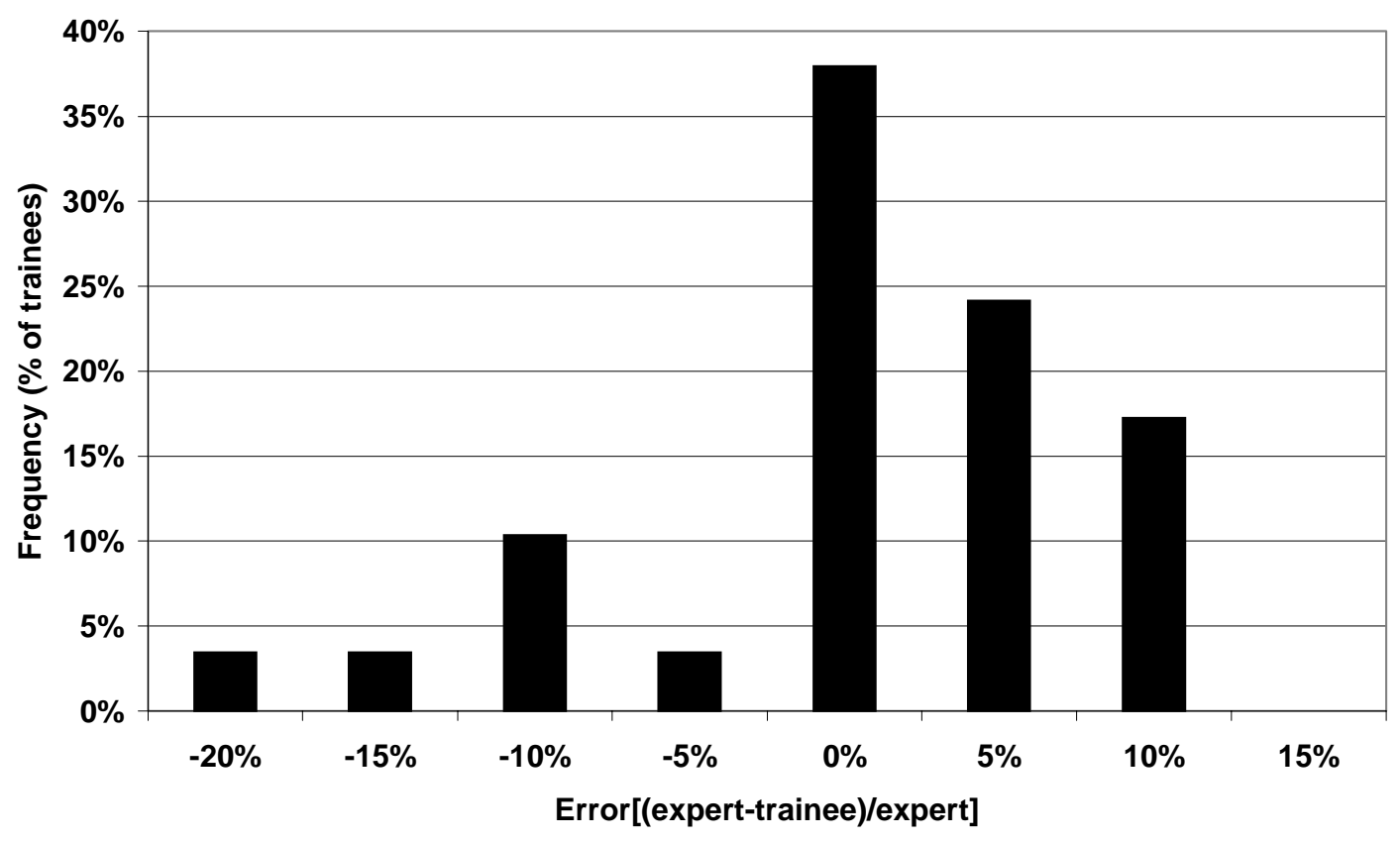

Figure 6.36 - Accuracy of assessment of Physical Form Sub-index by trainees

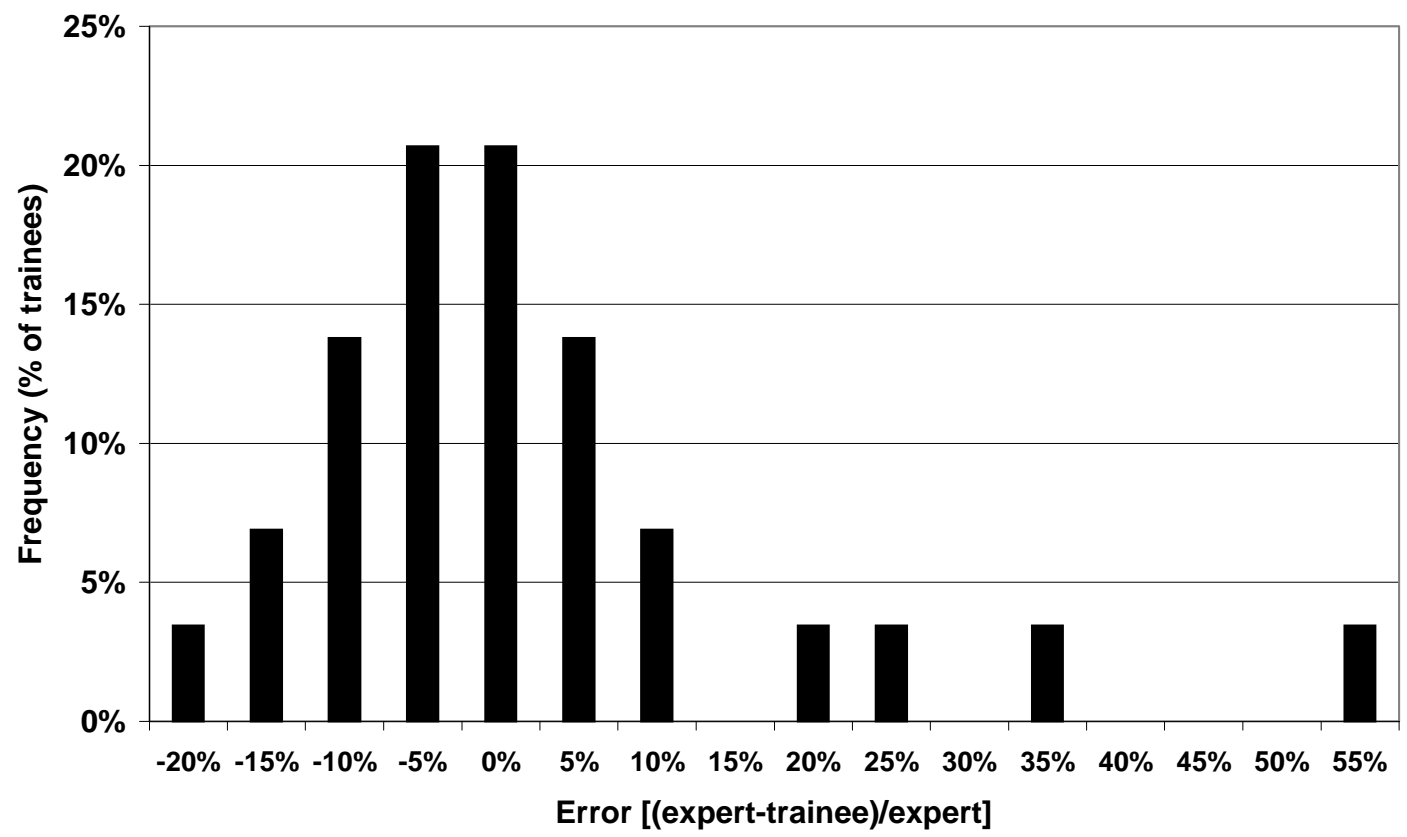

Figure 6.37 - Accuracy of assessment of Streamside Zone Sub-index by trainees 


\subsubsection{Reducing other sources of error}

It is possible to develop programs to reduce error associated with bias, drift and interoperator variability. Recommendations include training of assessors, developing guidelines for assessment, auditing results and assessment of standard reaches.

Hannaford et al. (1997) showed that training could reduce inter-operator variability in visual based assessments and training programs have been developed for the ISC (L. White pers. comm.). Assessors who undertake training are accredited and at least one member of an ISC assessment team must have undertaken training before the State Government will accept results. A similar accreditation scheme is used in the UK for the RHS (Fox et al., 1998). Hannaford et al. (1997) recommended that training should include assessments at sites in a range of conditions to ensure accurate assessments over the whole scale of measurements. This is not currently implemented in the ISC training programs and should be considered.

Guidelines for ISC assessments have been developed that include written descriptions, photographic examples, and field sheets (White and Ladson, 1999a). These are used during the training course (White pers. comm.) and in subsequent field assessment.

Expert auditing of ISC results has the potential to detect bias and drift. An auditing program has been developed by DNRE and it will be important to continue this throughout the time ISC assessments are being made. It will also be necessary to ensure that audits have sufficient statistical power to detect changes of interest. Preliminary results from audits could be used to quantify power and detectable effect size (Peterman, 1990). Auditing could be supplemented by inviting assessors from around the State to measure standard reaches that have been scored by experts. Results from these assessments could be used to check for bias and to target additional training.

\subsection{Sensitivity to management-induced change}

\subsubsection{Introduction}

If the ISC is to be useful as a management tool it must be sensitive to the types of changes that interest managers and capable of responding where there is management intervention that affects stream condition. A detailed assessment of the performance of the ISC as a tool to measure management effectiveness would require a time series of 
ISC measurements and information on management objectives and activities as well as spatial replication and control (Walters and Holling, 1990; see Section 8.5.3). This type of study is not possible at present, as ISC assessments are only now being undertaken. Instead, a preliminary assessment has been made using approximate values of the ISC derived from historical data. Information from the detailed assessment of Ryans Creek, discussed earlier, is used to develop a method to determine the statistical significance of changes in ISC scores.

\subsubsection{Calculating ISC values from historical data}

Historical data on stream conditions can be obtained from stream surveys, aerial photography, DNRE databases, and files and reports held by local, regional and State Government management agencies. A key source of information is the 1986 State of the Streams Survey (SSS) (reviewed in Section 4.2.1). This survey was undertaken by the Department of Water Resources, Victoria and included collection of 200 physical variables at 868 sites throughout the State along with photographs and written descriptions (Tilleard and DWR, 1986; Mitchell, 1990). This data can be used to estimate ratings for some indicators from the Physical Form and Streamside Zone Subindices (see Appendix O) and when supplemented with other data, complete sub-index scores can be calculated Table 6.11.

\subsubsection{Case study: Fifteen Mile Creek}

As a case study, techniques to generate indicator scores were applied to sites on the Fifteen Mile Creek in northeastern Victoria. ISC scores were estimated for 1986 from historical data and then measured during early 1997.

The Fifteen Mile Creek has a catchment area of $400 \mathrm{~km}^{2}$ and rises near Archerton at an elevation of about $900 \mathrm{~m}$ and flows north to join the Ovens River near Wangaratta $\left(146^{\circ} 20^{\prime} \mathrm{E}, 36^{\circ} 40^{\prime} \mathrm{S}\right.$, see Figure 6.38). 


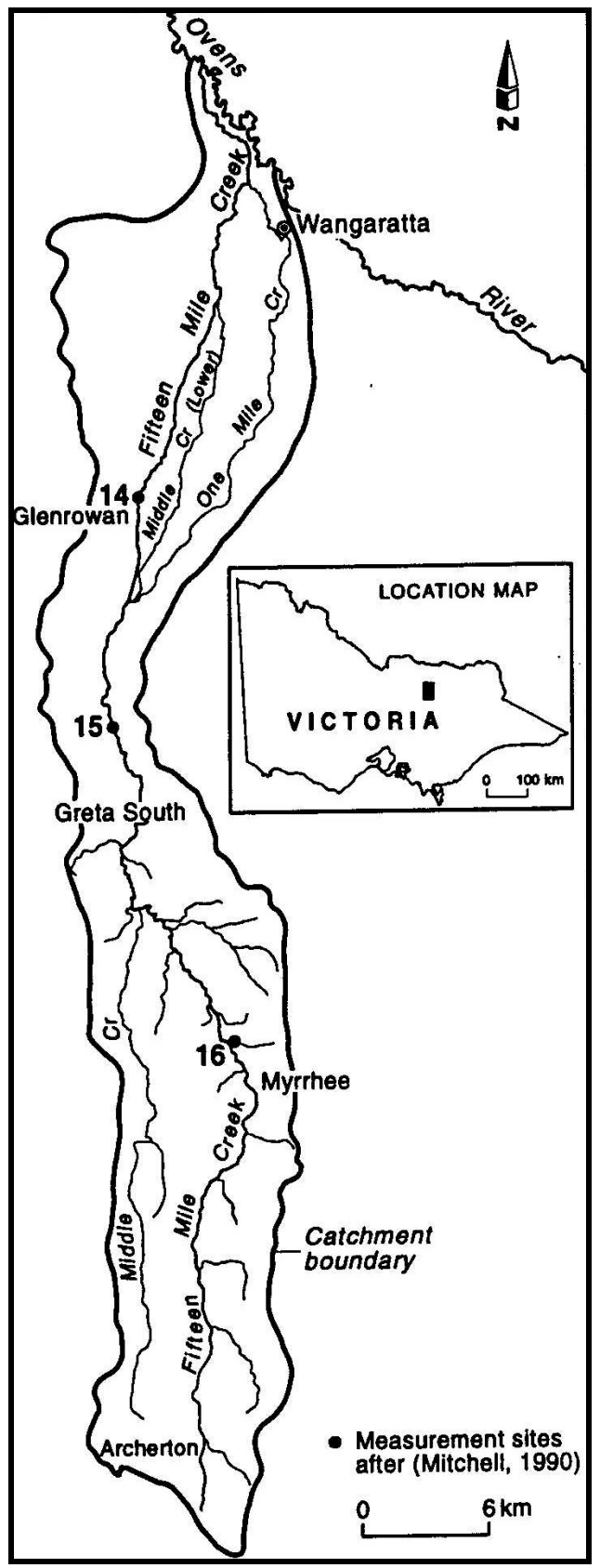

Figure 6.38 - Fifteen Mile Creek

\section{Catchment}

Land use includes sheep and cattle grazing on cleared land in the lower half of the catchment and cattle grazing combined with hop production higher in the catchment. Much of the steeper land at the top of the catchment remains forested.

The Fifteen Mile Creek was selected because the stream has been subject to extensive management effort by government authorities and there is documentation of objectives and works. Fifteen Mile Creek is also comparable to Ryans Creek, as it is in a neighbouring catchment, of like size, with similar land use and management issues.

Three authorities have been responsible for management of Fifteen Mile Creek during the period of interest (Table 6.12). Works and objectives are listed in authority documents including the Fifteen Mile Creek Improvement Trust: Master Strategy Plan (I. N. Drummond and Associates Pty Ltd 1984), annual reports and office files. Examining works programs and expenditure claims showed that \$A3.4 million had been spent on waterway management activities between 1966 and 1996 with \$A450 000 between 1986 and 1996. This amount of management effort is similar to other streams in northeastern Victoria and Gippsland. 
Table 6.11 - Methods for estimating streamside zone and physical form indicators from historical data

\begin{tabular}{|l|l|l|}
\hline \multicolumn{1}{|c|}{ Sub-index } & \multicolumn{1}{|c|}{ Indicators } & \multicolumn{1}{c|}{$\begin{array}{c}\text { Historical values of the ISC are } \\
\text { based on }\end{array}$} \\
\hline Physical Form & Bank stability & State of the Streams Survey \\
\cline { 2 - 3 } & Bed condition & State of the Streams Survey \\
\cline { 2 - 3 } & $\begin{array}{l}\text { Presence and influence of } \\
\text { artificial barriers }\end{array}$ & $\begin{array}{l}\text { DNRE barriers database and } \\
\text { information from managers }\end{array}$ \\
\cline { 2 - 3 } Zone & $\begin{array}{l}\text { Physical habitat in lowland } \\
\text { reaches - based on origin } \\
\text { and density of coarse woody } \\
\text { debris }\end{array}$ & $\begin{array}{l}\text { State of the Streams Survey and } \\
\text { information from managers }\end{array}$ \\
\hline \multirow{5}{*}{ Streamside } & $\begin{array}{l}\text { Width of streamside } \\
\text { vegetation }\end{array}$ & Aerial photography \\
\cline { 2 - 3 } & Longitudinal continuity & Aerial photography \\
\cline { 2 - 3 } & Structural intactness & State of the Streams Survey \\
\cline { 2 - 3 } & $\begin{array}{l}\text { Proportion of cover that is } \\
\text { indigenous }\end{array}$ & State of the Streams Survey \\
\cline { 2 - 3 } & $\begin{array}{l}\text { Regeneration of indigenous } \\
\text { woody vegetation }\end{array}$ & $\begin{array}{l}\text { Photographs from State of the } \\
\text { Streams Survey }\end{array}$ \\
\cline { 2 - 3 } & $\begin{array}{l}\text { Condition of wetlands and } \\
\text { billabongs }\end{array}$ & Aerial photography \\
\hline
\end{tabular}

The main activities have been to manage sedimentation in the downstream reaches and control incision upstream. There have also been activities designed to contribute to bank stability, including works to treat existing and new cases of bank erosion, willow planting and fencing and revegetation of stream verges (I. N. Drummond and Associates Pty Ltd, 1984, 58).

Table 6.12 - Authorities with responsibility for managing the Fifteen Mile Creek

\begin{tabular}{|c|c|}
\hline Authority & Period \\
\hline Fifteen Mile Creek Improvement Trust & $1966-1989$ \\
\hline Ovens River Management Board & $1989-1995$ \\
\hline North East Waterways & $1995-1997$ \\
\hline
\end{tabular}

\subsubsection{Results}

Historical ISC scores were generated for three sites on the Fifteen Mile Creek that were assessed during the State of the Streams Survey. These same sites were reassessed 


\section{Streamside zone and physical form}

using the ISC in 1997 (see Table 6.13. Results show that overall there has been a small increase in both the Streamside Zone and Physical Form Sub-indices.

The next step is to consider the accuracy of these assessments. As there are only three data points, it is not possible to examine statistical properties directly from the Fifteen Mile Creek data but information from detailed investigation of Ryans Creek can be used as an guide.

Firstly, it is possible to calculate approximate confidence intervals for the change in condition using Figures 6.28 and 6.29. For physical form, the estimated change is 1.1 (see Table 6.13. From Figure 6.28 there is a $70 \%$ probability that the true change is within \pm 0.5 of that estimate (assuming the sampling density is 1 site per $10 \mathrm{~km}$ of stream) i.e. the $70 \%$ confidence interval is $(0.6,1.6)$. Similarly, there is $95 \%$ chance the true change is within \pm 1 , so the $95 \%$ confidence interval is $(0.1,2.1)$. Similarly, for the streamside zone, the change is estimated as 0.7 from Table 6.13 and the confidence intervals can be estimated from Figure 6.29. In this case the approximate 50\% confidence interval is $(0.2,1.2)$ and the $75 \%$ confidence interval is $(-0.3,1.7)$. It would be possible to calculate other confidence intervals using the program CHANGEDETECTION if necessary. These confidence intervals suggest that there may have been a true change in physical form but the case for streamside zone is not so clear, since the $75 \%$ confidence interval includes zero. These confidence interval calculations should only be considered as approximate, as they assume that the variance in physical form and streamside zone is the same for the Fifteen Mile Creek as for Ryans Creek and ignores the fact that the Fifteen Mile Creek sites were not randomly selected.

It is also possible to calculate the $\mathrm{p}$ value of the measured change, $C_{m}$. That is, the probability of a change of at least this magnitude occurring if the underlying true change, $C_{t}$, is zero (see Section 6.5.3). The $\mathrm{p}$ value can be used to determine the statistical significance of a change. The program CHANGEDETECTION was used to explore this situation using the Ryans Creek data. The algorithm is shown in Figure 6.19. In this case the constant, $C_{c}$ is set to zero, that is, the true change between periods is assumed zero. Under the scenario of zero true change, the distribution of measured changes was examined using the replicated resampling approach described previously (Figure 6.19). The probability of measuring changes of various sizes for the Physical 
Form and Streamside Zone Sub-indices on Ryans Creek for various sampling densities is shown in Figures 6.39 and 6.40.

Table 6.13 - ISC scores for 1986 and 1997 for three sites on the Fifteen Mile Creek

\begin{tabular}{|c|c|c|c|c|c|c|}
\hline \multirow[t]{2}{*}{ Site } & \multicolumn{2}{|c|}{$14^{1}$} & \multicolumn{2}{|c|}{15} & \multicolumn{2}{|c|}{16} \\
\hline & 1986 & 1997 & 1986 & 1997 & 1986 & 1997 \\
\hline \multicolumn{7}{|l|}{ Physical form } \\
\hline Bank condition & 2.3 & 1.5 & 1.9 & 4 & 2 & 3.5 \\
\hline Bed condition & 4 & 3 & 2 & 4 & 1 & 1 \\
\hline Density and origin of coarse woody debris & 1 & 1 & 1 & 1 & 1 & 1 \\
\hline Influence of artificial barriers & 2 & 2 & 2 & 2 & 2 & 2 \\
\hline Total (out of 16) & 9.3 & 7.5 & 6.9 & 11 & 6 & 7.5 \\
\hline Physical Form Sub-index score (out of 10) & 5.8 & 4.7 & 4.3 & 6.9 & 3.8 & 4.7 \\
\hline \multicolumn{6}{|l|}{ Mean Physical Form Sub-index score 1986} & 4.6 \\
\hline \multicolumn{6}{|l|}{ Mean Physical Form Sub-index score 1997} & 5.4 \\
\hline \multicolumn{7}{|l|}{ Streamside zone } \\
\hline Width of streamside zone & 2 & 2 & 1 & 0 & 2.5 & 1 \\
\hline Structural intactness & 3.3 & 3.3 & 3.3 & 4 & 3.3 & 3 \\
\hline Proportion of cover which is indigenous & 1 & 1 & 1 & 2 & 1 & 0 \\
\hline $\begin{array}{l}\text { Regeneration of indigenous woody } \\
\text { vegetation }\end{array}$ & 0 & 0.8 & 1.5 & 1.5 & 0 & 0 \\
\hline Condition of billabongs & 0 & 0 & 0 & 0 & 0 & 0 \\
\hline Longitudinal continuity & 2 & 4 & 0 & 3 & 0 & 1 \\
\hline Total (out of 19) & 8.3 & 11.1 & 6.8 & 10.5 & 6.8 & 5 \\
\hline $\begin{array}{l}\text { Streamside Zone Sub-index score (out of } \\
10 \text { ) }\end{array}$ & 4.4 & 5.8 & 3.6 & 5.5 & 3.6 & 2.6 \\
\hline \multicolumn{6}{|l|}{ Mean Streamside Zone Sub-index score 1986} & 3.9 \\
\hline \multicolumn{6}{|l|}{ Mean Streamside Zone Sub-index score 1997} & 4.6 \\
\hline
\end{tabular}

1 - sites numbers are from Mitchell (1990).

For the Fifteen Mile Creek, sampling density assumed 1 site per $10 \mathrm{~km}$. Assuming the variance of the stream condition measurements is similar for Fifteen Mile Creek and Ryans Creek, and ignoring the fact that 1997 sites were not randomly selected, the statistical significance of the measured changes can be estimated from Figures 6.39 and 6.40. The change in the Physical Form Sub-index of 0.8 (from Table 6.13 is significant at the $10 \%$ level $(\alpha=0.1)$, while for streamside zone the change of 0.7 (from Table 6.13 is not significant at the $20 \%$ level $(\alpha=0.2)$. These probabilities are based on the null hypothesis, $\mathrm{H}_{0}$, scores are the same, compared to the alternative hypothesis $\mathrm{H}_{1}$, scores have increased. 


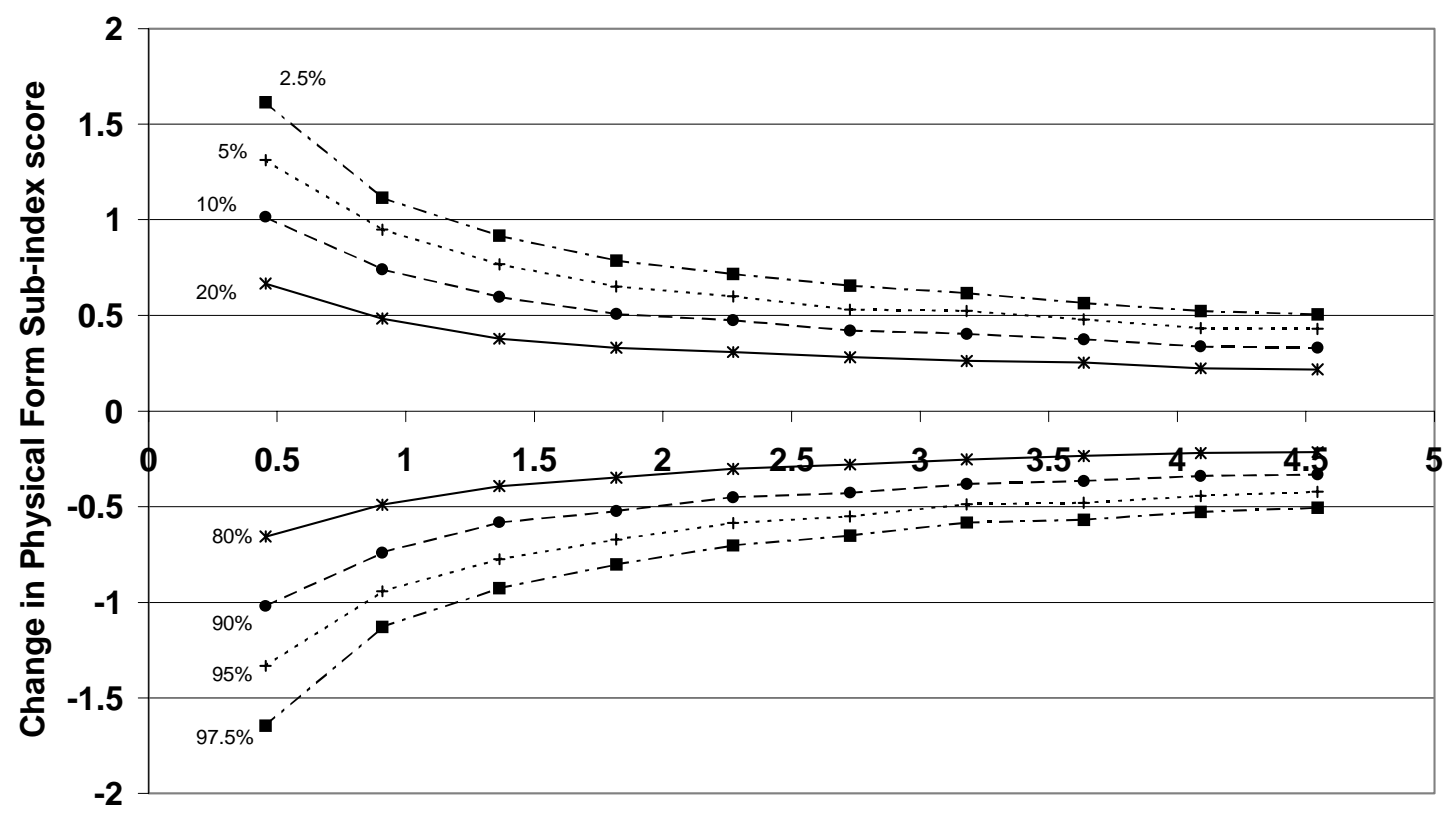

No. sites per $10 \mathrm{~km}$ of stream

Figure 6.39 - Approximate statistical significance for measured changes in Physical Form Sub-index score as a function of sampling density

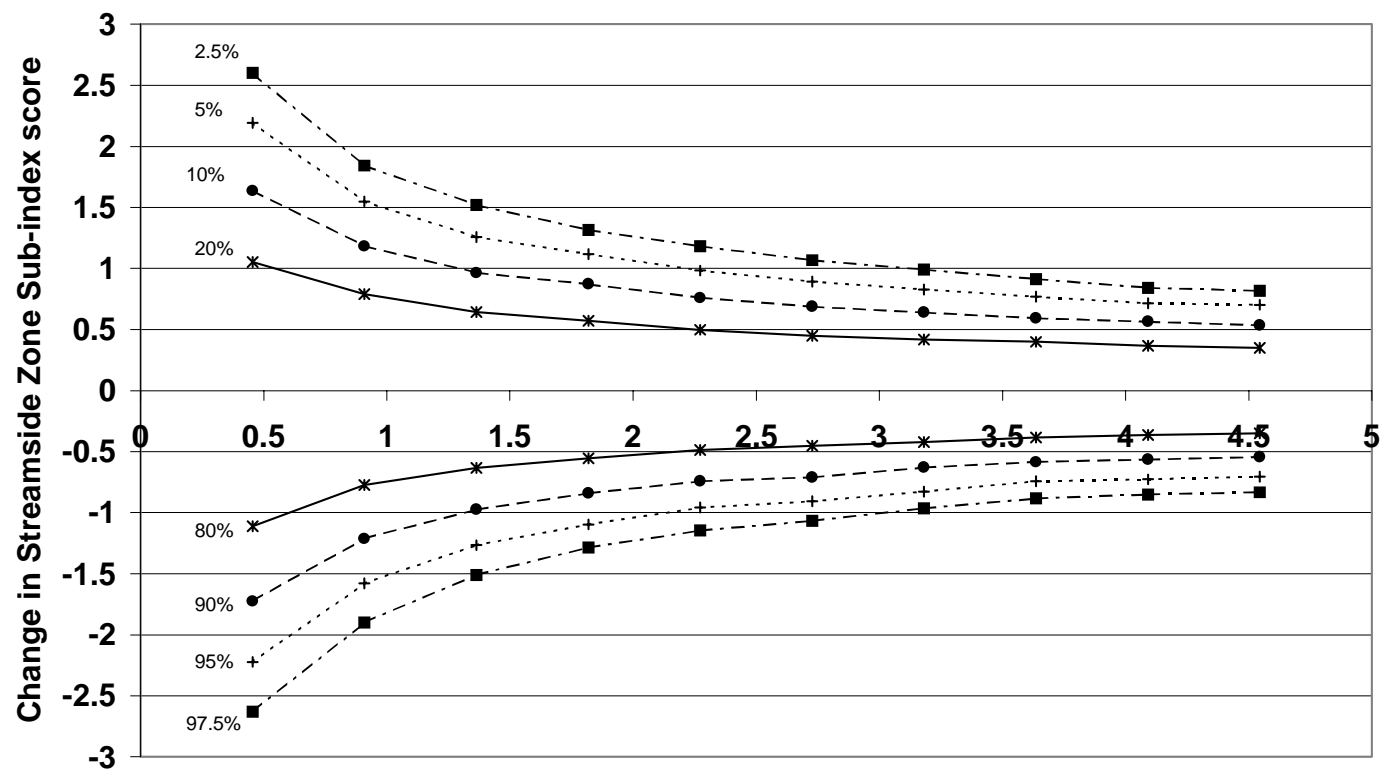

No. sites per $10 \mathrm{~km}$ of stream

Figure 6.40 - Approximate statistical significance for measured changes in Streamside Zone Sub-index score as a function of sampling density 
There are two reasons why change in physical form is easier to detect. Firstly, the Physical Form Sub-index is less variable than the Streamside Zone Sub-index and, secondly, most of the works were intended to improve the physical form, so a larger change would be expected. The Trust Master Plan (I. N. Drummond and Associates Pty Ltd, 1984) suggests that $75 \%$ of planned expenditure was on works such as erosion control that would contribute to physical form improvements, whereas only about $25 \%$ of expenditure would contribute to improvements in the streamside zone.

The sensitivity of the indicators to management-induced change was further investigated by developing a 'best management' scenario. The stream condition assessments Thable 6.13 show that scores of some indicators decreased between 1986 and 1997 although there was an overall increasing trend. As a 'best management' scenario, indicators are assumed to have either increased as shown in Table 6.13, or at worst, stayed the same. This makes the improvement larger and is suggested as a plausible indication as to what might have happened to the condition of Fifteen Mile Creek with a little more management effort. In this case, the change in the Physical Form Sub-index between 1986 and 1997 would be 1.2 (significant at the 2.5\% level) while the change in the Streamside Zone Sub-index would be 0.8 (significant at $20 \%$ level).

If management can be credited with all this improvement, it implies that the types of works undertaken on Fifteen Mile Creek could be reflected in changes in the Physical Form Sub-index scores under the 'best management' scenario. Issues associated with the role of statistical significance testing in deciding on the importance of changes in indicator scores are explored further in Chapter 8.

\subsection{Conclusion}

This chapter reports on sampling and sensitivity of the Streamside Zone and Physical Form Sub-indices. A detailed data set was collected and analysed to estimate the variance that could be attributed to various sampling schemes. Data came from the Broken River and Ryans Creek, two lowland streams with sub-index scores between 3.4 and 6.9 which is approximately in the middle of the possible range of 0 to 10 . The variance of estimates of condition for these streams is high but they are likely to be similar to many Victorian floodplain streams. Results showed that values for the streamside zone and physical form from a 'representative' sub-reach were subject to 


\section{Streamside zone and physical form}

error that could not be quantified. It would be difficult to have confidence in results based on this approach.

As an alternative, a sampling scheme based on the random selection of measuring sites was developed. Results are presented for the expected accuracy of condition assessment as a function of the number of measuring sites per reach and the number of transects per measuring site. Accuracy is also a function of the objectives of the monitoring program. Three objectives are analysed in this chapter: estimation of mean condition (benchmarking); detecting change; and providing an early warning of a critical change that requires intervention. The streamside zone was found to be the more variable sub-index in all cases, so determines the necessary sampling approach.

Based on the analysis, key results are summarised as follows. For benchmarking, if the desired accuracy is that the estimate of mean streamside zone be within $+/-1$ of the true mean $90 \%$ of the time, then about 1.3 measuring sites are required per $10 \mathrm{~km}$ of reach, with 3 transects per measuring site. Results show that detecting change is more demanding than benchmarking and about 2.3 measuring sites, and three transects per site are required per $10 \mathrm{~km}$ of reach to be $90 \%$ confident that the change detected is within $+/-1$ of the true change.

For early warning, several scenarios were investigated. There are five related parameters: the true change in condition; a critical value of change in the indicator; the statistical power to detect the change (1- $\beta)$; the probability that a critical change will be detected when, in fact, it has not occurred (Type I error or $\alpha$ ); and the sampling strategy. A sampling density of 2 sites, with 3 transects, per $10 \mathrm{~km}$ of stream provided a power (1- $\beta$ ) of $90 \%$ and a Type I error probability, $\alpha$, of $7 \%$ for the conditions investigated.

These results suggest that appropriate sampling density to assess the Physical Form and Streamside Zone Sub-indices in these streams is 1.3 to 2 measuring sites and three transects per $10 \mathrm{~km}$ of reach, depending on the monitoring objective. Results presented here allow confidence intervals to be calculated depending on the actual sampling density chosen.

Other sources of error were investigated and it was found that inter-operator variability could add significantly to the variance. Strategies to reduce these errors include training programs, auditing and assessment of standard sites. 
The final section of the chapter examined the sensitivity of the ISC to managementinduced changes, and a procedure was suggested to estimate approximate confidence intervals and statistical significance. Results suggest that the ISC is likely to be sensitive enough to detect changes in a practical application.

The depth of analysis presented here is in contrast with most of the other approaches discussed in Chapter 4 (except perhaps EMAP and SERCON/RHS). There seems to have been little consideration of sampling requirements, accuracy and power to detect changes, yet these factors are likely to be critical for the use of indicators. It is difficult to compare the performance of the ISC with other indicator systems when this type of analysis is not available. 


\section{ACCURACY AND SENSITIVITY OF HYDROLOGY, WATER QUALITY AQUATIC LIFE SUB-INDICIES}

\subsection{Introduction}

This chapter examines accuracy and sensitivity of the remaining three sub-indicators of the Index of Stream Condition, hydrology, water quality and aquatic life. Other subindicators in the ISC, streamside zone and physical form were discussed in the previous chapter.

The development of ratings for the Hydrology Sub-index is briefly reviewed. These ratings were based on measured flow changes in 21 streams in Victoria and New South Wales resulting from water resource development. A case study of the Campaspe River is used to test the ability of the Hydrology Sub-index to detect flow changes that result from the implementation of environmental flows.

The Water Quality Sub-index is investigated through a case study of the Latrobe River at Rosedale. The sensitivity of the four water quality indicators is reviewed followed by development and application of a technique to estimate confidence intervals around Water Quality Sub-index scores.

Accuracy of the Aquatic Life Sub-index was investigated through a literature review and discussion with scientists involved in its application in Victoria. Accuracy of the component indicators, AusRivAS and SIGNAL, are currently being investigated by others and reference is made to their work.

\subsection{Hydrology Sub-index}

\subsubsection{Introduction}

The Hydrology Sub-index is intended to measure change in flow from natural conditions and is based on differences in natural and current monthly flows along with an assessment of the effect of urbanisation and hydroelectric facilities (Ladson and White, 1999; Section 5.2.9). Only the assessment of monthly flow changes is examined 
further here, as the other indicators are rarely used in the assessment of streams in Victoria and make only a minor contribution to the sub-index score.

The major indicator within the Hydrology Sub-index is the Amended Annual Proportional Flow Deviation developed by Gehrke and others (Gehrke et al., 1995; Gehrke pers. comm., 1996).

$$
R_{a}=\left(\sum_{i=1}^{12}\left(\frac{\left(c_{i j}-n_{i j}\right)}{\bar{n}}\right)^{2}\right)^{\frac{1}{2}}
$$

Where, $R_{a}$ is the amended annual proportional flow deviation (AAPFD), $\bar{n}$ is the overall mean monthly flow for all months on record, $c_{i j}$ is the current flow for month $i$, in year $j$ and $n_{i j}$ is the modelled natural flow for that month. A rating table was developed for the AAPFD as shown in Table 7.1 and Figure 7.1 (Ladson and White, 1999).

The ISC was proposed to be reported every 5 years and originally it was intended that if data were available, the AAFPD be calculated, rated and reported for each of these 5 years with the average rating adopted as the Hydrology Sub-index score (Ladson and White, 1999). However, during the initial statewide application of the ISC, it was found difficult to obtain enough data to calculated AAPFD values for 5 years. Instead, DNRE made a pragmatic decision to use data from only one year. It became clear that reforms were needed to the reporting procedures from water authorities before natural flows could be routinely calculated. It is planned that better reporting arrangements will be in place prior to the next round of ISC data collection. In the analysis that follows (Section 7.2.3), the Hydrology Sub-index is calculated for individual years and averaged for periods of 5 years.

Unlike the Physical Form and Streamside Zone Sub-indicators examined in the previous chapter, the Hydrology Sub-index is much more under the immediate and direct control of water managers through flow regulation and diversions. The main issue for the Hydrology Sub-index examined here is its sensitivity to change and its usefulness for measuring management intervention. 
Table 7.1 - Rating table for the AAPFD

\begin{tabular}{|c|c|}
\hline AAPFD & Rating \\
\hline$<0.1$ & 10 \\
\hline $0.1-0.2$ & 9 \\
\hline$>0.2-0.3$ & 8 \\
\hline$>0.3-0.5$ & 7 \\
\hline$>0.5-1.0$ & 6 \\
\hline$>1-1.5$ & 5 \\
\hline$>1.5-2$ & 4 \\
\hline$>2-3$ & 3 \\
\hline$>3-4$ & 2 \\
\hline$>4-5$ & 1 \\
\hline$>5$ & 0 \\
\hline
\end{tabular}

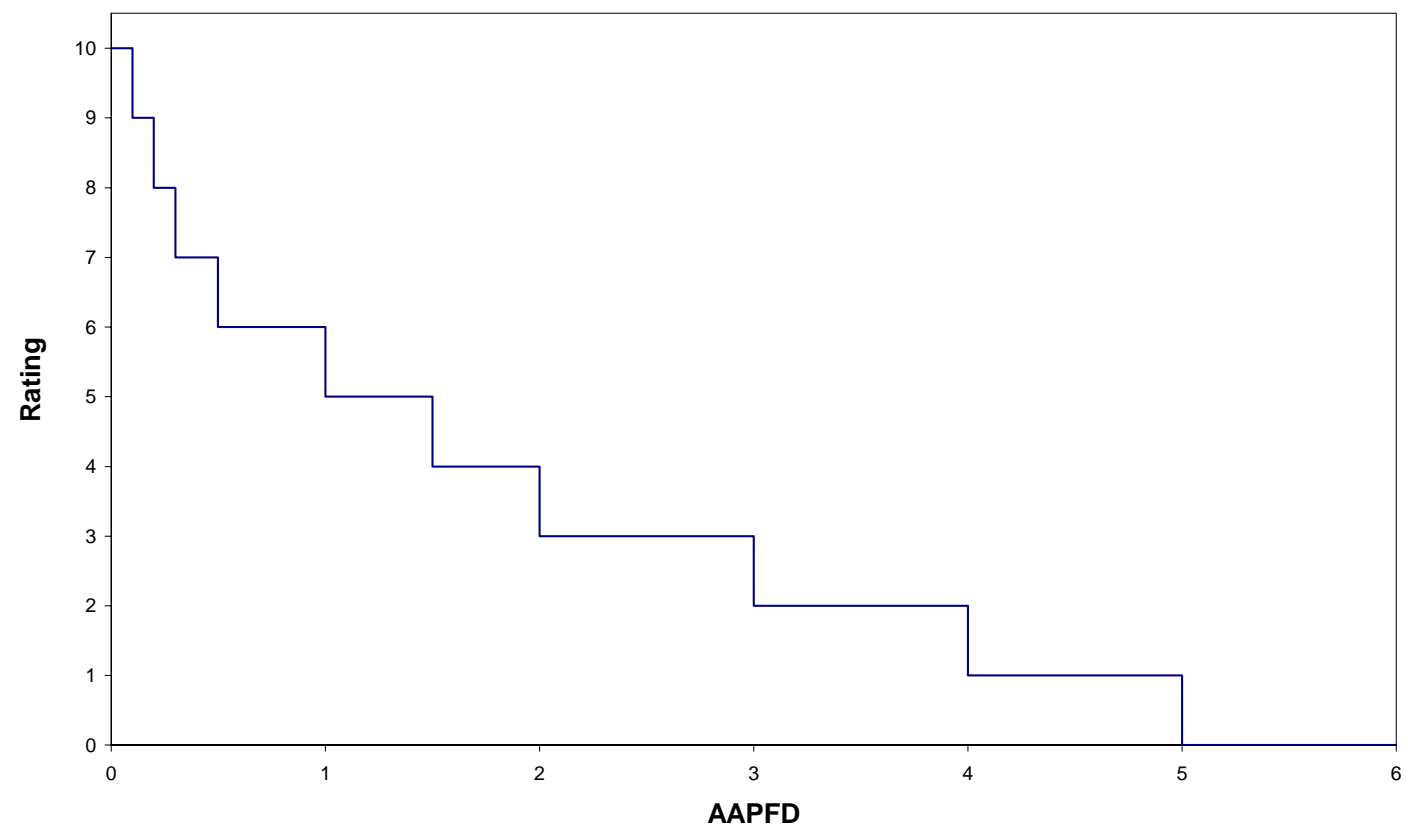

Figure 7.1 - Ratings for the AAPFD

\subsubsection{Sensitivity}

As part of the process for developing the rating table, the AAPFD was calculated for 21 streams in Victoria and New South Wales (Table 7.2 see Appendices E to G). These ranged from highly regulated streams, such as the Goulburn and Campaspe Rivers where there are large reservoirs to service irrigation needs, to rivers such as the Gellibrand, where there are smaller storages and limited diversions. 
Table 7.2 - Summary of results for the Amended Annual Proportional Flow Deviation for selected streams in Victoria and New South Wales

\begin{tabular}{|c|c|c|c|c|}
\hline No. & River & Station & AAPFD & Rating \\
\hline 1 & Gellibrand $^{1}$ & North Otway Pipeline $1987 / 88^{5}$ & 0.24 & 8 \\
\hline 2 & Buffalo $^{2}$ & Lake Buffalo & 0.30 & 8 \\
\hline 3 & Gellibrand $^{1}$ & South Otway Pipeline $1987 / 88^{5}$ & 0.31 & 7 \\
\hline 4 & Gellibrand $^{1}$ & North Otway Pipeline 1967/68 & 0.34 & 7 \\
\hline 5 & Gellibrand $^{1}$ & South Otway Pipeline 1967/68 & 0.48 & 7 \\
\hline 6 & Loddon $^{2}$ & Laanecoorie Reservoir & 1.3 & 5 \\
\hline 7 & Macalister $^{2}$ & Lake Glenmaggie & 1.4 & 5 \\
\hline 8 & Moorabool $^{2}$ & Bungal Dam & 1.6 & 4 \\
\hline 9 & Jackson $\mathrm{Ck}^{2}$ & Rosslynne Reservoir & 2.1 & 3 \\
\hline 10 & Tarago $^{2}$ & Tarago Reservoir & 2.3 & 3 \\
\hline 11 & Murray $^{3}$ & Euston & 2.5 & 3 \\
\hline 12 & Murray $^{3}$ & Yarrawonga Weir & 2.7 & 3 \\
\hline 13 & Murray $^{3}$ & Flow to SA & 2.7 & 3 \\
\hline 14 & Murray $^{3}$ & Barrages & 3.0 & 3 \\
\hline 15 & Darling $^{3}$ & Burtundy & 3.1 & 2 \\
\hline 16 & Loddon $^{2}$ & Cairn Curran & 3.2 & 2 \\
\hline 17 & Edward $^{3}$ & Deniliquin & 3.6 & 2 \\
\hline 18 & Goulburn $^{4}$ & Eildon & 3.9 & 2 \\
\hline 19 & Murray $^{3}$ & Doctors Point (near Albury) & 4.0 & 2 \\
\hline 20 & Mitta Mitta $^{2}$ & Dartmouth & 4.0 & 2 \\
\hline 21 & Campaspe $^{2}$ & Lake Eppalock & 5.0 & 1 \\
\hline
\end{tabular}

1. Flow data from John Woodland, Department of Natural Resources and Environment (pers. comm.), see notes 5 and 6 below.

2. Flow data from Phan (1994), modelled natural flows compared with measured current flows averaged over the post regulation period.

3. Flow data from Murray-Darling Basin Commission modelled natural flows compared with measured current flows averaged over the post-regulation period (L. White pers. comm.).

4. Flow data adapted from Erskine (1996).

5. AAPFD calculated for the 1 in 5 drought year 1987/1988 (Southern Rural Water, 1998).

6. AAPFD calculated for the 1 in 60 drought year 1967/1968 (Southern Rural Water, 1998).

In the highly regulated streams, there have been major changes to flow as is reflected in the high values for AAPFD and low ratings shown in Table 7.2. The impacts are smaller in rivers such as the Gellibrand ( 


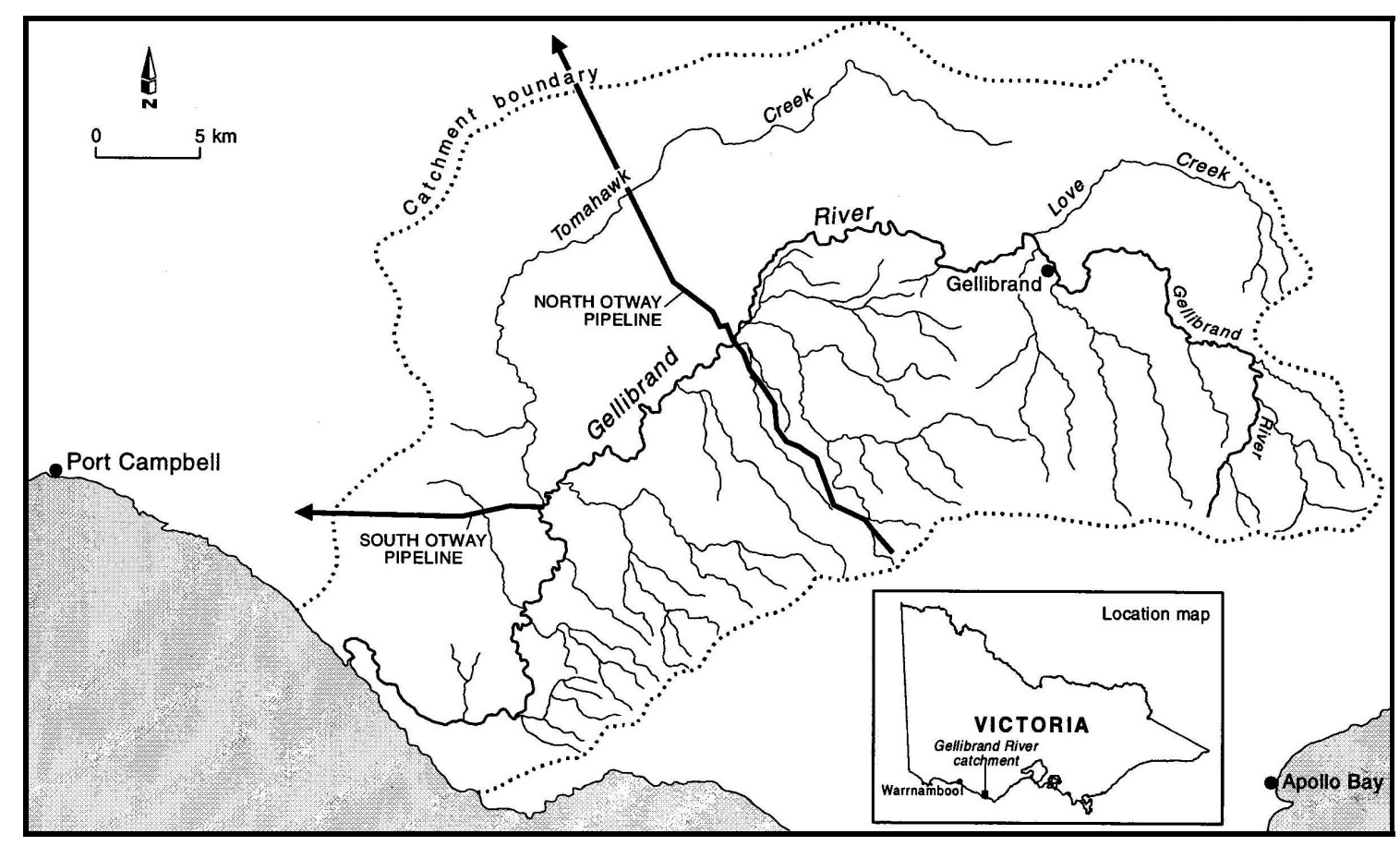

Figure 7.2. In most years the Gellibrand would be rated as 10; flow changes would be too small to be detected using the Hydrology Sub-index. For drought years there is greater impact as more of the available water is required for irrigation, stock and domestic use, winter fill storages and urban supply. On the Gellibrand, the two major diversions are the North Otway pipeline that supplies water to several towns north of the basin and the South Otway pipeline that supplies the city of Warrnambool (

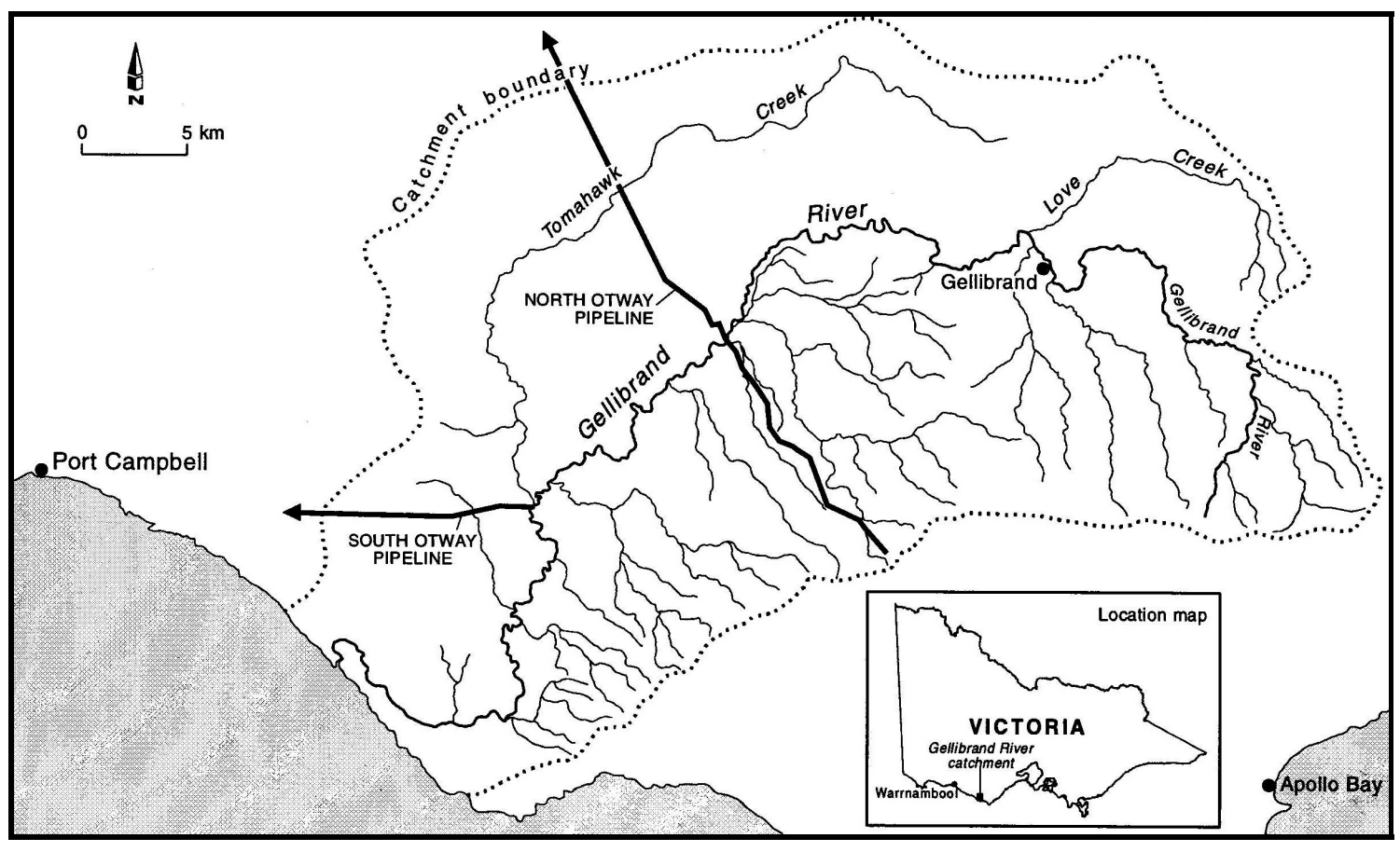


Figure 7.2. Actual and modelled natural flows downstream of these points have been used to calculate the AAPFD. A modelled scenario for a one in 60-year drought (1967/68) and a one in 5-year drought (1987/88) were available from the Department of Natural Resources and Environment (J. Woodland pers. comm.) and were used to calculate AAPFD values as shown in Table 7.2

Clearly, the flow alteration in the Gellibrand is much smaller than in rivers that are part of large irrigation schemes (Rivers 10 to 21 in Table 7.2 but there was still thought to be considerable impact. Development of a plan to control diversions was a priority for the State Government (Southern Rural Water, 1998).

This example shows an issue with the sensitivity of the ratings used for the AAPFD. The relationship between flow alteration and the impact on streams is unknown and subjective judgements have been required to develop the rating table (Table 7.1). There is a wide range of flow alterations within the State as measured by the AAPFD (Table 7.2. To cover this range, and still provide sensitivity to distinguish between different levels of alteration where there are limited diversions or flow changes, the rating table is non-linear as shown in Figure 7.1. This implies that the Hydrology Sub-index will be sensitive to small changes in flow when the flow is close to natural, but the same small changes are unlikely to alter the sub-index score for a stream that is highly modified.

\subsubsection{Case Study: implementing environmental flows on the Campaspe River}

'Environmental flows' are a response to concerns about the environmental impact of flow changes caused by water resource development. In the past, dam construction and operation occurred with little concern for the effects on downstream biota, the main objective being to maximise water available for uses such as irrigation or urban water supply. More recently there have been moves to recognise the environment as a legitimate user of water (Working Group on Water Resource Policy Secretariat, 1994a) and proposals to change release rules to protect or enhance environmental values (Gippel, 2000). 



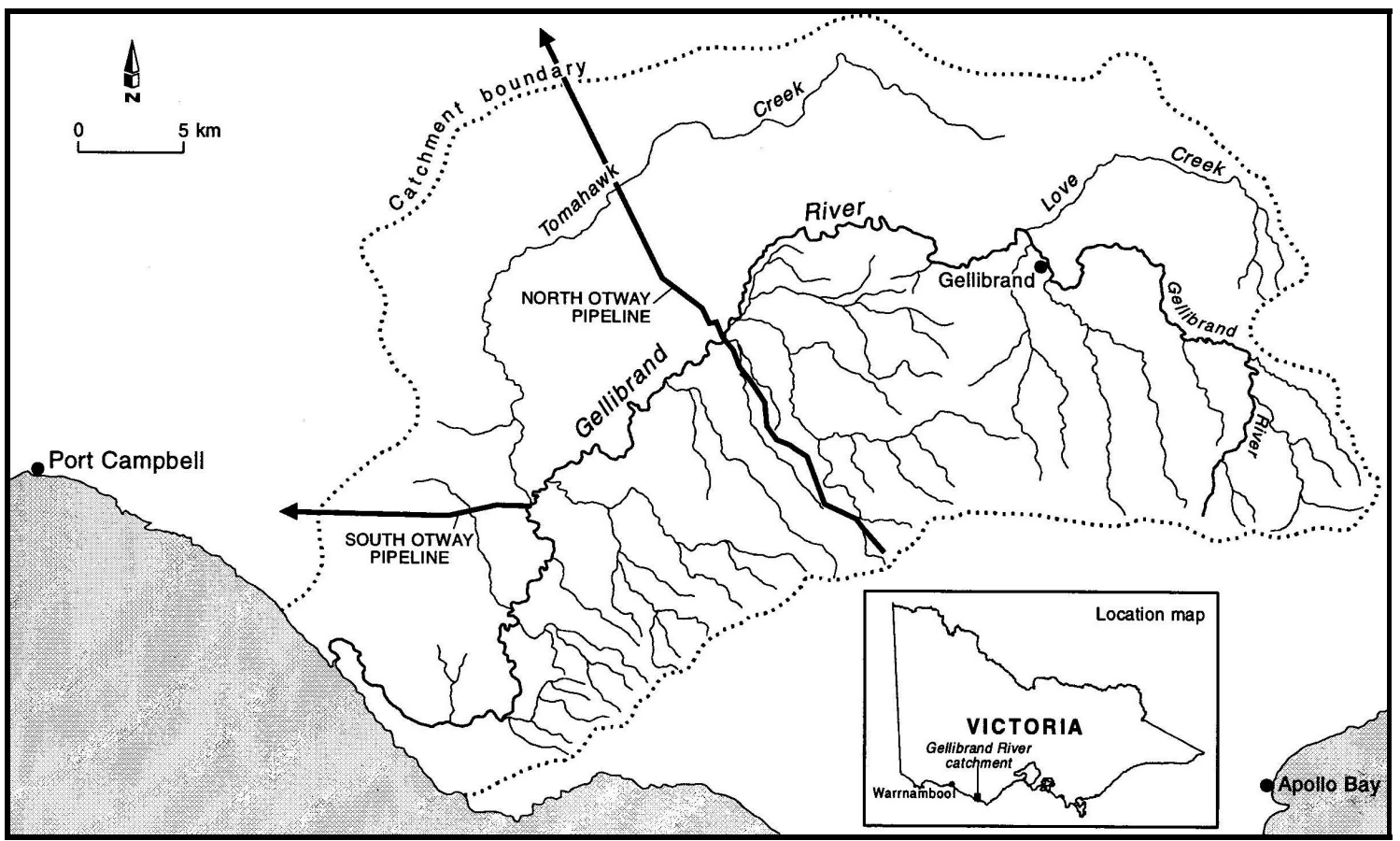

Figure 7.2 - Gellibrand River and Catchment showing the North Otway and South Otway Pipelines 

Clearly, the Hydrology Sub-index is capable of measuring the changes to hydrology that have occurred in Victorian streams as a result of water resource development Table 7.2. but it is also important to know if the sub-index is sensitive to the flow changes that result from implementation of environmental flows. As noted in the previous chapter, the ISC will be a more useful tool for managers if it is sensitive to management-induced changes, as well as being able to benchmark current condition.

The sensitivity of the Hydrology Sub-index was investigated by reviewing proposed environmental flows on the heavily regulated Campaspe River in Victoria. The river rises in the Great Dividing Range near Woodend and flows north to the Murray River near Echuca - the largest urban centre in the basin. Land use is dominated by agriculture with dairying under irrigation being the most important activity. There is also irrigated fruit and grape growing and dryland cereal cropping, beef cattle, lamb and wool production. The catchment area is $4180 \mathrm{~km}^{2}$ with mean annual discharge of 280 GL at the Murray River confluence (Department of Water Resources, 1989a; Figure 7.3 .

Flow in the Campaspe River has been extensively modified by the operation of the Malmsbury, Lauriston, and Upper Coliban Reservoirs and Lake Eppalock - the largest storage on the river system with a capacity of 312 GL (Boughton, 1999). Irrigation supply has changed the flow regime downstream of Lake Eppalock by increasing summer flows to cater for irrigation demand, and reducing autumn and winter flows when water is stored for the next irrigation season Figure 7.4. These flow changes have decreased the viability of native fish populations and caused other environmental degradation (Humphries and Lake, 1996).

The dam operators, Goulburn-Murray Water and the Cooperative Research Centres for Catchment Hydrology and Freshwater Ecology, have proposed new operating rules for Lake Eppalock that will allow water release for the environment without significantly decreasing the security of supply to irrigators (Humphries and Lake, 1996). These operating rules allow for release of $25 \%$ of Eppalock inflows between May and October when there is more than $200 \mathrm{GL}$ of water in storage. The previous operating rules resulted in very low flows downstream of Eppalock during this period, as the priority was to fill the reservoir as quickly as possible following the November to April irrigation season (Humphries and Lake, 1996). 


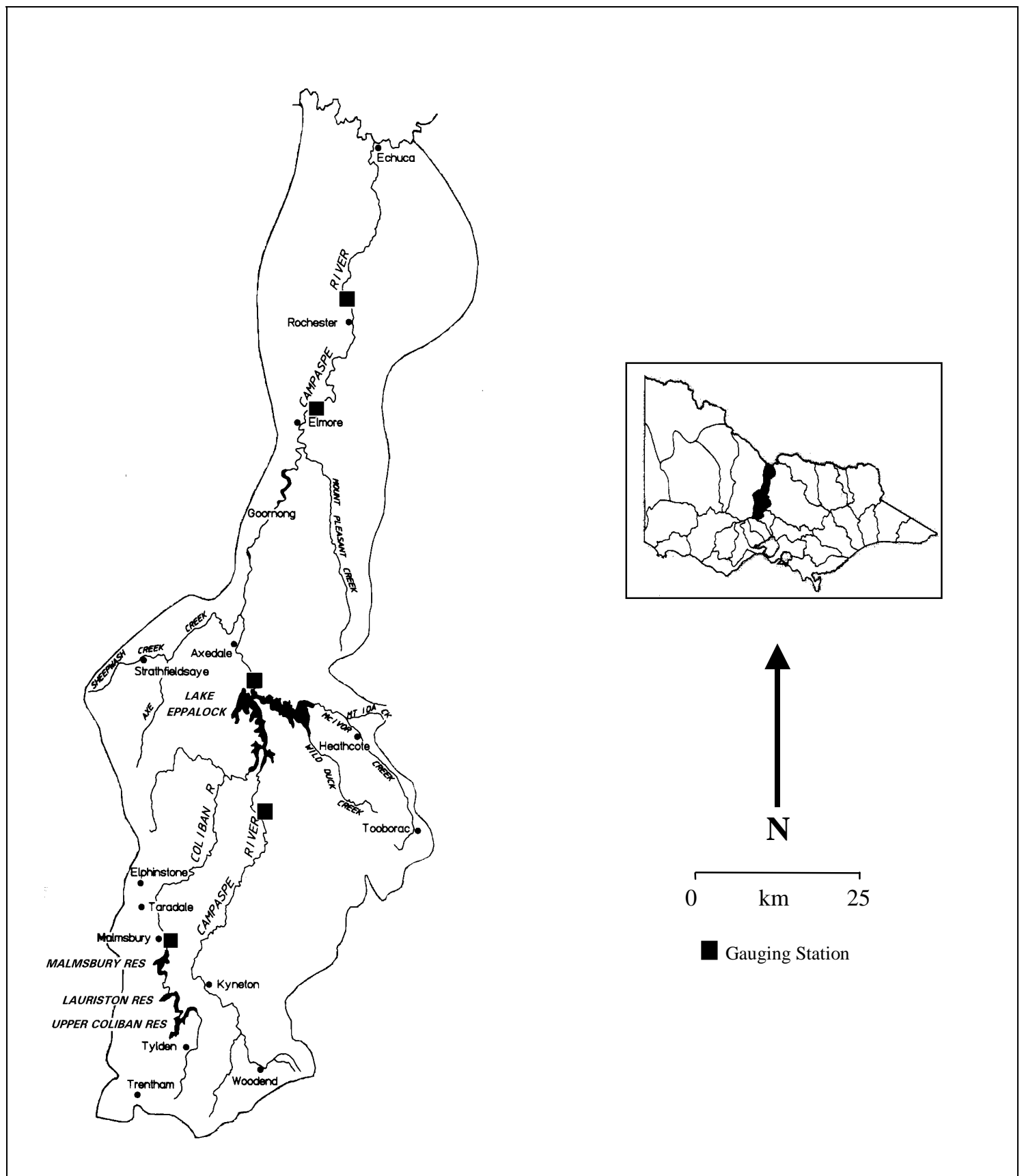

Figure 7.3 - Campaspe Catchment (adapted from Department of Water Resources, 1989a)

A model has been developed for the Campaspe River by Goulburn-Murray Water that simulates daily flow under the previous operating rules, the new environmental flow rules and natural conditions i.e. without Lake Eppalock. These modelled flows are summarised as average monthly values in Figure 7.4. Data were available from August 1974 to May 1997. 


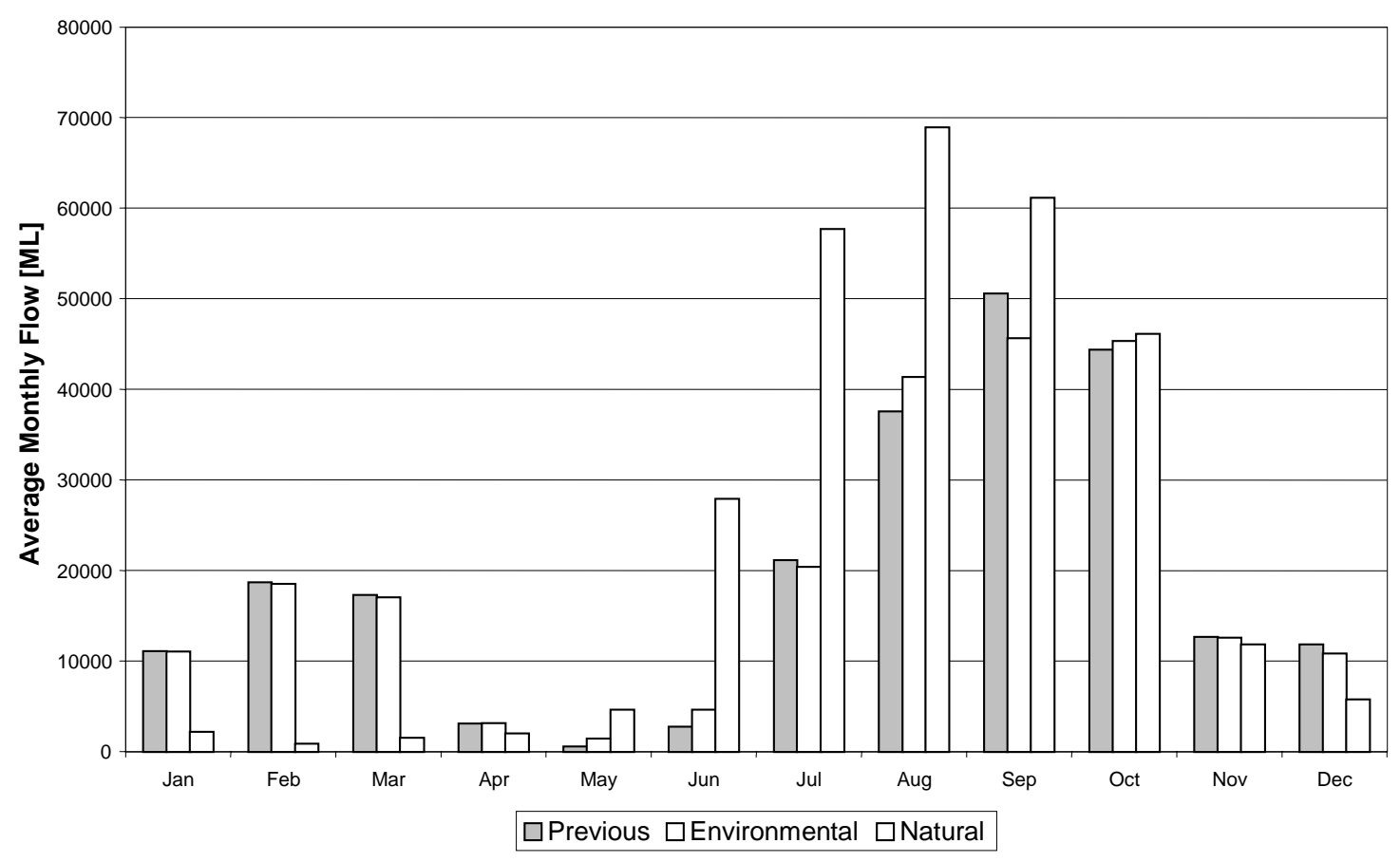

Figure 7.4 - Average monthly flows for the Campaspe River downstream of Lake Eppalock based on flows from August 1974 to May 1997. Flows are based on the previous operating rules, environmental operating rules and natural flows.

These flows were used to calculate the AAPFD for each year where there was a complete record of monthly flows (1975 to 1996). Ratings were then calculated for (1) the previous operating rules and (2) the proposed environmental operating rules, by comparing the flows under these scenarios with natural flows. Results presented for every year Figure 7.5 and averages over periods of 5 years Figure 7.6. Of the 22 years analysed, the ratings are equal in 16 years; ratings for flows based on the previous operating rules are greater in 2 years (1979 and 1981), and the environmental flows have higher ratings in 4 years (1978, 1980, 1985 and 1996).

The reason the previous operating rules can achieve higher ratings than the environmental operating rules is that they can result in flows that are closer to natural. This shows up in Figure 7.4 for the months of July and September. Once Lake Eppalock is full, any additional water is spilled so that natural flow and released flow are equal. The lake fills more rapidly under the previous operating rules, which results in natural flows in some months when the environmental flows are still limited to $25 \%$ of inflow. For some years, the difference in monthly flow between the two sets of rules is enough to result in a lower rating for the environmental flows, indicating that they are further from natural conditions. 


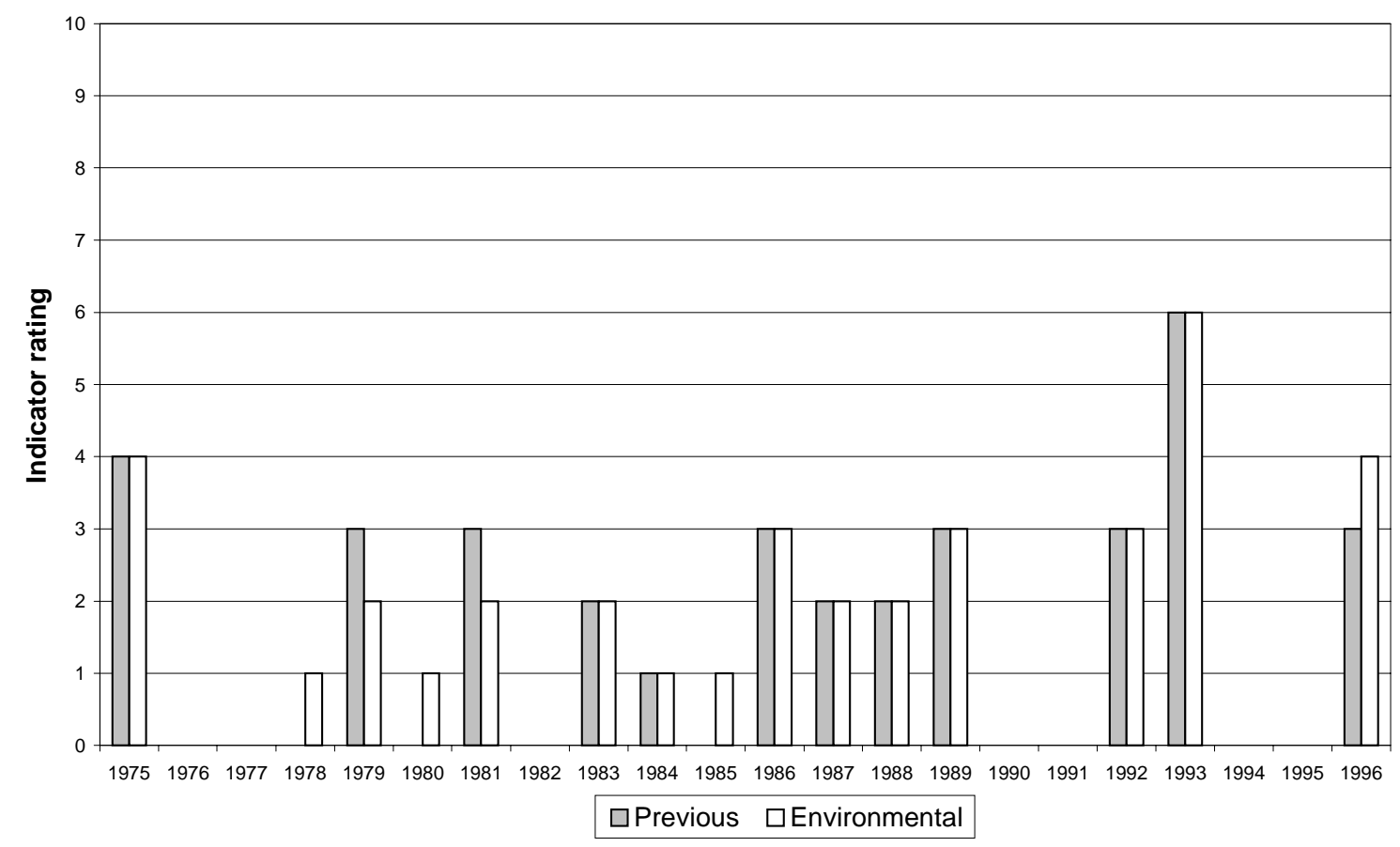

Figure 7.5 - Hydrology Sub-index rating for the Campaspe River downstream of Lake Eppalock for the previous, and environmental, operating rules (absence of bars indicates ratings are zero, not missing)

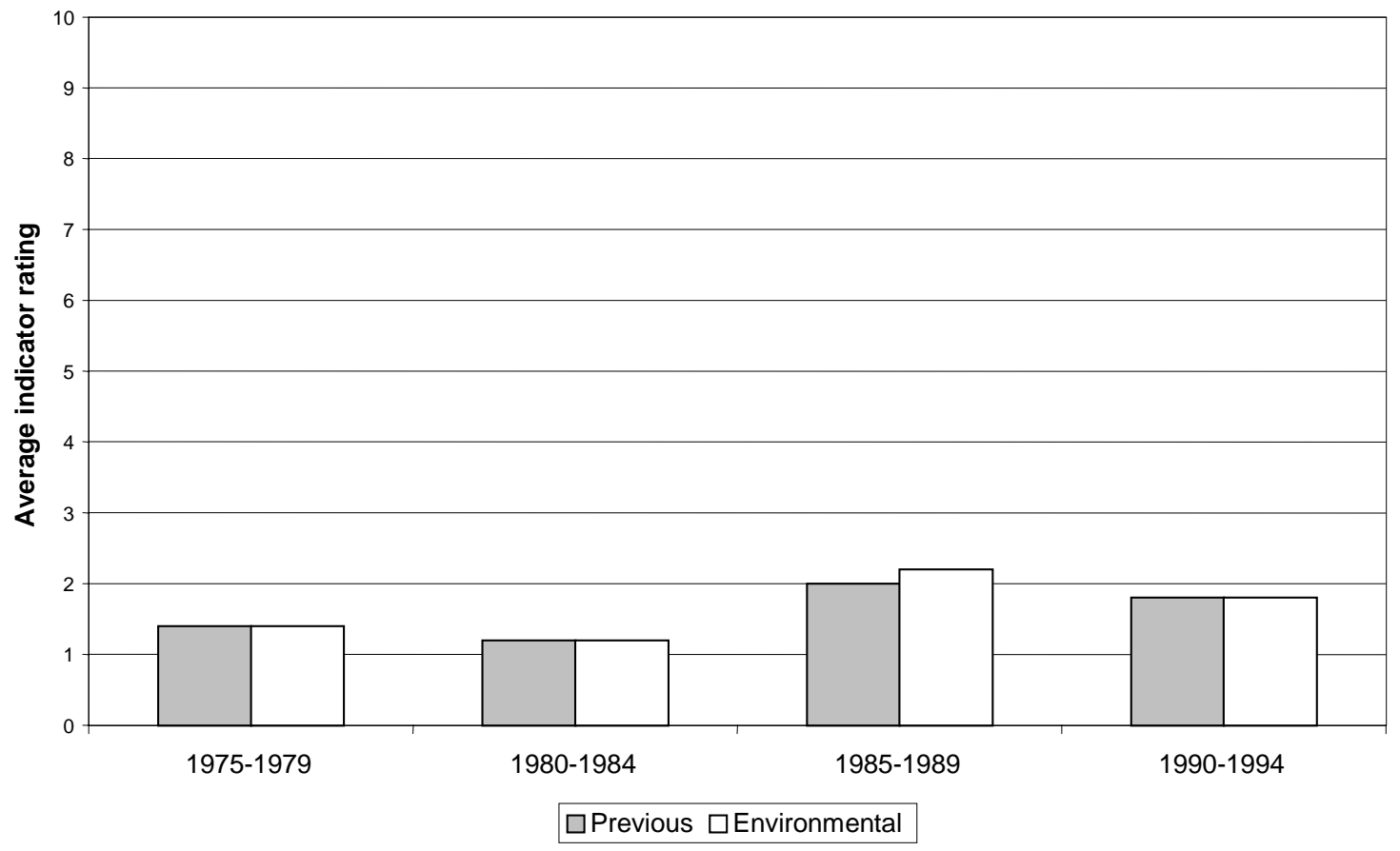

Figure 7.6 - Hydrology Sub-index for the Campaspe River downstream of Lake Eppalock for the previous and the environmental operating rules; averages for periods of 5 years 
The data also show that for most years, there is no change in the sub-index value between the two sets of operating rules and only 4 of the 22 years showed an improvement. For the 5-yearly averages, there is a small improvement with the environmental flow rules in only 1 period (1985-1989) and the indicator scores remain low for the whole period, being around 2 out of 10 or less (Figure 7.6).

The proposed environmental flows were the result of protracted negotiations between Goulburn-Murray Water and the Cooperative Research Centres and there was little opportunity to make major changes because they would threaten security of irrigation supplies. For example, there was no opportunity to reduce the high summer flows. Instead, the compromise agreement was to increase late autumn and winter flows that were often very low because the releases were shut off at the end of the irrigation season until the storage filled. The Cooperative Research Centre for Freshwater Ecology (CRCFE) is now testing whether there will be environmental benefits from these proposed minor flow changes. In assessing the performance of the Hydrology Subindex, there are several important results from this case study. Firstly, the Hydrology Sub-index scores suggest that flow regulation in the Campaspe River has had a major impact on hydrology. The sub-index score averaged around 1 to 2 out of 10 Figure 7.6 and the river was ranked the worst based on a comparison of hydrologic alteration in 21 other rivers from both Victoria and New South Wales using the AAPFD (Table 7.2. One of the proposed roles of the ISC was to flag situations where further investigations may be required and these results support the need for investigation of strategies to address environmental changes caused by hydrologic alteration.

Secondly, the proposed environmental releases result in a flow regime that is still a long way from natural because of the need to maintain security of supply for irrigators. Environmental flows achieved very little improvement in the sub-index scores and in some months the environmental flows were further from natural conditions than flows based on the previous operating rules. The performance of the Hydrology Sub-index accurately reflects the fact that the hydrologic effect of the environmental flow rules is very limited Figure 7.4. Flows from January to September remain greatly altered from natural conditions by the operation of Lake Eppalock. Similar problems are likely where environmental flows are implemented in other highly regulated rivers in Victoria. In fact, the environmental flows proposed on the Campaspe River are likely to be larger than in others systems because Lake Eppalock filled and spilled in most years, 
suggesting there could be changes to the operating rules without affecting security of supply. Most other large storages in the State do not have the same flexibility.

Although the hydrologic effect of the flow changes is small, whether there will be a significant ecological effect remains to be determined. The CRCFE is examining whether there will be increases in native fish populations, macroinvertebrates and macrophytes and other environmental improvements (Humphries and Lake, 1996). Results of this work will be useful to guide implementation of environmental flows in other rivers and will show whether the minor flow changes proposed actually have a positive effect. If there is an ecological improvement from implementing the environmental flows, then it may be possible to identify the biologically significant facets of the flow regime that have been provided by the new flow rules (Puckridge et al., 1998). Indicators that relate specifically to, the interaction of flow changes with habitat availability, and the hydraulic environment of streams, may be more appropriate than indicators based on hydrology (Gippel and Stewardson, 1998; Stewardson, 1999). However, there needs to be more research before they are suitable for routine use by management authorities.

Results suggest that the Hydrology Sub-index is useful for identifying the major changes in hydrology that have resulted from flow regulation. It also shows that the hydrologic effect of environmental flows are very minor compared with this alteration. The ecological significance of these environmental proposals are questionable and will have to be tested by a detailed scientific study.

\subsection{Water Quality}

\subsubsection{Introduction}

The ISC includes a water quality component, the Water Quality Sub-index, which is made up of four indicators: total phosphorus, turbidity, electrical conductivity and $\mathrm{pH}$. Each of these indicators is rated between 0 and 4 and the ratings are added and scaled to produce a value for the Water Quality Sub-index between 0 and 10 (see Table 7.3 and Equation 7.2). 
Table 7.3 - Indicators in the Water Quality Sub-index

\begin{tabular}{|l|c|c|}
\hline \multicolumn{1}{|c|}{ Indicator } & Symbol & Range \\
\hline Total phosphorus & $T P$ & $0-4$ \\
\hline Turbidity & $T$ & $0-4$ \\
\hline Electrical conductivity & $E C$ & $0-4$ \\
\hline Alkalinity/acidity & $p H$ & $0-4$ \\
\hline
\end{tabular}

$W Q_{r}=\frac{10}{16} \sum\left[T P_{r}+T_{r}+E C_{r}+p H_{r}\right]$

Where, $W Q$ is the Water Quality Sub-index, the subscript, $r$ shows that values are for a reach (see Figure 6.1) and the other symbols are defined in Table 7.3

The rating for each of the indicators is determined from values of the water quality parameters as measured during routine water quality monitoring. In Victoria, these samples would usually be collected monthly as part of the Victorian Water Quality Monitoring Network (VWQMN) or other water quality monitoring program (CLPC et al., 1996). The median value for samples collected over a year is given a rating between 0 and 4 using rating tables that were established as part of the development of the ISC (Tables 7.4 to 7.7; Ladson and White, 1999; see Chapter 5). The ISC is proposed to be reported every 5 years, with the Water Quality Sub-index to be calculated, rated and reported for each of these 5 years and the average value adopted where an overall ISC score is required.

For phosphorus, turbidity and EC, different ratings are provided for upland and lowland streams as defined in Ladson and White (1999) ${ }^{1}$. These ratings take account of the natural variation in streams where phosphorus, turbidity and EC would be expected to increase in lowland reaches even under pristine conditions. For $\mathrm{pH}$ only one rating table is provided (Section 5.2.10).

\footnotetext{
${ }^{1}$ In Chapter 6, streams were classified as upland, valley or lowland. The same classification scheme was originally adopted for water quality but a classification scheme, where streams are specified as either upland or lowland, has been developed following work on water quality guidelines (B. Hart pers. comm.).
} 
7. Hydrology, water quality, aquatic life

Table 7.4 - Ratings for total phosphorus ( $\mathrm{mg} \mathrm{m}^{-3}$ )

\begin{tabular}{|c|c|c|}
\hline Upland & Lowland & Rating \\
\hline$<10$ & $<20$ & 4 \\
\hline $10-<20$ & $20-<40$ & 3 \\
\hline $20-<30$ & $40-<75$ & 2 \\
\hline $30-<40$ & $75-<100$ & 1 \\
\hline$\geq 40$ & $\geq 100$ & 0 \\
\hline
\end{tabular}

Table 7.5 - Ratings for turbidity (NTU)

\begin{tabular}{|c|c|c|}
\hline Upland & Lowland & Rating \\
\hline$<5$ & $<15$ & 4 \\
\hline $5-<7.5$ & $15-<17.5$ & 3 \\
\hline $7.5-<10$ & $17.5-<20$ & 1 \\
\hline $10-<12.5$ & $20-<30$ & 0 \\
\hline$\geq 12.5$ & $\geq 30$ & 2 \\
\hline
\end{tabular}

Table 7.6 - Ratings for electrical conductivity $\left(\mu \mathrm{S} \mathrm{cm}^{-1}\right)$

\begin{tabular}{|c|c|c|}
\hline Upland & Lowland & Rating \\
\hline$<50$ & $<100$ & 4 \\
\hline $50-<150$ & $100-<300$ & 3 \\
\hline $150-<300$ & $300-<500$ & 2 \\
\hline $300-<500$ & $500-<800$ & 1 \\
\hline$\geq 500$ & $\geq 800$ & 0 \\
\hline
\end{tabular}


Table 7.7 - Ratings for $\mathrm{pH}$

\begin{tabular}{|c|c|}
\hline pH range & Rating \\
\hline $6.5-7.5$ & 4 \\
\hline $6.0-<6.5$ or $>7.5-8.0$ & 3 \\
\hline $5.5-<6.0$ or $>8.0-8.5$ & 2 \\
\hline $4.5-<5.5$ or $>8.5-9.5$ & 1 \\
\hline$<4.5$ or $>9.5$ & 0 \\
\hline
\end{tabular}

\subsubsection{Case study: examining sensitivity and errors in water quality indicators}

The performance of the Water Quality Sub-index and the four water quality indicators was examined through a case study of the water quality in the Latrobe River at Rosedale

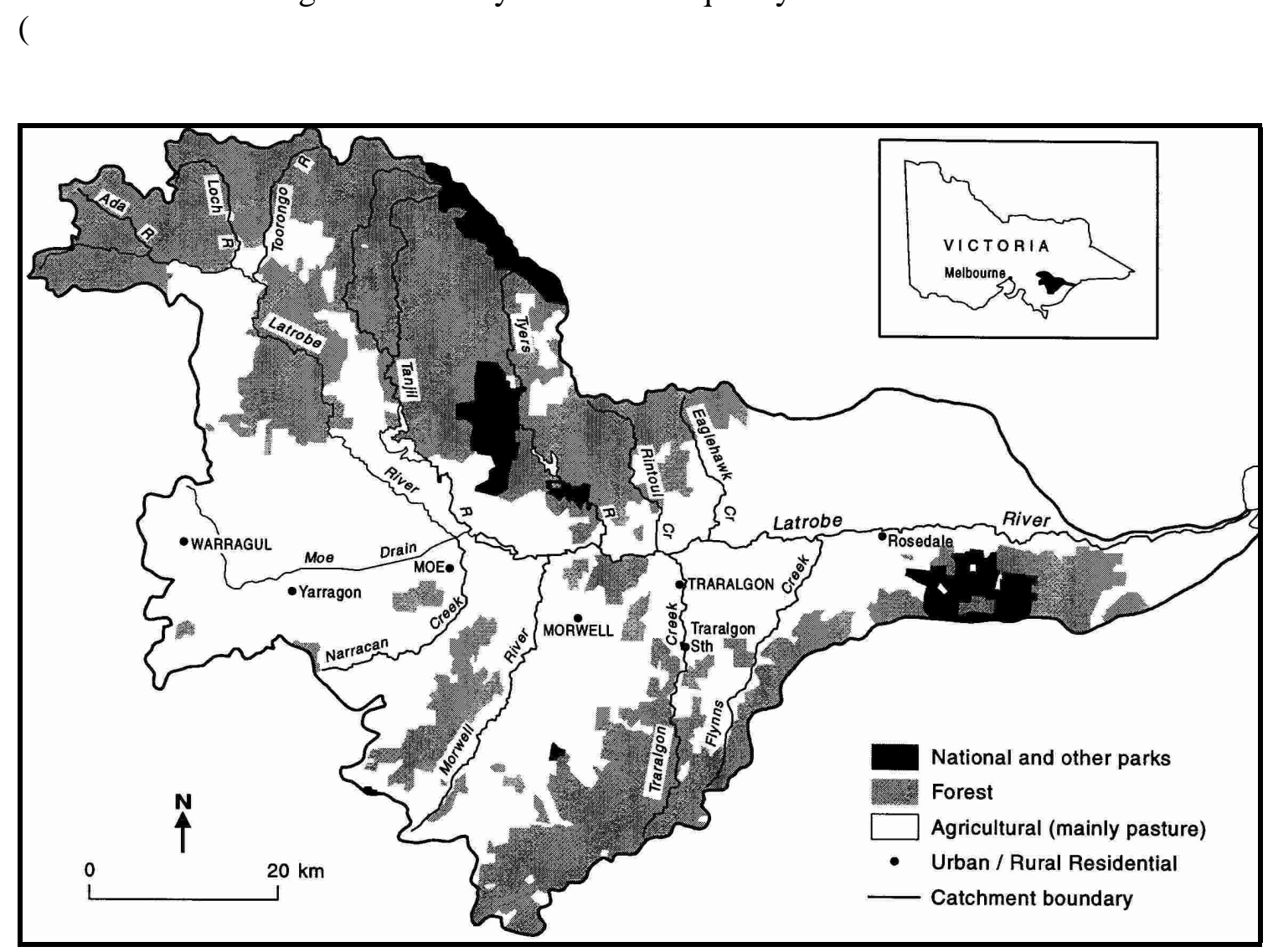

Figure 7.7. This site was chosen because there is a long record of water quality data, from the early 1960s to around 1995, and a history of water quality management (Grayson et al., 1994b; Central Gippsland Water Quality Working Group, 1995). 


\section{The water quality data}

Water quality data were collected from the 1960s to around 1995 by Gippsland Water and the organisations it succeeded. The sampling frequency varied but was usually monthly or twice monthly, although there are extensive periods of missing data. All the available data for phosphorus, turbidity, electrical conductivity and $\mathrm{pH}$ are shown in Figures 7.8 to 7.12 along with the annual thedian, plotted as a solid line, and bands showing the indicator ratings. Turbidity values are plotted on both Figure 7.9 and Figure 7.10. Figure 7.9 shb vs the full range of turbidity values plotted on a log scale. The indicator ranges could not be shown clearly on this graph so the values are reproduced on Figure 7.1 0 at a scale that allows the indicator ranges to be clearly displayed (but some of the higher turbidity readings are not shown).

\section{Sensitivity of indicator ratings}

The sensitivity of the Water Quality indicators to changes in underlying water quality is of interest as it can be used to determine how much improvement managers need to engineer before there is an increase in ratings. Some indicators are likely to be easier to improve than others, as shown in the analysis below.

For three indicators, phosphorus, turbidity, and electrical conductivity, the effect of improving water quality is shown in a series of figures. For example, the phosphorus indicator ratings are shown in Figure 7.13 which are based on the measured phosphorus concentrations that have been rated using Table 7.4 The effect of reducing phosphorus concentrations by $20 \%$ is shown in Figure 7.14 These indicator ratings are calculated by multiplying the measured phosphorus concentrations by 0.8 and then using Table 7.4 to determine the new rating. The effect of further decreases of $40 \%, 60 \%$ and $80 \%$ are shown in Figures 7.15 to 7.17. Similar resuts are prov ded for turbidity and electrical conductivity as shown on Figures 7.18 to 7.27. A similar analysis has not been undertaken for $\mathrm{pH}$, as for most of the historical period the indicator rating was at the maximum level of 4 .

The results show that major improvements in phosphorus, turbidity and electrical conductivity are required before the indicator ratings increase to the maximum possible score. For example, reducing phosphorus concentrations by $80 \%$ does not result in a score of 4 in all years Figure 7.17 and 80\% reductions in turbidity and EC are required before the ratings improve to 4 in all years. 
The response of these indicators to changes in water quality depends on the rating tables that were developed by the Specialist Reference Group. This was, at least partly, a subjective process but there is evidence to suggest that the behaviour of the phosphorus indicator is reasonable. Grayson et al. (1994b) found that phosphorus loads in the Latrobe River had increased by four to five times since European settlement, which suggests that concentrations would need to decrease by about $80 \%$ before they would be equivalent to pristine conditions. Figure 7.17 shows the effect of an $80 \%$ reduction in concentration where the indicator scores increase from 3 to 4 compared to around 1 under current conditions. Robinson (1995) argued that a 50\% reduction in phosphorus loads is required in the Latrobe River before there would be significant improvement in conditions in the river. A $50 \%$ reduction in concentrations would increase the indicator scores to a level around 2 to 3 (see Figures 7.15 and 7.16).

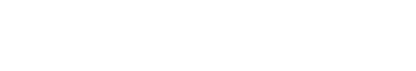





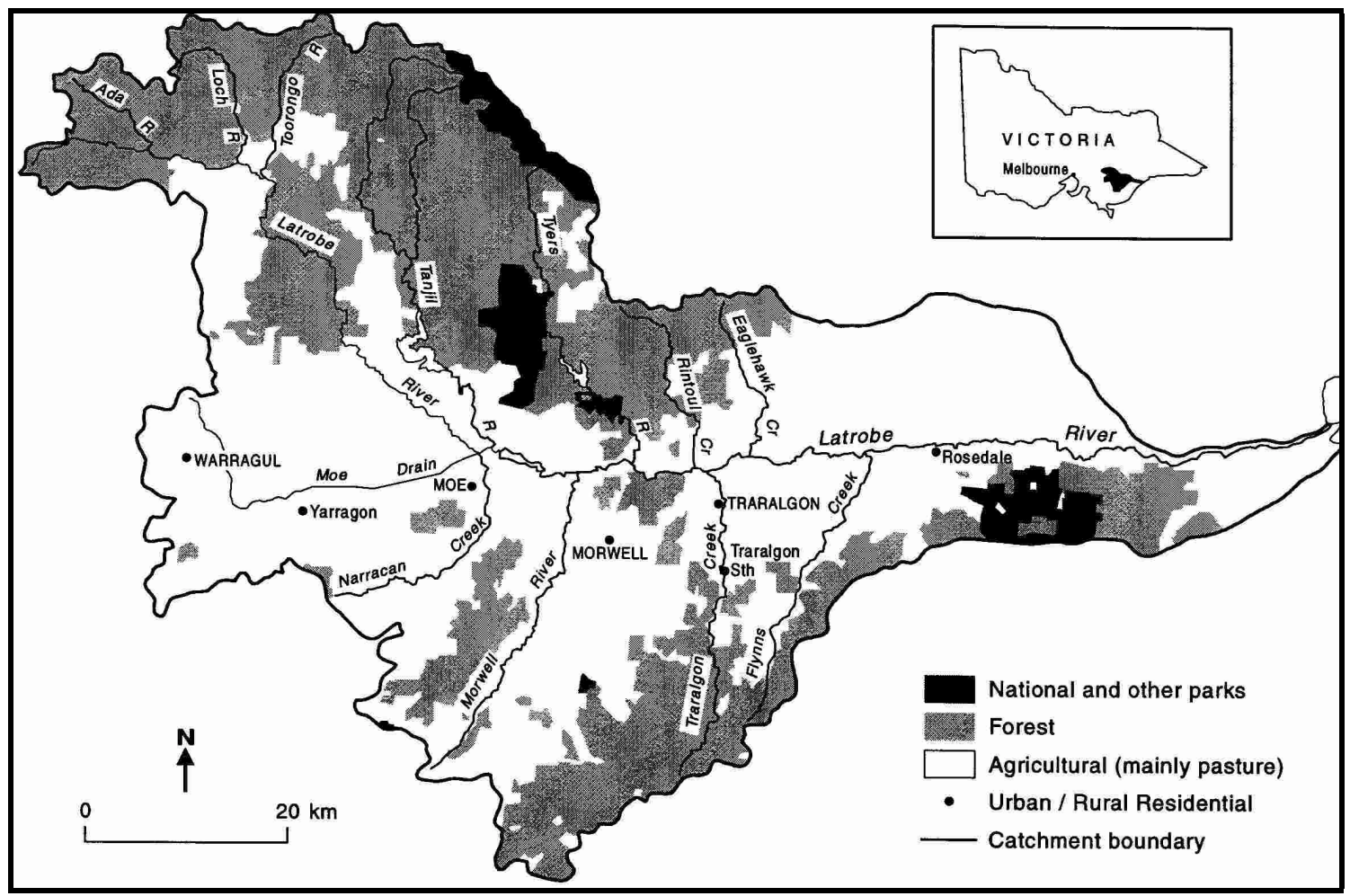

Figure 7.7 - Latrobe River Catchment 



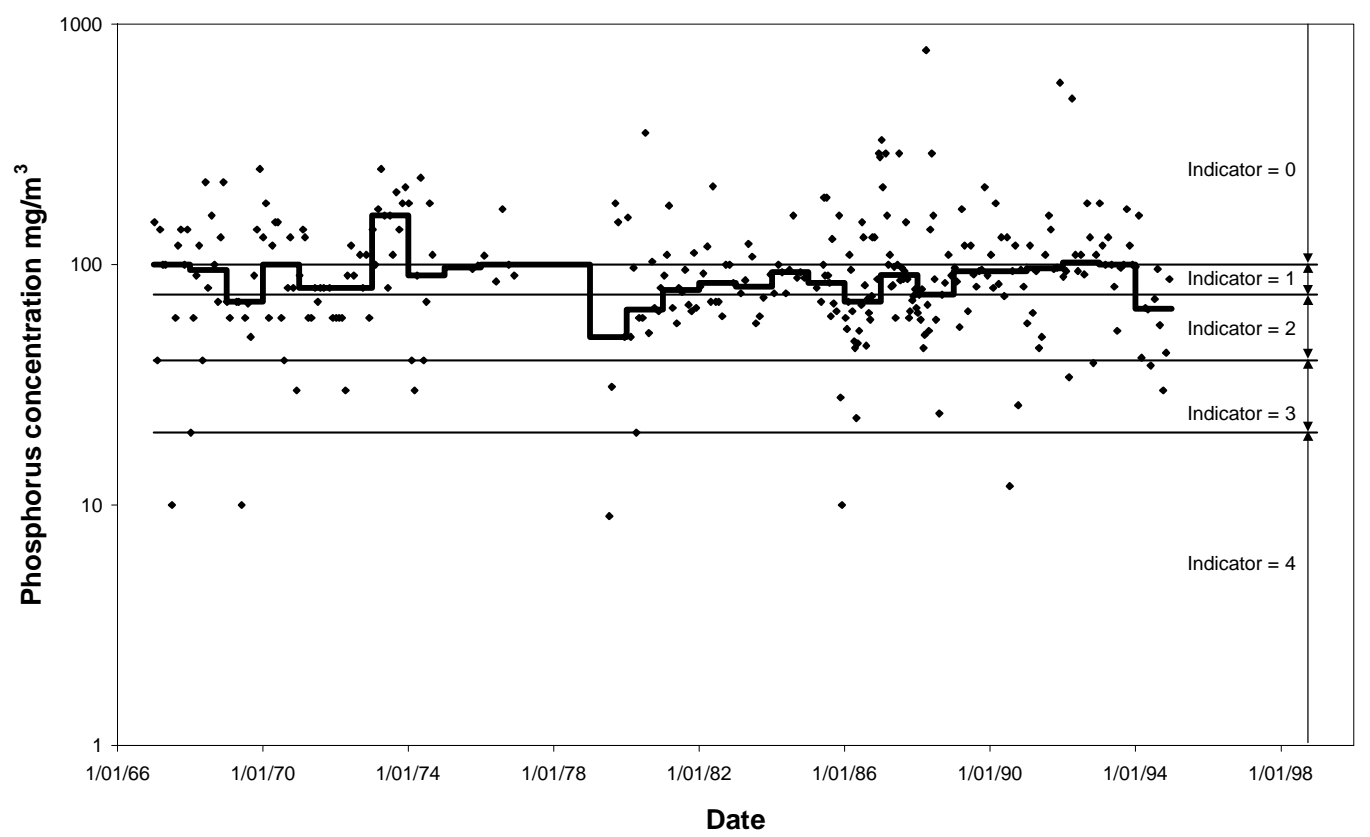

Figure 7.8 - Phosphorus concentration $\left[\mathrm{mg} \mathrm{m}^{-3}\right]$ for the Latrobe River at Rosedale showing recorded data, annual median (solid line) and indicator ratings

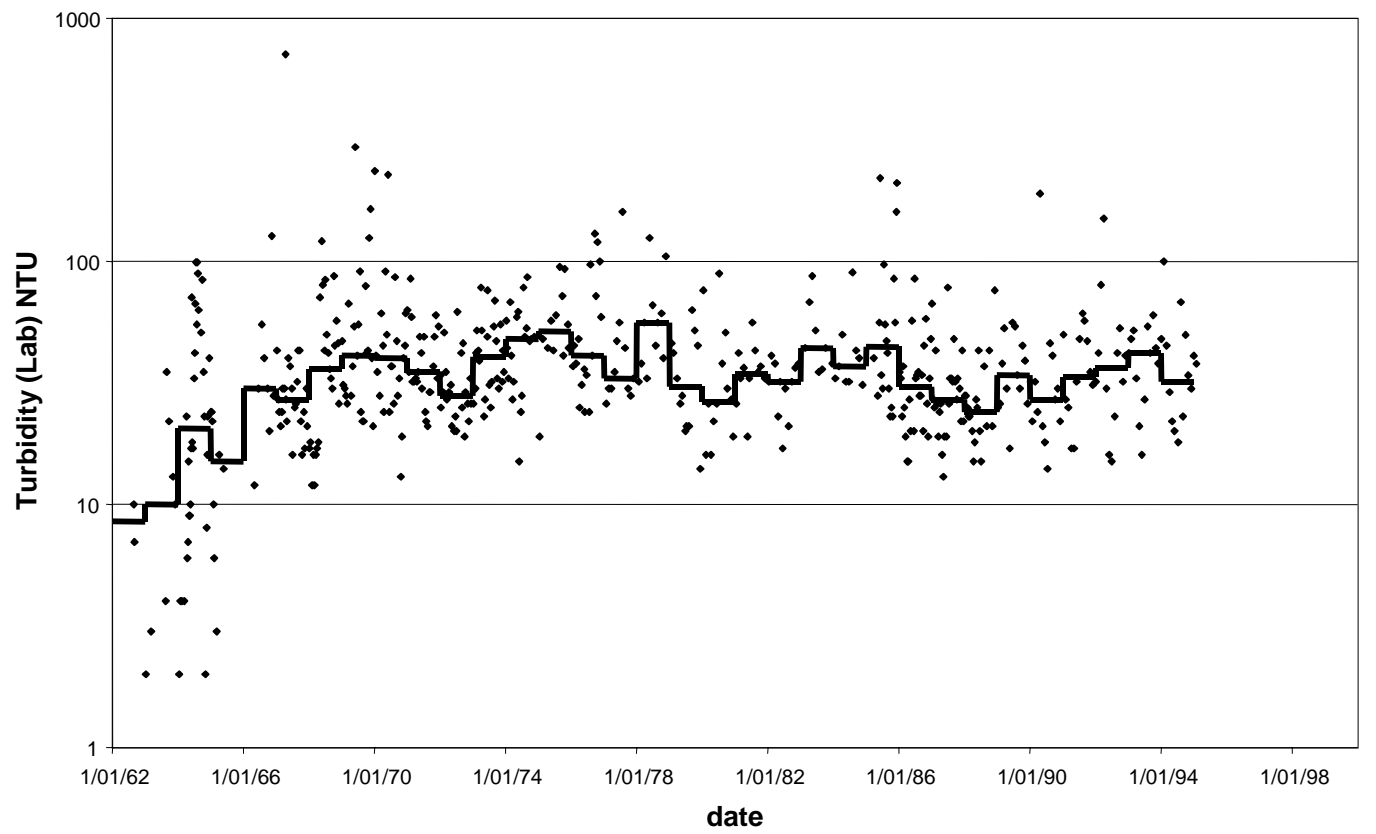

Figure 7.9 - Turbidity [NTU] for the Latrobe River at Rosedale showing recorded data and annual median (solid line). Data are plotted on a log scale to show the range of turbidity values. 


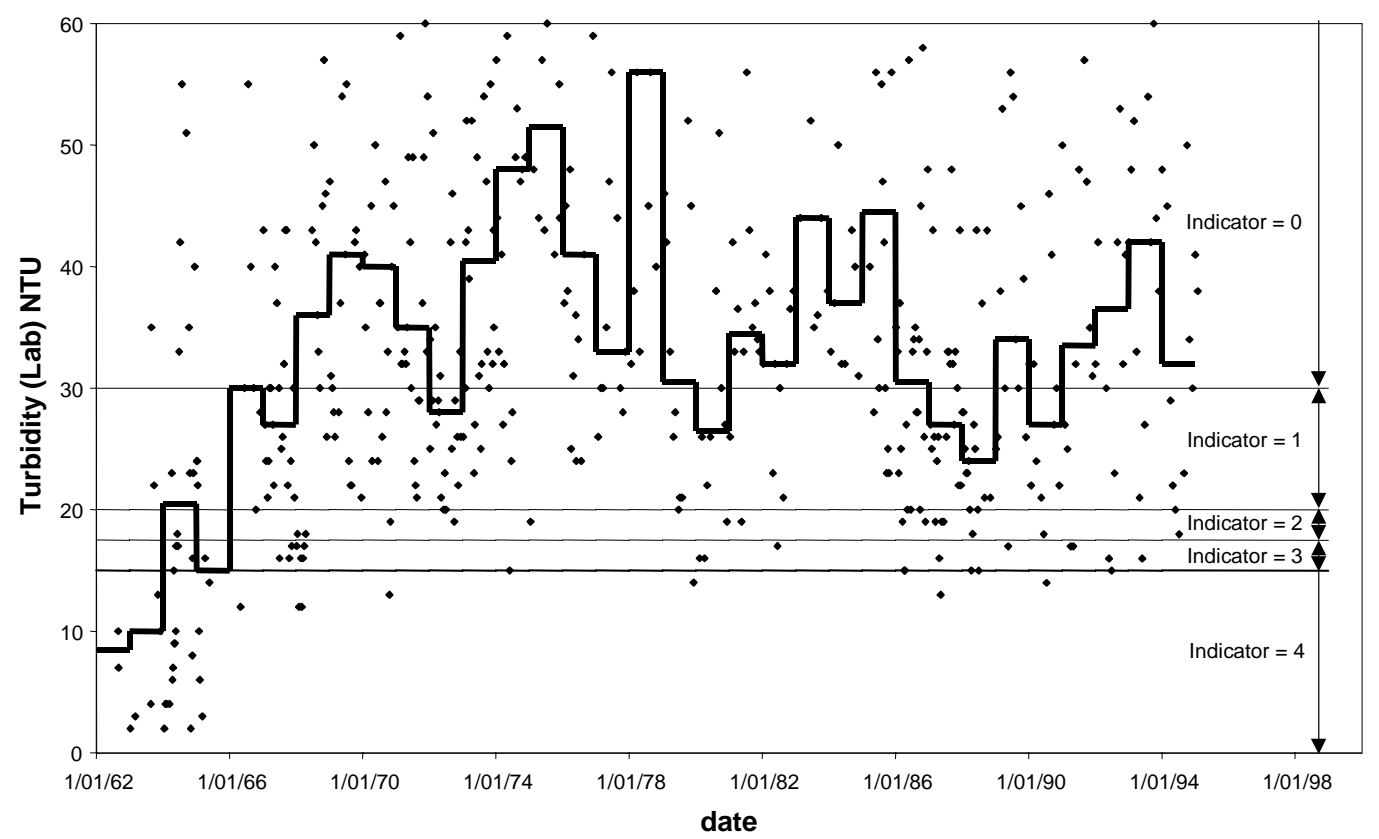

Figure 7.10 - Turbidity [NTU] for the Latrobe River at Rosedale showing recorded data, annual median (solid line) and indicator ratings

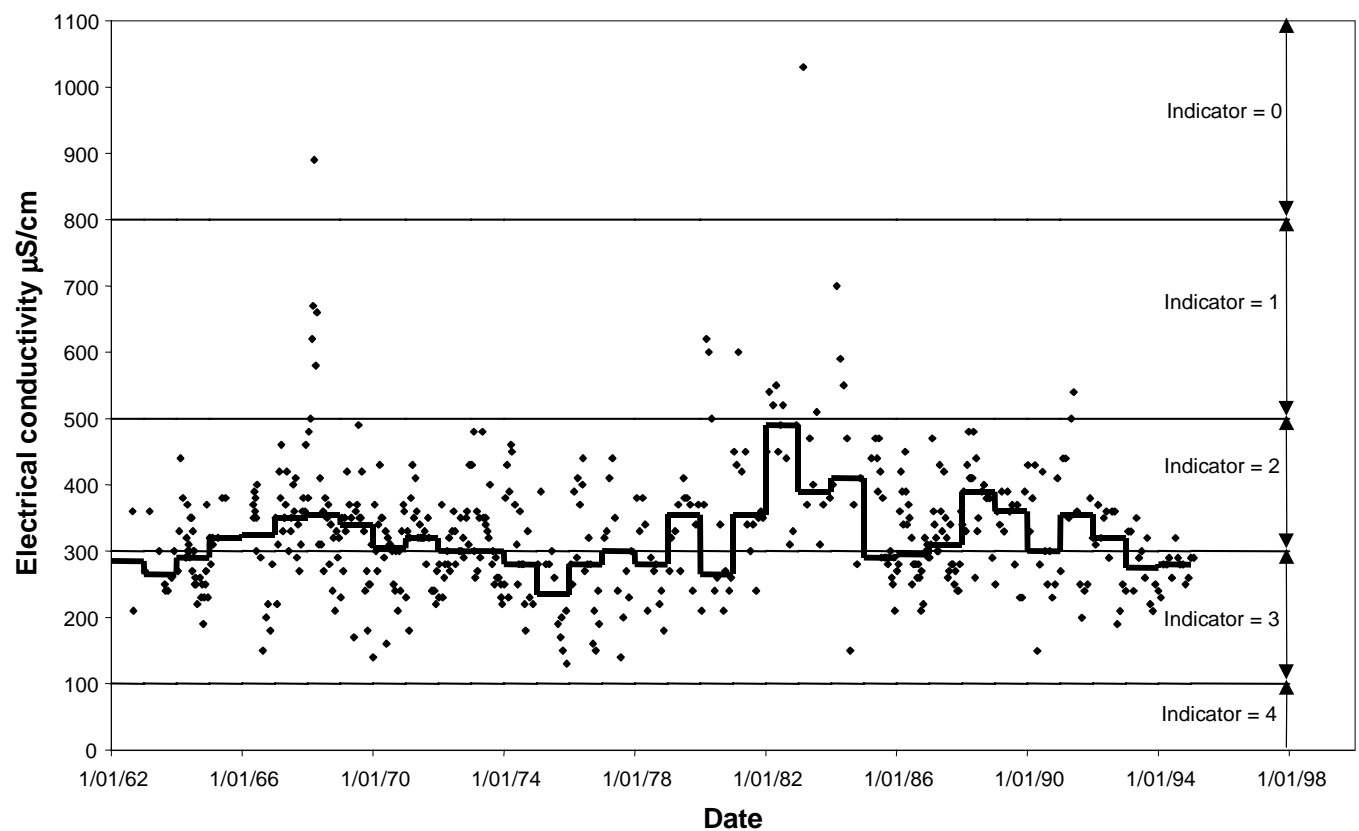

Figure 7.11 - Electrical conductivity $[\mu \mathrm{S} / \mathrm{cm}]$ for the Latrobe River at Rosedale showing recorded data, annual median (solid line) and indicator ratings 


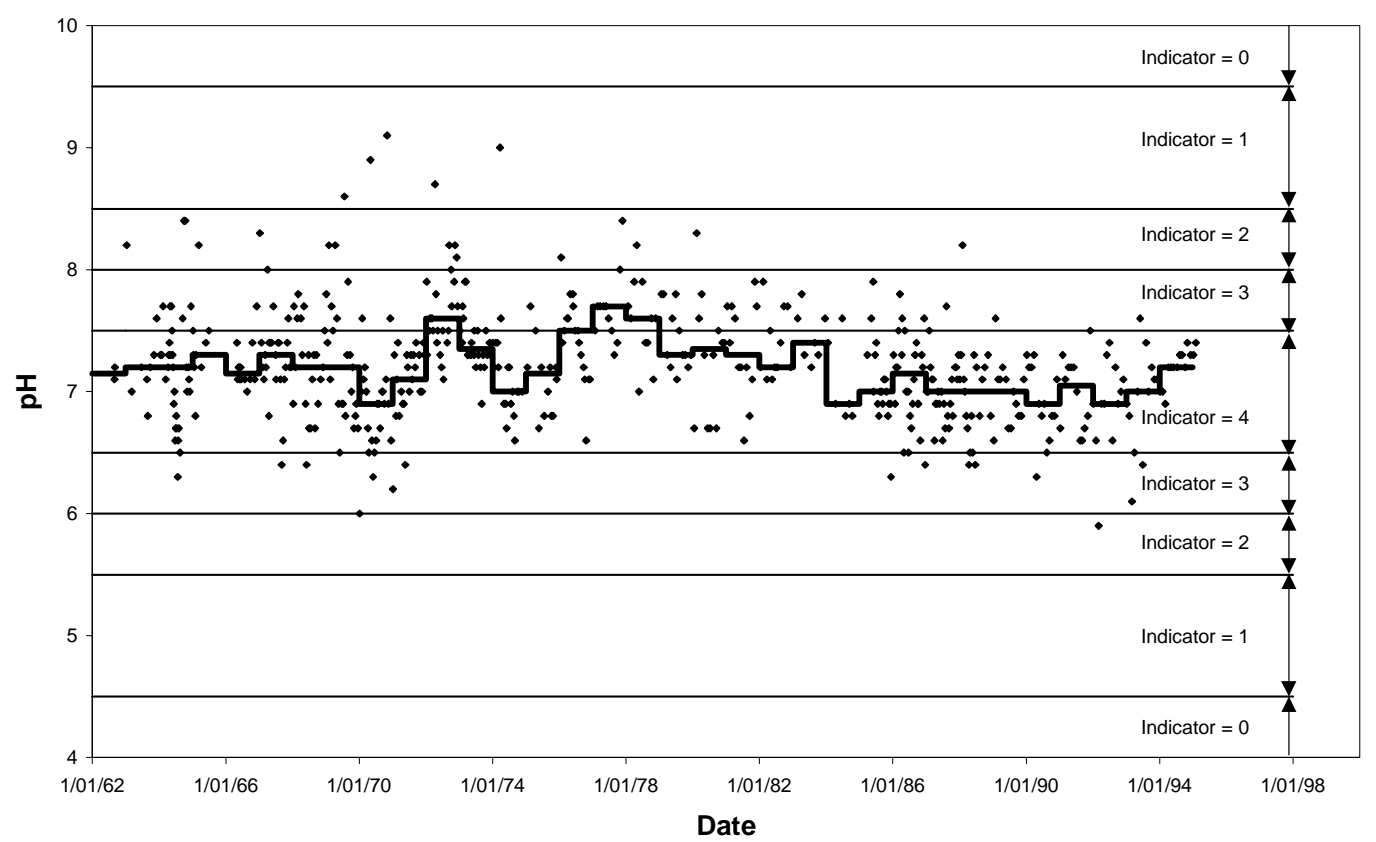

Figure 7.12 - pH for the Latrobe River at Rosedale showing recorded data and annual median (solid line) and indicator ratings

Results also show that the response to water quality improvement can be non-linear. For example, the change from a reduction of $40 \%$ to a reduction of $60 \%$ in EC has limited effect on indicators ratings Figure 7.25 and Figure 7.26, compared to the effect of a change from $60 \%$ to $80 \%$ Figure 7.26 and Figure 7.27. The response also varies for different indicators; compare the $40 \%$ to $60 \%$ reduction in EC with the equivalent change in phosphorus (Figures 7.25, 7.26, 7.15 and 7.16). This type $\phi$ f analysis could assist water manager develop cost effective water quality improvement strategies that focus on the greatest change in indicator scores for a given allocation of resources. This is likely to be an important issue if authorities are rewarded, and their performance judged, on the basis of ISC scores.

Results for the turbidity indicator show a large spread in scores following reductions of $40 \%$ to $60 \%$ (Figures 7.20 and 7.21). Large variation between measurement periods is an undesirable characteristic of an indicator (Reid and Brooks, 1998), so it may be appropriate to review the performance of the turbidity indicator in other streams to judge whether it should continue to be included it the ISC. Reid and Brooks (1988) discuss the need for long-term field testing of indicators to judge their performance and determine if they should be adopted in the final monitoring scheme. For the ISC, there was an imperative to get the statewide monitoring program started, so no long-term field 
7. Hydrology, water quality, aquatic life

testing was undertaken, but there does need to be ongoing evaluation of the chosen indicators to see if they continue to meet the chosen objectives (see Chapter 5).

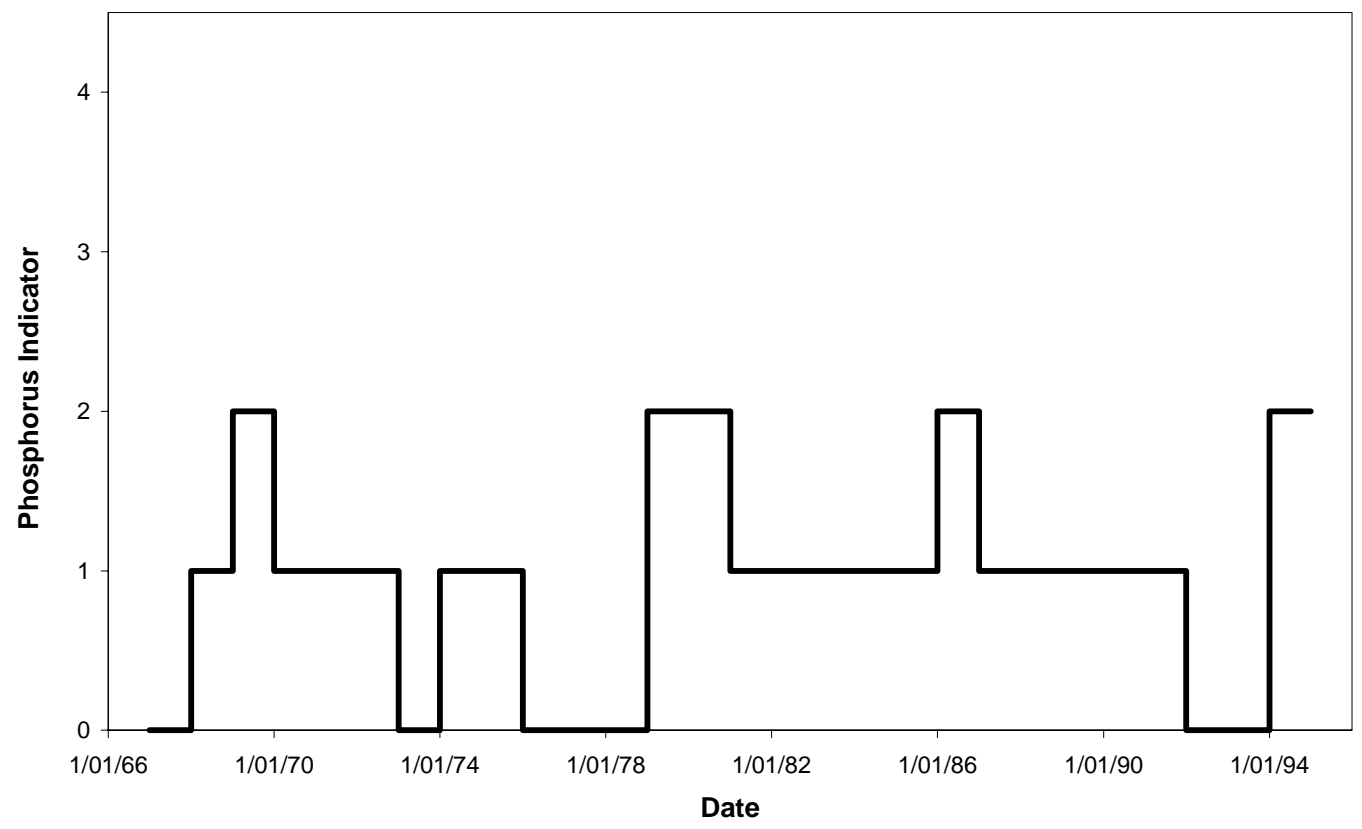

Figure 7.13 - Phosphorus indicator ratings from measured data

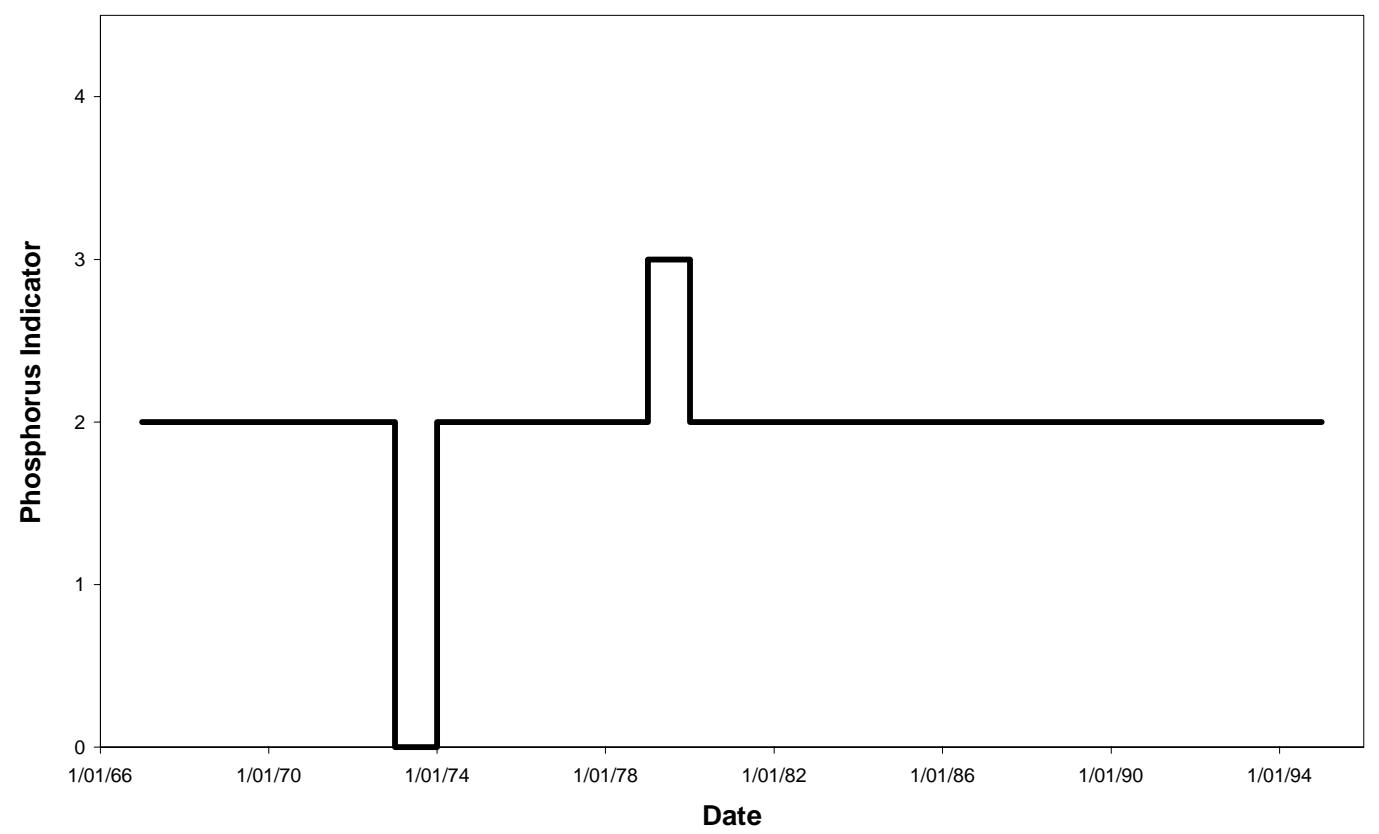

Figure 7.14 - Phosphorus indicator rating when phosphorus concentrations are reduced by $20 \%$ 


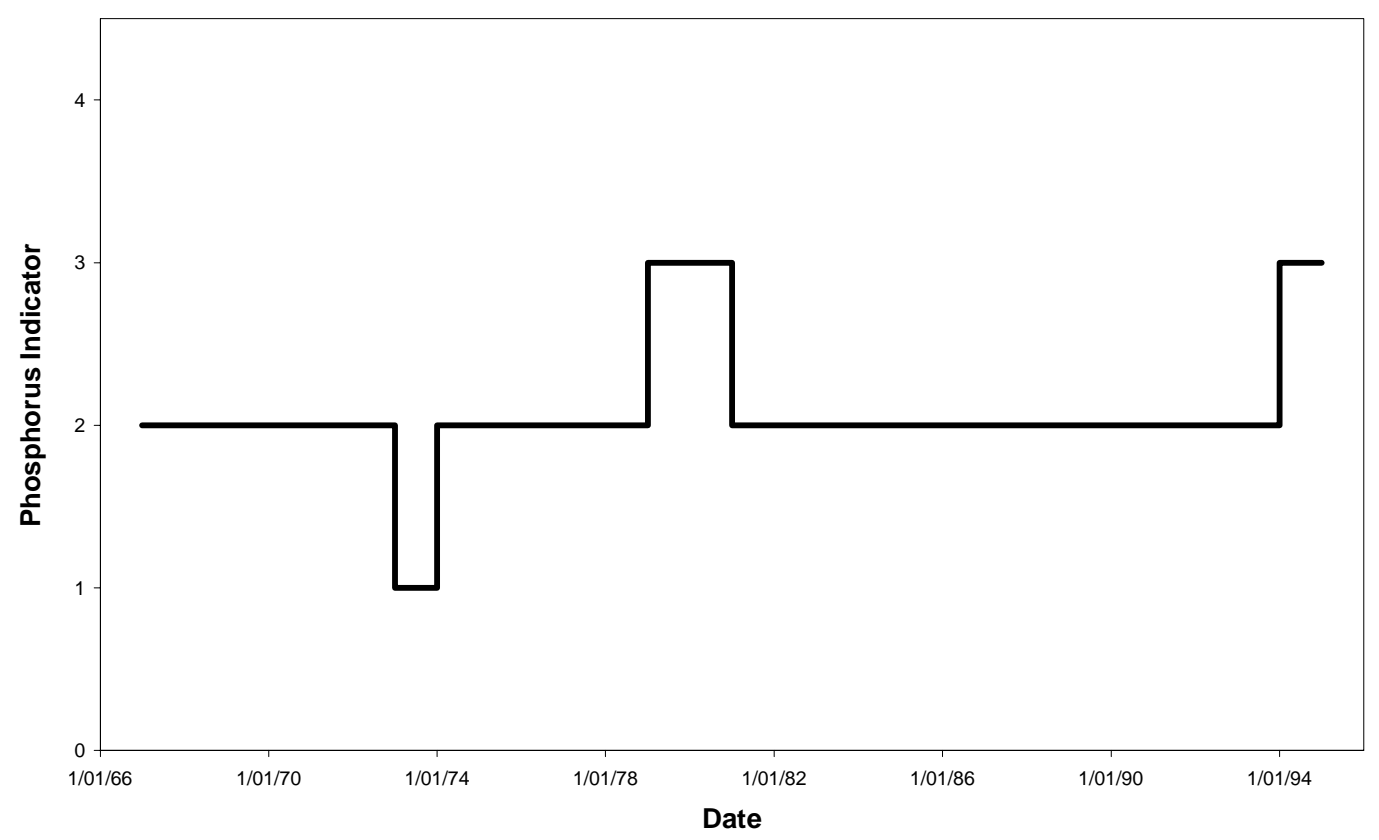

Figure 7.15 - Phosphorus indicator rating when phosphorus concentrations are reduced by $\mathbf{4 0 \%}$

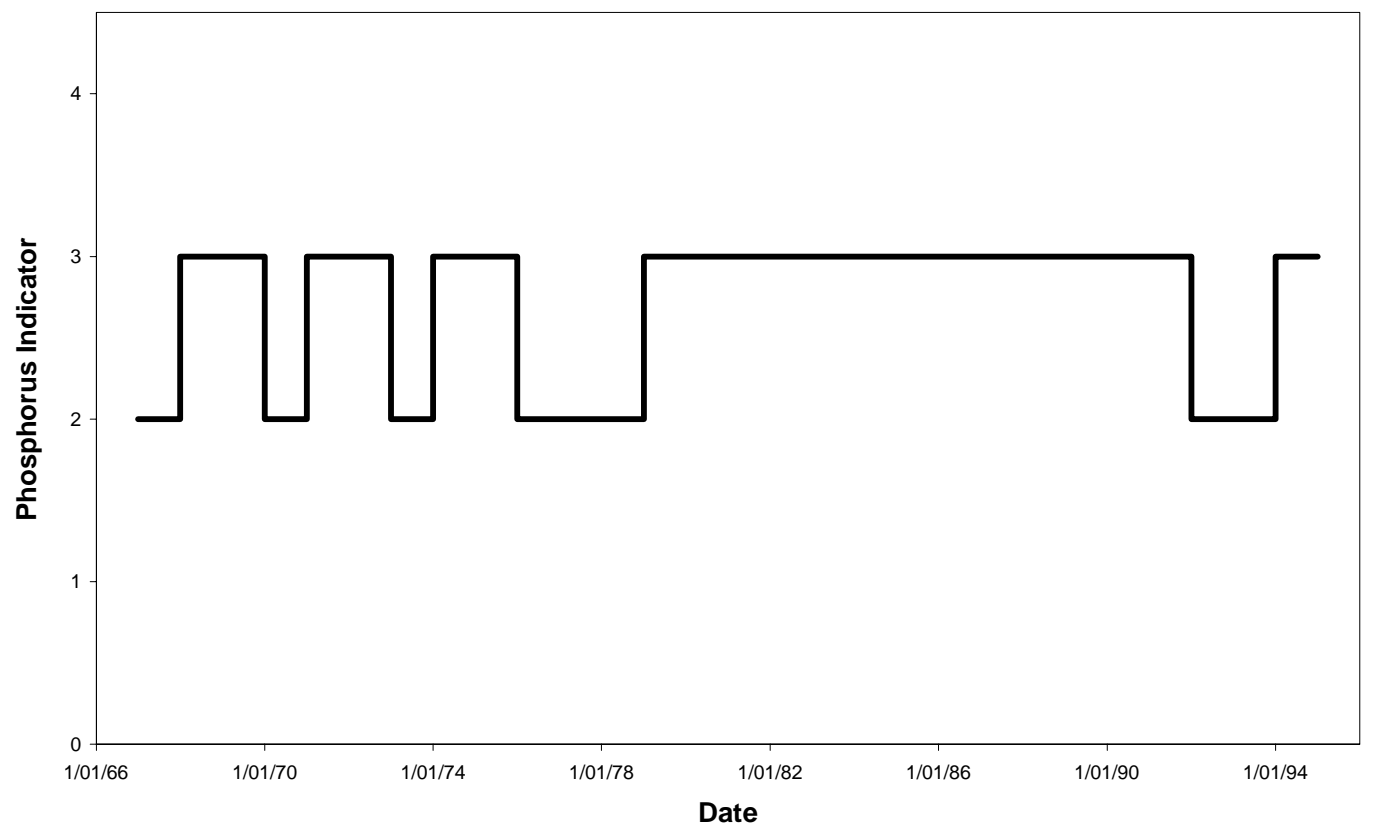

Figure 7.16 - Phosphorus indicator rating when phosphorus concentrations are reduced by $60 \%$ 


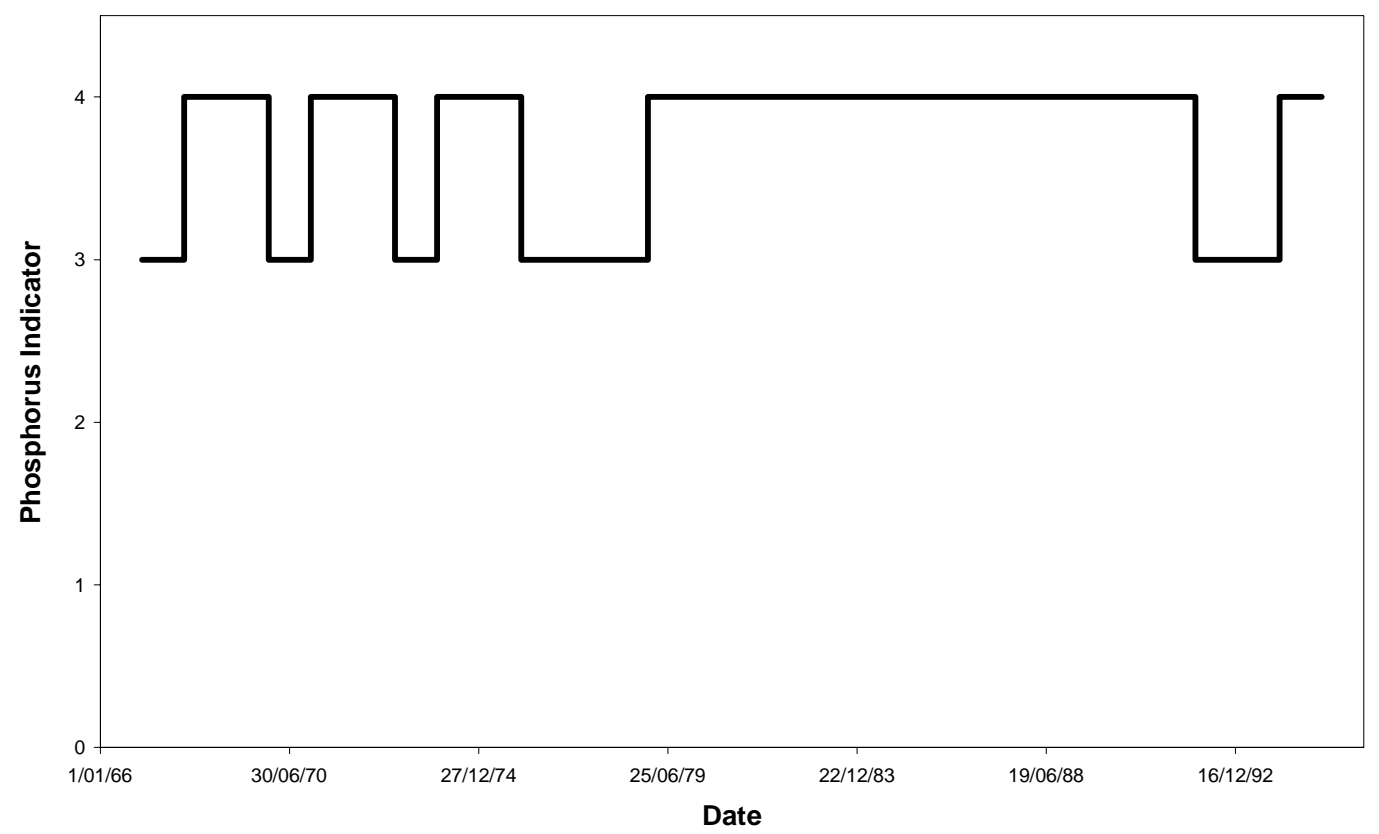

Figure 7.17 - Phosphorus indicator rating when phosphorus concentrations are reduced by $80 \%$

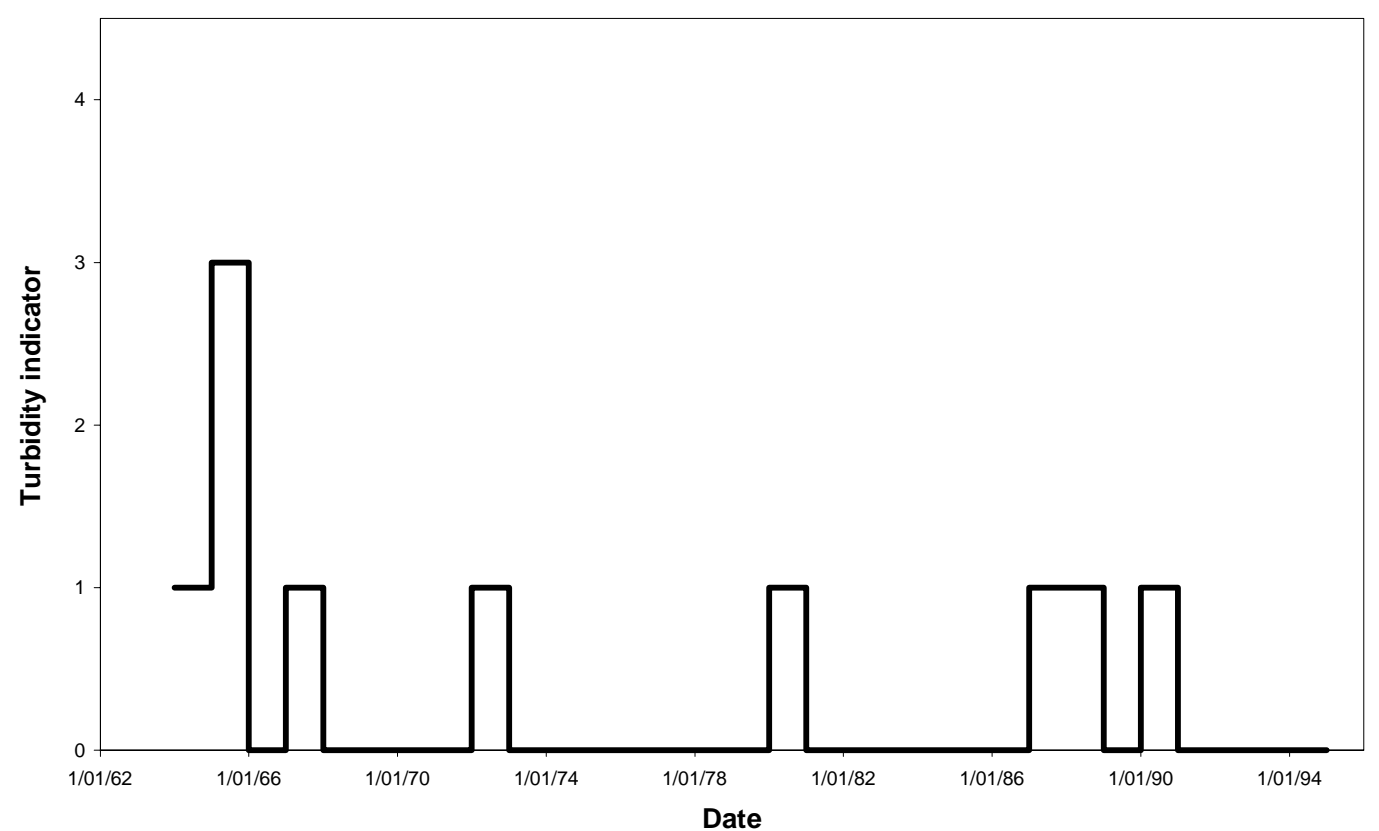

Figure 7.18 - Turbidity indicator ratings from measured data 


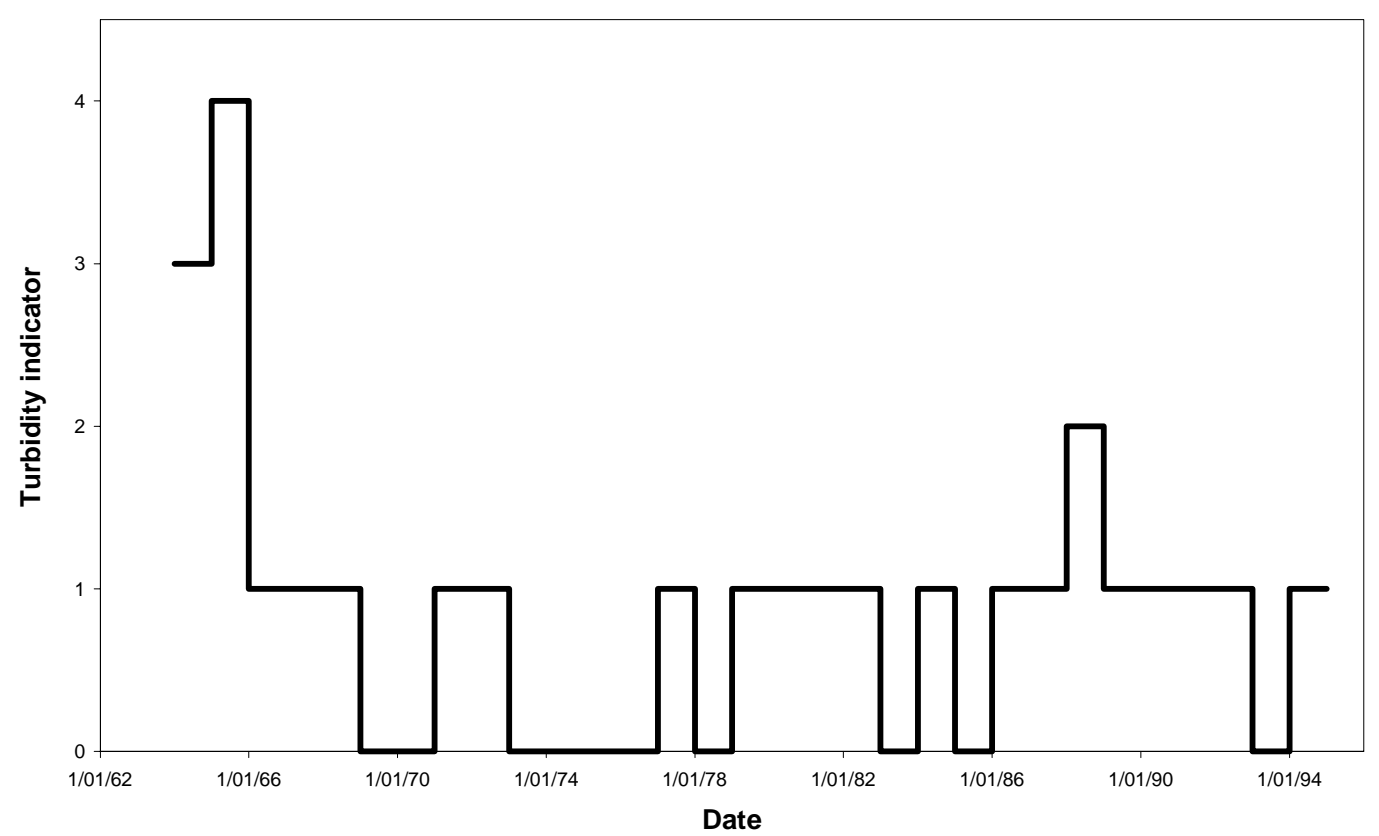

Figure 7.19 - Turbidity indicator rating when turbidity values are reduced by $20 \%$

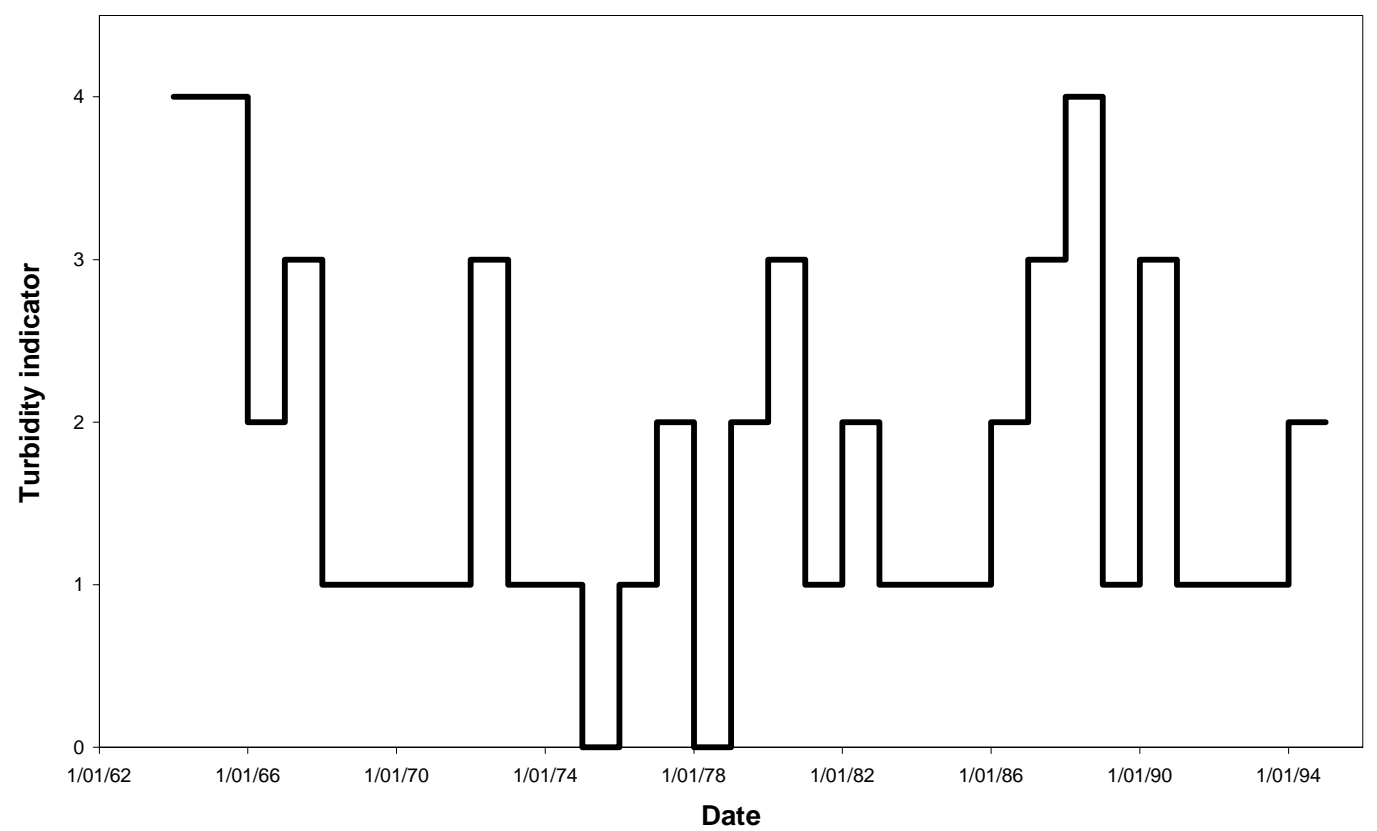

Figure 7.20 - Turbidity indicator rating when turbidity values are reduced by $\mathbf{4 0 \%}$ 


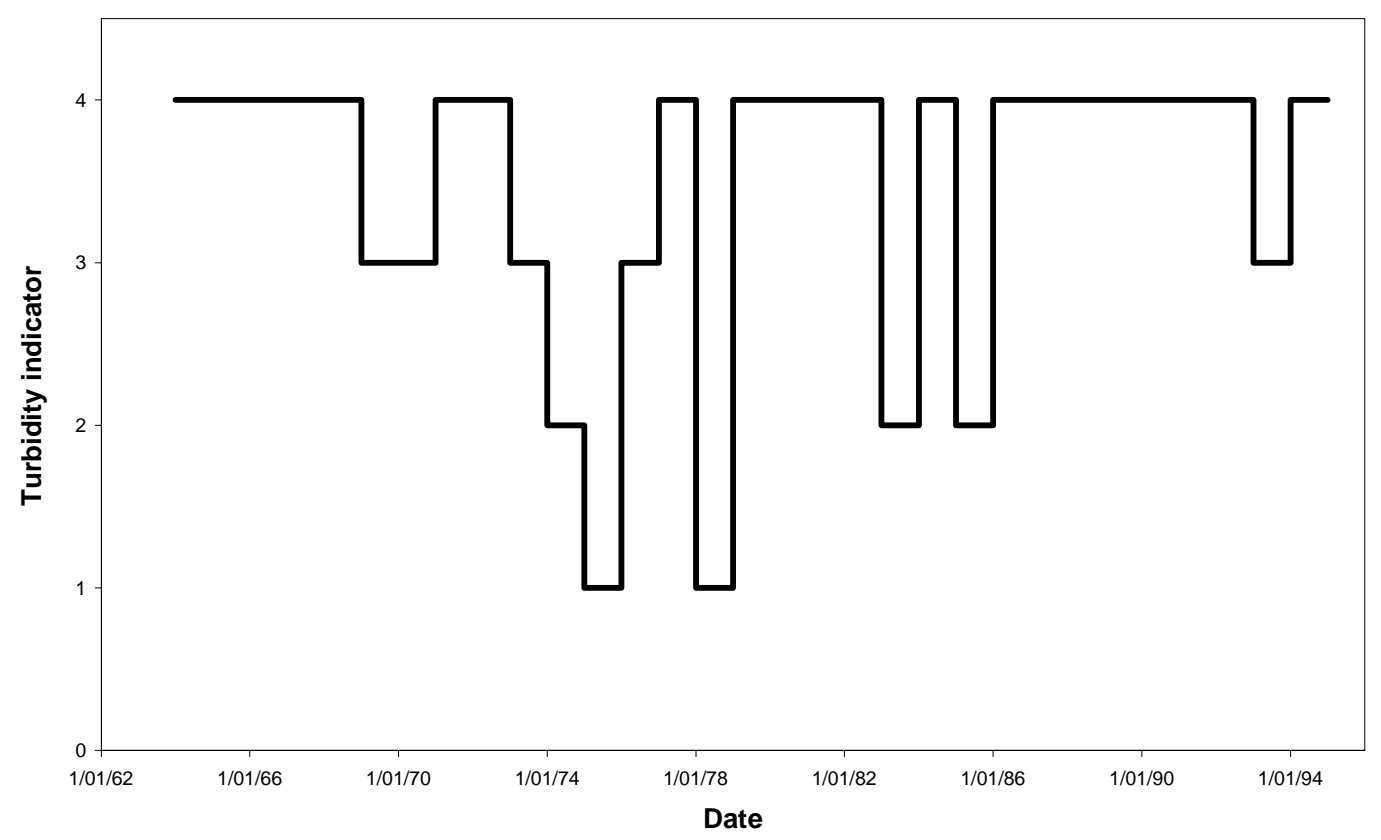

Figure 7.21 - Turbidity indicator rating when turbidity values are reduced by $60 \%$

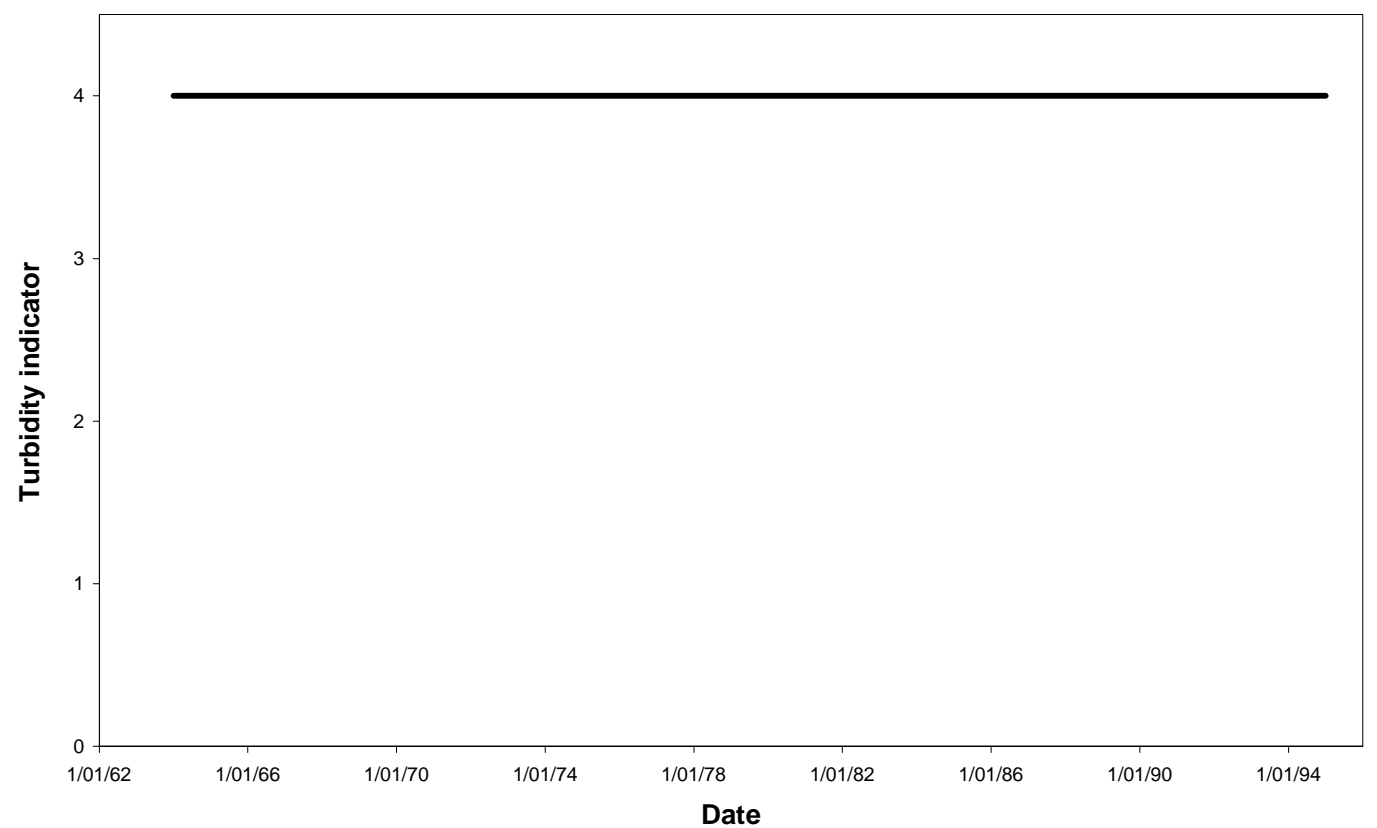

Figure 7.22 - Turbidity indicator rating when turbidity values are reduced by $80 \%$ 


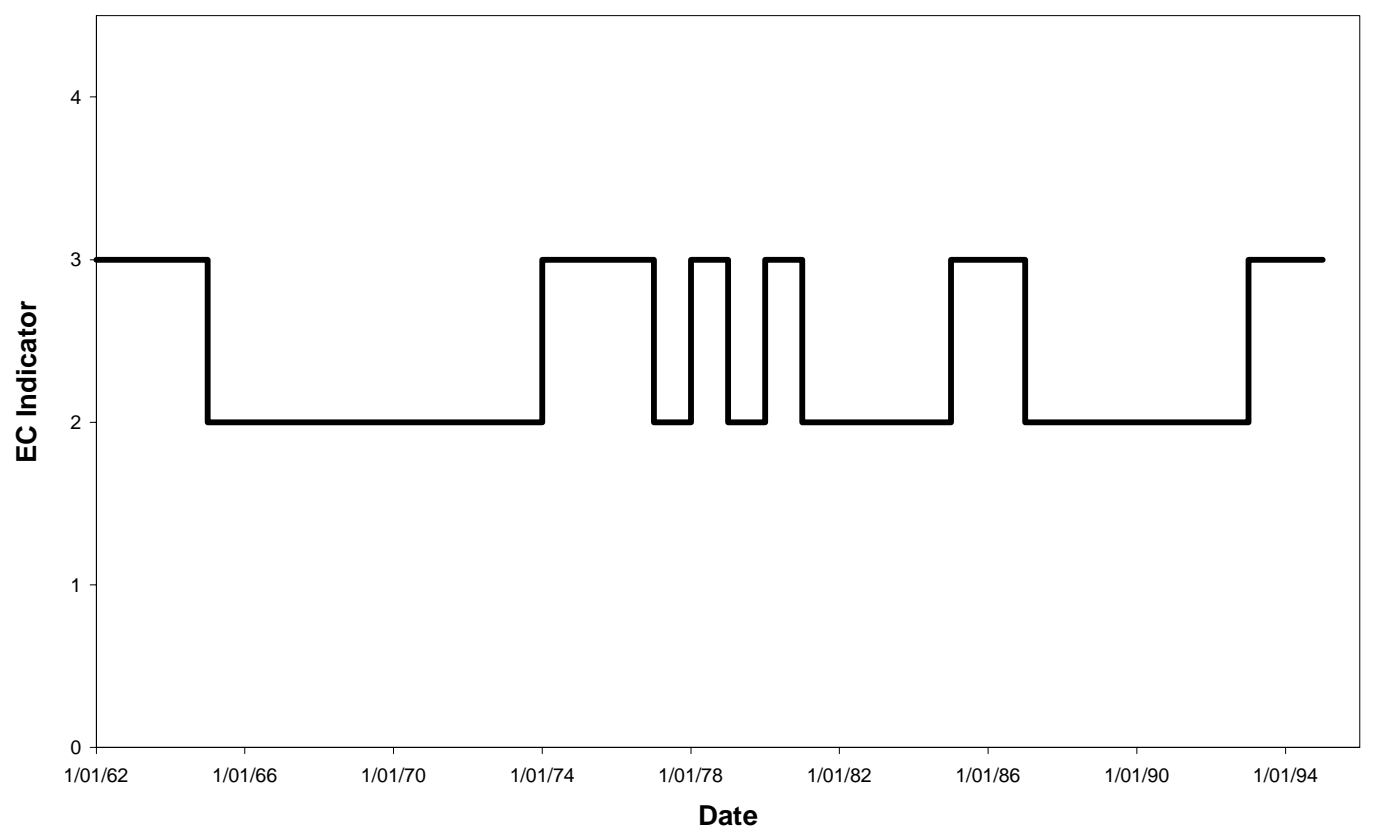

Figure 7.23 - Electrical conductivity indicator ratings from measured data

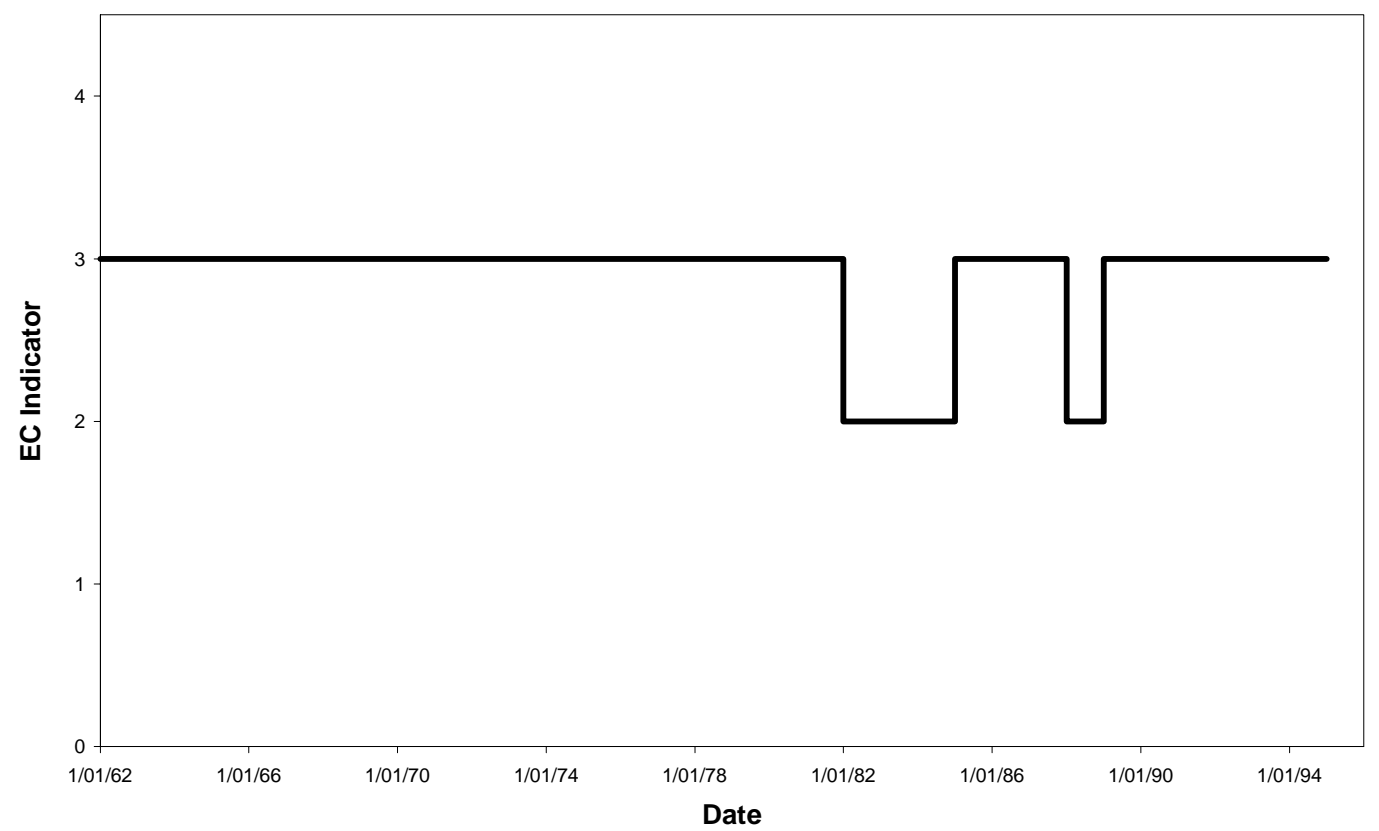

Figure 7.24 - Electrical conductivity indicator rating when EC values reduced by $20 \%$ 


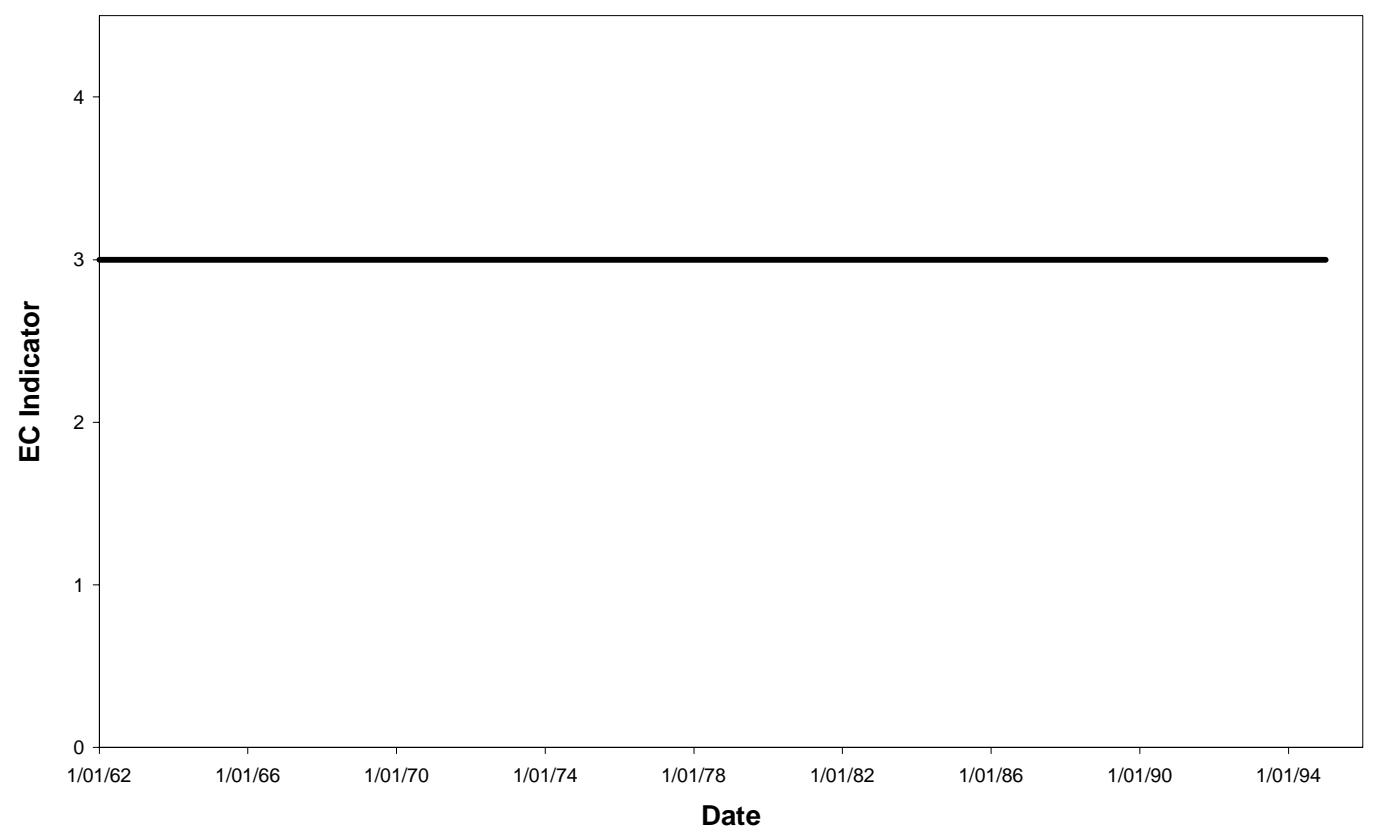

Figure 7.25 - Electrical conductivity indicator rating when EC values reduced by $40 \%$

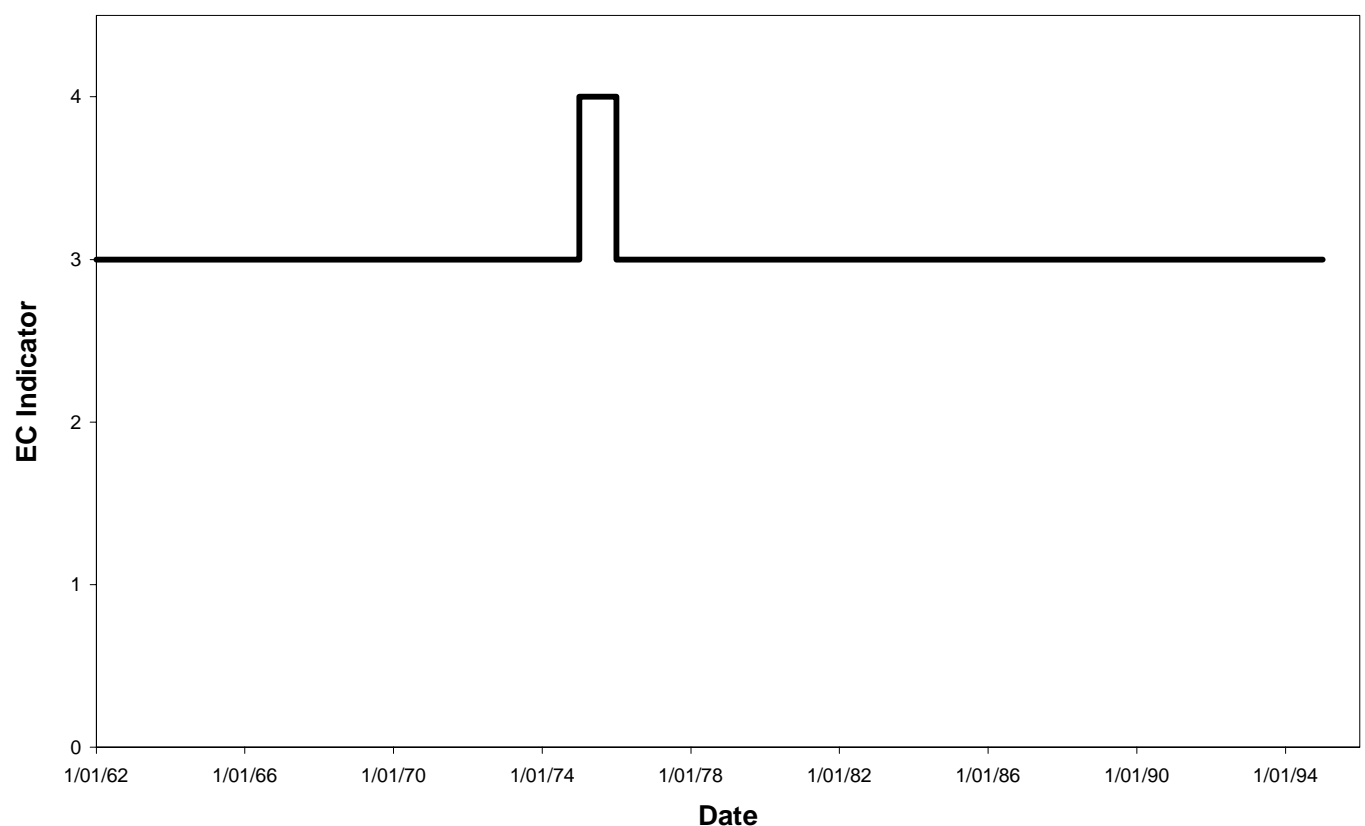

Figure 7.26 - Electrical conductivity indicator rating when EC values reduced by $60 \%$ 


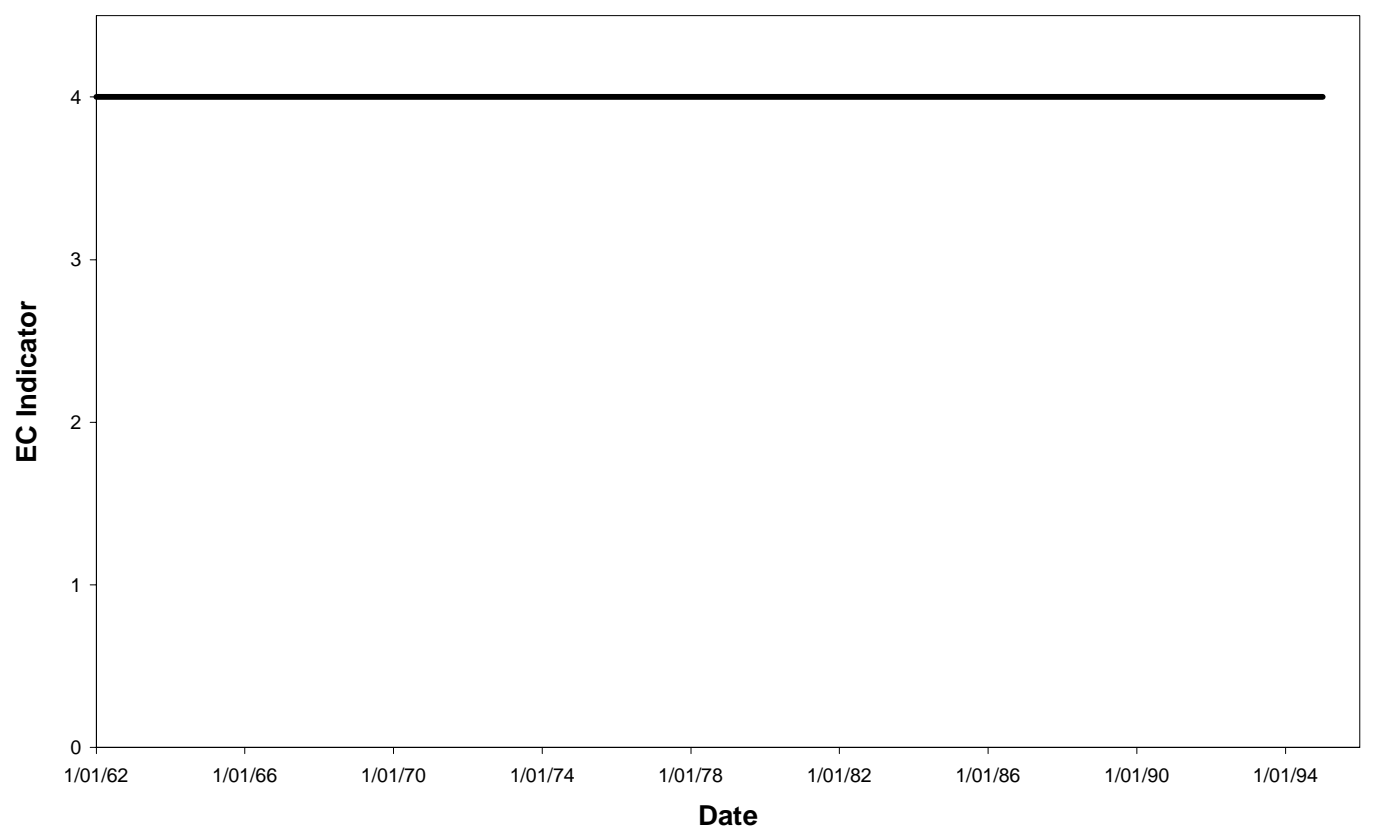

Figure 7.27 - Electrical conductivity indicator rating when EC values reduced by $80 \%$

\section{Water Quality Sub-index}

The Water Quality Sub-index is the sum of the four indicators values scaled to be between zero and ten (equation 7.2). Annual sub-index scores for the Latrobe River at Rosedale are shown in Figure 7.28. The following section reviews the accuracy, bias and precision of these sub-index values.

Bias of water quality measurements is unlikely to be a significant source of error in the Water Quality Sub-index. For water quality collected as part of the VWQMN or other large scale programs, there is considerable effort taken to minimise bias with Quality Assurance/Quality Control procedures that include inter-laboratory comparisons, regular calibration of field and laboratory equipment, guidelines for field data collection, data entry and retrieval (Eaton et al., 1995; Water Ecoscience Pty Ltd, 1998). Another possible source of bias is that the whole hydrograph may not be sampled. It is possible that high flows, with the poorest water quality, will be missed during regular sampling but this is unlikely to affect the median which is robust to infrequent large values (Helsel and Hirsch, 1992). Since the Water Quality Sub-index is based on the median of the measured concentrations, it seems reasonable to assume that the Water Quality Sub-index score based on the sample values will be an unbiased estimate of the true Water Quality Sub-index value. 


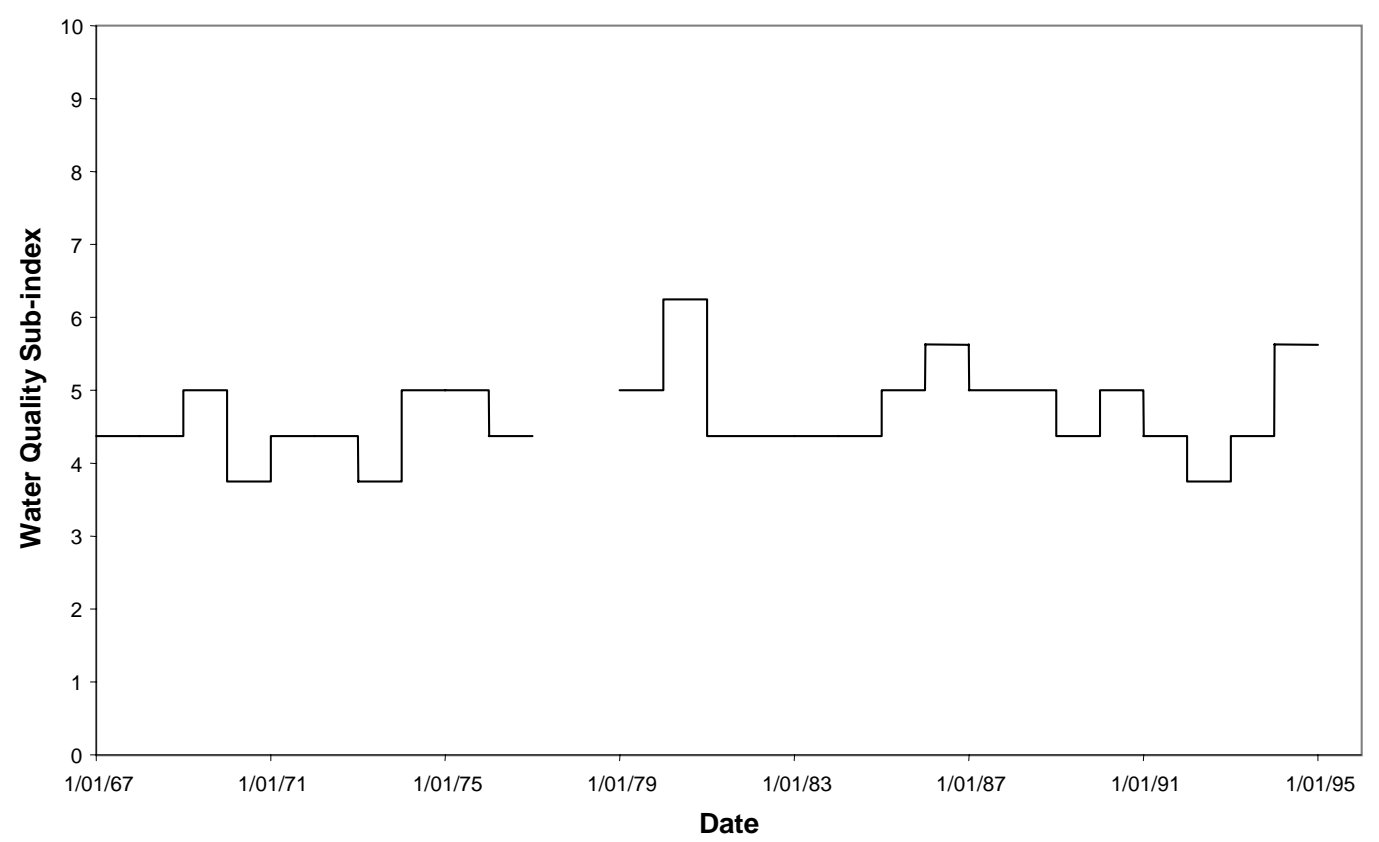

Figure 7.28 - Water Quality Sub-index for the Latrobe River at Rosedale from 1967 to 1995 (Water Quality Sub-index is not calculated where data are missing)

Precision of the Water Quality Sub-index can be estimated by calculating approximate confidence intervals around sub-index scores using bootstrap procedures (Efron and Tibshirani, 1993; Manly, 1997). The following steps were used. Firstly, the original data were used to calculate values for the Water Quality Sub-index, as shown in Figure 7.29 using equation 7.2. This resulted in one sub-index value for each year where all four water quality parameters were available (see Figure 7.28.

The next step was to repeat these calculations with bootstrap data sets for each water quality parameter. For each year where there was measured data, 2000 years of simulated data were created by randomly choosing values (with replacement) from the original measured data (see Figure 7.29. These bootstrap data sets were used to calculate 2000 values for the Water Quality Sub-index for each year using equation 7.2. This number of replicates is recommended by Efron and Tibshirani (1993) for confidence interval calculations. 


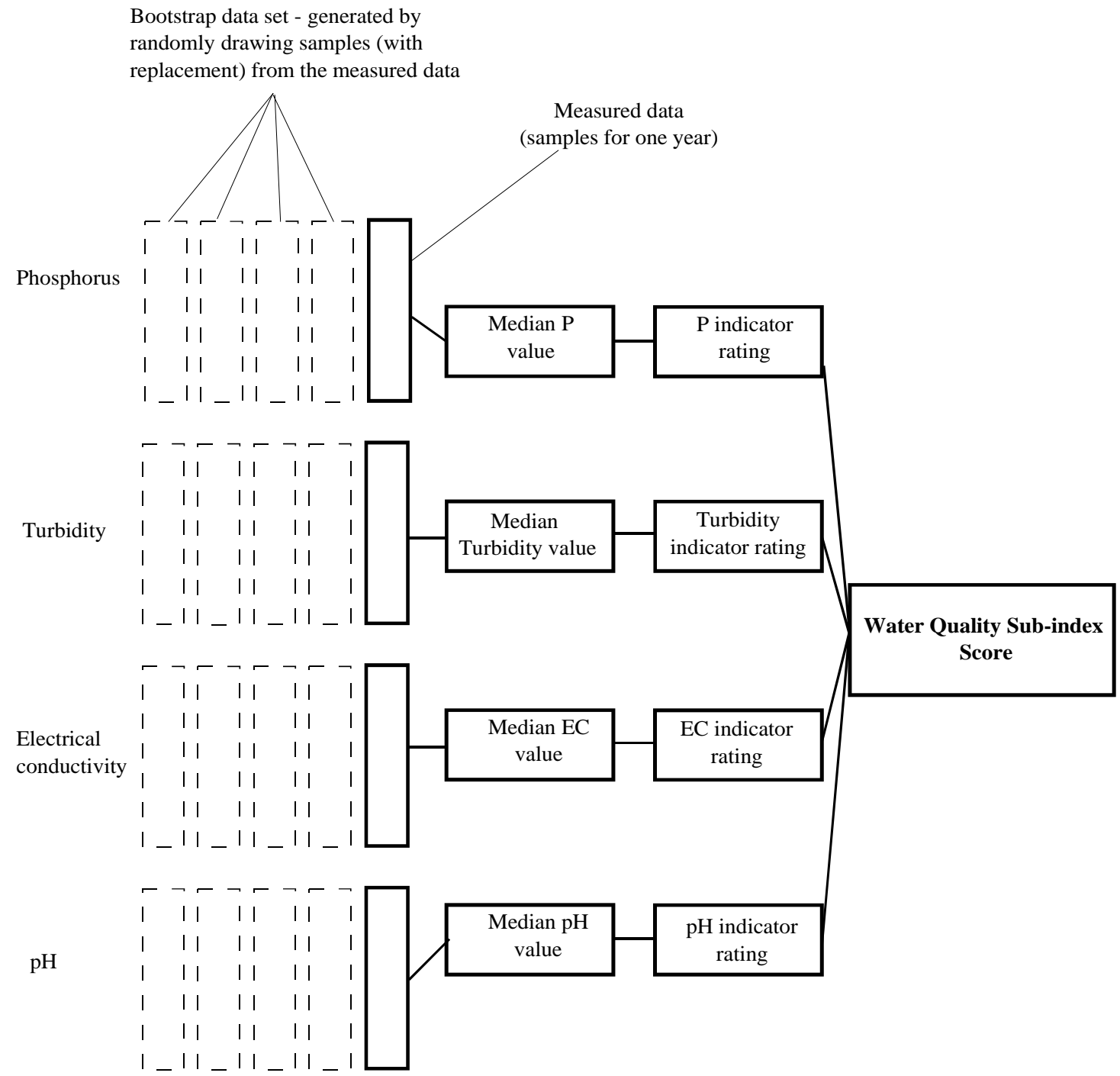

Figure 7.29 - Procedure to calculate confidence intervals for Water Quality Subindex scores

This set of Water Quality Sub-index scores was further analysed to calculate confidence intervals. The end points of the confidence intervals were based on the percentiles of the Water Quality Sub-index scores generated from the bootstrap data sets. For example, a 90\% confidence interval would have end points that were approximately the $5^{\text {th }}$ percentile and $95^{\text {th }}$ percentile of all the scores calculated from the bootstrap data. Techniques recommended by Efron and Tibshirani (1993), namely bias-correction and acceleration, were used to correct these end points so that the confidence interval is more accurate (Efron and Tibshirani, 1993, 185 - 187).

Let $1-2 \alpha$ be the interval of intended coverage. The end points of the confidence interval are given by $\left(\hat{\theta}^{*\left(\alpha_{1}\right)}, \hat{\theta}^{*\left(\alpha_{2}\right)}\right)$, where $\hat{\theta}^{*}$ is the statistic calculated from the 
bootstrap data set (the Water Quality Sub-index in this case), $\hat{\theta}^{*(\alpha)}$ is the $100 \alpha^{\text {th }}$ percentile of the $\hat{\theta}^{*}$, distribution and $\alpha_{1}$ and $\alpha_{2}$ correspond to the percentiles of the upper and lower bounds of the confidence interval respectively. Using bias correction and acceleration (Efron and Tibshirani, 1993):

$$
\begin{aligned}
& \alpha_{1}=\Phi\left(\hat{z}_{0}+\frac{\hat{z}_{0}+z^{(\alpha)}}{1-\hat{a}\left(\hat{z}_{0}+z^{(\alpha)}\right)}\right) \\
& \alpha_{2}=\Phi\left(\hat{z}_{0}+\frac{\hat{z}_{0}+z^{(1-\alpha)}}{1-\hat{a}\left(\hat{z}_{0}+z^{(1-\alpha)}\right)}\right)
\end{aligned}
$$

Where, $\Phi($.$) is the standard normal cumulative distribution function and z^{(\alpha)}$ is the $100 \alpha^{\text {th }}$ percentile point of the standard normal distribution, $\hat{a}$ and $\hat{z}_{0}$ are the acceleration and bias-correction respectively.

The value of the bias-correction, $\hat{z}_{0}$ is obtained from the proportion of statistics calculated from the bootstrap data sets that are less than the value of the statistic calculated from the original data.

$$
\hat{z}_{0}=\Phi^{-1}\left(\frac{\#\left\{\hat{\theta}^{*}(b)<\hat{\theta}\right\}}{B}\right)
$$

$\Phi^{-1}$ (.) is the inverse function of the standard normal cumulative distribution function, $\hat{\theta}$ is the value of the statistic calculated from the original data, $\hat{\theta}^{*}(b)$ is the value of the statistic calculated from the $b^{\text {th }}$ bootstrap data set, $B$ is the total number of bootstrap data sets, \#(.) is the count of number of times the condition in the bracket is satisfied.

The acceleration can be calculated as follows.

$$
\hat{a}=\frac{\sum_{i=1}^{n}\left(\hat{\theta}_{(.)}-\hat{\theta}_{(i)}\right)^{3}}{6\left\{\sum_{i=1}^{n}\left(\hat{\theta}_{(.)}-\hat{\theta}_{(i)}\right)^{2}\right\}^{3 / 2}}
$$

Where, $\hat{\theta}_{(i)}$ is the jackknife value of the statistic, that is the value of the statistic calculated from the original data set with the $i^{\text {th }}$ value removed, $n$ is the number of data points in the original data set, $\hat{\theta}_{(.)}$is the average of all the jackknife values. 


$$
\hat{\theta}_{(.)}=\sum_{i=1}^{n} \frac{\hat{\theta}_{(i)}}{n}
$$

The acceleration corrects for the differences between the standard error in $\hat{\theta}$ and the standard error in the true parameter $\theta$.

Using this procedure, 90\% confidence intervals for the Water Quality Sub-index for the Latrobe River at Rosedale were calculated for 1989 to 1995 Figure 7.30. The procedure was automated using the computer program WQ as listed in Appendix P.

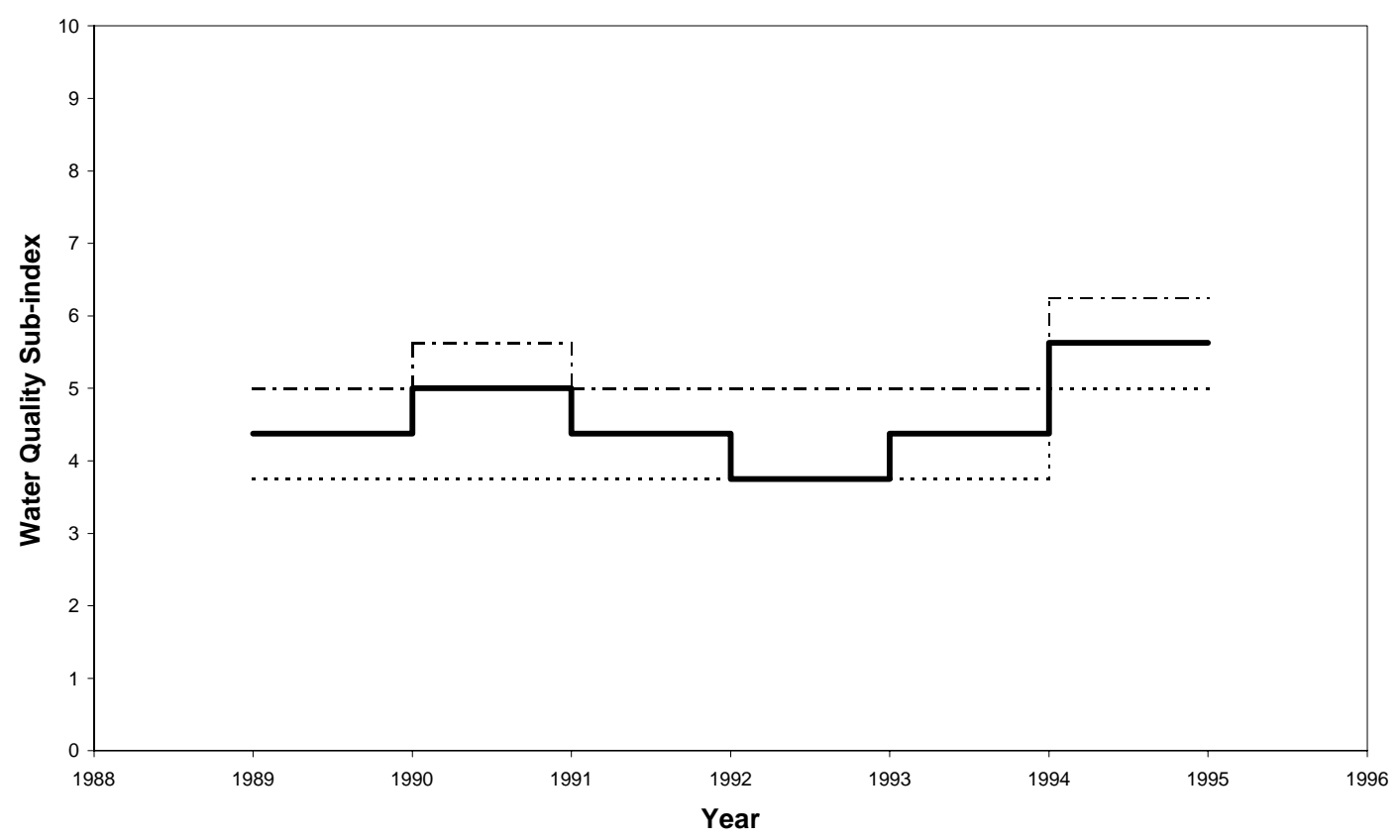

Figure 7.30 - Water Quality Sub-index scores and 90\% confidence intervals for the Latrobe River at Rosedale

Bootstrap procedures depend on the assumption that samples are independent (Singh, 1981) which is likely to be approximately true for water quality data where samples are taken monthly or at least bi-weekly (Lettenmaier, 1978). The data analysed here is collected approximately once per month with the interval varying from four to five weeks. Calculations showed the approximate lag 1 (one month) autocorrelations were not significant for phosphorus, turbidity and $\mathrm{pH}$ but were significant for EC; so the results should be treated with caution, as dependence is likely to increase the true width of the confidence interval. There is also evidence of cross correlation between turbidity and phosphorus, turbidity and $\mathrm{EC}$, turbidity and $\mathrm{pH}$, and $\mathrm{EC}$ and $\mathrm{pH}$, which has been ignored in this analysis. Seasonal dependence of the data has also been ignored with 
any of the measured water quality results assumed to be equally likely to occur in any month.

The procedures for estimating confidence intervals that are discussed here, and coded as shown in Appendix P, could be used anywhere that the Water Quality Sub-index can be calculated. Ideally, confidence intervals should be estimated whenever the Water Quality Sub-index scores are likely to have important consequences for waterway management or resource allocation. During the statewide application of the ISC, data will be collected from around Victoria and entered into a central database via the Internet. Indicator and sub-index scores are also generated centrally, so it would be possible to incorporate the procedures discussed here to calculate approximate confidence intervals.

It is also possible to use bootstrap procedures to assess the significance of changes in water quality by calculating confidence intervals around the difference between two Water Quality Sub-index values measured at different times. The procedure would be similar to that discussed in Section 6.7.4. Of course, it will be impossible to attribute that change to management action or natural variability, without more analysis and probably additional data.

\section{Power to detect change}

It is also important to consider the power of the Water Quality Sub-index to detect changes that may be of interest. In Chapter 3, it was shown that regular water quality monitoring has limited power to detect changes in many water quality parameters of a size that would be a reasonable management target (see Section 3.3.1).

Not surprisingly, there are similar problems of low power to detect changes with the Water Quality Sub-index. A scenario was run where Water Quality Sub-index scores for the period 1989 to 1995 were calculated when phosphorus, turbidity and electrical conductivity were all decreased by $10 \%$. With the improved water quality, all the subindex scores were within the $90 \%$ confidence intervals shown on Figure 7.30, suggesting the changes would not have been identified as being significant. With a $20 \%$ improvement in phosphorus, turbidity and electrical conductivity, 3 of the 6 years showed a significant change. Although there is low power to detect these changes, it is also true that changes of around $10 \%$ are likely to have very limited practical effect and changes of around $20 \%$ perhaps having a small practical effect. As noted earlier, 
improvements of around 50\% in phosphorus loads have been suggested as the minimum to see a positive change in environmental conditions (Robinson, 1995) and improvements of $80 \%$ or more required before water quality is comparable with pristine conditions.

The low power to detect change is a limitation of the Water Quality Sub-index but is likely to be an issue for any type of analysis of data, such as phosphorus and turbidity where the variance is high. The variability of water quality data was recognised as a problem in the earliest stages of the development of the ISC but it was thought that water quality indicators should be included, since water quality is an important issue in Victorian rivers and should have similar weighting as the other sub-indicators, namely hydrology, physical form, streamside zone, water quality and aquatic life.

As with the Hydrology Sub-index, quantifying management-induced changes in the short-term may require indicators in addition to those included in the ISC. These indicators could include a direct assessment of management actions or measurement of the adoption of strategies aimed at improving water quality. This issue is considered in more detail in Chapter 8.

\subsection{Aquatic Life}

\subsubsection{Introduction}

The Aquatic Life Sub-index is made up of two indicators, SIGNAL - Stream Invertebrate Grade Number Average Level (Chessman, 1995) and AusRivAS Australian River Assessment Scheme (Schofield and Davies, 1996). Both indicators are based on the assessment of macroinvertebrate taxa present at a site.

Macroinvertebrates respond to a wide range of environmental variables including water quality (Nasello and Nicosia, 1996), temperature (Jacobsen et al., 1997), stream morphology (Hawkins et al., 1997) hydrology (Petts et al., 1995; Armitage and Pardo, 1995; Growns and Growns, 1997; Rempel et al., 1999), substrate (Richards et al., 1993; Lammert and Allan, 1999), sediment concentration (Doeg and Milledge, 1991; Angradi, 1999), woody debris (O'Connor, 1992), riparian vegetation (Pidgeon, 1978; Pidgeon and Cairns, 1981), instream habitat features such as pools and riffles (Chessman et al., 1997; Parsons and Norris, 1996), microhabitat characteristics (Evans and Norris, 1997) 


\section{Hydrology, water quality, aquatic life}

and regional land use (Roth et al., 1996). Macroinvertebrates can also modify their own environments (Zanetell and Peckarsky, 1996).

AusRivAS and SIGNAL seek to quantify the anthropogenic impact on macroinvertebrate taxa by controlling for the natural variation caused by environmental variables, so that human impacts can be detected. The intention is to develop biotic indices that show strong response to human impacts and little variation in response to natural gradients (Chessman et al., 1997). Issues associated with the accuracy of these methods are briefly discussed below. Only limited analysis is included because the methods were developed by others and AusRivAS, in particular, is undergoing extensive development and testing as part of the Monitoring River Health Initiative, a Federal program concerned with biological monitoring of Australia's Rivers (Schofield and Davies, 1996). General problems of sampling for biological indicators are discussed by, for example, Norris et al. (1992), Rosenberg and Resh (1993), Underwood (1994) and Vinson and Hawkins (1996).

\subsubsection{SIGNAL}

SIGNAL was developed as a biological procedure for the routine assessment of water quality and is based on field sampling of macroinvertebrates that are identified to the family level. Pollution sensitivity grades are available for common families (Chessman, 1995; Chessman et al., 1997) and the average grade for the macroinvertebrates at a site is calculated as the SIGNAL score, which is converted to an indicator rating for the ISC (Ladson and White, 1999).

Sources of error in the SIGNAL score include, the bias and variance introduced during field sampling of macroinvertebrates, errors in pollution sensitivity grades and any spatial and temporal variability in macroinvertebrate taxa that may mask human impacts.

Standard procedures have been developed for field sampling (Chessman, 1995; EPA, 1998) and Growns et al. (1997) found that SIGNAL scores were robust to sampling method, suggesting that inter-operator variability was unlikely to be significant.

Error in the assignment of pollution sensitivity grades is currently being examined. Initially, pollution sensitivity grades were determined subjectively by Chessman mainly based on a relatively small number of published studies that had reviewed the impact on macroinvertebrates of a limited range of disturbances (Chessman, 1995; Chessman et 
al., 1997). These were refined for streams in the Hunter River catchment where Chessman et al. (1997) developed procedures for the objective determination of sensitivity grades for macroinvertebrate families. This revision, SIGNAL - HU97, led to higher correlation of scores with water quality variables, such as conductivity, and the results from an inventory of riparian, channel and environmental condition that was adapted from Petersen (1992). Unfortunately, it is uncertain how applicable the pollution sensitivity grades developed for the Hunter are to other catchments. There appears to be a relationship between sensitivity grades and specific types of pollutants, and other disturbance, and a project is currently underway to develop separate grade numbers for different types of impacts (Chessman et al., 1997).

Chessman et al. (1997) also looked at the temporal variation of pollution sensitivity grades and found that variation was negligible when macroinvertebrate sampling was undertaken in spring and autumn. There was no sampling in summer or winter but it is known from other similar assessment schemes, that there can be significant variation between these seasons. This suggests that sampling should be limited to spring and autumn for the SIGNAL assessments in Victoria.

Some variation of pollution sensitivity grades between habitats was found. Values for riffles differed, by an average of between 0.3 and 0.8 of a SIGNAL unit, from values for other habitats sampled at the same sites. It may be necessary to adjust signal scores depending on the habitat type or to restrict sampling to a particular habitat type (Chessman et al., 1997).

Chessman et al. (1997) acknowledge that further work is required to improve the accuracy of SIGNAL as a method of assessing impacts on streams. It may be appropriate to extend the pollution sensitivity grades to be based on the genus or species of sampled macroinvertebrates, rather than using the current family level grades. Within a family, there may be particularly tolerant or intolerant genera or species and these could add to the variability of SIGNAL assessments. There is also the need to consider the number of replicate samples required to obtain a sufficiently accurate estimate of the mean SIGNAL value at a site (Chessman et al., 1997).

\subsubsection{AusRivAS}

The rating of a site using AusRivAS is based on comparing the macroinvertebrate taxa observed at a site with those that would be expected to occur if there was no human 


\section{Hydrology, water quality, aquatic life}

disturbance. This comparison is expressed as the ratio of observed to expected taxa, the $\mathrm{O} / \mathrm{E}$ value. An ISC rating is then determined for this value.

The critical stage in the AusRivAS procedure is to develop the model that predicts the expected taxa at a test site. This prediction is based on physical and water quality variables that are known to be little affected by human activity (Reynoldson et al., 1997). Development of the model includes the following steps.

1. A large number of minimally disturbed reference sites are selected and macroinvertebrates are sampled at these sites, along with the collection of a large number of environmental variables. For example, in developing AusRivAS models for Victoria, Marchant et al. (1999) measured 40 environmental variables that included altitude, catchment area, distance of sample site from the stream source, latitude, longitude and other features including information on water quality, riparian vegetation, stream physical features and substratum. Similar environmental variables were used by Smith et al. (1999) in Western Australia and Turak et al. (1999) in New South Wales. Approximately 200 reference sites were sampled in Victoria with similar numbers in Western Australia and New South Wales (Marchant et al., 1999; Smith et al., 1999; Turak et al., 1999).

2. Secondly, reference sites are classified into groups based on similarities in their macroinvertebrates communities. A standard statistical technique is used to undertake this classification and various rules are specified to ensure that it robust. For example, rare taxa are excluded and a group must include more than a minimum number of sites (Smith et al., 1999).

3. Once the optimal reference site grouping is chosen, the next step is to identify those environmental variables that best discriminate between the groups and develop a model that predicts the probability of a site belonging to each of the groups. This model is checked and refined, based on how accurately the reference sites are assigned to the groups determined from step 2 (Marchant et al., 1997; Smith et al., 1999).

Once the model has been developed, it can be applied to test sites i.e. a site where there may be some disturbance. The model does not allocate a test site to a particular reference group; rather it calculates the probability of the site belonging to each of the 
groups (Reynoldson et al., 1997). The probability of finding particular macroinvertebrate families at the site can be expressed as follows.

$$
P(t \mid s)=\sum_{i=1}^{n} P\left(g_{i} \mid s\right) P\left(t \mid g_{i}\right)
$$

Where, $P(t \mid s)$ is the probability of taxa, $t$ occurring at a particular site $s$ ( $s$ would be a vector of environmental variables for the site that are used in the predictive model), $P\left(g_{i} \mid s\right)$ is the probability of membership of group $i$, given $s$ (this is calculated from the model developed in step 3 above), $\mathrm{P}\left(t \mid g_{i}\right)$ is the probability of taxa occurrence in group $i$, which is obtained from the frequency of occurrence found during field sampling, and $n$ is the number of groups.

Taxa with probabilities of occurrence of $50 \%$ or greater are the predicted taxa. The number of expected taxa at a site equals the sum of the individual probabilities of occurrence of all the predicted taxa. The number of observed taxa is the number of predicted taxa that were actually sampled at the test site (Marchant et al., 1997). Results are expressed as a ratio of the number of observed to number of expected taxa for a particular site, with values less than $80 \%$ indicating disturbance.

\section{Accuracy of the AusRivAS process}

As with the other indicators, the ability of the AusRivAS to be used for benchmarking and change detection depends on the bias and precision of the results. The accuracy of the AusRivAS assessments is still being determined with sampling of test sites only commencing in 1997 (R. Marchant pers. comm.) and a specific project to review results being commissioned by Environment Australia (a Commonwealth Government Department) in August 1999. The Victorian EPA is currently building up data sets to assess temporal and spatial variability of AusRivAS assessments. This will take some time but there are data from 3 sites in the Latrobe that are being analysed which go back to 1982. Results are at least one year away (L. Metzeling pers. comm.).

Spatial variability is yet to be investigated. The Victorian EPA have begun work in this area by sampling several sites along relatively short stretches of streams ( 7 sites along $30 \mathrm{~km}$ of the Tambo River, 5 sites along $8 \mathrm{~km}$ of the Western Tanjil River and 5 sites along $10 \mathrm{~km}$ of the Ovens River). Results may be available by early 2000 (L. Metzeling pers. comm.). 


\section{Field techniques and taxon identification}

The quality of AusRivAS assessments depends on the accuracy of macroinvertebrate collection at both the reference and test sites. Standard procedures have been developed (Davies, 1994; Marchant et al., 1997; Simpson et al., 1999) and inter-operator variability has been measured and was found not to contribute significantly to the variance of the results (R. Marchant pers. comm.). Accuracy of specimen identification and data entry has been independently audited in some states. In WA, in the first round of data collection, $22 \%$ of samples contained significant errors in identification or data entry but this was reduced to a zero error rate following additional training and experience (Smith et al., 1999).

\section{Stability of relationship between environmental variables and taxa at reference sites}

Accuracy of the AusRivAS models is based on the assumption that the relationship between environmental variables and taxa at reference sites does not change over time. It is proposed to test this assumption by sampling reference sites every time test sites are sampled and to check for changes in taxa and whether models are still accurate. So far, there has been limited testing but re-sampling of reference sites in the Australian Capital Territory found significant changes between years even though the environmental variables were constant (R. Marchant pers. comm.). This raises questions about the validity of assumptions behind the AusRivAS models although there are also concerns that field sampling in the ACT may not have been accurate and that unusually low flows may have influenced the results (R. Marchant pers. comm.). Routine monitoring of reference sites and checking at test sites is now underway so there will be opportunities to investigate this issue further.

\subsection{Conclusion}

This chapter has examined some of the issues associated with accuracy of the Hydrology, Water Quality and Aquatic Life Sub-indices of the Index of Stream Condition. For hydrology and water quality, case studies were undertaken of particular rivers, although there are general lessons for the statewide use of the ISC. For aquatic life, the discussion was restricted to a review of the work of others. 
The Hydrology Sub-index is capable of identifying streams that are heavily impacted because of regulation or diversions. Of 21 streams analysed in Victoria and New South Wales, the Campaspe River had the greatest hydrologic alteration because of flow regulation. The Campaspe River is also where there is a major focus on introducing environmental operating rules in an attempt to improve stream condition.

The Hydrologic Sub-index also shows that the effect of the environmental operating rules on hydrology is minor. The flow regime remains altered from natural conditions and in some years the previous operating rules result in flows that are closer to natural conditions than would be generated using the environmental rules. The constraint preventing larger changes to hydrology is that the security of supply to irrigators must be maintained.

Although the hydrologic effect of the proposed flow changes is small, the Cooperative Research Centre for Freshwater Ecology is testing if there will be a significant ecological effect. If the changes are ecologically significant, then the Aquatic Life Subindex should improve over time.

The results from the case study of water quality showed that the Water Quality Subindex is useful for revealing degradation. When examining phosphorus in the Latrobe River at Rosedale, the phosphorus indicator performed broadly as expected. It had been suggested that improvements of around 50\% were required to see a significant ecological change, with improvement of around $80 \%$ before water quality would return to pristine conditions. The response of the phosphorus indicator to improved water quality broadly matched these expectations.

For the Aquatic Life Sub-index, others are investigating precision and bias for both the SIGNAL and AusRivAS procedures. The key remaining tasks are to refine pollution sensitivity grades for SIGNAL and to check the stability of AusRivAS models that are used to predict taxa as test sites. Spatial and temporal variability also needs to be assessed. 


\section{IMPLICATIONS AND \\ CHALLENGES FOR THE \\ DEVELOPMENT AND USE OF \\ INDICATORS IN ENVIRONMENTAL \\ MANAGEMENT OF RIVERS}

\subsection{Introduction}

This chapter brings together the ideas that have been presented in this thesis and draws out the implications and challenges for the development and use of indicators in environmental management of rivers. This discussion is based on the analysis undertaken for the proceeding chapters and the broader experience of being involved in the Index of Stream Condition project.

A summary of the ideas discussed so far is as follows. Chapter 2 presented a brief history of river management and charted the rise of environmental concern and the need to incorporate environmental information into river management decision-making. Problems with the way environmental issues have been addressed were discussed in Chapter 3. Chapter 4 reviewed suites of indicators that had been developed and used and included a discussion of their role in adaptive management. Development of the Index of Stream Condition was described in Chapter 5 along with a discussion of the selected indicators and reflections on the process. The performance of some of the indicators of the ISC was reviewed in Chapters 6 and 7.

This chapter explores the key issues further. The need for stream condition indicators is reviewed. There has been increasing environmental awareness and concern associated with rivers and hence a need to include environmental information in management decision-making. If environmental indicators are to lead to better outcomes, they must be used in practice. This requires clear objectives along with consideration of users and scale. The processes required to develop a suite of indicators are discussed, including decisions about the aspects of the environment that should be measured and the rating or scoring of indicators where raw data are converted to information to guide management. Problems associated with the evaluation of indicators are described, including the assessment of accuracy and precision in indicator measurements. Finally, the 
limitations of use of environmental indicators are discussed. Sometimes the changes that managers aim for will be difficult to detect, because they are relatively small compared to natural variability in indicator scores. It may not be possible to measure outcomes over reasonable time scales, so indicators that directly measure management action may be needed.

\subsection{The need for environmental indicators}

For most of Victoria's history following European settlement, the dominant human influence on rivers has been associated with development. The use of rivers for navigation and their modification because of gold mining proceeded a major phase of water resource development in the $20^{\text {th }}$ century. The effect of these activities, the increase in environmental awareness of the community and changing institutional arrangements, have led to demands to incorporate environmental information into river management decision-making (see Chapter 2).

It is also necessary for the environment to be addressed in an appropriate way. An excessively narrow management focus, mainly concerned with short-term and local issues, can limit the consideration of environmental information (Section 3.4) and lead to a crises when it becomes clear that broader environmental issues are not being addressed (Holling, 1995). It is important to undertake broad scale monitoring but obviously not all aspects of the environment can be measured. Indicators have been proposed to provide an accessible summary of environmental data and to characterise environmental condition (Hammond et al., 1995).

It is also important that objective information be collected. Current and past river management intervention has often been in response to perceptions of environmental change that have been poorly investigated. The environmental information that was available was interpreted on the basis of local folklore. Often these perceptions have led to inappropriate proposals and sometimes strategies have been implemented that are difficult to support on the basis of a more complete investigation (Section 3.2).

A rigorous approach to collection and use of environmental information, using environmental indicators, could go part way to addressing these problems. But it is not enough that environmental information is just collected, even if this is done in a 


\section{Implications and challenges}

rigorous way. A case study of water quality data in Victoria showed that where the goals of managers and monitors are inconsistent, the information collected may not be capable of addressing management issues (Section 3.3). This can lead to the 'data rich but information poor syndrome' (Ward et al., 1986). A way forward is to develop improved management systems where information on important aspects of the environment is: (1) routinely collected to provide indicator values that are incorporated into planning and priority setting; and (2) used to evaluate outcomes. The Index of Stream Condition, described in Chapter 5, is an attempt to develop a managementfocused system of indicators.

The need for, and advantages of, environmental indicators have led to them being proposed in most States in Australia and there are Federal projects and international examples as discussed in Chapter 4 (see also Conacher, 1998). Instead of questioning if we should have environmental indicators - they are already being used and will continue to be developed and applied - it is important to understand their limitations and the requirements for them to work in practice.

\subsection{Indicators as management tools}

The promise of indicators, or indicator systems, is that they will be able to address the pathologies of river management where there is inadequate and imprecise consideration of environmental information. But, there are many issues to be overcome before they can work in practice.

\subsubsection{Using indicators to assist waterway management}

Johnson (1999b) proposed a framework for the way resource management agencies, which includes river managers, make decisions. Three types of decisions incorporate environmental information.

- Firstly, there is the best-current-data approach. Managers use the information that is available to assess options and choose the best one to implement.

- Second is the monitor-and-modify approach. A decision is made using the best-current-data method, then data are used to assess outcomes and strategies are periodically modified to achieve a specific goal. 
- The third approach is adaptive management, which involves developing an understanding of the operation of the system to be managed based on environmental data and knowledge of interested parties. A management plan is developed and implemented along with a monitoring program (Section 4.3.1). The collected data are used to revise understanding, which could lead to changes in strategy. Although adaptive management is a relatively new methodology and has had successes, the other methods will continue to be used along with less rigorous approaches (Johnson, 1999b).

Environmental indicators can be a key part in these practical decision-making procedures. Using indicators to gain an overview of current conditions, referred to as 'benchmarking' in Chapter 5, could guide decisions based on the best current data. This type of information could assist with priority setting, resource allocation and selection of strategies by waterway authorities. It could also assist broader priority setting by a central agency, if information was available on river condition over an area being managed by several authorities.

The other decision-making procedures, monitor-and-modify and adaptive management, are concerned with change detection, as well as assessment of current condition. Ideally, the changes in indicators could be used to evaluate the outcomes of management intervention and to refine strategies. They could also be used to judge the performance of managers and the overall impact on river condition of a number of programs delivered by several agencies.

\subsubsection{Ensuring indicators are used in practice}

For stream condition indicators to be used in practice, they have to be used by practitioners; that is, they have to be incorporated into planning and reporting by waterway managers. The case study of collection and use of water quality data in Section 3.3 showed the problems that occur where environmental information does not meet the needs of managers. Because the water quality data were not related to most management goals, they were unlikely to be used.

The basic requirements for the practical application of indicators are that indicators be at an appropriate level of sophistication for users, data must be able to be collected or obtained from others, and the expenditure on indicators must be within budgetary 


\section{Implications and challenges}

constraints. For adaptive management and monitor-and-modify approaches, accuracy and sensitivity become increasingly important.

The environmental indicators must be able to be used and understood by people with the types of skills available to waterway management authorities. This places a major constraint on the type of environmental data to be collected and the selection of indicators. In the Victorian context, most waterway management authorities would not be expected to have people with the expert knowledge that would be routinely accessible to organisations such as Universities, CSIRO or specialist consulting firms.

There is also the issue of data availability. The required information must be able to be collected by waterway managers or be readily available from another source. If the data requirements of indicators are unrealistically large, then indicator values cannot be calculated and the indicators will not be used. This problem occurred with the Index of Aquatic Environmental Quality (IAEQ) developed for Victorian streams. Excessive data requirements meant that many indicators could not be calculated (see Section 4.2.2).

It is also important to make best possible use of the information this is available. For example, in Victoria, there has been long-term monitoring of hydrology and water quality. Although this information may not be the best for an ideal environmental monitoring program, it would be politically untenable to collect similar data in other locations and ignore what was available. It is unlikely that there would be support to set up a new water quality or hydrology monitoring network, even if that would better serve the needs of a particular monitoring project.

Budgetary considerations are a critical issue. Allocation of resources to a monitoring program must compete with all the other demands that waterway management authorities face, including the political imperative to do works on the ground. Indicators must be cost effective, so that monitoring outcomes can be maximised, while maintaining a balance between the cost of the monitoring program and core activities. A report from the Victorian State Government A planning and reporting framework for Victorian river management authorities suggests that monitoring should be around 5\% of the total budget (Ian Drummond and Associates Pty Ltd, 1995), which is likely to severely restrict the choice of indicators. 
Long-term support of the institutional arrangements that facilitate collection of data and the calculation and reporting of indicators is required. The type of institutional reform that has occurred in Victoria over the last 10 years would not have provided the management stability required for the effective use of indicators. There have several major alterations to institutional arrangements with the change from River Improvement Trusts to whole-of-catchment River Management Boards as prescribed by the Victoria Water Act, 1989. There was a further change in 1994, with river management being brought under regional Catchment and Land Protection Boards and, in 1997, larger, integrated Catchment Management Authorities were formed (Chapter 2). There was a further change in November 1999, when funding arrangements for catchment management authorities were changed to become more reliant on the State Government and less on local sources of revenue (Barlow, 1999). These institutional changes have also coincided with changes in budgets and personnel, as well as management objectives. Using indicators to assess outcomes in comparison with goals, presupposes stability of those goals, and this is unlikely where management arrangements are changing.

Institutional changes have been part of the reason that attempts at regular assessment of the environmental condition of streams have not engendered the long-term support required (see Chapter 4). The Office of the Commissioner for the Environment was set up in the late 1980s in Victoria, to issue regular State of the Environment Reports. In the preface to State of the Environment Report 1988: Victoria's Inland Waters (Office of the Commissioner for the Environment, 1988), reports were promised about every 5 years. However there have not been any others that focused on waterways and the Office of the Commissioner for the Environment was disbanded in 1995, following a change in the State Government (Christoff, 1998). Similarly, the State of the Stream Survey (Tilleard and DWR, 1986) was used by Mitchell (1990) to prepare The Environmental Condition of Victorian Streams. In the preface of that report it was stated that this would be the first of many reports based on stream survey data; in fact, no more have been produced.

Realistically, changes in institutional arrangements, goals, budgets and personnel are always likely and there must be some matching flexibility in the type of environmental information used. Those indicators thought to be important will change over time, as will opinions about how they should be valued. A major challenge for indicator 


\section{Implications and challenges}

systems is to provide this flexibility, while still allowing comparison of measurements from different times.

If indicators meet the needs of managers, they are more likely to be measured, used and adapted for new circumstances when necessary. Results from the assessments by Mitchell (1990) and the Office of the Commissioner for the Environment (1998) were never incorporated into the planning and reporting of river management authorities in Victoria, which is possibly another reason why they were not continued. In fact, none of the indicator systems explored in Chapter 4 have a clear link with management. The ISC is different in this regard, as it was developed with input from managers and trialed by the intended users, the Catchment Management Authorities. Of course, it will only be possible to judge the effectiveness of the ISC as a long-term measurement of environmental condition, if it is still being used in the next 5 to 10 years. These assessments in Chapters 6 and 7 show that, with the right sampling strategies, the ISC can provide results that will be useful for managers.

If indicators are to be used by managers, practicality rather than science must drive the process. Without consideration of non-technical issues, indicators are unlikely to be used. The pragmatic constraints must be met and if what is left does not have enough scientific credibility, then the project should not proceed. There is little value in insisting on a high degree of scientific rigour, if practical requirements cannot be met.

\section{Using indicators for change detection}

The quality of underlying data largely determines the accuracy of the indicators. In the past, uncertainties associated with indicator values have not usually been explicitly estimated or quoted in reported results, suggesting this was not seen as an important issue for benchmarking despite the fact that it determines sampling density (as discussed in Chapter 6). There are additional requirements for accuracy and sensitivity if indicators are to support monitor-and-modify decision-making (Johnson, 1999b). Ideally, changes in indicators are used to refine strategies to achieve desired goals more quickly. The problem is, the management-induced change must be related to indicator values that will also be subject to spatial and temporal variability and the effects of uncontrolled influences. Where management effects are large, or there is a direct linkage between management action and measured outcome, then the use of indicators in this way may be straightforward. 
If the effect of management-induced changes are small, or there is uncertainty in the linkage between management action and desired system response, then it may be necessary to demonstrate statistically that programs, rather than uncontrolled influences, determine the outcomes as measured by the indicators (Land, 1971). This type of analysis is consistent with active adaptive management discussed by Walters and Holling (1990) which uses spatial replication and control in the undertaking of largescale management experiments. Results from these experiments are used to resolve key uncertainties in environmental understanding. Environmental indicators have a major role in these procedures as discussed in Section 4.3.1.

There are also some management strategies that are unlikely to produce a detectable change in the environment over reasonable periods. This could occur where temporal variability is high in comparison to the expected effects. In these cases, it may be appropriate to use indicators based on direct measurement of management actions, rather than on the outcomes of those actions (see Section 8.5.4.).

\subsection{Issues in the development of environmental indicators}

The need for stream condition indicators to work in practice should drive the process of their development. Setting objectives, selecting and valuing indicators, developing field procedures and managing data, are key requirements.

\subsubsection{Setting objectives}

The use of environmental indicators implies a deliberate attempt to simplify the problem of measuring environmental condition or change. Bernstein (1990) points out that including indicators of all potentially important disturbances, interactions, and sitespecific features leads to full-blown ecosystem studies. 'Our challenge is to develop ecological indicators that are suitable, elegant and simple, yet also ecologically realistic, by making appropriate trade-offs among realism, precision and generality' (Bernstein, 1990, 1106).

Clear objectives are the main guide to performing this trade-off. It is important to establish what indicators will be used for, and by whom. Of interest here is the use of environmental indicators by waterway managers to assist decision-making. As discussed in Section 8.2, uses include benchmarking and detecting change, with results 


\section{Implications and challenges}

used to guide priority setting, resource allocation and assessment of the effectiveness of management strategies.

A key requirement in the practical applicability of the ISC, was that indicator results would be used by Catchment Management Authorities (CMAs). Data would be collected by them, or routinely obtained from others. This restricted the types of indicators that could be chosen for all sub-indices, both because of the resources that could reasonably be expected to be applied to the task, and because of the skills available.

The objectives determine the temporal and spatial scale of interest, but there has to be a trade-off between the size of the area to be assessed and the response time of the indicators. For the ISC, broad spatial scale indicators were required but it was realised that indicators appropriate for a statewide assessment would only be likely to change over a period of 5 years or longer. Annual performance tracking would require a different set of indicators (see Section 5.3.7).

Selection of spatial scale also depends on institutional arrangements for river management. As discussed in Chapter 2, part of the motivation for the use of indicators in Victoria is that waterway management authorities have changed from small, narrowly-focused organisations with clear goals and limited authority and accountability, to large, autonomous organisations that are accountable through planning and reporting. Environmental indicators have a role in these planning and reporting procedures.

\subsubsection{Selecting indicators}

The selection of the indicators to include in an assessment of stream condition is a major part of the development process. Usually, there are hundreds of potential indicators to choose from but most will not be in a form where they can be adopted without further development. The issue is to narrow down the selection to a minimum set of potential indicators that can meet the needs of users and then develop, trial, and test these before deciding on the final set to be used for monitoring. Consideration of objectives, target audience and scale, provide criteria to restrict the choice of indicators. Other issues that guide indicator selection include cost, availability of historical data and ease of data collection. It is possible to develop a list of desirable features of indicators (see Table 5.3; also Cairns et al., 1993; DEST, 1994; Cranston et al., 1996). 
In general, it will be necessary to compromise on some of these desirable aspects, as it is unlikely that there will be indicators that meet all the requirements.

Several approaches have been used to achieve consensus about indicator selection including workshops (Conacher, 1998) and Delphi method (Dinius, 1987; Smith, 1990; Spellerberg, 1991), but the final selection is always, at least partly, subjective. Further detail is provided in Chapter 5 including a discussion of the development of the ISC, which was based on a series of workshops with specialists in different aspects of stream condition.

Brunton (1994) shows that the choice of indicators can have political consequences and that indicators can be chosen that favour a particular argument. He takes issue with the indicators used, by the London-based New Economics Foundation, to rate Australia's economy as having a low level of sustainability. Instead, he proposes a set of plausible sounding indicators that shows Australia as being one of the most sustainable economies. It is likely that similar techniques could be used by Australian states to present particular cases to the Commonwealth or by various CMAs to attempt to convince the State Government that their problems were the worst, or their performance the best. The example from Brunton (1994) suggests that there is merit in involving the organisations being assessed in the selection of indicators, as there is less likely to be argument about the results. It is important that the process of selecting indicators is transparent and that people with a range of expertise and opinions are consulted to confront these issues before assessments are made. These principles guided development of the ISC.

Once a preliminary set of indicators has been chosen, there needs to be an iterative process of development and trialing to refine the indicators to a stage where they are useable. Development is likely to include specification of sampling densities and field procedures, examination of inter-operator variability, and overall accuracy. This is followed by an initial program of short-term field testing by the target users, to determine if data collection procedures are appropriate and if the indicators behave as expected. It is also important to determine if they detect the changes that are thought to be important. The field testing will lead to further refinement, both to the indicators and methods of collection. For the ISC, sixty refinements were made following field testing, including elimination of some indicators, inclusion of others, clarification of terms, improvement of field data collection procedures and development of methods to 


\section{Implications and challenges}

guide interpretation of results (ID\&A Pty Ltd and CEAH 1997a). There was also a further round of refinements following the initial use of the indicators by the Catchment Management Authorities (Ladson and White, 1999; White and Ladson, 1999b)

Barber (1994) suggests that there should be testing of indicators in long-term field studies before they are finally accepted, but the imperative to get a monitoring system operational will mean this step is often excluded. For the ISC, ongoing evaluation of indicators once they are in use, has taken the place of these studies. Over time, new indicators may need to be added and others eliminated, as issues change or in the event that the performance of some indicators is not satisfactory.

\subsubsection{Valuing indicators}

Environmental indicators are based on measurements of raw data but the actual measurements rarely have significance by themselves. Instead, indicator scores or ratings are calculated by comparing the measured data with reference conditions. Reference conditions could include a chosen ideal state, conditions that favour a particular species, conditions that support designated uses or the natural state (Reynoldson et al., 1997; see Section 5.3.6).

It is necessary to decide how the difference between current conditions and reference conditions should be measured. For some indicators in the ISC, this has been done using rating tables (see Tables 7.4 to 7.7 and Figures 7.8 to 7.12), which are similar to the 'bands' used in AusRivAS (Marchant et al., 1997; Marchant et al., 1999). Anderson (1993b) uses mathematical equations to calculate scores from the raw data (see Section 4.2.3).

The use of rating tables requires the specification of the range of values for the raw data that are associated with particular ratings. Choosing the cut-off values - the upper and lower bounds on these ranges - is another decision that is, at least partly, subjective. In the ISC, ratings are based on a review of available literature and consultation with experts, with the final decision made on the basis of consensus reached at a workshop. The subjective nature of these cut-off values means that they would be likely to change if different people were consulted, or if more information became available. The final indicator scores are sensitive to the uncertainties in cut-off values in rating tables, as discussed in Section 8.5. 
Although these cut-off values are sometimes disparagingly referred to as 'magic numbers' (Peter Cullen, Cooperative Research Centre for Freshwater Ecology, pers. comm.), if they are based on the best available information, then their use represents a reasonable way of establishing targets and of rating condition. Certainly, they are widely used, particularly for water quality (e.g. Victorian Government Gazette, 1988; Office of the Commissioner for the Environment, 1988; Australian and New Zealand Environment and Conservation Council, 1992; Tiller and Newall, 1995). For the ISC, reviewing the literature, consulting with experts and finding a consensus during a workshop of specialists seems a defensible way of establishing the cut-offs.

Chessman et al. (1997) did develop an objective method of establishing macroinvertebrate family sensitivity grade numbers, which is a similar concept to the cut-off values. However, these were found to depend on the impact being assessed and have only been shown to be appropriate for the Hunter River System in New South Wales. These objective sensitivity assessments were also shown to be highly correlated with the subjective sensitivity grades that had previously been established by Chessman on the basis of a literature review and consultation with others (Chessman, 1995; Chessman et al. 1997). This suggests that basing cut-off values on a literature review and expert consultation could achieve reasonable results.

\subsubsection{Developing field procedures}

Minimising the errors associated with field measurements will be an important part of ensuring accurate indicator values. The aim should be for unbiased, precise results that are independent of those doing the measuring. Strategies include the development of standard field procedures, training of assessors, and auditing of results.

Standard field procedures involve the specification of particular methods to be undertaken every time a sample is collected. The availability of these methods depends on the type of indicator. For water quality, there has been extensive work on standardised procedures with detailed guidelines available that are used internationally (Eaton et al., 1995). Standard field methods for macroinvertebrate sampling for SIGNAL and AusRivAS have been developed (Chessman, 1995; Chessman et al., 1997; Marchant et al., 1997; Marchant et al., 1999) and tested (Growns et al., 1997), and there is an Australian Standard for hydrologic measurements (AS 3778). If new indicators are required, then field procedures will have to be developed and specified, as was done 


\section{Implications and challenges}

for the Physical Form and Streamside Zone Sub-indices of the ISC (White and Ladson, 1999a). Decisions about sampling density will be an important part of these standard procedures (see Chapter 6).

Along with the standard procedures, it is important to develop and implement training of field assessors. Training has been shown to reduce errors associated with field measurements and can decrease inter-operator variability (Wang et al., 1996; Hannaford et al., 1997; see Chapter 6). For the ISC, training courses have been developed and an accreditation system introduced, to ensure that only those with the appropriate training can undertake assessments (P. Wilson, Department of Natural Resources and Environment pers. comm.). A similar accreditation scheme was used for the River Habitat Survey assessment technique in the UK (Fox et al., 1998).

Auditing of results is also important. Smith et al. (1999) found that auditing reduced errors associated with AusRivAS assessments by allowing training to be targeted and by encouraging assessors to take care, because they knew their results would be checked. Auditing is undertaken as part of the statewide application of the ISC (P. Wilson pers. comm.).

\subsubsection{Data entry and management}

Once data have been collected in the field, or obtained form others, it will usually be stored and processed to calculate indicator scores and to provide comparisons with past condition. This is likely to be a major data management task. Firstly, there will be a lot of data; for example, with a broad-scale assessment such as the Victorian State of the Streams Survey (Tilleard and DWR, 1986), 200 variables were collected at 868 sites, along with several photographs at each site and information about site location and details of field assessors. Data storage demands for a national assessment such as AusRivAS are likely to be even larger. There may also be a need to link to databases held by others; for example, with the ISC, access to water quality and hydrology information is required.

Secondly, the data must be processed to produce indicator scores. Procedures can be mathematically sophisticated, such as the models that are generated for AusRivAS (Section 7.4.3), or the rating functions used by Anderson (1993b). These procedures are likely to be changed over time. It may be necessary to calculate indicator values using several procedures, if old and new indicator values are to be compared. Central storage 
of data, with entry and manipulation via an Internet interface, may be appropriate where similar procedures will be used over a large geographic area. It may also be cheaper to have one version of a database system at a central location, than to provide software and advice to a large number of users (S. Minchin, Department of Natural Resources and Environment, pers. comm.).

Thirdly, user-friendly procedures must be used for input and output, along with error checking and validation. Incorporating indicators into the everyday planning and reporting of waterway management authorities will be assisted, if data manipulation is straightforward.

Clearly, these types of data management tasks will be outside the expertise of most river management specialists and it will be necessary to seek advice from database experts. In the development of the ISC, the data management task was not considered in detail at the start of the project and there was no one with appropriate expertise on the Specialist Reference Group. Initial attempts to develop a computer system to store and manipulate data were not successful; the programs developed during the trial stage could not cope with the scale of the task once the ISC was expanded to cover the whole state. After these initial problems, consultants were requested to develop an Internet-based system (S. Minchin pers. comm.). The timing of this project meant that data collection had commenced before the database system was available and training for field assessment procedures had to be separated from that for data entry and manipulation, because the database system was not ready in time. The lesson is that data storage and manipulation requirements need be considered during the development of indicators.

\subsection{Evaluating indicators}

Once the development issues are resolved, next step is to begin collecting data and to calculate indicator values. Making use of these values requires consideration of their accuracy for both benchmarking and change detection.

Errors and accuracy have not been addressed in most stream condition assessments in the past (see Chapter 4). It has not been common to report standard errors or confidence intervals of the results, nor to consider spatial and temporal variability. For example, errors were not reported, nor are they mentioned, in documentation for the Victorian State of the Streams Survey (Tilleard and DWR, 1986), the assessment of the Environmental Condition of Victorian Streams (Mitchell, 1990), the Index of Aquatic 


\section{Implications and challenges}

Environmental Quality (Office of the Commissioner for the Environment, 1988), the RCE (Petersen 1992), or the Estuarine Health Index (Cooper et al., 1994).

\subsubsection{Sampling issues}

It has been uncommon to consider sampling requirements in detail. For example, the State of the Streams Survey (Tilleard and DWR, 1986; Mitchell, 1990) used a representative reach approach to sampling, where a short stream section was selected based on expert judgement, as representative of a longer reach. Measurements made in the representative reach were considered to reflect conditions in the longer reach. The accuracy of this technique was not assessed as part of the State of the Streams Survey but was reviewed in Chapter 6, where it was shown that it could be subject to large error that is difficult to quantify. This method has also been criticised by others (Williams, 1996; Jeffers, 1998).

In general, the statistical issues associated with sampling and errors in indicators are not straightforward. Many indicators will not be normally distributed, smooth, or continuous and sampling at random sites is difficult in practice because of access problems and the constraints of time and resources. A pilot study will usually be necessary to characterise the variance before the final sampling scheme can be specified. Some approaches to addressing these problems were discussed in Chapters 6 and 7 , where extensive use is made of resampling procedures including bootstrapping.

The sampling issues associated with the Streamside Zone and Physical Form Subindices are reviewed in Chapter 6. The sampling requirements are complex. A sampling scheme was proposed where sites were selected at random and then detailed measurements are undertaken near each site to reduce the number of sites that had to be visited, while still obtaining reasonable accuracy. In practice, this would involve driving to a particular site, surveying the area around the site and then driving to the next site. This sampling scheme was investigated by randomly resampling a detailed data set to test the accuracy of proposed sampling strategies (see Chapter 6). The decision about which strategy to use for the ISC was not made on this analysis alone, however the results informed the decision that was made ultimately by the project managers (DNRE), based on a consideration of the available budget, as well as likely accuracy. 


\subsubsection{Uncertainty in indicator values and detecting change}

If indicators are to be used for one-off assessments, then it is important to report the standard error in the indicator score or confidence intervals around indicator values. Bootstrapping offers a way of quantifying the errors and calculating confidence intervals in situations where standard statistical methods are difficult to apply (Efron and Tibshirani, 1993; Manly, 1997). In Chapter 7, bootstrapping was used to calculate approximate confidence intervals around values for the Water Quality Sub-index.

Often environmental indicators are not used just for a one-off assessment. Instead, values are collected over time, with the idea of using changes to show where there are problems or where intervention may be required. The ability of indicators to detect step changes depends on the size of the change and the standard deviation of the indicator score. The ratio of these quantities is commonly referred to as the effect size.

$d=\frac{I_{1}-I_{2}}{\sigma}$

Where $d$ is the effect size, $\mathrm{I}_{1}$ is the indicator score at time $1, \mathrm{I}_{2}$ is the indicator score at time 2 , and $\sigma$ is the standard deviation of the indicator measurements. The larger the effect size, the greater the ability for the indicators to unambiguously detect change (Section 3.3).

It is possible to consider the detection of change within the standard hypothesis-testing framework (see Table 6.9) and then to apply tests of statistical significance to examine if a change has occurred. This requires specification of a Type I error probability, which is the probability of concluding that there has been a change when, in reality, no change has taken place.

Although this approach is commonly used to assess the significance of recorded differences (see Section 6.7), there is a debate in the literature about its merits. Firstly, several authors have pointed out that it is important to consider the statistical power associated with the detection of changes of particular size (Green, 1989; Peterman, 1990; Fairweather, 1991; Power et al., 1995). Low power could lead to the erroneous conclusion that there has been no change in situations where environmentally significant change has occurred. There is often exclusive focus on the Type I error probability, which ignores the risks associated with committing a Type II error 


\section{Implications and challenges}

(Fairweather, 1991; Power et al., 1995). Section 6.5.4 includes a discussion of detection of change using indicators and calculates power for a range of effect sizes and sampling densities. Despite the arguments favouring power calculations, it is still common for this issue to be ignored (Sedlmeier and Gigerenzer, 1989).

Secondly, the use of statistical tests of significance in this way has been questioned (Tukey, 1960; Tukey, 1991; Shaver, 1993; Carver, 1993; McBride et al., 1993; Harlow et al. 1997; Johnson, 1999c). It is argued that a null hypothesis of no change is invalid since it is known that there will always be a difference in environmental condition between two places, or between times. Concluding that the change is significant just depends on collecting enough samples. McBride et al. (1993) argue that 'One cannot escape the practical realities of environmental sampling: change can always be expected. The real hypotheses of interest are whether some variable falls within or outside a range of practical importance.' There is also the issue about the validity of statistical tests if their assumptions are violated, which will commonly be the case (Montgomery and Loftis 1987). Equivalence testing has been proposed as a way to avoid specifying a null hypothesis of no change. An equivalence hypothesis relates to whether the difference in the statistic calculated for two data sets is within a specified range. Application of equivalence tests to environmental data analysis has been proposed (McBride et al., 1993; McBride, 1999).

Suggested alternatives to statistical hypothesis testing include the reporting of standard errors and the calculation of confidence intervals, which can then be examined to determine if a parameter or change is practically significant, rather than just being statistically significant (Johnson, 1999c). Thompson (1993) highlights the role of bootstrapping for this task. Although standard bootstrap procedures require data to be independent and identically distributed, there are techniques available where these requirements can be relaxed (Kunsch, 1989; Mannen, 1992; Cao, 1999). A bootstrap approach was used to explore the ability of the physical form and streamside zone indices to detect change (Section 6.5.3).

Another alternative is Bayesian approaches to environmental decision-making (Reckhow, 1990; Carpenter, 1990; Ellison, 1996; Wolfson et al., 1996). Bayesian approaches offer a way of accounting for pre-existing data and results from previous experiments. Ellison (1996) argues that Bayesian approaches to analysis of environmental data would allow stronger conclusions to be drawn from large-scale 
experiments with few replications and would be more relevant to environmental decision-making. Bayesian approaches are not discussed further in this thesis, although the development of practical Bayesian procedure to be used by managers is suggested as a worthwhile project.

A third issue is that the statistical procedures only deal with some of the errors. There are uncertainties in the procedures used to derive indicator scores that are not reflected in the variance of the data. These are associated with subjective decisions about indicator selection and specification of rating procedures. For the ISC, consulting a different group of experts would probably result in a different set of indicators and different cut-off values for the rating tables. There is likely to be a similar situation with other indicator schemes.

Two approaches could be used investigate the consequences of uncertainty in these subjective decisions (although they are not considered further in this thesis). The first approach is based on the method described by Hanks (1997) for taking account of the uncertainty in expert opinion. He outlines a situation where there were limited data to guide the selection of a parameter, so specialists were asked for an estimate of the parameter value and the uncertainty of that estimate. A number of specialists are sampled and the responses used to determine an average outcome and overall uncertainty. A sensitivity analysis could be undertaken to determine the importance of the differences amongst experts. This approach could be used, for example, to establish the cut-off scores for indicator ratings, along with their associated uncertainty. The contribution of these uncertainties to the errors in the indicator scores could then be examined.

A second approach would be to take account the uncertainty by the developing indicators based on fuzzy sets (Zadeh, 1965). This has been suggested as a methodology to deal with situations where there may be important non-quantitative information, missing observation and differing opinions. Fuzzy sets provide a procedure for incorporating ambiguity and lack of quantitative data when classifying environmental conditions, and for describing natural and human-induced changes. Fuzzy sets have been used in ecological impact assessment and fuzzy indicators of environmental condition have been proposed, although their application is at an early stage (Silvert, 1997; Silvert, 1999). Subjective decisions would still be required in setting up the fuzzy sets but they do represent a way of explicitly including uncertainty 


\section{Implications and challenges}

in environmental assessment. The application of fuzzy set theory to environmental indicators is still at the research stage so would not be appropriate for a managementfocused tool such as the ISC. Further work in this area may result in practical application.

\subsubsection{Attributing measured change to management action}

It is important to recognise the limitations of inferential statistics for identifying the causes of any identified changes. Care must be taken if the analysis of change in indicator values, before and after management intervention, is used to assess the effect of that intervention. Misapplication of statistics in this situation is a common problem that Hurlbert (1984) refers to as pseudoreplication - the use of inferential statistics to test for treatment effects with data from situations where, either treatments are not replicated (though samples may be), or replicates are not statistically independent.

An example of pseudoreplication provided by Hurlbert $(1984,204)$ is the analysis of wastes being discharged into a river. A common sampling strategy would be to take replicate samples both upstream and downstream from the discharge point and do this both before, and after, the discharge of wastes begins. However, it is not correct to use statistical inference to assert that the waste discharge is causing any measured change, since the relationship between the upstream and downstream samples would be expected to vary over time, even in the absence of the waste discharge. A rigorous assessment of the effect of the waste discharge would require an experimental design that controlled for these other influences. Similar problems are described by Underwood (1991) who argues that changes in a single location cannot just be attributed to a particular cause and conclusions cannot be drawn about unreplicated data. Hurlbert (1984) does not argue that it is invalid to make these sorts of measurements, merely that it is incorrect to use statistical inference to make conclusions about cause where there are important but uncontrolled influences.

The need to guard against pseudoreplication was recognised by Walters and Holling (1990) in their call for active adaptive management that requires spatial replication and control. They argue it is not possible to resolve uncertainties through sequential application of different management policies to whole systems because policy changes 
drastic enough to provide unequivocal responses would be socially or economically unacceptable.

These comments suggest a key limitation in the use of indicators to guide management. Indicators can be used to assess current condition and to assess change but, of themselves, may not be sufficient to show that a measured change is attributable to management action. In some situations, it may be necessary to use rigorous experimental design in setting up the monitoring system and to undertake management experiments if uncertainties are to be resolved (Walters and Holling, 1990).

Of course, there will be many situations where it will be pragmatic to ignore the possible effects of uncontrolled influences and to make decisions about the causes of changes in indicators, even if there is not enough information to make statistical inferences. If the effects of management actions are large and if there is a well understood mechanism linking actions to changes in indicator values, then it may be appropriate to ignore any uncertainties. The cost of replicating treatments and employing rigorous experimental design may also outweigh the value of the information that could be obtained. Tukey (1960) points out the difference between conclusions and decisions. Decisions are about choosing the best course of action given the present information and having regard to losses and gains of alternatives. Conclusions are withheld until adequate evidence has accumulated and are then based on the evidence; the consequences of specific actions in specific circumstances are not considered. The types of environmental indicators discussed here are intended to support decisions made by managers, rather than provide data for scientific conclusions. So, it may be appropriate to collect and use data in a way that would not satisfy all the demands of scientific rigour.

\subsubsection{Difficulty of detecting change in a variable world}

Regardless of the way indicator data are analysed, there are always likely to be problems detecting some types of changes that may be managerially significant but which will be lost amongst the spatial and temporal variability associated with indicator values. An example was presented in Chapter 4, where a change of $10 \%$ in phosphorus concentrations, a possible management target, was shown to be undetectable using monthly data over reasonable time frames. Similarly, the changes to hydrology from 


\section{Implications and challenges}

the proposed introduction of environmental flows on the Campaspe River, were generally too small to be detected by the Hydrology Sub-index (see Section 7.2).

One of the reasons that these types of changes are so difficult to detect is because they are small. In fact, they may be so small that there is no guarantee they will have an ecologically significant effect. For example, consider the Campaspe River. This river is highly regulated and the proposed environmental rules are constrained by the need to ensure security for irrigators. The flows that result from the environmental rules are little changed from those determined by the previous operating rules. The Hydrology Sub-index correctly shows that change in hydrology is small.

There is a similar situation with the phosphorus indicator when applied to the Latrobe River at Rosedale (see Section 7.3). This indicator is not sensitive to changes in concentration of around $10 \%$, but that seems reasonable since a change of this magnitude is unlikely to be ecologically important. It has been suggested that decreases in loads of at least $50 \%$ are required to have an environmentally significant effect (Robinson, 1995) with decreases of $80 \%$ required to return loads to pre-European levels (Grayson et al., 1994b).

If management-induced changes are not being detected by indicators such as the ISC, then there are a number of alternative approaches. Firstly, it may be appropriate to continue monitoring and wait for the significant change to occur, if it does. If a $50 \%$ reduction in phosphorus loads is required, then that will take some time. If substantial reform of hydrologic operating rules is necessary to improve environmental condition, then large changes will have to be made and these will show up in indicator values.

Secondly, it may be appropriate to undertake a detailed study of the proposed changes. For example, the ecological significance of environmental flows in the Campaspe is being rigorously examined by the Cooperative Research Centre for Freshwater Ecology (Humphries and Lake, 1996). Similarly, there is a program of integrated monitoring of environmental flows (IMEF) in New South Wales by the Department of Land and Water Conservation, that uses a hypothesis-based approach and rigorous sampling designs (Department of Land and Water Conservation, 1999). These studies may show whether there are likely to be ecological benefits from the relatively small changes that are proposed as part of the implementation of environmental flows. 
Thirdly, there may be a role for different types of indicators, other than the condition or state indicators that are included in the ISC. The 'Pressure, State, Response' model of indicators was discussed in Section 5.2.7 where it was concluded that, for the ISC, emphasis would be placed on the development of indicators of state or condition. Pressures on the environment, or responses to environmental problems, would be expected to show up in changes in condition, so pressure and response indicators were seen as being less important than condition indicators. The difficulty of detecting some types of changes shows the need for these other indicators.

Even where there is no detectable change in condition, it may still be important to acknowledge a response by managers to a problem. Implementation of environmental flows in the Campaspe River is an example. There is little change in the Hydrology Sub-index, and any change in the Aquatic Life Sub-index will take some time (if it occurs at all), yet there has been a genuine response to the issue of environmental degradation caused by flow regulation. It may be appropriate to acknowledge this, in addition to reporting the values of the ISC. A similar argument could be made for indicators of pressure, which could track human impacts that are likely to cause a deleterious effect but where there will be time lag in changes in condition.

There are other indicator frameworks in use. The Murray-Darling Basin Commission uses three types of indicators: empowerment, implementation and resource condition (B. Lawrence pers. comm.). Empowerment indicators could include, for example, an agreement that some action could take place, establishment of management responsibility, or adoption of new operating rules. Implementation indicators could include evidence, based on monitoring, that the agreed operating rules were actually implemented. Resource condition indicators are concerned with the measurement of changes in the system being managed e.g. an assessment of changes in river health. Indicator frameworks such as the ISC would fit into this category. There are other indicator types that should be considered as shown in Table 8.1 (also see Rutherfurd et al., 1999).

All of these types of indicators may have a role in assessing the overall task of managing rivers. Systems such as the ISC, and the others discussed in Chapter 4, are mainly concerned with measurement of outcomes. Outcome indicators are the only ones that will measure if there has been any change in the real world. The other types of indicators have their place but assume that management actions are basically correct. 


\section{Implications and challenges}

For example, if it is assumed that certain changes in flows will improve environmental condition, then it is enough to measure that flow change occurred. The level of scientific input into these indicators is limited, as is the need for system understanding.

Table 8.1 - Range of indicator types and targets (adapted from Ian Drummond and Associates Pty Ltd, 1995)

\begin{tabular}{|c|c|c|c|}
\hline Indicator type & Comment & Example indicator & Example target \\
\hline Output & $\begin{array}{l}\text { Quantity of a } \\
\text { product or service }\end{array}$ & $\begin{array}{l}\text { Number of } \mathrm{km} \text { of } \\
\text { fencing }\end{array}$ & $10 \mathrm{~km}$ \\
\hline Responsiveness & $\begin{array}{l}\text { Elapsed time to } \\
\text { execute work tasks }\end{array}$ & $\begin{array}{l}\text { Amount of time } \\
\text { between receiving a } \\
\text { complaint of point } \\
\text { source pollution and } \\
\text { inspecting the site }\end{array}$ & 1 day \\
\hline Productivity & $\begin{array}{l}\text { Workload per staff } \\
\text { unit }\end{array}$ & $\begin{array}{l}\text { Number of trees } \\
\text { planted per day }\end{array}$ & 300 trees per day \\
\hline Efficiency & $\begin{array}{l}\text { Cost per unit of } \\
\text { output }\end{array}$ & Cost per tree planted & $\begin{array}{l}\text { Same cost as } \\
\text { commercial supplier }\end{array}$ \\
\hline Effectiveness & $\begin{array}{l}\text { The extent to which } \\
\text { a program reaches } \\
\text { its objectives }\end{array}$ & $\begin{array}{l}\text { Reduction in the } \\
\text { number of algal } \\
\text { blooms }\end{array}$ & $\begin{array}{l}\text { Reduce blooms } \\
\text { from } 4 \text { per year to } 3 \\
\text { per year }\end{array}$ \\
\hline Cost effectiveness & $\begin{array}{l}\text { Unit cost of } \\
\text { outcome }\end{array}$ & $\begin{array}{l}\text { Cost per unit } \\
\text { reduction in algal } \\
\text { blooms }\end{array}$ & $\begin{array}{l}\text { Cost of } \$ 100000 \text { to } \\
\text { reduce annual algal } \\
\text { blooms by one }\end{array}$ \\
\hline Qualitative & $\begin{array}{l}\text { Performance against } \\
\text { some benchmark }\end{array}$ & $\begin{array}{l}\text { Standards of } \\
\text { service, peer group } \\
\text { assessment, } \\
\text { customer surveys, } \\
\text { opinion polls }\end{array}$ & $\begin{array}{l}\text { Management of } \\
\text { algal blooms to } \\
\text { international best } \\
\text { practice }\end{array}$ \\
\hline
\end{tabular}

In river management there is a need to develop and use outcome indicators such as the ISC. In a review of the US Clean Water Act, Hunter and Waterman (1996) argue that measurements of improvement in the quality of the water in the United States is a neglected area. Most of the process of enforcement and regulation is driven by other types of indicators and, so far, measured outcomes have been relatively unimportant. They see this as a key problem to be addressed if water quality is to be improved. Similarly, in river management in Victoria, outcome indicators are only now being considered. Prior to the development of the ISC, planning and reporting requirements focused on financial aspects (e.g. Ovens River Management Board, 1994; Ian Drummond and Associates, 1995). 


\subsection{Conclusion}

This chapter has brought together the main ideas from the thesis, particularly those related to the implications and challenges for the development and use of indicators in environmental management of rivers. There is a clear demand for broad scale environmental indicators and they are continuing to be developed by various jurisdictions in Australia and internationally.

To be effective, they must be used in practice so must meet the constraints imposed by financial resources and available skills. They must be incorporated into the everyday planning and reporting processes and be able to provide guidance within time frames of interest to managers. They should also be based on 'good science' but the other constraints are primary, if the indicators are to be actually used.

Development of an indicator system requires clear objectives and decisions about users and temporal and spatial scale, to guide the many pragmatic decisions that are required to select a preliminary set of indicators. The next step is to specify standard field procedures, and undertake short-term field testing, to develop a final set of indicators that can be adopted. Storage and manipulation of environmental data and indicator values is a key issue.

The use of indicators in practice requires evaluation of results and consideration of accuracy and sensitivity. Non-traditional statistical methods may have application, since indicator values are unlikely to be well behaved mathematically. Extensive use was made of resampling, including bootstrapping, in the analysis presented in Chapters 6 and 7.

Finally, the ability of indicators to detect the types of changes of interest to managers must be considered. Some strategies may be a valid response to environmental concerns but may result in only small effects. Other types of indicators, along with those of environmental condition, may be required to meet the needs of managers in these cases. These other types of indicators do not reflect actual improvements in stream condition; rather, they require the assumption that a particular strategy is desirable and then measure that the strategy has been implemented. Outcome indicators, such as the ISC, will continue to be important to measure actual changes in environmental condition. 


\section{CONCLUSION}

\subsection{Introduction}

At the start of this thesis, I outlined the impact of development on Victorian rivers since the formation of the State in 1851. Many rivers have been physically altered by activities such as gold mining, works to improve navigation, water resources development and river clearing and channelisation. There has also been introduction of exotic flora and fauna, pollution and indirect affects of catchment clearing and agricultural development. The cumulation of these effects, and changing societal values, have led to a rise in environmental concern that is reflected in changes in institutional arrangements and management objectives.

Environmental indicators have a role in meeting the challenge of incorporating environmental information into river management decision-making. This thesis explores the use of environmental indicators as a tool to assist management of rivers. In the introduction, I discussed the promise of environmental indicators - that they can turn large amounts of environmental data into simple, timely results to guide management intervention.

Can environmental indicators live up to this promise? I have examined this question by reviewing indicator systems that have been developed by others and then exploring, in detail, the Index of Stream Condition (ISC) that is intended as a tool to assist the management of rivers in Victoria. Although a complete evaluation of the success of the ISC is probably not possible until it has been in operation for 10 to 15 years, it is timely to review the likely elements of its success or failure, as similar river-focused indicators are being developed in other jurisdictions.

I argue that environmental indicators have a role at the level of regional waterway management authorities but only if they are closely aligned with managers' needs. Without consideration of non-technical issues, indicators are unlikely to be used, so establishing a balance between pragmatic constraints and a need for scientific rigour is critically important. A procedure to achieve this balance is proposed in this thesis and was applied to the development of the ISC.

My findings suggest that environmental indicators can be useful for benchmarking stream condition and for measuring change; but it is also important to be aware of their 
limitations. Developing appropriate sampling approaches is important, together with consideration of accuracy and temporal variability of the indicators. Some management actions are unlikely to result in improved environmental outcomes in the short-term, so it may be necessary to supplement environmental indicators with measurements that relate directly to management action.

\subsection{The promise of environmental indicators}

Chapter 3 describes some of the pathologies with the way environmental information has been collected and used by river managers, and the opportunities for environmental indicators to address these issues. Firstly, river management has often been in response to environmental change but information about the environment has not been obtained rigorously. Instead, management actions have been in response to perceptions of the state of the environment, which may not be supported by objective information. This can lead to inappropriate proposals and conflict. Systematic collection and reporting of environmental indicators could help to overcome this problem.

Secondly, there are cases where there has been rigorous monitoring of the environment but the information is not suitable to assist management decision-making. Disagreement between the goals of managers and of those that established the monitoring program, means the collected information may not be suitable to guide decisions made by managers. If monitoring is to be effective, there must be clear goals, it must meet the needs of managers and the results should be incorporated into routine planning and reporting.

A third difficulty arises where there is a narrow, short-term management focus which can result in an attempt to ignore both the wider environmental consequences of actions and the uncertainties in the behaviour of river systems. Monitoring that is restricted to local issues will not be useful to evaluate and modify strategies. A narrow management focus has been widely criticised and is partly responsible for the consequences, we now see, of past activities. There is recognition at the broader policy level, by the Council of Australian Governments, that the environmental degradation of waterways needs to be addressed. Broad scale monitoring of environmental condition, and reporting appropriate indicators, may be an appropriate approach to this issue.

Changing institutional arrangements in Victoria have also created the demand for environmental indicators to assist with reporting and accountability requirements. 


\section{Conclusion}

Environmental management of rivers is now undertaken by large, regional, Catchment Management Authorities that have a great deal of autonomy and opportunities for funding from a wide variety of sources, but with increased requirements of accountability to the State Government. Reporting of environmental condition is a legislated requirement of these authorities.

\subsection{Developing environmental indicators}

There are many existing approaches to assessing the environmental condition of rivers and a review in Chapter 4 highlighted the range of issues to be considered including selection, sampling, rating and reporting of indicators. The different objectives of the assessment schemes and development methods have led to a variety of approaches to serve different ends.

A contribution of this thesis is in the devising of a process to develop the ISC, which is presented in detail in Chapter 5. This was based on lessons from the review of other approaches and consideration of ISC objectives. The basis of the method is to ensure a balance between scientific rigour and non-technical issues, by achieving consensus between scientists and managers at a series of workshops. These workshops were attended by a Specialist Reference Group (SRG), including industry and State Government representatives and scientists with expertise in aspects of rivers. Prior to each workshop, the issues were researched, both by consulting the academic literature and government reports and through discussions with experts. Using the information obtained, discussion papers were prepared that included 'straw man' recommendations that were then presented to the workshops for discussion. Based on feedback and decisions at the workshops, alternatives were sought and recommendations modified, until a group of preliminary indicators were selected that were acceptable to the SRG for later refining through field testing, peer review and trial application.

The process of developing the Index of Stream Condition highlighted important issues to ensure that these indicators could be used in practice. The specification of objectives was important, as this was to guide all subsequent stages. Initial decisions were required about who would use the indicators, what aspects of stream condition would be measured and for what purpose the indicators would be used.

The problem was not to come up with indicators; there are literally hundreds to choose from and others can be created at will. Rather, the difficulty was to determine the 
minimum set of indicators that can be measured, used and understood by the intended users and to meet specified objectives where possible. Pragmatic, judgement-based, decisions were required throughout the development of the ISC and the workshops facilitated this approach and proved successful in addressing the complexities of this project.

The valuing of indicators was an area of debate. Indicators are scored or rated, to place them in context with some reference condition or ideal state. Several different types of reference condition are discussed in Chapter 5. Originally, it was planned to judge stream conditions against naturalness but this proved difficult in practice. Instead, the pragmatic application of the concept of an ideal stream, guided by best professional judgement and in many cases based on natural conditions, was used throughout the development of the ISC. Rating tables were developed for each indicator and again these were presented to the workshop as drafts following a literature review. They were then revised within the workshops until there was agreement amongst the Specialist Reference Group members.

\subsection{Performance of environmental indicators}

The ISC development process resulted in five groups of indicators referred to as subindices. These included: hydrology (based on change in volume and seasonality of flow from natural conditions); physical form (based on bank stability, bed erosion or aggradation, influence of artificial barriers, and abundance and origin of coarse woody debris); streamside zone (based on type of plants, spatial extent, width, and intactness of riparian vegetation, regeneration of overstorey species, and condition of wetlands and billabongs); water quality (based on an assessment of phosphorus, turbidity, electrical conductivity, and $\mathrm{pH}$ ); and aquatic life (based on presence of macroinvertebrate families). Details of the ISC are available in Ladson et al. (1999a) and Ladson and White (1999). These indicators were the result of input from a large number of people as noted in Chapter 5 and I do not claim the ISC itself as a contribution of this thesis. My contribution lies primarily in the process of development of the ISC and in the testing and investigation of individual indicators and their use in practice.

I examined the performance of these indicators in detail, as described in Chapters 6 and 7 , including their ability to detect different types of changes that could be related to management action. The non-traditional statistical methodology illustrated here, that of 


\section{Conclusion}

resampling (Mac Nally, 1997), including bootstrapping (Efron and Tibshirani, 1993), provided the flexibility to deal with situations where application of standard statistical procedures would have been difficult. These techniques will have application in similar studies. The computer programs developed during this study are presented in the appendices.

Sampling and sensitivity of the Streamside Zone and Physical Form Sub-indices were examined by analysing a detailed data set collected along the Broken River and Ryans Creek, two lowland streams in northeastern Victoria. These streams had sub-index scores between 3.4 and 6.9, which is roughly in the middle of the possible range of 0 to 10, and are likely to be similar to many Victorian floodplain streams.

Many previous assessments of stream condition have used subjectively chosen samples (Jeffers, 1988) and originally, it was proposed that ISC scores be measured at 'representative' reaches chosen on the basis of local knowledge. This procedure was used in an earlier State of the Streams survey in Victoria (Tilleard and DWR, 1986). The 'representative' reach procedure was tested along Ryans Creek and the Broken River. Results showed that values for the streamside zone and physical form from a 'representative' reach were subject to error that could not be quantified, so it would be difficult to have confidence in results based on this approach. As an alternative, a sampling scheme, based on the random selection of measuring sites and then detailed assessment at those sites, was developed and analysed. The required sampling density was related to the variance of the data and the objectives of the indicators.

Based on the analysis for Ryans Creek and the Broken River, key results are summarised as follows. Streamside zone was the most variable sub-index so it is the limiting factor in determining sampling density. For benchmarking, if the desired accuracy is that the estimate of mean streamside zone be within $+/-1$ of the true mean $90 \%$ of the time then about 1.3 measuring sites are required per $10 \mathrm{~km}$ of reach, with 3 transects per measuring site. Results show that detecting change is more demanding than benchmarking, and about 2.3 measuring sites and three transects per site are required per $10 \mathrm{~km}$ of reach, to be $90 \%$ confident that the change detected is within $+/-$ 1 of the true change. Results presented allow confidence intervals to be calculated, depending on the actual sampling density chosen. 
Several scenarios were investigated that examined the use of indicators as triggers for management intervention. If an indicator changes by more than a critical amount then the manager may decide to intervene on the basis that a critical change in the indicator is equivalent to a change in the underlying stream condition that is cause for concern. However, this decision could be subject to error, as the indicator may not accurately reflect the true change in condition. Firstly the indicator could suggest that a critical change had occurred when the underlying 'true' change was less than critical - a false alarm or Type I error. Secondly, the indicator could show a change less than critical when the 'true' change was large enough to be of concern - a false complacency or Type II error. Graphs are presented in Chapter 6 that relate probabilities of the Type I and Type II errors with three parameters: the true change in condition; a critical value of change in the indicator that will trigger management intervention; and the sampling density. These graphs can guide decisions about the required sampling density to achieve acceptable performance of the indicators.

Other sources of variance for the Streamside Zone and Physical Form Sub-indices were investigated. Data from situations where a number of people had assessed the same sites were used to examine inter-operator variability. It was found that inter-operator variability could be a significant source of the variance of the Streamside Zone and Physical Form Sub-indices. Techniques to reduce these errors are discussed, including training programs, auditing of results and assessment of standard sites.

Issues associated with accuracy of the Hydrology, Water Quality and Aquatic Life Subindices of the Index of Stream Condition were also examined. For hydrology and water quality, case studies were undertaken of particular rivers. For aquatic life, the discussion was restricted to a review of the work of others.

The Hydrology Sub-index is capable of identifying streams that are heavily impacted because of regulation or diversions. Of 21 streams analysed in Victoria and New South Wales, the Campaspe River had the greatest hydrologic alteration because of flow regulation. The Campaspe River is also where there is a major focus on introducing environmental operating rules in an attempt to improve stream condition.

The Hydrologic Sub-index correctly shows that the effect of the environmental operating rules on hydrology is minor. The flow regime remains altered from natural conditions and for some years, the previous operating rules result in flows that are 


\section{Conclusion}

closer to natural conditions than flows generated according to the environmental rules. The constraint preventing larger changes to hydrology is that the security of supply to irrigators must be maintained.

Although the hydrologic effect of the proposed flow changes is small, the Cooperative Research Centre for Freshwater Ecology is testing if there will be a significant ecological effect. If there is an ecological improvement from implementing the environmental flows, then it may be possible to use the results to improve the hydrology component of the ISC, by identifying the biologically significant facets of the flow regime that have been provided by the new flow rules and then devising an indicator that captures these changes. Making general conclusions about these biologically significant flow facets will be difficult since the response to the environmental flow changes is likely to be site-specific and biology-specific.

The results from the case study of water quality showed that the Water Quality Subindex is useful for revealing degradation. When examining phosphorus in the Latrobe River at Rosedale, the phosphorus indicator performed broadly as expected. The current conditions at Rosedale are that phosphorus loads are four to five times what they would have been under natural conditions and the phosphorus indicator generally scores 0 to 1 out of 4 . Two simple scenarios were investigated. Modelling a reduction in phosphorus to levels that Robinson (1995) suggested could result in an ecological improvement in the river, resulted in scores of 2 to 3 out of a maximum of 4 . Similarly, a decrease in phosphorus to levels that would have been found in the pristine river, resulted in indicator scores of 3 to 4 out of a maximum of 4 .

For hydrology and water quality, the case studies show that the likely management strategies in these situations will result in changes that are small compared with the difference between current stream condition and 'ideal' conditions as defined by the ISC. Other evidence also suggests that these streams are degraded and that water quality and hydrology have been highly modified from natural conditions, and that large changes are required to improve their environmental values. The ISC indicators were shown not be sensitive to changes such as the environmental flows proposed for the Campaspe River, or decreases in phosphorus concentrations of around $10 \%$ at the Latrobe River at Rosedale. However, this is to be expected, since the changes are small compared to those required to rehabilitate these streams. This suggests that improving the ISC scores will be a long-term process that will require continuing effort but that when 
improvement is seen in ISC scores, it will reveal a genuine improvement in stream condition

For the Aquatic Life Sub-index, others are investigating precision and bias for both the SIGNAL and AusRivAS procedures. These two procedures are now in widespread use in Victoria, and throughout Australia, and their performance will be subject to further analysis.

As noted above, there are some management interventions that are unlikely to be reflected in improved environmental outcomes at least in the short-term, so it may be necessary to use other types of indicators that are directly related to management responses, rather than changes in condition. These indicators require the assumption that outcomes will be as expected, and that all that is required is to measure that a strategy has been implemented. Various indicators are discussed in Chapter 8. Although these indicators have a role in reporting on performance, management success will ultimately be judged by outcomes. Therefore it is appropriate to measure changes in environmental state using tools such as the ISC, even if improvement can only be expected in the long term for some indicators.

\subsection{Implications}

The development and analysis of the ISC have clarified requirements for indicators that can directly assist environmental management of rivers. It is important that these indicators are used by river management authorities and, to this end, they must be included in routine planning and reporting arrangements. This requirement was reflected in the development process for the ISC, which made use of scientific input to build a system of indicators founded in science but was tempered by practical requirements related to the objectives and users. The trade-off between the demands of scientific rigour and management practicality was achieved through a series of workshops with scientists and managers, with iterative revision of proposals, until an acceptable preliminary group of indicators was chosen that could be further refined by field testing. Science is only able to assist management if it is used by managers. The methodology used here was an effective way of achieving the compromises necessary to incorporate the best available scientific information into a monitoring tool with management application. There is also the requirement to use multidisciplinary knowledge when managing a complex system, such as a river, and the use of a 


\section{Conclusion}

Specialist Reference Group was effective in tapping the combined expertise of a range of scientists.

The practical application of multidisciplinary scientific knowledge will be a common requirement of environmental management projects. Individual scientists are likely to have to compromise on the techniques they recommend and the rigour they consider appropriate. They will also have to work with scientists in different disciplines when recommending approaches to addressing problems of environmental degradation.

There are also implications for adaptive management. As noted in Section 4.3.1, monitoring is an important part of adaptive management, along with integration of existing knowledge, modelling to determine possible scenarios, and implementation of large-scale management experiments that include, where possible, replication and control (Walters and Holling, 1990). Routine monitoring systems such as the ISC may be useful in the process of adaptive management, in the event that management experiments require these types of measurements.

Routine monitoring systems are likely to be most useful for the monitor-and-modify approach to resource management, which is less rigorous than adaptive management and involves implementing strategies, assessing their performance through monitoring and refining the management intervention if appropriate (Johnson, 1999b). This a useful approach where uncertainties are not great enough to warrant the expense of adaptive management (Lee, 1999). The analysis in Chapters 6 and 7 shows that some types of management actions are unlikely to produce changes that can be measured during routine monitoring so measuring management response, rather than environmental outcomes, may be appropriate where there is limited uncertainty.

The practical implication of the work presented here is that a system of indicators has been developed that will provide an ongoing and consistent set of data to enable assessments of stream condition over the long term. Because of this work, and that of others, the management of rivers in Victoria has been changed to specifically include assessment of environmental outcomes.

\subsection{Further research}

Three main areas for further research on indicators follow from this thesis. As discussed in Section 8.5.2, there may be a role for better ways to incorporate value judgements in indicator scores. Indicators of environmental condition based on fuzzy 
sets may be appropriate, as these can incorporate ambiguity and non-quantitative information when classifying environmental conditions (Silvert, 1997; 1999). Practical application of this approach under similar conditions to the ISC would be worthwhile.

Secondly, the statistical issues associated with indicators require further clarification. There are arguments about the appropriateness of statistical significance tests (Harlow et al. 1997) although these continue to be used (see Section 8.5.2). The resampling and bootstrapping analysis presented here represents a reasonably new and appropriate approach to testing and evaluation of indicators although other procedures should also be considered. As discussed in Section 8.5.2, Bayesian approaches may be an appropriate way of analysing indicator data but these are yet to be widely applied. Application of Bayesian approaches to the practical interpretation of indicators is a worthwhile area of further research.

The third suggestion for further research is to study how indicators actually get used. The field is littered with indicator schemes that have been developed, applied once with the intension that monitoring would continue, and then abandoned (Dovers, 1995). Some of the likely problems with various indicator schemes where discussed in Chapter 4 but it would be appropriate to examine these issues in more depth. Part of this research could involve a review the performance of the ISC, once its strengths and weaknesses are revealed in 5 to 10 years. 


\section{REFERENCES}

Anderson, J. R. (1993a). State of the rivers project, report 1: development and validation of methodology. Queensland Department of Primary Industries. Brisbane.

Anderson, J. R. (1993b). State of the rivers project, report 2: implementation manual. Queensland Department of Primary Industries. Brisbane.

Anderson, J. R. (1993c). State of the rivers, Maroochy River and tributary streams. An ecological and physical assessment of the condition of streams in the Maroochy River Catchment. Maroochy Shire Council and Department of Primary Industries, Brisbane.

Angradi, T. R. (1999). "Fine sediment and macroinvertebrate assemblages in Appalachian streams: a field experiment with biomonitoring applications." Journal of the North American Benthological Society 8(1): 49-66.

Anon. (1870a). Journal of a trip from the Gilbert to Townsville via the valley of the Herbert and the coast. Brisbane Courier, vol. 24, no. 3879 (Friday 11 March), 2-3.

Anon. (1870b). Journal of a trip from the Gilbert to Townsville via the valley of the Herbert and the coast. Brisbane Courier, vol. 24, No. 3878 (Thursday 10 March), 3.

Anon. (1939). Through forest and jungle: Herbert River, 1900-1905 by "Tramp". Hinchinbrook Shire historical notes series 1, 48. Copy held in the Ingham Library Local Historical Anthology. Ingham, Queensland (unpublished).

Anon. (1984). Ingham in uproar. Townsville Bulletin (Tuesday May 25), 1.

Armitage, P. and Pardo, I. (1995). "Impact assessment of regulation at the reach level using macroinvertebrate information from mesohabitats." Regulated Rivers: Research and Management 10: 147-158.

Arthington, A. H. and Zalucki, J. M., (eds.) (1998). Comparative evaluation of environmental flow assessment techniques: review of methods. Land and Water Resources Research and Development Corporation. Canberra.

Aspie, D. and Barnes, R. J. (1990). "Infill-sampling design and the cost of classification errors." Mathematical Geology 22(8): 915-932. 
Australian and New Zealand Environment and Conservation Council (1992). Australian water quality guidelines for fresh and marine waters.

Australian Bureau of Statistics (1999). <www.abs.gov.au> 18 August 1999.

AWRC (Australian Water Resources Council) (1988). Overview. From the Proceedings of the National Workshop on Integrated Catchment Management, 17-19 May, University of Melbourne. Australian Water Resources Council, xi-xx.

Balls, P. W. (1989). "Trend monitoring of dissolved trace metals in coastal sea water - a waste of effort?" Marine Pollution Bulletin 20: 546-548.

Barber, M. C. (1994). Environmental monitoring and assessment program: indicator development strategy. EMAP Office of Research and Development. US Environmental Protection Agency. Research Triangle Park. (cited by Reid and Brooks, 1998).

Barbour, M. T., Gerritsen, J., Snyder, B. D. and Stribling, J. B. (1997). $\underline{\text { Revision to rapid }}$ bioassessment protocols for use in streams and rivers: periphyton, benthic, macroinvertebrates, and fish. US Environmental Protection Authority. <http://www.epa.gov/OWOW/monitoring/AWPD/RBP/bioasses.html> (20 August 1999). Washington D. C.

Barlow, G. (1999). Water levy axed. The Weekly Times. Melbourne No. 6646 Wednesday November 3, 1-2.

Barmuta, L. A., Marchant, R. and Lake, P. S. (1992). Degradation of Australian streams and progress towards conservation and management in Victoria. River Conservation and Management. P. J. Boon, P. Calow and G. E. Petts. (eds) John Wiley and Sons, 65-79.

Bayley, G. V. and Hammersley, J. M. (1946). "The effective number of independent observations in an autocorrelated time series." Journal of the Royal Statistical Society 8(1-B): 184-197.

Beard, D. (1979). Bucket dredging in the upper Ovens Valley. Honours thesis. Department of Geography, University of Melbourne. Melbourne. (unpublished).

Bernstein, B. B. (1990). A framework for trend detection: coupling ecological and managerial perspectives. Proceedings of the International Symposium on Ecological Indicators, October 16-18, Fort Lauderdale, FL. Elsevier, 1101-1114. 
Biswas, A. K., (ed.) (1978). United Nations water conference: summary and main documents. Pergamon Press.

Bjornlund, H. and McKay, J. (1995). "Can water trading achieve environmental goals?" Journal Australian Water and Wastewater Association 22(6): 31-34.

Boon, P. J., Holmes, N. T. H., Maitland, P. S. and Rowell, T. A. (1994). “A system for evaluating rivers for conservation (SERCON): an outline of the underlying principles." Verhandlungen der Internationalen Vereinigung for theoretische und angewandte Limnologie 25: 1510 - 1514.

Boon, P. J., Holmes, N. T. H., Maitland, P. S., Rowell, T. A. and Davies, J. (1997). A system for evaluating rivers for conservation (SERCON): development, structure and function. Freshwater quality: defining the indefinable? P. J. Boon and D. L. Howell. (eds) HMSO \& Scottish Natural Heritage. Edinburgh, 299-326.

Born, S. and Sonzogni, W. C. (1995). "Integrated environmental management: strengthening the conceptualisation.” Environmental Management 19(2): 167-181.

Boughton, W., (ed.) (1999). A century of water resources development in Australia, 1900-1999. The Institution of Engineers Australia. Canberra.

Boulton, A. J. (1999). "An overview of river health assessment: philosophies, practice, problems and prognosis." Freshwater Biology 41: 469-479.

Brierley, G. (1998). "River changes since European settlement on the Bega Catchment, NSW." Rivers for the Future 1(6): 16-29.

Brierley, G., Cohen, T., Fryirs, K. and Brooks, A. (1999). "Post-European changes to the fluvial geomorphology of Bega catchment, Australia: implications for river ecology." Freshwater Biology 41: 839-848.

Brizga, S. O. and Finlayson, B. L. (1994). "Interactions between upland catchments and lowland rivers: an applied case study from the Snowy River, southeastern Australia." Geomorphology 9: 189-201.

Brizga, S. O., Finlayson, B. L. and Chiew, F. H. S. (1993). Flood dominated episodes and river management: a case study of three rivers in Gippsland, Victoria. Hydrology and Water Resources Symposium, June 30 - July 2, Newcastle. Institution of Engineers, Australia, 99-103. 
Brookes, A., Knight, S. S. and Shields, F. D. J. (1996). Habitat enhancement. River channel restoration: guiding principles for sustainable projects. A. Brookes and F. D. J. Shields (eds). John Wiley and Sons, 103-126.

Brown, J. A. H. (1972). "Hydrological effects of a bushfire in a catchment in southeastern New South Wales.” Journal of Hydrology 15: 77-96.

Brunton, R. (1994). Environmental indicators: sustainable development or political tool. Tasman Institute. Melbourne.

Budiansky, S. (1995a). “Chaos in Eden.” New Scientist 14 October, 156(1999): 33-35.

Budiansky, S. (1995b). Nature's keepers. Phoenix. London.

Burston, J. and Brown, W. (1996). Watercourse revegetation - just a walk in the park! Proceedings of the first national conference on stream management in Australia, 1923 February, Merrijig. Cooperative Research Centre for Catchment Hydrology. Melbourne, 247-251.

Cadwallader, P. L. (1979). "Some causes of the decline in range and abundance of native fish in the Murray-Darling river system." Proceedings of the Royal Society of Victoria 90(2): 211-224.

Cairns, J. J., McCormick, P. V. and Niederlehner, B. R. (1993). “A proposed framework for developing indicators of ecosystem health." Hydrobiologia 263: 1-44.

Cameron McNamara (1980a). Herbert River flood management study. Ref. No. 781168, September. Herbert River Improvement Trust. Ingham, Queensland.

Cameron McNamara (1980b.) Herbert River flood management study: summary report. Ref. No. 78-1168, September. Herbert River Improvement Trust. Ingham, Queensland.

Cao, R. (1999) "An overview of bootstrap methods for estimating and predicting in time series". Test 8(1): 95-116.

Carpenter, S. (1990). "Large-scale perturbations: opportunities for innovation.” Ecology 7(6): 2038-2043.

Carter, D. (1997). State of the Rivers, Lockyer Creek and major tributaries: an ecological and physical assessment of the condition of streams in the Lockyer Creek Catchment. Department of Natural Resources, Resource Sciences Centre. Brisbane. 
Carver, R. P. (1993). "The case against statistical significance testing, revisited." Journal of Experimental Education 61(4): 293-316.

Casey, S., Grey, M., Khoo, K., Ladson, A. R., Morrow, A., Power, J. and Smith, H. (1997). Placing postgraduate research in the advocacy coalition framework. Public Policy Network Annual Conference, 30-31 January 1997, University of Melbourne. The Centre for Public Policy, University of Melbourne. Melbourne.

Catchment Management Structures Working Party (1997). Review of catchment management structures in Victoria. Ministry for Agriculture and Resources and the Ministry for Conservation and Land Management. Melbourne.

Central Gippsland Water Quality Working Group (1995). Central Gippsland water quality management strategy. West Gippsland Catchment and Land Protection Board. Traralgon.

CEAH (Centre of Environmental Applied Hydrology) and ID\&A Pty Ltd (1995) Development of an Index of Stream Condition. Report prepared for the Waterways Unit of the Department of Conservation and Natural Resources. Melbourne.

CEAH (Centre of Environmental Applied Hydrology) and ID\&A Pty Ltd (1997) An Index of Stream Condition: reference manual. Report prepared for the Waterways Unit of the Department of Natural Resources and Environment.

Chessman, B. C. (1986). "Impact of the 1983 wildfires on river water quality in east Gippsland, Victoria." Australian Journal of Marine and Freshwater Research 37: 399-420.

Chessman, B. C. (1995). "Rapid assessment of rivers using macroinvertebrates: a procedure based on habitat specific sampling, family level identification and a biotic index." Australia Journal of Ecology 20: 122-129.

Chessman, B. C., Growns, J. E. and Kotlash, A. R. (1997). "Objective derivation of macroinvertebrate family sensitivity grade numbers for the SIGNAL biotic index: application to the Hunter River system, New South Wales." Marine and Freshwater Research 48: 159-172.

Christoff, P. (1998). "Degreening government in the garden state: environmental policy under the Kennett Government, 1992-1997." Environmental and Planning Law Journal 15(1): 10-32. 
CIA (Central Intelligence Agency) (1998) 1998 World Fact Book. <http://www.odci/gov/cia/publications/factbook/index.html> (August 18, 1999).

Clark, I. D. (1989). Themes relating to the past 150 years of Victoria's rivers, streams and water systems. Report for the Land Conservation Council from the Heritage and Environment Division, Ministry for Planning and the Environment, Victoria. Melbourne.

Clark, S. and Scovell, J. (1982). Legislative and institutional arrangements for water resources administration in Victoria. Report no. 1: river management, drainage and flood-plain management. University of Melbourne. Melbourne.

CLPC (Catchment and Land Protection Council), Department of Natural Resources and Environment and Environment Protection Authority (1996). Testing the waters: the 1996 review of Victorian water quality monitoring. State Government of Victoria. Melbourne.

Codner, G. P., Laurenson, E. M. and Mein, R. G. (1988). Hydrologic effects of urbanisation: a case study. Hydrology and Water Resources Symposium, 1-3 Feb 1988, ANU Canberra. Institution of Engineers, Australia.

Cohen, J. (1988). Statistical power analysis for the behavioral sciences. Erlbaum. Hillside, N. J.

Commoner, B. (1972). The closing circle: confronting the environmental crisis. Jonathan Cape. London.

Commonwealth of Australia (1992). National strategy for ecologically sustainable development. Australian Government Publishing Service. Canberra.

Conacher, A. (1998). "Environmental quality indicators: where to from here." Australian Geographer 29(2): 175-189.

Conservation Council of Victoria (1977). River improvement. Conservation Council of Victoria. Melbourne.

Cooper, J. A. G., Harrison, T. D., Ramm, A. E. L. and Singh, R. A. (1993). Refinement, enhancement and application of the estuarine health index to Natal's estuaries, Tugela - Mtamvuna. Technical report EFP. 05. 930401. Department of Environmental Affairs. Pretoria, South Africa. 
Cooper, J. A. G., Ramm, A. E. L. and Harrison, T. D. (1994). "The Estuarine Health Index: a new approach to scientific information transfer." Ocean \& Coastal Management 25: 103-141.

Cordery, I. (1976). "Some effects of urbanisation on streams." Civil Engineering Transactions, The institution of Engineers, Australia 18: 7-11.

Cosser, P. R. (1989). "Nutrient concentration-flow relationships and loads in the South Pine River, south-eastern Queensland. 1. phosphorus loads.” Australian Journal of Marine and Freshwater Resources 40: 613-630.

Costa, J. E., Miller, A. J., Potter, K. W. and Wilcock, P. R., (eds.) (1995). Natural and anthropogenic influences in fluvial geomorphology. Geophysical monograph No. 89. American Geophysical Union. Washington.

Costanza, R., Norton, B. G. and Haskell, B. D., (eds.) (1992). Ecosystem health: new goals for environmental management. Island Press. Washington, D.C.

Council of Australian Governments (1994). Communique of the meeting of the Council of Australian Governments. Hobart, June 1993.

Cowley, A. (1878). References are from letters collected in the Ingham Library Local Historical Anthology: 900022:B. Ingham, Queensland (Unpublished).

Cranston, P. S., Fairweather, P. and Clarke, G. (1996). Biological indicators of water quality. Indicators of catchment health: a technical perspective. J. Walker and D. J. Reuter (eds). CSIRO. Melbourne, 143-154.

Cullen, P. (1990). "Biomonitoring and Environmental Management." Environmental Monitoring and Assessment 14: 107-114.

Cushman, R. M. (1985). "Review of ecological effects of rapidly varying flows downstream of hydroelectric facilities." North American Journal of Fisheries Management 5: 330-339.

Dallas, H. F. and Day, J. A. (1993). The effect of water quality variables on riverine ecosystems: a review. Water Research Commission. Pretoria.

Darwin, C. (1859) On the origin of species by means of natural selection. Murray, London. 
Davidson, N., Jeffrey, G. and Wagg, C. (1994). The environmental condition of streams in the Glenelg Basin. Glenelg Waterways Team. Melbourne.

Davies, O. L., (ed.) (1966). The design and analysis of industrial experiments. Longman Group Limited.

Davies, P. E. (1994). River bioassessment manual, version 1.0. Department of Environment Sports and Territories, Land Water Resources Research and Development Corporation and Commonwealth Environmental Protection Authority, Commonwealth of Australia. Canberra.

Davies, B. R., Thoms, M. and Meador, M. (1992). "An assessment of the ecological impacts of inter-basin water transfers, and their threats to river basin integrity and conservation." Aquatic Conservation: Marine and Freshwater Ecosystems 2: 325349.

Davis, J.A. (1996). Catchment management for the control of sediment delivery: the case of the Eppalock Catchment, Victoria. PhD thesis, Department of Civil and Environmental Engineering, University of Melbourne, Melbourne.

Davis, J. A., Bird, J. F. and Finlayson, B. L. (1997). Avon River gravel extraction study. CEAH report No. 4/97. Centre for Environmental Applied Hydrology, University of Melbourne. Melbourne.

Davis, J. R. and Young, W. J. (1998). A decision support system for planning environmental flows. Restoration of degraded river systems: challenges, issues and experiences. D. P. Loucks. Kluwer Academic Publishers. Netherlands, 357-376.

Day, D. G. (1987). Geomorphological and hydrological monitoring for environmental change in Australia: a critical analysis of developments and organisational performance. CRES Working Paper 1987/6. Centre for Resource and Environmental Studies. Australian National University. Canberra.

Day, D. G. (1988). River mismanagement: policy, practice or nature. CRES Working Paper 1988/1, Centre for Resource and Environmental Studies, Australian National University. Canberra.

DCE (Department of Conservation and Environment) (1991). Water Victoria: the next 100 years. Department of Conservation and Environment. State Government of Victoria, Melbourne. 
DCE (Department of Conservation and Environment) (1992). Bulk water entitlements. part 1, the new framework of bulk entitlements and conversion of existing rights. Water Resource Management Report Series. Report No. 42. Melbourne.

DCNR (Department of Conservation and Natural Resources) (1995). The bulk entitlement conversion process. Report No. 2. Bulk Water Entitlements Report Series. Department of Conservation and Natural Resources. Melbourne.

De Deckker, P. (1986). What happened to the Australian aquatic biota 18000 years ago? Limnology in Australia. De Deckker, P. and W. D. Williams (eds). CSIRO and Dr. W. Junk. Melbourne, 487-496.

Department of Land and Water Conservation (1999). Integrated monitoring of environmental flows: scoping report. Department of Land and Water Conservation. Sydney (unpublished).

Department of Resources and Energy (1983). Water 2000: consultants report No. 9, in-

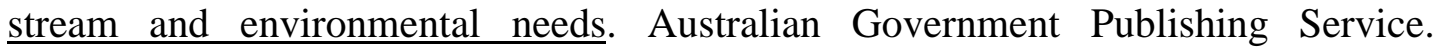
Canberra.

Department of Resources and Energy and Australian Water Resources Council (1984). Proceedings of the joint AWRC-AAES seminar on transferable water rights. Australian Government Publishing Service, Canberra, 162.

Department of Water Resources (1987). Annual report 1986/87. Government of Victoria, Melbourne.

Department of Water Resources (1989a). Water Victoria: a resource handbook. Victorian Government Printing Office. Melbourne.

Department of Water Resources (1989b). Water Victoria: an environmental handbook. Victorian Government Printing Office. Melbourne.

Department of Water Resources (1992). NSW state rivers and estuaries policy: state of the rivers and estuaries, environmental indicators, a literature review. Department of Water Resources, New South Wales. Sydney.

DEST (Department of the Environment Sport and Territories) (1994). State of the environment reporting: framework for Australia. Australian Government Publishing Service. Canberra. 
Dinius, S. H. (1987). "Design of an index of water quality." Water Resources Bulletin 23(5): 833-843.

Division of Water Resources (1992). Towards healthy rivers. CSIRO Division of Water Resources. Canberra.

DNRE (Department of Natural Resources and Environment) (1997). Future arrangements for catchment management in Victoria: response by the Victorian Government to the catchment management structures review. Department of Natural Resources and Environment. Melbourne.

DNRE (Department of Natural Resources and Environment) (1999). North East Catchment Management Authority <http://www.nre.vic.gov.au/catchmnt/partner/ northest/neascon.htm> (1 Sept. 1999).

Doeg, T. J. and Milledge, G. A. (1991). "Effect of experimentally increasing concentrations of suspended sediment on macroinvertebrate drift." Australian Journal of Marine and Freshwater Research 42: 519-536.

Dovers, S. (1995). "Information, sustainability and policy" Australian Journal of Environmental Management 2: 142-156.

Dryzek, J. S. (1987). Rational ecology. Basil Blackwell. New York.

Dublin Statement on Water and Sustainable Development (1992). Statement from the International Conference on Water and the Environment, Dublin Ireland 26-31, January http://www-esd.worldbank.org/rdv/training/icwedece.html (1 Sept. 1999).

Dudgeon, D. (1995). "River regulation in southern China - ecological implications, conservation and environmental management." Regulated Rivers - Research and Management 11(1): 35-54.

East, L. R. (1952). River improvement land drainage and flood protection. State Rivers and Water Supply Commission. Melbourne.

Eaton, A., Clesceri, L. S. and Greenberg, A., E., (eds.) (1995). Standard methods for the examination of water and wastewater. American Public Health Association. Washington.

Efron, B. and Tibshirani, R. J. (1993). An introduction to the bootstrap. New York, Chapman \& Hall. 
Elliott (1996). A conceptual framework for geoenvironmental indicators. Geoindicators: assessing rapid environmental changes in earth systems. A. R. Berger and W. J. Iams. (eds) A. A. Balkema. Rotterdam, 337-349.

Ellis, J. C. and Lacey, R. F. (1980). "Sampling: defining the task and planning the scheme." Water Pollution Control. 79:452-467.

Ellison, A. (1996). "An introduction to Bayesian inference for ecological research and environmental decision-making.” Ecological Applications 6(4): 1036-1046.

Environment Agency (1997). River Habitat Survey: 1997 field survey guidance manual (incorporating SERCON). The Environment Agency. Bristol.

EPA (Environment Protection Authority) (1996). Policy impact assessment: protecting water quality in Central Gippsland: variation of State Environment Protection Policy (Waters of Victoria). State Government of Victoria. Melbourne.

EPA (Environment Protection Authority) (1998). Rapid bioassessment of Victorian streams: the approach and methods of the Environment Protection Authority. Environment Protection Authority, Melbourne.

Erdfelder, E., Faul, F. and Buchner, A. (1996). "GPOWER: A general power analysis program." Behaviour Research Methods, Instruments and Computers 28(1): 1-11.

Erskine, W. D. (1996). "Downstream hydrogeomorphic impacts of Eildon Reservoir on the Mid-Goulburn River, Victoria." Proceedings of the Royal Society of Victoria 108(1): 1-15.

Evans, L. J. and Norris, R. (1997). "Prediction of benthic macroinvertebrate composition using microhabitat characteristics derived from stereo photography." Freshwater Biology 37: 621-633.

Ewing, S. A. (1985). Ingham and the Herbert River: a study of flood hazard. Master of Science Thesis, Faculty of Science of James Cook University of North Queensland, Townsville, 255.

Ewing, S. A. (1999). "Landcare and community-led watershed management in Victoria, Australia.” Journal of the American Water Resources Association 35(3): 663-673. 
Ewing, S. A., Grayson, R. B. and Argent, R. M. (1997). Research Integration in ICM. CEAH Report 1/97 (March 1997). Centre for Environmental Applied Hydrology, University of Melbourne. Melbourne.

Fairweather, P. G. (1991). "Statistical power and design requirements for environmental monitoring." Australian Journal of Marine and Freshwater Research 42: 555-567.

Fairweather, P. G. (1999). "State of the environment indicators of 'river health': exploring the metaphor." Freshwater Biology 41: 211-220.

Fairweather, P. G. and Napier, G. M. (1998). Environmental indicators for national state of the environment reporting - inland waters. Department of Environment. Canberra.

Faul, F. and Erdfelder, E. (1992). GPOWER: A priori, post-hoc and compromise power analysis for MS-DOS. Bonn University, Department of Psychology. Bonn, FRG.

Felton, R. and Martin, M. (1996). The Ovens Basin AEAM model. North East Catchment and Land Protection Board, Department of Natural Resources and Environment. Wangaratta.

Finlayson, B. L. and Brizga, S. O. (1995). "The oral tradition, environmental change and river basin management: case studies from Queensland and Victoria." Australian Geographical Studies 33(2): 180-192.

Flannery, T. F. (1995). The future eaters: an ecological history of the Australian lands and people. Reed Books. Chatswood.

Fleming, B. (1999). Watershed health: an evaluation index for New Mexico. Rio Grande ecosystems: linking land, water, and people. Toward a sustainable future for the Middle Rio Grande Basin. Proceedings, June 2-5, 1998, Albuquerque, NM. US Department of Agriculture, Forest Service, Rocky Mountain Research Station. RMRS-P-7 Ogen UT, 93-96.

Flora and Fauna Guarantee Act 1988 (Victoria, Australia) Government Printer for the State of Victoria, Melbourne.

Forsyth, M. (1997). "The economics of site investigation for groundwater protection: sequential decision making under uncertainty." Journal of Environmental Economics and Management 34(1): 1-31. 
Fortner, B. and Schechter, D. (1996). "U. S. water quality shows little improvement over 1992 inventory." Water Environment and Technology 8(2):15-16.

Fox, P. J. A., Naura, M. and Scarlett, P. (1998). "An account of the derivation and testing of a standard field method, River Habitat Survey." Aquatic Conservation, Marine and Freshwater Ecosystems 8(4): 455-475.

Gagliardi, J. (1984a). Ingham - a township torn in two. Townsville Bulletin (Monday May 21), 4.

Gagliardi, J. (1984b). Ingham: town 'divided' on flood issue. Townsville Bulletin (Friday, May 28), 8.

Gagliardi, J. (1984c). Ingham merchants speak up on river flood study. Townsville Bulletin (Tuesday July 17), 5.

Gehrke, P. C., Brown, P., Schiller, C. B., Moffatt, D. B. and Bruce, A. M. (1995). "River regulation and fish communities in the Murray-Darling river system, Australia.” Regulated Rivers: Research and Management 11: 363-375.

Gerrodette, T. (1987). “A power analysis for detecting trends.” Ecology 68(5): 13641372.

Gerrodette, T. (1991). "Models for power of detecting trends - a reply to Link and Hatfield.” Ecology 72(5): 1889-1892.

GHD (Gutteridge Haskins and Davey Pty Ltd) (1987). Farm dams in catchments study. Department of Water Resources. Melbourne.

Gilmour, A., Walkerden, G. and Scandol, J. (1999). “Adaptive management of the water cycle on the urban fringe: three Australian case studies." Conservation Ecology 3(1): 11. [online] URL:http://www.consecol.org/vol3/iss1/art11.

Gippel, C. J. (1995). "Environmental hydraulics of large woody debris in streams and rivers." Journal of Environmental Management 121(5): 388-395.

Gippel, C. J. (2000). Managing regulated rivers for environmental values: selected case studies from southeastern Australia. River management: the Australasian experience. (eds) S. O. Brizga and B. L. Finlayson. John Wiley and Sons, London (in press).

Gippel, C. J. and Finlayson, B. L. (1993). Downstream environmental impacts of regulation of the Goulburn River, Victoria Hydrology and Water Resources 
Symposium, Newcastle, June 30-July 2, 1993, Institution of Engineers, Australia, 3338.

Gippel, C. J. and Stewardson, M. J. (1998). "Use of wetted perimeter in defining minimum environmental flows.” Regulated Rivers: Research \& Management 14: 5367.

Gippel, C. J., Finlayson, B. L. and O'Neill, I. C. (1996). "Distribution and hydraulic significance of large woody debris in a lowland Australian river." Hydrobiologia 318: $179-194$.

Gippel, C. J., O'Neill, I. C. and Finlayson, B. L. (1992). The hydraulic basis of snag management. Centre for Environmental Applied Hydrology, University of Melbourne, Parkville, Australia. Melbourne.

Good, M. and McMurray, D. (1997). The management of farm dams and their environmental impacts in the Mount Lofty Ranges, South Australia. Proceedings of Dams in the Environment. Sydney Hilton, 27 June 1997. Australian National Committee on Large Dams and Institutional of Engineers, Australia joint seminar. ANCOLD. Sydney.

Gore, J. A., (ed.) (1985). The Restoration of rivers and streams: theories and experience. Butterworth Publishers. Boston.

Grayson, R. B. (1994). Advances and challenges in Integrated Catchment Management - from a technical perspective. River Basin Management Society Conference, July 1994, Albury. River Basin Management Society. Melbourne.

Grayson, R. B. and Doolan, J. M. (1995). Adaptive Environmental Assessment and Management (AEAM) and Integrated Catchment Management. Land and Water Resources Research and Development Corporation. Canberra.

Grayson, R. B., Argent, R. M., Nathan, R. J., McMahon, T. A. and Mein, R. G. (1996). Hydrological recipes. Cooperative Research Centre for Catchment Hydrology. Melbourne.

Grayson, R. B., Doolan, J. M. and Black, T. (1994a). “Application of AEAM (Adaptive Environmental Assessment and Management) to water quality in the Latrobe River Catchment." Journal of Environmental Management 41(3): 245-258. 
Grayson, R. B., Gippel, C., Finlayson, B. L., Hart, B. T., Hawken, R., McMahon, T. A. and Tilleard, J. W. (1994b). Mitigation of sediment and nutrient movement from sources in the Latrobe River catchment into the Gippsland Lakes. Report on Land and Water Research and Development Corporation Project UME8. Centre for Environmental Applied Hydrology, University of Melbourne. Melbourne.

Green, R. H. (1989). "Power analysis and practical strategies for environmental monitoring." Environmental Research 50: 195-205.

Green, W. (1975). How our river systems are being blighted. National Times August 11-16, 26-27.

Gregory, B. (1981). "The Allyn River: a case study of "river improvement"." Habitat 9(5): 22-24.

Gregory, B. and Pressey, B. (1982). “River improvement.” Wildlife in Australia 19: 5255.

Growns, I. O. and Growns, J. E. (1997). The relationships between biota and hydrology in the Hawkesbury-Nepean River System and their implications for environmental flow allocation decisions. Science and Technology in the Environmental Management of the Hawkesbury-Nepean Catchment, University of Western Sydney, Nepean Kingswood, NSW. Institution of Engineers, Australia. Canberra, 54-60.

Growns, J. E., Chessman, B. C., Jackson, J. E. and Ross, D. G. (1997). "Rapid assessment of Australian rivers using macroinvertebrates: cost and efficiency of 6 methods of sample processing." Journal of the North American Benthological Society 16(3): 682-693.

Gunderson, L. (1999). "Resilience, flexibility and adaptive management: antidotes for spurious certitude?" Conservation Ecology 3(1) 7. [online] URL: http://www.consecol.org/vol3/iss1/art7.

Gunderson, L. H., Holling, C. S. and Light, S. S., (eds). (1995). Barriers and bridges to the renewal of ecosystems and institutions. Columbia University Press. New York.

Haines, A. T., Finlayson, B. L. and McMahon, T. A. (1988). “A global classification of river regimes." Applied Geography 8: 255-272.

Hammer, T. R. (1972). "Stream channel enlargement due to urbanization." Water Resources Research 8: 1530-1540. 
Hammond, A., Adriaanse, A., Rodenburg, E., Bryand, D. and Woodward, R. (1995). Environmental indicators: a systematic approach to measuring and reporting on environmental policy performance in the context of sustainable development. World Resources Institute. Washington.

Haney, A. and Power, R. L. (1996). “Adaptive management for sound ecosystem management." Environmental Management 20(6): 879-886.

Hanks, T. C. (1997). "Imperfect science: uncertainty, diversity and experts." EOS 78(35): 373 .

Hannaford, M. J., Barbour, M. T. and Resh, V. H. (1997). “Training reduces observer variability in visual-based assessment of stream habitat." Journal of the North American Benthological Society 16(4): 843-860.

Harlow, L., Mulaik, S. and Steiger, J., (eds.) (1997). What if there were no significance tests? Lawrence Erlbaum Associates. Mahwah, New Jersey.

Harris, J. H. (1984a). "A survey of fishways in streams of coastal south-eastern Australia." Australian Zoologist 21(3): 219-233.

Harris, J. H. (1984b). "Impoundment of coastal drainage of south-eastern Australia, and a review of its relevance to fish migrations." Australian Zoologist 21(3): 235-250.

Hart, B. T., Campbell, I. C., Angehrn-Bettinazzi, C. and Jones, M., J. (1993). "Australian water quality guidelines: a new approach for protecting ecosystem health." Journal of Aquatic Ecosystem Health 2: 151-163.

Hawkins, C. P., Hogue, J. N., Decker, L. M. and Feminella, J. W. (1997). "Channel morphology, water temperature, and assemblage structure of stream insects.” Journal of the North American Benthological Society 16(4): 728-749.

Healthy Rivers Commission of New South Wales (1996). Independent inquiry into the Williams River. Sydney.

Heeps, D. P. (1994). Index of River Health consultancy. Department of Conservation and Natural Resources. Melbourne, 7.

Helsel, D. R. and Hirsch, R. M. (1992). Statistical methods in water resources. Elsevier. Amsterdam. 
Hilmer, F., Raynor, M., Taperell, G. and Smith, W. (1993). National competition policy. Commonwealth of Australia. Canberra.

Holling, C. S., (ed.) (1978). Adaptive environmental assessment and management. Wiley IIASA international series on applied systems analysis. Wiley. Chichester, New York.

Holling, C. S. (1995). What barriers? What bridges? Barriers and bridges to the renewal of ecosystems and institutions. L. H. Gunderson, C. S. Holling and S. S. Light. (eds) Columbia University Press, 3-34.

House, M. A. (1989). "A water quality index for river management." Journal of the Institution of Water and Environmental Management 3: 336-344.

Howitt, W. (1972). Land, labour and gold; or two years in Victoria, with visits to Sydney and Van Dieman's Land. Facsimile edition Sydney. First published London 1855. (as cited by Powell 1976).

Hughes, R. M., Whittier, T. R., Thiele, S. A., Pollard, J. E., Peck, D. V., Paulsen, S. G., McMullen, D., Lazorchak, J., Larsen, D. P., Kinney, W. L., Kaufmann, P. R., Hedtke, S., Dixit, S. S., Collins, G. B. and Baker, J. R. (1990). Lake and stream indicators for the United States Environmental Protection Agency's Environmental Monitoring and Assessment Program. Proceedings of the International Symposium on Ecological Indicators, October 16-18, Fort Lauderdale, FL. Elsevier, 305-335.

Humphries, P. and Lake, P. S. (1996). Environmental flows in lowland rivers: experimental flow manipulation in the Campaspe River, northern Victoria. 23rd Hydrology and Water Resources Symposium, 21-24 May, Hobart. Institution of Engineers, Australia. Canberra, 197-202.

Hunter, S. and Waterman, R. W. (1996). Enforcing the law: the case of the clean water acts. M. E. Sharpe.

Hurlbert, S. H. (1984). "Pseudoreplication and the design of ecological experiments." Ecological Monographs 54(2): 187-211.

I. N. Drummond and Associates Pty Ltd (1984). Fifteen Mile Creek Improvement Trust: master strategy plan. Fifteen Mile Creek Improvement Trust. Wangaratta.

Ian Drummond and Associates Pty Ltd (1985). Statewide assessment of physical stream conditions: phase 1. Department of Water Resources, Victoria. Melbourne. 
Ian Drummond and Associates Pty Ltd (1993). Stream management plan: Herbert River and district. Herbert River Improvement Trust, Ingham, Queensland.

Ian Drummond and Associates Pty Ltd (1995). A planning and reporting framework for Victorian river management authorities. Waterways Unit, Department of Conservation and Natural Resources. Melbourne.

ICAM (Integrated Catchment Assessment and Management) Centre and SKM (Sinclair Knight Merz) (1999) Impacts and implications of farm dams on catchment yield. Natural Resources Management Strategy, Project R7028. Murray-Darling Basin Commission, Canberra.

ID\&A Pty Ltd and CEAH (Centre of Environmental Applied Hydrology) (1997a) An Index of Stream Condition: trial applications. Report prepared for the Waterways Unit of the Department of Natural Resources and Environment. Melbourne.

ID\&A Pty Ltd and CEAH (Centre of Environmental Applied Hydrology) (1997b) An Index of Stream Condition: users' manual. Report prepared for the Waterways Unit of the Department of Natural Resources and Environment. Melbourne.

Industry Commission (1998). A full repairing lease: inquiry into ecologically

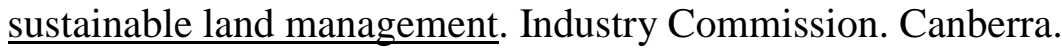

International Commission for the Protection of the Rhine (1999). Salmon 2000. http://www.iksr.org/icpr/.

ITFM (Intergovernmental Task Force on Monitoring Water Quality) (1995). The strategy for improving water quality monitoring in the United States. United States Geological Survey. Virginia.

Jackson, P. D. and Anderson, J. (1994). A rapid assessment technique for determining the physical and environmental condition of rives in Queensland. Classification of Rivers, and Environmental Health Indicators. Proceedings of a joint South African/Australian workshop, February 7-14, 1994, Cape Town. Water Research Commission, South Africa.

Jacobsen, D., Schultz, R. and Encalada, A. (1997). "Structure and diversity of stream invertebrate assemblages: the influence of temperature with altitude and latitude." Freshwater Biology 38: 247-261. 
James, D. (1998). Performance management: an old idea is given a new spin. Business Review Weekly. August 17, 86-87.

Jeffers, J. N. R. (1998). “The statistical basis of sampling strategies for rivers: an example using River Habitat Survey." Aquatic Conservation: Marine and Freshwater Research 8: 477-454.

Johnson, B. L. (1999a). "Introduction to the special feature: adaptive management scientifically sound, socially challenged?" Conservation Ecology 3(1): 10. [online] http://www.consecol.org/vol3/iss1/art10.

Johnson, B. L. (1999b). "The role of adaptive management as an operational approach for resource management agencies." Conservation Ecology 3(2): 8. [online] URL: http://www.consecol.org/vol3/iss2/art8.

Johnson, D. H. (1999c). "The insignificance of statistical significance testing.” Journal of Wildlife Management 63(3): 763-772.

Johnson, D. P. (1997). State of the Rivers: Mary River and major tributaries. An ecological and physical assessment of the condition of streams in the Mary River Catchment. Department of Natural Resources, Resource Sciences Centre. Brisbane.

Johnson, R. (1978). “River improvement?” Wildlife in Australia 15(1): 2-4.

Johnson, I. W. and Law, F. M. (1995). "Computer Models for Quantifying the HydroEcology of British Rivers." Journal of the Chartered Institution of Water and Environmental Management 9(3): 290-297.

Johnson, M. and Rix, S., (eds.) (1993). Water in Australia: managing economic, environmental and community reform. Pluto Press. Sydney.

Karr, J. R. (1999). “Defining and measuring river health.” Freshwater Biology 41: 221234.

Karr, J. R. and Dudley, D. R. (1981). "Ecological perspective on water quality goals." Environmental Management 5(1): 55-68.

Kay, J. J. (1993). On the nature of ecological integrity: some closing comments. Ecological integrity and the management of ecosystems. S. Woodley, J. Kay and G. Francis. St Lucie Press. 
Knighton, A. D. (1988). "The hydrological impact of the Parangana Dam on the Mersey River, Tasmania." Papers and Proceedings of the Royal Society of Tasmania 122(2): 85-96.

Kunsch, H. R. (1989). "The jackknife and the bootstrap for general stationary observations." Annals of Statistics 17: 1217-1241.

Ladson, A. R. and Doolan, J. D. (1997). Integrated measures of river health. Monitoring river health, proceedings of the River Basin Management Society winter conference, July 7, Latrobe University, River Basin Management Society. Melbourne.

Ladson, A. R. and Tilleard, J. W. (1999). “The Herbert River, Queensland, tropical Australia: is sedimentation an issue for management?" Australian Geographical Studies. 37(3):284-299.

Ladson, A. and White, L. (1999). Index of Stream Condition: reference manual. Department of Natural Resources and Environment. Melbourne.

Ladson, A. R. and White, L. J. (2000). Measuring Stream Condition. River management: the Australasian experience. S. O. Brizga and B. L. Finlayson. (eds) John Wiley and Sons (in press).

Ladson, A. R., Doolan, J., White, L., Metzeling, L. and Robinson, D. (1996). Index of stream condition as a tool to aid management of rivers. 23rd Hydrology and Water Resources Symposium, 21-24 May, Hobart, Institution of Engineers, Australia 325331.

Ladson, A. R., Gerrish, G., Carr, G. and Thexton, E. (1997a). Willows along waterways: towards a willow management strategy. Department of Natural Resources and Environment. Melbourne.

Ladson, A. R., Tilleard, J. W., Ewing, S. A., Stewardson, M. and Rutherfurd, I. D. (1999b). Successful stream rehabilitation: first set the goals. Second National Conference on Stream Management in Australia, 8-11 February 1999, Adelaide, Cooperative Research Centre for Catchment Hydrology. Melbourne, 381-387.

Ladson, A. R., White, L. and Doolan, J. (1995). Index of Stream Condition, a tool to aid management of rivers. 1995 Fall meeting, December 11-15, 1995, San Francisco, California, American Geophysical Union. 
Ladson, A. R., White, L. J. and Doolan, J. A. (1997b). Trialing the Index of Stream Condition in Victoria, Australia. 24th Hydrology and Water Resources Symposium, 25-27 November 1997, Auckland, New Zealand. Institution of Engineers, Australia. Canberra, 109-114.

Ladson, A. R., White, L. J., Doolan, J. A., Finlayson, B. L., Hart, B. T., Lake, P. S. and Tilleard, J. W. (1999a). "Development and testing of an Index of Stream Condition for waterway management in Australia." Freshwater Biology 41(2): 453-468.

Lake, P. S. (1980). Conservation. An ecological basis for water resource management. W. D. Williams (ed). Australian National University Press. Canberra, 165-173.

Lake, P. S. (1994). Understanding the ecology of Australia's running waters: an assessment of current endeavours and future priorities. Land and Water Resources Research and Development Corporation. Canberra.

Lammert, M. and Allan, J. D. (1999). "Assessing biotic integrity of streams: effects of scale in measuring the influence of land use/cover and habitat structure on fish and macroinvertebrates.” Environmental Management 23(2): 257-270.

Land Conservation Council (1989). Rivers and streams special investigation report. Government of Victoria. Melbourne.

Land, K. C. (1971). "On the definition of social indicators." The American Sociologist 6(November): $322-325$.

Larsen, D. P., Dudley, D. R. and Hughes, R. (1988). "A regional approach for assessing attainable surface water quality: an Ohio case study." Journal of Soil and Water Conservation 43(5, March-April): 171-176.

Laut, P. and Taplin, B. J. (1988). Catchment management in Australia in the 1980's [microform]. Background Paper No. 6 to the National Workshop on Integrated Catchment Management. Australia Water Resources Council Conference Series No. 16. Melbourne.

Lee, K. N. (1993). Compass and gyroscope: integrating science and politics for the environment. Island Press. Washington D.C.

Lee, K. N. (1999). “Appraising adaptive management.” Conservation Ecology 3(2): 3. [online] URL:http://www.consecol.org/vol3/iss2/art3. 
Lettenmaier, D. P. (1976). "Detection of trends in water quality data from records with dependent observations.” Water Resources Research 12(5): 1037-1046.

Lettenmaier, D. (1978). "Design considerations for ambient stream quality monitoring." Water Resources Bulletin 14(4): 884-902.

Lewis, M. W. (1992). Green Delusions. Duke University Press. London.

Link, W. A. and Hatfield, J. S. (1990). "Power calculations and model selection for trend analysis: a comment.” Ecology 71(3): 1217-1220.

Linstone, H. A. and Turoff, M. (1975). The Delphi Method: techniques and applications. Addison-Wesley.

Littlewood, I. G. (1992). Estimating contaminant loads in rivers: a review. Institute of Hydrology. Wallingford.

Lloyd, B. (1996). "State of the environment reporting in Australia: a review." Australian Journal of Environmental Management 3: 151-162.

Lucas, A., Nicol, S. and Koehn, J. (1999). River restoration: a comprehensive framework. Second Australian Stream Management Conference, 8-11 February 1999, Adelaide, South Australia. Cooperative Research Centre for Catchment Hydrology. Melbourne, 405-410.

McBride, G. B. (1999). "Equivalence tests can enhance environmental science and management." Australian and New Zealand Journal of Statistics 41(1): 19-29.

McBride, G. B., Loftis, J. C. and Adkins, N. C. (1993). "What do significance tests really tell us about the environment." Environmental Management 17(4): 423-432.

McCoy, C. G. (1988). The supply of water for irrigation in Victoria from 1881 to 1981. Rural Water Commission of Victoria. Melbourne.

McDonald, G. and Bellamy, J. (1997). ICM [Integrated Catchment Management] in the Herbert River Valley. Queensland Planners Conference 10-13 September 1997, Roma, Royal Australian Planning Institute. Brisbane.

McMahon, T. A., Finlayson, B. L., Haines, A. T. and Srikanthan, R. (1992). Global runoff - continental comparisons of annual flows and peak discharges. Catena Verlag. 
Macmillan, L. (1990). Conservation value and status of Victorian rivers. Part 2 East Gippsland Rivers. Faculty of Environmental Design and Construction Research, Royal Melbourne Institute of Technology. Melbourne.

Macmillan, L. and Kunert, C. (1990). Conservation value and status of Victorian Rivers. Part 1 Methodology. Faculty of Environmental Design and Construction Research, Royal Melbourne Institute of Technology. Melbourne.

Mac Nally, R. (1997). "Monitoring forest bird communities for impact assessment: the influence of sampling intensity and spatial scale." Biological Conservation 82: 355 367.

Maheshwari, B. L., Walker, K. F. and McMahon, T. A. (1995). "Effects of regulation on the flow regime of the river Murray, Australia." Regulated Rivers: Research and Management 10: 15-38.

Mallen-Cooper, M. (1993). Habitat changes and declines of freshwater fish in Australia: what is the evidence and do we need more? Australian Society for Fish Biology Workshop on sustaining fisheries through sustaining habitat. 12-13 August, 1992, Victor Harbour, SA. Bureau of Resource Sciences, Department of Primary Industries and Energy. Canberra, 118-123.

Mallen-Cooper, M. and Copeland, C. (1997). Science and the management of freshwater fish: a case study of fishways and fish migration in the Murray-Darling Basin. Saving our natural heritage: the role of science in managing Australia's ecosystems. C. Copeland and D. Lewis (eds) Halstead Press. Sydney, 262-271.

Manly, B. (1997). Randomization, bootstrap and Monte Carlo methods in biology, Chapman and Hall.

Mannen, E. (1992). When does the bootstrap work? : asymptotic results and simulations. Springer-Verlag. New York.

Mapstone, B. D. (1995). "Scalable decision rules for environmental impact studies: effect size, Type I and Type II errors.” Ecological applications 5(2): 401-410.

Marchant, R., Hirst, A., Norris, R. H., Butcher, R., Metzling, L. and Tiller, D. (1997). "Classification and prediction of macroinvertebrate assemblages from running waters in Victoria." Journal of the North American Benthological Society 16(3): 664-681. 
Marchant, R., Hirst, A., Norris, R. and Metzeling, L. (1999). "Classification of macroinvertebrate communities across drainage basins in Victoria, Australia: consequences of sampling on a broad spatial scale for predictive modelling." Freshwater Biology 41: 253-268.

Marsh, G. P. (1864). Man and nature, or, physical geography as modified by human action. Sampson Low, Son and Marston. London.

Meijers, E. M. J. (1986). "Defining confusions - confusing definitions.” Environmental Monitoring and Assessment 7: 157-159.

Mein, R. G. and Goyen, A. G. (1988). "Urban runoff.” Civil Engineering Transactions 30: $225-238$.

Melbourne Parks and Waterways (1994). Stream Watch annual report 1994. Melbourne Parks and Waterways and Melbourne Water, Melbourne.

Melbourne Water Corporation (1995). Stream condition and resource inventory program. Melbourne Water. Melbourne.

Millard, S. (1987). "Environmental monitoring, statistics and the law: room for improvement." The American Statistician 41(4): 249-259.

Mitchell, P. (1990). The environmental condition of Victorian streams. Department of Water Resources, Victoria. Melbourne.

Moller, G. (1996). State of the rivers: Herbert River and major tributaries. Department of Natural Resources, Resource Sciences Centre. Brisbane.

Montgomery, R. H. and Loftis, J. C. (1987). "Applicability of the t test for detecting trends in water quality variables." Water Resources Bulletin 23(4): 653-662.

Moore, C. A. (1990). Classification systems and indices for reporting and determining the effect of management on water quality in South African waterbodies. Department of Water Affairs. Pretoria.

Murray-Darling Basin Commission (undated) Inland Shipping: the navigation of the Murray-Darling River system. Murray-Darling Basin Commission, Canberra.

Murray-Darling Basin Ministerial Council (1995). An audit of water use in the MurrayDarling Basin. Murray-Darling Basin Ministerial Council. Canberra. 
Nasello, C. and Nicosia, S. (1996). Chemical and biotic indices in river environment quality assessment - the case of the Belice River (Western Sicily). Ecohydraulics 2000, 2nd International Symposium on habitat hydraulic, June, Quebec. A: A777A784.

National Competition Council (1999) Competition policy reform: much achieved, more to be done. National Competition Council Media Release 26 July 1999 <http://www.ncc.gov.au/nationalcompet/Speeches\%20and\%20press\%20releases/Pre ss\%20Releases.htm> (1 Sept. 1999).

National Research Council (1992). Restoration of aquatic ecosystems: science, technology and public polity. National Academy of Sciences.

Neame, A. (undated) The diary of Arthur Neame. Ingham Library Local Historical Anthology: 900008:B (Unpublished, undated). Ingham, Queensland.

Neimanis, V. and Kerr, A. (1996). Developing national environmental indicators. Geoindicators: assessing rapid environmental changes in earth systems. A. R. Berger and W. J. Iams. (eds) A. A. Balkema. Rotterdam, 369-376.

Neller, R. (1998) 'State of the Rivers': Students and Community take the plunge!. Community Relations, Media Release, 7/10/1998. Faculty of Science, University of the Sunshine Coast, Queensland.

Newbury, R. (1995). Rivers and the art of stream restoration. Natural and anthropogenic influences in fluvial geomorphology. J. E. Costa, A. J. Miller, K. W. P. Potter and P. R. Wilcock. (eds) Geophysical Monograph Series, American Geophysical Union. Washington, D. C., 137-150.

Newbury, R. W. and Gaboury, M. N. (1993). Stream analysis and fish habitat design: a field manual. Newbury Hydraulics Ltd. British Colombia.

Norris, R., H. and Cullen, P. (1987). Water quality monitoring: how do we get it right? CRES Working Paper 1987/8. Centre for Resource and Environmental Studies, Australian National University. Canberra.

Norris, R. H. and Thoms, M. C. (1999). "What is river health?” Freshwater Biology 41: 197-209. 
Norris, R. H., McElraby, E. P. and Resh, V. H. (1992). The sampling problem. The Rivers Handbook. P. Calow and G. Petts (eds), Blackwell Science. Volume 1: 282308.

Norris, R. H., Simpson, J. and Beggs, K. (1998). "Assessing water quality in Kosciuszko National Park using AusRivAS." Journal Australian Water and Wastewater Association 25(3): 28-29.

North East Waterways (1994). North East Waterways Annual Report 1995/96. Ovens River Management Board. Wangaratta.

O'Connor, N. A. (1992). "Quantification of submerged wood in a lowland Australian stream system.” Freshwater Biology 27: 387-395.

OECD (Organisation for Economic Co-operation and Development) (1994). Environmental Indicators: OECD core set. OECD. Paris.

Office of the Commissioner for the Environment (1988). State of the Environment Report 1988: Victoria's inland waters. Government of Victoria. Melbourne.

Osenbert, C. W., Shmitt, R. J., Holbrook, S. J., Abu-Saba, K. E. and Flegal, A. R. (1994). "Detection of environmental impacts: natural variability, effect size, and power analysis." Ecological Applications 4: 16-30.

Ott, W., R. (1978). Environmental indices: theory and practice. Ann Arbor Science. Ann Arbor.

Ovens River Management Board (1994). ORMB Annual Report 1993/94. Ovens River Management Board. Wangaratta.

Parsons, M. and Norris, R. H. (1996). "The effect of habitat-specific sampling on biological assessment of water quality using a predictive model." Freshwater Biology 36: $419-434$.

Peel, L. J. (1974). Rural industry in the Port Phillip region 1835-1880. Melbourne University Press. Melbourne.

Peel, M. C. (1999). Annual runoff variability in a global context. PhD thesis, Department of Geography. University of Melbourne. Melbourne.

Pen, L. (1994). The condition of the Kalgan River foreshores 1992/93. Waterways Commission. Perth. 
Peterman, R. M. (1990). "Statistical power analysis can improve fisheries research and management." Canadian Journal of Fisheries and Aquatic Science 47: 2-15.

Petersen, R. C. (1992). “The RCE: a riparian channel and environmental inventory for small streams in the agricultural landscape." Freshwater Biology 27: 295-306.

Petts, G., Maddock, I., Bicketon, M. and Ferguson, A. (1995). Linking hydrology and ecology: the scientific basis for river management. The ecological basis for river management. D. M. Harper and A. J. D. Ferguson. John Wiley \& Sons Ltd, 1-16.

Phan, V. H. (1994). Impacts of dams on downstream hydrology and water quality of rivers in Victoria, Australia. Master of Engineering Science thesis. Faculty of Engineering. University of Melbourne. Melbourne.

Phillips, N. and Moller, G. (1995). State of the Rivers, Upper Condamine River and major tributaries: an ecological and physical assessment of the condition of streams in the Upper Condamine River Catchment. Department of Primary Industries, Water Resources. Brisbane.

Pickett, S. T. A. and McDonnell, M. J. (1993). Humans as components of ecosystems: a synthesis. Humans as components of ecosystems. M. J. McDonnell and S. T. A. Pickett. (eds.) Springer Verlag, 310-316.

Pidgeon, R. W. J. (1978). Energy flow in a small stream community: an evaluation of the effects of different riparian vegetation. Ph.D. thesis, Department of Zoology, University of New England. Armidale.

Pidgeon, R. W. J. and Cairns, S. C. (1981). "Decomposition and colonisation by invertebrates of native and exotic leaf material in a small stream in New England (Australia)." Hydrobiologia 77: 113-127.

Plafkin, J. L., Barbour, M. T., Porter, K. D., Gross, S. K. and Hughes, R. M. (1989). Rapid bioassessment protocols for use in streams and rivers: benthic macroinvertebrates and fish. US Environmental Protection Agency. Washington D. C.

Platts, W. S., Armou, C., Booth, G. D., Bryant, M., Bufford, J. L., Guplin, P., Jensen, S., Lienkaemper, G. W., Minshall, G. W., Monsen, S. B., Nelson, R. L., Sedell, J. R. and Tufig, J. S. (1987). Methods for evaluating riparian habitats with applications to management. United States Department of Agriculture. Washington D.C. 
Poff, N. L., Allan, J. D., Bain, M. B., Karr, J. R., Prestegaard, K. L., Richter, B. D., Sparks, R. E. and Stromberg, J. C. (1997). "The natural flow regime.” Bioscience 47(11): 769-783.

Pollard, D. and Scott, T., D. (1966). River and reef. The great extermination: a guide to Anglo-Australian stupidity, wickedness \& waste. A. J. Marshall. (ed) William Heinemann, 95-115.

Potter, K. W. (1991). "Hydrological impacts of changing land management practices in a moderate sized agricultural catchment." Water Resources Research 27(5): 845-855.

Powell, J. M. (1976). Environmental management in Australia 1788-1914. Oxford University Press. Melbourne.

Power, M., Power, G. and Dixon, D. G. (1995). "Detection and decision-making in environmental effects monitoring." Environmental Management 19(5): 629-639.

Public Bodies Review Committee (1984). Twelfth Report to Parliament: future

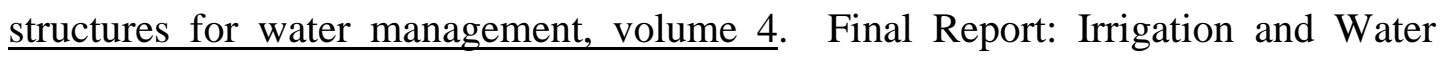
Resource Management. Parliament of Victoria. Melbourne.

Puckridge, J. T., Sheldon, F., Walker, K. F. and Boulton, A. J. (1998). "Flow variability and the ecology of large rivers." Marine and Freshwater Research 49: 55-72.

Queensland, Department of Lands, 1874: Plan K124395.

Queensland, Parliament (1876). Votes and proceedings of the Queensland Legislative Assembly [microform]. $7^{\text {th }}$ Parliament, $3^{\text {rd }}$ Session, vol. 1, 987. James C. Beal, Government Printer, W. \& F. Pascoe, Milsons Point, NSW.

Queensland, Parliament (1879). Votes and proceedings of the Queensland Legislative Assembly [microform]. $8^{\text {th }}$ Parliament, $2^{\text {nd }}$ Session, vol. 2, 905. James C. Beal, Government Printer, W. \& F. Pascoe, Milsons Point, NSW.

Queensland, Parliament (1880). Votes and proceedings of the Queensland Legislative Assembly [microform]. $8^{\text {th }}$ Parliament, $3^{\text {rd }}$ Session vol. 2, 1139. James C. Beal, Government Printer, W. \& F. Pascoe, Milsons Point, NSW.

Queensland, Parliament (1884). Votes and proceedings of the Queensland Legislative Assembly [microform]. $9^{\text {th }}$ Parliament, $2^{\text {nd }}$ Session vol. 3, 823. James C. Beal, Government Printer, W. \& F. Pascoe, Milsons Point, NSW. 
Queensland, Parliament (1885). Votes and proceedings of the Queensland Legislative Assembly [microform]. $9^{\text {th }}$ Parliament, $3^{\text {rd }}$ Session vol. 3, 373. James C. Beal, Government Printer, W. \& F. Pascoe, Milsons Point, NSW.

Queensland, Parliament (1887). Report on Harbours and Lighthouses. Department of Ports and Harbours, Brisbane, July 30, 1887. Votes and proceedings of the Queensland Legislative Assembly [microform] vol. 4, 11. W. \& F. Pascoe, Milsons Point, NSW.

Queensland, Parliament (1888). Votes and proceedings of the Queensland Legislative Assembly [microform]. 10 ${ }^{\text {th }}$ Parliament, $1^{\text {st }}$ Session vol. 3, 683. James C. Beal, Government Printer, W. \& F. Pascoe, Milsons Point, NSW.

Queensland, Parliament (1889). Report on Harbours and Lighthouses. Department of Ports and Harbours, Brisbane, September 10, 1889. Votes and proceedings of the Queensland Legislative Assembly [microform] vol. 4, 833. W. \& F. Pascoe, Milsons Point, NSW.

Queensland, Parliament (1891). Votes and proceedings of the Queensland Legislative Assembly [microform]. 10 ${ }^{\text {th }}$ Parliament, $4^{\text {th }}$ Session vol. 4, 529. James C. Beal, Government Printer, W. \& F. Pascoe, Milsons Point, NSW.

Queensland, Parliament (1991a). Official record of the debates of the Legislative Assembly. $46^{\text {th }}$ Parliament, $1^{\text {st }}$ Session, 16 April p7250. V. R. Ward, Government Printer, Brisbane.

Queensland, Parliament (1991b). Official record of the debates of the Legislative Assembly. $46^{\text {th }}$ Parliament, $1^{\text {st }}$ Session, 16 April p7256. V. R. Ward, Government Printer, Brisbane.

Queensland, Parliament (1991c). Official record of the debates of the Legislative Assembly [microform]. $46^{\text {th }}$ Parliament, $1^{\text {st }}$ Session, 26 February p6420-6435. V. R. Ward, Government Printer, Brisbane.

Ramm, A. E. L. (1988). "The community degradation index: a new method for assessing the deterioration of aquatic habitats." Water Research 22: 293-301.

Ramm, A. E. L., Cooper, J. A. G., Harrison, T. D. and Singh, R. A. (1994). The Estuarine Health Index: a new approach to scientific information transfer. Classification of Rivers and Environmental Health Indicators, Proceedings of a joint 
South Africa/Australia workshop, February 7-14, Report No. TT 63/94. Water Research Commission. Cape Town, 271-280.

Rankin, E. T. (1995). Habitat indices in water resource assessments. Biological assessment and criteria: tools for water resource planning and decision making. W. S. Davis and S. P. Thomas. (eds) Lewis Publishers. Boca Raton, 415.

Raven, P. J., Holmes, N. T. H., Dawson, F. H., Fox, P. J. A., Everard, M., Fozzard, I. R. and Rouen, K. J. (1998). River Habitat Quality: the physical characteristics of rivers and streams in the UK and the Isle of Man. The Environment Agency, Scottish Environment Protection Agency, and Environment and Heritage Service, Northern Island. Bristol.

Raven, P. J., Fox, P., Everard, M., Holmes, N. T. H. and Dawson, F. H. (1997). River Habitat Survey: a new system for classifying rivers according to their habitat quality. Freshwater Quality: Defining the Indefinable. P. J. Boon and D. L. Howell. (eds) HMSO. Edinburgh, 215-234.

Reckhow, K. H. (1990). "Bayesian inference in non-replicated ecological studies." Ecology 71(6): 2053-2059.

Reid, M. and Brooks, J. (1998). Measuring the effectiveness of environmental water allocations: recommendations for the implementation of monitoring programs for adaptive hydrological management of floodplain wetlands in the Murray-Darling Basin. Cooperative Research Centre for Freshwater Ecology. Monash University. Melbourne.

Rempel, L. L., Richardson, J. S. and Healey, M. (1999). "Flow refugia for benthic macroinvertebrates during flooding of a large river." Journal of the North American Benthological Society 18(1): 34-48.

Reynoldson, T. B., Norris, R. H., Resh, V. H., Day, K. E. and Rosenberg, D. M. (1997). "The reference condition: a comparison of multimetric and multivariate approaches to assess water quality impairment using benthic macroinvertebrates." Journal of the North American Benthological Society 16(4): 833-852.

Richards, C., Host, G. E. and Arthur, J. W. (1993). "Identification of predominant environmental factors structuring stream macroinvertebrate communities within a large agricultural catchment.” Freshwater Biology 29: 285-294. 
Richards, K. (1985). Rivers: form and process in alluvial channels. Methuen. New York.

Richter, B. D., Baumgartner, J. V., Wigington, R. and Braun, D. P. (1997). "How much water does a river need?" Freshwater Biology 37: 231-249.

Risser, P. G. (1985). “Toward a holistic management perspective.” Bioscience 35: 414418.

River Basin Management Society (1997). Monitoring river health. RBMS Winter Conference, 7 July, Latrobe University, Melbourne, River Basin Management Society. Melbourne.

River Improvement Act 1958 (Victoria, Australia).

Robinson, D. P. (1995). Water quality and nutrient status of Lake Wellington. Publication No. 460, Environment Protection Authority. Melbourne.

Robinson, N., A., (ed.) (1992). Agenda 21 and the UNCED proceedings. Oceana Publications. New York.

Rosenberg, D. M. and Resh, V. H. (1993). Freshwater biomonitoring and benthic macroinvertebrates. Chapman and Hall.

Roth, N. E., Allan, J. D. and Erickson, D. E. (1996). "Landscape influences on stream biotic integrity assessed at multiple spatial scales." Landscape Ecology 11(3): 141156.

Roughley, T. C. (1950). Is the Murray Cod doomed? Sydney Morning Herald. No. 35224 (Saturday, November 11, 1950), Sydney, 8.

Rutherfurd, I. D. (2000). Some human impacts on Australian stream channel morphology. River management: the Australasian experience. S. O. Brizga and B. L. Finlayson (eds). John Wiley and Sons, 11-49.

Rutherfurd, I. D. and Bartley, R. (1999). Proceedings of the second Australian stream management conference: the challenge of rehabilitating Australia's streams. 8-11 February, Adelaide, South Australia. Cooperative Research Centre for Catchment Hydrology, Melbourne. 
Rutherfurd, I. D. and Walker, M. (1996). Proceedings of first national conference on stream management. 19-13 February, Merrijig, Victoria. Cooperative Research Centre for Catchment Hydrology, Melbourne.

Rutherfurd, I. D., Jerie, K. and Marsh, N. (1999). A rehabilitation manual for Australian

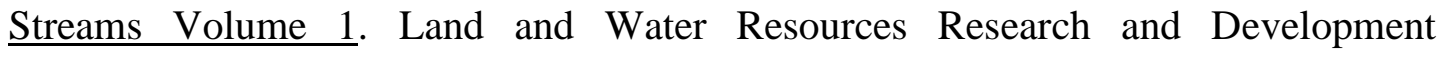
Corporation, Cooperative Research Centre for Catchment Hydrology. Canberra.

Rutherfurd, I. D., Ladson, A. R., Tilleard, J. W., Stewardson, M. J., Ewing, S. A., Brierley, G. and Fryirs, K. (1998). Research and development needs for river restoration in Australia. Land and Water Resources Research and Development Corporation. Canberra.

Salinity Committee (1984). Fourth report to Parliament, final report on water allocations in northern Victoria. Parliament of Victoria. Melbourne.

Schofield, N. J. and Davies, P. E. (1996). "Measuring the health of our rivers." Journal Australian Water and Wastewater Association 23(2): 39-43.

Schumm, S. A. (1977). The fluvial system. Wiley Interscience. New York.

SEAC (State of the Environment Advisory Council) (1996). Australia: state of the environment 1996. CSIRO Publishing. Melbourne.

Sedlmeier, P. and Gigerenzer, G. (1989). "Do studies of statistical power have an effect on the power of studies." Psychological Bulletin 105(2): 309-316.

SERU (State of the Environment Reporting Unit) (1996). Key environmental indicators of inland waters in State of the Environment Reporting and monitoring. Proceedings of a workshop 15-16 April 1996, University of Canberra. Department of the Environment, Sport and Territories, Cooperative Research Centre for Freshwater Ecology. Canberra.

Shattock, W. H. (1966). "A review of the river improvement works in the non-tidal streams in NSW." Journal of the Institution of Engineers, Australia 38: 275-282.

Shaver, J. P. (1993). "What statistical significance testing is, and what it is not." Journal of Experimental Education 61(4): 293-316.

Silvert, W. (1997). "Ecological impact classification with fuzzy sets." Ecological Modelling 96: 1-10. 
Silvert, W. (1999). "Fuzzy indices of environmental conditions.” Ecological Modelling (in press).

Simpson, J., Norris, R., Barmuta, L. and Blackman, P. (1999). AusRivAS - National River Health Program: User Manual. Cooperative Research Centre for Freshwater Ecology, University of Canberra, Canberra. HTML document available at <http://enterprise.canberra.edu.au/Databases/AusRivAS.nsf/ffba6e4d52ded155ca256 4c700097bc5?OpenView>, 7 May 1999.

Singh, K. (1981). "On the asymptotic accuracy of Efron's bootstrap." The Annals of Statistics 9(6): 1187-1195.

Smith, D. G. (1990). "A better water quality indexing system for rivers and streams." Water Research 24(10): 1237-1244.

Smith, D. G. (1991). "Effect of vegetation on lateral migration of anastomosed channels of a glacier meltwater river." Geological Society of American Bulletin 87: 857-860.

Smith, D. I. (1997). "Review of 'State of the Environment 1996 - Chapter 7, inland waters'.” Australian Journal of Environmental Management 4(2): 171-175.

Smith, D. I. (1998). Water in Australia: resources and management. Oxford University Press. Melbourne.

Smith, D. G. and McBride, G. B. (1990). "New Zealand's national water quality monitoring network - design and the first year's operation." Water Resources Bulletin 26(5): 767-775.

Smith, M. J., Kay, W. R., Edward, D. H. D., Papas, P. J., Richardson, K. S., Simpson, J. C., Pinder, A. M., Cale, D. J., Horwitz, P. H. J., Davis, J. A., Yung, F. H., Norris, R. H. and Halse, S. A. (1999). "AusRivAS: using macroinvertebrates to assess ecological condition of rivers in Western Australia." Freshwater Biology 41: 269282.

Southern Rural Water (1998). Gellibrand River streamflow management plan - draft. Southern Rural Water, Mafra.

Spellerberg, I. F. (1991). Monitoring ecological change. Cambridge University Press. Cambridge. 
Spence, J. D. (1988). Emperor of China: self portrait of K'ang-Hsi. Vintage Books. New York.

SRWSC (State Rivers and Water Supply Commission) (1979) Guidelines for river management: a report on the principles to be used and guidelines for the planning and implementation of river management works. State Rivers and Water Supply Commission, Melbourne.

Standing Committee on Rivers and Catchments (1990). Environmental guidelines for river management works. Department of Conservation and Environment. Melbourne.

Standing Committee on Rivers and Catchments (1991). Guidelines for stabilising waterways. Standing Committee on Rivers and Catchments. Rural Water Commission, Melbourne.

Standing Consultative Committee on River Improvement (1983). The state of the rivers. State Rivers and Water Supply Commission. Melbourne.

State of the Rivers Task Force (1987). Better Rivers and Catchments. Department of Conservation Forests and Lands. Melbourne.

Stewardson, M. J. (1999). Characterising and modelling the hydraulic environment of streams. $\mathrm{PhD}$ thesis, Department of Civil and Environmental Engineering. University of Melbourne. Melbourne.

Strom, H. G. (1941). River control in New Zealand and Victoria. State Rivers and Water Supply Commission. Melbourne.

Strom, H. G. (1951). "River improvement in Victoria." Journal of the Institution of Engineers, Australia 23: 129-139.

Strom, H. G. (1962). River improvement and drainage in Australia and New Zealand. State Rivers and Water Supply Commission. Melbourne.

Suren, A. (1997). Measuring the effect of physical habitat quality on ecological health in urban streams. 24th Hydrology and Water Resources Symposium, 25-27 November, Auckland, New Zealand. Institution of Engineers, Australia. Canberra, 268-273.

Suter, G. W. (1993). "A critique of ecosystem health concepts and indexes." Environmental Toxicology and Chemistry 12: 1533-1539. 
Telfer, D., Carter, D., Johnson, D. and Moller, G. (1998). State of the Rivers, Bremer $\underline{\text { River and major tributaries: an ecological and physical assessment of the condition }}$ of streams in the Bremer River Catchment. Department of Natural Resources, Resource Sciences Centre. Brisbane.

Templet, P. H. and Sorensen, J. (1995). Eco-hydrological consequences of environmental degradation. Environmental Hydrology. V. P. Singh. Kluwer Academic Publishers, 427-461.

Thomas, L. and Krebs, C. J. (1997). "A review of statistical power analysis software.” Bulletin of the Ecological Society of American 78(2): 128-139.

Thompson, B. (1993). “The use of statistical significance tests in research: bootstrap and other alternatives." Journal of Experimental Education 61(4): 361-377.

Thompson, G. T. (1938). "River Surveys.” The Australian Surveyor 7(1): 28-34.

Thoms, M. C. (1998). The condition of the Namoi River. Cooperative Research Centre for Freshwater Ecology. Canberra.

Tilleard, J. W. and Department of Water Resources (1986). A statewide assessment of physical stream conditions in Victoria. Hydrology and Water Resources Symposium, 25-27 November, Griffith University, Brisbane. The Institution of Engineers, Australia. Canberra, 380-381.

Tiller, D. and Newall, P. (1995). Preliminary nutrient guidelines for Victorian inland streams. Environment Protection Authority. Melbourne.

Tukey, J. W. (1960). “Conclusions vs decisions.” Technometrics 2(4): 423-433.

Tukey, J. W. (1991). “The philosophy of multiple comparisons.” Statistical Science 6(1): 100-116.

Turak, E., Flack, L. K., Norris, R. H., Simpson, J. and Waddell, N. (1999). “Assessment of river condition at a large spatial scale using predictive models." Freshwater Biology 41: 283-298.

Turnbull, C. K. (1973). River improvement in Victoria (Part I). Aqua, Winter. 13-14.

Turnbull, C. K. (1974). River improvement in Victoria (Part II). Aqua, Spring 1973Summer 1974. 14-17. 
Umwelt (Australia) Pty Ltd (1995). Williams River Planning Study. Unpublished report prepared for the Department of Urban Affairs and Planning as part of the Independent inquiry into the Williams River. Sydney.

Underwood, A. J. (1990). Biological monitoring for human impact: how little it can achieve. Proceedings of the 29th Congress of the Australian Society of Limnology, Jabiru, N. T. Officer of the Supervising Scientist Alligator Rivers Region, Australian Government Publishing Service, Canberra, 105-123.

Underwood, A. J. (1991). Stupidity, myths and guess-work in the detection of marine environmental impacts: dead bird watching for hydrographers. Second Australasian Hydrographic Symposium, 9-12 December, University of NSW, Sydney. The Hydrographic Society, 43-53

Underwood, A. J. (1994). Spatial and temporal problems with monitoring. The rivers handbook: hydrological and ecological principles. P. Calow and G. E. Petts (eds). Blackwell, 182-204.

US Environmental Protection Agency (1996). The Quality of our nation's water, 1994: national summary of water quality conditions. <ww.epa.gov\305blexecsum.html> (January 19, 1996) Washington, D. C.

USGS (United States Geological Survey) (1999a). Intergovernmental Task Force on Monitoring Water Quality (1992-1996) <http://water.usgs.gov/wicp/itfm.html> last updated 16JAN97, maintained by Lorna Schmid Kendrix (20 August 1999).

USGS (United States Geological Survey) (1999b). National Water Quality Monitoring Council (1997-present) <http://water.usgs.gov/public/wicp/nwqmc.html> last updated 11AUG99, maintained by C.I. Lewis, (20 August 1999).

Uys, M. C., (ed.) (1994). Classification of Rivers, and Environmental Health Indicators. Proceedings of a joint South African/Australian workshop. Water Research Commission, South Africa. Cape Town.

Verhallen, E., de Kruijf, C. A. K. and de Kruijf, H. A. M. (1996). How to develop environmental indicators. Ecological Summit 96, The Royal Danish School of Pharmacy Copenhagen 64.16. Elsevier Science.

Victoria, Parliament (1867). Report of the Royal Commission appointed to examine into and report upon the best means of clearing the River Murray. Papers and 
Proceedings of the Victorian Legislative Assembly, $1^{\text {st }}$ session 1867. Paper No. 3, vol. 4, 711-828. John Ferres, Government Printer, Melbourne.

Victoria, Parliament (1887). Report of the board appointed by His Excellency the Governor in Council to inquire into the sludge question. Papers and Proceedings of the Victorian Legislative Assembly, session 1887. Paper No.10, vol. 2, 443. John Ferres, Government Printer, Melbourne.

Victoria, Parliament (1902). Report of the Inter-State Royal Commission on the River Murray. Papers and Proceedings of the Victorian Legislative Assembly, $2^{\text {nd }}$ session 1902-3. Paper No. 35, vol. 3, 129. Robert S. Brain, Government Printer, Melbourne.

Victoria, Parliament (1906). Annual report of the secretary for mines and water supply for the year 1905. Papers and Proceedings of the Victorian Legislative Assembly, session 1906. Paper No. 22, 1467. J. Kemp, Acting Government Printer, Melbourne.

Victoria, Parliament (1908). Annual report of the secretary for mines for the year 1907. Papers and Proceedings of the Victorian Legislative Assembly, session 1908. Paper No. 14, vol. 2, 51. J. Kemp Government Printer, Melbourne.

Victoria, Parliament (1909) Annual report of the secretary for mines for the year 1908. Papers and Proceedings of the Victorian Legislative Assembly, $2^{\text {nd }}$ Session 1909. Paper No. 11, vol. 2, 661. J. Kemp, Government Printer, Melbourne.

Victoria, Parliament (1913). Annual report of the secretary for mines for the year 1912. Papers and Proceedings of the Victorian Legislative Assembly, session 1913-14. Paper No. 20, vol. 2, 1889. Albert J. Mullett, Government Printer, Melbourne.

Victoria, Parliament (1915). Annual report of the secretary for mines for the year 1914. Papers and Proceedings of the Victorian Legislative Assembly, session 1915. Paper No. 31, vol. 3, 17. Albert J. Mullett, Government Printer, Melbourne.

Victoria, Parliament (1919). Annual report of the secretary of mines for the year 1918. Papers and Proceedings of the Victorian Legislative Assembly, session 1919. Paper No. 24, $2^{\text {nd }}, 489$. Albert J. Mullett, Government Printer, Melbourne.

Victoria, Parliament (1931). State Rivers and Water Supply Commission Annual Report 1930-31. Papers and Proceedings of the Victorian Legislative Assembly, session 1931. Paper No. 9, 1303. R. J. Green Government Printer, Melbourne. 
Victorian Catchment Management Council (1997). Know your catchments. Department of Natural Resources and Environment, Environment Protection Authority.

Victorian Government Gazette (1988). State Environment Protection Policy - Waters of Victoria. Victorian Government Gazette - Special. Melbourne (26 February) 1-32.

Vinson, M. R. and Hawkins, C. P. (1996). "Effects of sampling area and subsampling procedure on comparisons of taxa richness among streams." Journal of the North American Benthological Society 15(3): 392-399.

Wagner, F. H. and Kay, C. E. (1993). "Natural or Healthy" ecosystems: are U.S. National Parks providing them. Humans as components of ecosystems. M. J. McDonnell and S. T. A. Pickett (eds). Springer Verlag.

Walker, J. and Reuter, D. J. (1996). Key indicators to assess farm and catchment health. Indicators of Catchment Health: a technical perspective. J. Walker and D. J. Reuter. (eds) CSIRO. Melbourne: 21-33.

Walker, J., Alexander, D., Irons, C., Jones, B., Penridge, H. and Rapport, D. (1996). Catchment health indicators: an overview. Indicators of catchment health: a technical perspective. J. Walker and D. J. Reuter. (eds) CSIRO. Melbourne, 3-18.

Wallace, J. R. (1971). The effects of landuse change on the hydrology of an urban watershed. School of Civil Engineering, Environmental Resources Center, University of Florida.

Walling, D. E. and Webb, B. W. (1985). "Estimating the discharge of contaminants to coastal waters by rivers: some cautionary comments.” Marine Pollution Bulletin 16: 488-492.

Walpole, R. E. and Myers, R. H. (1978). Probability and statistics for engineers and scientists. MacMillan Publishing Co. Inc. New York.

Walsh, C. J. and Breen, P. F. (1999). Urban stream rehabilitation through a decisionmaking framework to identify degrading processes and prioritize management actions. Second Australian Stream Management Conference, 8-11, February, Adelaide, South Australia. Cooperative Research Centre for Catchment Hydrology. Melbourne, 673-678.

Walters, C. J. (1986). Adaptive management of renewable resources. Macmillan. New York. 
Walters, C. (1997). "Challenges in adaptive management of riparian and coastal ecosystems." Conservation Ecology [online] 1(2): 1. URL: http://www.consecol.org/vol1/iss2/art3.

Walters, C. and Holling, C. S. (1990). "Large scale management experiments and learning by doing." Ecology 71(6): 2060-2068.

Walters, C., Gunderson, L. and Holling, C. S. (1992). "Experimental policies for water management in the Everglades." Ecological Applications 2(2): 189-202.

Wang, L., Simonsom, T. D. and Lyons, J. (1996). “Accuracy and precision of selected stream habitat estimates." North American Journal of Fisheries Management 16: 340-347.

Ward, R. C., Loftis, J. C. and McBride, G. B. (1986). "The "data-rich but information poor" syndrome in water quality monitoring." Environmental management 10(3): 291-297.

Ward, R. C., Loftis, J. C. and McBride, G. B. (1990). Design of water quality monitoring systems. Van Nostrand. New York.

Wasson, R., Banens, R., Davies, P., Maher, W., Robinson, S., Volker, R., Tait, D. and Watson-Brown, S. (1996). Inland Waters. Australia: state of the environment 1996. Commonwealth of Australia, Department of the Environment, Sport and Territories. Canberra.

Water Act 1989 (Victoria, Australia) Government Printer for the State of Victoria.

Water Authority of Western Australia (c1995). Living Streams Survey (draft). Water Authority of Western Australia. Perth.

Water Ecoscience Pty Ltd (1998). State water quality monitoring annual report: Victoria 1997. Department of Natural Resources and Environment. Melbourne.

Wharton, J. C. (1969). "Recreation and conservation in the aquatic environment." Proceedings of the Royal Society of Victoria 83: 47-54.

White, L. J. and Ladson, A. R. (1999a). Index of Stream Condition: field manual. Waterways Unit, Department of Natural Resources and Environment. Melbourne.

White, L. J. and Ladson, A. R. (1999b). Index of Stream Condition: catchment managers' manual. Department of Natural Resources and Environment. Melbourne. 
Wilkinson, J., Martin, J. and Boon, P. J. (1998). "Convergence of field survey protocols for SERCON (System for Evaluating River for Conservation) and RHS (River Habitat Survey)." Aquatic Conservation: Marine and Freshwater Ecosystems 8(4): 579-596.

Willen, E., Andersson, B. and Soderback, B. (1997). System Aqua: a biological assessment tool for Swedish lakes and watercourses. Freshwater quality: defining the indefinable? P. J. Boon and D. L. Howell. (eds) HMSO \& Scottish Natural Heritage. Edinburgh.

Williams, J. G. (1996). "Lost in space: minimum confidence intervals for idealized PHABSIM studies." Transactions of the American Fisheries Society 125: 458-465.

Williams, W. D. (1967). The changing limnological scene in Victoria. Australian inland waters and their fauna. Weatherley, A. H. (ed) Australian National University Press. Canberra, 240-251.

Williams, W. D., (ed.) (1980). An ecological basis for water resource management. Australian National University Press. Canberra.

Wilson, C., Argent, R., Bunn, S., Davies, P., Grayson, R., Hairsine, P. and Rutherfurd, I. (1996). A simple model to illustrate the effects of riparian revegetation on stream values in large catchments. First National Conference on Stream Management in Australia, 19-23 February, Merrijig. Cooperative Research Centre for Catchment Hydrology. Melbourne, 189-195.

Wilson, P. (1995). Index of River Condition, 7 June 1995, Minutes. Department of Natural Resources and Environment. Melbourne.

Wolfson, L. J., Kadane, J. B. and Small, M. J. (1996). "Bayesian environmental policy decisions: two case studies." Ecological Applications 6(4): 1056-1066.

Woodley, S., Kay, J. and Francis, G., (eds.) (1993). Ecological integrity and the management of ecosystems. St Lucie Press.

Working Group on Water Resource Policy Secretariat (1994a). Report of the Working Group on Water Resource Policy to the Council of Australian Governments. Commonwealth State Relations Secretariat, Department of Prime Minister and Cabinet. Canberra. 
Working Group on Water Resource Policy Secretariat (1994b). The Council of Australian Governments' strategic framework for water resource policy. Proceedings of the Irrigation Policy Workshop, 16-17 November 1994, Mildura. Centre for Water Policy Research. Armidale, 9-19.

Working Group on Water Resource Policy Secretariat (1995). The second report of the Working Group on Water Resources Policy to the Council of Australian Governments. Commonwealth State Relations Secretariat, Department of Prime Minister and Cabinet, Canberra.

Yoder, C. O. and Rankin, E. T. (1994). Biological Criteria Program Development and Implementation in Ohio. Biological assessment and criteria: tools for water resource planning and decision making. W. S. Davis and S. P. Thomas. (eds). Lewis Publishers. Boca Raton, 415.

Young, W. J. (1998). River health. Methods paper. National Land and Water Resources Audit. Environment Australia, Commonwealth of Australia, Canberra.

Young, W. J., Davis, J. R., Bowmer, K. H. and Fairweather, P. G. (1995). The feasibility of a decision support system for environmental flows. CSIRO Division of Water Resources. Canberra.

Zadeh, L. T. (1965). “Fuzzy sets.” Information and control 8: 338-353.

Zanetell, B. A. and Peckarsky, B. L. (1996). "Stoneflies as ecological engineers hungry predators reduce fine sediments in stream beds." Freshwater Biology 36: 569-577.

Zimmerman, R. C., Goodlett, J. C. and Comer, G. H. (1967). The influence of vegetation on channel form of small streams. Symposium on River Morphology, General Assembly of Berne, International Association of Hydrological Sciences. 


\section{University Library}

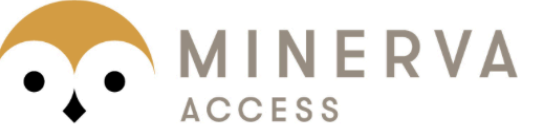

A gateway to Melbourne's research publications

Minerva Access is the Institutional Repository of The University of Melbourne

Author/s:

Ladson, Anthony Richard

Title:

A multi-component indicator of stream condition for waterway managers: balancing scientific rigour with the need for utility

Date:

2000-01

\section{Citation:}

Ladson, A. R. (2000). A multi-component indicator of stream condition for waterway managers: balancing scientific rigour with the need for utility. PhD thesis, Department of Civil and Environmental Engineering, University of Melbourne.

Publication Status:

Unpublished

Persistent Link:

http://hdl.handle.net/11343/38792

\section{Terms and Conditions:}

Terms and Conditions: Copyright in works deposited in Minerva Access is retained by the copyright owner. The work may not be altered without permission from the copyright owner. Readers may only download, print and save electronic copies of whole works for their own personal non-commercial use. Any use that exceeds these limits requires permission from the copyright owner. Attribution is essential when quoting or paraphrasing from these works. 